UNIVERSIDAD POLITÉCNICA DE MADRID

ESCUELA TÉCNICA SUPERIOR DE INGENIEROS DE CAMINOS, CANALES Y PUERTOS

TESIS DOCTORAL

\title{
CORROSIÓN DE ARMADURAS EN EL HORMIGÓN ARMADO EN AMBIENTE MARINO AÉREO
}

SUSANA FERNÁNDEZ GARCÍA.

Ingeniera de Caminos, Canales y Puertos.

Madrid, 2016 



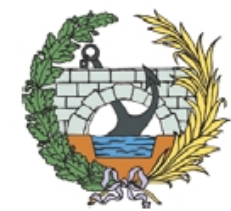

DEPARTAMENTO DE INGENIERÍA CIVIL: CONSTRUCCIÓN

ESCUELA TÉCNICA SUPERIOR DE INGENIEROS DE CAMINOS, CANALES Y PUERTOS

TESIS DOCTORAL

\section{CORROSIÓN DE ARMADURAS EN EL HORMIGÓN ARMADO EN AMBIENTE MARINO AÉREO}

Autor: Susana Fernández García. Ingeniera de Caminos, Canales y Puertos.

Directora: Ma Pilar Alaejos Gutiérrez. Doctora Ingeniera de Caminos, Canales y Puertos. 



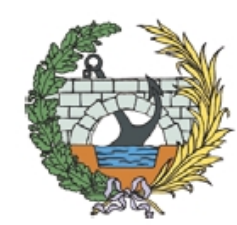

TESIS DOCTORAL

\section{CORROSIÓN DE ARMADURAS EN EL HORMIGÓN ARMADO EN AMBIENTE MARINO AÉREO}

Autor:

Susana Fernández García

Directora de Tesis:

Ma Pilar Alaejos Gutiérrez

Tribunal nombrado por el Mgfco. y Excmo. Sr. Rector de la Universidad Politécnica de Madrid, el día de de 2016.

PRESIDENTE:

VOCAL:

VOCAL:

VOCAL:

VOCAL SECRETARIO:

Acuerda otorgarle la calificación de:

Madrid, de de 2016 



\section{AGRADECIMIENTOS}

Quiero expresar mi sincero agradecimiento a $\mathrm{M}^{\mathrm{a}}$ Pilar Alaejos, directora de esta tesis, por su dedicación y respaldo, por guiarme a lo largo de la investigación, y por creer en mí y en el buen fin de este trabajo. Gracias por reforzar mi autoestima en momentos clave y por hacerme creer que era capaz de conseguirlo.

También quiero dar las gracias a la Dirección General del CEDEX, especialmente al Laboratorio Central de Estructuras y Materiales, por sus iniciativas para fomentar la formación de postgrado y la realización de tesis doctorales.

Se agradece a Puertos del Estado el interés por el tema planteado y por la financiación del estudio que ha permitido la realización de esta tesis.

Del mismo modo quiero expresar mi agradecimiento a las Autoridades Portuarias a las que pertenecen los Muelles inspeccionados, por su inestimable colaboración y las facilidades ofrecidas para poder llevar a cabo el trabajo de campo, sin el cual el estudio experimental no se hubiera podido desarrollar.

Dar las gracias especialmente a Alicia Rosado y Manuel Rivas, secretaria y director del Departamento de Construcción de la Escuela de Ingenieros de Caminos de Madrid, por su información puntual y por su diligencia atenta y eficiente para resolver todas mis dudas.

A mi predecesor Miguel Ángel Bermúdez por iniciarme en el tema y ser, a través de su tesis, un guía incuestionable en mi trabajo.

Quiero expresar mi reconocimiento al personal del Laboratorio Central de Estructuras y Materiales del CEDEX, por su buen hacer y el apoyo prestado durante este tiempo. Mención especial merece Víctor Lanza, por su ayuda incondicional. Tampoco puedo olvidarme de compañeros como Félix Martín, Carlos Gimeno, Alberto Velasco, Marta Sanchez, Javier Pintado y Antonio Rodríguez.

Por último y desde lo más profundo, agradecer el aliento incondicional a mis padres, a mis amigos, a todos aquellos que con palabras de ánimo han mantenido mi ilusión a lo largo del camino. Y sobre todo, a mi compañero de viaje Kike y a mi hijo Mateo, por su compresión, por su amor y por todo el tiempo que he dejado de pasar con ellos. 



\section{RESUMEN}

La presente tesis doctoral surge ante la necesidad de completar el estudio sobre la corrosión en el hormigón armado expuesto al ambiente marino iniciado por D. Miguel Ángel Bermúdez Odriozola en 2007 con la tesis doctoral con título "Corrosión de las armaduras del hormigón armado en ambiente marino: zona de carrera de mareas y zona sumergida".

Una vez realizado el estudio bibliográfico, se ha planteado un estudio experimental en el que se analizan cuatro muelles de distintas edades y localizados en distintos lugares de la geografía española. Uno de ellos contiene adiciones en el hormigón. Una vez inspeccionados, se extraen testigos de cada uno de ellos con el fin de realizar ensayos de caracterización y se analizan sus resultados en paralelo con los coeficientes de difusión.

Uno se los objetivos ha sido comprobar el mejor método de ensayo que permita controlar la durabilidad del hormigón en ambiente IIla. La tesis que se presenta ha demostrado la efectividad del ensayo de penetración de agua para discriminar los hormigones que presentarán un buen comportamiento frente a la difusión de cloruros y por tanto para predecir la vida útil de la estructura.

Asimismo, otro objetivo ha sido valorar el uso de adiciones en el hormigón y cómo afectan a la mejora del comportamiento del hormigón expuesto al ambiente marino. Se han obtenido valores del coeficiente de eficacia de cenizas volantes y humo de sílice frente a la difusión de cloruros, muy superiores a los actualmente considerados en términos de resistencia.

El ambiente marino aéreo engloba estructuras situadas en primera línea de costa así como aquellas que se sitúan hasta $5 \mathrm{~km}$ de distancia de la línea del mar. La investigación realizada ha demostrado la necesidad de establecer una nueva subdivisión en este ambiente introduciendo la zona Spray, siguiendo criterios internacionales, que permita diferenciar la zona más desfavorable del mismo que comprende las estructuras ubicadas sobre el nivel del mar tal como los tableros de pantalanes portuarios estudiados.

Se han analizado en profundidad los valores del contenido de cloruros en superficie de hormigón en los diferentes tipos de ambiente marino recogidos por la Instrucción EHE08 contrastando los requisitos normativos. Como conclusión se han hecho nuevas propuestas normativas que afectan al ambiente sumergido y al ambiente marino aéreo (zona spray). Asimismo se ha realizado un análisis en profundidad de la concentración 
crítica de cloruros recogida por la Instrucción EHE-08, a partir de los datos obtenidos en estructuras reales.

Se ha evaluado el ensayo de resistividad para estimar el valor del coeficiente de difusión de cloruros. Este ensayo ha demostrado su efectividad para discriminar hormigones con adiciones y con muy baja penetración de agua, si bien no resulta sensible para detectar hormigones con elevada permeabilidad.

Finalmente en la tesis se ha obtenido un modelo de difusión de cloruros (a/c-D) en ambiente marino aéreo a fin de poder estimar la difusión de cloruros en el hormigón a partir de un requisito normativo como es la relación a/c. 


\begin{abstract}
This Thesis is focussed to complete the previous study on the corrosion of reinforced concrete exposed to marine environment, carried out by Dr. Miguel Ángel Bermúdez Odrizola in 2007. That Thesis title was "Corrosion of concrete reinforcement located in marine environment: tidal zone and submerged zone".
\end{abstract}

After the literature review presented in the State of the Art, an experimental programme was carried out. Four docks of different ages and locations have been studied, one of them was a fly ash concrete. The structures were inspected on site and several cores extracted in order to develop characterization tests and obtain diffusion profiles at the laboratory.

One of the objectives has been to check the best laboratory test method to control concrete durability when exposed to atmospheric marine environment. This Thesis has proven the effectiveness of the water penetration test to differentiate concretes well behaved against chloride diffusion and also to predict the structure service life.

Another objective has been to study the effect of mineral additions in concrete and how they improve the durability of concrete in this environment. Efficiency factors have been obtained for fly ashes and silica fume, much higher than those consider for strength.

According to the Spanish Concrete Code EHE 08, the atmospheric marine environment includes structures located at the cost, from the sea line up to $5 \mathrm{~km}$ inland. The research conducted has shown the need to consider a spray zone which is the most unfavourable area of the atmospheric environment, affecting structures over the sea level as the decks of the wharves here studied.

Surface chloride contents of structures in the different marine environments have been deeply analysed, checking the actual standard limits. As a conclusion, new normative values have been proposed for submerged and atmospheric zone (spray zone). A complete analysis of the chloride threshold concentration from the data obtained in real structures has also been performed.

It has been evaluated the resistivity test as a tool to estimate the chloride diffusion coefficient. This test has proven effectiveness to discriminate concrete with mineral additions and low water penetration values, while it is not sensitive to detect concretes with high permeability. 
Finally, a chloride diffusion model (w/c) has been obtained in atmospheric marine environment in order to estimate the chloride diffusion of the concrete knowing a normative requirement as $\mathrm{w} / \mathrm{c}$. 


\section{ÍNDICE}

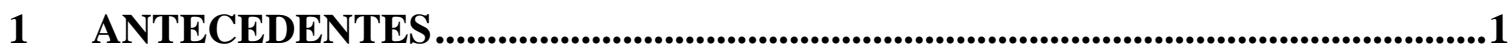

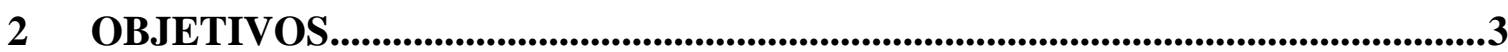

3 METODOLOGÍA

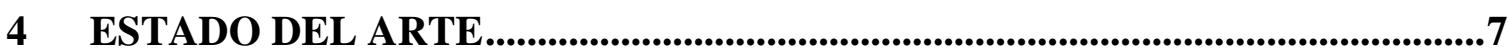

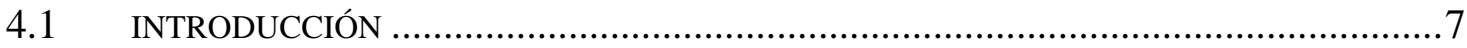

4.2 ASPECTOS GENERALES DE LA CORROSIÓN DEL ACERO EN EL HORMIGÓN ...............8

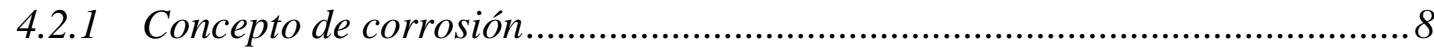

4.2.2 La corrosión del acero embebido en el hormigón ...........................................9

4.2.3 Protección del hormigón frente a la corrosión de las armaduras .................11

4.2.4 Despasivación de la armadura .....................................................................13

4.3 CORROSIÓN DEL ACERO POR LA ACCIÓN DE LOS CLORUROS.................................15

4.3.1 Mecanismo de rotura de la capa pasiva .....................................................15

4.3.2 Formación de Macropilas ...........................................................................

4.3.3 Tipos de cloruros. Limitaciones de contenido para un hormigón más

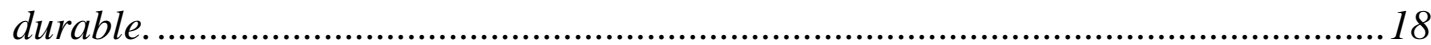

4.3.3.1 Cloruros internos y procedentes del exterior .........................................18

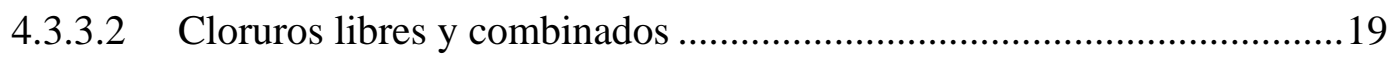

4.3.3.3 Limitaciones al contenido de cloruros en el hormigón.........................20

4.3.4 Factores que influyen en la corrosión ${ }^{2.8}$..................................................22

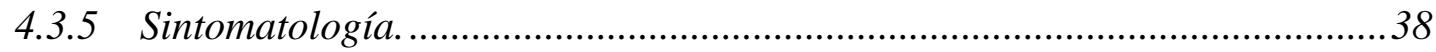

4.3.6 Técnicas para el estudio de la corrosión por cloruros ${ }^{2}$................................40

4.4 MODELACIÓN DE LA DIFUSIÓN DE CLORUROS EN EL HORMIGÓN ..........................47

4.4.1 Definición del Ambiente Marino Aéreo ...........................................................47

4.4.2 Fases de la corrosión del acero en el hormigón: Iniciación y Propagación 52

4.4.3 Modelos de Difusión de Cloruros. Periodo de Iniciación. ..............................54

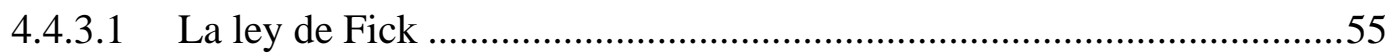

4.4.3.2 Modelos de difusión fickianos ..........................................................56

4.4.3.3 Valores del coeficiente de difusión........................................................71 
4.4.4 Parámetros que influyen en el Coeficiente de Difusión................................ 72

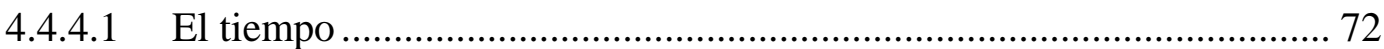

4.4.4.2 Calidad del hormigón............................................................................ 75

4.4.4.3 Concentración de cloruros en superficie ............................................ 76

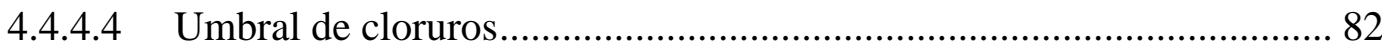

4.4.5 Modelos de corrosión de las armaduras. Periodo de Propagación.............. 87

4.4.6 Métodos para prevenir la corrosión y aumentar la vida útil de las

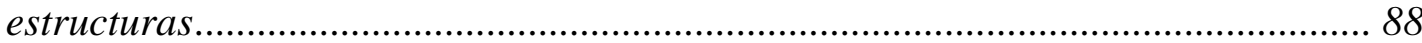

4.4.6.1 Medidas de prevención y protección....................................................... 88

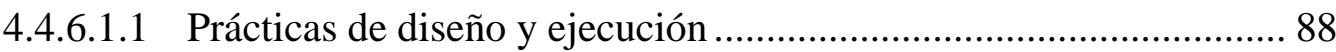

4.4.6.1.2 Tratamientos no metálicos sobre la armadura ................................ 91

4.4.6.1.3 Aceros especiales...................................................................... 93

4.4.6.1.4 Empleo de protecciones metálicas para armaduras ......................... 95

4.4.6.1.5 Protección de las armaduras frente a la corrosión mediante

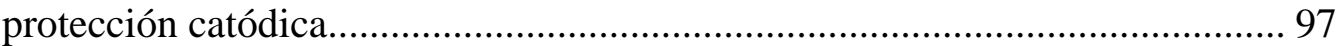

4.4.6.1.6 Tratamientos especiales del hormigón ........................................... 99

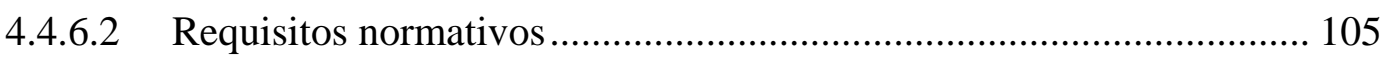

4.5 ESTRUCTURAS REALES EN AMBIENTE MARINO AÉREO ...................................... 111

4.6 TÉCNICAS DE REPARACIÓN. TRATAMIENTO DE HORMIGÓN DETERIORADO. ..... 126

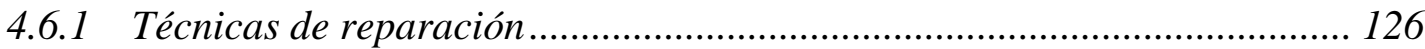

4.6.2 Tratamiento del hormigón deteriorado...................................................... 129

4.7 CONCLUSIONES. ASPECTOS EN LOS QUE ES NECESARIA LA INVESTIGACIÓN ...... 131

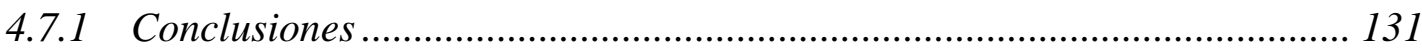

4.7.2 Aspectos en los que es necesaria la investigación...................................... 135

5 ESTUDIO EXPERIMENTAL SOBRE DIFUSIÓN DE CLORUROS EN

PANTALANES...................................................................................................................... 137

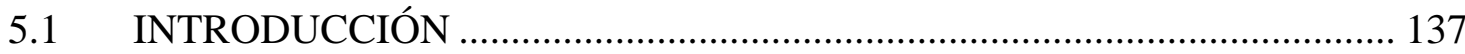

5.2 DESCRIPCIÓN DE LOS PANTALANES OBJETO DE ESTUDIO .............. 138

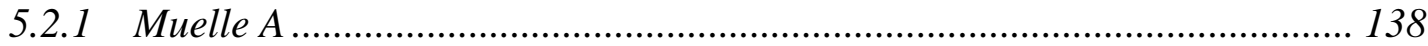

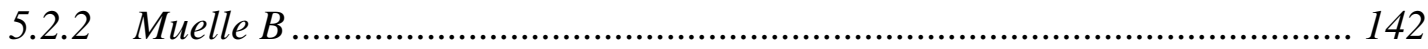

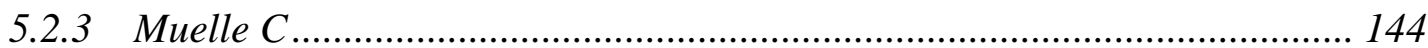

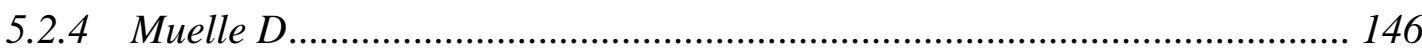


5.2.5 Tabla de Características de los Muelles objeto de estudio .149

5.3 INSPECCIÓN VISUAL Y EXTRACCIÓN DE TESTIGOS ............................150

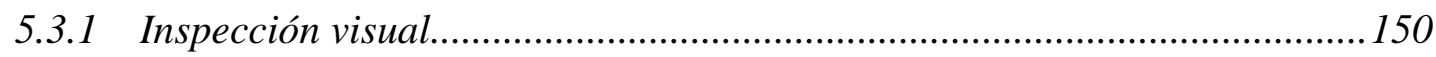

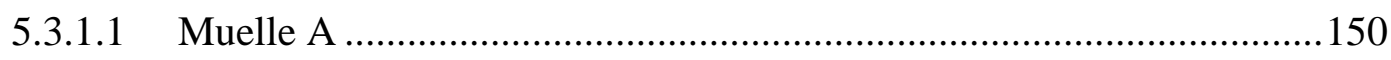

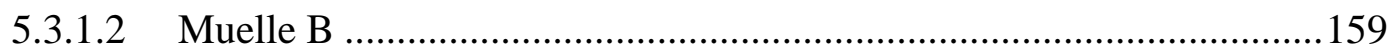

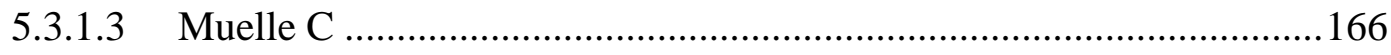

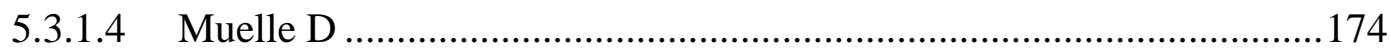

5.3.2 Medidas in situ y Extracción de testigos ..................................................178

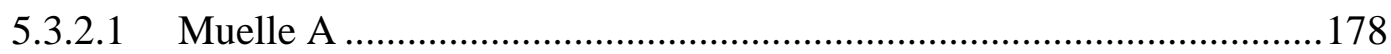

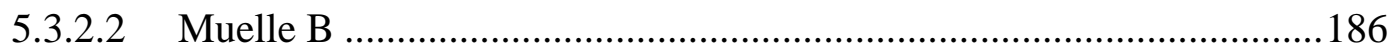

5.3.2.2.1 Velocidad de propagación de ultrasonidos ....................................186

5.3.2.2.2 Medidas electroquímicas de la corrosión ......................................188

5.3.2.2.3 Valoración de los resultados y justificación de los puntos de

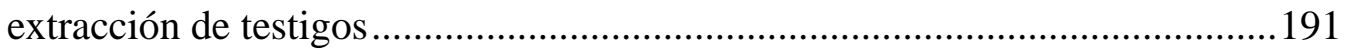

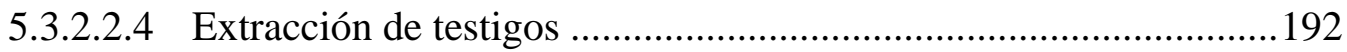

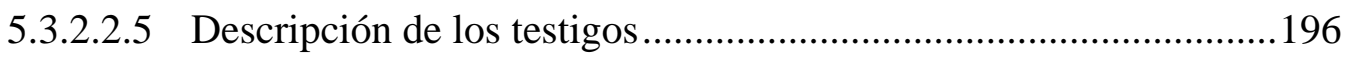

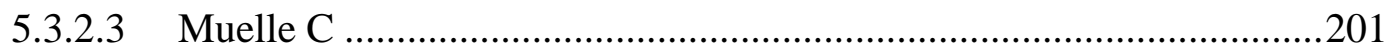

5.3.2.3.1 Velocidad de propagación de ultrasonidos ...................................201

5.3.2.3.2 Medidas electroquímicas de la corrosión ........................................203

5.3.2.3.3 Valoración de los resultados y justificación de los puntos de

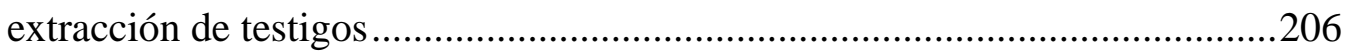

5.3.2.3.4 Extracción de los testigos ............................................................208

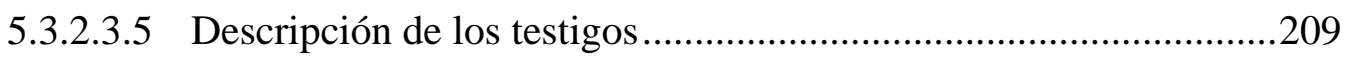

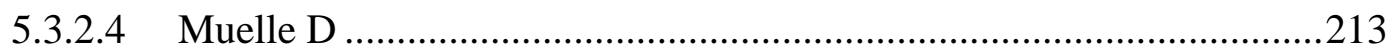

5.3.2.4.1 Velocidad de propagación de ultrasonidos ...................................213

5.3.2.4.2 Medidas electroquímicas de la corrosión ........................................214

5.3.2.4.3 Valoración de los resultados y justificación de los puntos de

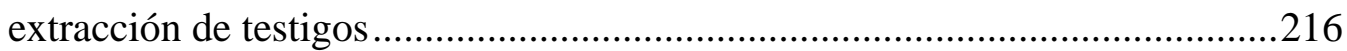

5.3.2.4.4 Extracción de los testigos ..............................................................219

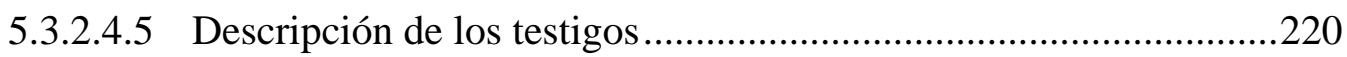

5.4 PLANIFICACIÓN DE LOS ENSAYOS …......................................................228

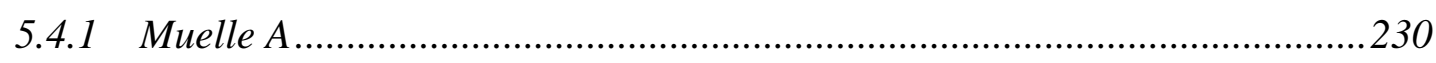

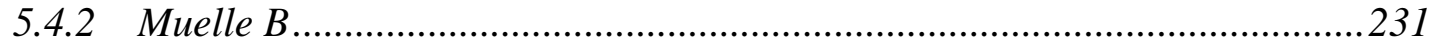


5.4.3 Muelle C.....

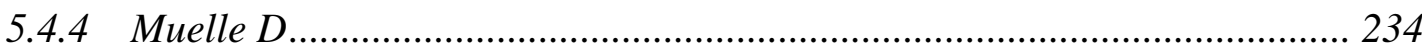

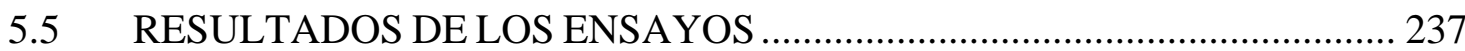

5.5.1 Ensayos mecánicos. Resistencia a compresión del hormigón y Velocidad de

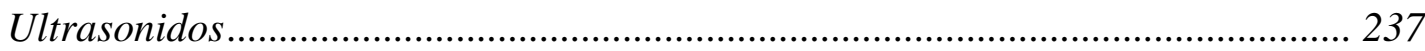

5.5.2 Profundidad de Penetración de Agua, Porosidad y Permeabilidad........... 239

5.5.3 Porosidad Abierta ........................................................................................... 242

5.5.4 Absorción de Agua y Capilaridad................................................................... 243

5.5.5 Permeabilidad al Oxígeno ....................................................................... 246

5.5.6 Penetración de Cloruros (expresado en \% en peso de hormigón y de

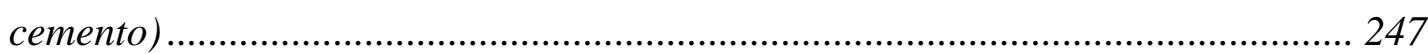

5.5.7 Profundidad de Carbonatación.................................................................. 252

\subsection{VALORACIÓN DE LOS RESULTADOS: CALIDAD DE LOS}

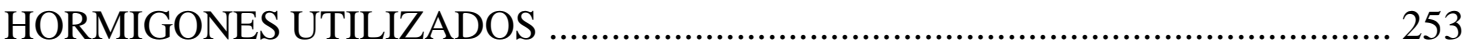

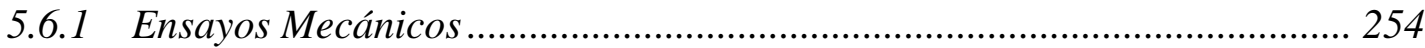

5.6.2 Penetración de Agua, Porosidad y Permeabilidad ...................................... 257

5.6.3 Absorción de Agua y Capilaridad................................................................ 261

5.6.4 Resumen Cualitativo de la Calidad del Hormigón ...................................... 265

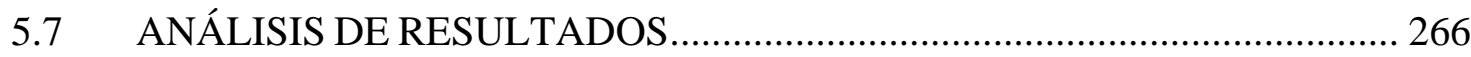

5.7.1 Análisis del perfil de penetración de cloruros ............................................ 266

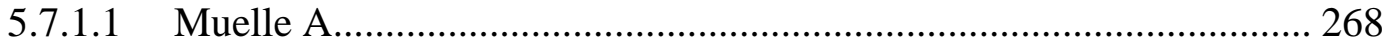

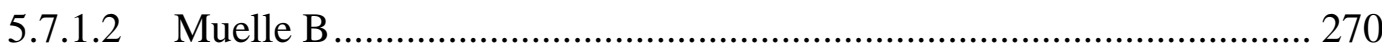

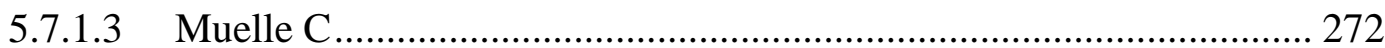

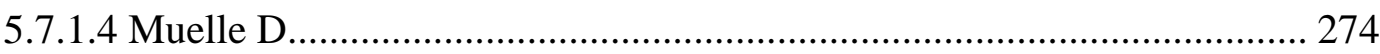

5.7.2 Cálculo del coeficiente de difusión de cloruros ......................................... 275

5.7.3 Análisis de la concentración de cloruros en superficie ............................... 281

5.7.4 Análisis de la concentración crítica de cloruros. ....................................... 284

5.7.5 Análisis de los coeficientes de difusión y los resultados de los ensayos de caracterización

5.7.6 Contraste de los resultados de penetración de agua (IIIa) con los obtenidos

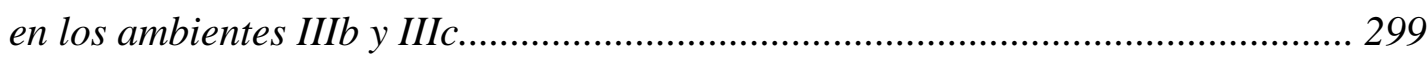

5.7.7 Influencia de la dosificación en el coeficiente de difusión del hormigón ... 300

5.7.8 Valoración de la calidad del hormigón de los pantalanes estudiados ....... 307 
5.7.9 Aplicación del modelo desarrollado en esta investigación . 309

6 ESTUDIO DE LA RESISTIVIDAD COMO ENSAYO DE CONTROL DE LA DURABILIDAD DEL HORMIGÓN ..........................................................................315

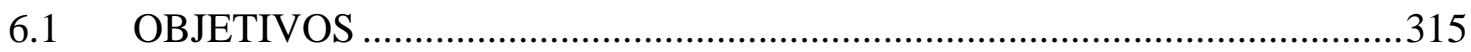

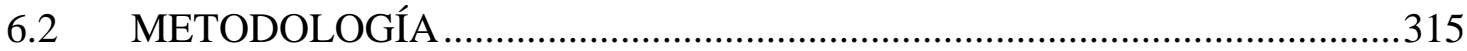

6.3 MATERIALES ENSAYADOS. RESULTADOS DE RESISTIVIDAD..........315

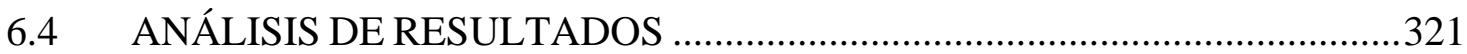

6.4.1 Influencia de la presencia de adiciones......................................................322

6.4.2 Relación de la resistividad con la difusión de cloruros.................................325

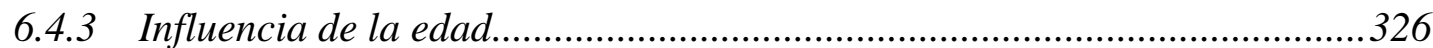

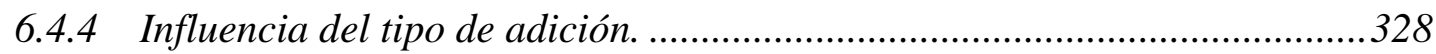

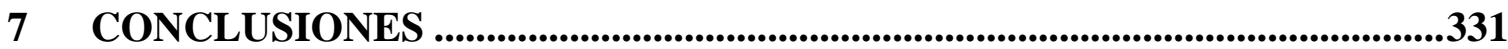

7.1 CLORUROS EN SUPERFICIE EN HORMIGONES EXPUESTOS A AMBIENTE MARINO

7.2 ESTUDIO SOBRE LA CONCENTRACIÓN CRÍTICA DE CLORUROS PARA EL INICIO DE LA CORROSIÓN. .333

7.3 DIFUSIÓN DE CLORUROS EN AMBIENTE MARINO AÉREO (ZONA SPRAY) 334

7.4 ESTUDIO DE LA RESISTIVIDAD COMO ENSAYO DE CONTROL DE LA DURABILIDAD DEL HORMIGÓN

7.4.1 Medida de la Resistividad del Hormigón 337

7.4.2 Influencia de la Resistividad en la Durabilidad del Hormigón en Ambiente Marino 338

8 FUTURAS LÍNEAS DE INVESTIGACIÓN. 341

9 BIBLIOGRAFÍA CONSULTADA. 343

ANEJO 1: ESTUDIO DE LA CONCENTRACIÓN DE CLORUROS EN SUPERFICIE. 355

ANEJO 2: ESTUDIO DE LA CONCENTRACIÓN CRÍTICA DE CL (C ANEJO 3: MEDIDA DE LA RESISTIVIDAD ELÉCTRICA EN EL HORMIGÓN ARMADO. 


\section{ANTECEDENTES}

La corrosión es la primera causa de deterioro en estructuras costeras de hormigón armado y pretensado, aspecto de especial importancia en países con una gran longitud de costa, como es el caso de España.

La Instrucción española EHE-08 emplea una clasificación de ambientes definiendo como clases generales de exposición las que se refieren a procesos relacionados con la corrosión de armaduras y clases específicas las relacionadas con el deterioro del hormigón. La clase III es la que corresponde a la exposición marina y se subdivide en tres subclases: IIla (aérea), IIlb (sumergida) y IIIc (en zona de carrera de mareas y en zonas de salpicaduras). El estudio que ahora se inicia centrará su análisis en el Ambiente Marino Aéreo (IIla).

Dada la importancia de definir la calidad de los hormigones pertenecientes a estructuras situadas en ambiente marino, se realizó previamente un estudio sobre el comportamiento del hormigón situado en zona sumergida (IIIb) y en zona de carrera de mareas y salpicaduras (IIIc) (Tesis doctoral de Miguel Ángel Bermúdez presentada en la ETSICCP de Madrid, año 2007). Con el fin de profundizar en el análisis del comportamiento de hormigones situados en ambiente marino, el presente trabajo de investigación centra su estudio en estructuras de hormigón expuestas a ambiente IIla. En este ambiente se engloban elementos de estructuras marinas situados por encima del nivel de pleamar así como elementos exteriores de estructuras situadas en las proximidades de la línea costera (a menos de $5 \mathrm{~km})$. 
ANTECEDENTES 


\section{OBJETIVOS}

El objetivo global de la presente tesis ha sido analizar el comportamiento del hormigón situado en ambiente marino aéreo (IIla), comprobando la eficacia de los requisitos de dosificación y control de la permeabilidad del hormigón exigidos por la Instrucción EHE. Para ello, se han definido los siguientes objetivos parciales:

- Estudio de la posible subdivisión del ambiente marino aéreo (IIla) planteado por la Instrucción EHE-08, ya que engloba dentro de un mismo grupo a estructuras situadas en primera línea de costa así como a aquellas que se encuentran hasta $5 \mathrm{~km}$ de distancia de la línea del mar.

- Análisis de los contenidos de cloruros en superficie y las concentraciones críticas de cloruros de los muelles estudiados y de otros consultados en la bibliografía con el fin de comprobar los valores planteados por la normativa EHE 08 y ver si se adecúan a los resultados obtenidos en estructuras reales.

- Valoración del uso de adiciones en el hormigón con el fin de mejorar su comportamiento frente a la durabilidad en ambiente marino.

- Estudio de la aplicación de un ensayo de resistividad eléctrica del hormigón para caracterizar la durabilidad del mismo en ambiente marino, como alternativa al ensayo de penetración de agua, que es el actualmente planteado por la Instrucción EHE-08 para tal fin.

- Obtención de un modelo a/c-D para el caso del ambiente marino aéreo (estructuras sobre el mar), con el fin de poder estimar la difusión de los cloruros en el hormigón a partir de un dato previo conocido como es la relación $\mathrm{a} / \mathrm{c}$. 
OBJETIVOS 


\section{METODOLOGÍA}

La metodología seguida en el desarrollo de la tesis doctoral ha sido la siguiente:

- Estudio bibliográfico con recopilación y lectura de artículos publicados en la materia para completar el Estado del Arte de la tesis. La base de partida de la investigación es otra tesis doctoral previa realizada por D. Miguel Ángel Bermúdez Odriozola en 2007 con título "Corrosión de las armaduras del hormigón armado en ambiente marino: zona carrera de mareas y zona sumergida". En la investigación actual se realiza un estudio específico de estructuras situadas en la zona aérea, en particular aquellos elementos estructurales situados sobre el mar.

- Selección de pantalanes para el desarrollo de la parte experimental de la tesis. Descripción y recopilación de la información existente de los mismos. Inspección visual en obra, realización de medidas in situ y extracción de testigos para su posterior ensayo en laboratorio. Caracterización de la durabilidad del hormigón utilizando diferentes ensayos: penetración de agua, porosidad, absorción, capilaridad, perfil de penetración de cloruros. Recopilación de bibliografía y normativa referente a la resistividad eléctrica del hormigón.

- Montaje y puesta a punto del ensayo de resistividad en el laboratorio. Elaboración de un anejo en el que se analiza la normativa nacional referente a la medida de la resistividad y se ajustan algunos parámetros para la realización del ensayo que no aparecen suficientemente definidos en la norma. Aplicación a muestras de testigos procedentes de diferentes puertos. Obtención de muestras complementarias a partir de amasadas de hormigón fabricadas en laboratorio con determinadas relaciones $\mathrm{a} / \mathrm{c}$.

- Valoración y análisis de los resultados obtenidos al objeto de establecer relaciones entre la difusión de los cloruros y la calidad del hormigón evaluada a través del ensayo de penetración de agua y del ensayo de resistividad.

- Creación de una base de datos a partir de obras reales citadas en artículos pertenecientes a la bibliografía para la obtención del máximo $\mathrm{n}^{\circ}$ de datos posible (a/c, resistencia, recubrimientos, medida de la resistividad..etc.) y en los casos 
que sea posible, valores de coeficientes de difusión o de perfiles de cloruros para su cálculo. Todo ello, con la intención de obtener finalmente un modelo de difusión-a/c para el ambiente marino aéreo (estructuras sobre el mar), valorando el efecto real de las adiciones para reducir el coeficiente de difusión del hormigón.

- Contraste del modelo obtenido con otros tomados de la bibliografía.

- Aplicación de los resultados de la investigación para evaluar los requisitos de dosificación del hormigón y los requisitos de control (penetración de agua y resistividad) que garantizan una vida útil de $\mathbf{5 0}$ años en el hormigón situado en ambiente marino aéreo (estructuras sobre el mar). Contraste con lo exigido por la Instrucción EHE-08. 


\section{ESTADO DEL ARTE}

\subsection{INTRODUCCIÓN}

Como ya se ha citado, la corrosión de estructuras de hormigón armado y pretensado situadas en zona costera es una de las causas fundamentales de su deterioro. En el caso de un país como España, con una longitud de costa significativa, este hecho resulta de especial importancia.

En el ámbito internacional, otros países tienen también problemas en el mantenimiento de las estructuras costeras. A modo de ejemplo, en Japón existen aproximadamente 75.000 puentes de carretera de hormigón de longitud superior a 15 metros. En zonas costeras, algunos puentes han tenido que ser reemplazados tras décadas de uso y en algunos casos, los costes de mantenimiento superan los de construcción inicial, por lo que los nuevos métodos de diseño de puentes más durables tratan de minimizar dicho mantenimiento?

En Japón, ya en el año 1984 se estableció como criterio para el diseño durable de estructuras costeras la "Guía de Especificaciones sobre medidas contra el ataque de cloruros en puentes de carretera"("Guide specifications on measures against chloride attackfor highway bridges"). Una de las medidas principales que planteó el documento para aumentar la durabilidad fue incrementar el espesor de recubrimiento en función de la distancia a la costa, con el fin de mantener los cloruros alejados de la armadura. Cuando se establecen por diseño vidas útiles superiores a 100 años, pueden requerirse mayores recubrimientos así como protecciones adicionales?

Hasta el año 1995, se construyeron en Japón más de 400 puentes de acuerdo con las citadas especificaciones. La durabilidad de los puentes mejoró en comparación con la de los puentes diseñados según otros criterios anteriores. Sin embargo, se estimó que se necesitaban nuevos métodos para establecer el recubrimiento adecuado según la vida útil requerida por la estructura ${ }^{7}$, y se realizó un profundo estudio para reducir al máximo los costes de mantenimiento por problemas de corrosión.

En el estudio que se plantea en el presente trabajo de investigación se establece una estrategia similar al caso descrito en Japón. Así, se trata de comprobar en 
estructuras reales el nivel de efectividad alcanzado por las medidas de durabilidad tomadas en la normativa española para mejorar el comportamiento de estructuras sometidas al ambiente marino aéreo.

\subsection{ASPECTOS GENERALES DE LA CORROSIÓN DEL ACERO EN EL HORMIGÓN}

\subsubsection{Concepto de corrosión}

La corrosión es un ataque destructivo del metal por vía QUÍMICA o ELECTROQUÍMICA, por el que, durante sus vidas de servicio, los metales adquieren niveles de energía menores y más estables ${ }^{2}$.

Existen dos tipos de corrosión: la SECA, que es una oxidación directa en presencia

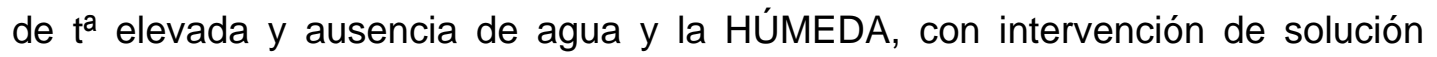
acuosa, de mayor gravedad².

Otra posible clasificación de la corrosión sería la siguiente: GENERALIZADA, la que afecta a toda la superficie del metal y se debe a un descenso de la alcalinidad del hormigón y GALVÁNICA, cuyo caso más agresivo es el ataque por cloruros y también puede deberse a ataque por sulfuros y sulfatos ${ }^{2}$.

Cuando en el proceso interviene una solución acuosa, el mecanismo que se produce comprende distintas reacciones químicas, unas en las que se disuelve metal (zonas anódicas) y otras en las que permanece inalterado (zonas catódicas), lo que supone la formación de una pila con cada uno de sus elementos diferenciados: el ánodo, el cátodo, la conexión metálica entre ambos y el electrolito. Las reacciones son²:

$\mathrm{M} \rightarrow \mathrm{M}^{+\mathrm{n}}+\mathrm{ne}^{-}$

$\mathrm{O}_{2}+2 \mathrm{H}_{2} \mathrm{O}+4 \mathrm{e}^{-} \longleftrightarrow 4 \mathrm{OH}^{-}$

En el caso del medio ácido, son los iones hidrógenos los que reaccionan con los electrones liberados ${ }^{2}$ :

$2 \mathrm{H}^{+}+2 \mathrm{e}^{-} \longrightarrow \mathrm{H}_{2}$ 
En el proceso de la corrosión, las pilas que se forman pueden ser de dos tipos: de COMPOSICIÓN, por la existencia de distintos metales en el acero o variaciones en su superficie, o de CONCENTRACIÓN, por diferencia de concentraciones de los iones disueltos. Esta última es la más frecuente en el acero del hormigón².

\subsubsection{La corrosión del acero embebido en el hormigón}

En el caso del hormigón, las armaduras de acero que se encuentran en su interior son susceptibles de sufrir corrosión. El hormigón es un material poroso y fisurable, aspectos que influyen en gran medida en los procesos que afectan a la durabilidad de las estructuras ${ }^{16}$.

La estructura de poros (tipo y distribución de tamaño), la configuración de las fisuras así como el contenido de agua existente en ambos son factores determinantes en la permeabilidad del hormigón. El cemento del hormigón reacciona con el agua formando una pasta no homogénea, con discontinuidades en composición, distribución y volumen, dando lugar a huecos y espacios intercristalinos. Dentro de la masa de pasta hidratada que constituyen cemento y agua, pueden formarse otras discontinuidades de mayor tamaño, causadas por una deficiente puesta en obra o bien por el empleo de ciertos aditivos. En cuanto a los tipos de poros, cabe citar los poros de gel, los poros capilares, los huecos de aire y los poros de compactación ${ }^{16}$.

La porosidad llamada fundamental es la relacionada con los poros interconectados entre sí que favorecen el transporte de líquidos y/o gases a través del hormigón, ya que se forma un entramado a través del cual circulan fundamentalmente agua y aire, permitiendo así el ingreso de sustancias agresivas desde el exterior. El agua albergada en dicha red de poros es el electrolito del proceso electroquímico de la corrosión $^{16}$.

Para que ocurra tal reacción electroquímica, en ausencia de una fuente externa de corriente, deben existir dos reacciones de media pila: Una, capaz de producir electrones (la reacción anódica o la oxidación del hierro para formar iones ferrosos) y otra, capaz de consumir electrones (la reacción catódica o la reducción de oxígeno para formar iones hidroxilo). La fuerza electromotriz de la pila que se forma durante la corrosión es la diferencia entre el potencial del ánodo y el cátodo ${ }^{2,8}$. 
Cuando las citadas reacciones ocurren entre puntos ampliamente separados, se forma una macropila; cuando se produce entre localizaciones próximas, se trata de una micropila. El primer caso es el de las llamadas celdas de macro-corrosión. Es un fenómeno propio de la corrosión inducida por cloruros y se debe a la elevada conductividad del hormigón a través de la solución acuosa y de cloruros de sus $\operatorname{poros}^{2,5}$.

La velocidad de corrosión de la armadura embebida en el hormigón depende de factores ambientales. El oxígeno y la humedad deben estar presentes para que se produzca la corrosión electroquímica ${ }^{8}$ del acero embebido en el hormigón. Las reacciones que se producen en la corrosión son las indicas en la figura 4.18:

$$
\begin{gathered}
\mathrm{Fe} \rightarrow \mathrm{Fe}^{++}+2 \mathrm{e}^{-} \\
2 \mathrm{Fe}^{++}+4 \mathrm{OH}^{-} \rightarrow 2 \mathrm{Fe}(\mathrm{OH})_{2} \\
2 \mathrm{Fe}(\mathrm{OH})_{2}+1 / 2 \mathrm{O}_{2} \rightarrow 2 \mathrm{FeOOH}+\mathrm{H}_{2} \mathrm{O} \\
\mathrm{Fe}+\mathrm{OH}^{-}+\mathrm{H}_{2} \mathrm{O} \rightarrow \mathrm{HFeO}_{2}^{-}+\mathrm{H}_{2}
\end{gathered}
$$

y las reacciones de media pila más propicias son:

$$
\begin{gathered}
2 \mathrm{H}_{2} \mathrm{O}+\mathrm{O}_{2}+4 \mathrm{e}^{-} \rightarrow 4(\mathrm{OH})^{-} \\
2 \mathrm{H}^{+}+2 \mathrm{e}^{-} \rightarrow \mathrm{H}_{2}
\end{gathered}
$$

Fig.4.1. Reacciones que tienen lugar en el proceso de corrosión.

La velocidad de corrosión puede determinarse como una corriente de corrosión a partir de la medida de la velocidad a la que los electrones se apartan del hierro en las reacciones anódicas descritas. Dicha velocidad de corrosión puede expresarse como la velocidad de pérdida de metal mediante la ley de Faraday, cuya expresión y parámetros se citan a continuación ${ }^{8}$ :

$$
\mathrm{M}=\mathrm{I} \cdot \mathrm{t} \cdot \mathrm{Aw} / \mathrm{n} \cdot \mathrm{F}
$$

donde $\mathrm{M}$ es la masa de metal disuelta o convertida en óxido (gramos)

I es la intensidad de corriente (Amperios)

t es el tiempo (segundos)

$A_{w}$ es el peso atómico

n es la valencia química 
F es la constante de Faraday (96.500 C/equivalente gramo)

Dividiendo por la densidad, la masa puede convertirse en espesor de capa disuelta u oxidada y para el hierro o acero, $1 \mu \mathrm{A} / \mathrm{cm}^{2}=11,8 \mu \mathrm{m} / \mathrm{año}$. La densidad de corriente, que es equivalente a la corriente neta dividida por la sección del electrodo, no puede determinarse directamente, ya que el requerimiento de un equilibrio de carga significa que las velocidades de producción y consumo de electrones mediante reacciones anódicas y catódicas son siempre iguales y además la corriente no neta puede medirse. Como consecuencia, para determinar la corriente de corrosión, el sistema debe ser desplazado del equilibrio aplicando un potencial externo y midiendo la corriente neta resultante (alternativamente, aplicar una corriente conocida y medir el cambio resultante en potencial electroquímicomedidas galvano-estáticas) (medidas potencio-estáticas). La diferencia entre el potencial aplicado E, y el potencial de corrosión original $E_{\text {CORR }}$ se denomina polarización $(\eta)^{8}$.

En ausencia de pasividad, la corriente neta aumentaría con la polarización anódica y la polarización catódica resultaría ser menor. Tafel ha demostrado que para valores de $\eta$ comprendidos entre $\pm 100-200 \mathrm{mV}$, $\eta$ es directamente proporcional al logaritmo de la densidad de corriente ${ }^{8}$

$$
\mathrm{D}=\mathrm{a}+\mathrm{b} \cdot \log (\mathrm{i})
$$

donde $\eta$ es la polarización

a es una constante

b es la pendiente de Tafel

i es la intensidad de corrosión

\subsubsection{Protección del hormigón frente a la corrosión de las armaduras}

Los poros del hormigón contienen una disolución de alta alcalinidad $(\mathrm{pH} \approx 13)$ que le proporciona la portlandita $\left(\mathrm{Ca}(\mathrm{OH})_{2}\right)$ procedente de la hidratación del cemento, así como los alcalinos aportados por el cemento ${ }^{17}$.

El acero, cuando se sitúa en un ambiente alcalino como la solución de los poros del hormigón, desarrolla en superficie una capa pasiva de productos de corrosión. Dicha capa está compuesta por óxidos e hidróxidos de hierro y es muy densa. Con el tiempo, esta capa pasiva alcanza un espesor suficiente para proteger el metal base y la velocidad de corrosión se hace prácticamente nula. La corrosión no se 
iniciará si dicha capa permanece intacta, pero si el acero se despasiva, la corrosión activa se inicia ${ }^{15}$.

En cuanto a la naturaleza de la capa pasiva, ésta puede ser relativamente gruesa e inhibir la corrosión activa proporcionando una barrera ante la difusión de los productos de reacción ( $\mathrm{Fe}$ y $\mathrm{O}_{2}$ ) o con mayor frecuencia, puede ser fina, normalmente de un espesor menor que una capa molecular. En este caso, las moléculas de óxido simplemente ocupan los lugares de los átomos reactivos en la superficie del metal, evitando la disolución de estos átomos metálicos. Una capa pasiva realmente no frena la corrosión; sólo reduce la velocidad con que se produce hasta un nivel insignificante. Para el caso del acero en el hormigón, la velocidad de corrosión pasiva es normalmente 0,1 $\mu \mathrm{m} / \mathrm{año}$; sin embargo, en ausencia de capa pasiva, el acero se corroería a una velocidad al menos tres órdenes de magnitud mayor $(0,1 \mathrm{~mm} / \mathrm{año})^{8}$.

Las reacciones catódicas y anódicas dependerán, en cada caso, de la disponibilidad de oxígeno y del pH de la disolución en los poros de la pasta de cemento en las inmediaciones del acero. Esto se muestra en el diagrama de Pourbaix (Fig.4.2), que sirve para delimitar las zonas de peligro por corrosión o de estabilidad, ya que representa el equilibrio entre potencial eléctrico y $\mathrm{pH}$. El diagrama delinea las áreas termodinámicas de estabilidad para cada caso como una función entre el potencial electroquímico y el pH del ambiente, es decir, el diagrama establece para cada metal las condiciones de $\mathrm{pH}$ y de potencial en las que el metal se corroe, se encuentra en zona pasiva o permanece inmune $e^{2,8}$.

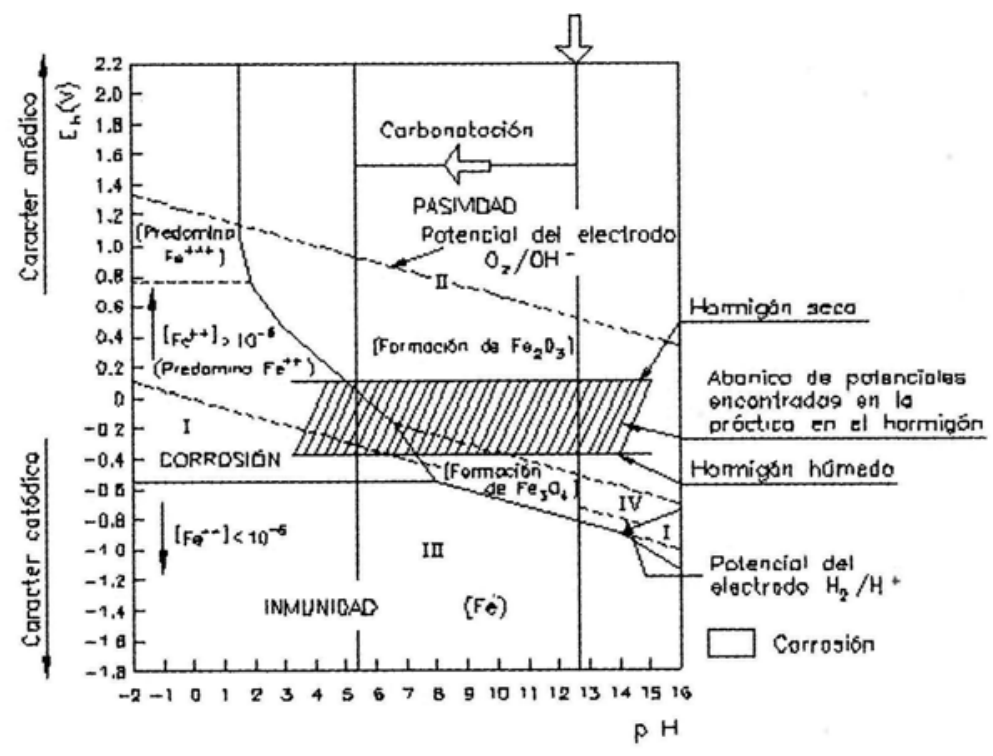

Fig.4.2. Diagrama de Pourbaix 
- Zona I: corrosión generalizada.

- Zona II: pasividad del acero. La existencia de cloruros puede destruir la capa pasiva y producir corrosión localizada por picaduras.

- Zona III: inmunidad. El hierro no pasa a estado anódico.

- Zona IV: pasividad, por formación de $\mathrm{Fe}_{3} \mathrm{O}_{4}$ y $\mathrm{Fe}_{2} \mathrm{O}_{3}$.

El potencial electroquímico es una medida de la facilidad de transferencia de carga eléctrica, en forma de electrones, entre un metal y su ambiente, en este caso, entre el acero de la armadura y la disolución sita en los poros de la pasta de cemento. Es una propiedad de la interfaz acero/hormigón y no sólo del acero. No es posible determinar el valor absoluto del potencial y por ello, en la práctica es necesario medir el potencial entre la superficie de acero y un electrodo de referencia, ya sea un electrodo de hidrógeno-SHE, un electrodo saturado de calomel-SCE o un electrodo $\mathrm{Cu} / \mathrm{Cu} \mathrm{SO}_{4}$-CSE. El valor del potencial en un sistema de corrosión libre es comúnmente conocido como potencial de corrosión, potencial de circuito abierto o potencial libre ${ }^{8}$.

Como consecuencia de la corrosión se forman diversos compuestos: hidróxido ferroso (verdoso), hidróxido férrico (rojizo) y óxido de hierro hidratado, este último compuesto es expansivo, pudiendo aumentar hasta un $600 \%$ el volumen de la barra de acero $^{2}$, produciendo la consecuente fisuración e incluso desprendimiento del recubrimiento de hormigón de la armadura.

\subsubsection{Despasivación de la armadura}

Ante el mecanismo de la corrosión, el acero cuenta con dos protecciones: la FíSICA (el recubrimiento de hormigón) y la QUÍMICA (el pH alcalino del hormigón, que favorece la formación de la capa pasiva) ${ }^{2}$. Esta capa protectora puede perderse por $^{2}$ :

- Pérdida de alcalinidad del hormigón.

El $\mathrm{CO}_{2}$ accede a través de los poros del hormigón, reaccionando de la forma siguiente:

$\mathrm{CO}_{2}+\mathrm{Ca}(\mathrm{OH})_{2} \rightarrow \mathrm{CaCO}_{3}+\mathrm{H}_{2} \mathrm{O}$ 
El dióxido de carbono penetra en el hormigón a través de sus poros por difusión y en presencia de humedad, reacciona con el hidróxido cálcico del cemento para formar carbonato cálcico, lo que elimina los iones hidroxilo de la solución de poros, reduciendo así el pH del hormigón. El consumo de hidróxido cálcico provoca una reducción del pH hasta valores no superiores a 9, lo que sitúa al acero fuera de la zona de pasividad y dentro de la de corrosión. Un efecto similar se produce si los álcalis del cemento son arrastrados por el agua, lo que puede ocurrir en puntos concretos en hormigones de baja calidad.

La carbonatación no es perjudicial para la integridad del hormigón hasta que llega a la armadura. En este momento, el pH cae por debajo de 9 ó 10, despasivándola y provocando la corrosión del acero si se encuentra en condiciones suficientes de agua y oxígeno.

La velocidad de carbonatación, que depende de la permeabilidad del hormigón a la penetración del dióxido de carbono, la humedad del hormigón y el contenido total de los productos de la hidratación, entre otros, es máxima cuando la humedad relativa se encuentra entre el 60 y el $75 \%$. Por otra parte, la corrosión del acero, en ausencia de cloruros, sólo es significativa si la humedad relativa es superior al $80 \%$.

Distintos estudios realizados sobre penetración de carbonatación y de cloruros concluyen que en hormigones de calidad media o alta, la velocidad de carbonatación es mucho menor que la de penetración por cloruros, por lo que la carbonatación apenas tendrá importancia en ambiente marino.

- Por la acción de los cloruros².

La corrosión por cloruros, que se describirá con mayor amplitud posteriormente, se produce por la pérdida de la capa pasiva en pequeñas áreas de la superficie, produciéndose así la llamada corrosión por picaduras, con reducción local de la sección de armadura en algunos casos. Es el proceso de corrosión habitual en ambiente marino aéreo, en el que se centra el presente estudio. 


\subsection{CORROSIÓN DEL ACERO POR LA ACCIÓN DE LOS CLORUROS}

\subsubsection{Mecanismo de rotura de la capa pasiva}

Como ya se ha citado en el apartado anterior, para que se inicie la corrosión debe producirse la desprotección del acero, bien sea por pérdida de alcalinidad del hormigón o por la acción de los cloruros².

La exposición del hormigón armado a los cloruros es la mayor causa de corrosión prematura en la armadura de acero, ya que aunque la carbonatación del hormigón reduce su alcalinidad, permitiendo así la corrosión de su armadura, se trata normalmente de un proceso más lento ${ }^{8}$.

En el caso de la corrosión por acción de cloruros presentes en la solución de poros del hormigón, éstos pueden provocar roturas localizadas en puntos de la capa protectora del acero. De este modo se forman pequeños ánodos de metal activo rodeados por grandes áreas catódicas de metal pasivo².

Así pues, el ataque por cloruros comienza con la picadura en los puntos débiles de la interfase acero-hormigón que se forman por caída local del pH, por huecos de aire debidos a una deficiente compactación, fisuras en el hormigón o defectos en la superficie de acero².

El mecanismo real de rotura de la capa pasiva por cloruros resulta difícil de examinar en las capas pasivas extremadamente finas (escala atómica). Se cree que los cloruros se incorporan a la película en pequeños puntos, creando defectos iónicos y facilitando su transporte hacia el interior. En el caso de pasividad de sub-capa, los cloruros pueden competir con los iones hidroxilo por localizaciones de alta actividad sobre la superficie del metal, evitando que estas zonas reactivas sean despasivadas ${ }^{8}$.

Los iones cloruro poseen un efecto catalítico en el proceso de la corrosión. Forman complejos solubles con los iones de hierro, que se difunden alejándose del ánodo. La formación de este tipo de compuesto puede consumir los iones de hierro libres en la solución y cambiar el equilibrio de las ecuaciones de formación de la capa pasiva (por ejemplo, cuando el citado 
compuesto llega a una región de elevado $\mathrm{pH}$ se rompe, precipitando en un hidróxido de hierro no soluble y liberando cloruros). Por otro lado, la presencia de nuevos iones cloruro aumenta la solubilidad de la capa pasiva. Este efecto catalítico es aún mayor en presencia de oxígeno, ya que los complejos de cloro no son estables en tal caso. Como resultado de todo ello, se produce una acidificación mayor y una liberación de iones cloruro. Esta corrosión se acelera en la propia picadura, es decir, la región de rotura local se convierte en ánodo, más cloruros son atraídos hacia él y la concentración de éstos aumenta. Este aspecto de retroalimentación diferencia la corrosión localizada de la galvánica ${ }^{2,8}$.

\subsubsection{Formación de Macropilas}

El hormigón armado con gradientes significativos de contenido de cloruros es vulnerable a la corrosión por formación de macro pilas, sobre todo, con los ciclos de humedad-sequedad. Estas condiciones se dan fundamentalmente en puentes de carretera y estructuras de aparcamiento expuestas a sales fundentes o bien situadas en ambientes marinos ${ }^{8}$.

Los cloruros aportados por los componentes del hormigón se distribuyen de modo uniforme y por lo general, no forman pilas, mientras que los cloruros procedentes del exterior no siguen una distribución uniforme y favorecen la formación de pilas 2,8 .

En el hormigón endurecido, el contenido de cloruros alrededor de la armadura no es uniforme debido a diferencias de concentración de los cloruros en la superficie del hormigón, a diferencias locales de permeabilidad y a posibles variaciones en el espesor de recubrimiento de la armadura, incluyendo el espacio entre capa superior e inferior. Todos estos factores suponen diferencias en el oxígeno, en la humedad y en los contenidos de cloruros alrededor de la armadura. Además, la mayoría de las estructuras tienen armaduras a distintas profundidades que normalmente se conectan eléctricamente. Por otro lado, cuando los cloruros penetran en el hormigón, algunas armaduras están en contacto con el hormigón contaminado de cloruros mientras que otras lo están con el hormigón libre de cloruros. Esta diferencia de concentraciones de cloruros dentro del hormigón crea una macro pila de corrosión con un gran voltaje de conducción y gran relación cátodo/ánodo que acelera la velocidad de corrosión ${ }^{8}$. 
En un estudio realizado en Japón ${ }^{50}$ se trataba de investigar de forma experimental y exhaustiva la formación de pilas en el proceso de la corrosión (micropilas y macropilas) así como la velocidad de corrosión empleando muestras de mortero con defectos simulando fisuras y/o juntas. Las probetas empleadas presentaban un ancho de fisura de $0,5 \mathrm{~mm}$ (valor superior al permitido por la normativa internacional y también por la Instrucción EHE, donde la abertura de fisura, en el caso más favorable de agresividad del ambiente, no debe superar $0,4 \mathrm{~mm}^{3}$ ).

En tal estudio se concluyó que, en la corrosión por cloruros, el descenso de la relación a/c $(0,3)$ aumentará la corrosión debida a macropilas. Por otro lado, el aumento de la relación a/c $(0,7)$ elevará la aparición de corrosión por micropilas. Además, una relación a/c más baja no necesariamente garantiza una velocidad de corrosión más baja. Por ejemplo, según esta experiencia, si los cloruros acceden por una junta (o un defecto o fisura) y sus alrededores cuando el ambiente está seco o con ciclos de humedad-sequedad, las muestras con relación $\mathrm{a} / \mathrm{c}=0,3$ muestran una velocidad de corrosión de

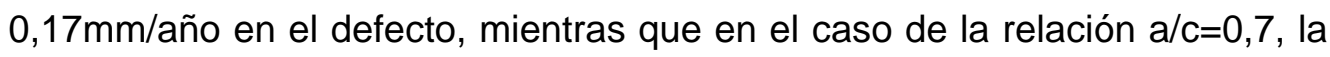
velocidad de corrosión fue de $0,04 \mathrm{~mm} / \mathrm{año}^{50}$, debido a la presencia de micropilas.

Respecto a la comparación en la formación de celdas de corrosión, se demostró que las macro-celdas prevalecen cuando existe una gran diferencia en el flujo de las sustancias corrosivas entre el mortero y la junta. Por contra, las micro-celdas prevalecen cuando la diferencia en el flujo de estas sustancias entre el mortero y la junta desciende ${ }^{50}$.

El mayor daño por corrosión siempre se concentra en la zona de armadura coincidente con el defecto o en zonas contiguas, produciéndose el daño incluso con a/c baja ${ }^{50}$.

Este tipo de macropilas se detectaron en las paredes de un muelle afectado por corrosión, donde se registraron medidas de resistividad en el hormigón entre 1,5 y $3,0 \mathrm{k} \Omega \cdot \mathrm{cm}$. A través de la pérdida de sección de barras en varios

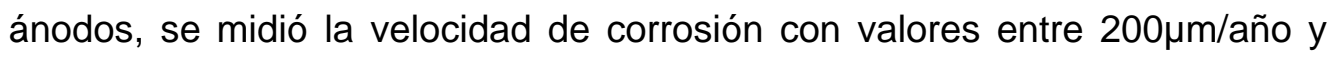
$400 \mu \mathrm{m} / a$ ño y hasta puntas de $600 \mu \mathrm{m} / a$ ño, valores similares a los obtenidos en estudios in situ y en laboratorio ${ }^{2,5}$. 


\subsubsection{Tipos de cloruros. Limitaciones de contenido para un hormigón más durable.}

\subsubsection{Cloruros internos y procedentes del exterior}

La procedencia de los cloruros puede ser interior, si provienen de los propios componentes del hormigón, o exterior, si se encuentran en el agua que circula por los poros ${ }^{2,8}$.

No es realista establecer un contenido nulo de cloruros en los ingredientes que componen el hormigón, ya que pequeñas trazas de ellos están presentes de forma natural en dichos componentes. Sin embargo, el riesgo de corrosión aumenta con el contenido de cloruros y superado cierto límite y en presencia de humedad y oxígeno que favorezcan las reacciones, la corrosión se produce. Es imposible establecer un umbral de cloruros único por debajo del cual el riesgo de corrosión sea despreciable para todos los ingredientes de la mezcla, bajo todas las condiciones de exposición y que pueda ser medido por un ensayo estándar ${ }^{8}$.

Cuando los cloruros se añaden a la mezcla, de forma intencionada o no, la corrosión puede ocurrir rápidamente en estados muy tempranos, cuando la mezcla aún se encuentra en estado plástico y la alcalinidad de la solución de los poros aún no se ha desarrollado. Una vez que el hormigón empieza a fraguar y el $\mathrm{pH}$ aumenta, hay un descenso general de la velocidad de corrosión, dependiendo de la concentración existente de cloruros $^{8}$.

Los cloruros añadidos a la mezcla tienen tres efectos adicionales sobre las velocidades de corrosión posteriores. Primero, se ha demostrado que el efecto acelerador de los cloruros supone una reducción de la finura de la red de poros para una relación agua/cemento constante, lo que permite un ingreso más rápido de los cloruros adicionales, velocidades de carbonatación mayores, y también reduce la resistividad del hormigón. Segundo, los cloruros aumentan la concentración iónica de la solución de los poros y su conductividad eléctrica. Ambos factores implican un aumento de la velocidad de corrosión. Tercero, los cloruros alteran el pH de la solución de los poros del hormigón, el cloruro sódico y potásico aumentan el $\mathrm{pH}$ mientras que el cálcico lo reduce. Por todo esto se deben 
cumplir los contenidos límites de cloruros internos ${ }^{8}$, recogidos en la normativa (ver apartado 4.4.6.2, requisitos normativos).

Por otro lado en el caso de los cloruros exteriores, éstos interactúan químicamente con la pasta de cemento, precipitando productos de reacción (cloruros combinados descritos en el apartado siguiente), disminuyendo así la porosidad de la citada pasta, si bien este efecto depende del tipo de cemento y es un mecanismo que retrasa ligeramente el avance de los cloruros ${ }^{8}$.

\subsubsection{Cloruros libres y combinados}

Los cloruros pueden encontrarse en el hormigón combinados (unidos química o físicamente a los minerales del cemento o a los productos de hidratación) o bien libres en la solución de los poros del hormigón².

Existe diversidad de opiniones entre el porcentaje de cloruros libres y combinados pero sí se afirma que la elevada presencia de aluminato tricálcico, $\left(\mathrm{C}_{3} \mathrm{~A}\right)$ en el cemento contribuye a aumentar los iones cloruro fijados, que los iones hidroxilo hacen disminuir la cantidad de cloruros en disolución y que una mayor cantidad de sulfato cálcico favorece la corrosión, ya que afecta significativamente a la relación $\mathrm{Cl} / \mathrm{OH}$ Asimismo, la temperatura y duración del curado así como el $\mathrm{pH}$ del hormigón afectan a la capacidad de fijar cloruros².

En cuanto a la influencia de emplear adiciones sobre la capacidad de fijación de cloruros al hormigón, cabe decir que, en general la incorporación de cenizas o escorias supone la reducción del contenido de cloruros fijados. En el caso del humo de sílice, si se sustituye al cemento por esta sustancia, se reduce intensamente la fijación de cloruros².

Con objeto de conocer el contenido de cloruros en el hormigón se puede medir la concentración de cloruros libres o totales, lo que resulta un tema controvertido. La concentración de cloruros libres se mide mediante la concentración de cloruros solubles en agua (cloruros extraíbles del agua bajo condiciones definidas) y la de cloruros totales mediante la concentración de cloruros solubles en ácido (ácido nítrico). Normalmente, los cloruros solubles en ácido coinciden con los cloruros totales, pero no 
siempre. La diferencia entre los dos valores es la concentración de cloruros combinados. Los resultados varían según el procedimiento de análisis, sobre todo respecto al tamaño de partícula, tiempo de extracción, temperatura, edad y ambiente de exposición. Ha sido discutido que los cloruros combinados fueran susceptibles de iniciar o propagar la corrosión, sin embargo, se ha demostrado que según avanza la corrosión, los combinados pueden liberarse y pasar a estar disponibles para continuar con el proceso de la corrosión ${ }^{8,15}$.

A pesar de que los peligrosos frente al ataque por corrosión son los cloruros libres, la mayoría de las normativas limitan el contenido de cloruros totales, ya que una simple bajada del pH del hormigón liberaría cloruros combinados, pasando a ser libres y así susceptibles de producir corrosión².

\subsubsection{Limitaciones al contenido de cloruros en el hormigón}

Investigaciones de la Administración Federal de Carreteras de Estados Unidos mostraron que para el hormigón sometido a la acción de cloruros externos, el contenido límite de cloruros era de 0,20\% del peso de cemento para los cloruros solubles en ácido. El contenido medio de cloruros solubles en agua resultó ser $75-80 \%$ del contenido de cloruros solubles en ácido ${ }^{8}$.

Otras fuentes indican que cuando la concentración de cloruros totales procedentes del exterior es menor al 0,4\%, la cantidad de cloruros en la disolución de los poros resulta despreciable y no supone riesgo para la corrosión de armaduras ${ }^{2}$.

En el apartado 4.4.6.2 (requisitos normativos) se recogen los límites aplicados por diferentes normativas.

La tabla 4.1 indica los límites de cloruros en nuevas construcciones según diferentes normativas $8,18,19,20,64,65,21$, que se relacionan a continuación. Esta tabla aparece más desarrollada en el anejo $n^{\circ} 2$ referente a la concentración crítica de cloruros: 
- ASTM C1152 "Standard Test Method for Acid Soluble Chloride in Mortar and Concrete".

- ASTM C1218 "Standard Test Method for Water Soluble Chloride in Mortar and Concrete"

- $\mathrm{ACl}$ 318-95 Building Code Requirements for Structural Concrete and Commentary

- EHE "Instrucción del Hormigón Estructural"

- British Standard Code for concrete structure CP 110

- NS 3420-L "Specifications texts for building, construction and installations. Part L: Concrete Works."

\begin{tabular}{|c|c|c|c|c|c|c|}
\hline \multirow{3}{*}{ NORMATIVA } & \multicolumn{6}{|c|}{ Contenido Límite de $\mathrm{Cl}^{-}$para nuevas construcciones (\% por masa de cemento) } \\
\hline & \multicolumn{3}{|c|}{$\mathrm{Cl}^{-}$solubles en ácido } & \multicolumn{3}{|c|}{$\mathrm{Cl}^{-}$solubles en agua } \\
\hline & H.Pretensado & $\begin{array}{c}\text { H.Armado } \\
\text { Húmedo }\end{array}$ & $\begin{array}{c}\text { H.Armado } \\
\text { Seco }\end{array}$ & H.Pretensado & $\begin{array}{l}\text { H.Armado } \\
\text { Húmedo }\end{array}$ & $\begin{array}{c}\text { H.Armado } \\
\text { Seco }\end{array}$ \\
\hline ASTM C 1152 & 0,08 & 0,10 & 0,20 & ב-- & "-- & ב-- \\
\hline "ASTM C 1218 & ב-- & "-- & "-- & 0,06 & 0,08 & 0,15 \\
\hline ACI 318-95 & -- & -- & -- & 0,06 & $\begin{array}{c}0,015 \\
\text { (expuesto) }\end{array}$ & $\begin{array}{c}1,00 \\
\text { (protegido) }\end{array}$ \\
\hline EHE & 0,2 & \multicolumn{2}{|c|}{0,4} & \multicolumn{3}{|c|}{-- } \\
\hline СР 110 & \multicolumn{3}{|c|}{0,35} & --- & ב-- & -- \\
\hline "NS 3420-L & 0,002 & \multicolumn{2}{|c|}{0,6} & --- & ב-- & --- \\
\hline CEB & \multicolumn{6}{|c|}{ 0,4 (no especifica si en ácido o en agua) } \\
\hline Univ. Kyoto & 0,1 & \multicolumn{2}{|c|}{0,2} & & & \\
\hline
\end{tabular}

Tabla.4.1. Límites de Cloruros en construcciones según normativas de distintos países 


\subsubsection{Factores que influyen en la corrosión ${ }^{2.8}$}

Los factores que intervienen en la corrosión son múltiples, tal como se refleja en la tabla $4.2^{8}$ :

\begin{tabular}{|c||c||}
\hline Intervienen en la Corrosión & Factores de Influencia \\
\hline \hline Cloruros en el Aire & $\begin{array}{c}\text { Diferencias regionales por viento } \\
\text { Reducción de cloruros en aire a mayor } \\
\text { distancia de la costa }\end{array}$ \\
\hline \hline Cloruros en Superficie & Diferencias locales en la misma estructura \\
\hline Espesor de Recubrimiento & Establecido en el diseño \\
& Errores en el encofrado \\
& Disminución durante el hormigonado \\
\hline \hline Corrosión en el Hormigón & Alcalinidad elevada \\
& Cloruros presentes en el propio hormigón \\
& Presencia de agua y oxígeno \\
\hline \hline Permeabilidad a Cloruros & Calidad y tipo de hormigón \\
& Relación a/c \\
& Condiciones de construcción \\
& Deterioros \\
\hline \hline
\end{tabular}

Tabla.4.2. Factores que intervienen en la corrosión

Para que se produzca la corrosión, además de la despasivación, local o generalizada, es indispensable la presencia de humedad y oxígeno, esenciales para que se dé la corrosión a un ritmo significativo ${ }^{8}$.

De los factores listados en la tabla anterior, los principales son la calidad del hormigón de recubrimiento (espesor, a/c) y el microclima en la superficie expuesta. Seguidamente se detallan los factores listados que influyen en la corrosión:

- Recubrimiento 2,8 :

Se requiere impermeabilidad y espesor (entre $25-40 \mathrm{~mm}$ ). Sin embargo, el espesor de recubrimiento influye sobre el valor de tolerancia de cloruros para anchuras de fisura hasta $0,4 \mathrm{~mm}^{8}$. 
La permeabilidad depende del curado y de la compactación del hormigón, así como de su relación a/c. A nivel superficial y con una exposición limitada a los cloruros, la relación a/c afecta. En profundidad y con una exposición prolongada, afecta fundamentalmente el tipo de cemento ${ }^{8}$.

En la figura 4.3 puede observarse el efecto combinado entre la profundidad de recubrimiento y la relación $a / c^{8}$.

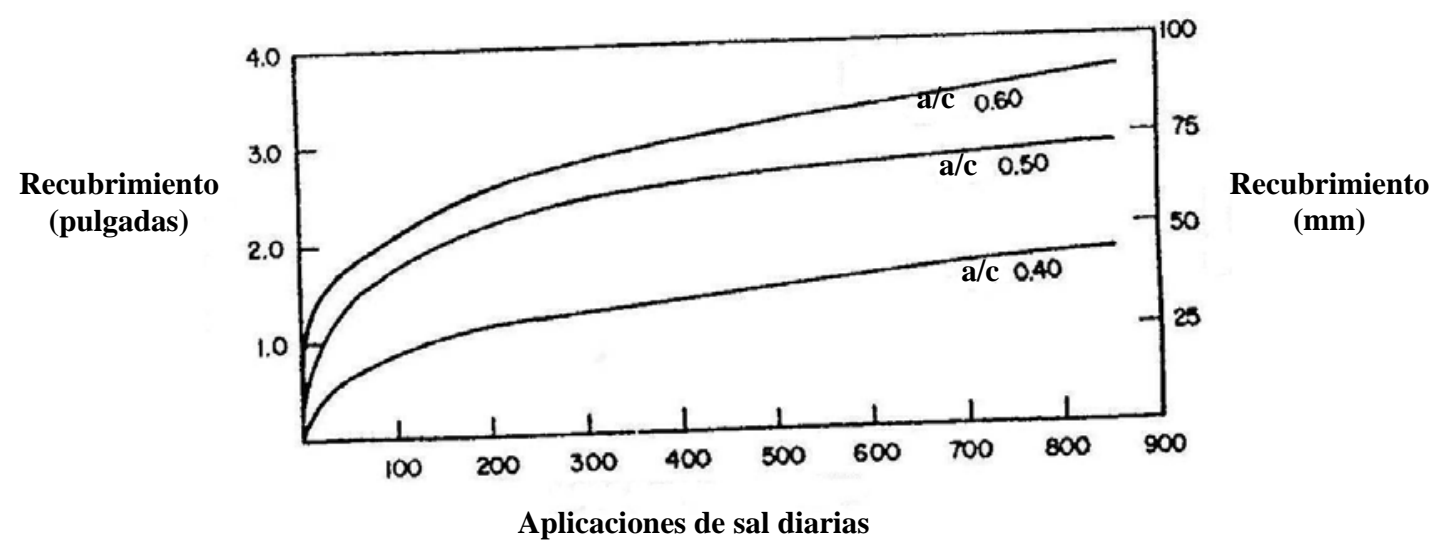

Fig. 4.3. Efecto de la relación a/c y la profundidad de recubrimiento en relación al tiempo para que comience la corrosión

El $\mathrm{ACl} 201.2 \mathrm{R}^{22}$ recomienda un recubrimiento mínimo de $50 \mathrm{~mm}$ para la armadura superior de tableros de puente con relación a/c de 0,40 y 65 $\mathrm{mm}$, cuando a/c es 0,45 . Es importante que se cumplan estas especificaciones, considerando las tolerancias de colocación en obra, los métodos de construcción y el nivel de inspección empleados ${ }^{8}$.

Para una vida útil de 50 años ${ }^{7}$, incluso en ambiente severo, el mínimo recubrimiento requerido para puentes de hormigón postesado era $35 \mathrm{~mm}$ hasta que se estableció la Guía de Especificaciones de Japón en 1984. Este recubrimiento no resultaba suficiente para las estructuras situadas a pocos cientos de metros desde la costa cuando la relación a/c es 0,43 (figura 4.4). La figura 3.2.b demuestra que el mínimo recubrimiento de 25 $\mathrm{mm}$ para puentes de hormigón pretensado prefabricado empleado hasta entonces no era suficiente para a/c de 0,36. Esto se corresponde con la existencia de muchos puentes de hormigón deteriorados en estas regiones en el pasado. 
Los puentes construidos con hormigón de relación a/c $=0,36$ y situados a más de $300 \mathrm{~m}$ de la costa requerían un recubrimiento inferior al mínimo de $25 \mathrm{~mm}$ requerido para hormigón pretensado prefabricado, lo que se corresponde con que la corrosión de este tipo de puentes es poco usual en esta zona ${ }^{7}$ (figura 4.5).

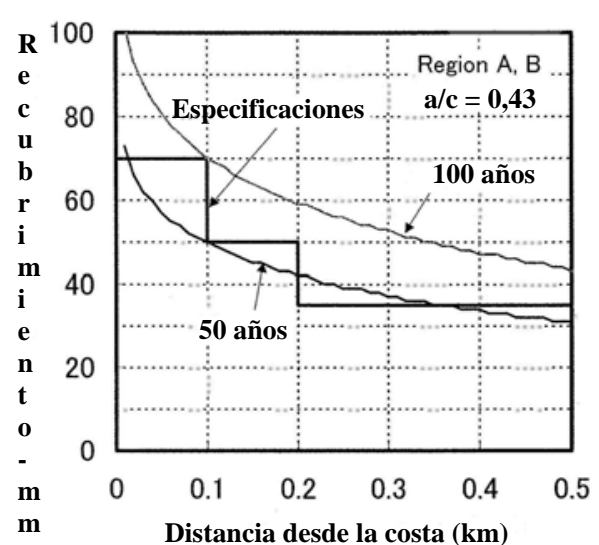

Fig.4.4. Recubrimiento requerido hormigón postesado $a / c=0,43$

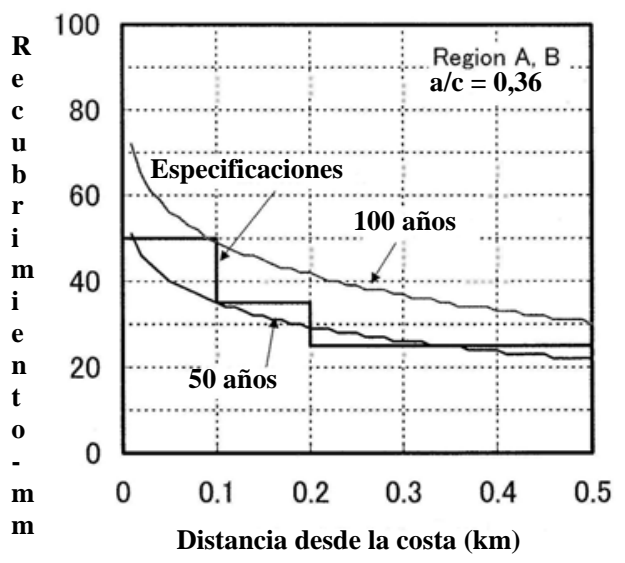

Fig.4.5. Recubrimiento requerido hormigón postesado $a / c=0,36$

Para el caso de la vida útil de 100 años, los resultados también se reflejan en las figuras anteriores. Si el periodo de vida útil se aumenta a 100 años, es necesario expandir el área donde se necesita un mayor recubrimiento. Para $\mathrm{a} / \mathrm{c}=0,43$ y vida útil de 100 años, el mínimo recubrimiento requerido de $70 \mathrm{~mm}$ en el caso de vida útil de 50 años (dentro de los 100 metros desde la costa en Región A y B o dentro de los 20 metros en Región C) no es suficiente. Sobre todo en superestructuras, es necesario afinar la estructura de poros del hormigón o aplicar una protección epoxy a las barras, ya que demasiado recubrimiento aumenta el peso propio de la estructura y el riesgo de fisuración por retracción?.

En Japón7, la tabla 4.3 establece el mínimo recubrimiento requerido según la distancia a costa (Nivel I, II y III, ver apartado 4.4.1) y el tipo de elemento de que se trate: 


\begin{tabular}{|c|c|c|c|c|c|}
\hline \multirow{3}{*}{ NIVEL } & \multicolumn{3}{|c|}{ Superestructura } & \multicolumn{2}{|c|}{ Subestructura } \\
\hline & \multirow{2}{*}{$\begin{array}{c}\text { Fondo de } \\
\text { tablero, borde } \\
\text { o bordillo }\end{array}$} & \multicolumn{2}{|c|}{ Viga } & \multirow[b]{2}{*}{ Viga } & \multirow[b]{2}{*}{ Pila } \\
\hline & & $\begin{array}{l}\text { H. prefabricado } \\
\text { pretensado }\end{array}$ & Otro tipo & & \\
\hline$\overline{I I}$ & 50 & 50 & 70 & 70 & 70 \\
\hline II & 40 & 35 & 50 & 50 & 50 \\
\hline III & 30 & 25 & 35 & 35 & 40 \\
\hline
\end{tabular}

Tabla.4.3. Recubrimiento mínimo (en mm) en estructuras según distancia a la costa

Dicha tabla se ve ligeramente modificada por la tabla 4.4 en la que se indica la mínima profundidad de recubrimiento (expresada en $\mathrm{mm}$ ) requerida en función del nivel de daño por sales. Se definen dos niveles de daño: "S" que corresponde a daño severo y "I, II y III" que corresponden a daños moderados. Más adelante, cuando se hace mención a los subambientes dentro del ambiente marino en Japón, se indican las condiciones de entorno que definen los dos niveles de daño (localización regional y distancia a costa). La tabla 4.4 pertenece a las Japanese Specifications for Highway Bridges (SHB, 2002) ${ }^{76}$.

\begin{tabular}{|c||c||c|}
\hline Nivel de daño por sales & Condiciones Entorno & Vigas-Pilares-Muros \\
\hline \hline Efecto Severo & S & $90^{(*)}$ \\
\hline \multirow{2}{*}{ Efecto Moderado } & I & 90 \\
\cline { 2 - 3 } & II & 70 \\
\cline { 2 - 3 } & III & 50 \\
\hline
\end{tabular}

${ }^{(*)}$ Este recubrimiento debe acompañarse del uso de armaduras protegidas, empleando protecciones superficiales o aplicándolas en el molde.

Tabla.4.4. Recubrimiento mínimo (en mm) en estructuras según SHB, Japón

De forma análoga a lo establecido por Japón, en España la Instrucción $\mathrm{EHE}^{3}$ plantea la tabla 4.5 donde se indica el recubrimiento mínimo requerido para la clase general de exposición III: 


\begin{tabular}{|c|c|c|c|c|c|}
\hline \multirow{2}{*}{ Hormigón } & \multirow{2}{*}{ Cemento } & \multirow{2}{*}{$\begin{array}{l}\text { Vida Útil } \\
\text { Proyecto } \\
\text { ( } \mathrm{t}_{\mathrm{g}} \text { en } \\
\text { años) }\end{array}$} & \multicolumn{3}{|c|}{ Clase General de Exposición } \\
\hline & & & IIIa & IIIb & IIIc \\
\hline \multirow{4}{*}{ Armado } & \multirow{2}{*}{$\begin{array}{l}\text { CEM III/A, CEM III/B, CEM } \\
\text { IV, CEM II/B-S, B-P, B-V, A- } \\
\text { D u hormigón con adición de } \\
\text { microsílice superior al 6\%. }\end{array}$} & 50 & 25 & 30 & 35 \\
\hline & & 100 & 30 & 35 & 40 \\
\hline & \multirow{2}{*}{ Resto cementos utilizables } & 50 & 45 & 40 & $*$ \\
\hline & & 100 & 65 & $*$ & $*$ \\
\hline \multirow{4}{*}{ Pretensado } & \multirow{2}{*}{$\begin{array}{l}\text { CEM II/A-D o bien con } \\
\text { adición de humo de sílice } \\
\text { superior al } 6 \%\end{array}$} & 50 & 30 & 35 & 40 \\
\hline & & 100 & 35 & 40 & 45 \\
\hline & \multirow{2}{*}{$\begin{array}{c}\text { Resto de cementos utilizables } \\
\text { según Art. } 26^{\circ}\end{array}$} & 50 & 65 & 45 & $*$ \\
\hline & & 100 & $*$ & $*$ & $*$ \\
\hline
\end{tabular}

El $\left({ }^{*}\right)$ significa que tales situaciones obligarían a unos recubrimientos excesivos, desaconsejable desde el punto de vista de ejecución del elemento.

\section{Tabla.4.5.Recubrimiento mínimo en estructuras según Instrucción EHE}

La diferencia entre normativas es que en el caso de Japón se especifica únicamente el tipo de elemento y en el caso de España, el recubrimiento depende del tipo de hormigón, tipo de cemento y vida útil.

- Relación agua-cemento y adecuada compactación ${ }^{8}$

Cuando el hormigón está expuesto a los cloruros, debe tener una relación a/c lo más baja posible compatible con una adecuada compactación, ya que una baja relación a/c por sí sola no es suficiente para asegurar una baja permeabilidad, como se muestra en las figuras 4.6 y $4.7^{8}$ : 


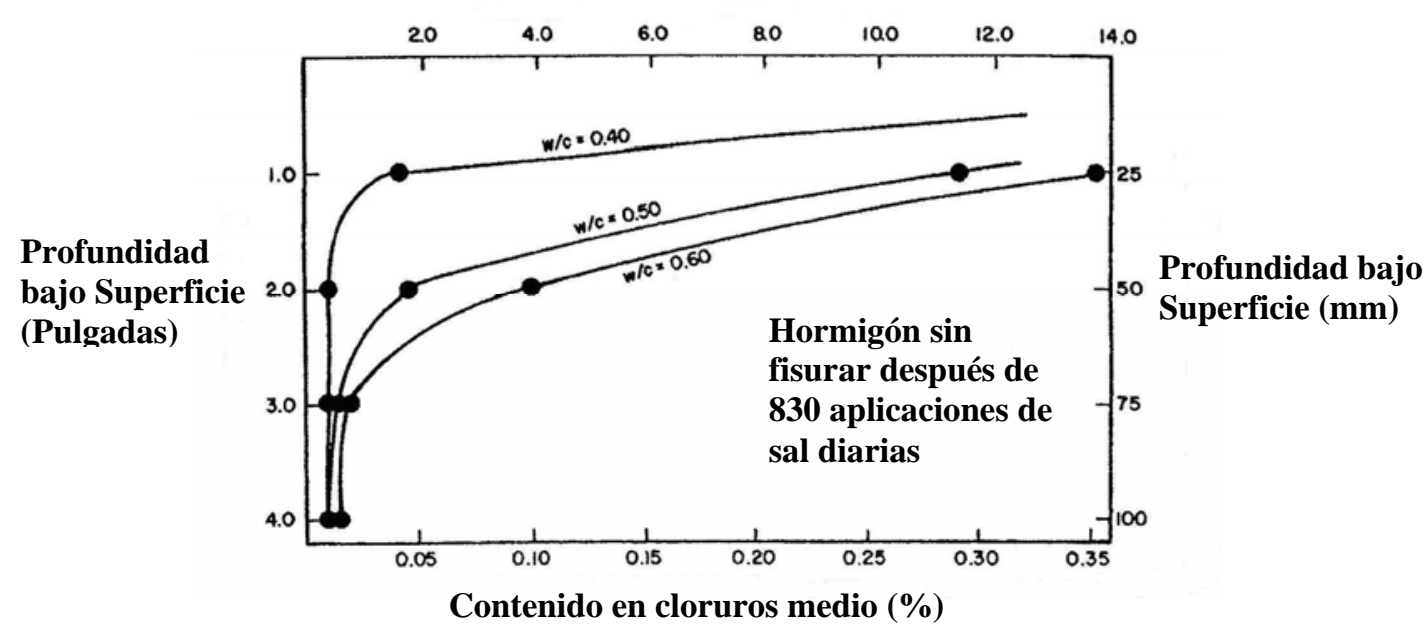

Fig.4.6. Efecto de la relación a/c en la penetración de cloruros

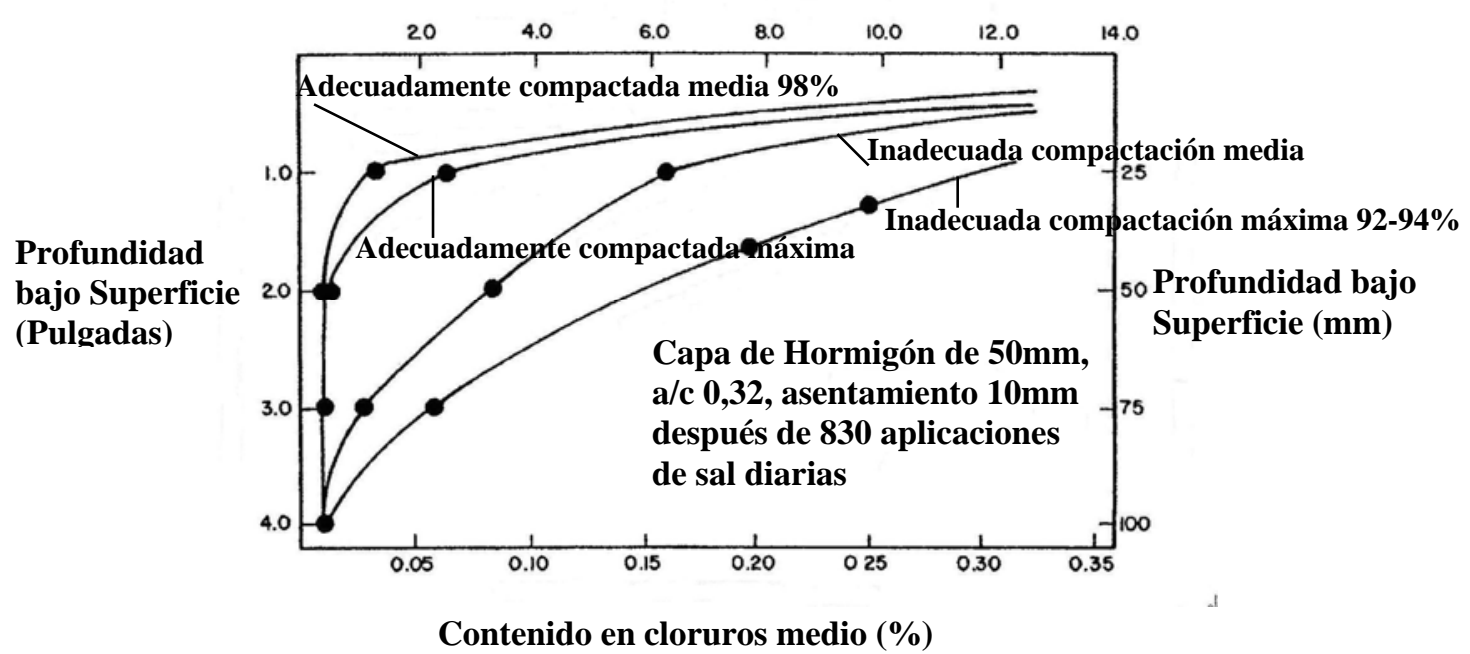

Fig.4.7. Efecto de la compactación en la penetración de cloruros

De acuerdo con lo establecido por la JSCE ${ }^{88}$, la relación a/c máxima para hormigón situado en ambiente marino según criterios de durabilidad no debe superar lo establecido en la tabla 4.6. En el caso de emplear hormigón en masa con aire ocluido, las relaciones a/c podrían ser un $10 \%$ mayores que los valores aportados: 


\begin{tabular}{|c|c|c|}
\hline $\begin{array}{c}\text { Condiciones de } \\
\text { construcción o ambientales }\end{array}$ & $\begin{array}{c}\text { Construcción } \\
\text { Normal }\end{array}$ & $\begin{array}{c}\text { Productos prefabricados u hormigón } \\
\text { cuya calidad garantiza ser igual o } \\
\text { superior de los elaborados en planta por } \\
\text { el empleo de materiales adecuados y } \\
\text { buena ejecución }\end{array}$ \\
\hline $\begin{array}{c}\text { Por encima de la superficie } \\
\text { del agua }\end{array}$ & 45 & 50 \\
\hline Zona de salpicaduras & 45 & 45 \\
\hline Zona sumergida & 50 & 50 \\
\hline
\end{tabular}

Tabla 4.6. Máxima relación a/c para hormigón con aire ocluido con consideración de la durabilidad (\%)

Nota: Si se dispone de resultados experimentales u procedentes de obras reales, las relaciones a/c máximas a emplear pueden fijarse un 5-10\% mayores que las presentadas en la tabla.

Puede observarse la exigencia de una relación a/c más baja en el caso de la construcción normal que la realizada con alta calidad, en prefabricación, etc. En cuanto a los ambientes y para construcción normal, la relación a/c exigida es igual en el caso de la zona de salpicaduras que en la zona situada por encima de la superficie del agua lo que implica que para este nivel de construcción ambos ambientes resultan igualmente pésimos. Sin embargo para el caso de la construcción prefabricada o de calidad más controlada, resulta pésima la zona de salpicaduras. En el caso de poder aportar resultados de ensayos o de la propia obra que supongan conocer de forma más fiable el comportamiento de la estructura frente a la durabilidad, las especificaciones $^{88}$ permiten aumentar las relaciones a/c en un 5-10\%.

- Contenido de cemento:

Cantidades de cemento próximas a $300 \mathrm{~kg} / \mathrm{m}^{3}$ consiguen hormigones de permeabilidad baja.

Según las especificaciones japonesas de la JSCE $^{88}$, el contenido de cemento del hormigón situado en ambiente marino debe cumplir los requisitos recogidos en la tabla 4.7 para conseguir la durabilidad requerida teniendo en cuenta el ambiente y el tamaño de árido máximo: 


\begin{tabular}{|c|c|c|}
\hline \multirow{2}{*}{ Condiciones ambientales } & \multicolumn{2}{c|}{ Tamaño máximo de árido grueso } \\
\cline { 2 - 3 } & $25 \mathrm{~mm}$ & $40 \mathrm{~mm}$ \\
\hline \hline $\begin{array}{c}\text { Salpicaduras y sobre la superficie } \\
\text { del agua }\end{array}$ & 330 & 300 \\
\hline \hline Zona sumergida & 300 & 280 \\
\hline \hline
\end{tabular}

Tabla 4.7. Mínimo contenido de cemento considerando criterios de durabilidad $\left(\mathrm{kg} / \mathrm{m}^{3}\right)$

- Tipo de cemento:

En cuanto a la influencia del tipo de cemento sobre el coeficiente de difusión de cloruros, según un estudio realizado en Japón sobre el recubrimiento requerido en estructuras próximas a la costa ${ }^{7}$, la diferencia entre los coeficientes de difusión de los hormigones obtenidos a partir de cemento convencional, de fraguado rápido o de bajo calor de hidratación es pequeña para la misma relación a/c. La influencia, sin embargo puede ser elevada si se utilizan cementos con adiciones o bien éstas se incorporan directamente al hormigón.

Así lo demuestran los datos analizados para observar la variación de la concentración de cloruros en superficie y el coeficiente de difusión tomados de 26 tableros de puentes situados en ambiente de sales fundentes, en Virginia, Estados Unidos ${ }^{14}$. Tales datos fueron separados en dos grupos: los relativos a tableros de hormigón convencional con relación $\mathrm{a} / \mathrm{c}=0,45$ y los referentes a hormigón de baja permeabilidad con igual relación a/c, pero que contenían adiciones puzolánicas. Los resultados medios pueden observarse en la tabla 4.8:

\begin{tabular}{|c||c||c||}
\hline Parámetro & $\begin{array}{c}\text { H. Convencional } \\
(\mathbf{a} / \mathbf{c m}=\mathbf{0 , 4 5})\end{array}$ & $\begin{array}{c}\text { H. Baja Permeabilidad } \\
\mathbf{( a / c m = 0 , 4 5 )}\end{array}$ \\
\hline \hline Cloruros en Superficie $\left(\mathrm{kg} / \mathrm{m}^{3}\right)$ & 3,47 & 3,95 \\
\hline \hline Recubrimiento $(\mathrm{mm})$ & 59,4 & 61,5 \\
\hline \hline Coeficiente Difusión $\left(\mathrm{mm}^{2} / \mathrm{año}\right)$ & 26,3 & 3,45 \\
\hline \hline
\end{tabular}

Tabla 4.8. Influencia del uso de adiciones en los valores de contenido de cloruros en superficie y coeficiente de difusión con similares a/c y recubrimientos

La referencia ${ }^{1}$ realizó un estudio específico de la influencia de las adiciones (ceniza volante y humo de sílice) sobre el coeficiente de 
difusión del hormigón sumergido y en carrera de mareas. Se concluyó que el coeficiente de eficacia de estas adiciones, en cuanto a la difusión de cloruros, tenía un valor de 1,31 para la ceniza volante (carrera de mareas) y de 6,42 y 5,56 para el humo de sílice (en carrera de mareas y sumergido, respectivamente) (datos analizados incluyendo estructuras reales). Estos coeficientes de eficacia hacen que ${ }^{1}$, en el caso de carrera de mareas, la relación a/c límite a partir de la cual se dispara el coeficiente de difusión de cloruros podría tomarse como 0,55 en el caso de cemento Pórtland sin adiciones y 0,70 para el caso de cemento con humo de sílice o cenizas volantes; en el caso del ambiente sumergido, la relación a/c podría tomarse como 0,45 para el hormigón de cemento Pórtland y 0,55 para hormigones de cemento con adición de humo de sílice.

Por otra parte, en ambiente marino hay que tener en cuenta que los cementos sulforresistentes fijan menos cloruros (mayor riesgo de corrosión), por lo que en este ambiente y en cuanto al contenido de aluminatos de calcio, $\mathrm{C}_{3} \mathrm{~A}$, éste debería estar comprendido entre el $4 \%$ y el $10 \%$ del peso de cemento, para permitir la formación de capa pasiva y a la vez, resistir al ataque por sulfatos. En ambientes de carbonatación, los cementos Pórtland sin adiciones aportan mayor reserva alcalina y con ello, una mayor protección contra la corrosión. En todos los casos, los cementos con adiciones (escorias, puzolanas...) dan lugar, en general, a hormigones más impermeables.

En un estudio realizado en la ría de Huelva con bloques de hormigón parcialmente enterrados $(50 \times 50 \times 200 \mathrm{~cm})^{39}$, se obtienen los siguientes perfiles de cloruros de hormigones fabricados a partir de cemento Pórtland ordinario y cemento Pórtland resistente a los sulfatos, ambos con un contenido en cemento de $350 \mathrm{~kg} / \mathrm{m}^{3}$. Puede observarse (salvo alguna medida puntual) la escasa influencia del tipo de cemento en la difusión y por ende, en la corrosión. La relación a/c era de 0,5 y los recubrimientos de $3 \mathrm{~cm}$, como puede verse en las fig 4.8 y 4.9 . 


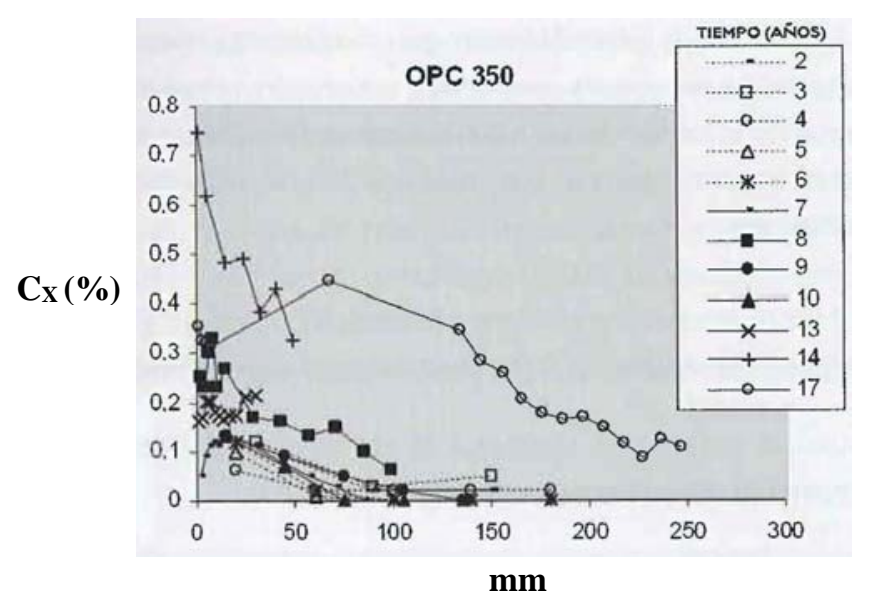

Fig.4.8. Perfiles de cloruros de los hormigones de cemento Pórtland (350 kg/m ${ }^{3}$ cemento)

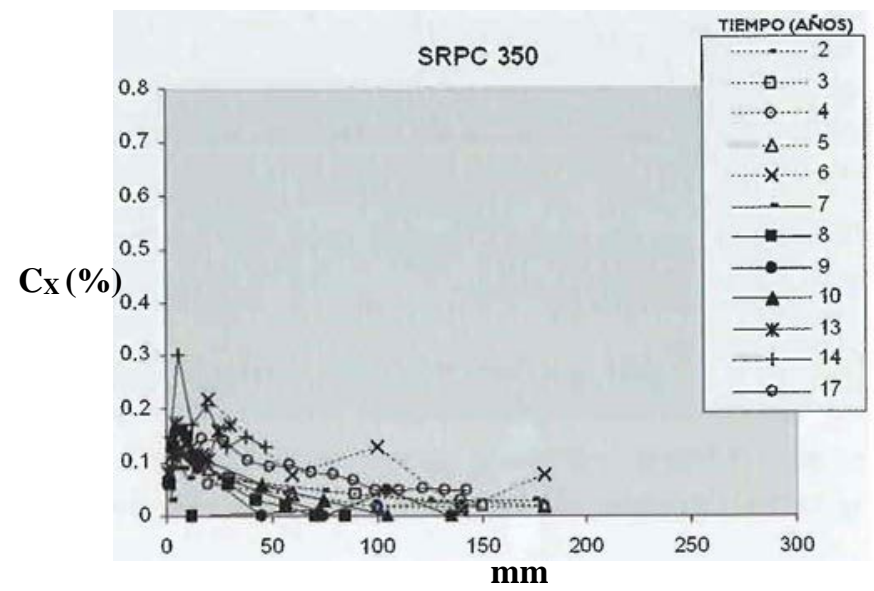

Fig.4.9. Perfiles de cloruros de los hormigones de cemento Pórtland sulforresistente (350 $\mathrm{kg} / \mathrm{m}^{3}$ cemento)

- Estado superficial del acero:

El estado superficial del acero resulta controvertido. Si el acero ha estado expuesto, tiene óxido que dificulta la pasivación y queda desprotegido. Sin embargo, algunos consideran la propia película de óxido como una protección.

- Condiciones ambientales (humedad, temperatura...):

En cuanto al efecto de la temperatura, su incremento favorece el aumento de la velocidad de corrosión, pero su disminución puede provocar condensación y con ella, incrementos locales de contenido de humedad. 
La velocidad de ingreso de cloruros así como el mojado, secado y efecto de la concentración de sales en la penetración de cloruros son sensibles a la temperatura. En la referencia ${ }^{4}$ se realizó un ajuste de los coeficientes de difusión estimados a $8^{\circ} \mathrm{C}$ para obtener los valores a $23^{\circ} \mathrm{C}$, mediante la ecuación de Aarhenius4:

$$
D_{\mathrm{e}}\left(8^{\circ} \mathrm{C}\right)=0,47 \cdot D_{\mathrm{e}}\left(23^{\circ} \mathrm{C}\right)
$$

Los valores del coeficiente de difusión a temperatura ambiente $\left(21^{\circ} \mathrm{C}\right)$ están relacionados con los valores correspondientes a una temperatura estándar según la expresión ${ }^{68}$, donde $21^{\circ} \mathrm{C}$ equivale a $294 \mathrm{~K}$ :

$$
D(T)=D_{294 K} \cdot \frac{T}{294} \cdot \exp \left[-\frac{E_{A}}{R}\left(\frac{1}{T}-\frac{1}{294}\right)\right]
$$

A continuación se expone la tabla 4.9 donde se recoge el valor de la energía de activación ${ }^{68}$ para la difusión de cloruros recogida por Saetta et al (1993) para pastas de cemento Pórtland elaboradas con distintas relaciones a/c. Las pastas de cemento con una estructura de poros más

\begin{tabular}{|c|c|}
\hline Relación a/c & $\bar{E}_{\mathrm{A}}(\mathrm{kJ} / \mathrm{mol})$ \\
\hline 0,4 & $41,8 \pm 4,0$ \\
\hline 0,5 & $44,6 \pm 4,3$ \\
\hline 0,6 & $32,0 \pm 2,4$ \\
\hline
\end{tabular}
abierta (mayor relación a/c) presentan valores más bajos de $\mathrm{E}_{\mathrm{A}}$.

Tabla 4.9. Valores de la energía de activación según a/c

En la referencia ${ }^{68}$ se indica la siguiente figura 4.10 donde se refleja el efecto de la temperatura en la probabilidad de fallo de una estructura a lo largo del tiempo. 
Probabilidad de fallo $(\%)$

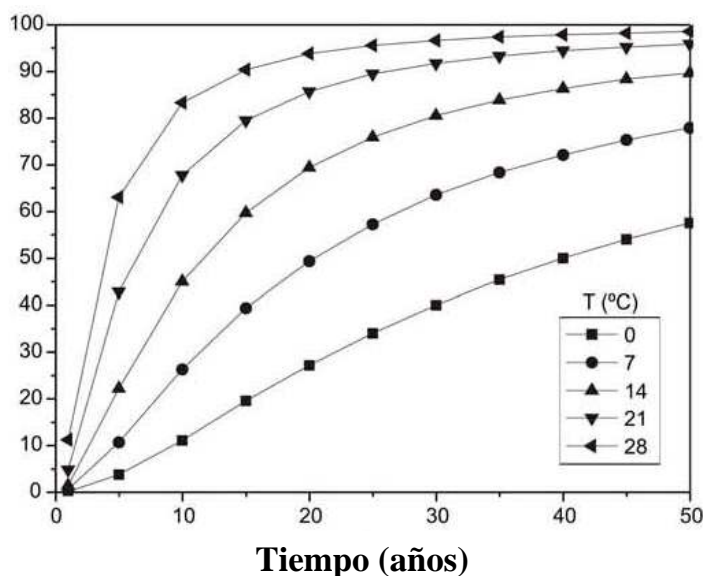

Fig.4.10. Efecto de la temperatura en la probabilidad de fallo a lo largo del tiempo

Referente a la humedad, en ambiente seco (con valores de humedad relativa por debajo del 60\%), o muy húmedo, el riesgo de corrosión es bajo. El secado del hormigón endurecido requiere el transporte y evaporación del vapor de agua desde la superficie. El hormigón seco se humedece por succión capilar, proceso generalmente más rápido que su secado. Por ello, raramente el hormigón se encuentra totalmente seco, salvo una capa fina superficial. Por debajo de ella, suele existir humedad en las paredes de sus capilares y cuellos de botella del sistema de poros. Dado que la difusión del oxígeno disuelto es aproximadamente cuatro órdenes de magnitud menor que la del oxígeno gaseoso, éste será primero el proceso de control de la velocidad en condiciones de humedad relativa normal ${ }^{8}$.

Los estudios de laboratorio sugieren que existe un límite de humedad relativa dentro del hormigón, en el rango del $70-85 \%$ por debajo del cual la corrosión activa no se produce ${ }^{8}$.

- Resistividad eléctrica:

La elevada resistividad eléctrica puede inhibir el paso de la corriente de corrosión a través del hormigón. Esto es muy importante en el caso de las macro-pilas, donde existe una separación significativa entre ánodo y cátodo ${ }^{8}$.

Una vez destruida la capa pasiva, la corrosión se produce por resistividad eléctrica y por presencia de oxígeno. Los criterios de interpretación de las 
medidas de la resistividad varían, pero a pesar de ello son un parámetro efectivo para evaluar el riesgo de corrosión de la armadura. Así, las barras parecen alcanzar un estado activo de corrosión cuando la resistividad es menor de $10 \mathrm{k} \Omega \cdot \mathrm{cm}$ y un comportamiento pasivo cuando la resistividad es mayor que $30 \mathrm{k} \Omega \cdot \mathrm{cm}$.

- Fisuración del hormigón 2,8 :

Las fisuras reducen la distancia de ataque a la armadura y favorecen la formación de pilas, por la más rápida y profunda penetración de cloruros, de oxígeno y humedad hasta el nivel de armadura. Las fisuras aceleran la corrosión al tiempo que proporcionan espacio para alojar los productos de la misma.

Existen diferencias entre el efecto de unas fisuras y otras según su origen, anchura, profundidad, separación y orientación. Así, si las fisuras son perpendiculares a la armadura o transversales, la longitud afectada por corrosión es susceptible de no ser mayor de tres diámetros de barra y resultan más desfavorables para el ataque por cloruros o corrosión localizada, mientras que si las fisuras siguen la longitud de la barra son mucho más dañinas ya que la zona susceptible de ser corroída es mayor y la resistencia del hormigón a estallar se reduce, siendo más perjudiciales para la carbonatación y la corrosión generalizada. Las fisuras longitudinales favorecen el inicio y la propagación de la corrosión, mientras que las transversales sólo el inicio, ya que la propagación dependerá de las propiedades de la fisura, del hormigón, del acero y del ambiente.

Las normativas limitan el valor de anchura de fisura, ya que valores inferiores a 0,3-0,4 mm tienden al autosellado ${ }^{1,8}$. Algunas investigaciones incluso indican que no hay relación entre la anchura de fisura y la corrosión; aún más, que no existe relación entre el ancho de fisura superficial y el interno ${ }^{8}$.

Sin embargo, en las especificaciones japonesas de la JSCE (Japan Society of Civil Engineers) sobre materiales y construcción ${ }^{88}$, el valor del coeficiente de difusión del hormigón se calcula teniendo en cuenta el ancho de fisura de acuerdo con la expresión : 


$$
D_{d}=\gamma_{c} \cdot D_{k}+(w / l) \cdot\left(w / w_{a}\right)^{2} \cdot D_{0}
$$

donde

" $D_{d}$ " es el valor de diseño del coeficiente de difusión de cloruros en el

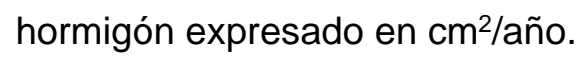

" $\gamma c$ " es un factor a considerar en función de las propiedades del hormigón,

" $D_{k}$ " es el coeficiente de difusión de cloruros en el hormigón expresado en $\mathrm{cm}^{2} / a n ̃ o$,

" $D_{0}$ " es una constante que expresa la influencia de la fisuración en el avance de los cloruros dentro del hormigón ( $\left.\mathrm{cm}^{2} / a n ̃ o\right)$, que en general se considera $200 \mathrm{~cm}^{2} / a n ̃ o$,

"w" es el ancho de fisura en $\mathrm{mm}$,

" $\mathrm{w}_{\mathrm{a}}$ " en el ancho de fisura permitido en $\mathrm{mm}$,

"l" es la distancia entre fisuras.

- Estado tensional

En las zonas sometidas a tracción, el valor del coeficiente de difusión de cloruros es mayor.

- Efecto sinérgico de la carbonatación y la penetración de cloruros 8,46

El contenido de cloruros en el frente de carbonatación alcanza niveles mayores que en el hormigón no carbonatado y puede ser mucho más elevado que los niveles medidos justo debajo de la superficie. Esto aumenta el riesgo de inicio de corrosión cuando el frente de carbonatación llega al acero. El descenso en el pH del hormigón carbonatado también aumenta el riesgo de corrosión debido a que la concentración de cloruros necesaria para iniciar la corrosión desciende con el $\mathrm{pH}^{8}$. Cabe decir que en ambiente marino, las condiciones de exposición y la calidad del hormigón tienen una mayor influencia en la velocidad de carbonatación. Las mayores velocidades de carbonatación se producen en el ambiente marino aéreo, donde el contenido de humedad del hormigón es menor que en los casos de carrera de mareas y sumergido, por lo que la carbonatación resulta casi inexistente y su 
efecto es menos importante. Sin embargo, en el caso de la penetración de cloruros, las velocidades más bajas se producen en esta zona ${ }^{46}$.

En el apartado 4.5 sobre Estructuras Reales en ambiente marino aéreo, se incluye el Caso 2 (Portugal) en el que se hicieron medidas de profundidad de carbonatación en losas de hormigón expuestas a la rotura de olas y zona atmosférica. En hormigones con $a / c=0,5$ expuestos a la zona marina aérea se registraron profundidades de carbonatación de $9 \mathrm{~mm}$ en 6 años y de $4 \mathrm{~mm}$ en 4 años para la zona de rotura de olas.

Varios estudios indican los efectos interactivos entre la carbonatación y los cloruros para desarrollar una mayor velocidad de corrosión de las armaduras. Este efecto fundamentalmente se debe a la inestabilidad de los cloroaluminatos en presencia de dióxido de carbono, lo que favorece la descomposición de dichos compuestos con la consecuente liberación de cloruros en la disolución presente en los poros del hormigón ${ }^{46}$.

Asimismo, la carbonatación contribuye a la destrucción de la capa pasiva pero no influye en la velocidad de corrosión ${ }^{8}$.

- Otros factores: La ejecución

Otros factores que afectan a la velocidad y al nivel de corrosión son la heterogeneidad del hormigón y la armadura, el pH del agua de los poros del hormigón, la existencia de corrientes parásitas y los efectos galvánicos debidos al contacto entre metales diferentes ${ }^{8}$.

Los aspectos de diseño y las prácticas de construcción también juegan un papel importante ${ }^{8}$. En estudios ${ }^{37}$ específicos se demuestra claramente que el factor crítico es la ejecución en obra. Si esto está amenazado, no importa lo cerrada que se haya diseñado la mezcla ante el ingreso de cloruros y lo elevado que sea el espesor de recubrimiento especificado. No se trata de un problema del material (dada su calidad al ser fabricado en una planta de hormigón) o del espesor de recubrimiento, sino de problemas durante el hormigonado. Para mejorar la construcción de estructuras en ambientes de corrosión, el objetivo no sólo debe estar en la composición de la mezcla de hormigón y en el aumento de recubrimiento, sino también en los aspectos de ejecución. 
Así ${ }^{37}$, el daño local por corrosión en las estructuras se observa cuando:

- El recubrimiento de la armadura es menor del especificado. A pesar de que las normativas fijen unos recubrimientos mínimos a cumplir en las estructuras en el momento de su construcción, estudios llevados a cabo en estructuras deterioradas tanto en zonas costeras como interiores demuestran que una escasez imprevista de recubrimiento puede producir el inicio de la corrosión. Esto puede ocurrir incluso habiéndose diseñado la estructura de acuerdo a las normativas existentes, por lo que es muy importante el control de calidad del recubrimiento y el desarrollo de técnicas no destructivas de inspeccion?

- El recubrimiento de la armadura es insuficiente, la compactación del mismo es complicada y la calidad del hormigón del recubrimiento es a menudo pobre, lo que resulta particularmente relevante en el caso del deslizamiento de encofrado (por ejemplo en cajones portuarios).

- En ciertas zonas de la superficie del hormigón, pueden observarse fisuras debidas a la elevación del encofrado y la presencia de un hormigón de calidad pobre; las causas principales de estos defectos son principalmente:

a) Recubrimiento de hormigón insuficiente

b) Cambios geométricos en las paredes de hormigón

c) Compactación insuficiente del hormigón de recubrimiento

d) Inadecuada (demasiado baja) velocidad de elevación de partes de compleja geometría, partes con inserciones o con grandes cantidades de armadura.

En una misma estructura, la deficiente ejecución de los distintos elementos que la componen, o bien, detalles constructivos puntuales resueltos erróneamente pueden conducir a la existencia de zonas de la estructura más susceptibles de sufrir corrosión ${ }^{5}$.

En el caso de un embarcadero analizado, los tendones de pretensado de la losa de cubierta se localizaban bajo las canaletas de la grúa. En estas canaletas se generó un microambiente especialmente agresivo, ya que la 
falta de drenaje de las mismas supuso la acumulación de agua salada sobre el hormigón durante largos periodos de tiempo. Al evaporarse el agua, quedaban las sales, aumentando así la concentración de cloruros. La falta de drenaje unida a unos materiales y ejecución deficientes provocó una elevada velocidad de penetración de cloruros así como un desarrollo temprano de la corrosión de los tendones. Las vainas de acero se mostraban casi destruidas y en algunos casos parecía existir fisuración de los cables por corrosión bajo tensión. Este tipo de corrosión resulta muy peligrosa por no dar signos externos del problema ${ }^{5}$.

Sin embargo, en el caso del hormigón situado alrededor de las vainas de las vigas externas, se apreciaron escasos daños al encontrarse saturado de agua, por hallarse en zona de carrera de mareas.

Otro caso es el del deterioro de un puente arco de hormigón armado de 35 años localizado en un resguardo de mar, con una luz de 278,40m y dos vanos de aproximación, con una longitud total de 493,20m.

La causa principal del deterioro del hormigón del puente fue su mala ejecución, a pesar de que la calidad del hormigón era muy buena. Los principales detalles de mala ejecución fueron las juntas de construcción mal ejecutadas, los nidos de grava abundantes y el espesor de recubrimiento con grandes variaciones, existiendo áreas significativas de vigas con recubrimientos inferiores a $2 \mathrm{~cm}^{5}$.

\subsubsection{Sintomatología.}

A continuación se exponen algunos de los aspectos a detectar al inspeccionar estructuras susceptibles de presentar corrosión, incluyendo casos particulares en pantalanes portuarios:

- Fisuración y desprendimiento del hormigón por el aumento de volumen de la armadura corroída 5 .

En los casos de suficiente disponibilidad de oxígeno y humedad, el deterioro del hormigón debido a la corrosión de armaduras se manifiesta en forma de expansión (la armadura, al oxidarse, aumenta de volumen 
hasta más de seis veces), fisuración y pérdida de recubrimiento, lo que en ocasiones puede conducir a roturas frágiles si las fisuras se producen en zonas de anclaje. La fisuración del recubrimiento también puede provocar la pérdida de adherencia entre hormigón y barras en determinados puntos, pudiendo comprometer así la seguridad estructural.

En el caso particular de losas de algunos muelles estudiados, el acceso de oxígeno restringido a la armadura debido a la mayor saturación del hormigón y a la acumulación de agua y suciedad en las paredes, disminuyen la corrosión y la delaminación respecto a otras zonas anexas ${ }^{5}$.

Por el contrario, una mayor incidencia del agua en zonas puntuales puede provocar una mayor delaminación y expulsión de recubrimiento, como en el caso de las vigas de tableros de puentes sobre un río, especialmente en las caras aguas abajo así como en las esquinas inferiores, por una mayor proximidad con las aguas 5 .

A la vista de la relación directa que parece existir entre la corrosión y la delaminación, en las inspecciones puede establecerse como modo cualitativo de evaluar la corrosión de una estructura la medida del porcentaje de delaminación de su superficie.

- Desarrollo de corrosión negra o verde ${ }^{5}$

En la corrosión que se desarrolla en ambientes con baja disponibilidad de oxígeno (corrosión negra o verde), el volumen de los productos de corrosión puede ser solamente dos veces mayor que el volumen del acero. Es el caso de algunas zonas de carrera de mareas, cerca del nivel máximo; donde el contenido de agua en los poros del hormigón es muy alto, limitando así el acceso de oxígeno a los ánodos. Al no producirse aumento significativo de volumen y pudiendo difundirse los productos de la corrosión a través de los poros sin causar delaminación, la corrosión puede llegar a ser muy severa, incluso con pérdidas de sección de armadura, sin mostrar síntomas externos ${ }^{5}$. 


\subsubsection{Técnicas para el estudio de la corrosión por cloruros²}

Son muchas las técnicas de detección de la corrosión. A continuación se detallan las más habituales:

- Inspección visual.

El objetivo es comprobar el aspecto de la estructura, detectar posibles defectos y elegir los puntos donde realizar los ensayos. En caso de no existir signos externos de daño, pero cuando se suponga la existencia de corrosión, se requiere eliminar el recubrimiento dejando la armadura expuesta.

- Contenido de Cloruros y obtención de perfil de profundidades.

Se trata de analizar muestras pulverizadas de hormigón para obtener el porcentaje en peso de muestra o en peso de cemento, de los cloruros totales, solubles en ácido o en agua. UNE, AASHTO, RILEM y ASTM describen distintos procesos. Una vez realizado el ensayo, se intenta obtener el perfil de concentración de cloruros según la profundidad de penetración (zonas según capas de hormigón, zonas carbonatadas o no, lavado por lluvia...).

- Determinación de la constante de difusión de cloruros

Este proceso se puede simular por la célula de difusión (método estacionario), por inmersión (método no estacionario que establece la concentración de cloruros a distintas profundidades) o por ensayos acelerados, que obtienen la constante de difusión a partir de la medida de otros parámetros. Como referencia, un hormigón bueno presenta una $\mathrm{D}<1 \times 10^{-12} \mathrm{~m}^{2} / \mathrm{s}$ y uno malo, una $\mathrm{D}>5 \times 10^{-12} \mathrm{~m}^{2} / \mathrm{s}$.

- Estimación del espesor de recubrimiento

Se emplea el pachómetro para detectar el espesor de recubrimiento aproximado, así como el diámetro y la localización de la armadura. No siempre resulta fiable y habrá que relacionarlo con otras técnicas. 
- Potencial de media pila

Es un método sencillo pero de difícil interpretación. Se basa en que durante la corrosión, los iones hierro se desplazan de la armadura al hormigón, dejando así en ésta electrones que dan carga negativa. El potencial electroquímico mide la facilidad del paso de los electrones al ambiente. No se puede medir de modo absoluto, pero sí como diferencia de potencial entre la superficie de acero y un electrodo de referencia (en un sistema con corrosión, el potencial será de corrosión, de circuito abierto o libre). El método es válido para acero normal, inoxidable y de pretensar e indicado para estructuras expuestas a la atmósfera. Es adecuado para localizar barras con corrosión, definir posición de ensayos o evaluar corrosión tras reparación. El ASTM da el criterio de interpretación de resultados más conocido. Los resultados pueden llevar a engaño por la carbonatación, la resistividad del hormigón o la química de la solución en contacto con el acero. Como indicación, valores de potencial $>-200 m V$ indican probabilidad de corrosión $<10 \%$, y valores <$350 \mathrm{mV}$, probabilidad de corrosión $>90 \%$ (cuanto más negativo sea el potencial, mayor probabilidad de corrosión).

- Medida de la resistencia a la polarización lineal

La reacción anódica supone un aumento de potencial y la catódica, un descenso. En este método se mide la diferencia entre ambos, la polarización. En zona pasiva, hay dificultad para la polarización, lo que implica baja velocidad de corrosión. La polarización de la armadura es la base para estudios de velocidad de corrosión por resistencia a polarización y corriente galvánica. Para medir la polarización, se aplica un incremento de potencial y se mide el flujo de corriente. Cuando el sistema se corroe de forma uniforme, es válida la ecuación de Stern Geary (intensidad de corrosión inversamente proporcional a la resistencia a la polarización). Se mide la velocidad de corrosión como la velocidad con la que los electrones son arrancados del hierro en las reacciones anódicas. Cuando se cree que hay corrosión, se aplica un potencial. La polarización sería la diferencia entre dicho potencial aplicado y el original. Como valores indicativos, $v_{\text {CORR }}$ (velocidad de corrosión) $<0,1-0,2 \mu \mathrm{A} / \mathrm{cm}^{2}$ indica estado pasivo, mientras que $\mathrm{v}_{\mathrm{CORR}}>1,0 \mu \mathrm{A} / \mathrm{cm}^{2}$ indica corrosión alta. El equipo más común para su realización presenta un anillo de guarda para conseguir una mayor precisión. Los resultados pueden ser erróneos si el 
efecto del confinamiento del anillo no es adecuado, por el ambiente, por la superficie del hormigón o incluso debido a la velocidad de escaneado de la señal del equipo de medida.

- Medidas de resistividad 2,49

Se mide la capacidad del hormigón para conducir corrientes de corrosión. Si existe corrosión, la resistividad del hormigón es proporcional a la velocidad de corrosión. En estructuras nuevas donde podemos colocar electrodos, se aplica la corriente entre ellos situados a una distancia $L$ y se obtiene $\rho$ (resistividad); en estructuras ya existentes, se puede emplear la sonda de cuatro puntas de Wenner (no situar electrodos sobre armaduras) o medir la caída iR aplicando corriente entre la armadura y un electrodo en superficie. Los valores obtenidos pueden variar mucho, entre $10^{1}$ y $10^{5} \Omega \mathrm{m}$, ya que depende de numerosos factores como la humedad, la relación a/c, las adiciones... Hay muchos criterios de interpretación, pero como indicación $\rho<10 \mathrm{k} \Omega \mathrm{cm}$ indica estado activo de corrosión y $\rho>30 \mathrm{k} \Omega \mathrm{cm}$ indica estado pasivo. Puede haber errores en la medida por la geometría y heterogeneidad del hormigón, por mal contacto en superficie, capas de distinta resistividad, existencia de armaduras, ambiente...etc.

El método de medida de la resistividad del hormigón es no destructivo, pero sólo es efectivo en las zonas del hormigón donde el acero no influye en las medidas, pero no en aquel hormigón donde el acero presente ya un alto riesgo de corrosión.

Un reciente estudio propone un método de evaluación de la corrosión incluyendo la estimación de la resistividad de la superficie del acero. Así, el método utiliza un circuito no destructivo que determina la resistividad del hormigón y del acero en superficie ${ }^{49}$.

Los resultados obtenidos indican que la resistividad del hormigón aumenta con el progreso de la corrosión electrolítica, tal y como muestra la figura $4.11^{49}$ : 


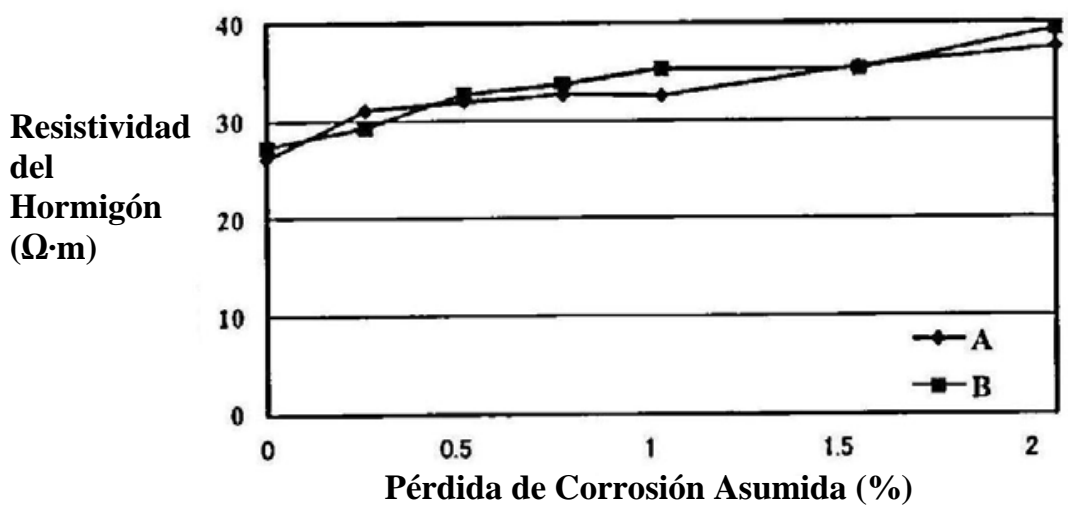

Fig.4.11. Resistividad estimada del hormigón para A y B a diferentes velocidades de corrosión

Asimismo, la resistividad del acero decrece claramente con el avance de la corrosión. En las fisuras que resultan del aumento en la cantidad de los productos de corrosión en las muestras, la resistividad cae hasta aproximadamente $0 \Omega \mathrm{m}$. A partir de estos resultados, se concluye que el método de estimación de la resistividad con respecto a la evaluación de la corrosión podría evaluar cuantitativamente la corrosión como en el caso del método de la resistencia a la polarización. En las figuras 4.12 y 4.13, puede verse la resistividad del acero como un índice de la evaluación cuantitativa de la corrosión ${ }^{49}$ :

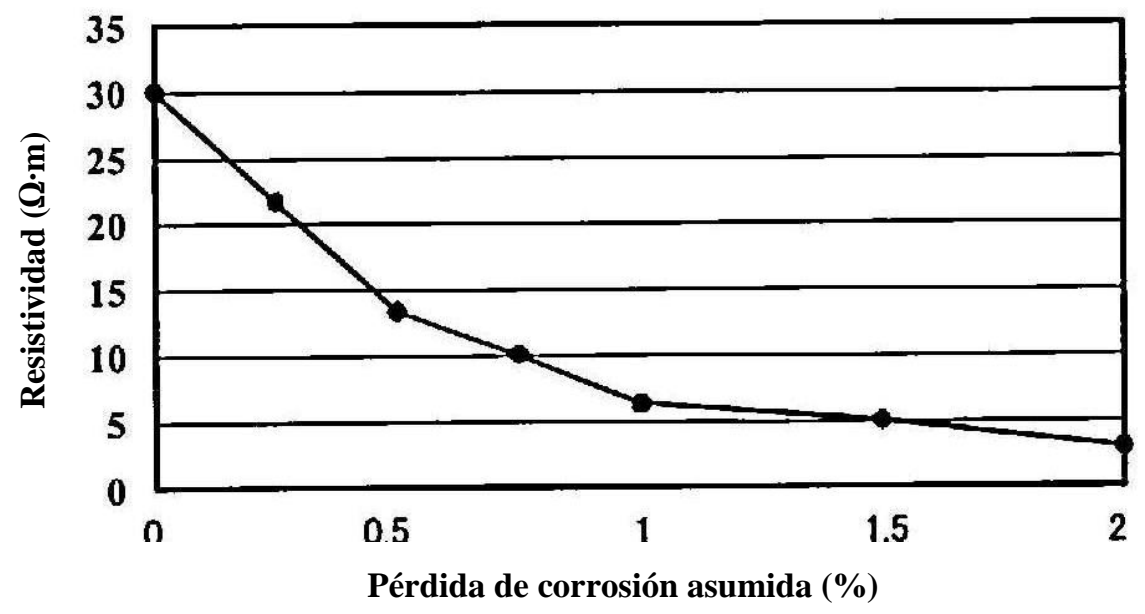

Fig.4.12. Resistividad estimada del acero a diferentes velocidades de corrosión para intervalos de electrodo de 4cm (espécimen A) 


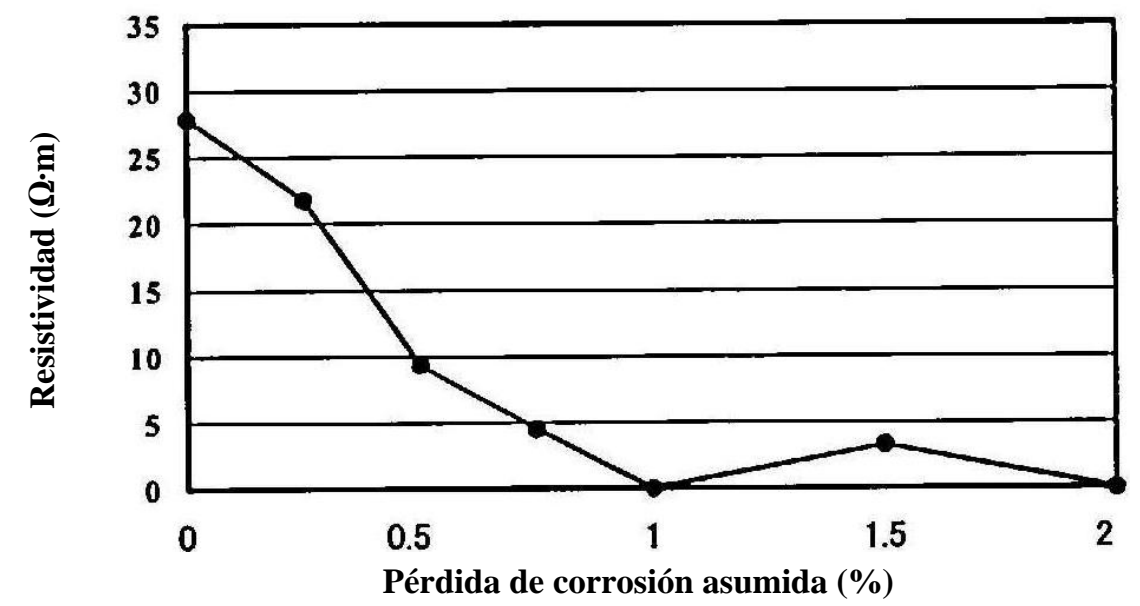

Fig.4.13. Resistividad estimada del acero a diferentes velocidades de corrosión para intervalos de electrodo de $4 \mathrm{~cm}$ (espécimen $B)$.

- Técnicas gravimétricas

Consiste en medir el peso de las barras antes y después de ser introducidas en el hormigón. Permite definir el factor de picadura (referido a masa) como la relación entre la mayor profundidad y la profundidad media de picadura. Es una técnica de laboratorio que permite verificar otras.

- Evaluación de la corrosión por picaduras (ASTM) 2,41

Sobre la superficie limpia y sin elementos de corrosión, se mira a través de microscopio para detectar tamaño, distribución y forma de las picaduras. Para evaluar las picaduras, se requiere densidad, tamaño y profundidad, ésta se mide con microscopio metalográfico.

La profundidad de picadura en el acero corroído se mide mediante un calibre micrométrico. Sin embargo, debe mencionarse que esta medida no resulta fácil. Al menos deben realizarse cinco medidas de la profundidad por cada picadura y el valor máximo medido debe registrarse como máxima profundidad de picadura ${ }^{41}$.

Recientemente, se ha realizado un estudio de corrosión acelerado para obtener parámetros estadísticos de distribución de la profundidad de picadura máxima del acero corroído en estructuras de hormigón armado. En él, la base de las muestras se sumergía en una solución de cloruro 
sódico al 5\%. Se empleó un cemento tipo GP, también conocido como tipo I para las series del ensayo y se añadió a la mezcla de hormigón un $3 \%$ de cloruro de calcio $\left(\mathrm{CaCl}_{2}\right)$ por peso de cemento para inducir la corrosión. Todas las mezclas de hormigón tenían la misma relación a/c y mismas características resistentes $\left(\mathrm{a} / \mathrm{c}=0,5 ; \mathrm{f}_{\mathrm{c}}{ }^{\prime}=40 \mathrm{MPa}\right)$. Asimismo, todas las muestras fueron curadas durante 28 días antes del ensayo. El ensayo empleó dos losas de hormigón armado, de dimensiones $1500 \mathrm{~mm} \cdot 1000 \mathrm{~mm} \cdot 250 \mathrm{~mm}$. Nueve barras de $16 \mathrm{~mm}$ de diámetro separadas cada $100 \mathrm{~mm}$ se colocaron en cada losa, con un recubrimiento de $70 \mathrm{~mm}$ cada una. Se introdujo una velocidad de corrosión nominal de $100 \mu \mathrm{A} / \mathrm{cm}^{2}$ durante 28 días. Se midió la profundidad de picadura máxima cada $325 \mathrm{~mm}$ de longitud de barra ${ }^{41}$. Los resultados obtenidos se utilizan en un modelo teórico de propagación de picaduras cuya extrapolación en el tiempo se analiza variando diferentes parámetros.

Las figuras 4.14., 4.15. y 4.16 ilustran el efecto del tiempo desde el inicio de la corrosión, el efecto del tiempo en la reducción del área de sección transversal y el efecto de la velocidad de corrosión, respectivamente.

En el primer caso, cuando el tiempo aumenta de 10 a 50 años, la profundidad de picadura máxima media aumenta de $3,5 \mathrm{~mm}$ a $7,2 \mathrm{~mm}^{41}$.

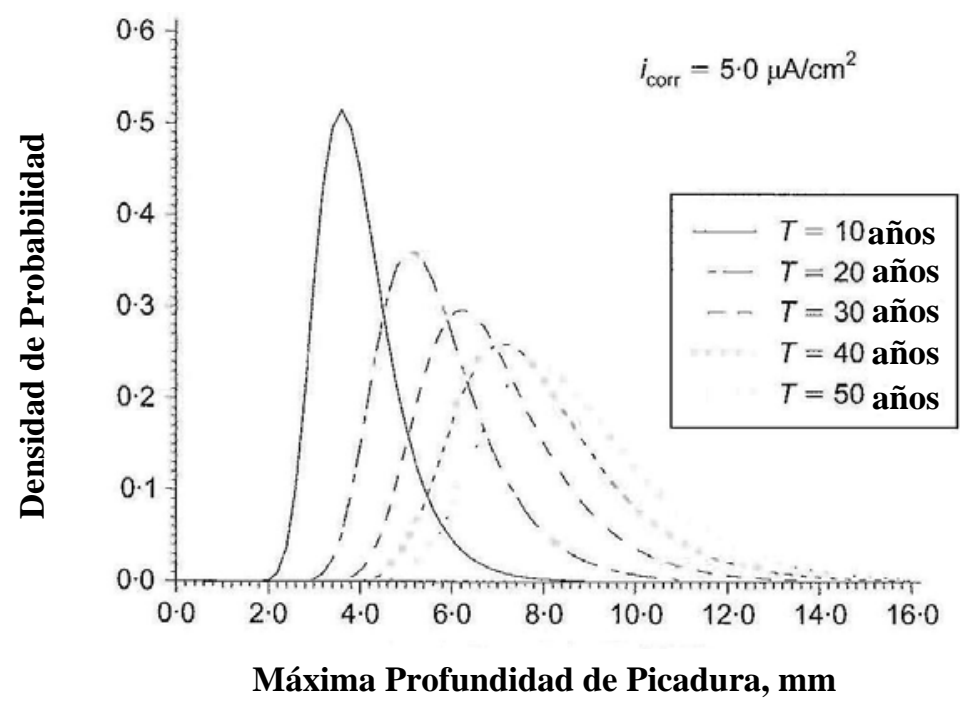

Fig.4.14. Distribución de máxima profundidad de picadura respecto al tiempo

En el segundo caso (fig 4.15), se refleja que 50 años después del inicio de la corrosión, la reducción media en el área de sección transversal está entorno al 
$30 \%$, sin embargo hay un $2 \%$ de posibilidad de que esta reducción sea superior al $80 \%{ }^{41}$.

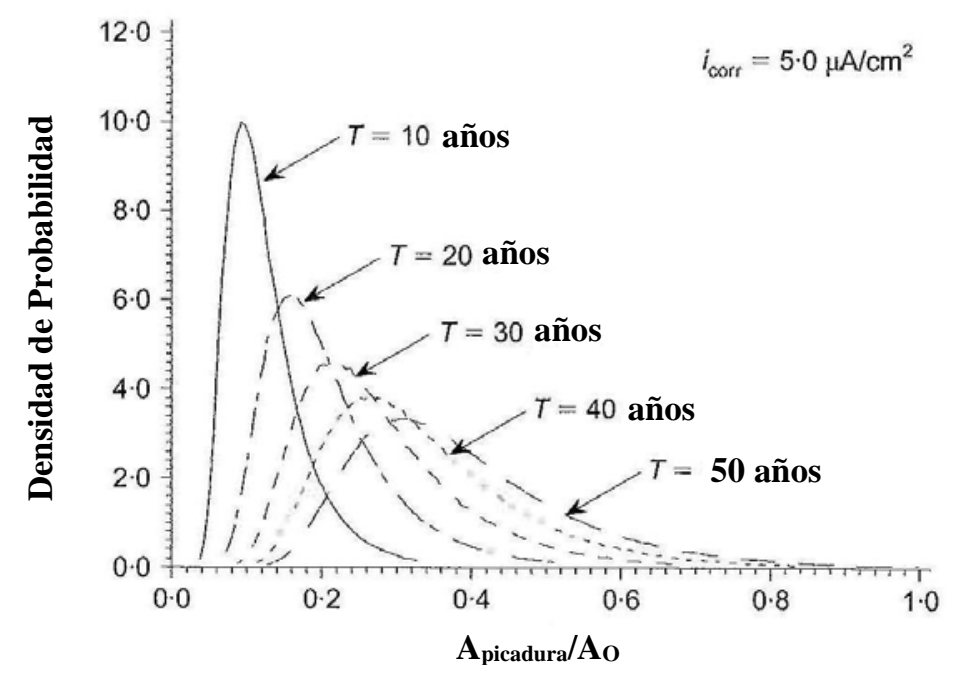

Fig.4.15. Distribución de la reducción del área de sección de armadura con el tiempo

Por último, ya que la velocidad de corrosión es variable con el tiempo y se asume que desciende con el tiempo, la profundidad de picadura máxima se espera menor que la recogida por la figura $4.16^{41}$.

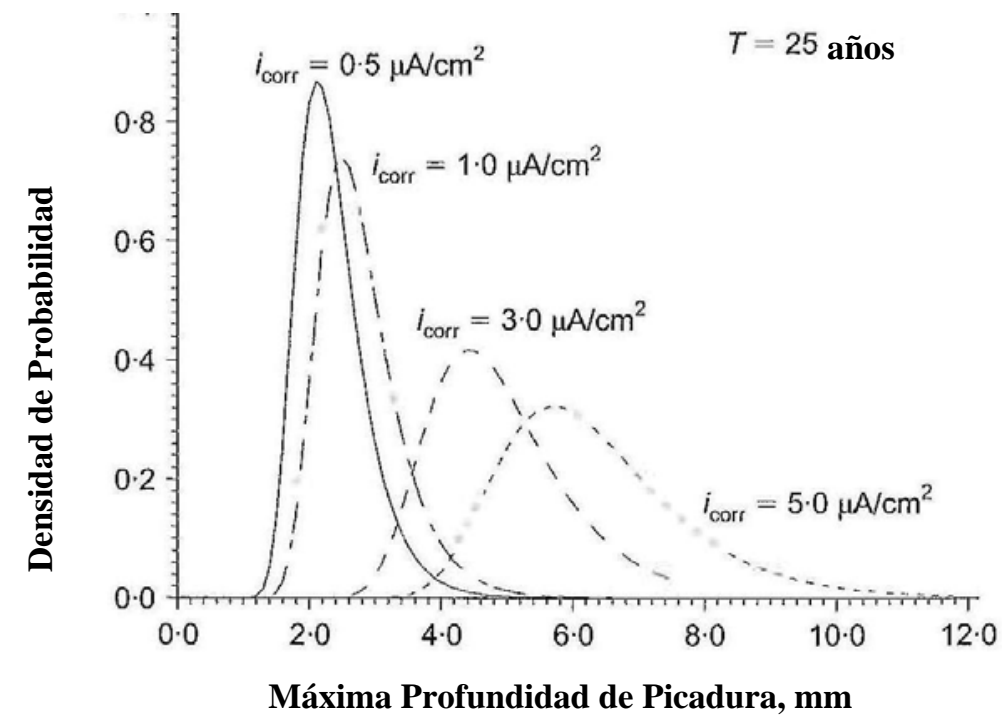

Fig.4.16. El efecto de las velocidades de corrosión en la distribución de máxima profundidad de picadura en la armadura para velocidades de corrosión invariables con el tiempo 
- Termografía infrarroja (ASTM)

Mide las variaciones en la radiación superficial motivadas por huecos y desprendimientos del hormigón. Al medir la temperatura superficial, detecta posibles anomalías. Permite también la estimación de la humedad. Las medidas se pueden alterar por el ambiente y las radiaciones externas, entre otras, por lo que se plantean la termografía selectiva y la externa controlada.

\subsection{MODELACIÓN DE LA DIFUSIÓN DE CLORUROS EN EL HORMIGÓN}

\subsubsection{Definición del Ambiente Marino Aéreo}

La Instrucción Española de Hormigón Estructural (EHE) designa el ambiente marino como Clase III, que se divide a su vez en tres subclases (IIIa, IIIb y IIIc) en función del tipo de exposición al que esté sometido el elemento estructural ${ }^{1}$, tal y como se muestra en la tabla 4.10.

\begin{tabular}{|c|c|c|c|c|}
\hline \multicolumn{4}{|c|}{ Clase General de Exposición } & \multirow{2}{*}{ Descripción } \\
\hline Clase & Subclase & Designación & Proceso & \\
\hline \multirow{3}{*}{ Marina } & Aérea & IIIa & \multirow{3}{*}{$\begin{array}{l}\text { Corrosión } \\
\text { por } \\
\text { Cloruros }\end{array}$} & $\begin{array}{l}\text { - } \\
\text { Elementos de estructuras marinas por } \\
\text { - } \\
\text { Elementos exteriores de estructuras } \\
\text { situadas en las proximidades de la } \\
\text { línea costera (a menos de } 5 \mathrm{~km} \text { ) }\end{array}$ \\
\hline & Sumergida & IIIb & & $\begin{array}{l}\text { - } \text { Elementos de estructuras marinas } \\
\text { sumergidas permanentemente por } \\
\text { debajo del nivel mínimo de bajamar }\end{array}$ \\
\hline & $\begin{array}{l}\text { En zona de } \\
\text { carrera de } \\
\text { mareas y en } \\
\text { zonas de } \\
\text { salpicaduras }\end{array}$ & IIIC & & $\begin{array}{l}\text { - Elementos de estructuras marinas } \\
\text { situadas en la zona de salpicaduras o } \\
\text { en zona de carrera de mareas }\end{array}$ \\
\hline
\end{tabular}

Tabla.4.10.Clases de exposición referentes al ambiente marino según la Instrucción EHE

Esta investigación se centra en el estudio de la corrosión de las armaduras del hormigón situado en Ambiente Marino Aéreo (IIla), es decir elementos de estructuras marinas por encima del nivel de pleamar o en elementos exteriores de estructuras situadas en las proximidades de la línea costera (a menos de $5 \mathrm{~km})^{3}$. 
Existen estructuras, que por su propia configuración y/o tamaño, se encuentran sometidas a distintas subclases de exposición a lo largo de los elementos que las componen. Por ejemplo, un embarcadero localizado en clase de exposición marina (III) presenta su losa de cubierta y la parte superior de las vigas en zona de salpicaduras (IIIc), la parte inferior de vigas y la superior de las pilas en zona de carrera de mareas (IIIC) y la zona inferior de las pilas así como la cimentación en zona sumergida (IIIb). La parte del embarcadero que no se encuentre en ninguna de estas subclases, se ubicará en ambiente marino aéreo (IIIa) ${ }^{5}$.

En el diseño de estructuras en Japón ${ }^{7}$ se plantea la distribución regional y niveles de agresividad ambiental recogidos en la tabla 4.11. y fig. 4.17.

\begin{tabular}{|c|c|c|}
\hline$\underline{\text { Regiones }}$ & $\underline{\text { Distancia desde la costa }}$ & $\underline{\text { Nivel }}$ \\
\hline \multirow{2}{*}{$\begin{array}{l}\text { A (Prefectura de Okinawa) } \\
\text { (Situada en ruta de tifones) }\end{array}$} & $\begin{array}{c}\text { Menos de 100m y por encima del } \\
\text { mar }\end{array}$ & I \\
\hline & Excepto la región anterior & II \\
\hline \multirow{3}{*}{$\begin{array}{l}\text { B (Áreas hasta 300m y por encima } \\
\text { del mar) } \\
\text { (Presencia de viento de tormenta en } \\
\text { invierno) }\end{array}$} & $\begin{array}{c}\text { Menos de 100m y por encima del } \\
\text { mar }\end{array}$ & I \\
\hline & Entre 100 y $200 \mathrm{~m}$ & II \\
\hline & Entre 200 y $300 \mathrm{~m}$ & III \\
\hline \multirow{3}{*}{$\begin{array}{l}\text { C (Áreas hasta 200m y por encima } \\
\text { del mar excepto las anteriores) }\end{array}$} & Por encima del mar & $\overline{\overline{I I}}$ \\
\hline & Menos de $100 \mathrm{~m}$ & II \\
\hline & Entre 100 y $200 \mathrm{~m}$ & III \\
\hline
\end{tabular}

Tabla 4.11. Distribución regional de los niveles de agresividad ambiental 


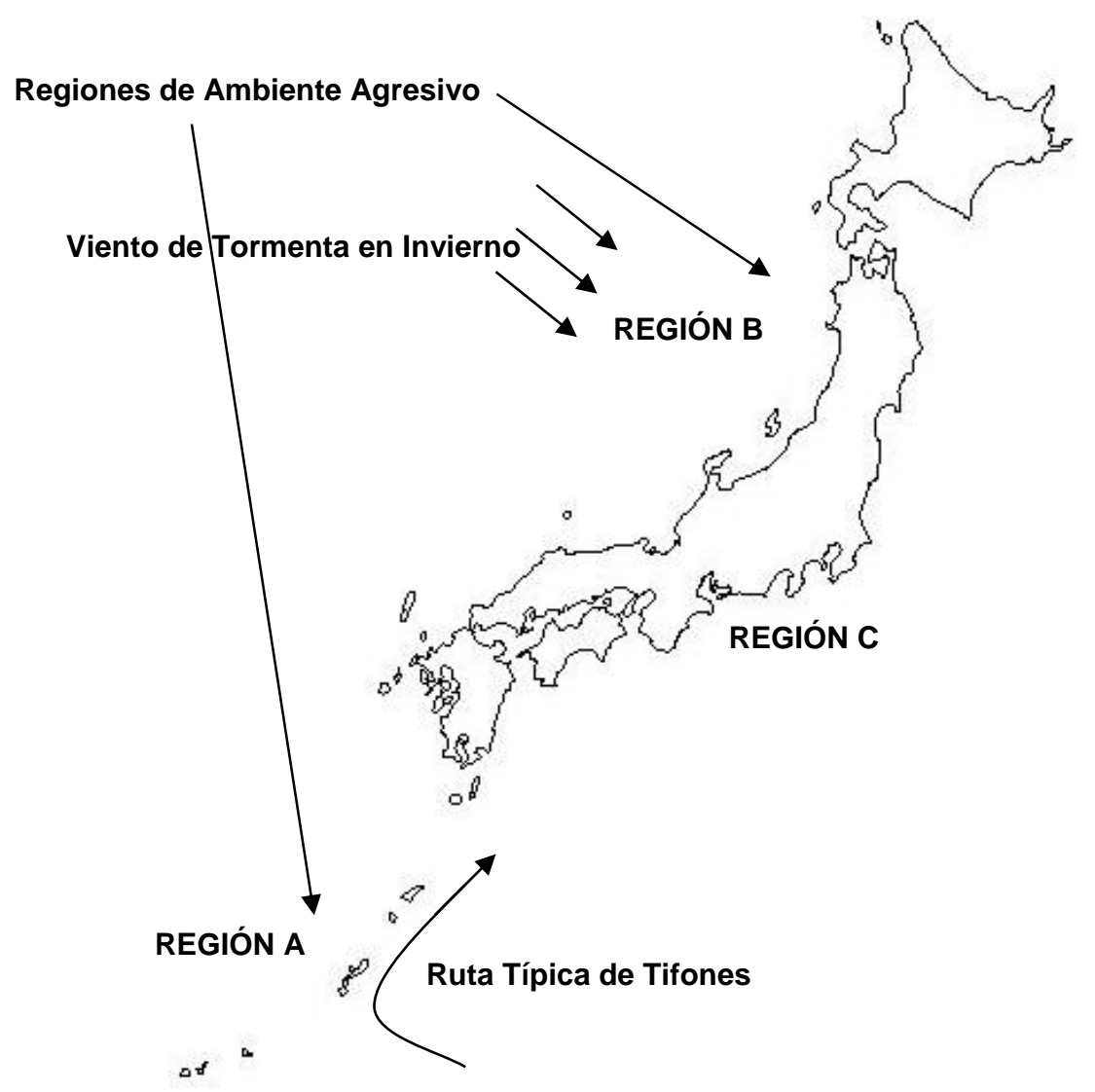

Fig 4.17. Mapa regional obtenido tras un estudio de 1982

En un documento posterior" las "Japan Specifications of Highway Bridges" modifican los niveles de agresividad, realizando una subdivisión de ambientes más acotada en lo a distancia a la costa se refiere (ver tabla 4.12):

\begin{tabular}{|c|c|c|c|}
\hline Clasificación de Regiones & Distancia desde la costa, L (m) & Nivel & Tipo de daño \\
\hline \multirow{3}{*}{$\begin{array}{l}\text { A (Prefectura de Okinawa, } \\
\text { situada en ruta de tifones) }\end{array}$} & Sobre el mar o $\mathrm{L} \leq 100$ & S & Severo \\
\hline & $100 \leq \mathrm{L} \leq 300$ & I & \multirow{2}{*}{ Moderado } \\
\hline & Otras & II & \\
\hline \multirow{4}{*}{$\begin{array}{l}\text { B (Presencia de viento de } \\
\text { tormenta en invierno) }\end{array}$} & "Sobre el mar o L $\leq 100$ & 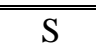 & Severo \\
\hline & $100 \leq \mathrm{L} \leq 300$ & I & \multirow{3}{*}{ Moderado } \\
\hline & $300<\mathrm{L} \leq 500$ & II & \\
\hline & $500<\mathrm{L} \leq 700$ & III & \\
\hline \multirow{4}{*}{$\mathrm{C}$} & Sobre el mar o $\mathrm{L} \leq 20$ & $\overline{S S}$ & Severo \\
\hline & $20 \leq \mathrm{L} \leq 50$ & I & \multirow{3}{*}{ Moderado } \\
\hline & $50<\mathrm{L} \leq 100$ & II & \\
\hline & $100<\mathrm{L} \leq 200$ & III & \\
\hline
\end{tabular}

Tabla 4.12. Distribución regional ligeramente más acotada de los niveles de agresividad ambiental 
Dentro de una planificación llevada a cabo dentro de la red federal de México en la década de los noventa con el fin de incorporar parámetros relacionados con la clasificación de estructuras de acuerdo con el riesgo de corrosión se consideran los siguientes ambientes de exposición ${ }^{38}$ relacionados con el riesgo de corrosión:

- Situación sobre ríos permanentes y canales

Se considera como variable ante el riesgo de sufrir corrosión el hecho de que los puentes se localicen sobre ríos y canales, debido a la influencia permanente de la evaporación del agua sobre ellos, omitiendo los arroyos debido a su caudal insignificante.

- Distancia a la línea de costa

Se estiman dos áreas de influencia o radios de acción distintos respecto a este fenómeno: las estructuras situadas dentro de una franja hasta 5 $\mathrm{km}$ de la costa y las emplazadas hasta $20 \mathrm{~km}$, cuando en esta área se encuentran ríos, buscando de este modo captar el efecto combinado de la humedad y la posible presencia de altas concentraciones de cloruros en dichos caudales.

- Zona climática

Enfocado más hacia la corrosión por carbonatación, se consideraron los climas secos y semisecos, es decir, aquéllos que tienen temperaturas medias que oscilan alrededor de los $18^{\circ} \mathrm{C}$ y el cociente temperatura/precipitación alrededor de 22,9, sólo superiores al de los climas muy secos y muy áridos.

- Proximidad a emplazamientos industriales

También para el caso de corrosión por carbonatación, se incluyeron aquellos municipios donde existen dos o más parques, ciudades y/o corredores industriales, debido a que las actividades económicas industriales generalmente están muy próximas a los grandes centros urbanos del país, donde es mayor la generación de desechos precursores de corrosión por carbonatación. 
Los distintos subambientes en una estructura pueden generar distintos defectos y/o diferente intensidad de daño ${ }^{5}$. A continuación se relacionan factores a tener en cuenta, que pueden generar estos subambientes:

- Composición del agua 5

La corrosión está generada por sustancias que se encuentran en el agua, por eso

la composición del agua que incide sobre la estructura y sus posibles cambios a lo largo del tiempo, como los causados por la aportación de flujo de un río próximo, tienen su efecto. Tal es el caso, por ejemplo, de casos reales de muelles situados en el estuario de un río, donde la medida de los principales elementos agresivos del agua en un año fueron: cloruros $\left(\mathrm{Cl}^{-}\right)$ 16-21 g/l, sulfatos $\left(\mathrm{SO}_{4}\right)$ 2,1-2,9 g/l, magnesio $\left(\mathrm{Mg}^{++}\right)$1,1-1,6 g/l, $\mathrm{pH}$ 7,8-8,0.

- Saturación del hormigón ${ }^{5}$

Se refiere al grado de colmatación de los poros, si están llenos de agua o si presentan un porcentaje libre para el acceso de oxígeno. De este modo, determinadas zonas de las estructuras de hormigón pueden presentar, en su red de poros, un mayor contenido de agua, lo que hace que la corrosión quede controlada por el proceso catódico dado el limitado acceso de oxígeno a las armaduras. Este hecho explica la menor expulsión de recubrimiento en las zonas de hormigón saturadas.

En ambiente muy húmedo, como en el caso de las estructuras completamente sumergidas, éstas se encuentran protegidas de la corrosión por la ausencia de oxígeno en los poros del hormigón. A pesar de encontrarse altamente contaminadas por elevadas concentraciones de cloruros, este tipo de estructuras no están sujetas a una corrosión significativa. La parte de estructura que se encuentre en zona de salpicaduras, sin embargo, experimenta condiciones particularmente agresivas al encontrarse generalmente saturada, con alto contenido en sales, y suficientemente cerca de las partes expuestas de la estructura donde pueden establecerse las macropilas fácilmente. Los niveles elevados de cloruros aumentan por la sal de mar transportada por capilaridad a través del recubrimiento y la evaporación de agua desde la superficie, que deja atrás las sales ${ }^{8}$. 
- Exposición al Sol ${ }^{5}$

La radiación solar contribuye a una temperatura y una velocidad de evaporación del agua de los poros mayores. Así, al existir zonas de una estructura con mayor soleamiento que otras, éstas se encuentran sometidas a una mayor temperatura, lo que implica un secado del hormigón y acceso de oxígeno más rápidos. Esto explica que la parte norte de un muelle real estudiado, con una mayor exposición solar, reflejaba mayor deterioro que las paredes este y oeste del mismo, con menor soleamiento.

- Exposición al viento ${ }^{5}$

Uno de los factores que puede generar un subambiente de exposición es el viento. Éste incide sobre los elementos de estructuras situadas en ambiente marino y puede contener sal del agua de mar o arrastrar niebla salina. Es el caso de un puente ${ }^{5}$ expuesto a un ambiente marino atmosférico donde el hormigón no está nunca en contacto con el agua. Sin embargo, la parte central del mismo está más expuesta al viento y por tanto, a la sal de salpicaduras y de niebla salina ${ }^{5}$, lo que supone una mayor susceptibilidad a la corrosión.

- Combinación de factores

La superposición de factores puede aumentar la severidad del ambiente. En un estudio noruego realizado en plataformas de almacenamiento de combustible en el Mar del Norte $^{37}$ se define como clima severo el caracterizado por los siguientes parámetros: salinidad $35 \mathrm{~g} / \mathrm{l}$, temperatura de la superficie del agua entre $5-17^{\circ} \mathrm{C}$, altura máxima de ola entre $25-30 \mathrm{~m}$ y velocidad del viento $45 \mathrm{~m} / \mathrm{s}$.

\subsubsection{Fases de la corrosión del acero en el hormigón: Iniciación y Propagación}

La corrosión de las armaduras de acero embebidas en el hormigón consta de dos fases o periodos: iniciación y propagación. En el caso particular de la corrosión por acción de los cloruros, la iniciación cubre el periodo en el que los cloruros avanzan por el recubrimiento hasta alcanzar la armadura en proporción suficiente y en la propagación se origina la corrosión del acero propiamente dicha. El concepto de durabilidad del hormigón armado se 
fundamenta en evitar que se alcance el periodo de propagación durante la vida de servicio de la estructura, poniendo los medios necesarios para dilatar lo máximo posible la fase de iniciación².

Para que la corrosión se inicie y mantenga una cierta velocidad, la concentración de cloruros en el espesor de recubrimiento debe alcanzar un valor determinado, es el llamado umbral de cloruros. No se trata de un valor único, puede variar ampliamente puesto que son muchos los factores que afectan el inicio de la corrosión ${ }^{15}$.

Según Williamson ${ }^{15}$, se define el periodo de inicio de la corrosión como el tiempo requerido para que el umbral de cloruros se alcance en el $2 \%$ de la armadura de una estructura.

En cuanto a los mecanismos de ingreso de cloruros en el hormigón durante el periodo de iniciación, se pueden distinguir los siguientes: permeabilidad, capilaridad, absorción y difusión. La permeabilidad y la absorción son procesos muy rápidos, mientras que la difusión es mucho más lenta².

Si lo relacionamos con los ambientes de exposición, en el caso de un hormigón húmedo, prevalece el mecanismo de la DIFUSIÓN; para un hormigón con superficie mojada, es la SUCCIÓN CAPILAR el mecanismo dominante (los ciclos de humectación-desecación favorecen el aumento de cloruros y la diferencia de concentraciones de los mismos fomenta la formación de pilas) y para un hormigón sumergido, es también la SUCCIÓN CAPILAR acelerada por el aumento de presión hidráulica o permeabilidad (aunque en este caso, la ausencia de oxígeno protege del ataque por corrosión) ${ }^{2}$. La difusión pura es un mecanismo de transporte lento, mientras que la succión capilar y la permeabilidad son notablemente más rápidas.

En el caso de las paredes internas de un muelle sometido a los ciclos de humedad-sequedad ${ }^{5}$ (dos anuales), debido a la elevada porosidad capilar del hormigón, el mecanismo de transporte dominante fue la succión capilar. Al ser un proceso rápido, después de los primeros ciclos de llenado del muelle, la armadura quedó despasivada. La concentración elevada de cloruros, la baja resistividad del hormigón y el fácil acceso del oxígeno a las armaduras durantes los periodos secos resultaron en una elevada velocidad de corrosión que supuso la temprana expulsión del recubrimiento. ${ }^{5}$ 
La profundidad de penetración de cloruros es proporcional a la raíz cuadrada del tiempo y se estudia por medio de la ley de Fick ${ }^{10}$. La duración del periodo de iniciación es objeto de diferentes modelos propuestos en la bibliografía consultada y serán tratados en el apartado 4.4.3.2.

Definir el tiempo de propagación de la corrosión es complicado, ya que una vez que la corrosión ha superado el nivel del $2 \%$ citado en el periodo de iniciación, el proceso de la difusión de los cloruros no sigue la ley de Fick, sino complicadas reacciones electroquímicas y mecanismos de transporte de iones ${ }^{15}$. Así pues, Williamson ${ }^{15}$ establece el tiempo de propagación total de la corrosión como el requerido para que el deterioro por corrosión avance del nivel del $2 \%$ al del $12 \%$, estableciéndose en ese punto el fin de la vida útil de una estructura.

En este mismo sentido, en un programa de análisis de vida útil desarrollado por Virginia Tech mediante ordenador, el modelo estima que la vida útil de una estructura se divide en tres etapas: tiempo hasta que se inicia la corrosión en el $2 \%$ de la armadura, tiempo desde el inicio de la corrosión hasta que exista fisuración y expulsión de recubrimiento en más del $2 \%$ de la armadura y tiempo de propagación de la corrosión desde que está dañada el $2 \%$ hasta el $12 \%$ de la armadura ${ }^{14}$.

\subsubsection{Modelos de Difusión de Cloruros. Periodo de Iniciación.}

Dado que una de las causas principales del deterioro de las estructuras de hormigón es la corrosión de las armaduras y puesto que los costes de reparación y/o rehabilitación son elevados, se han desarrollado distintos métodos para estudiar la iniciación de la corrosión, prevenirla o tratar de retrasarla, planteando vidas útiles de 100 años para las estructuras ${ }^{14}$.

Los modelos de difusión de cloruros para estimar la vida de servicio de las estructuras pueden ser fickianos, de elementos finitos y comerciales. La complejidad de estos modelos ha ido aumentando a lo largo del tiempo, desde los modelos simples iniciales hasta complejas ecuaciones no lineales que consideran un elevado número de parámetros ${ }^{14}$.

Los modelos de difusión fickianos, los más comúnmente utilizados, asumen que la difusión de cloruros dentro del hormigón sigue la segunda ley de Fick. Los modelos de difusión de elementos finitos se basan en promediar 
ecuaciones de transporte a nivel microscópico de la difusión de la humedad y los iones en un elemento de volumen representativo. Estos modelos son capaces también de considerar los efectos de reacciones químicas localizadas y daños químicos ${ }^{15}$.

\subsubsection{La ley de Fick}

La fase de iniciación puede modelizarse según la segunda ley de Fick. Los modelos fickianos para determinación de vida útil se basan en las propiedades de transporte de cloruros en el hormigón, la concentración de cloruros en superficie, el espesor de recubrimiento de la armadura y los umbrales de cloruros. Así, para una losa de profundidad infinita, concentración de cloruros en superficie constante y coeficiente de difusión constante, la expresión de la ley de Fick, según Crack (1975) es la siguiente ${ }^{15,2}$ :

$$
\mathrm{C}_{\mathrm{x}}-\mathrm{Cb}_{\mathrm{b}}=\left(\mathrm{C}_{\mathrm{s}}-\mathrm{Cb}_{\mathrm{b}}\right) *\{1-\operatorname{erf}(\mathrm{x} / 2 * \sqrt{\mathrm{D}} * \mathrm{t})\}
$$

en la que Cx es la concentración de cloruros a una profundidad " $x$ "

Cs es la concentración de cloruros en superficie

$\mathrm{Cb}$ es la concentración de cloruros inicial del hormigón

D es el coeficiente de difusión efectiva de los cloruros

t es el periodo de exposición

erf es la función error

Esta ley no es exacta, ya que considera el hormigón con estructura homogénea, el coeficiente de difusión independiente de la cantidad de cloruros y de la temperatura así como el desplazamiento libre de los iones. Dado que los cloruros siguen distintos mecanismos de penetración, D es una constante de difusión APARENTE².

En cuanto a la metodología de evaluación de la corrosión, el perfil de cloruros es una de las más potentes y económicas herramientas disponibles para analizar los problemas de corrosión en una estructura. Cuando se realiza adecuadamente, obteniendo buenas estimaciones de "D" y " $\mathrm{C}_{0}$ ", los perfiles de cloruros tratados mediante la ley de Fick pueden utilizarse para la localización e identificación de problemas de corrosión y estimaciones del tiempo restante hasta fisuración. Manteniendo constantes los demás parámetros, "D" es la medida de la durabilidad del 
hormigón y " $\mathrm{C}_{0}$ " lo es de la corrosividad del ambiente, por lo que varía a través de la estructura y conduce a modelos distintos de daños por corrosión. Un recubrimiento inadecuado en estribos o en capa inferior de armaduras junto con un ambiente agresivo son las causas principales de fallos de estructuras por corrosión ${ }^{10}$.

Asumir que los tableros de puente se comportan como losas de espesor infinito sólo es válido para espesores aproximados de $20 \mathrm{~cm}$, ya que los cloruros no se difunden a través del espesor total durante la vida de la estructura. Por otro lado, $C_{0}$ y D se están considerando como constantes cuando se sabe que son parámetros dependientes del tiempo ${ }^{15}$.

Según Bamfoth (1999) y Mangat y Molloy (1994), la velocidad de ingreso de cloruros se reduce con el tiempo, en mayor o menor intensidad según la composición del hormigón y las condiciones ambientales ${ }^{15}$.

\subsubsection{Modelos de difusión fickianos}

Como ya se ha citado anteriormente, el tiempo de iniciación de la corrosión se determina empleando la segunda ley de Fick de difusión, que obtiene el tiempo requerido para alcanzar una concentración límite de cloruros especifica ${ }^{15}$.

Los factores que normalmente intervienen en estos modelos son la concentración de cloruros en superficie, el espesor de recubrimiento, el coeficiente de difusión de cloruros y el umbral de cloruros, es decir la concentración de cloruros requerida para que se inicie la corrosión ${ }^{14}$.

Según Williamson ${ }^{15}$, los principales modelos que siguen la ley de Fick son los siguientes: Mangat and Molloy (1994), Maheshwaran and Sanjayan (2004) y Bamforth (1999), que se comentan a continuación:

- Mangat y Molloy ${ }^{15,23}$

Mangat y Molloy (1994) desarrollaron un modelo de difusión que tiene en cuenta el efecto del tiempo en el coeficiente de difusión. El modelo aproxima la relación entre $D_{c}$ y el tiempo mediante la siguiente expresión:

$$
\mathrm{DC}_{\mathrm{C}}=\mathrm{Di}_{\mathrm{i}} * \mathrm{t}^{-\mathrm{m}}
$$


Dc es el coeficiente de difusión efectiva en el tiempo "t" $\left(\mathrm{cm}^{2} / \mathrm{s}\right)$

$\mathbf{D}_{i}$ es el coeficiente de difusión efectiva en tiempo igual a $1 \mathrm{~s}$

t es el tiempo (s)

$\mathbf{m}$ es un coeficiente empírico que varía con las proporciones de la mezcla

Con el fin de estimar "Di" para una mezcla particular de hormigón se debe realizar un análisis de regresión de datos empíricos ajustados a una función logarítmica. " $D_{i}$ " se proyecta según este análisis y " $m$ " se toma como la pendiente de la recta de regresión. También " $m$ " puede estimarse si la relación a/c de la mezcla es conocida mediante la siguiente expresión:

$$
\mathrm{m}=2,5 *(\mathrm{a} / \mathrm{c})-0,6
$$

La limitación que presenta este modelo se encuentra en que hacer numerosas medidas de $D_{c}$ no es factible en la práctica y estimar "m" puede no ser preciso. Adicionalmente, el modelo asume que la primera exposición a los cloruros se produce en el $t=1 \mathrm{~s}$, lo que podría resultar en una sobreestimación de las concentraciones de cloruros ${ }^{15}$.

- Maheshwaran y Sanjayan ${ }^{15,24}$

Es una variación del modelo anterior que permite emplear diferentes tiempos de aplicación de cloruros y la medida de $D_{c}$. Su expresión es la siguiente:

$$
C_{(x, t)}=C_{o}\left[1-e r f\left(\frac{x}{2 \sqrt{\frac{D_{r e f}\left(t_{r e f}\right)^{m}}{1-m}}\left[(t)^{1-m}-\left(t_{i}\right)^{1-m}\right]}\right]\right)
$$

$D_{\text {ref }}$ es el coeficiente de difusión medido en el tiempo $t_{\text {ref }}$ $t_{i}$ es la edad de primera exposición a los cloruros

La solución que presenta la ecuación anterior emplea una forma general de la ecuación de $D_{c}$ desarrollada por Mangat y Molloy representada por Nokken et al (2006) y es como sigue:

$$
\mathrm{D}(\mathrm{t})=\mathrm{Dref}^{*}\left(\mathrm{tref}_{\mathrm{re}} / \mathrm{t}\right)^{\mathrm{m}}
$$


El coeficiente empírico " $m$ " depende en gran medida de la composición de la mezcla de hormigón así como de la edad de la primera exposición del hormigón a los cloruros. Se han determinado valores para " $m$ " para mezclas de hormigón específicas y tiempos concretos, pero es dudosa su aplicación en otras mezclas y condiciones de exposición, siendo necesaria una mayor investigación para su cálculo más fiable. Su estimación resulta complicada.

Este modelo se adaptó para que se pudiera utilizar un valor $D_{c}$ avalado por la experiencia en lugar de $D_{i}$ y así tener en cuenta la posibilidad de que la primera exposición a los cloruros se produzca en tiempo distinto a $1 \mathrm{~s}$.

- Bamforth ${ }^{15,25}$

Bamforth (1999) tuvo en cuenta en su modelo la dependencia del tiempo de $D_{c}$ basándose en predicciones del valor a un año mediante la siguiente ecuación:

$$
\mathrm{D}_{\mathrm{ca}}=\mathrm{a}^{*} \mathrm{t}^{\mathrm{n}}
$$

$\mathbf{D}_{\mathbf{c a}}$ es el coeficiente de difusión aparente

a es el coeficiente de difusión aparente a 1 año

n es una constante empírica

Este modelo emplea un coeficiente de difusión aparente $D_{c a}$ que es una aproximación de $D_{c}$. Maheswaran y Sanjayan demostraron numéricamente que la constante empírica "n" es una función del tiempo.

A los modelos anteriores, pueden sumarse los siguientes tomados de la referencia²:

- Modelo del FIB ${ }^{69}$ :

Se trata de un modelo probabilístico basado en la ley de Fick, de donde se obtiene la expresión: 


$$
C_{c r i t}=C(x=a, t)=C_{0}+\left(C_{S . \Delta x}-C_{0}\right) *\left[1-\operatorname{erf} \frac{a-\Delta x}{2 * \sqrt{D_{a p p, C}{ }^{*} t}}\right]
$$

En la expresión anterior, aparece " $\Delta x^{" 2,69}$ que se define como la profundidad de la zona de convección (capa de hormigón, en la cual el proceso de penetración de cloruros no sigue la $2^{\mathrm{a}}$ ley de difusión de Fick), debido al efecto de lavado del hormigón.

La profundidad de la zona de convección $(\Delta x)$ depende del ambiente de exposición:

- Para zona de salpicaduras (splash zone), es una función beta, con $m=8,9 ; s=5,6 ; a=0,0 ; b=50,0$. En este caso la profundidad media $\Delta x$ hasta la que los cloruros pueden acceder rápidamente se puede limitar $6,0 \mathrm{~mm} \leq \Delta x \leq 11,0 \mathrm{~mm}$.

- Para zona sumergida y zona de spray (niebla salina), es un parámetro constante de valor 0 . Así, el FIB considera que en una distancia del agua de mar a la superficie mayor de 1,5m (zona de spray), la formación de la zona de convección es nula.

- Para zona de carrera de mareas, se trata de una función beta en la que hay que determinar los parámetros $\mathrm{m}, \mathrm{s}$, a y b.

El contenido de cloruros en superficie ${ }^{69}$ de un elemento estructural en zona de salpicaduras o de spray aumenta a medida que disminuye la distancia a los cloruros. Esto se ha comprobado tanto para distancias en horizontal como en vertical.

Aunque $\mathrm{C}_{\mathrm{s}, \Delta \mathrm{x}}$ teóricamente es una variable que depende del tiempo, para simplificar se puede considerar como una constante.

En el caso de estructuras sumergidas, el contenido de cloruros en superficie es igual al contenido de saturación de cloruros, $\mathrm{C}_{\mathrm{s}, 0}$. Dicho parámetro se obtiene de la figura 4.18 que se indica a continuación, donde se entra con el contenido de cloruros del agua en $\mathrm{g} / \mathrm{l}$. 


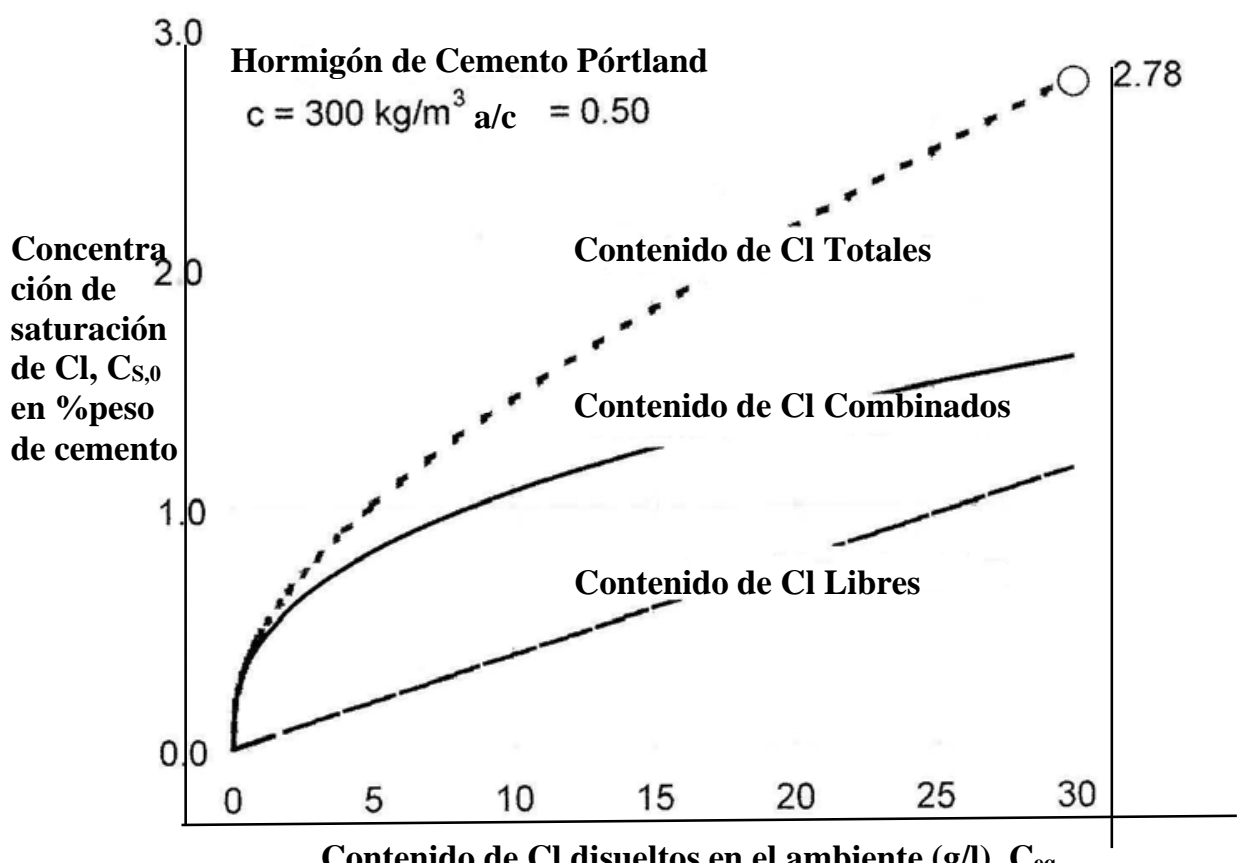

Contenido de $\mathrm{Cl}$ disueltos en el ambiente (g/l), $\mathrm{C}_{\text {eq }}$

Fig4.18. Obtención del contenido de saturación de cloruros

Así, en el caso de $\mathrm{C}_{\mathrm{eq}}=30 \mathrm{~g} / \mathrm{l}$, la concentración de saturación $\mathrm{C}_{\mathrm{s}, 0}$ resulta ser 2,78 en $\%$ en peso de cemento.

Para estructuras en zona de salpicaduras, el contenido de cloruros en superficie $C_{s, \Delta x}$ se define como el contenido máximo de cloruros $C_{\max }$. Dado que los ensayos demuestran que el hormigón situado a una altura mayor de 1,50 $\mathrm{m}$ sobre el mar (zona de spray) no desarrolla zona de convección $(\Delta \mathrm{x}), \mathrm{C}_{\max }$ es igual al contenido de cloruros en superficie $\mathrm{C}_{\mathrm{s}}$. En estos casos, el valor de $\mathrm{C}_{\mathrm{s}, \Delta x}$ puede cuantificarse como una distribución normal respecto a $C_{s}$ con parámetros $\mathrm{m}$ y s. El valor de $\mathrm{m}$ no se ha localizado en el texto referenciado y el de $\mathrm{s}$ es 0,75 .

Para el caso de ambiente marino aéreo y para una estructura de características siguientes:

- Localización: zonas urbanas y rurales de Alemania

- Tiempo de exposición considerado: 5-40 años

- Hormigón: CEM I, a/c entre 0,45 y 0,60

El contenido de cloruros máximo en el hormigón $\mathrm{C}_{\max }$ puede determinarse según la ecuación: 


$$
\mathrm{C}_{\max }\left(\mathrm{x}_{\mathrm{a}}, \mathrm{x}_{\mathrm{h}}\right)=0.465-0.051 \cdot \ln \left(\mathrm{x}_{\mathrm{a}}+1\right)-\left(0.00065 \cdot\left(\mathrm{x}_{\mathrm{a}}+1\right)^{-0.187}\right) \cdot \mathrm{x}_{\mathrm{h}}
$$

$\mathbf{C}_{\max }$ es el contenido máximo de cloruros dentro del perfil de cloruros (\% peso de hormigón)

$\mathbf{x}_{\mathbf{a}}$ es la distancia horizontal

$\mathbf{x}_{\mathbf{h}}$ es la distancia vertical

Esta ecuación se deduce empíricamente para las condiciones antes indicadas. Para el caso de distintas clases de exposición o diferentes dosificaciones, debe determinarse una ecuación equivalente.

Por otro lado, el coeficiente de difusión aparente de cloruros en el hormigón se puede determinar mediante la ecuación:

$$
\mathrm{D}_{\mathrm{app}, \mathrm{C}}=\mathrm{k}_{\mathrm{e}}^{*} \mathrm{D}_{\mathrm{RCM}, 0}{ }^{*} \mathrm{k}_{\mathrm{r}}^{*} \mathrm{~A}(\mathrm{t})
$$

Dicho coeficiente de difusión aparente, $D_{a p p, c}$ depende, entre otros factores, de las condiciones ambientales, del coeficiente de migración de cloruros y de una subfunción que considera el envejecimiento, $A(t)$.

$$
A(t)=\left(t_{0} / t^{a}\right.
$$

Donde $\mathbf{a}$ es el coeficiente de envejecimiento y $\mathbf{t}_{0}$ el instante de tiempo de referencia en años.

Los coeficientes de difusión aparentes se obtienen de perfiles de cloruros recogidos de la bibliografía y agrupados en función de la dosificación del hormigón y el ambiente de exposición. Con el ensayo de migración acelerada, realizado según NT Build 492 empleando probetas de esas dosificaciones, se ajustan las regresiones y se obtiene el coeficiente de envejecimiento.

El coeficiente de envejecimiento oscila entre 0,30 (cemento Pórtland) y 0,60 (cemento con cenizas) como puede verse en la tabla 4.13: 


\begin{tabular}{||c||c||}
\hline \hline Tipo de Hormigón & Exponente de envejecimiento a \\
\hline \hline Con Cemento Pórtland CEM I & Beta $(\mathrm{m}=0,30 ; \mathrm{s}=0,12 ; \mathrm{a}=0,0 ; \mathrm{b}=1,0)$ \\
$0,40 \leq \mathrm{a} / \mathrm{c} \leq 0,60$ & Beta $(\mathrm{m}=0,60 ; \mathrm{s}=0,15 ; \mathrm{a}=0,0 ; \mathrm{b}=1,0)$ \\
\hline $\mathrm{f} \geq 0,2 * \mathrm{z} ; \mathrm{k}=0,50 ; 0,40 \leq \mathrm{a} / \mathrm{ceq} \leq 0,60$ & Beta $(\mathrm{m}=0,45 ; \mathrm{s}=0,20 ; \mathrm{a}=0,0 ; \mathrm{b}=1,0)$ \\
\hline Con escorias & \\
\hline CEM III/B; $0,40 \leq \mathrm{a} / \mathrm{c} \leq 0,60$ & \\
\hline
\end{tabular}

Tabla 4.13. Valores del coeficiente de envejecimiento según el tipo de cemento utilizado.

El exponente de envejecimiento viene definido por una función beta definida por "m" (valor medio), "s" (desviación estándar); "a" (límite inferior) y "b" (límite superior).

El contenido crítico de cloruros (en \% en peso de cemento) es una función beta, con $m=0,6 ; s=0,15 ; a=0,2 ; b=2,0$.

- Modelo de Sagüés et al

En este caso, se estima el coeficiente de difusión de estructuras con a/c comprendido entre 0,32 y 0,41 y contenidos de cemento entre 390 y $446 \mathrm{~kg} / \mathrm{m} 3$, mediante la expresión siguiente:

$$
D_{\text {estimado }}=1,1 * 10^{-8 *} F_{1} * F_{2} * 1+\left(\frac{a / c-0,32}{0,09}\right) *\left(1+\frac{446-c}{56}\right)
$$

En el modelo se introducen dos factores: $F_{1}$ (factor de influencia de adiciones) con un valor de 1 si el contenido de cenizas volantes oscila entre $18-30 \%$, o el de humo de sílice entre $8-10 \%$ o el de escorias es superior al $70 \%$ y $\mathrm{F}_{2}$ (factor de edad), que sirve para actualizar el coeficiente de difusión al año, ya que la expresión lo calcula para 11 años, mediante la expresión: $F_{2}=(1 / 11)^{-0,7}$. 
- Modelo de Izquierdo

Este modelo es para un cemento Pórtland sin empleo de adiciones y permite conocer el coeficiente de difusión de cloruros a un año que viene dado por la siguiente expresión:

$$
\sqrt{D_{C l}}=\left(-2,181+1,369 * e^{(a / c)}+\frac{721,8}{C_{c e m}}\right) * 10^{-6}
$$

También da otra expresión para hormigón con cemento Pórtland y humo de sílice, que es la siguiente:

$$
D_{C l}=1,636 * 10^{-6 *} C_{c e m}{ }^{-1,975} *\left(\frac{a}{c}\right)^{0,8862} * H S^{-0,740}
$$

En ambas expresiones, D se expresa en $\mathrm{m}^{2} / \mathrm{s}$; a/c es la relación agua/cemento; $\mathrm{C}_{\text {cem }}$ es el contenido de cemento en $\mathrm{kg} / \mathrm{m}^{3}$ y $\mathrm{HS}$ es el contenido de humo de sílice en $\%$.

- Modelo Bermúdez-Alaejos

Tras la investigación realizada por la referencia ${ }^{1,2}$ en la que se llevó a cabo un estudio análogo al que aborda el presente trabajo pero referido a los sub-ambientes de carrera de mareas y sumergido, se llegó a sendas expresiones que permiten relacionar el coeficiente de difusión de cloruros con la dosificación del hormigón. Se obtuvieron también los coeficientes de eficacia, respecto a la penetración de cloruros, de las adiciones de humo de sílice y cenizas volantes.

En el modelo se emplearon distintos valores del coeficiente de envejecimiento. Así, se ha tomado $\alpha=0,3$ para hormigones fabricados con cemento Pórtland, $\alpha=0,6$ para el caso de los que tengan como adición cenizas volantes y $\alpha=1-(1,1 \cdot a / c)$ para los que tengan humo de sílice ${ }^{66}$.

En el caso del ambiente de carrera de marea, las expresiones son: (OPC) 


$$
\ln D_{1}+2,2395=7,9358^{*} \mathrm{a} / \mathrm{c} \rightarrow D_{1}=\left(\frac{e^{a / c}}{e^{0,2822}}\right)^{7,9358}
$$

(Humo Sílice)

$$
\ln D_{1}+2,2395=5,5984 * \mathrm{a} / \mathrm{c} \rightarrow D_{1}=\left(\frac{e^{a / c}}{e^{0,4000}}\right)^{5,5984}
$$

(Cenizas Volantes)

$$
\ln D_{1}+2,2395=6,1315^{*} \mathrm{a} / \mathrm{c} \rightarrow D_{1}=\left(\frac{e^{a / c}}{e^{0,3652}}\right)^{6,1315}
$$

Partiendo de la expresión para hormigones fabricados con cemento Pórtland sin adiciones y los coeficientes de eficacia de las adiciones $\mathrm{K}_{\mathrm{S}}$ (humo de sílice) y $\mathrm{K}_{\mathrm{V}}$ (cenizas volantes) obtenidos en dicho estudio, $K_{S}=6,42$ y $K_{V}=1,31$, la fórmula para el cemento Pórtland podría generalizarse como:

$$
D_{1}=\left(\frac{e^{a /\left(c+6,4^{*} H S+1,3^{*} C V\right)}}{e^{0,2822}}\right)^{7,9358}
$$

En el caso del ambiente sumergido, las expresiones obtenidas son las siguientes:

(OPC)

$$
\ln D_{1}+2,9061=11,7320 * \mathrm{a} / \mathrm{c} \rightarrow D_{1}=\left(\frac{e^{a / c}}{e^{0,2477}}\right)^{11,732}
$$

(Humo de sílice)

$$
\ln D_{1}+2,9061=8,6509 * \mathrm{a} / \mathrm{c} \rightarrow D_{1}=\left(\frac{e^{a / c}}{e^{0,3359}}\right)^{8,6509}
$$

Partiendo de la expresión para hormigones fabricados con cemento Pórtland sin adiciones y el coeficiente de eficacia de las adiciones $\mathrm{K}_{\mathrm{S}}$ (humo de sílice) obtenido en dicho estudio, $K_{S}=5,56$, la fórmula para el cemento Pórtland podría generalizarse como:

$$
D_{1}=\left(\frac{e^{a /\left(c+5,56^{*} H S\right)}}{e^{0,2477}}\right)^{11,732}
$$


- Modelo estudio en Japón ${ }^{7}$

En un estudio realizado en Japón sobre el recubrimiento de hormigón requerido en zonas costeras $^{7}$, éste se calcula según las ecuaciones siguientes con los parámetros que se indican a continuación:

$$
\begin{aligned}
& C(x, t)=C_{0} \cdot\left\{1-e r f\left(x / 2 \sqrt{D_{c}} \cdot t\right)\right\}<C_{\text {corr }}-C_{\text {init }} \\
& C_{\text {air }}=C_{1} \cdot d^{-0,6} \\
& C_{o}=1,5 \cdot C_{\text {air }}{ }^{0,4}
\end{aligned}
$$

Donde $C_{1}=0,6$ mdd en región $A$ y $B$, y 0,2 mdd en región $C$, regiones especificadas en la figura 4.1

$$
\begin{aligned}
& \mathbf{C}_{\text {corr }}=1,2 \mathrm{~kg} / \mathrm{m}^{3} \\
& \mathbf{C}_{\text {init }}=0,3 \mathrm{~kg} / \mathrm{m}^{3} \\
& \mathbf{D}_{\mathbf{c}} \text { sería obtenido de la función siguiente } \quad D_{c}=\left(5 \cdot 10^{-7}\right) \cdot e^{-1,6(c / a)}
\end{aligned}
$$

Donde a/c es 0,36 para hormigón pretensado prefabricado y 0,43 para hormigón posteso.

Vida útil: 50 ó 100 años

- Modelo JSCE (Japan Society of Civil Engineers) ${ }^{88}$.

El coeficiente de difusión de cloruros del hormigón debe cumplir:

$$
\gamma_{p} \cdot\left(D_{p} / D_{k}\right) \leq 1,0
$$

Donde,

" $\gamma_{p}$ " es un coeficiente de seguridad a considerar afectado por la precisión en el cálculo de $D_{p}$ y generalmente considerado entre 1-1,3. " $D_{k}$ " es el valor característico del coeficiente de difusión de cloruros expresado en $\mathrm{cm}^{2} / a n ̃ o$,

" $D_{p}$ " es el valor estimado del coeficiente de difusión de cloruros expresado en $\mathrm{cm}^{2} /$ año y normalmente obtenido a partir de una ecuación del tipo:

$$
\log D p=a \cdot(a / c) 2+b \cdot(a / c)+c
$$


en la que "a/c" es la relación agua-cemento y "a, b y c" son constantes en función de los resultados obtenidos a partir de la experimentación.

Se han propuesto algunas regresiones para la predicción de la difusión de cloruros en el hormigón basadas en resultados de investigación realizados en estructuras actuales, recomendando el empleo de un coeficiente de seguridad de 1,2.

- Para cemento Pórtland: $\log D_{p}=-3,9 \cdot(a / c)^{2}+7,2 \cdot(a / c)-2,5$

- Para cemento con escorias: $\quad \log D_{p}=-3,0 \cdot(a / c)^{2}+5,4 \cdot(a / c)-$ 2,2

En las especificaciones de la JSCE referentes a mantenimiento de estructuras de hormigón ${ }^{89}$, se indican dos expresiones para el cálculo de la difusión aparente " $D$ " en función de la relación a/c. Las expresiones corresponden a hormigón fabricado con cemento Pórtland ordinario y tratado con escorias, respectivamente:

$$
\begin{aligned}
& \log D=\left[4,5(a / c)^{2}+0,14(a / c)-8,47\right]+\log \left(3,15 \cdot 10^{7}\right) \\
& \log D=\left[19,5(a / c)^{2}-13,8(a / c)-5,74\right]+\log \left(3,15 \cdot 10^{7}\right)
\end{aligned}
$$

donde $\mathrm{D}$ es el coeficiente de difusión aparente expresado en $\mathrm{cm}^{2} / a n ̃ o$ y a/c es la relación agua-cemento.

- Modelo obtenido por estudio noruego ${ }^{37}$

En un estudio noruego realizado en plataformas de combustible en el mar del Norte $^{37}$, el ingreso de cloruros obedece a una versión modificada de la expresión de la segunda Ley de Fick donde el coeficiente de difusión varía con el tiempo, tal y como se explica más adelante. La expresión es la siguiente:

$$
C(x, t)=C_{s}-\left(C_{s}-C_{i}\right)^{*} \operatorname{erf}\left(\frac{x}{\sqrt{4 t D}}\right)
$$


Donde "Cs" representa la concentración de cloruros en el ambiente y "D" es el coeficiente de difusión de cloruros que caracteriza la habilidad del material para la penetración de los cloruros.

- Modelo Instrucción española EHE-08³.

Según la Instrucción $\mathrm{EHE}^{3}$, el período de tiempo necesario para que se produzca una concentración de cloruros $C_{\text {th }}$ a una distancia $d$ respecto a la superficie del hormigón puede estimarse con la siguiente expresión:

$$
t=\left(\frac{d}{K_{d}}\right)^{2}
$$

Donde $\mathrm{d}$ es la profundidad en mm y t es el tiempo en años.

El coeficiente de penetración de cloruros $\mathrm{K}_{\mathrm{Cl}}$ tiene la siguiente expresión:

$$
K_{c l}=\alpha \sqrt{12 D(t)}\left(1-\sqrt{\frac{C_{n}-C_{b}}{C_{s}-C_{b}}}\right)
$$

Donde $\alpha$ es el factor de conversión de unidades que vale 56157.

$\mathbf{D}(\mathbf{t})$ es el coeficiente de difusión efectivo de cloruros, para la edad $\mathrm{t}$, expresado en $\mathrm{cm}^{2} / \mathrm{s}$.

$\mathbf{C}_{\text {th }}$ es la concentración crítica de cloruros, expresada en \% en peso en cemento.

$\mathbf{C}_{\mathbf{s}}$ es la concentración de cloruros en superficie del hormigón, expresada en $\%$ en peso de cemento.

$\mathbf{C}_{\mathbf{b}}$ es el contenido de cloruros aportado por las materias primas (áridos, cemento, agua, etc.) en el momento de la fabricación del hormigón.

El coeficiente de difusión de cloruros varía con la edad del hormigón de acuerdo con la siguiente expresión:

$$
D(t)=D\left(t_{0},\left(\frac{t_{0}}{t}\right)^{n}\right.
$$

Donde $\mathbf{D}\left(\mathbf{t}_{\mathbf{0}}\right)$ es el coeficiente de difusión de cloruros a la edad $\mathrm{t}_{0}, \mathbf{D}(\mathbf{t})$ el coeficiente a la edad $t$, y $\mathbf{n}$ es el coeficiente de envejecimiento, que 
puede tomarse, a falta de valores específicos obtenidos mediante ensayos sobre el hormigón de que se trate, igual a 0,5.

Para la utilización del modelo de penetración de cloruros puede emplearse el valor de $\mathrm{D}\left(\mathrm{t}_{0}\right)$ obtenido mediante ensayos específicos de difusión (en cuyo caso to sería la edad del hormigón a la que se ha realizado el ensayo), o bien emplear los valores de la tabla 4.14 (obtenidos para $t_{0}=0,0767$ años).

\begin{tabular}{||c||c||c|c|c|c||}
\hline $\begin{array}{c}\text { Tipo de } \\
\text { Cemento }\end{array}$ & $\mathrm{a} / \mathrm{c}=0,40$ & $\mathrm{a} / \mathrm{c}=0,45$ & $\mathrm{a} / \mathrm{c}=0,50$ & $\mathrm{a} / \mathrm{c}=0,55$ & $\mathrm{a} / \mathrm{c}=0,60$ \\
\hline CEM I & 8,9 & 10,0 & 15,8 & 19,7 & 25,0 \\
\hline CEM II/A-V & 5,6 & 6,9 & 9,0 & 10,9 & 14,9 \\
\hline CEM III & 1,4 & 1,9 & 2,8 & 3,0 & 3,4 \\
\hline
\end{tabular}

Tabla 4.14. Coeficientes $D\left(t_{0}\right)\left(\times 10^{-12} \mathrm{~m}^{2} / \mathrm{s}\right)$.

La concentración crítica de cloruros $\left(\mathrm{C}_{\text {th }}\right)$ deberá ser establecida por el Autor del proyecto de acuerdo con las consideraciones específicas de la estructura. En condiciones normales, puede adoptarse un valor del 0,6\% del peso de cemento para la comprobación del Estado Límite en relación con la corrosión de las armaduras pasivas. En el caso de armaduras activas pretesas, puede adoptarse un valor límite de $\mathrm{C}_{\text {th }}$ de $0,3 \%$ del peso de cemento.

El valor de $\mathrm{C}_{\mathrm{s}}$ depende de las condiciones externas, especialmente de la orografía del terreno y el régimen de vientos predominantes en la zona, en el caso de ambientes próximos a la costa. Además, Cs varía con la edad del hormigón, alcanzando su valor máximo a los 10 años. A falta de valores obtenidos a partir de ensayos en estructuras de hormigón situadas en las proximidades, el Autor del proyecto valorará la posibilidad de adoptar un valor de $\mathrm{C}_{\mathrm{S}}$ de acuerdo con la tabla 4.15, en función de la clase general de exposición: 


\begin{tabular}{|c|c|c|c|c|c|}
\hline $\begin{array}{c}\text { Clase General de } \\
\text { Exposición }\end{array}$ & \multicolumn{2}{|c|}{ IIIa } & IIIb & IIIC & IV \\
\hline $\begin{array}{c}\text { Distancia respecto } \\
\text { a la costa }\end{array}$ & $\begin{array}{l}\text { Hasta } \\
500 \mathrm{~m}\end{array}$ & $\begin{array}{l}500 \mathrm{~m}- \\
5000 \mathrm{~m}\end{array}$ & \multicolumn{2}{|c|}{ Cualquiera } & --- \\
\hline $\begin{array}{l}\text { Cs (\%peso de } \\
\text { hormigón) }\end{array}$ & 0,14 & 0,07 & 0,72 & 0,50 & 0,50 \\
\hline
\end{tabular}

Tabla 4.15. Concentración de cloruros en la superficie de hormigón.

En el caso de que $\mathrm{C}_{\mathrm{th}}-\mathrm{C}_{\mathrm{b}}>\mathrm{C}_{\mathrm{s}}$ se considerará comprobado el Estado Límite sin necesidad de efectuar ninguna comprobación numérica.

- Modelos de elementos finitos y comerciales ${ }^{15}$

En el caso de la referencia ${ }^{15}$, se relacionan otros modelos distintos a los de origen fickiano hasta aquí considerados. Se trata de modelos de elementos finitos y modelos de tipo comercial. Este tipo de modelos precisan una información y toma de datos completa, información de la que no se suele disponer en la fase de proyecto. En el caso de la presente investigación se estudian modelos de tipo fickiano, dado que manejan un menor número de variables, lo cual resulta más viable a la hora de realizar un estudio de difusión previo a la construcción de una estructura.

Así los modelos de difusión de elementos finitos recogidos por la referencia ${ }^{15}$ serían:

- Saetta, Scotta y Vitaliani (1993)

- Boddy, Bentz, Thomas y Hooton (1999)

- Martín-Pérez, Pantazopoulou y Thomas (2001)

En el caso de los modelos de tipo comercial se citan dos: STADIUM y Life-365 (Thomas y Bentz, 2000). 
- Comparación entre modelos del Fib ${ }^{69}$, Bermúdez-Alaejos ${ }^{1,2}$ y Japón ${ }^{7}$

A continuación la figura 4.19 recoge la comparación entre los modelos de Japón ${ }^{7}$, del FIB ${ }^{69}$ y de Bermúdez-Alaejos ${ }^{1}$ para el caso del cemento Pórtland. En el caso del modelo de Japón no se dispone del dato de la edad del hormigón en el momento del ensayo por lo que se ha supuesto tres situaciones: 28 días, 1 año y 10 años.

En el caso del modelo del $\mathrm{FIB}^{69}$ se ha empleado un coeficiente de envejecimiento $m=0,3$; para el contenido de cloruros en superficie, no se dispone de un valor único como ya se ha reflejado en el apartado 4.4.3.2; en cuanto al contenido inicial de cloruros $C_{b}$ no especifica un valor concreto, aunque sí señala que puede asumirse como constante.

En el modelo de Bermúdez-Alaejos no se ha empleado coeficiente de envejecimiento ya que el modelo nos permite directamente obtener el coeficiente de difusión a un año. En cuanto la concentración de cloruros en superficie, el valor que se ha considerado se basa en los resultados obtenidos en el estudio ${ }^{2}$ y oscilan entre 1,46 y $4,67 \%$ en peso de cemento y para el contenido inicial de cloruros $C_{b}$, entre 0,0034 y 0,1094).

En el modelo de Japón ${ }^{7}$ se ha empleado como coeficiente de envejecimiento $m=0,3$. En cuanto la concentración de cloruros en superficie, el valor vendría dado por la expresión:

$$
\mathrm{C}_{0}=\mathbf{1 , 5} \cdot\left(\mathrm{C}_{1} \cdot \mathrm{d}^{-0,6}\right)^{0,4}
$$

que depende del contenido de aire en la zona en la que nos encontremos y de distancia a la costa y para el contenido inicial de cloruros $C_{b}$ es igual a $0,3 \mathrm{~kg} / \mathrm{m}^{3}$.

Como conclusión de esta comparación puede decirse que el modelo planteado por el fib es único independientemente del ambiente marino en el que se encuentre; el modelo de Bermúdez-Alaejos plantea dos coeficientes de difusión distintos, uno en el caso de ambiente sumergido y otro para carrera de mareas, siendo el primero de valor superior al segundo; y por último, el modelo de Japón (estudiado para 
ambiente marino aéreo) presenta velocidad inferior de difusión en los tres supuestos planteados. La figura 4.19 muestra esta comparación:

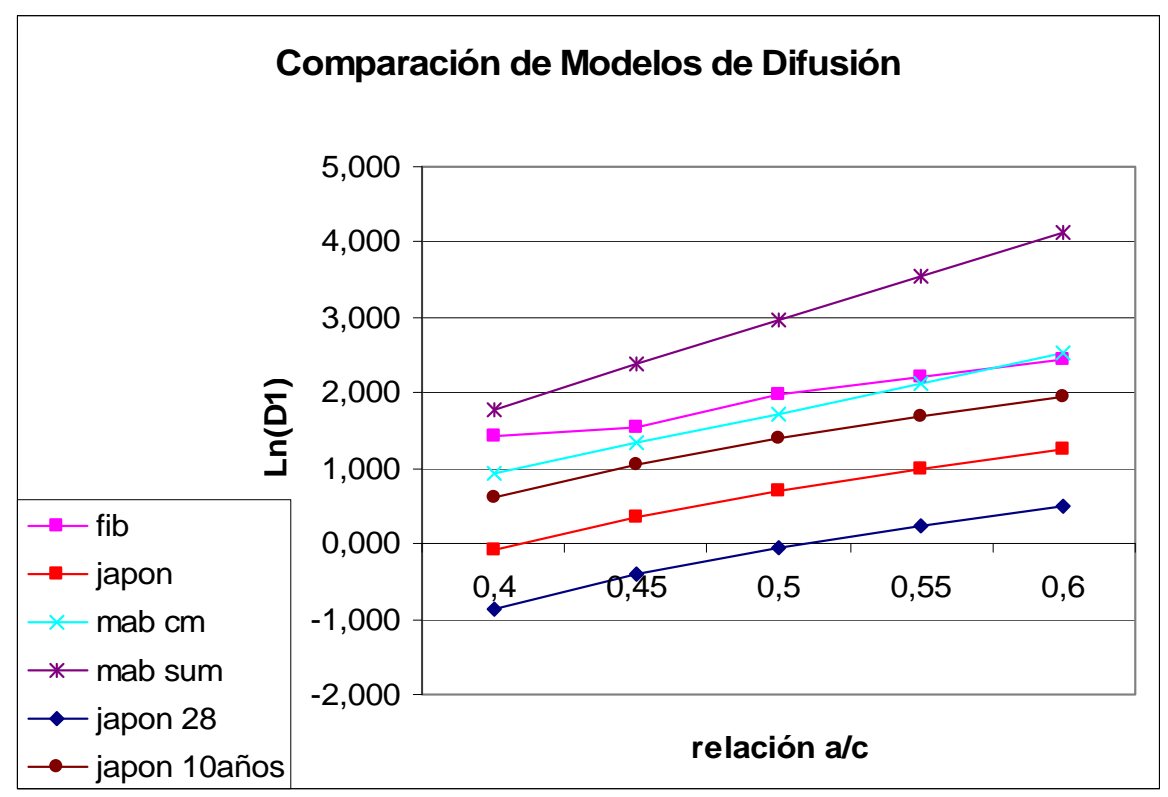

Fig.4.19. Gráfico comparativo entre modelos de difusión para cemento Portland.

\subsubsection{Valores del coeficiente de difusión}

A continuación se muestra la tabla 4.16 que recoge los valores de los coeficientes de difusión en el estudio realizado en Japón sobre estructuras con diferentes calidades de hormigón?:

\begin{tabular}{|c|c|c|c|c|c|c|c|c|c|c|c|c|}
\hline \multirow{3}{*}{$\begin{array}{l}\text { TIPO DE PUENTE } \\
\text { Hormigón } \\
\text { Armado (18-21 } \\
\text { MPa) }\end{array}$} & \multirow{2}{*}{$\begin{array}{c}\mathbf{N}^{\circ} \text { DE } \\
\text { PUENTES } \\
\text { ESTUDIADOS } \\
25\end{array}$} & \multicolumn{11}{|c|}{$\begin{array}{c}\text { COEF. DIFUSIÓN (cm²/s) } \\
\text { (Se indica el no de puentes y debajo el coeficiente medio de difusión) }\end{array}$} \\
\hline & & 1 & 3 & 4 & 1 & 4 & 5 & 3 & 1 & 3 & -- & -- \\
\hline & Valores $\cdot 10^{-8}$ & 0,30 & 0,50 & 0,70 & 0,90 & 1 & 3 & 5 & 7 & 9 & -- & -- \\
\hline \multirow{2}{*}{$\begin{array}{c}\text { H. Pretensado } \\
\text { Posteso (40 MPa) }\end{array}$} & 47 & 1 & 1 & 3 & 5 & 12 & 7 & 7 & 4 & 3 & 3 & 1 \\
\hline & Valores $\cdot 10^{-8}$ & 0,07 & 0,09 & 0,10 & 0,30 & 0,50 & 0,70 & 0,90 & 1 & 3 & 5 & 7 \\
\hline \multirow{2}{*}{$\begin{array}{c}\text { H. Pretensado } \\
\text { Prefabricado (50 } \\
\text { MPa) }\end{array}$} & 17 & 1 & 3 & 2 & 3 & 3 & 1 & 1 & 3 & -- & -- & -- \\
\hline & Valores $\cdot 10^{-8}$ & 0,05 & 0,07 & 0,09 & 0,10 & 0,30 & 0,50 & 0,70 & 0,90 & -- & -- & -- \\
\hline
\end{tabular}

Tabla 4.16. Valores del coeficiente de difusión obtenidos en estudio realizado en Japón. 
En la tabla puede observarse que los menores coeficientes de difusión se dan en el hormigón pretensado y los mayores en el hormigón armado convencional ${ }^{7}$.

\subsubsection{Parámetros que influyen en el Coeficiente de Difusión}

\subsubsection{El tiempo}

Inicialmente, se consideró que el coeficiente de difusión "D" era un parámetro independiente del tiempo. Sin embargo, se ha confirmado a través de ensayos de laboratorio e inspecciones de campo en estructuras expuestas a los cloruros durante 37 años que la resistencia a la penetración de los cloruros se mejora con el tiempo (Maage et al. 1996,1999) y obedece a la expresión matemática ${ }^{37}$ :

$$
\mathrm{D}(\mathrm{t})=\mathrm{D}\left(\mathrm{t}_{0}\right) \cdot\left(\mathrm{t}_{0} / \mathrm{t}\right)^{\mathrm{n}}
$$

La razón más citada para explicar la reducción del valor de $D_{c}$ con el tiempo es la continua hidratación del cemento. Las reacciones puzolánicas dentro de la matriz de hormigón también contribuyen a la reducción de $D_{c}$ Adicionalmente, se ha considerado que la presencia de sales insolubles en la superficie del hormigón retrasará el ingreso de cloruros actuando como una barrera física. Todos los mecanismos citados se manifiestan dentro del hormigón por separado, sin embargo, todos ellos coinciden en la reducción de $D_{c}$ constriñendo la red capilar de poros. Mientras que el fenómeno químico y físico que produce cambios en $D_{c}$ no se comprende completamente, estos mecanismos pueden ser modelizados de forma razonable a partir de datos empíricos ${ }^{15}$.

Según la Instrucción española $\mathrm{EHE}^{3}$, el coeficiente de difusión de cloruros varía con la edad del hormigón de acuerdo con esta expresión, en la que $D\left(t_{0}\right)$ es el coeficiente de difusión de cloruros a la edad " $t_{0}$ ", $D(t)$ es el coeficiente a la edad " $\mathrm{t}$ " $\mathrm{y}$ " $\mathrm{n}$ " (o " $\alpha$ " en algunos casos) es el factor de edad o también llamado factor de envejecimiento, que a falta de valores específicos obtenidos mediante ensayos, puede tomarse como 0,5.

En este sentido, el modelo de difusión del FIB (apartado 4.4.3.2) recoge diferentes valores del coeficiente de envejecimiento al utilizar adiciones (tabla 4.13). La referencia ${ }^{68}$ recoge la siguiente tabla 4.17 tomada del Duracrete 
Project (1998) donde se realizó una caracterización del coeficiente de envejecimiento " $a$ " según el tipo de cemento y las condiciones de exposición:

\begin{tabular}{|c|c|c|c|c|c|}
\hline \multirow{2}{*}{ Cemento } & \multirow{2}{*}{ Tipo de Ambiente } & \multicolumn{2}{|c|}{ Distribución Normal } & \multicolumn{2}{|c|}{ Beta $(a=0: b=1)$} \\
\hline & & Media & Average & $\mathbf{q}$ & $\mathbf{R}$ \\
\hline \multirow{3}{*}{ Pórtland } & Sumergido & 0,30 & 0,005 & 24,9 & 58,1 \\
\hline & $\begin{array}{c}\text { Carrera de mareas } \\
\text { y salpicaduras }\end{array}$ & 0,37 & 0,007 & 17,2 & 29,3 \\
\hline & Aéreo & 0,65 & 0,07 & 29,5 & 15,9 \\
\hline \multirow{3}{*}{$\begin{array}{c}\text { Con } \\
\text { Cenizas } \\
\text { volantes }\end{array}$} & Sumergido & 0,69 & 0,05 & 58,3 & 26,2 \\
\hline & $\begin{array}{c}\text { Carrera de mareas } \\
\text { y salpicaduras }\end{array}$ & 0,93 & 0,07 & 1234 & 92,9 \\
\hline & Aéreo & 0,66 & 0,07 & 29,6 & 15,2 \\
\hline \multirow{3}{*}{$\begin{array}{c}\text { Con } \\
\text { Escorias }\end{array}$} & Sumergido & 0,71 & 0,05 & 57,8 & 23,6 \\
\hline & $\begin{array}{c}\text { Carrera de mareas } \\
\text { y salpicaduras }\end{array}$ & 0,80 & 0,07 & 5,8 & 3,87 \\
\hline & Aéreo & 0,85 & 0,07 & 21,3 & 3,75 \\
\hline \multirow{3}{*}{$\begin{array}{l}\text { Con Humo } \\
\text { de sílice }\end{array}$} & Sumergido & 0,62 & 0,05 & 57,8 & 35,4 \\
\hline & $\begin{array}{c}\text { Carrera de mareas } \\
\text { y salpicaduras }\end{array}$ & 0,39 & 0,07 & 18,5 & 29,0 \\
\hline & Aéreo & 0,79 & 0,07 & 26 & 6,9 \\
\hline
\end{tabular}

Tabla 4.17. Valores del coeficiente de envejecimiento según DURACRETE.

En el caso del estudio realizado en las plataformas noruegas situadas en el Mar del Norte ${ }^{37}$, las variaciones en los coeficientes de difusión en general fueron demasiado grandes y el tiempo transcurrido entre medidas demasiado pequeño como para obtener valores fiables de "a", por lo que basándose en experiencias previas (Fluge, 2001) se adoptó $\alpha=0,6$. Para validar la robustez de la elección del coeficiente de envejecimiento, se realizaron cálculos paralelos con $\alpha=0,50$, con muy poca influencia en los tiempos de iniciación calculados $^{37}$.

Así, en el caso de la estructura Heidrun ${ }^{37}$, que resultó ser la única del estudio donde se recogieron datos con suficiente precisión y diferencia de edad para estimar el coeficiente de envejecimiento, se obtuvo un " $\alpha$ " $=0,82$. En otros casos, con tiempo de exposición entre 2 y 9 años, " $\alpha=0,88$ y algunos autores (Helland, 199537,26; Maage et al., 1996 ${ }^{37,27}$ ) recogen valores de " $\alpha "=0,70$ para puentes de hormigón situados en la costa con más de 37 años en servicio. 
En un estudio realizado en la ría de Huelva con bloques de hormigón parcialmente enterrados $(50 \times 50 \times 200 \mathrm{~cm})^{39}$, se analiza la variación del coeficiente de difusión con el tiempo, comprobándose que disminuye con el tiempo aunque obteniendo grandes oscilaciones, tal como se refleja en la figura 4.20 .

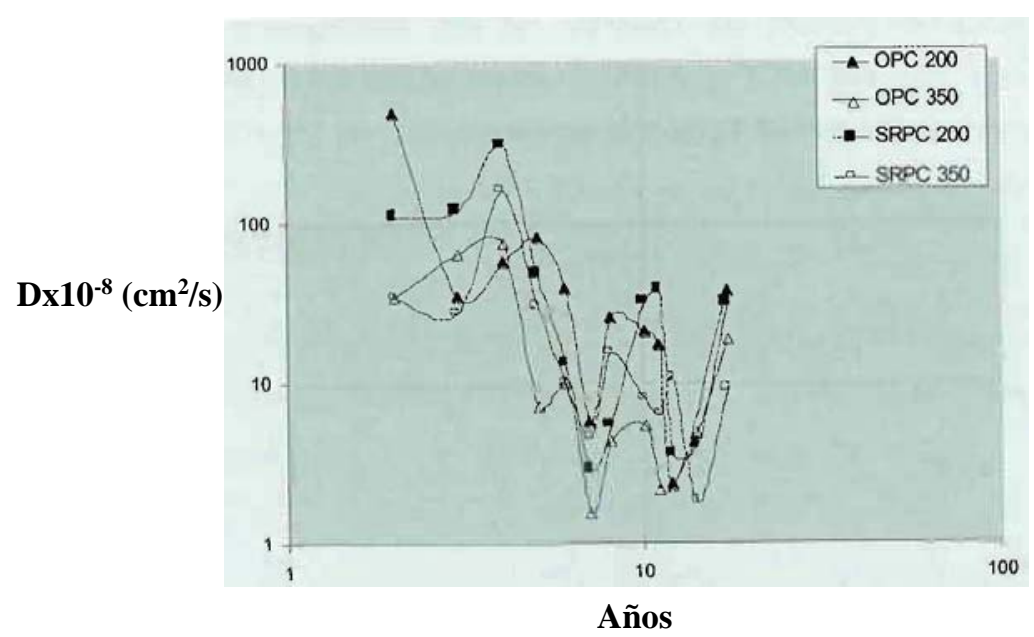

Fig.4.20 Variación de los valores de D con el tiempo

El parámetro " $\alpha$ " afecta especialmente cuando se emplean datos relativos a hormigones jóvenes, por lo que para que sea fiable conviene trabajar con datos de hormigón maduro ${ }^{37}$. Se ha demostrado que la $D$ inicial para una mezcla es relativamente alta, pero se ve reducida rápidamente tras los 5-10 primeros años. La magnitud y velocidad de descenso de $D$ depende fundamentalmente de la relación a/c del hormigón, de la cantidad y tipo de puzolanas presentes y de la velocidad de hidratación. La forma más efectiva de conseguirlo es mediante la adición de puzolanas, ya que actúan como un material cementicio secundario al reaccionar para formar productos de hidratación que rellenan los poros capilares y reducen la permeabilidad del hormigón ${ }^{15}$.

La dependencia del tiempo de D varía según el ratio de reducción y el momento de primera exposición a los cloruros. Por ello, para modelizar de forma precisa el coeficiente de difusión efectiva es necesario conocer la edad en que el hormigón fue inicialmente expuesto a los cloruros ${ }^{15}$.

Como resultado de la variabilidad de los valores adoptados se concluye que este coeficiente no tiene demasiada influencia en el cálculo de D. 
En la referencia ${ }^{68}$ se indica la siguiente figura 4.21 donde se refleja el efecto del umbral de cloruros en la probabilidad de fallo de una estructura a lo largo del tiempo.

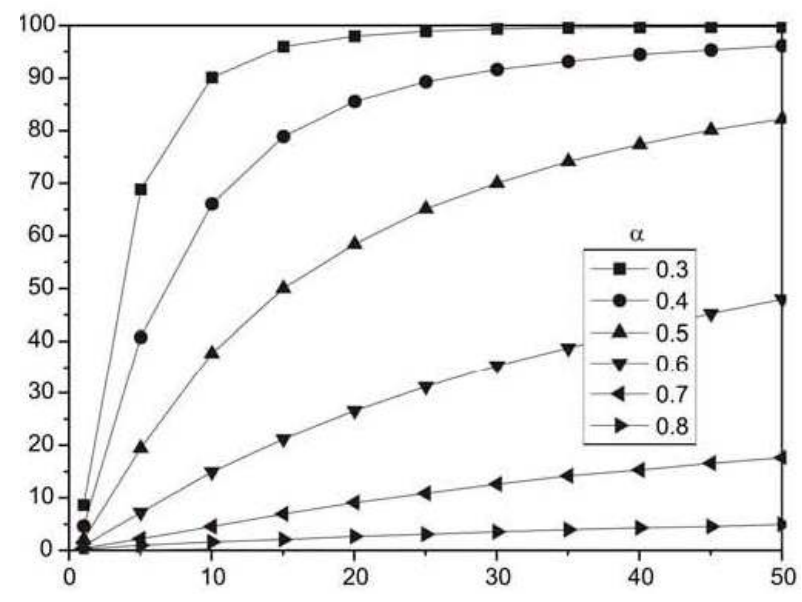

Tiempo (años)

Fig.4.21. Efecto del coeficiente de envejecimiento en la probabilidad de fallo a lo largo del tiempo.

\subsubsection{Calidad del hormigón}

Los factores relacionados con la calidad del hormigón que influyen en la velocidad de penetración de cloruros son diversos, entre ellos el curado (a mayor curado, menor difusión de $\mathrm{Cl}^{-}$), la compactación (a mayor compactación, menor difusión), la relación a/c (a menor relación, menor difusión), el contenido y tipo de cemento (mayor cantidad, menor difusión)².

De los factores mencionados, es la relación a/c el más importante y el que suele aparecer en los modelos propuestos para el cálculo del coeficiente de difusión. Puede decirse que el coeficiente de difusión de cloruros depende de la estructura de poros, a su vez función de la relación a/c, del tipo de cemento y de las proporciones y calidad de la mezcla. La relación a/c es un factor de gran influencia sobre " $\mathrm{D}_{\mathrm{c}}$ " en el caso del hormigón de cemento Portland convencional. A partir del ensayo de exposición, se obtiene la siguiente expresión que relaciona $a / c$ y $\mathrm{D}_{\mathrm{c}}{ }^{7}$ :

$$
D_{c}=\left(5 \cdot 10^{-7}\right) \cdot e^{-1,6(c / a)}
$$

Encontrándose a/c dentro del rango entre 0,25 y 0,55. Por debajo de 0,4, la reducción de $\mathrm{a} / \mathrm{c}$ es particularmente efectiva para disminuir $\mathrm{D}_{\mathrm{c}}$. Esta tendencia se corresponde con el hecho de que hay menos puentes deficientes construidos con hormigón pretensado prefabricado (suelen 
presentar una baja relación a/c, de 0,3 a 0,4). El hormigón de elevada durabilidad fabricado con relación a/c baja resulta cada vez más manejable debido al mayor empleo de los súperplastificantes por el desarrollo del hormigón autocompactable, de alta resistencia, etc. Aún hay temas por mejorar como la capacidad de bombeo, la fisuración inducida por la temperatura y la reacción álcali-sílice causadas por el empleo de un gran volumen de cemento?

\subsubsection{Concentración de cloruros en superficie}

La carga ambiental se representa por la concentración de cloruros en superficie " $\mathrm{C}_{\mathrm{S}}$ "37.

La Instrucción EHE-08 plantea en la tabla 4.18 la concentración de cloruros en superficie en función del tipo de ambiente y de la distancia a la costa3:

\begin{tabular}{|c|c|c|c|c|c|}
\hline Clase General de & \multicolumn{2}{|c|}{ IIIa } & IIIb & IIIC & IV \\
\hline $\begin{array}{c}\text { Distancia respecto a } \\
\text { la costa }\end{array}$ & Hasta $500 \mathrm{~m}$ & $500 \mathrm{~m}-5000 \mathrm{~m}$ & \multicolumn{2}{|c|}{ Cualquiera } & ---- \\
\hline $\begin{array}{l}\mathrm{C}_{\mathrm{S}} \text { (\%peso de } \\
\text { hormigón) }\end{array}$ & 0,14 & 0,07 & 0,72 & 0,50 & 0,50 \\
\hline
\end{tabular}

Tabla 4.18. Valores de concentración de cloruros en superficie según la Instrucción EHE.

En el caso de las especificaciones japonesas ${ }^{88,89}$, el valor de la concentración de cloruros en superficie, $\mathrm{C}_{0}$, para estructuras que se encuentran sometidas al efecto de los cloruros del agua de mar puede tomarse a partir de la siguiente tabla 4.19:

\begin{tabular}{|c||c|c|c|c|c|}
\hline \multirow{2}{*}{$\begin{array}{c}\text { Zona de } \\
\text { salpicaduras }\end{array}$} & \multicolumn{5}{|c|}{ Distancia a la costa $^{1}(\mathrm{~km})$} \\
\cline { 2 - 6 } & $\begin{array}{c}\text { Junto a línea de } \\
\text { costa }\end{array}$ & 0,1 & 0,25 & 0,5 & 1,0 \\
\hline \hline 13,0 & 9,0 & 4,5 & 3,0 & 2,0 & 1,5 \\
\hline
\end{tabular}

Tabla 4.19. Concentración de cloruros en superficie expresada en $\mathrm{kg} / \mathrm{m}^{3}$.

${ }^{1}$ Considerando el efecto de elevación sobre la superficie del mar, un aumento de $1 \mathrm{~m}$ en la altura podría considerarse equivalente a una distancia horizontal de $25 \mathrm{~m}$. Así pues, el $\mathrm{C}_{0}$ equivalente podría calcularse a partir de la tabla anterior

Puede observarse una diferenciación entre la zona de salpicaduras y la zona aérea, (aunque no se cita de forma explícita) reduciendo la concentración de 
cloruros en superficie a medida que nos alejamos de la costa. En el pie de tabla se indica el efecto de la elevación en vertical, apuntando que para obtener el $\mathrm{C}_{0}$ equivalente bastaría con considerar que $1 \mathrm{~m}$ de distancia en vertical equivale a $25 \mathrm{~m}$ en horizontal.

Se sabe que la concentración de cloruros de un tablero de un puente se incrementa durante un periodo de tiempo y llega a estabilizarse, lo que resulta evidente en datos recogidos por Weyers et al en 15 tableros de puentes en regiones de frío y nieve durante 15 años $(1994)^{15}$. El estudio realizado por Weyers se refiere fundamentalmente al efecto de los cloruros en estructuras situadas en zonas de climas fríos donde se emplean regularmente sales fundentes y también trata zonas de clima más templado y con acción de cloruros procedentes de ambiente marino. Tal es el caso del estado de Florida, donde se obtiene como valor medio, para las estructuras analizadas, de la concentración de cloruros en superficie $1,47 \mathrm{~kg} / \mathrm{m}^{3}$, con un coeficiente de variación de 1,1171.

Según estudios realizados comparando exposiciones a ambiente severo y moderado, la concentración de cloruros en ambiente severo es del orden de 1,5-2 veces mayor que en ambiente moderado ${ }^{14}$. En Estados Unidos, los valores comunes de cloruros en superficie se sitúan en el entorno de 1,2-8,2 $\mathrm{kg} / \mathrm{m}^{3}$ (datos medidos en puentes incluyendo efecto de aplicación de sales fundentes) según algunos autores ${ }^{10,73}$. Otros recomiendan los siguientes valores para usar en proyecto ${ }^{74,75}$ : para un ambiente marino severo (zona de salpicaduras), $C_{0}=17,8 \mathrm{~kg} / \mathrm{m}^{3}(0,77 \%$ en peso de hormigón, considerando una densidad del hormigón de $2300 \mathrm{~kg} / \mathrm{m}^{3}$ ); para exposición a una atmósfera salina (zona aérea), $C_{0}=15 \mathrm{~kg} / \mathrm{m}^{3}(0,65 \%$ en peso de hormigón). Estos valores dependen del tiempo por lo que si se adopta un valor constante, se obtiene un resultado bastante conservador en cuanto a la durabilidad de la estructura. En la capa inmediata después de superficie, debido a la carbonatación o a la lixiviación, el contenido de $\mathrm{Cl}^{-}$puede ser menor².

En un estudio español ${ }^{39}$ realizado con probetas en una playa de Huelva en carrera de mareas, se analiza la variación de la concentración de cloruros en superficie con el tiempo, comprobando que aumenta. Aunque con grandes variaciones en los valores, las últimas medidas (tras 10 años) se sitúan en torno a $0,2 \%$ peso de hormigón para mezclas ricas en cemento. Cabe señalar que los valores de $\mathrm{C}_{\mathrm{s}}$ son los de la altura máxima de pico y no los superficiales que resultan casi nulos en los años más recientes. La ausencia 
de cloruros en la superficie de hormigón se atribuye a un deslavado o lixiviación de la superficie que no permite la formación de la sal de Friedel. Además, la variación de ambos parámetros está relacionada entre sí. La siguiente fig 4.22 lo muestra.

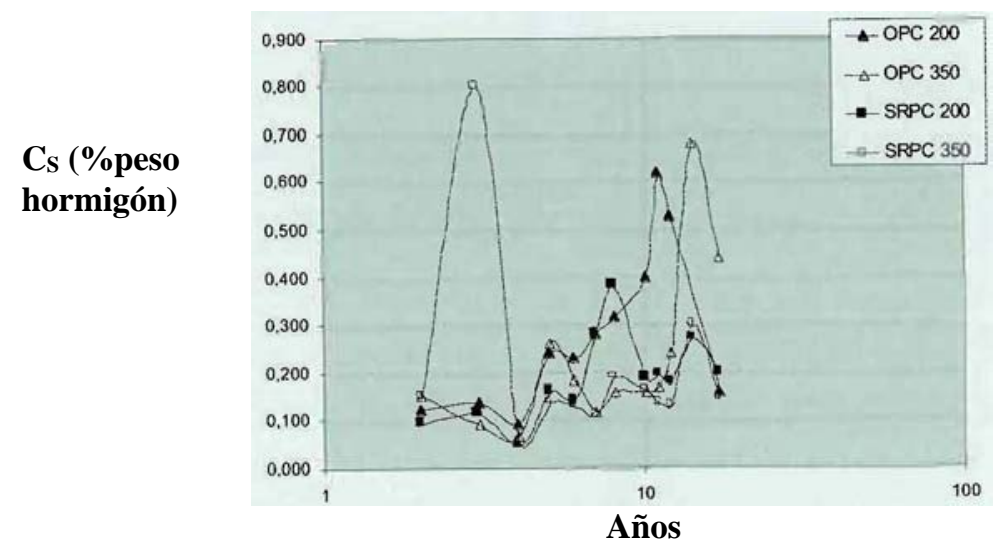

Fig.4.22. Variación de los valores de Cs con el tiempo.

En el caso de un estudio realizado en Noruega ${ }^{37}$, el cálculo de $C_{S}$ se realiza por ajuste de la curva al modelo y tiene que utilizarse junto con el correspondiente coeficiente de difusión. Dado que los valores empleados en este estudio se refieren a testigos de más de dos años, se asume que las $C_{S}$ han alcanzado un nivel estable. Esta hipótesis se corrobora con los datos recogidos en la figura 4.23 , que muestra los valores de la concentración de cloruros en superficie en función del tiempo (se ha considerado una estabilización de los valores a partir de dos años):

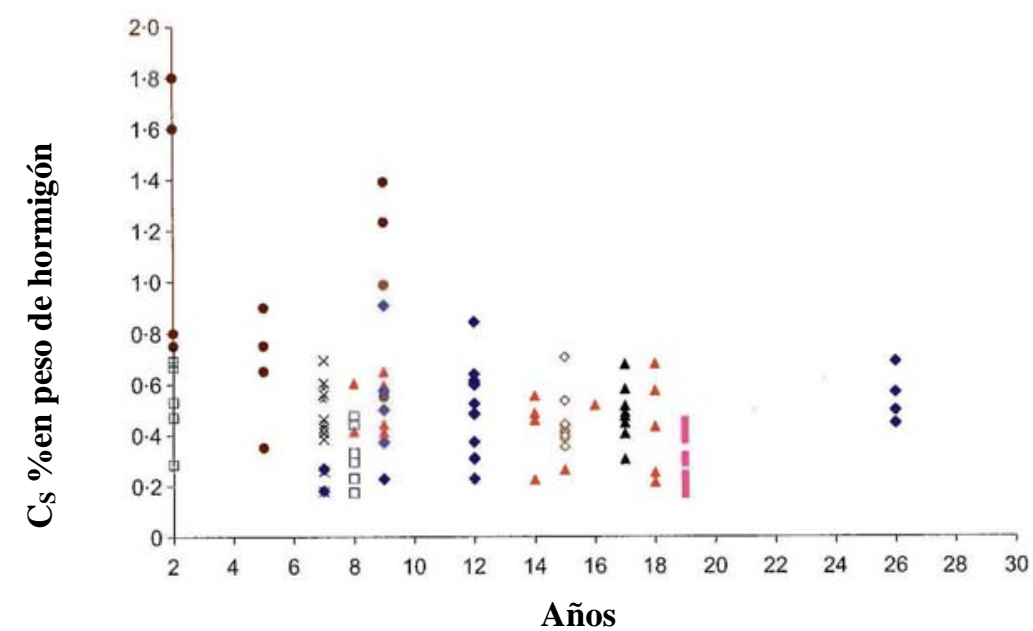

Fig.4.23. Cloruros en superficie- tiempo. Datos de campo recogidos de nueve estructuras.

También se estudió el efecto de las condiciones locales ${ }^{37}$ de exposición en estas estructuras, en concreto el efecto de la altura sobre el nivel del mar (los 
fustes/pilotes de hormigón normalmente se elevan algo menos de $30 \mathrm{~m}$ desde el nivel del mar). Los resultados se dan en la figura 4.24 y se observa que apenas presentan variaciones significativas (valores entre $-10 m$ y $+30 m$ ). Las condiciones climáticas obviamente hacen el ambiente salino igualmente agresivo a lo largo de todo el fuste.

En este estudio, el valor medio de $C_{s}$ para los 137 testigos que se analizaron resultó $0,63 \%$ de cloruros por peso de hormigón, con una desviación estándar de $0,43 \%{ }^{37}$.

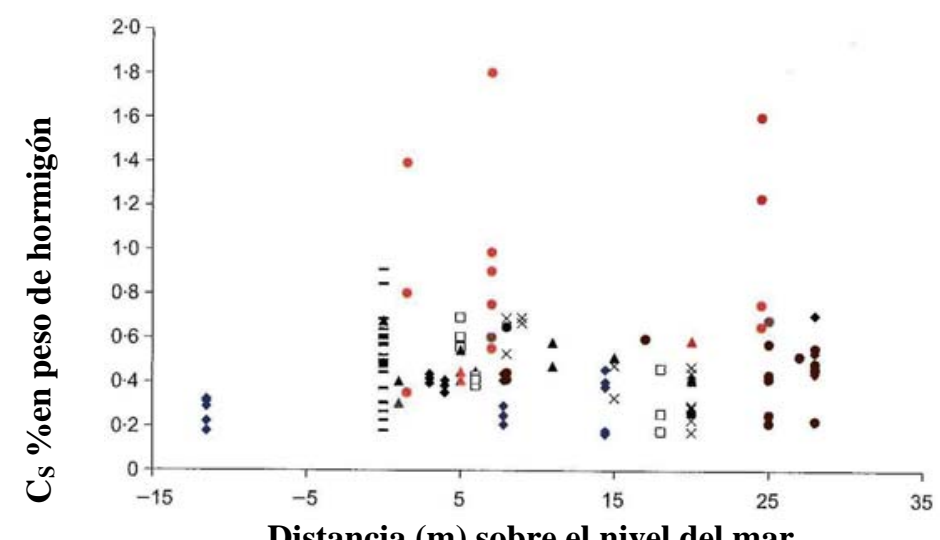

Fig.4.24. Cloruros en superficie- altura sobre el nivel del mar. Datos de nueve estructuras.

El efecto de la orientación ${ }^{37}$ también fue analizado. La dirección del viento dominante es suroeste. En la figura 4.25 se aprecia que la carga ambiental es algo mayor en esta parte, pero el efecto apenas resulta significativo.

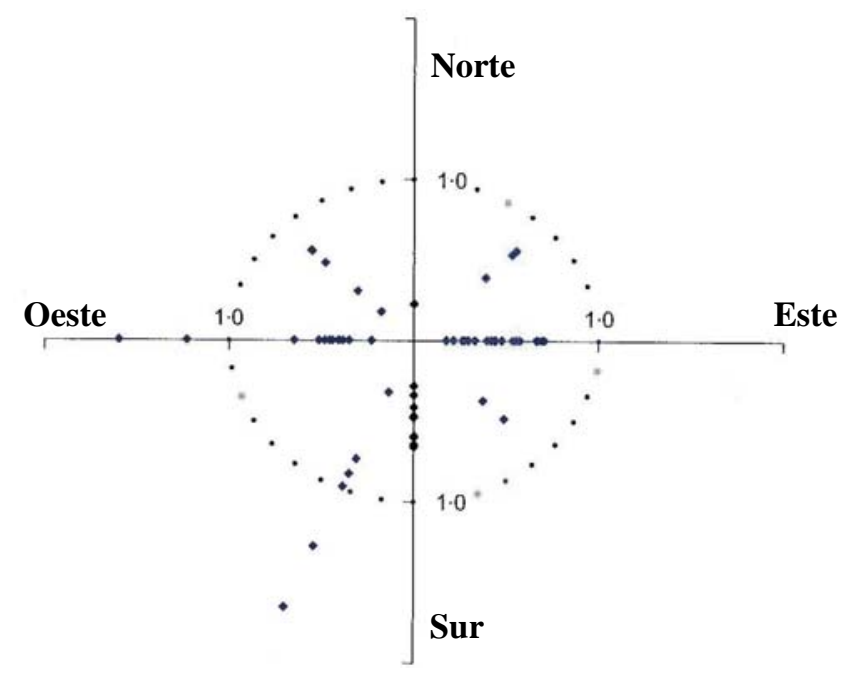

Fig.4.25. Cloruros en superficie según la orientación. Datos recogidos de ocho estructuras. 
Muchos investigadores emplean un valor constante de $\mathrm{C}_{0}$ en los modelos de predicción de vida útil, a pesar de que según Kassir y Gosh (2002), las diferencias en las estimaciones de la vida útil pueden alcanzar el 100\% cuando $\mathrm{C}_{0}$ varía exponencialmente con el tiempo dentro de la ley de Fick. Las diferencias más comunes en las predicciones de los modelos están en el entorno del 5-15\%, que resultan pequeñas considerando valores de vida útil de 100 años. Adicionalmente, estos cálculos no tienen en cuenta que la variación de $\mathrm{D}$ en el tiempo interactúa con la de $\mathrm{C}_{0}$. Por ello, para estimaciones precisas de vida útil se requiere conocer la edad de la estructura al ser expuesta así como la naturaleza de la dependencia del tiempo de la mezcla de hormigón ${ }^{15}$.

En Japón en 1984, se llevó a cabo un estudio para determinar la relación entre la cantidad de cloruros disponible en el aire (masa de iones cloruro captados por una área de 0,1m×0,1m de acero inoxidable durante un mes) y la distancia a la costa, así como la relación entre la concentración de cloruros en superficie y dicho nivel de cloruros en el aire. Para ello ${ }^{7}$, durante tres años se recogieron resultados en 266 puntos dentro de los $10 \mathrm{~km}$ próximos a la costa. Con estos datos, se pudo establecer una relación entre " $\mathrm{C}_{\text {air" }}$ (masa media de iones cloruro medidos en un año) y la distancia a la costa, viendo que el logaritmo de ambos tiene una relación lineal. La pendiente de esta recta es normalmente constante a pesar de la región, mientras que el nivel de cloruros varía con la situación geográfica. La ecuación siguiente se propone para ilustrar la medida de los cloruros en el aire.

$$
\mathrm{C}_{\text {air }}=\mathrm{C}_{1} \cdot \mathrm{d}^{-0,6}
$$

Donde $\mathbf{C}_{\text {air }}$ es el nivel de cloruros en el aire ( $\left.\mathrm{mdd}=\mathrm{mg} / \mathrm{dm}^{2} / \mathrm{día}\right), \mathbf{C}_{\mathbf{1}}$ es el nivel de cloruros en el aire equivalente al valor a distancia de $1 \mathrm{~km}$ (mdd) y d es la distancia a la costa $(\mathrm{km}) . \mathrm{C}_{1}$ expresa el nivel de cloruros en el aire de cada región. " $\mathrm{C}_{1}$ " de una región donde el deterioro por corrosión es frecuente será mayor que el de otras regiones. Las diferencias se deben principalmente al viento local y a las variaciones del oleaje, incluso a las variaciones estacionales del nivel de cloruros en el aire. Para el caso particular de regiones de Japón, considerando la situación del deterioro en las zonas $\mathrm{A}, \mathrm{B}$ y $C$ (figura 4.17), se consideran $C_{1 A}=0,6, C_{1 B}=0,6$ y $C_{1 C}=0,2^{7}$.

Para el mismo estudio de los cloruros en el aire también se realizaron ensayos de exposición de bloques de hormigón con relación a/c de 0,39 y 0,58 . Los datos empleados para estudiar el nivel de cloruros en el aire se 
tomaron dentro de los $10 \mathrm{~km}$ más próximos a la costa. $\mathrm{C}_{\text {air }}$ es la masa media de cloruros en el aire en un año. Se observó que el logaritmo de $C_{\text {air }}$ tiene una relación lineal con el logaritmo de la distancia a la costa, que viene dado por la siguiente expresión:

$$
\mathrm{C}_{\text {air }}=\mathrm{C}_{1} \cdot \mathrm{d}^{-0,6}
$$

donde $\mathrm{C}_{1}$ es el contenido de cloruros en el aire equivalente al valor a una distancia de $1 \mathrm{~km}$ y se establece por regiones y d es la distancia a la costa.

Se establece la siguiente relación entre " $\mathrm{C}_{0}$ " y " $\mathrm{C}_{\text {air", }}$ ", donde " $\mathrm{C}_{0}$ " es el nivel de cloruros límite en superficie de hormigón $\left(\mathrm{kg} \mathrm{Cl} / \mathrm{m}^{3}\right)^{7}$ :

$$
\mathrm{C}_{0}=1,5 \cdot \mathrm{Cair}^{0,4}
$$

En la referencia ${ }^{68}$ se indica la siguiente figura 4.26 donde se refleja el efecto del contenido de cloruros en superficie sobre la probabilidad de fallo de una estructura a lo largo del tiempo.

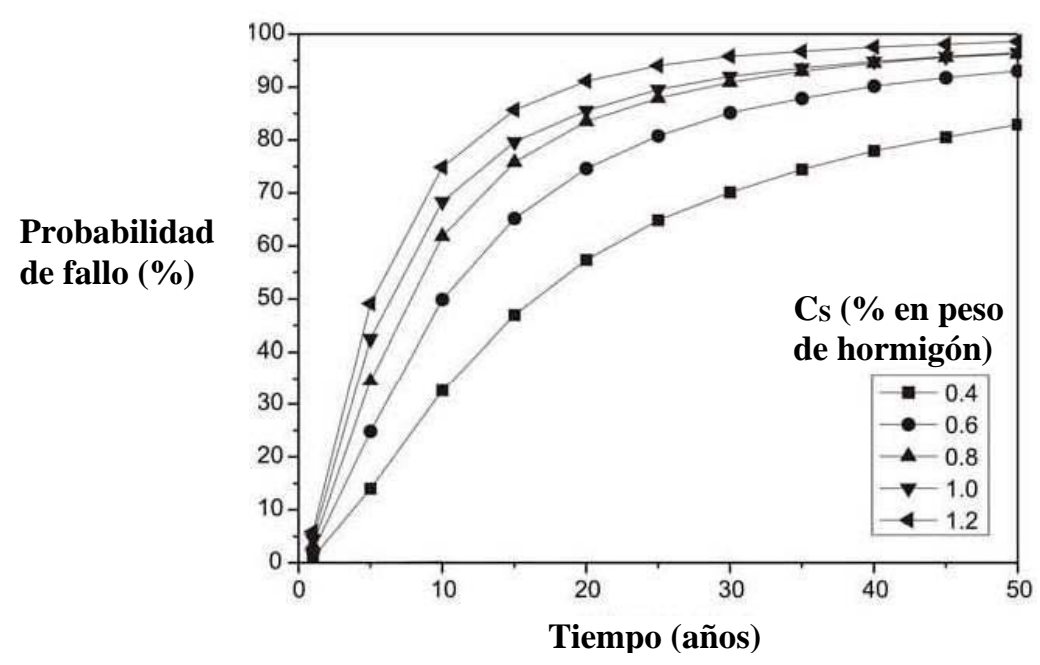

Fig.4.26. Efecto del contenido de cloruros en superficie sobre la probabilidad de fallo en el tiempo

En el Anejo 1 se completa la revisión bibliográfica $[1,2,3,5,7,10,14,15,37$, $39,51,52,53,69,73,74,75,76,83]$ sobre la concentración de cloruros en superficie, ya que se ha profundizado más sobre el tema al ser uno de los objetivos de la presente tesis. 


\subsubsection{Umbral de cloruros}

El contenido crítico o umbral de cloruros es la concentración límite de éstos a partir de la cual comienza a desarrollarse la corrosión activa del hormigón. No se trata de un valor único, sino que depende de las características del hormigón $\left(\mathrm{pH}\right.$, humedad, temperatura, contenido de $\mathrm{C}_{3} \mathrm{~A}$, cemento, adiciones) así como del propio acero (composición, impurezas, defectos) que constituye la armadura. Dado que no es un valor único, se ha tratado de establecer valores experimentales del umbral de cloruros, obteniéndose resultados muy dispares ${ }^{2}$.

Algunos de los factores que intervienen en el umbral de cloruros a veces funcionan de forma opuesta. Así, por ejemplo, a mayor $\mathrm{pH}$, mayor cantidad de cloruros que puede tolerar el acero sin mostrar picaduras debidas a la corrosión, pero por otro lado, la cantidad de cloruros presente en la disolución también aumenta con el pH. En la figura 4.27 se muestran los efectos sobre el umbral de cloruros de dos factores: la humedad relativa y la calidad del recubrimiento de hormigón ${ }^{8}$.
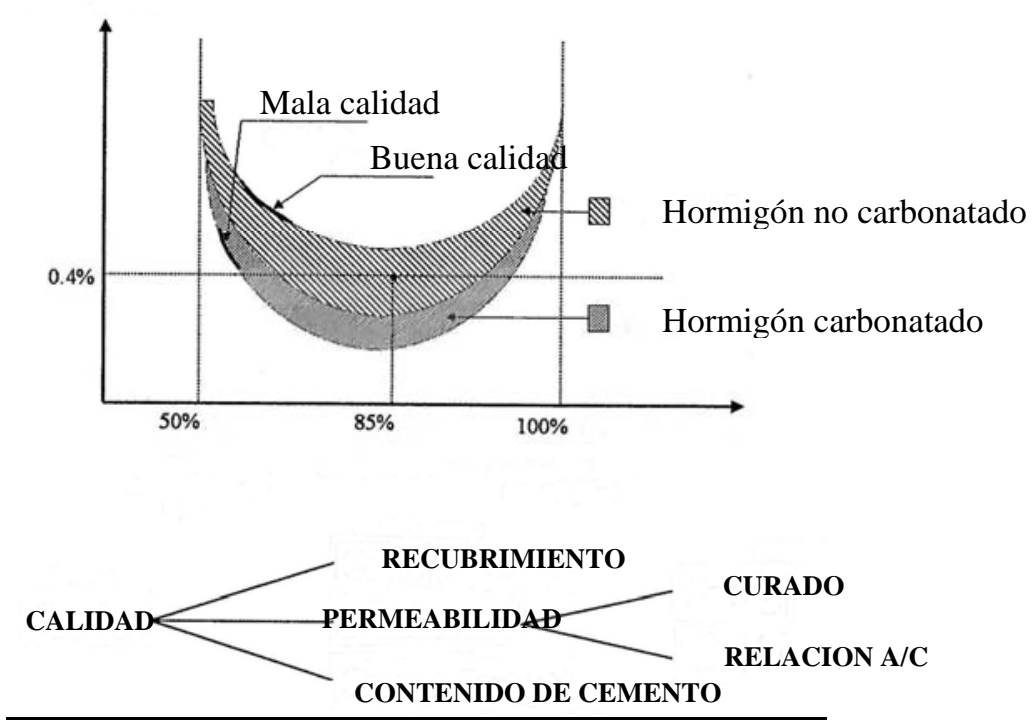

Fig.4.27. Contenido crítico de cloruros según recomendaciones del CEB.

Los contenidos críticos de cloruros recogidos en la bibliografía de la referencia ${ }^{2}$ varían entre 0,26 y 0,40, expresados como relación $\mathrm{Cl}^{-} / \mathrm{OH}^{-}$ 
(donde $\mathrm{Cl}^{-}$son los cloruros libres) y entre 0,17 y $2,2 \%$, expresado como $\% \mathrm{Cl}^{-}$ totales en peso de cemento.

A partir de los datos extraídos de la bibliografía ${ }^{1,2}$, complementando con los resultados experimentales de la investigación realizada en la citada referencia, se estiman adecuados como valores conservadores los siguientes datos necesarios en la aplicación del modelo: contenido crítico de cloruros igual al $1,8 \%$ y al $1 \%$ en peso de cemento en ambientes sumergido y de carrera de mareas, respectivamente, y concentración de $\mathrm{Cl}^{-}$en superficie igual a $0,70 \%$ en peso de hormigón en ambientes sumergido y de carrera de mareas.

En la tabla 4.20 se presenta el contenido crítico de cloruros expresado en \%peso de cemento que provoca el inicio de la corrosión según varias normativas consultadas. En la tabla 4.21 se establecen los contenidos críticos de cloruros según algunos autores $3,70,45,8,21,28,29,30$ en función de la relación a/c, del ambiente de exposición y del contenido de adiciones:

\begin{tabular}{|c|c||}
\hline Normativa & $\begin{array}{c}\text { Solubles en Ácido (Cloruros } \\
\text { totales en \%peso cemento) }\end{array}$ \\
\hline \hline EHE-08 ${ }^{1}$ (H.A/H.P) & $\leq 0,4 / \leq 0,2$ \\
\hline ACI 318-08 (H.A/H.P) & $0,15 / 0,06^{(1)}$ \\
\hline EN 206-1 & $0,20-0,40 / 0,10-0,20^{(2)}$ \\
\hline ACI 222 R (H.A/H.P) & $0,10 / 0,08$ \\
\hline CP 110 British Code & 0,35 \\
\hline NS 3420 L (H.A/H.P) & $0,6 / 0,002$ \\
\hline ACI 375 R (H.A/H.P) & $0,1^{(3)} / 0,06$ \\
\hline $\begin{array}{c}\text { Technical Standards for Port and } \\
\text { Harbour Facilities in Japan }\end{array}$ & 0,3 \\
\hline Universidad de Kyoto & 0,3 \\
\hline
\end{tabular}

Tabla 4.20. Contenido crítico de cloruros totales en \%peso de cemento para el inicio de la corrosión.

\footnotetext{
${ }^{(1)}$ En el caso del hormigón pretensado, se expresa el contenido de cloruros solubles en agua

${ }^{(2)}$ La norma da valores según la clase a aplicar dependiendo de las disposiciones válidas en el lugar de uso del hormigón

${ }^{(3)}$ En el caso del hormigón armado, se expresa el contenido de cloruros solubles en agua
} 


\begin{tabular}{|c||c|c||c|c|c|}
\hline a/c & Tipo de Ambiente & OPC & $\mathbf{2 0 \%} \mathbf{C V}$ & $\mathbf{5 \%}$ HS & $\mathbf{1 0 \%}$ HS \\
\hline \multirow{2}{*}{0,3} & Carrera de Mareas & 1,0 & 0,5 & 0,6 & 0,4 \\
\cline { 2 - 5 } & Aéreo & 1,2 & 0,5 & 0,7 & 0,5 \\
\hline \multirow{2}{*}{0,4} & Carrera de Mareas & 0,8 & 0,4 & 0,5 & 0,3 \\
\cline { 2 - 6 } & Aéreo & 1,0 & 0,4 & 0,5 & 0,3 \\
\hline \multirow{2}{*}{0,5} & Carrera de Mareas & 0,6 & 0,3 & 0,4 & 0,2 \\
\cline { 2 - 5 } & Aéreo & 0,6 & 0,3 & 0,4 & 0,2 \\
\hline
\end{tabular}

Tabla 4.21. Contenido crítico de cloruros expresado en \%peso de cemento para el inicio de la corrosión en función de la relación a/c, el ambiente y el contenido de adiciones.

En el caso de Japón, el umbral límite de cloruros totales (solubles en ácido) para iniciar la corrosión del acero en el hormigón se fija en el entorno de 1,2 a $2,5 \mathrm{~kg} / \mathrm{m}^{3}$. Según indican las especificaciones japonesas ${ }^{88}$, en las inmediaciones de las armaduras la concentración de cloruros que podría iniciar su corrosión se encuentra entre $0,3-1,2 \mathrm{~kg} / \mathrm{m}^{3}$. La corrosión de la armadura depende del aporte de oxígeno y del propio hormigón, este rango estará influenciado por el recubrimiento, la red de poros y la humedad ${ }^{7}$. Así se ha registrado valores en el entorno de 0,3-0,6 $\mathrm{kg} / \mathrm{m}^{3}$ en el caso de ensayos acelerados realizados con cloruros añadidos a la mezcla de hormigón fresco, mientras que para el caso de ensayos de exposición llevados a cabo en campo, los valores registrados son $1,2-2,4 \mathrm{~kg} / \mathrm{m}^{3}$. Estas diferencias entre los valores de la concentración crítica de cloruros pueden atribuirse a factores como las diferentes relaciones $\mathrm{a} / \mathrm{c}$ en los hormigones ensayados, el espesor de recubrimientos empleados, etc. Las altas temperaturas empleadas en los ensayos acelerados también pueden ser un factor a tener en cuenta. Considerando todo lo expuesto anteriormente, las especificaciones japonesas ${ }^{88}$ establecen un límite de $1,2 \mathrm{~kg} / \mathrm{m}^{3}$ (cloruros por metro cúbico de hormigón) como la concentración crítica de cloruros que podría provocar corrosión en armaduras.

En un estudio realizado en plataformas noruegas en el Mar del Norte ${ }^{37}$, se han considerado los siguientes umbrales de cloruros para inicio de corrosión activa cuando los cloruros han alcanzado la concentración límite a $50 \mathrm{~mm}$ de profundidad de hormigón (tabla 4.22). 


\begin{tabular}{|c||c||c||}
\hline \%Clen peso de cemento & $\begin{array}{c}\text { \%Cl'en peso de hormigón } \\
\text { (con } \mathbf{4 4 0} \mathbf{~} \mathbf{~ c e m e n t o} / \mathbf{m}^{\mathbf{3}} \text { ) }\end{array}$ & $\begin{array}{c}\text { Probabilidad de corrosión } \\
\text { de la armadura }\end{array}$ \\
\hline \hline$>2,0$ & $>0,36$ & Seguro \\
\hline $1,0-2,0$ & $0,18-0,36$ & Probable \\
\hline $0,4-1,0$ & $0,07-0,18$ & Posible \\
\hline$<0,4$ & $<0,07$ & Mínima \\
\hline
\end{tabular}

Tabla 4.22. Umbrales de cloruros considerados en estudio noruego.

Los modelos que utilizan la ley de Fick se basan en las propiedades del hormigón, la concentración de cloruros en superficie, el espesor de recubrimiento y el umbral de cloruros que inicia la corrosión. En los modelos deterministas iniciales se pensaba que con asignar un valor único a las variables de entrada era suficiente; modelos posteriores concluyeron que era necesario considerar la variabilidad de dichos parámetros para una mayor precisión y por ello, emplearon técnicas de muestreo estadístico, como la de Monte Carlo ${ }^{14}$.

En este sentido, el nivel de $0,07 \% \mathrm{Cl}^{-}$en peso de hormigón se interpreta, según el fib bulletin $34^{69}$ como una probabilidad de presentar despasivación del $10 \%$ y según Alonso (2008), como una probabilidad entre 10-15\%.El contenido crítico de cloruros para el inicio de la corrosión activa del acero se asume normalmente como una variable independiente de los parámetros que gobiernan la penetración de cloruros ( $\mathrm{C}_{\mathrm{S}}$, D y recubrimiento) ${ }^{37}$.

El acero normal o el tratado con epoxy presentan un umbral de $0,74 \mathrm{~kg} \mathrm{Cl}$ $/ \mathrm{m}^{3}$, mientras que para el acero inoxidable tipo 304 o el tipo 316, los umbrales de cloruros son de $11 \mathrm{~kg} \mathrm{Cl} / \mathrm{m}^{3}$ y $18 \mathrm{~kg} \mathrm{Cl} / \mathrm{m}^{3}$, respectivamente. Una ventaja del acero inoxidable es que su umbral de cloruros supera los valores de las concentraciones de cloruros en superficie observados en puentes en Oregón, por lo que en estos casos no debería existir corrosión por cloruros ${ }^{10}$.

En el citado estudio realizado sobre puentes expuestos a ambiente marino en Oregón, Estados Unidos ${ }^{10}$, se cita que numerosas fuentes consultadas han mostrado valores de umbral de cloruros comprendidos entre $0,6-1,2 \mathrm{~kg} \mathrm{Cl}^{-}$ $/ \mathrm{m}^{3}$. Una estimación frecuentemente empleada del umbral de cloruros es el $0,2 \%$ del peso de cemento, que equivaldría a unos $0,74 \mathrm{~kg} \mathrm{Cl} / \mathrm{m}^{3}$. Esta estimación conservadora se empleó en este estudio para ilustrar el efecto de los cloruros en la corrosión de las armaduras. 
Otro estudio concluye que los umbrales de cloruros para aceros de armar especiales se obtienen multiplicando a los del acero al carbono por los siguientes factores: 2,5 para acero galvanizado (Yeomans 2004)14,31, 10,4 para acero inoxidable (Clemena $2003^{14,32}$ ) y 3,5 para acero tratado con cromo (Darwin et al. $2002^{14}$ ). En la tabla 4.23 se muestran los valores mínimo, máximo y la moda de una distribución de datos recogidos para distintos $\operatorname{aceros}^{14}$ :

\begin{tabular}{||c||c||c||c||}
\hline Tipo de Acero & Mínimo $\mathbf{( k g / \mathbf { m } ^ { 3 } )}$ & Máximo $\left.\mathbf{( k g} / \mathbf{m}^{\mathbf{3}}\right)$ & Moda $\mathbf{( k g} / \mathbf{m}^{\mathbf{3}} \mathbf{)}$ \\
\hline \hline Al carbono & 0,39 & 6,26 & 1,4 \\
\hline \hline Galvanizado & 0,975 & 15,6 & 3,5 \\
\hline \hline Inoxidable & 4,06 & 65,0 & 14,6 \\
\hline \hline Tratado con Cromo & 1,36 & 21,9 & 4,9 \\
\hline
\end{tabular}

Tabla 4.23. Valores de umbral de cloruros recogidos para distintos aceros.

En la referencia ${ }^{68}$ se indica la siguiente figura 4.28 donde se refleja el efecto del umbral de cloruros en la probabilidad de fallo de una estructura a lo largo del tiempo.

Probabilidad de fallo (\%)

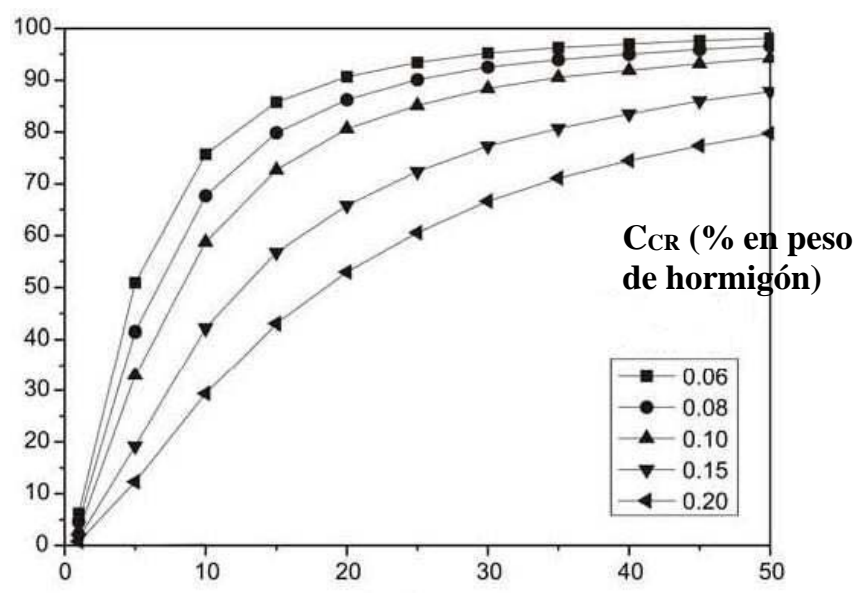

Tiempo (años)

Fig.4.28. Efecto del umbral de cloruros en la probabilidad de fallo a lo largo del tiempo.

En el Anejo 2 se completa la revisión bibliográfica $[1,2,3,4,5,8,10,14,22$, $28,29,30,37,45,53,55,57,68,69,70,74,79,80,86,88]$ sobre la concentración crítica de cloruros, ya que se ha profundizado más sobre el tema al ser uno de los objetivos del presente estudio. 


\subsubsection{Modelos de corrosión de las armaduras. Periodo de Propagación.}

Una vez iniciada la corrosión, ésta continúa hasta que el recubrimiento se fisura y el deterioro se hace patente por la expulsión de éste. Según modelos de fisuración y datos de campo, se estima que para el acero suave al carbono, este proceso dura unos seis años; para otros aceros alternativos, como el galvanizado, unos 20 años. En el caso del acero inoxidable no se ha cuantificado, pero se estima que se comporta de forma similar al galvanizado, así como el acero tratado se comporta de modo parecido al acero al carbono $^{14}$.

En el acero convencional, la velocidad de corrosión oscila entre 11-23 $\mu$ m/año

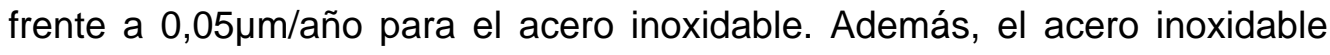
tarda más tiempo en generar productos de corrosión capaces de fisurar el hormigón ${ }^{10}$.

El tiempo requerido por la corrosión para avanzar afectando desde el $2 \%$ al $12 \%$ de la armadura de la estructura es el periodo de propagación, que constituye el fin de la vida de servicio de una estructura desde el punto de vista funcional, ya que comúnmente se decide realizar reparaciones cuando se alcanza un deterioro del $12 \%$ en el vano pésimo. Modelizar esta etapa es complejo porque ya no depende de la ley de Fick, sino de reacciones de corrosión electroquímicas y mecanismos de transporte de iones. Con el fin de estimar la velocidad de propagación del deterioro por corrosión, se desarrolló la siguiente expresión empírica a partir del análisis de datos de campo ${ }^{14}$ :

Tiempo hasta deterioro=8,61 $(\sqrt{(\% \text { Deterioro }+1,38)}-1,45)-3,34$

El tiempo requerido para que el daño por corrosión se propague del $2 \%$ al $12 \%$ de la armadura en el acero al carbono es de 16 años. La tabla 4.24 recoge los tiempos estimados desde el inicio de la fisuración hasta completar la propagación para cuatro tipos de aceros analizados. Los valores del acero al carbono se han determinado usando modelos de fisuración que coinciden con las observaciones de campo y el periodo de propagación se determina con medidas de campo. Para el resto de aceros se toman valores conservadores ${ }^{14}$. 


\begin{tabular}{|c||c|c||}
\hline Tipo de acero & $\begin{array}{c}\text { Inicio de Fisuración } \\
\text { (años) }\end{array}$ & Propagación (años) \\
\hline \hline Al carbono & 6 & 16 \\
\hline Galvanizado & 20 & 16 \\
\hline Inoxidable & 20 & 16 \\
\hline Tratado con Cromo & 6 & 16 \\
\hline
\end{tabular}

Tabla 4.24. Tiempos estimados de inicio de fisuración hasta completar propagación para distintos tipos de acero.

La referencia ${ }^{15}$ contiene un completo repaso de modelos de cálculo del período de propagación, que no se recogen en este documento por estar fuera del objeto de la investigación.

\subsubsection{Métodos para prevenir la corrosión y aumentar la vida útil de las estructuras}

\subsubsection{Medidas de prevención y protección}

Las medidas que pueden tomarse en la construcción con hormigón armado para proteger la armadura de la corrosión pueden dividirse en tres categorías:

- Prácticas de diseño y ejecución que maximizan la protección propia del hormigón fabricado con cemento Pórtland.

- Técnicas que previenen la corrosión de la armadura directamente

- Tratamientos que penetran o se aplican en superficie de los elementos de hormigón para prevenir la entrada de cloruros ${ }^{8}$.

\subsection{Prácticas de diseño y ejecución}

En cuanto a las prácticas de diseño y ejecución, se trata de optimizar la protección proporcionada por el hormigón que rodea la armadura. No se trata de emplear sofisticadas técnicas de diseño, sino de cuidar los detalles y las buenas prácticas de construcción. El grado de protección de una estructura ante la corrosión se determina por el recubrimiento de sus armaduras y la permeabilidad de su hormigón ${ }^{8}$. 
Los métodos de protección incluyen aquellos empleados para reducir la velocidad de difusión de cloruros en el hormigón, extender el periodo de propagación o prevenir el inicio de la corrosión activa ${ }^{15}$.

Uno de los métodos más fáciles y efectivos para retrasar el inicio de la corrosión o prevenirla es mejorar las propiedades del hormigón. La característica del hormigón que más afecta a la concentración de cloruros al nivel de la armadura es su permeabilidad. El medio más habitual de disminuir la permeabilidad del hormigón es reducir la relación a/c de la mezcla de hormigón. Adicionalmente se pueden añadir adiciones minerales, puzolanas, para reducir aún más la permeabilidad, siendo las más empleadas las cenizas volantes y el humo de sílice. Estas adiciones reaccionan con los hidróxidos de calcio libres para formar productos cementicios que rellenan los poros de la matriz de hormigón ${ }^{15}$.

Así, para una relación agua/materiales cementicios dada, la finura del cemento y de sus componentes puzolánicos determina la porosidad y el tamaño de poro de la distribución. Dado que, en general las adiciones minerales reducen y refinan la porosidad, los hormigones que contienen estos minerales muestran una resistencia considerablemente mejorada ante la penetración de cloruros del exterior. Si se emplean muchas puzolanas, todo el hidróxido de calcio puede reaccionar, destruyendo el tope de $\mathrm{pH}$ y permitiendo que éste descienda hasta niveles en los que la armadura ya no se encuentra en estado pasivo ${ }^{8}$.

Otra forma de mejorar la protección frente a la corrosión de las armaduras es dotar al cemento de un mayor contenido en álcalis. Cuando el cemento Pórtland se hidrata, los silicatos de calcio reaccionan para formar silicatos de calcio hidratados e hidróxido de calcio. Éste proporciona un freno sustancial a la disolución de los poros, manteniendo su nivel de $\mathrm{pH}$ a 12,6 . El pH normalmente supera este valor_(valor típico $\approx$ 13,5) por la presencia de hidróxidos de potasio y sodio, considerablemente más solubles que el hidróxido de calcio. Sin embargo, dichos compuestos están presentes en cantidades limitadas y cualquier reacción de carbonatación o puzolánica reduce rápidamente el $\mathrm{pH}$ de la disolución saturada de hidróxido de calcio. Por otro lado, los áridos reactivos posiblemente presentes en la mezcla pueden conducir a reacciones árido-álcali expansivas y destructivas ${ }^{8}$. 
La capacidad de retener cloruros del cemento se ha considerado directamente relacionada con el contenido de $\mathrm{C}_{3} \mathrm{~A}$ del mismo, ya que los cloruros reaccionan para formar cloroaluminatos insolubles. Cada vez existe mayor evidencia de que la reacción con $\mathrm{C}_{3} \mathrm{~A}$ es sólo uno de los mecanismos para retirar cloruros de la disolución de forma efectiva. En los cementos Pórtland ordinarios, no existe relación directa entre la concentración de cloruros fijos y el contenido de $\mathrm{C}_{3} \mathrm{~A}$, pero sí una relación cuantitativa con $\mathrm{C}_{3} \mathrm{~A}+\mathrm{C}_{4} \mathrm{AF}$ y el pH de la disolución de los poros. Además la fijación de cloruros se aumenta por la presencia de ceniza volante en el cemento, al margen de que contenga o no $\mathrm{C}_{3} \mathrm{~A}^{8}$.

En el caso de la protección por el recubrimiento debe decirse que es función del propio recubrimiento y también de la relación a/c. Es decir, un recubrimiento muy pequeño, por ejemplo $25 \mathrm{~mm}$, resulta inadecuado, incluso con relaciones a/c tan bajas como 0,28. Empleando adiciones como el humo de sílice, el recubrimiento citado resultaría efectivo. $Y$ es que, aunque el hormigón fabricado a partir de cemento Pórtland no es impermeable en sí mismo, puede obtenerse un hormigón de baja permeabilidad mediante el uso de materiales adecuados, con una relación a/c baja y con una compactación y un curado apropiados ${ }^{8}$.

Respecto al curado, cuanto mayor sea el que recibe el hormigón antes de estar expuesto al medio agresivo, mejor resistencia tendrá a la penetración de cloruros y $\mathrm{CO}_{2}$. Esto resulta especialmente importante en el caso de los cementos que contienen ceniza volante, ya que la reacción puzolánica es mucho más lenta que las reacciones de hidratación del cemento Pórtland. A edad temprana, el hormigón con ceniza volante muestra normalmente menor resistencia a la penetración de cloruros que el hormigón de cemento Pórtland convencional, mientras que a mayor madurez, el hormigón de cenizas puede tener mejores propiedades ${ }^{8}$.

Para conseguir aumentar la vida útil de las estructuras, se debe actuar empleando hormigones con bajo coeficiente de difusión de cloruros que retarda el transporte de sales dentro del hormigón, alargando el tiempo de acceso de los cloruros a la armadura. Así, el Departamento de Transportes de Oregon especifica el uso de hormigón con microsílice (4\% microsílice máximo más cenizas volantes) en puentes de nueva construcción. Por otro lado, el recubrimiento mínimo es $38 \mathrm{~mm}$, siendo 51 $\mathrm{mm}$ un valor medio y $76 \mathrm{~mm}$, en ambientes especialmente severos. Estas 
especificaciones se aplican a toda la armadura, incluso estribos y armaduras inferiores de vigas y/o tableros ${ }^{10}$.

\subsection{Tratamientos no metálicos sobre la armadura}

La armadura convencional tratada con epoxy comenzó a usarse ampliamente en los años 80 como un método de prevención de la corrosión por su coste relativamente pequeño en relación con el sustancial y esperado aumento en la vida útil de la estructura. Esta técnica protege de la corrosión al impedir la entrada de oxígeno, agua y cloruros a través de la superficie del acero. También restringe la capacidad de una barra corroída de desarrollar macro-celdas al limitar la cantidad de barras expuestas que pueden actuar como cátodo ${ }^{15}$.

El proceso de recubrir con epoxy consiste en preparar la superficie de la barra, calentarla, aplicar la capa en polvo y curar y apagar la barra. Cuando el polvo de epoxy entra en contacto con la barra caliente, se funde y cubre la superficie. El calor inicia una reacción que proporciona el recubrimiento epoxy con sus necesarias propiedades físicas y mecánicas ${ }^{15}$.

Las especificaciones ASTM A775 y AASHTO se desarrollaron con intención de crear especificaciones Standard y los ensayos de la aplicación del recubrimiento con epoxy ${ }^{8}$.

Numerosos estudios de campo y en laboratorio se han realizado sobre barras tratadas con epoxy. Para que la capa protectora proporcione resistencia a la corrosión a largo plazo, debe presentar escasas roturas y defectos, conservar una elevada resistencia eléctrica, mantener la corrosión confinada a áreas sin tratamiento así como resistir el escaso desarrollo así como el movimiento de iones, oxígeno y agua. La ASTM A775 trata estos temas planteando los siguientes requerimientos standard: el grosor de la capa protectora debe estar entre 130 y 300 micras; la curvatura de una barra recubierta alrededor de un eje común no debería tener fisuras; el número de picaduras no debería superar 6 por metro y el área dañada no exceder el $2 \%{ }^{8}$.

Una de las ocasiones más conocida de aplicación defectuosa en campo de este tipo de barras se produjo en algunos puentes reconstruidos en 
Florida Keys. Se estableció que la causa principal de corrosión fue la deficiente preparación de las barras antes de aplicar la capa y la pérdida de adherencia de ésta antes de colocar las barras en estructuras ${ }^{8}$.

Desde 1991, se ha producido una mejora sustancial en la calidad de las barras tratadas con epoxy y de la adherencia de estas capas al acero, como resultado de la investigación adicional y los programas de certificación. En 1992, el Instituto de Acero para Armar Hormigón (CRSI) comenzó un programa de certificación de plantas que aplican capas de epoxy a armadura 8 .

El recubrimiento con epoxy incrementa poco el coste total, pero estudios realizados en tableros de puentes en Virginia concluyen que el aumento de vida útil resultante de aplicar este método está entorno a los 5 años y no resulta rentable (Brown and Weyers, 2003). La escasa efectividad del método podría deberse a los defectos en fabricación, los daños en la capa protectora durante el transporte y/o la construcción o la falta de adherencia entre la capa protectora y la superficie de acero en hormigón húmedo ${ }^{15}$.

Puede reportar un aumento de vida útil de unos 10-20 años siempre que se inspeccione, se mantenga y repare adecuadamente dicha capa protectora. Este aumento no justifica el uso generalizado de este tipo de protección, ya que cuando se buscan vidas útiles de las estructuras en torno a los 100-120 años, este objetivo no se consigue únicamente con el empleo de esta medida. Se desconoce su comportamiento frente a fuego y resulta más efectivo cuando se pulveriza ${ }^{2,810}$.

Muchas protecciones no metálicas se han evaluado, resultando sólo las de epoxy comerciales y ampliamente utilizadas. Aíslan al acero del contacto con el oxígeno, la humedad y los cloruros a la vez que controlan el paso de la corriente electroquímica producida. Su uso consiste en aplicar electrostáticamente polvo de epoxy pulverizado sobre barras completamente limpias y calientes. Su uso se ha generalizado desde 1973.

La mayor dificultad en el empleo de las barras tratadas con epoxy es prevenir daños durante su transporte y manejo. Puede incluso producirse 
la fisuración de la capa de epoxy, bien por falta de limpieza antes de su aplicación o por tener un espesor fuera de tolerancias. Deben minimizarse los daños en colocación en el caso de alambres de atado, soportes o bloques de pretensado. Todos los daños deben repararse y si el número total de faltas supera cierta cantidad, la barra no se acepta y debe retirarse. Así pues, para una larga vida útil en ambiente severo de cloruros se debe proteger todo el acero; si sólo se protege parte, debe asegurarse que dichas barras no se conecten eléctricamente con grandes cantidades de acero sin proteger.

Se ha demostrado que la resistencia a la adherencia y a la deformación progresiva es similar en el caso de las barras tratadas con epoxy que en las convencionales; sin embargo, parecen tener menor resistencia al deslizamiento ${ }^{8}$.

\subsection{Aceros especiales}

El acero inoxidable es una alternativa al acero convencional ya que presenta como mínimo valores de umbral de cloruros 10 veces mayores que el acero al carbono (Clemeña, 2003) y velocidades de corrosión hasta 50 veces menores ( $\mathrm{Gu}$ et $\mathrm{al}, 1996)$. El acero para considerarse inoxidable debe contener un mínimo de 10,5\% de cromo y elementos como el níquel y el molibdeno, que se añaden para mejorar su resistencia a la corrosión y sus propiedades mecánicas. Hay cuatro tipos de acero inoxidable: ferrítico, austenítico, martensitico y dúplex. Por su mayor resistencia a tracción y su menor ductilidad, sólo el acero austenítico y el dúplex son adecuados para sustituir al acero al carbono, por su buena combinación de resistencia a la corrosión, resistencia a la tracción, disponibilidad y coste ${ }^{10,15}$. La resistencia a la corrosión adicional del acero inoxidable se debe a la formación de una capa pasiva de óxido de cromo sobre la superficie de la barra, cuya concentración de cloruros crítica es mucho mayor que la del acero al carbono. Los beneficios de usar acero inoxidable por encima de otra alternativa son que la resistencia a la corrosión es sustancialmente mayor y que la resistencia adicional a la corrosión es una propiedad del conjunto del material. Es decir, si las armaduras se dañan durante la construcción, la resistencia a la corrosión de la armadura permanece constante mientras que en el caso de las armaduras galvanizadas o protegidas con epoxy si se daña la capa exterior, la resistencia adicional a la corrosión queda comprometida ${ }^{15}$. 
A pesar de esta ventaja, su coste resulta prohibitivo para algunas estructuras y no se usa mucho, siendo sólo rentable en aquellas donde se deba garantizar una larga vida útil por efectos climáticos adversos asociados a cortes de servicio o ambientes marinos severos con elevados contenidos de cloruros. Para que su empleo resulte más barato, puede usarse combinándolo con el acero convencional, empleándose sólo en la capa superior de la armadura, estando aislados eléctricamente para que no exista riesgo significativo de corrosión galvánica por la diferencia de aceros (Abreu et al. 2002) ${ }^{14}$ y también puede emplearse en el hormigón con microsílice ${ }^{10}$.

Otro modo de emplear el acero inoxidable como protección ante la corrosión es revestir barras de acero convencional con acero inoxidable. Se reduce la fisuración por corrosión, ya que el acero inoxidable es menos expansivo. El objetivo es reducir el coste de la armadura usando núcleos de acero de carbono manteniendo las excelentes propiedades del acero inoxidable frente a la corrosión. El coste por barra se reduce así a la tercera parte. Un estudio (Clemena et al, 2003) ha concluido que este tipo de armadura puede ser directamente sustituto de la armadura convencional o la recubierta por epoxy por su efectividad frente a la corrosión. Sin embargo, se necesita más investigación ya que se desconoce el comportamiento de esta armadura en defectos y extremos de barras ${ }^{8,15}$.

En algún caso, puede interesar el empleo de armadura de plástico reforzado $^{2}$. Este tipo de armadura se encuentra bajo investigación como material para armar estructuras en ambientes particularmente agresivos. Mientras que el acero inoxidable ASTM A304 puede tolerar mayores cantidades de cloruros, es necesario emplear el grado más caro, ASTM A $316 \mathrm{~L}$, para conseguir propiedades mejoradas siginificativamente, sobre todo en mallas de barras soldadas ${ }^{8}$

El uso del acero inoxidable supone un plus del $10 \%$ en el coste total del proyecto, pudiendo llegar a encarecerlo hasta tres veces más de su coste normal comparado con el acero convencional. Sin embargo, implica la obtención de una vida útil de la estructura superior a los 120 años así como reducir sus costes de mantenimiento un $50 \%{ }^{8}$. 
El acero tratado con micro-compuesto de cromo es una alternativa reciente. Se trata de un acero micro compuesto que contiene cromo, lo que le proporciona una resistencia a la corrosión similar que la del acero inoxidable, aunque algo menor. Sin embargo, las propiedades mecánicas son mejores y el coste inferior. El umbral de cloruros (Clemena, 2003) es de 4,7 a 5,9 veces el del acero al carbono. En otros casos, se dice que es 3,5 veces y que la velocidad de corrosión puede ser de 2 a 3 veces menor (Darwin et al., 2002). Se plantean valores de $4,6 \mathrm{~kg} / \mathrm{m}^{3}$ para el umbral de cloruros de este tipo de acero frente a $0,5 \mathrm{~kg} / \mathrm{m}^{3}$ que se

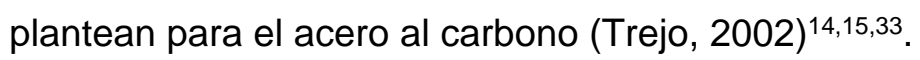

Un resultado interesante es que en ambiente moderado, el acero tratado con cromo se comporta significativamente mejor que el galvanizado, pero a medida que el ambiente se hace más severo, el comportamiento de ambos se hace similar ${ }^{14}$.

\subsection{Empleo de protecciones metálicas para armaduras}

Este tipo de protecciones pueden ser de dos tipos: las de sacrificio y las nobles. En general, los metales con un potencial de corrosión más negativo que el acero, como el zinc y el cadmio, proporcionan una protección de sacrificio al acero. Si se daña la protección, se forma un par galvánico en el que el ánodo es la protección.

Las protecciones nobles, como el cobre y el níquel, protegen al acero mientras que no se rompan, ya que cualquier metal expuesto es anódico frente a la protección noble. Incluso cuando el acero no está expuesto, la macro corrosión de la protección puede ocurrir en el hormigón a través de un mecanismo similar a la corrosión del acero sin protección.

Níquel, cadmio y zinc han mostrado ser capaces de retrasar e incluso prevenir la corrosión del acero en el hormigón, pero sólo las protecciones de zinc (galvanizado) son frecuentes.

Los resultados de emplear armadura galvanizada son controvertidos. Estudios marinos y de campo acelerados han mostrado que el galvanizado retrasa el inicio de delaminaciones y estallidos pero no los previene. En general, parece_que sólo se consigue un leve aumento de la vida útil de la estructura. Cuando se aplica galvanizado debe hacerse en 
todo el acero de la estructura para evitar la formación de pares galvánicos entre zonas galvanizadas y no galvanizadas.

El acero galvanizado se obtiene sumergiendo el acero en zinc fundido a una temperatura entre 435 y $454^{\circ} \mathrm{C}$, con el fin de hacerlo más estable al oxígeno y a los cloruros. El zinc reacciona con el acero y el oxigeno, formándose una capa pasiva de óxido de zinc de unos 100-150 $\mu \mathrm{m}$ de espesor. Los umbrales de cloruros son al menos 2,5 veces mayores que en el caso del acero al carbono, debido a que la capa pasiva comienza a destruirse a un $\mathrm{pH}$ de 9,5 frente al 11,5 del acero al carbono. Los productos de la corrosión son en este caso menos voluminosos y se ha observado que rellenan fisuras y huecos en el espesor de recubrimiento, con lo que el hormigón resulta más difícil de fisurar y los coeficientes de difusión se reducen, lo que contribuye a aumentar su vida útili2,8,14.

Las propiedades mecánicas del acero galvanizado son comparables a las del acero al carbono y la adherencia entre el hormigón y las armaduras galvanizadas es aceptable ${ }^{15}$.

El empleo del acero galvanizado presenta limitaciones. La primera es que si la capa de óxido de zinc se daña durante la construcción, quedando expuesto el acero al carbono, éste se corroe como si fuera acero al carbono convencional. Sin embargo, se ha demostrado que la capa de zinc alrededor de las zonas dañadas se sacrifica para proteger al acero base. Por otro lado, el coste del acero galvanizado es más de dos veces el del acero al carbono. No es viable su empleo en el caso de estructuras con alta concentración de cloruros, ya que si el umbral de cloruros se supera rápidamente, los beneficios adicionales de la capa de zinc sólo extenderán el periodo de propagación durante cinco años ${ }^{15}$.

Como ventaja, debe señalarse que los productos de la corrosión del acero galvanizado son mucho menos voluminosos que los del acero al carbono (150\% frente a $250 \%)$. Adicionalmente, son friables y se difunden dentro del hormigón de recubrimiento rellenando fisuras y huecos, lo que densifica el hormigón, le hace menos susceptible a la penetración de cloruros y aumenta su vida útil ${ }^{15}$.

Resulta más adecuado para cementos bajos en álcalis y para casos de corrosión por carbonatación, ya que el zinc permanece en estado pasivo 
a niveles menores de $\mathrm{pH}$. Por otro lado, cuando el acero galvanizado se emplea en el hormigón, puede formarse una capa porosa en el hormigón alrededor de la armadura que provoque la evolución del hidrógeno. Esto debe evitarse, ya que el zinc se disuelve en una solución de pH elevado con la evolución del hidrógeno. Para evitarla, puede añadirse una pequeña cantidad de sal cromato del hormigón fresco y el nitrato/nitrito de calcio se ha utilizado con el mismo fin en formas prefabricadas ${ }^{8}$.

Es necesaria su planificación previa, pero una vez empleado no es necesario el mantenimiento durante sus 20 años de duración. Su coste aproximado es de 5-8 $€ / \mathrm{m}^{22,8,14}$.

\subsection{Protección de las armaduras frente a la corrosión mediante protección catódica}

Es una técnica empleada para prevenir el inicio de la corrosión activa. Hay dos tipos de sistemas de prevención catódica: los de corriente impresa o los ánodos de sacrificio. En el caso de corriente impresa, la armadura pasiva se polariza catódicamente para aumentar su potencial mediante una corriente baja y así evitar la corrosión por picaduras. Aumentar el potencial eléctrico del acero elevará el umbral de cloruros hasta un punto que en teoría no se alcanzará durante la vida útil de la estructura. El proceso reduce el ingreso de cloruros y rellena de iones hidroxilo inhibidores el hormigón que rodea al acero ${ }^{2,15}$.

Se trata de un método que funciona mejor en zona sumergida y de carrera de mareas que en zona atmosférica. El voltaje a aplicar para la protección está comprendido entre los -1000 y $-1200 \mathrm{mV}$, supone un coste del $0,5 \%$ del total de la obra y requiere personal cualificado así como mantenimiento continuo ${ }^{2}$.

Otro tipo de prevención catódica es la introducción de ánodos de sacrificio en la estructura, normalmente zinc. El zinc, al ser un metal menos noble, actuará como ánodo haciendo que la armadura funcione como cátodo. El beneficio de que el zinc se corroa en lugar del acero es que la corrosión del zinc es un proceso menos expansivo y los productos de la corrosión son capaces de difundirse alrededor de la matriz de hormigón sin causar daño a la estructura ${ }^{15}$. 
El factor crítico en el diseño y la efectividad de la protección o prevención catódica es la distribución de la corriente a las armaduras. Así, en el caso de California, se promovió el uso de ánodos planos de zinc pulverizado y también en Oregón se han instalado protecciones catódicas en diversas estructuras. En otros casos, como en Depoe Bay o Cape Perpetua, se han empleado como protecciones catódicas ánodos no consumibles pulverizados con titanio, ánodos de hidrogel-zinc y pulverizados con Al$12 Z n-0,2 \ln ^{10}$.

Los ánodos planos son los más efectivos para reducir la resistencia del electrolito y mejorar la distribución de corriente a las armaduras de puentes de hormigón. En cuanto a los de zinc pulverizado, su vida podría superar los 25 años. Se desarrolla una capa resistiva interna con aumento de la edad electroquímica aumentando así la polarización del ánodo. En los sistemas de corriente impresa esto se refleja en una mayor resistencia del circuito y en los de corriente galvánica, en un menor registro de la corriente. Humedecer periódicamente el ánodo es importante para la reducción de la polarización. Otra alternativa son los ánodos catalizados con titanio, que no desarrollan polarización con la edad electroquímica. Se comportan bien a largo plazo al margen de la humedad. El catalizador se sitúa en la interfaz y es resistente al lavado. En corriente galvánica, los ánodos de zinc-hidrogel proporcionan una protección suficiente frente a la corrosión. En los ensayos de campo, no hay efecto de las condiciones ambientales ni del envejecimiento. Además, este tipo de protecciones son compatibles visualmente con el entorno ${ }^{10}$.

Una forma de mejorar el funcionamiento de los ánodos es el uso de humectantes. La humedad existente en la interfaz hormigón-ánodo reduce la resistencia de la capa de mineral de zinc producida con el tiempo. Por eso se emplean los humectantes, ya que atraen la humedad, como el $\mathrm{LiNO}_{3}$ y el $\mathrm{LiBr}$. Este segundo es más poderoso en las protecciones galvánicas y da un registro de corriente elevado. El mejor momento para aplicar un humectante es tras la colocación del ánodo ${ }^{10}$.

Se han aplicado en la rehabilitación de estructuras de hormigón existentes contaminadas por sales durante años, pero su uso en estructuras nuevas es reciente. La densidad de corriente catódica necesaria para mantener una capa pasiva sobre el acero se contamina 
con los cloruros; sin embargo, es relativamente baja y los cloruros tienden a migrar hacia el ánodo. El rango de corrientes típicas va de 0,2 a 2,0 $\mathrm{mA} / \mathrm{m}^{2}$ para protecciones catódicas de estructuras de hormigón armado nuevas, frente a 2,0-20 mA/m² para estructuras existentes contaminadas por sales. Las protecciones catódicas pueden utilizarse por sí solas o junto con otros métodos de control de corrosión ${ }^{8}$.

Los sistemas de prevención catódica no se usan de forma masiva, empleándose en estructuras costeras expuestas a concentraciones de cloruros muy elevadas o cuando se espera una corrosión severa o estructuralmente problemática. Implementar un sistema de prevención catódica es asumir que la estructura no está diseñada en términos durables a largo plazo. Es una técnica cara, que requiere mantenimiento constante y si la corriente se interrumpe la corrosión activa puede iniciarse de inmediato ${ }^{15}$.

En el caso de un estudio realizado en Huelva con bloques de hormigón sumergidos $^{39}$, se ha observado una protección catódica inesperada: el gancho metálico de sujeción y transporte de los bloques analizados que se encuentra conectado a la armadura interior. Ya que se empezó a corroer, inmediatamente se colocaron los bloques en la playa, y debió polarizar la armadura interior hacia valores catódicos, lo que hace que sean necesarias cantidades mucho más elevadas de cloruros para iniciar la corrosión. Como conclusión práctica de este hecho, puede decirse que si se dejan trozos de acero conectados a la armadura en medios sumergidos, dichos trozos la protegen eficazmente a pesar de que puedan llegar elevadas cantidades de cloruros hasta ellas.

\subsection{Tratamientos especiales del hormigón}

Entre las medidas especiales de protección contra la corrosión podemos $\operatorname{citar}^{2,8,15}$ :

- Uso de aditivos inhibidores de la corrosión:

Su función es prolongar el tiempo hasta el inicio de la corrosión, reduciendo significativamente la velocidad de corrosión si ya ha comenzado o ambas, bien creando una capa protectora o bien inmovilizando a los elementos corrosivos, pero sin mermar la 
concentración de los mismos. (Así, se distinguen de las adiciones, que mejoran la resistencia a la corrosión reduciendo el ingreso de cloruros). Para conseguirlo, pueden actuar mediante un proceso competitivo de adsorción por superficie del inhibidor y los cloruros, por aumento y neutralización de $\mathrm{pH}$ en ambiente local (picadura) o por migración de inhibidor y cloruros dentro de la picadura (de modo que no se den las condiciones de bajo $\mathrm{pH}$ y elevado contenido de cloruros para mantener el crecimiento de las picaduras). Una reducción significativa de la velocidad de las reacciones anódicas o catódicas supondrá una reducción de la velocidad de corrosión y aumentará el límite admisible de corrosión por cloruros. En ningún caso se plantean como un sustituto del hormigón sano y pueden ser anódicos, catódicos, multifuncionales o captadores de oxígeno, resultando más efectivos los de tipo anódico ${ }^{2,8,15}$.

La efectividad de los inhibidores anódicos depende en gran medida de emplear la dosis correcta. Si la concentración de inhibidor es muy baja, puede incluso aumentar la velocidad de corrosión, ya que al controlar la zona anódica, esto aumentaría la relación cátodo-ánodo. Para determinar la dosis correcta es necesario predecir el nivel de cloruros que estarán presentes en el hormigón en el futuro. En el caso de los inhibidores catódicos, reducen la velocidad de corrosión independientemente de la dosis de inhibidor. Al mantenerse el tamaño del ánodo, si reducimos el área catódica, se reduce el ratio cátodoánodo y por tanto también la velocidad de corrosión ${ }^{15}$.

Se aplican de dos formas: por adición a la mezcla de hormigón o por aplicación en superficie. En el primer caso, se añaden mayoritariamente durante la construcción para asegurar que hay suficiente inhibidor a la altura de la armadura. Los de aplicación en superficie se suelen colocar una vez iniciada la corrosión. Son numerosos compuestos químicos los que se han estudiado como inhibidores de la corrosión: cromatos, fosfatos, hipofosfitos, álcalis, nitratos, fluoradas y aminas. Se añaden al agua y deben ser reactivos en un medio alcalino. Duran 10 años y su coste oscila entre los 8-9 $€ / \mathrm{m}^{2}$ para las pinturas y entre los $11-15 € / \mathrm{m}^{2}$ para los aditivos ${ }^{2,15}$.

Algunos de ellos resultan efectivos; otros tienen resultados controvertidos al ser negativos frente a las propiedades del hormigón 
y no quedar muy clara su penetración hasta la armadura. Sus limitaciones principales son la dificultad de determinar la dosis apropiada, la posibilidad de que el inhibidor se sude durante el inicio de la vida de la estructura y la incapacidad de los inhibidores de superficie de alcanzar el nivel de la armadura ${ }^{15}$.

- Revestimiento o impregnación del hormigón mediante monómero más polimeración, para obtención de un hormigón más impermeable:

Los materiales que mejor resultado dan son los de base epoxi. Se recomienda su ensayo previo antes de emplearlos para la reparación de estructuras marinas.

El tratamiento consiste en rellenar algunos de los huecos del hormigón mediante un monómero y polimerizarlo in situ. El hormigón así tratado resulta fuerte, durable y casi impermeable. Es una técnica cara, poco utilizada por la necesidad de secar el hormigón con su consecuente fisuración por retracción. Este tipo de revestimiento con pinturas supone el $2 \%$ del coste total de la obra $\left(1,5-7 € / \mathrm{m}^{2}\right)$ y dura 10 años sin necesidad de mantenimiento ${ }^{2}$.

- Sellado:

Los productos utilizados como sellado pueden ser disolventes o líquidos de base acuosa que se aplican sobre la superficie creando una fina capa impermeable que previene la entrada del agua cargada de cloruros en la estructura de hormigón. En el caso de tableros de puentes, sólo se recomiendan los sellados penetrantes, ya sean silanos o sioloxanos o una combinación de ambos, ya que otros tipos de sellado tienen inadecuada profundidad de penetración y se deterioran rápidamente debido a la abrasión del tráfico (Weyers et al, 1983). Con el sellado se previene la entrada del agua en el hormigón, al tiempo que el vapor de agua puede evaporarse, lo que permite al hormigón secarse, aumentando así la resistencia de la celda de corrosión por limitarse el electrolito ${ }^{15}$.

Su efectividad depende de la permeabilidad del hormigón original, que no siempre puede estimarse debido a la variabilidad de las prácticas constructivas ${ }^{15}$. 
- Empleo de capas de Hormigón Polímero

Estas capas están formadas por árido en una capa de polímero. Se usan normalmente poliésteres, acrílicos y epoxys. Pueden colocarse bien extendiendo la resina sobre la parte superior del hormigón y difundiendo el árido dentro de la resina o bien, mezclando previamente los ingredientes y aplicándolos a continuación. Su colocación es rápida, pueden presentar distintas resistencias y flexibilidades y resultan resistentes a la abrasión así como al ingreso de agua y cloruros. Suelen colocarse espesores entre los 5-40 mm.

La mayoría de los monómeros son poco tolerantes a la humedad y las bajas temperaturas, por lo que el sustrato sobre el que se apliquen deberá encontrarse seco y a una temperatura superior a $4^{\circ} \mathrm{C}^{8}$.

- Utilización de capas de Hormigón de Cemento Pórtland8

Se aplican en dos etapas. La capa superior de hormigón puede colocarse a continuación de que la primera se haya colocado o bien varios días más tarde (en este caso, se usa una capa intermedia de adherencia). La primera alternativa resulta más rápida, no requiere mucha preparación del sustrato, minimizando así los costes; en la segunda, es más fácil asegurar la disposición del recubrimiento de hormigón y se cumplen las tolerancias de construcción.

Previamente a colocar la segunda capa, es necesario aplicar un tratamiento para sanear la capa anterior y proporcionarle rugosidad para una adecuada adherencia. No es adecuado aplicar con este fin resinas para el curado ni tratamientos con ácido, pues pueden incorporar cloruros.

Pueden utilizarse distintos tipos de hormigón: convencional, de fibras e internamente sellado, siendo los más comunes, el modificado con humo de sílice o con látex ${ }^{8}$.

- Empleo de Hormigón modificado con humo de sílice ${ }^{8}$

Resulta muy utilizado por ser de fácil compactación y acabado. Mediante el empleo de humo de sílice y un reductor de agua de alto 
rango, puede obtenerse una baja permeabilidad. Este hormigón debe tener aire ocluido si se emplea en el exterior. Antes de la aplicación de la capa correspondiente, el hormigón se prepara colocando sobre él una pasta de cemento o mortero. El hormigón base no suele humedecerse y para mejorar la adherencia, se frota con un cepillo de alambre. El curado se realiza convencionalmente ${ }^{8}$.

- Uso de Hormigón modificado con Látex8.

Se trata de hormigón fabricado con cemento Pórtland convencional con adición de látex. El látex es una dispersión coloidal de partículas de polímero en agua. Dichas partículas se estabilizan para prevenir la coagulación y se emplean agentes anti-espumantes para evitar que se fije mucho aire a la mezcla. El agua de la dispersión del látex ayuda a hidratar el cemento y el polímero proporciona propiedades de fijación para producir un hormigón con baja relación $\mathrm{a} / \mathrm{cm}$, buena durabilidad, buena adherencia y una elevada resistencia a la penetración de cloruros.

Los más empleados son los látex de estireno butadieno, aunque también se están popularizando las fórmulas acrílicas. El porcentaje de látex que se añade es aproximadamente el 15\% de látex por peso de cemento.

El proceso de aplicación es similar al del hormigón modificado con sílice citado anteriormente, salvo las siguientes diferencias:

$\rightarrow$ El hormigón base debe humedecerse al menos una hora antes de colocar el látex, ya que el agua ayuda a la penetración de la base y retrasa la formación de película de látex.

$\rightarrow$ El equipamiento debe disponer de medios para almacenar y dispensar el látex

$\rightarrow$ No se requiere la aplicación de aire ocluido.

$\rightarrow$ Se precisa una combinación de humedad inicial para la hidratación del cemento y secado con aire para la coalescencia del látex. Los tiempos de curado oscilan entre las 24-72 horas de 
curado húmedo, seguidas de $72 \mathrm{~h}$ de curado seco; la coalescencia del látex es un proceso sensible a la temperatura y su resistencia se desarrolla lentamente por debajo de $13^{\circ} \mathrm{C}$. Los periodos de curado necesitan ampliarse a temperaturas menores y no se recomienda aplicarlo por debajo de los $7^{\circ} \mathrm{C}$.

Los climas calurosos producen un secado rápido, que junto a la reducción del sudado por el látex, promueve la fisuración por retracción plástica. También es deseable controlar la cantidad de aire total en la mezcla $(6,5 \%)$ para evitar reducir la resistencia a flexión, compresión y adherencia de la capa.

Su precio elevado y su compleja realización hacen que sea de menor utilización, siendo los espesores comunes variables entre $40-50 \mathrm{~mm}$. Aunque se comenzó a usar en 1957, la mayoría de aplicaciones se dieron a partir de 1975. Su empleo ha sido satisfactorio, a pesar de la fisuración y pérdida de adherencia, sobre todo en el caso de capas inferiores de $20 \mathrm{~mm}$. La deficiencia más común es la fisuración por retracción plástica de las capas (ACI 548.3R y ACI 548.4R $)^{8}$.

- Empleo de membranas resistentes al agua

Se emplean para minimizar el ingreso de cloruros al hormigón. Algunas membranas ofrecen resistencia al paso de los cloruros y la humedad, incluso con burbujas, agujeros o fisuras. Para medir esta resistencia se realiza el ensayo según ASTM D 5385.

Los requerimientos para un sistema resistente al agua ideal son: fácil instalación, buena adherencia con el sustrato, compatibilidad con todos los elementos del sistema e impermeabilidad a los cloruros y a la humedad bajo condiciones de servicio, ya sean temperaturas extremas, movimientos de fisuras, envejecimiento y/o cargas impuestas.

Existen dos sistemas: de hoja preformada o de aplicación líquida. El primero, de difícil instalación y muy sensible a la mano de obra en localizaciones complicadas; el segundo, más fácil de aplicar y menos caro. 
La formación de ampollas es el mayor problema en el empleo de estas membranas. Se produce por la expansión de gases atrapados, disolventes o humedad en el hormigón tras la colocación de la membrana. La frecuencia con que se forman puede controlarse mediante la porosidad, el contenido de humedad del hormigón y las condiciones atmosféricas. Pueden aparecer por un aumento en la temperatura del hormigón o un descenso en la presión atmosférica poco antes o durante la aplicación de la membrana. Una técnica utilizada para prevenir su formación son las capas de ventilación, que permiten dispersar las presiones de vapor por debajo de la membrana ${ }^{8}$.

\subsubsection{Requisitos normativos}

La tabla 4.25 establece una comparativa entre la clasificación del ambiente marino en la Instrucción española EHE y las especificaciones en Japón ${ }^{3,7}$. En este último caso, como ya se ha visto en el apartado 4.4.1 de Ambiente Marino Aéreo se diferencian tres regiones en función de la climatología ( $A$, B y C) y dentro de ellas se realiza una subdivisión en función de la distancia a la costa mucho más pormenorizada que en el caso español además de incluir como ambiente específico el de estructuras situadas sobre el mar:

\begin{tabular}{|c|c|c|}
\hline España & & Japón \\
\hline \multirow{5}{*}{$\begin{array}{l}\text { Ambiente IIIa: Elementos de estructuras } \\
\text { marinas por encima del nivel de pleamar. } \\
\text { Elementos exteriores de estructuras situadas } \\
\text { en las proximidades de la línea costera (a } \\
\text { menos de } 5 \mathrm{~km} \text { ) }\end{array}$} & Zona & "Nivel Agresividad (*) \\
\hline & \multirow{2}{*}{$\begin{array}{c}\text { A (ruta de } \\
\text { tifones) }\end{array}$} & $\begin{array}{c}\text { I (Menos de } 100 \mathrm{~m} \text { y por encima } \\
\text { del mar) }\end{array}$ \\
\hline & & II (Excepto la región anterior) \\
\hline & \multirow{3}{*}{$\begin{array}{l}\text { B (Viento } \\
\text { de } \\
\text { tormenta } \\
\text { en } \\
\text { invierno) }\end{array}$} & $\begin{array}{c}\text { I (Menos de } 100 \text { m y por encima } \\
\text { del mar) }\end{array}$ \\
\hline & & II (Entre 100 y 200m) \\
\hline \multirow{4}{*}{$\begin{array}{l}\text { Ambiente IIIc: Elementos de estructuras } \\
\text { marinas situadas en la zona de salpicaduras o } \\
\text { en zona de carrera de mareas }\end{array}$} & & III (Entre 200 y 300 m) \\
\hline & \multirow{3}{*}{$\mathrm{C}$} & I (Por encima del mar) \\
\hline & & II (Menos de 100m) \\
\hline & & III (Entre 100 y 200m) \\
\hline
\end{tabular}

$\left(^{*}\right)$ De acuerdo con la tabla de recubrimientos asignados (ver tabla 3.3) los niveles de agresividad serían nivel I o de mayor agresividad, nivel II o de agresividad media y nivel III o de menor agresividad.

Tabla 4.25. Comparativa de Ambientes EHE-Normativa Japonesa

En la tabla anterior se han comparado los ambientes IIIa y IIIc planteados por la Instrucción con las divisiones establecidas por Japón. Así la norma EHE 08 incluye en el ambiente IIla estructuras situadas por encima de la 
pleamar y aquellas localizadas en la proximidad de la línea costera hasta $5 \mathrm{~km}$. Por otro lado Japón define un nivel de agresividad I hasta $100 \mathrm{~m}$ y por encima del mar. En el caso español, la definición de los ambientes resulta confusa, ya que el ambiente IIla recoge la zona "por encima de la pleamar" y en el ambiente IIIc se habla de salpicaduras y de carrera de mareas, sin establecer un límite en altura tal y como hace el FIB. Adicionalmente, hay que señalar que la Instrucción EHE-08 recoge el ambiente Qb en hormigón en contacto con agua de mar, que siempre aplica a los ambientes IIIb y IIIc.

En una publicación posterior ${ }^{76}$ referente a las Japan Specifications in Highway Bridges, se localiza una tabla que discretiza algo más los niveles de agresividad a las sales en función de su distancia al mar. Se observa que las estructuras situadas sobre el mar o dentro de los 100 metros más próximos a la costa se localizan en el nivel máximo de agresividad, "S", nivel severo. En la tabla 4.26 se realiza, de forma análoga a la tabla 4.25 , una comparativa entre los ambientes definidos por las normativas española y japonesa.

\begin{tabular}{|c|c|c|}
\hline España & & Japón \\
\hline \multirow{6}{*}{$\begin{array}{c}\text { Ambiente IIIa: Elementos de } \\
\text { estructuras marinas por encima del } \\
\text { nivel de pleamar. Elementos exteriores } \\
\text { de estructuras situadas en las } \\
\text { proximidades de la línea costera (a } \\
\text { menos de } 5 \mathrm{~km} \text { ) }\end{array}$} & Zona & Nivel (distancia $L$ al mar en m) \\
\hline & \multirow{3}{*}{$\begin{array}{l}\text { A (Prefectura de } \\
\text { Okinawa, situada } \\
\text { en ruta de tifones) }\end{array}$} & S (Sobre el mar o L $\leq 100$ ) \\
\hline & & $\mathrm{I}(100 \leq \mathrm{L} \leq 300)$ \\
\hline & & II (Otras) \\
\hline & \multirow{4}{*}{$\begin{array}{l}\text { B (viento de } \\
\text { tormenta en } \\
\text { invierno) }\end{array}$} & S S (Sobre el mar o L $\leq 100$ ) \\
\hline & & $\mathrm{I}(100 \leq \mathrm{L} \leq 300)$ \\
\hline \multirow{6}{*}{$\begin{array}{l}\text { Ambiente IIIc: Elementos de } \\
\text { estructuras marinas situadas en la zona } \\
\text { de salpicaduras o en zona de carrera de } \\
\text { mareas }\end{array}$} & & II $(300<\mathrm{L} \leq 500)$ \\
\hline & & III $(500<\mathrm{L} \leq 700)$ \\
\hline & \multirow{4}{*}{ C } & S (Sobre el mar o L $\leq 20$ ) \\
\hline & & $\mathrm{I}(20 \leq \mathrm{L} \leq 50)$ \\
\hline & & II $(50<\mathrm{L} \leq 100)$ \\
\hline & & III $(100<\mathrm{L} \leq 200)$ \\
\hline
\end{tabular}

Tabla 4.26. Comparativa de Ambientes EHE-Normativa Japonesa.

Según el FIB $^{69}$, los datos recogidos para su estudio (Model Code for Service Life Design) se clasifican en cuatro grupos de exposición: estructuras sumergidas, estructuras expuestas a la acción de la mareas, 
estructuras expuestas a agua de salpicaduras que contiene cloruros y partes de estructuras únicamente expuestas a niebla salina (zona de spray). Los elementos o estructuras de hormigón que se sitúan a más de $1,5 \mathrm{~m}$ de distancia del agua de mar se considera que se encuentran en zona de spray.

El Model Code for Service Life Design ${ }^{69}$ del FIB se basa en sus planteamientos en la normativa europea CEN Eurocódigo 0 (EN 1990:2002) "Bases para diseño" y CEN ENV 13670-1:2000 "Execution of Concrete Structures".

Por ello y dado que tal referencia no detalla explícitamente los distintos ambientes marinos, se incorpora aquí la definición de los mismos según la EN 206-145:

- XS1 Exposición al aire que transporta sales marinas, pero sin contacto directo con el agua del mar. (Estructuras en la costa o en sus proximidades)

- $\quad$ XS2 Sumergido permanente (Elementos de estructuras marinas)

- XS3 Zonas sometidas a la marea, a la salpicadura y a la espuma de mar (elementos de estructuras marinas)

Las normativas generales y específicas dan una serie de especificaciones relativas a los factores ${ }^{2}$ siguientes: máxima relación agua/cemento, mínimo contenido de cemento, resistencia mínima del hormigón, mínimo recubrimiento, máximos cloruros solubles en ácido (\%peso de cemento) y contenido de $\mathrm{C}_{3} \mathrm{~A}(\%)$.

Para el control de la permeabilidad, aspecto clave para la protección contra la corrosión, se debe prestar atención a la relación a/c, el contenido mínimo en cemento y las adiciones minerales, en su caso².

Los siguientes requisitos han sido tomados de la referencia ${ }^{2}$ y los datos más relevantes se exponen a continuación cubriendo las siguientes normativas:

- EHE-083“"Instrucción de Hormigón Estructural”

- $\mathrm{ACl}$ 318-08 "Building Code Requirements for Structural Concrete and Commentary" 
- EN 206-145 “Hormigón. Parte 1: Especificaciones, Prestaciones, Producción y Conformidad"

- ACI 222 R-018 "Protection of Metals in Concrete Against Corrosion"

- CP 110 BS Code 21 "Code of Practice for Structural Use of Concrete"

- NS 3420-L "Specification Texts for Building, Construction and Installation. Part L: Concrete Works"

- FHWA Documento de la Federal Highway Administration

- US ARMY COASTAL ENGINEERING "Shore Protection Manual"35

- ACI 375 R $^{28}$ "Design and Construction of Fixed Offshore Concrete Structures"

- BS 634964,65 "Maritime Structures. Code of Practice for General Criteria"

- Technical Standards for Port and Harbour Facilities in Japan ${ }^{29}$

- Documento de Universidad de Kyoto ${ }^{30}$

- FIP Recommendations ${ }^{36}$. "Design and Construction of Concrete Sea Structures"

- RILEM "Durability Design of Concrete Structures. Rilem Report 14"

Respecto al valor de la relación a/c, la Instrucción española EHE-08 coincide con la Instrucción británica BS 6349 , fijando contenidos de 0,50 para hormigón armado y 0,45 para hormigón pretensado. Las recomendaciones RILEM fijan una relación a/c entre 0,45 y 0,50 sin especificar tipo de hormigón. La normativa europea EN 206-1 establece un único valor de 0,5. La normativa americana $\mathrm{ACl}$ 318-08 establece un contenido de 0,4 , al igual que la CP 110 BS Code y las normas noruegas que dan valores similares, tal y como se aporta a continuación. De la bibliografía consultada, solamente el caso de Japón refleja relaciones a/c de $0,55-0,65$.

En cuanto al mínimo contenido de cemento, la Instrucción EHE-08 y la normativa europea EN-206-1 plantean contenidos mínimos de cemento de $300 \mathrm{~kg} / \mathrm{m}^{3}$, valores muy similares a los planteados por la normativa japonesa $\left(300-330 \mathrm{~kg} / \mathrm{m}^{3}\right)$. Valores algo más elevados plantean la FIP (320-360 kg/m³), la RILEM (350 kg/m³), la norma británica BS 6349 (350$\left.400 \mathrm{~kg} / \mathrm{m}^{3}\right)$ y el $\mathrm{ACl} 375\left(365 \mathrm{~kg} / \mathrm{m}^{3}\right)$.

Referente al tipo de cemento a emplear, la EHE-08 exige el uso de cemento resistente al agua de mar si la estructura a construir estará en contacto con el mar. También limita al $0.1 \%$ el contenido inicial de $\mathrm{Cl}^{-}$. BS 
y $\mathrm{ACl}$ indican que el contenido de $\mathrm{C}_{3} \mathrm{~A}$ debe estar comprendido entre $4 \%$ y $10 \%$, incluso la BS permite la sustitución de parte del cemento por escorias o cenizas. Para la norma japonesa y la FIP, los cementos con adiciones (tipo escorias o cenizas volantes) son los mejores frente al agua de mar. La RILEM también limita el contenido de $C_{3} A^{2}$.

Respecto a los valores mínimos de resistencia a compresión la mayoría de las normas consultadas muestra valores comprendidos entre los $30 \mathrm{y}$ los $35 \mathrm{~N} / \mathrm{mm}^{2}$. La Instrucción EHE-08 indica que se trata de valores orientativos dado que con los contenidos mínimos de cemento y las máximas relaciones a/c empleados en las dosificaciones conducen a hormigones con valores de resistencia en esos rangos.

En cuanto al contenido de cloruros totales (solubles en ácido) y cloruros libres, la tabla 4.20 presenta un resumen de los datos encontrados.

El contenido de $\mathrm{Cl}$ - en el agua de amasado y curado será menor de $3 \mathrm{~g} / \mathrm{l}$ en el hormigón armado y menor de $1 \mathrm{~g} / \mathrm{l}$ en el hormigón pretensado, según la Instrucción EHE. Permite, como la norma BS y la RILEM, el uso de agua de mar para amasado o curado de hormigón en masa. La FIP recomienda curar con agua dulce y la norma japonesa dice que sólo se usará agua de mar para hormigón en masa y cuando no se pueda obtener otra ${ }^{2}$.

En cuanto a los áridos, la EHE-08 limita el contenido máximo de finos en $6 \%$ para áridos de machaqueo no calizos y en $10 \%$ para áridos de machaqueo calizos, también establece el contenido máximo de $\mathrm{Cl}$ - de los áridos en 0,05\% para el hormigón armado y 0,03\% para el pretensado. En las normativas internacionales, la RILEM dice que el contenido total de finos más cemento no supere los $450 \mathrm{~kg} / \mathrm{m} 3$, la norma japonesa fija el tamaño máximo de árido en 20-25-40 mm, la British Standard da numerosas especificaciones sobre los áridos (resistentes a sulfatos, absorción, árido grueso, árido fino...) $)^{2}$.

Respecto a los recubrimientos a emplear, las normas ACl 318-08, BS 6349 y la normativa japonesa establecen recubrimientos entre los 50 y los $70 \mathrm{~mm}$. En general, estos valores son superiores a los planteados por la Instrucción EHE-08 que plantea, para el caso del hormigón armado, un rango de recubrimientos entre 25 y $65 \mathrm{~mm}$ (dependiendo del tipo de 
cemento empleado y de la vida útil de la estructura) y para el caso del hormigón pretensado, un rango de recubrimientos entre 30 y $65 \mathrm{~mm}$.

En cuanto al ancho de fisura, la Instrucción EHE-08 se muestra muy restrictiva con un valor límite de $0,1 \mathrm{~mm}$, la norma británica BS plantea $0,3 \mathrm{~mm}$, la japonesa incluso $1 \mathrm{~mm}$. Por último, la EHE-08 sugiere que el esquema estructural, la geometría y los detalles constructivos sean los propios para una adecuada durabilidad. En este sentido, FIP, RILEM y US plantean que las estructuras tengan geometría sencilla y superficies redondeadas y lisas; la normativa japonesa minimiza el número de juntas de construcción por considerarlas puntos débiles².

Seguidamente se describen otros requisitos exigidos para mejorar la durabilidad del hormigón en ambiente marino. La Instrucción EHE-08 obliga a comprobar la impermeabilidad del hormigón, fijando los valores de penetración máxima y media de agua para el ambiente de exposición IIla en 50 y $30 \mathrm{~mm}$, respectivamente ${ }^{2}$.

En cuanto al empleo de aditivos para mejorar la durabilidad, la Instrucción EHE no dice nada. La norma japonesa recomienda emplear aire ocluido en el hormigón y en el caso de la US, el empleo de aditivos para rebajar la a/c y la porosidad².

Como conclusión, la normativa internacional se muestra más restrictiva con los materiales (dosificación, cemento, a/c, áridos...) y la Instrucción EHE lo es más con recubrimientos y ancho de fisura ${ }^{2}$.

En el caso de la normativa noruega NS3473/NS-EN 1992-1-1 (Standard Noruegos, 2003, 2008) y NS EN 206-1 (Standard Noruego, 2007) requieren una relación a/c menor a 0,4 combinado con el uso de puzolanas o escorias y un recubrimiento mínimo de $50 \mathrm{~mm}$ (50 años) y de $60 \mathrm{~mm}$ (100 años) adecuados para asegurar una vida útil de servicio con un nivel de confianza de más del $90 \%{ }^{37}$. 


\subsection{ESTRUCTURAS REALES EN AMBIENTE MARINO AÉREO}

\section{PORTUGAL (CASO 1) $)^{5}$}

Se describe el deterioro de tres muelles $(20,21$ y 22$)$ de un astillero situado en el estuario del río Sado, en la costa oeste de Portugal. Son de hormigón armado construidos entre 1973 y 1975. El muelle 20 es una plataforma de construcción de barcos con dimensiones en planta de $420 \mathrm{~m} \times 75 \mathrm{~m}$ y paredes de $8 \mathrm{~m}$ de altura. El muelle 21 tiene como fin la reparación de barcos y sus dimensiones son $450 \mathrm{~m} x$ $75 \mathrm{~m}$ con paredes de $18 \mathrm{~m}$ de altura. El muelle 22 , también para la reparación de barcos, tiene dimensiones de $350 \mathrm{~m} \times 55 \mathrm{~m}$ y paredes de $12 \mathrm{~m}$. A continuación se muestran las secciones transversales de los muelles. ${ }^{5}$ (véase fig 4.29 y 4.30 )

Las características de los muelles se incluyen en la tabla 4.27:
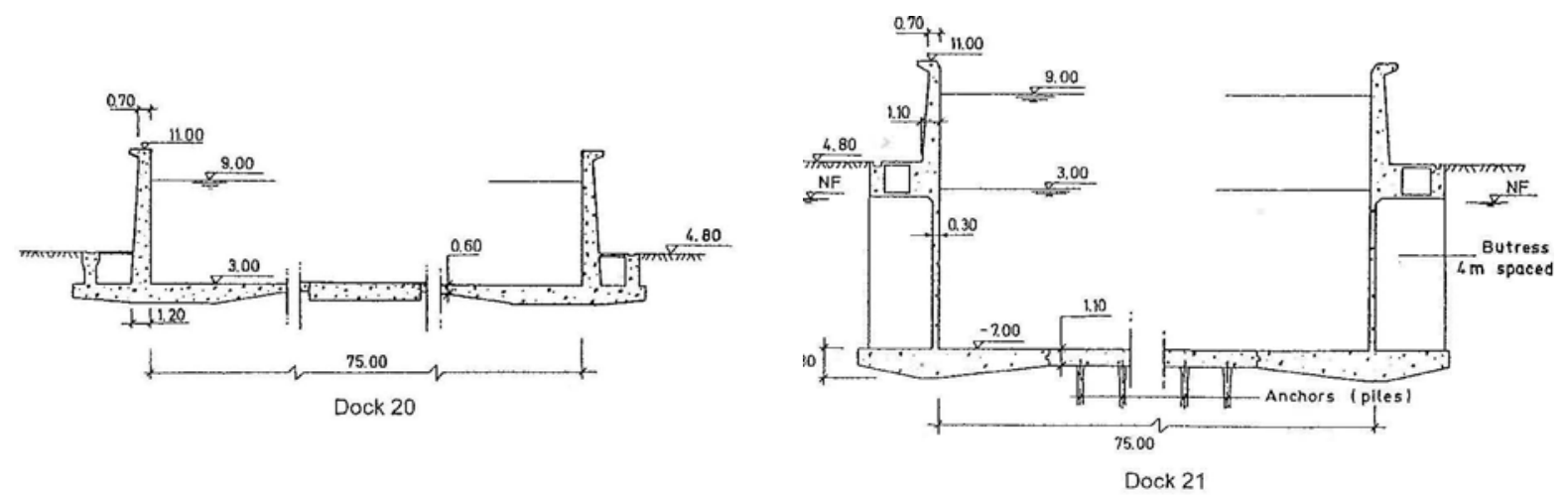

Fig.4.29. Secciones transversales de muelles 20 y 21 (medidas en m).

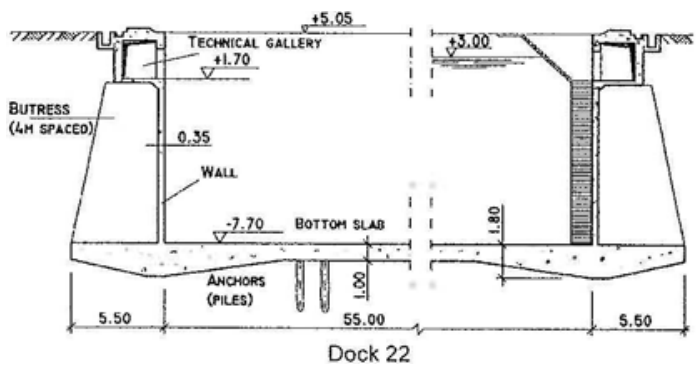

Fig. 4.30. Sección transversal de muelle 22 (medidas en m). 


\begin{tabular}{|c|c|c|c|}
\hline Datos & Muelle 20 & Muelle 21 & Muelle 22 \\
\hline Año Construcción & \multicolumn{3}{|c|}{ Entre 1973-1975 } \\
\hline $\begin{array}{c}\text { Dimensiones en Planta } \\
(\mathrm{m})\end{array}$ & $420 \times 75$ & $450 \times 75$ & $350 x 55$ \\
\hline Altura Paredes (m) & 8 & 18 & 12 \\
\hline \multicolumn{4}{|c|}{ Datos de Proyecto } \\
\hline Tipo de Hormigón & \multicolumn{3}{|c|}{ B225 } \\
\hline Resistencia (MPa) & \multicolumn{3}{|c|}{22,5} \\
\hline Relación a/c & \multicolumn{3}{|c|}{0,7} \\
\hline $\begin{array}{c}\text { Contenido Cemento } \\
\left(\mathrm{kg} / \mathrm{m}^{3}\right)\end{array}$ & \multicolumn{3}{|c|}{300} \\
\hline Recubrimientos (cm) & \multicolumn{3}{|c|}{4 (en paredes)/ 6 (en losas de fondo) } \\
\hline \multicolumn{4}{|c|}{ Ensayos realizados año 1991} \\
\hline Resistencia (MPa) & \multicolumn{3}{|c|}{ 17,6 (en paredes)/ 20,6 (en losas de fondo) } \\
\hline $\begin{array}{c}\begin{array}{c}\text { Permeabilidad al agua } \\
(\mathrm{m} / \mathrm{s})\end{array} \\
\end{array}$ & \multicolumn{3}{|c|}{$14 \cdot 10^{-11}$ (paredes)/ 0,6 $10^{-11}$ (losas de fondo) } \\
\hline Porosidad abierta (\%) & \multicolumn{3}{|c|}{ 17,8 (paredes)/16,4 (losas de fondo) } \\
\hline \multicolumn{4}{|c|}{ Condiciones Ambientales } \\
\hline Ambiente & \multicolumn{3}{|c|}{ Marino } \\
\hline Clima & \multicolumn{3}{|c|}{ Templado (Portugal, río Sado) } \\
\hline $\begin{array}{c}\text { Composición } \\
\text { Agua(Cl/SO } / \text { Mg) (g/l) }\end{array}$ & \multicolumn{3}{|c|}{$16-21 / 2,1-2,9 / 1,1-1,6$} \\
\hline pH & \multicolumn{3}{|c|}{$7,8-8$} \\
\hline \multicolumn{4}{|c|}{ Otros datos recogidos } \\
\hline $\begin{array}{c}\text { Resistividad del } \\
\text { Hormigón }(\mathbf{k} \Omega \cdot \mathrm{cm}) \\
\end{array}$ & \multicolumn{3}{|c|}{$1,5-3,0$} \\
\hline $\begin{array}{c}\text { Velocidad de } \\
\text { corrosión }(\mu \mathrm{m} / \mathrm{año})\end{array}$ & \multicolumn{3}{|c|}{ Entre 200 y 400, puntualmente 600} \\
\hline Polarización ( $\mu \mathrm{m} / \mathbf{a n ̃ o})$ & \multicolumn{3}{|c|}{$17-23$} \\
\hline \multicolumn{4}{|c|}{ Reparaciones realizadas } \\
\hline $\begin{array}{c}M^{2} \text { reparados (año } \\
1984)\end{array}$ & 3600 (paredes) & --- & --- \\
\hline $\begin{array}{c}M^{2} \text { reparados (año } \\
1988)\end{array}$ & --- & 5600 (paredes) & --- \\
\hline $\begin{array}{l}M^{2} \text { reparados (año } \\
\text { 1991) }\end{array}$ & \multicolumn{2}{|c|}{ 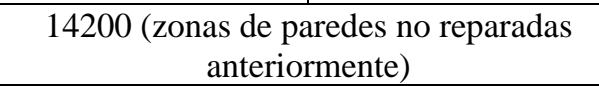 } & --- \\
\hline $\begin{array}{c}M^{2} \text { reparados (año } \\
\text { 1999) }\end{array}$ & \multicolumn{2}{|c|}{--} & 14200 \\
\hline
\end{tabular}

Tabla 4.27. Datos referentes a los muelles 20,21 y 22. 


\section{PORTUGAL (CASO 2)}

Se trata de un estudio realizado en la costa oeste de Portugal ${ }^{46}$ en estructuras de unos 25 años de antigüedad emplazadas en un muelle construido con hormigón de mala calidad, con el fin de evaluar la importancia de la carbonatación en el hormigón situado en ambiente marino. Aunque la carbonatación no es objeto directo del presente estudio, se cita este caso ya que en él se analiza la interacción entre la carbonatación y la penetración por cloruros.

Se estudiaron tres mezclas de hormigón distintas, dos de ellas para hormigón in situ y otra para hormigón proyectado. Todas las mezclas se fabricaron con cemento Pórtland CE I 32.5. En la tabla 4.28 se adjuntan las características fundamentales de las tres mezclas.

\begin{tabular}{|c||c||c||c|}
\hline Tipo de Mezcla & C1 & C2 & C3 \\
\hline Cemento $\left(\mathrm{Kg} / \mathrm{m}^{3}\right)$ & 300 & 425 & 500 \\
\hline Microsílice $\left(\mathrm{Kg} / \mathrm{m}^{3}\right)$ & ---- & ---- & 21,5 \\
\hline Relación a/c & 0,5 & 0,3 & 0,35 \\
\hline $\begin{array}{c}\text { Resistencia Compresión } \\
(\mathrm{MPa})\end{array}$ & 34 & 54 & 66 \\
\hline
\end{tabular}

Tabla 4.28. Datos de composición de las mezclas y valor de la resistencia a compresión.

El sitio elegido para la exposición de las losas de ensayo fue el complejo naval de Setenave, situado en el estuario del río Sado, cerca de Setúbal.

Se trata de un clima de ambiente marino con temperaturas templadas. Las principales características climáticas durante el periodo desde 1974 a 1990 se recogen en la tabla 4.29 .

\begin{tabular}{|c||c||c||}
\hline & Media Anual & Media Diaria \\
\hline \hline Temperatura del Aire $\left.\mathbf{~}^{\circ} \mathbf{C}\right)$ & $+16,8$ & $+11,1$ (Enero)/+22,2 (Julio) \\
\hline Humedad Relativa (\%) & $78(9 \mathrm{~h}) / 64(15 \mathrm{~h})$ & $\begin{array}{c}\text { Enero } 89(9 \mathrm{~h}) / 73(15 \mathrm{~h}) \\
\text { Julio } 68(9 \mathrm{~h}) / 54(15 \mathrm{~h})\end{array}$ \\
\hline Precipitaciones (mm) & 538,6 & $72,4($ Enero)/5,4 (Julio) \\
\hline Evaporación (mm) & 1505,4 & $66,6($ Enero)/203,2 (Julio) \\
\hline \hline
\end{tabular}

Tabla 4.29. Características climáticas. 
La medida de las velocidades con que se depositan los cloruros queda recogida en la tabla 4.30:

\begin{tabular}{|c||c||c|c|c|c||c|c||c|c|c|c|c||}
\hline Mes & Ene & Feb & Mar & Ab & Ma & Jun & Jul & Ag & Sep & Oct & Nov & Dic \\
\hline \hline $\begin{array}{c}\text { Cl } \\
\left(\mathbf{m g} / \mathbf{m}^{2} / \mathbf{d} \mathbf{a}\right)\end{array}$ & 262 & 42,9 & 78,9 & 21 & 36 & 15,8 & 20,3 & 26,7 & 22,6 & 37,3 & 157 & 95,7 \\
\hline
\end{tabular}

Tabla 4.30. Velocidades a las que se depositan los cloruros a lo largo del año.

Las losas de hormigón quedaron expuestas en varias localizaciones del muelle y en distintas condiciones ambientales. Las condiciones seleccionadas para el estudio fueron las siguientes:

A. Zona de Spray. Es la zona sometida al spray provocado por la rotura de las olas cuando el mar está agitado.

B. Zona dentro del muelle 20. Es el lugar sometido a los ciclos infrecuentes de llenado del muelle con agua procedente del estuario. Después de colocar las losas, se les aplicaron 30 ciclos de llenado y vaciado en seis años.

C. Zona atmosférica. Es el área expuesta al efecto de los cloruros en el aire transportados por la brisa del mar.

Los ensayos realizados con fenolftaleína indican la ausencia de signos de carbonatación en la muestra C3 en todas las clases de exposición estudiadas. EI comportamiento de este hormigón debe asociarse a dos factores: el primero, su elevado contenido de cemento, que le proporciona un mayor aporte de compuestos alcalinos; el segundo, su baja relación a/c así como la incorporación de microsílice a la mezcla, lo que resulta en un hormigón con una estructura de poros muy refinada y así, una resistencia a la penetración de dióxido de carbono muy elevada ${ }^{46}$. En la figura 4.31 se muestran las profundidades de carbonatación medias obtenidas en las losas de hormigón C1 y C2 durante el tiempo de exposición considerado. 

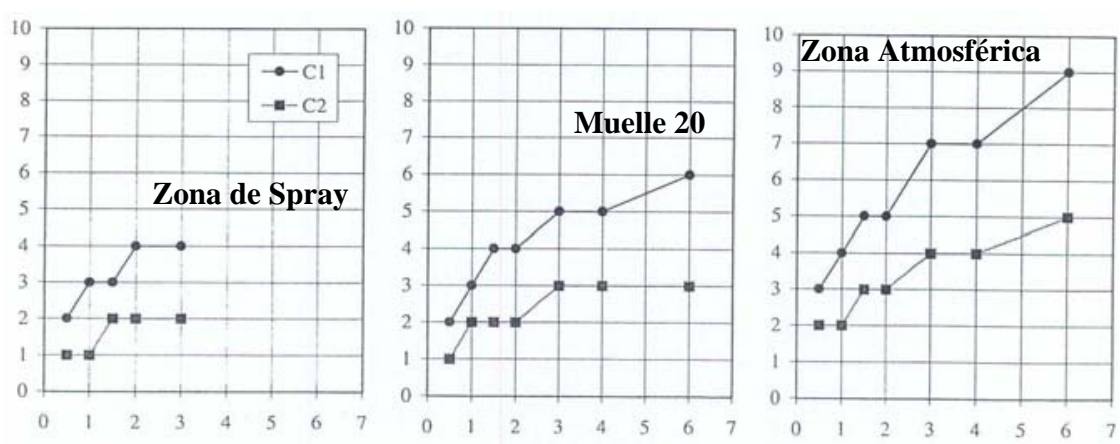

Tiempo (años)

Fig. 4.31. Profundidad de carbonatación ( $\mathrm{mm}$ ) media en muestras C1 y C2.

\section{NORUEGA ${ }^{37}$}

En un estudio extensivo realizado en Noruega sobre plataformas de combustible situadas en el mar del Norte $^{37}$ se han obtenido los siguientes gráficos que representan el tiempo transcurrido hasta alcanzar el contenido critico de $\mathrm{Cl}^{-}$en 50 $\mathrm{mm}$ de espesor de hormigón obtenido a partir de testigos extraídos de las estructuras. Cada una de las figuras muestra en ordenadas el porcentaje de muestras que han alcanzado el umbral de cloruros y las abscisas los años transcurridos desde la construcción de la estructura.

Así en el caso del cajón Ekofisk ${ }^{37}$ (fig 4.32) a partir de diez testigos extraídos en 1990, se indica el tiempo transcurrido hasta alcanzar concentraciones de cloruros de $0,07 \%$ y $0,18 \%$ respecto al peso de hormigón a $50 \mathrm{~mm}$ de profundidad. Puede verse que para la mayoría de las muestras (desde 20-80\% aprox.) el umbral del $0,07 \%$ se alcanza en el intervalo entre los 20 y 40 años, mientras que un pequeño porcentaje llega al 0,18\% tras más de 100 años de puesta en servicio.

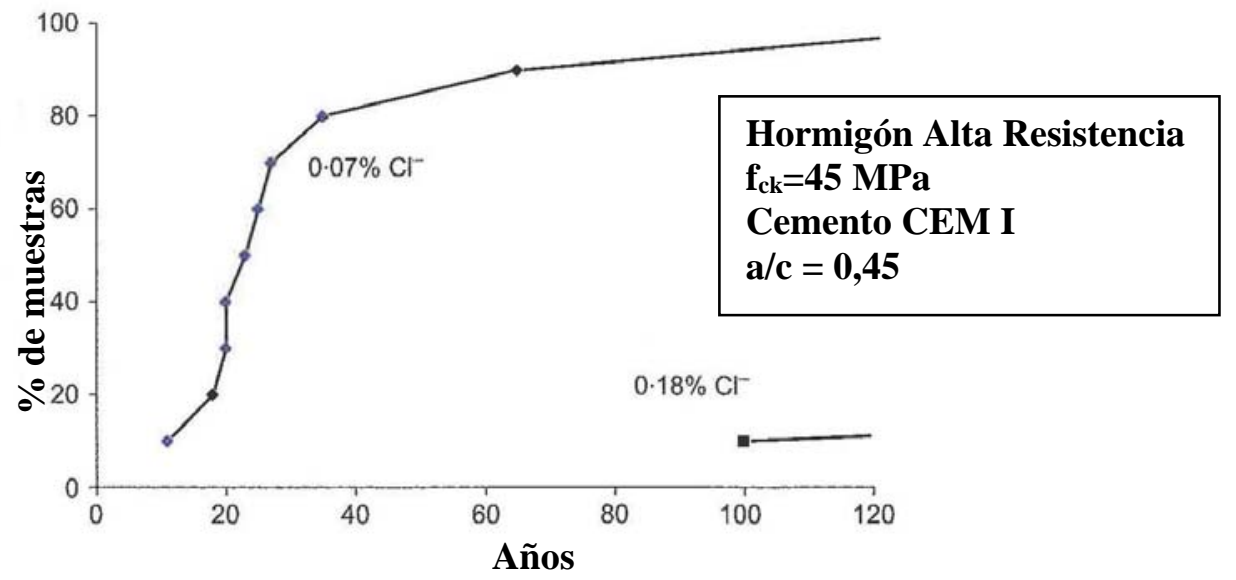

Fig. 4.32. Relación entre el tiempo trascurrido y el \% de muestras que alcanza un determinado umbral de cloruros. Estructura Ekofisk. 
Así en el caso de la estructura Brent $B^{37}$ (fig 4.33) con una relación a/c inferior, a partir de quince testigos extraídos, se indica el tiempo transcurrido hasta alcanzar concentraciones de cloruros de $0,07 \%$ y $0,18 \%$ respecto al peso de hormigón a $50 \mathrm{~mm}$ de profundidad. En este caso puede verse que para el porcentaje de muestras entre $20 \%$ y $40 \%$ la gráfica es bastante tendida, es decir existe bastante variación en los años en que tarda en alcanzarse el umbral del 0,07\% (para algunas muestras, entre 0 y 20 años y para otras, entre 100-120), mientras que un pequeño porcentaje llega al $0,18 \%$ tras más de 100 años de puesta en servicio.

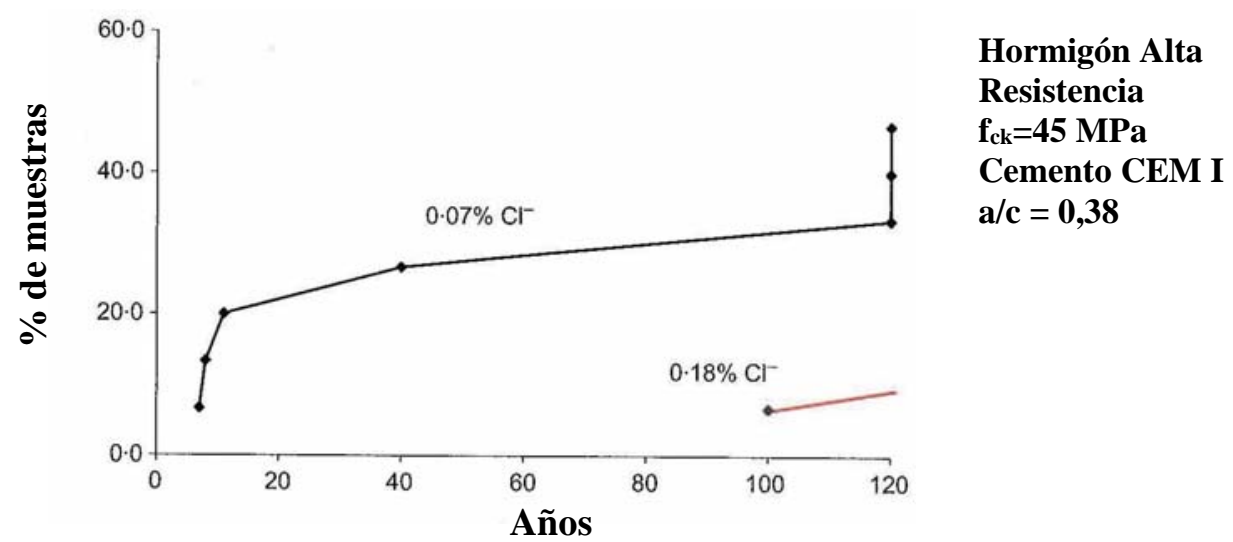

Fig. 4.33. Relación entre el tiempo trascurrido y el \% de muestras que alcanza un determinado umbral de cloruros. Estructura Brent B.

En el caso del Oseberg $A^{37}$ (fig 4.34) con una relación a/c aún inferior, a partir de ochenta y siete testigos extraídos entre los 9-18 años de exposición, se indica el tiempo transcurrido hasta alcanzar concentraciones de cloruros de $0,07 \%$ y $0,18 \%$ respecto al peso de hormigón a 50mm de profundidad. Puede verse que entre el 20-40\% aprox. de las muestras alcanza el umbral del 0,07\% de forma progresiva entre los 20-100 años de exposición, un porcentaje próximo al 10\% llega al 0,18\% cerca de los 60 años de puesta en servicio y un pequeño porcentaje (1\% aprox) alcanzará el 0,36\%.

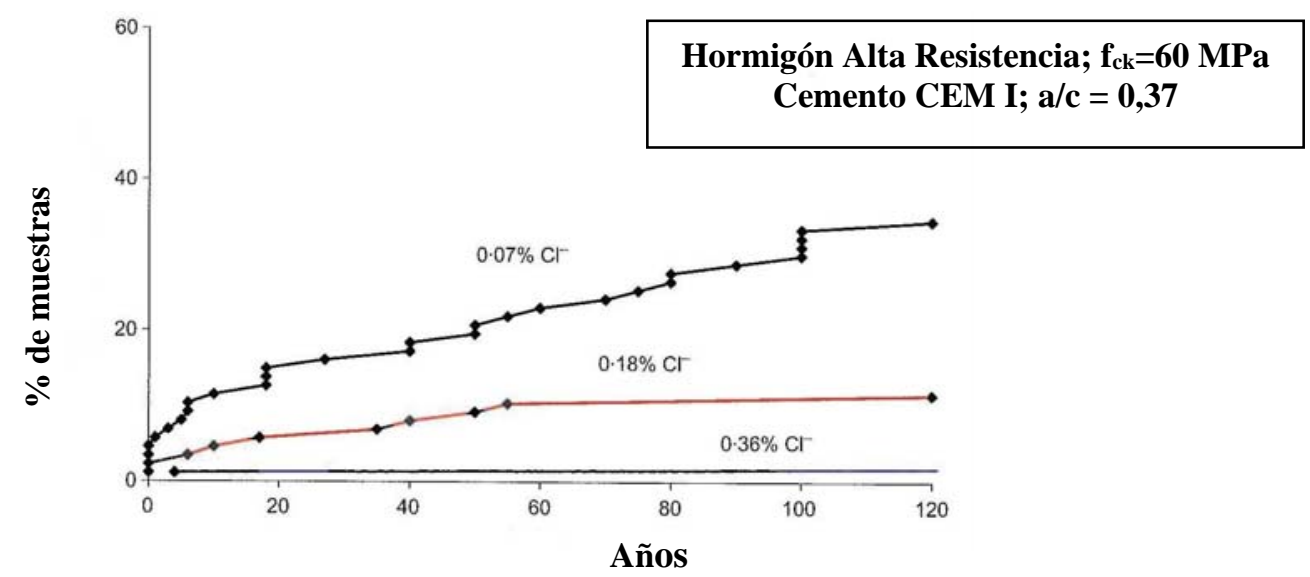

Fig. 4.34. Relación entre el tiempo trascurrido y el \% de muestras que alcanza un determinado umbral de cloruros. Estructura Oseberg A. 
Para el caso del túnel Shore Approach $^{37}$ (fig 4.35) que además de una baja relación a/c incorpora humo de sílice, a partir de diez testigos extraídos tras 12 y 26 años en servicio, se indica el tiempo transcurrido hasta alcanzar concentraciones de cloruros de $0,07 \%$ respecto al peso de hormigón a $50 \mathrm{~mm}$ de profundidad. Puede verse que el $20 \%$ de las muestras no alcanza el umbral hasta los 40-60 años y entre el 20-30\% lo alcanza en un largo periodo de tiempo (ente 60-120 años de puesta en servicio).

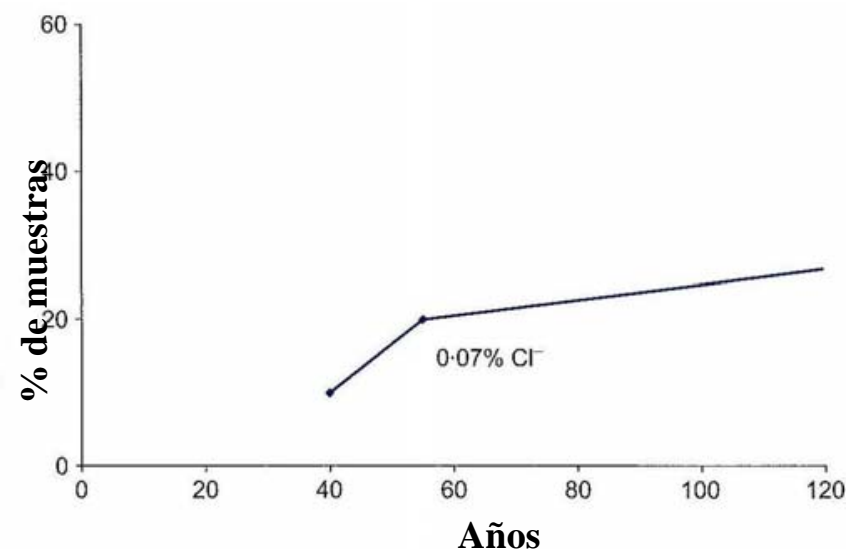

Horm. Alta Resistencia $f_{c k}=60 \mathrm{MPa}$

Cemento CEM I $\mathrm{a} / \mathrm{c}=\mathbf{0 , 3 6}$ Humo sílice $8 \%$

Fig.4.35. Relación entre el tiempo trascurrido y el \% de muestras que alcanza un determinado umbral de cloruros. Estructura Shore Approach.

A partir de los datos incluidos en la citada referencia, en la tabla 4.31 se adjuntan aquellos datos de dosificación más significativos de los hormigones de las cuatro plataformas estudiadas así como los \% de muestras que han alcanzado el umbral de cloruros $(0,07 \%)$ trascurridos 50 y 100 años.

\begin{tabular}{||c||c||c||c||c||c||}
\hline \hline Plataforma & $\begin{array}{c}\text { Resistencia } \\
\text { Hormigón } \\
\text { (MPa) }\end{array}$ & $\begin{array}{c}\text { Tipo de } \\
\text { Cemento }\end{array}$ & Relación a/c & $\begin{array}{c}\text { \%Muestras } \\
\text { alcanza umbral en } \\
\mathbf{5 0} \text { años }\end{array}$ & $\begin{array}{c}\text { \%Muestras } \\
\text { alcanza umbral en } \\
\mathbf{1 0 0} \text { años }\end{array}$ \\
\hline \hline Ekofisk & 45 & CEM I & 0,45 & 82 & 92 \\
\hline Brent B & 45 & CEM I & 0,38 & 25 & 28 \\
\hline Oseberg A & 60 & CEM I & 0,37 & 20 & 25 \\
\hline $\begin{array}{c}\text { Shore } \\
\text { Approach }\end{array}$ & 60 & CEM I & $0,36\left(^{*}\right)$ & 17 & 28 \\
\hline \hline
\end{tabular}

(*) En este caso se añade humo de sílice (8\%) a la dosificación de hormigón.

Tabla 4.31. Datos referentes a las plataformas estudiadas.

Se observa claramente el efecto favorable de la disminución de la relación a/c y de la incorporación del humo de sílice en la dosificación. 
Según este estudio realizado a partir de inspecciones en campo en estructuras offshore $^{37}$, la difusión se ve afectada de manera importante por factores externos a la dosificación del hormigón como el espesor de recubrimiento (si es insuficiente, la difusión es mayor), la difícil compactación del hormigón (un hormigón más poroso aumenta la difusión) y la pobre calidad del hormigón. A todo ello contribuyen defectos puntuales durante la ejecución, incluyendo el posible deslizamiento de encofrado durante la construcción.

El estudio ${ }^{37}$ concluye que la durabilidad potencial de hormigones con relaciones a/c en el entorno de 0,40 y recubrimiento de $50 \mathrm{~mm}$ lleva a vidas útiles de 50 años y de 100 con recubrimientos mínimos de $60 \mathrm{~mm}$.

Según dicho estudio ${ }^{37}$, se refleja que el factor crítico en la durabilidad es la ejecución insitu. Si ésta se arriesga, no sirve de nada el diseño de la mezcla para evitar la penetración de cloruros o el espesor de recubrimiento. No se trata de un problema de material o de recubrimiento, sino de dificultades durante la ejecución. Para una mejora de la durabilidad de las estructuras, el objetivo no sólo pasa por mejorar las condiciones de la mezcla o el espesor de recubrimiento sino los aspectos constructivos y de ejecución.

Así, en la figura $4.36^{37}$, se observan los valores de los coeficientes de difusión para una de las estructuras estudiadas respecto al tiempo, donde se observa la dispersión en los testigos de hormigón analizados.

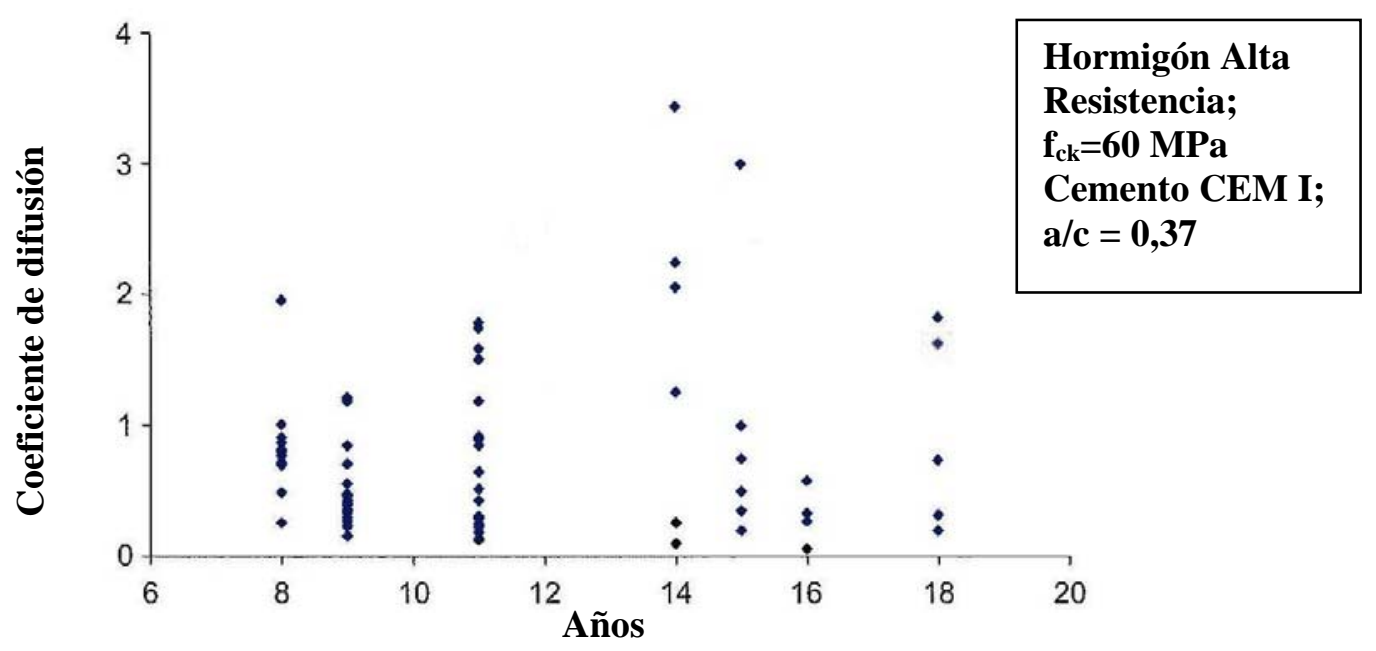

Fig.4.36. Coeficientes de difusión de cloruros tomados de la estructura Oseberg A respecto al tiempo. La variación en las observaciones y el limitado tiempo estudiado complica derivar algún efecto del tiempo. 
JAPON $^{7,12}$

\section{Puentes prefabricados}

Dentro de un estudio realizado en Japón en 1982 sobre puentes de carretera de hormigón situados hasta $500 \mathrm{~m}$ de la costa, el número de puentes prefabricados deteriorados resultó menor que el de otro tipo de puentes. Una de las causas del menor deterioro fue la diferencia en el coeficiente de difusión de cloruros en el hormigón, siendo mucho menor en los puentes prefabricados que en el resto. Esto puede deberse a que la relación a/c es más baja en los puentes prefabricados ${ }^{7}$ (véase tabla 4.16 del apartado 4.4.3.3).

\section{Puente de Kure-Tsubo}

En algunos puentes de hormigón pretensado prefabricado se han observado pérdidas de ductilidad y capacidad de absorber momento flector en vigas debido al ataque de sales. El fallo de estas vigas se producía por la rotura de los tendones de pretensado, aunque también frecuentemente lo hacían por rotura del hormigón. Esto podría estar causado por la pérdida de elongación de los tendones debido a la corrosión. Dicha pérdida así como la reducción de área de los tendones deben considerarse para evaluar correctamente el comportamiento a flexión de las vigas $^{12}$.

\section{Cálculo de la capacidad estructural del puente}

Con la intención de estudiar la influencia de la corrosión en la capacidad de absorber carga de las vigas, se realizaron ensayos de flexión y corte de las mismas, estudiando en concretos dos vigas (S3 y S5) del puente de Kure-tsubo. Las resistencias medias obtenidas de los testigos de hormigón tomados de S3 y S5 fueron $42 \mathrm{MPa}$ y $46 \mathrm{MPa}$, respectivamente ${ }^{12}$.

Las dos vigas estudiadas habían sido tratadas en dos ocasiones por la corrosión de sus armaduras, en 1980 y 1990. En la viga S3, en la que muchos alambres rompieron por corrosión, ya aparecía entonces el deterioro más grave del puente. Además, la zona vulnerable de S3 solía estar directamente salpicada por agua de mar, afectada por su forma y posición de borde, lo que hizo que la corrosión fuera más severa. En el caso de esta viga, el radio restante de la sección transversal RRCT (cociente del área restante no corroída entre área de tendones original) de los tendones en esta sección era sólo del $21 \%$. Por otro lado, en la viga S5 no se 
encontró rotura de alambres, pero sí pérdida de sección en algunos cables del ala inferior en la primera y quinta viga del quinto vano durante la reparación ${ }^{12}$.

El ensayo de carga de S3 consistió en aplicar dos cargas puntuales en el centro de vano. Resultó más o menos sencillo retirar los apoyos salvo en el caso del intermedio que recogía parte del peso propio. Dado que la corrosión había deteriorado bastante los tendones, al tratar de retirar uno de los apoyos provisionales se produjo una gran fisura de cortante y la viga quedó suspendida por alambres a un tercio de la luz ${ }^{12}$, es decir, su_capacidad de absorber carga se había mermado tanto que incluso era incapaz de soportar su propio peso, por lo que el ensayo finalmente no se realizó.

En el caso de la viga S5 (simplemente apoyada), se aplicaron dos cargas puntuales separadas a una distancia de $1,5 \mathrm{~m}$. El fallo de la viga se produjo por la rotura del hormigón en su fibra más comprimida ${ }^{12}$.

La tabla 4.32 indica los valores de los esfuerzos absorbidos por las vigas ensayadas y su nivel de corrosión, para poder establecer una relación entre ellos ${ }^{12}$.

\begin{tabular}{|c|c|c|c|c|c|}
\hline \multirow{2}{*}{ Espécimen } & \multicolumn{3}{|c|}{ S3 } & \multicolumn{2}{|c|}{ S5 } \\
\hline & & ulado & "Experimental & "Calculado & "Experimental \\
\hline " Nivel de Corrosión & "Nada & "Corrosión & "Corrosión & Nada & \\
\hline RRCT & 100 & 21,4 & 21,4 & 100 & 99 \\
\hline M Útimo & 21000 & 4420 & 4360 & 6480 & 6210 \\
\hline
\end{tabular}

Tabla 4.32. Valores de esfuerzos absorbidos por vigas y nivel de corrosión de éstas.

El RRCT (cociente del área restante no corroída entre el área original de tendones) en la sección de rotura de la viga S3 es del 21\%, tan bajo que el fallo de flexión de la viga se produjo por rotura de tendón, a pesar de que tal sección se encontraba a un cuarto de vano. El momento último calculado $(4420 \mathrm{KNm})$, teniendo en cuenta la pérdida de área del tendón y la reducción de resistencia por la corrosión, estaba muy próximo al momento debido a la carga muerta $(4360 \mathrm{KNm})^{12}$. Sin embargo, el fallo de la viga S5 se produjo por rotura del hormigón debido a la ligera corrosión de sus tendones. El momento último experimental de la viga estaba bastante cerca del calculado, asumiendo no existencia de corrosión ${ }^{12}$.

\section{Zonas de las vigas más dañadas por la corrosión}

Al realizar los ensayos de corte se detectó la pérdida de 12 cables de tendón por la corrosión en una zona del alma próxima al ala inferior. En las vigas postesadas 
dañadas por ataque de sales es común encontrar primeramente daños en la armadura pasiva, ya que en estos casos se dispone un recubrimiento menor. En los puentes del tipo de Kure-tsubo. (Puente de vigas postesadas), el espesor de recubrimiento en el alma es menor que en el ala. Así, la viga S5 tenía recubrimientos de $5 \mathrm{~cm}$ por vaina en el alma. El espesor de recubrimiento del tendón cerca del ala inferior era prácticamente el de la armadura pasiva. Además, los cloruros tienden a concentrarse cerca de la superficie superior del ala inferior. Todo esto favorece que los tendones situados en el alma próximos a las alas se corroan antes que otras partes de armadura activa ${ }^{12}$.

En la figura 4.37 se muestra la concentración de cloruros medida en distintos puntos de la sección así como el nivel de corrosión y la reducción de los tendones ${ }^{12}$.

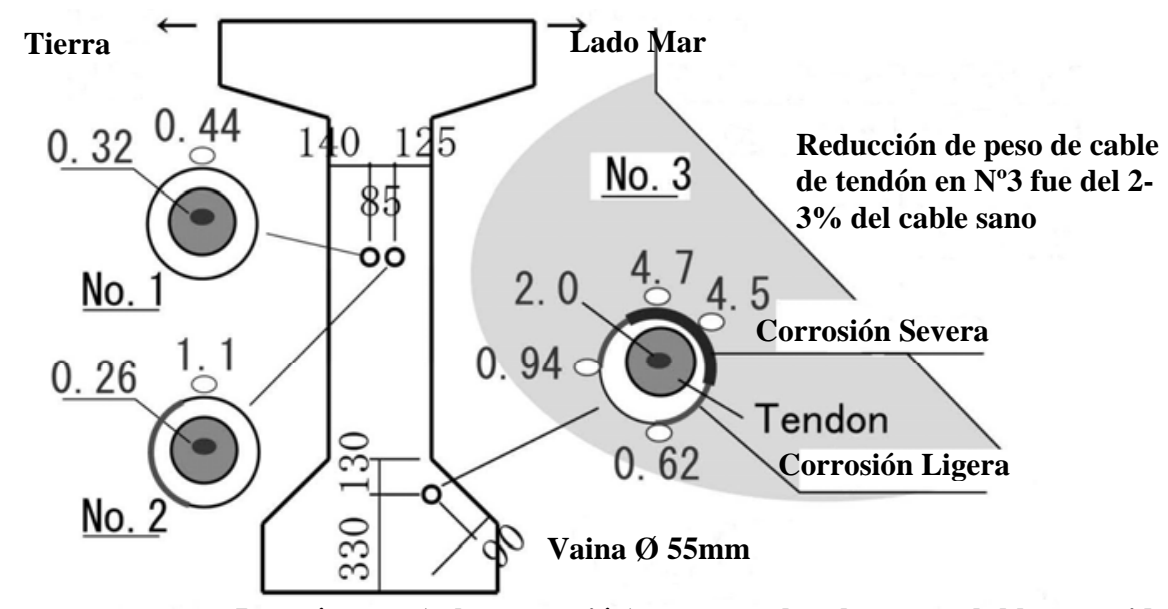

Los números (salvo acotación) muestran los cloruros solubles en acido $\left(\mathrm{kg} / \mathrm{m}^{3}\right)$. La anchura de trazado de las vainas muestra los niveles de corrosión. Cuanto más grueso, mayor nivel de corrosión.

Fig.4.37. Concentraciones de cloruros y corrosión alrededor de vainas.

Las concentraciones de cloruros solubles en ácido fueron $4,5-4,7 \mathrm{~kg} / \mathrm{m}^{3}$ en la cara exterior y $0,62-0,94 \mathrm{~kg} / \mathrm{m}^{3}$ en la otra cara. Los resultados concuerdan con el límite de contenido de cloruros conocido de 1,2-2,5 kg/m ${ }^{3}$, que indica la posible corrosión dentro del hormigón. La vaina parecía empezar a corroerse en este nivel ${ }^{12}$.

\section{Corrosión de los anclajes}

Los anclajes normalmente se cubren con hormigón una vez colocados los tendones y se rellenan las vainas con lechada. Se suponen dos rutas de penetración de cloruros desde el exterior. Una, desde la superficie del hormigón de relleno; otra, la de ingreso por la interfaz entre hormigón original y de relleno. Los 
datos muestran que la primera ruta era predominante en general. Así, la concentración de cloruros solubles en ácido alcanzó $1 \mathrm{~kg} / \mathrm{m}^{3}$, aunque la distancia desde superficie era $25 \mathrm{~cm}$. En el tendón, alrededor del anclaje, se encontró corrosión leve ${ }^{12}$ (fig 4.38).

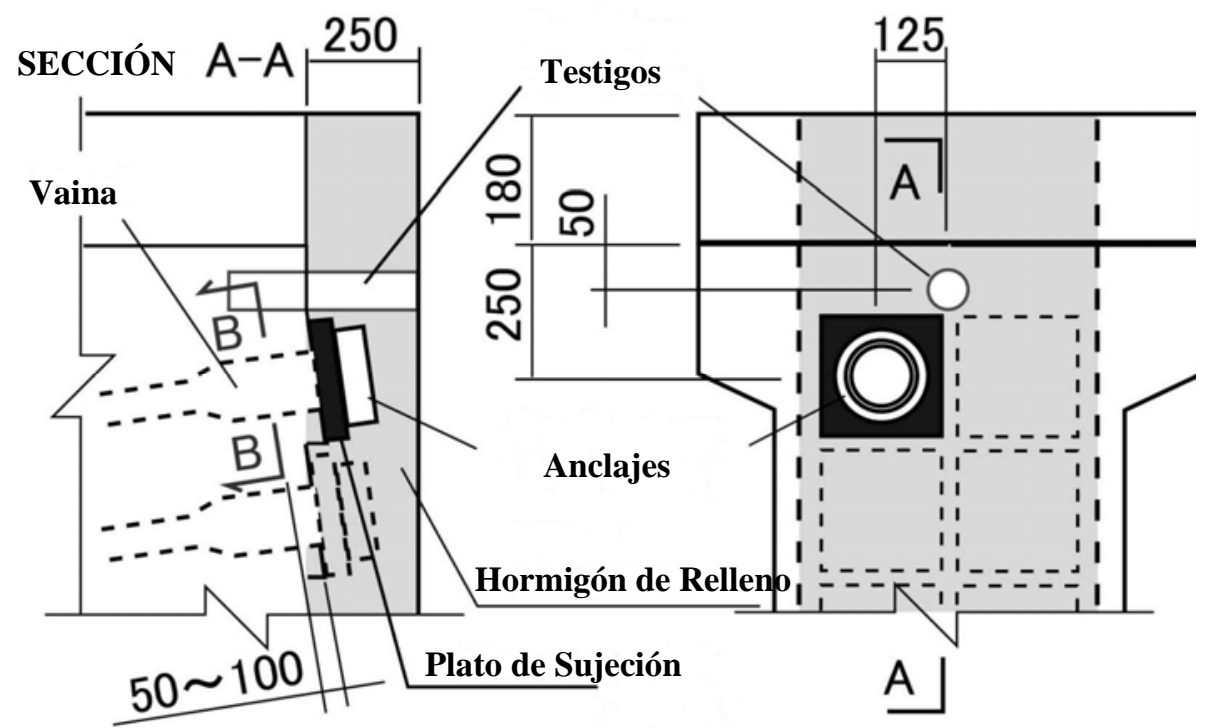

Fig.4.38. Detalles alrededor de anclajes y posición de testigos en S3.

Las concentraciones de cloruros solubles en ácido dentro y fuera de la vaina cónica próximo al anclaje eran menores que los otros casos a la misma profundidad de testigos. Este hecho probablemente se deba a la existencia de los platos de acero de los anclajes, que podrían funcionar como barrera para impedir el ingreso de cloruros ${ }^{12}$.

\section{$\mathrm{ESCOCIA}^{4}$}

El puente de Tay Road se encuentra sobre un estuario en Dundee, Escocia y fue construido entre los años 1963 y 1966. Está expuesto a la acción de las olas y el viento del mar del Norte con una salinidad de $19 \mathrm{ppm}$ de cloruros y una temperatura media anual de $8^{\circ} \mathrm{C}^{4}$.

Para la construcción del puente, según los criterios del momento, se fijaron recubrimientos entre 75 y $100 \mathrm{~mm}$. El hormigón de las muestras presentaba una resistencia característica de $34 \mathrm{MPa}$, con unas condiciones de curado y compactación aceptables y no contenía cloruros de calcio ${ }^{4}$. 
Debido a un deterioro por corrosión severo detectado en la zona inferior de las pilas, se decide realizar un estudio de las mismas y se procede a la extracción de testigos. Se observa una gran falta de uniformidad en los contenidos de cemento, la relación a/c y los valores de resistencia de los testigos ${ }^{4}$.

Al analizar los datos procedentes de los testigos se estudia la relación de dos factores (altura sobre el nivel del mar y situación aguas arriba o aguas abajo) con la penetración de cloruros, además de la variación con la altura del coeficiente de difusión y el contenido de cloruros en superficie ${ }^{4}, \mathrm{C}_{0}$.

Así, los gráficos siguientes (fig 4.39 y 4.40) muestran la variación entre muestras de distintas tongadas de hormigón a la misma altura $(7 \mathrm{~m}$ o $1 \mathrm{~m}$ sobre el nivel más elevado de agua) con los coeficientes de difusión de la Ley de Fick a $23^{\circ} \mathrm{C}$ y las concentraciones de cloruros en superficie ajustadas a los límites superior, inferior y medio de los perfiles de cloruros ${ }^{4}$.

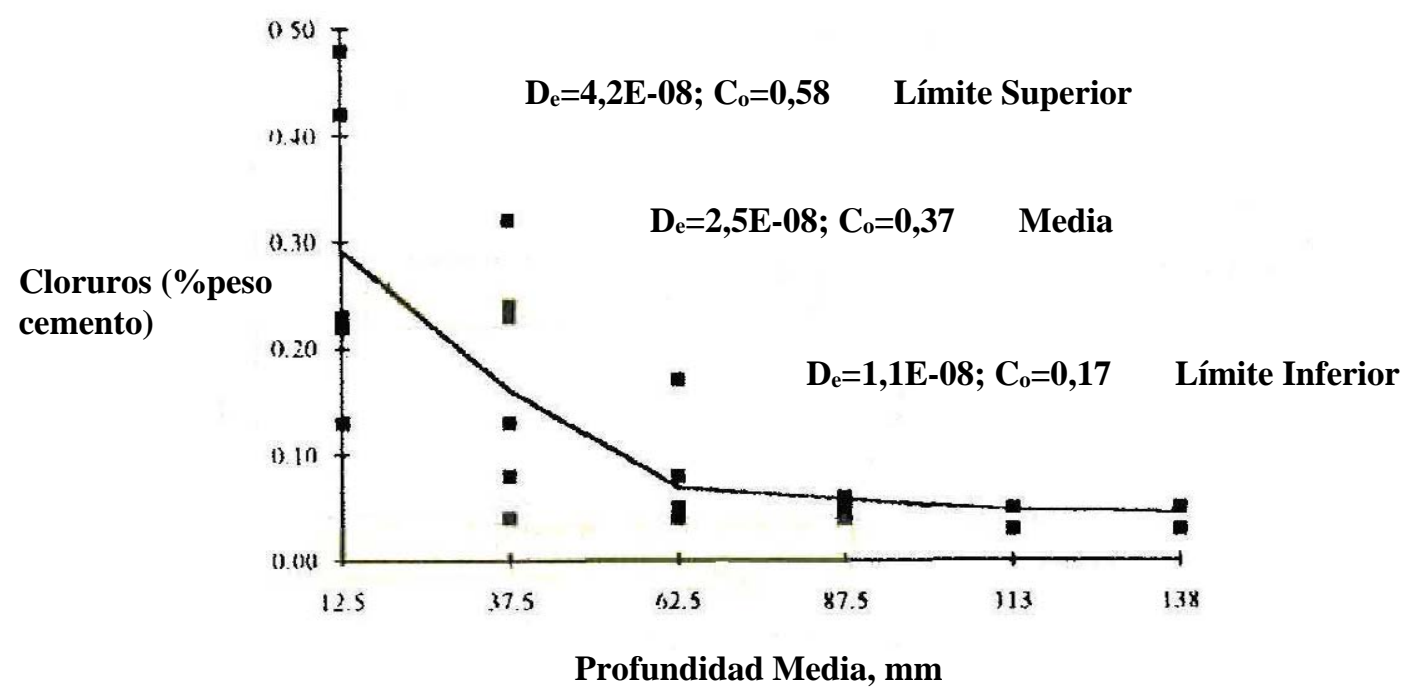

Fig.4.39. Variación de ingreso de cloruros a $7 \mathrm{~m}$. 


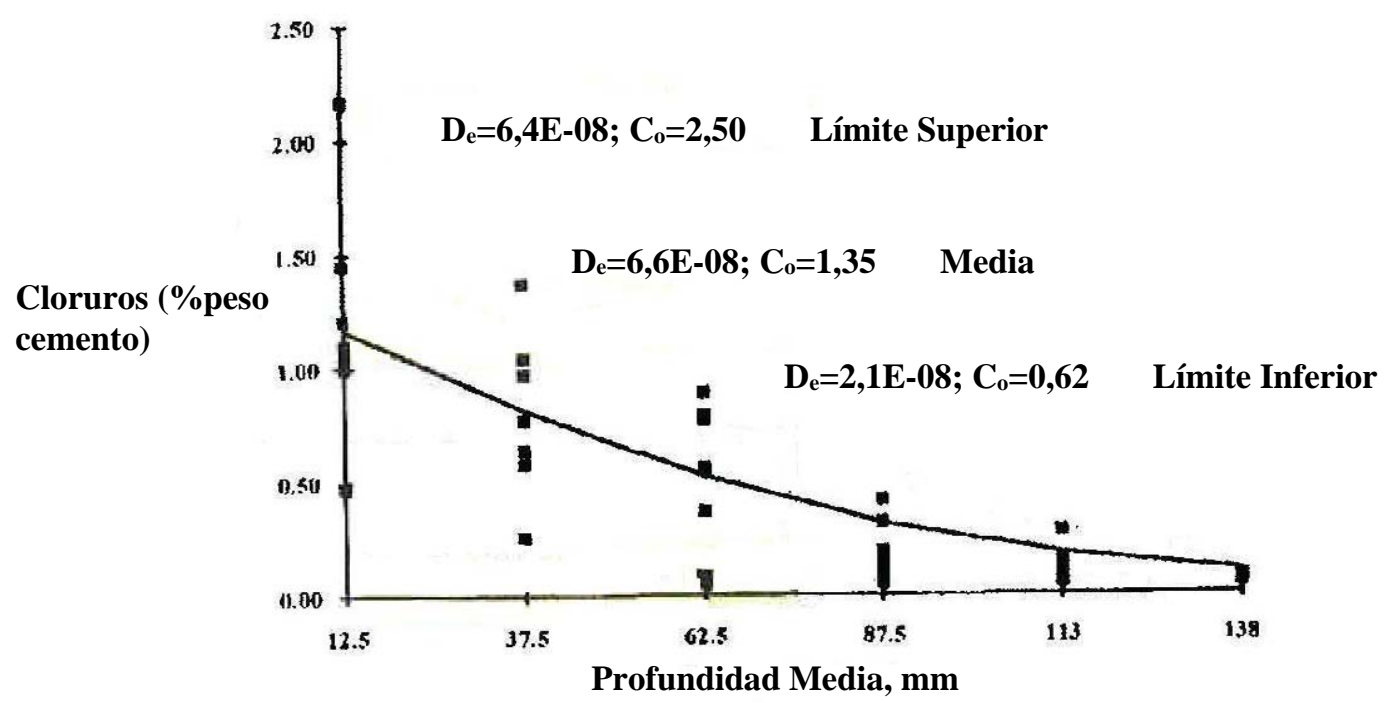

Fig.4.40. Variación de ingreso de cloruros a $1 \mathrm{~m}$.

En las figuras anteriores se observa que el efecto de la variación ambiental es mayor que el de la falta de uniformidad en la mezcla y la compactación de la misma 4 .

\section{MEXICO ${ }^{43}$}

El puerto de Progreso de Castro, en el estado de Yucatán, México, se localiza en la costa norte de la Península de Yucatán. Tiene clima tropical, con temperaturas que oscilan entre los 25 y 40 grados. El viento normalmente sopla de NE y SE, aunque el más fuerte viene del $\mathrm{N}$ y NO durante el invierno. Entre Abril y Octubre son comunes en la región vientos de hasta $175 \mathrm{~km} / \mathrm{h}^{43}$.

El muelle fue construido entre 1937 y 1941. La empresa encargada de su construcción ganó la oferta, entre otras razones, por el reducido uso de acero que proponía. Las autoridades querían construir un muelle con escaso o nulo mantenimiento ${ }^{43}$.

El muelle cuenta con tres partes diferenciadas: el acceso al viaducto, el propio viaducto y la plataforma. El viaducto se compone de 145 arcos soportados por vigas de hormigón masivo armadas con acero inoxidable 304. Las vigas se sujetan por dos tipos de pilas: circulares o elípticas ${ }^{43}$.

Se realizó una primera inspección de la estructura en 1998, en la que se mostró el buen estado del muelle. Los recubrimientos estimados estaban en el entorno de $10,5 \mathrm{~cm}$. Se midieron concentraciones de cloruros altas, entre 1,5-1,9\% en masa de 
hormigón seco a $10 \mathrm{~cm}$ de profundidad. El análisis petrográfico sugirió una relación a/c comprendida entre 0,5 y 0,7. No había indicios de reacción álcali sílice o ataque por sulfatos ${ }^{43}$.

Se llevó a cabo una nueva inspección en 2001, para caracterizar los materiales e inspeccionar 100 de los 145 arcos del muelle. Asimismo, se realizaron medidas de potencial de media pila y velocidad de corrosión. Finalmente, se extrajeron testigos para la determinación de propiedades físicas y químicas del hormigón: contenido de cloruros, contenido de huecos totales, resistividad eléctrica y resistencia a compresión ${ }^{43}$.

En la citada inspección visual se detectaron fisuras de abertura superior a 3mm en seis de los arcos. Dichas fisuras eran de origen estructural y no resultado de la corrosión ${ }^{43}$.

Las medidas de resistividad eléctrica realizadas oscilaban entre 0,5 y $2,5 \mathrm{k} \Omega$, valor típico para un hormigón expuesto a un ambiente agresivo y que sugiere riesgo elevado de corrosión. El contenido total de poros se estimó entre 19 y $24 \%$. La carbonatación era prácticamente inexistente. Los valores de resistencia a compresión se encontraban entre 24 y $35 \mathrm{MPa}$, acorde con el contenido de huecos obtenido. La concentración de cloruros en peso de cemento oscilaba entre 1,0$2,5 \%$, valores elevados debidos al efecto acumulativo durante 60 años $^{43}$.

A continuación se aporta un perfil de concentración de cloruros del estudio realizado $^{43}$ (fig.4.41):

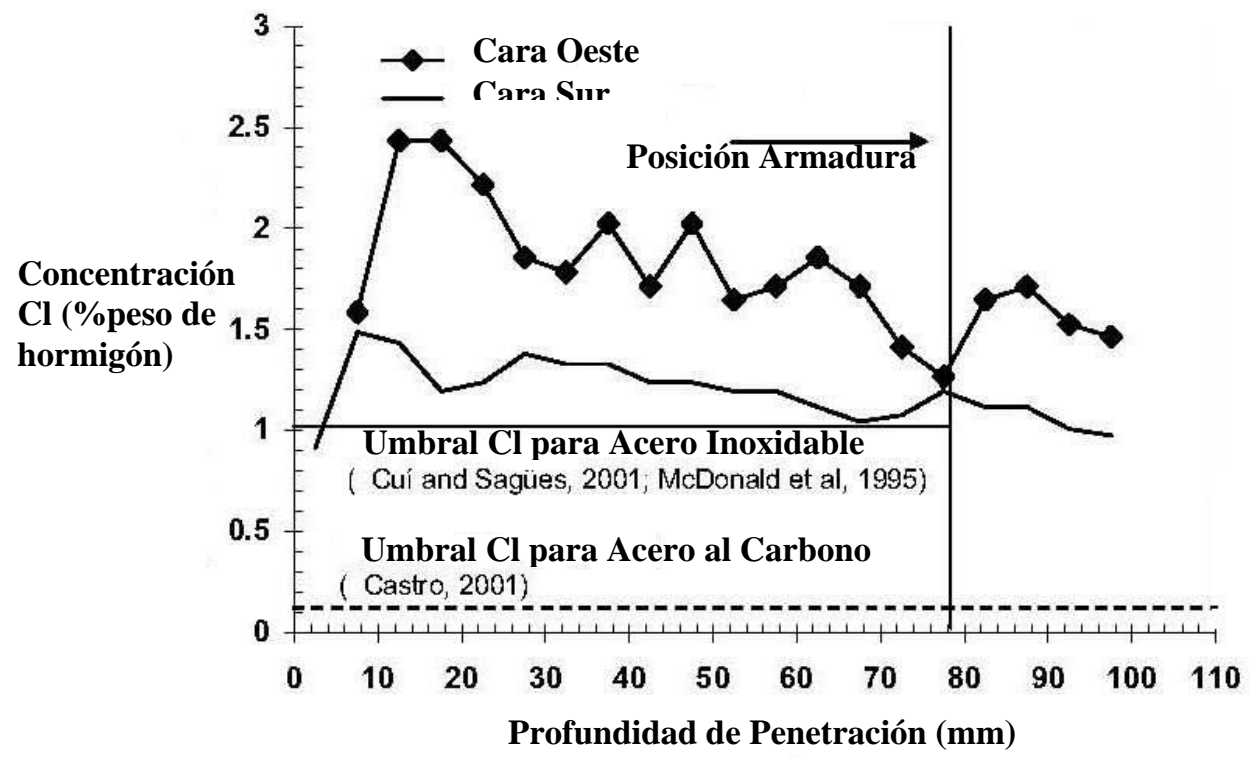

Fig.4.41. Perfiles de concentración de cloruros del voladizo 9. 
Como se ha podido observar, las concentraciones de cloruros en el hormigón han alcanzado los valores de umbral del acero inoxidable para que se inicie la corrosión, afectando a algunos voladizos, no existiendo daños por corrosión tras más de 60 años de puesta en servicio. Sin embargo, según los ensayos de capacidad de carga realizados (estáticos, dinámicos y de carga aleatoria), los síntomas de deterioro principal estaban relacionados con las cargas, que son unas diez veces mayores que las inicialmente pensadas para la vida útil del viaducto del muelle. A pesar de ello, a la vista de las medidas electroquímicas obtenidas cabe pensar que la estructura se encuentra en estado activo de corrosión ${ }^{43}$.

\subsection{TÉCNICAS DE REPARACIÓN. TRATAMIENTO DE HORMIGÓN DETERIORADO.}

\subsubsection{Técnicas de reparación}

Aunque no es este el objeto del presente trabajo de investigación, se pueden esbozar cuáles son los métodos empleados en la reparación de la corrosión en estructuras situadas en ambiente marino aéreo.

Los métodos de reparación se usan temporalmente para extender la vida útil de una estructura sin el gasto de una mayor rehabilitación. Las reparaciones tratan de restaurar el nivel de funcionalidad sin detectar la causa del deterioro. En el caso de reparación de tableros de puentes se plantean dos tipos: el parcheo y la aplicación de nuevas capas sobre el tablero ${ }^{15}$.

Los métodos de reparación de la corrosión quedan recogidos por la norma DD ENV 1504-9 y se dividen en los siguientes grupos²:

- Preservar o restaurar la pasividad

- Aumentar la resistividad

- Control Catódico

- Protección catódica o prevención catódica

- Control de zonas anódicas

- Retirada de capa superficial de hormigón contaminado $2,5,15$

El hecho de sustituir el hormigón contaminado por cloruros es el método de reparación más empleado. Como consecuencia de la corrosión, el hormigón puede presentar expulsiones de recubrimiento y delaminaciones. 
El parcheo puede ser parcial o total dependiendo del alcance del deterioro. La reparación parcial requiere la retirada mínima de $2 \mathrm{~cm}$ por encima de la capa de armadura superior y por otro lado, la reparación total no debe superar la mitad del espesor del elemento reparado

El procedimiento podrá variar según la calidad de la superficie, las condiciones de la estructura así como las restricciones de acceso y seguridad, pero en general incluirá: limpieza de la superficie, inspección para localización de defectos, eliminación del hormigón, preparación de la armadura y rehabilitación.

Los materiales normalmente empleados en este tipo de reparaciones son hormigón de cemento Pórtland, morteros y hormigones hidráulicos así como modificados mediante polímeros ${ }^{15}$.

Se trata sólo de soluciones a corto plazo, ya que no atacan la base del problema y el proceso de corrosión de las armaduras continúa, pudiendo incluso incrementarse ya que la zona parcheada resulta ser un cátodo rodeada de zonas anódicas activas. Por este motivo, se valora la posibilidad de introducir pequeños cubos de zinc dentro de las zonas reparadas a modo de ánodos de sacrificio, lo que vuelve a resultar un remedio temporal hasta que estos cubos se consuman ${ }^{15}$.

En el caso estudiado ${ }^{5}$ se retira completamente la capa superficial de hormigón deteriorado y contaminado por cloruros hasta una profundidad más allá de la armadura (mínimo $2 \mathrm{~cm}$ ) y se reemplaza con un hormigón nuevo y de alta calidad. De este modo se restaura la capa pasiva y se frena el proceso anódico. Además de efectiva, es una técnica bastante económica.

- Colocación de capas de hormigón sano ${ }^{15}$

Puede emplearse como método de reparación o de rehabilitación. Cuando se trata de reparación, las capas deben situarse sobre la superficie de hormigón sano que no se haya deteriorado como consecuencia de la corrosión. El motivo por el que se colocan estas capas es para reducir la permeabilidad del hormigón y aumentar la profundidad de recubrimiento, lo que a su vez aumenta la distancia que los cloruros deben difundir para alcanzar la armadura ${ }^{15}$. 
Pueden ser de hormigón modificado con látex, de hormigón de baja densidad, de hormigón tratado con polímeros, de hormigón con microsílice o mezcla de hormigón tratado con productos bituminosos y membranas. Según el tipo de capa aplicada, se puede incrementar la vida útil de la estructura por encima de 25 años (Weyers et al, 1993). Por otro lado, hay que tener en cuenta que la aplicación de esta medida supone el aumento de la carga muerta que soporta la estructura, lo que se traduce en un descenso de la capacidad de carga de la misma a lo largo de su vida útil. Además, si la estructura ya presenta un nivel crítico de cloruros, la colocación de una de estas capas sólo supondrá un escaso aumento de la vida útil por la reducción del contenido de humedad del hormigón inferior ${ }^{15}$.

Limitaciones de este método son la falta de adherencia entre capas, la fisuración por retracción de la propia capa y la determinación del tiempo apropiado para la_instalación de una capa. Como técnica de reparación, la capa más aplicada es la de hormigón tratado con polímeros ${ }^{15}$.

- Elementos de control y medida ${ }^{2,5}$

Para vigilar las reparaciones realizadas, es conveniente medir la penetración de cloruros en la estructura a lo largo de un periodo de tiempo posterior a la actuación con el fin de comprobar que ha sido efectiva. Así en un muelle estudiado ${ }^{5}$ se realizaron medidas de penetración de cloruros durante cinco años y se consiguió establecer la predicción a 20 años, comprobando que los daños no eran significativos durante la vida útil requerida por la estructura.

También pueden colocarse otros elementos para el control y la medida de la corrosión, como electrodos de referencia para monitorizar el potencial electroquímico de la armadura, sensores de temperatura y resistividad y sensores de macro-celda para controlar la aparición de la corrosión, ya que colocados a distintas profundidades en el recubrimiento, permiten medir la penetración de la concentración crítica de los cloruros.

En el caso de los tendones deteriorados de los embarcaderos, es necesario fortalecer el elemento estructural. Para ello, se aplica una capa de $20 \mathrm{~cm}$ de espesor de hormigón in situ de buena calidad $(\mathrm{a} / \mathrm{c}=0,30$; contenido cemento $=400 \mathrm{~kg} / \mathrm{m3}$; adición de microsílice $=40 \mathrm{~kg} / \mathrm{m3}$ ) y barras de armar convencionales. Por razones económicas, no se interviene en las vigas. 
Para proteger éstas así como otros elementos en carrera de marea, debería colocarse un sistema de protección catódica a corto plazo 5 .

La estrategia de reparación adoptada en el puente ${ }^{5}$ fue un parcheo local con mortero seguido de aplicación de capas protectoras. Los principios básicos de esta reparación consisten en frenar el proceso anódico donde la armadura se está corroyendo, aplicar una barrera superficial de control de entrada de agentes agresivos y limitar el contenido de humedad del hormigón. La protección impermeable al agua resulta básica, ya que no se puede asegurar la retirada de todo el hormigón contaminado. Si dicha protección es permeable al vapor de agua, permite el secado del hormigón elevando así su resistividad y controlando el proceso de conducción electrolítica de la corrosión.

\subsubsection{Tratamiento del hormigón deteriorado}

El primero de los principios que se trata es preservar o restaurar la pasividad. Es cualquier método que retrase o detenga la carbonatación o restaure la alcalinidad o bien que reduzca el contenido de $\mathrm{Cl}^{-}$o su penetración (Parcheo de hormigón, realcalinización por difusión o métodos electro químicos).

El parcheo con hormigón puede consistir en el aumento del recubrimiento con hormigón o mortero o en la sustitución completa del hormigón carbonatado o con ataque de $\mathrm{Cl}$-. En cuanto al material a emplear, si es para una pequeña reparación, podrá ser de preparación in situ; si es para un gran volumen, se empleará hormigón convencional, proyectado, inyecciones...El revestimiento que se emplee deberá ser resistente a los agentes causantes de la corrosión, al ambiente, presentar un aspecto adecuado y requerir un mantenimiento aceptable. En ocasiones, resulta complicada la sustitución completa del hormigón, pero en algunos casos, una reparación localizada podría fomentar una mayor corrosión.

La realcalinización por difusión es un método adecuado cuando la carbonatación es limitada (penetración $<10 \mathrm{~mm}$ ) y consiste en la aplicación de un hormigón o mortero alcalino en la superficie.

Los métodos electroquímicos son la realcalinización electroquímica (restaura la alcalinidad alrededor del acero; cuestionada por su alcance y duración, consiste en aplicar protección extra al hormigón) y la extracción electroquímica de $\mathrm{Cl}^{-}$(por medio de una corriente se fuerza a los $\mathrm{Cl}^{-}$a ir hacia el ánodo, no 
permite extraer los $\mathrm{Cl}^{-}$que están tras la armadura y supone aplicar elevadas corrientes sin garantías de extraer totalmente los $\mathrm{Cl}^{-}$), también la protección catódica que se tratará como un principio de reparación.

El segundo principio de reparación sería aumentar la resistividad. Se trata de limitar el contenido de humedad del hormigón mediante la colocación de revestimiento como capa protectora, aplicación de impregnación hidrófuga que repela el agua o aislamiento del hormigón en casos de carbonatación o ataque leve por $\mathrm{Cl}^{-}$.

El tercer principio es el control catódico. Consiste en controlar la reacción catódica restringiendo el acceso del oxígeno. Es un método no probado.

El cuarto principio es la protección o prevención catódica. Supone asegurar que el acero se polarice lo suficiente para que no haya corrosión. Lo más común es fijar otros ánodos que sean el foco de ataque y proteger así a la armadura (protección catódica de sacrificio). Otro método es la aplicación de corriente impresa. En general, es difícil la distribución uniforme de corriente y se desconoce su efecto en las estructuras pretensadas.

El último de los principios de reparación es el control de ánodos. Para pequeñas aplicaciones, puede emplearse el uso de pinturas para revestimiento con pigmentos activos o revestimiento barrera. Otro método sería la aplicación de inhibidores de corrosión para reducir la velocidad de corrosión (pueden ser anódicos, catódicos o ambióticos).

Como conclusión, la protección catódica es un método que funciona bien, pero el método más simple y efectivo es la sustitución del hormigón deteriorado.

La rehabilitación se diferencia de la reparación en que la primera buscar restaurar la estructura hasta un nivel aceptable detectando la causa del deterioro, mientras que la segunda no busca dicha causa. Los principales métodos de rehabilitación son la aplicación de capas sobre tableros y la protección catódica ${ }^{15}$.

Como ya se ha citado, las capas cuando se usan como método de reparación se sitúan sobre el hormigón sano. Cuando un tablero de un puente refleja daños significativos, estas áreas se reparan antes de la aplicación de las capas y esto se considera rehabilitación. Aquellas áreas que experimentan corrosión 
activa, que están deterioradas o que tienen concentración crítica de cloruros deben retirarse y reemplazarse antes de la instalación de la capa. Esto permite detectar la causa del deterioro que es la corrosión de la armadura. De este modo, la corrosión futura se retrasa debido al incremento del recubrimiento y a la reducción de la permeabilidad. Se ha estimado que las capas empleadas en rehabilitación de tableros de puentes pueden proporcionar más de 70 años de vida adicional (Weyers et al, 1993) ${ }^{15}$.

Otro modo de rehabilitación es la protección catódica. Se diferencia de la prevención catódica en que se emplea en estructuras que ya presentan corrosión. Como protección catódica se colocan ánodos de titanio dentro del hormigón y se introduce una corriente para reducir el potencial de corrosión hasta un nivel donde la corrosión se ralentice o se pare. Si dicha corriente es suficientemente fuerte, la armadura restablecerá su pasividad y frenará la corrosión. La protección catódica se ha probado como un medio efectivo de rehabilitación de estructuras de hormigón con altas concentraciones de cloruros sin tener que acudir a una mayor rehabilitación. El_problema asociado a este método es que la incorporación de este tipo de sistemas tiende a ser costosa y requiere monitorización constante ${ }^{15}$.

\subsection{CONCLUSIONES. ASPECTOS EN LOS QUE ES NECESARIA LA INVESTIGACIÓN}

\subsubsection{Conclusiones}

\section{Ambiente Marino Aéreo}

La corrosión es la primera causa de deterioro en estructuras costeras de hormigón armado y pretensado, aspecto de especial importancia en países con una gran longitud de costa, como España.

El Ambiente Marino Aéreo (IIla), según la Instrucción EHE, corresponde a elementos de estructuras marinas por encima del nivel de pleamar o a elementos exteriores de estructuras situadas en las proximidades de la línea costera (a menos de $5 \mathrm{~km})^{3}$. Este ambiente marino es el de menor agresividad según la Instrucción, en comparación con los ambientes III b y IIIc.

En Japón ${ }^{7}$, la normativa presenta una clasificación del ambiente marino aéreo más detallada, incluyendo a su vez distintos subambientes. Así, el designado como ambiente marino aéreo I es el de mayor agresividad abarcando estructuras por 
encima del mar y situadas a una distancia hasta $100 \mathrm{~m}$ de la costa en zona de vientos de tormenta o tifones. En este ambiente se exigen valores de recubrimiento entre 50 y 70 mm frente a los 25-45 mm (50 años de vida útil) ó 30-65mm (100 años de vida útil) pedidos por la Instrucción EHE para el ambiente IIla.

La correcta clasificación de ambientes para exigir requisitos de durabilidad al hormigón cobra especial importancia en pantalanes portuarios, en los que parte de la estructura se sitúa encima del nivel de pleamar (zona de salpicaduras y zona de spray) y también en la propia línea de costa. Se plantea incertidumbre si sería conveniente para estas estructuras (que actualmente son clasificadas en ambiente IIla) establecer una definición de subambientes más precisa, como el caso japonés.

\section{Factores que influyen en la corrosión. Importancia de la ejecución}

Los factores que intervienen en la corrosión de la armadura en el hormigón son múltiples, siendo los principales la calidad del recubrimiento (espesor, a/c) y el microclima en la superficie expuesta. Estos factores conocidos son objeto de requisitos específicos en las normativas internacionales. Sin embargo, no puede decirse que por sí sola una relación a/c baja asegure una velocidad lenta de corrosión. Así, se han encontrado estudios ${ }^{50}$ en los que se comprueba que hormigones con muy baja relación a/c pero con presencia de algún defecto, fisura, junta mal ejecutada, etc. presenta altas velocidades de corrosión por formación de macropilas, superiores a las que experimentan hormigones de elevada a/c sin defectos, en los que la corrosión se establece por formación de micropilas.

Los aspectos de diseño y las prácticas de construcción juegan un papel importante $^{8}$ en la corrosión. En estudios ${ }^{37}$ específicos se demuestra claramente que el factor crítico es la ejecución en obra. Las causas de estos defectos son principalmente:

a) Recubrimiento de hormigón insuficiente

b) Cambios geométricos en las paredes de hormigón

c) Compactación insuficiente del hormigón de recubrimiento (nidos de grava ${ }^{5}$ )

d) Juntas de construcción mal ejecutadas ${ }^{5}$

e) Falta de drenaje ${ }^{5}$. Este es un aspecto a cuidar en todo tipo de estructuras, pero de modo especial en lugares ocultos o de difícil acceso. Aún de una forma más significativa en el caso de las estructuras pretensadas, por el riesgo de desarrollar corrosión bajo tensión. 
f) En estructuras con encofrado deslizante, inadecuada (demasiado baja) velocidad de elevación de partes de compleja geometría, partes con inserciones o con grandes cantidades de armadura.

\section{Modelización de la fase de Iniciación}

La corrosión por cloruros se compone de dos fases: iniciación y propagación. E presente estudio se centra en la fase de iniciación, que puede modelizarse según la segunda ley de Fick. Dado que los cloruros siguen distintos mecanismos de penetración, el coeficiente de difusión " $D$ " debe considerarse como una constante de difusión APARENTE². Así en el caso de un hormigón situado en aire húmedo (IIIa), los procesos de transporte de gases, agua o sustancias disueltas en agua son procesos de difusión, en función de la humedad del aire. En el caso de hormigón con la superficie mojada por agua, es la succión capilar el mecanismo de penetración de cloruros dominante².

Los factores que normalmente intervienen en estos modelos de difusión para la predicción de vida útil son la concentración de cloruros en superficie, el espesor de recubrimiento, el coeficiente de difusión de cloruros y el umbral de cloruros, es decir la concentración de cloruros requerida para que se inicie la corrosión ${ }^{14}$.

El valor del coeficiente de envejecimiento es objeto de controversia y hay propuestos valores diferentes en la literatura. Hay fuentes que, en función del tipo de cemento utilizado, le asignan un valor entre 0,30 (Pórtland) y 0,60 (C.con cenizas). La Instrucción EHE adopta un valor único de 0,5. Estudios sobre obras reales realizadas en Noruega ${ }^{37}$, adoptaron $\alpha=0,6$. Asimismo, con el fin de validar la robustez de esta elección, se realizaron cálculos paralelos con $\alpha=0,50$, con muy poca influencia en los tiempos de iniciación calculados ${ }^{37}$.

La Instrucción EHE propone, para el caso del ambiente marino aéreo (IIla) y hasta una distancia de $500 \mathrm{~m}$ desde la costa, una concentración de cloruros en superficie $^{3}$ de 0,14 (\%peso de hormigón) (tabla A.9.4 del Anejo $9^{\circ}$ de la Instrucción). Para estructuras en zona de salpicaduras (IIIc) asigna un valor de 0,50 (\%peso de hormigón). Por otro lado, según estudios noruegos ${ }^{37}$ realizados con testigos de más de dos años de exposición en plataformas offshore (lo que supone niveles de $C_{S}$ estables) se obtiene un valor medio de $C_{s}$ de 0,63 (\%peso de hormigón), con una desviación estándar de $0.43 \%$. En dicho estudio se analizó la influencia de las condiciones locales de exposición (altura sobre el nivel del mar y dirección del viento dominante), con variaciones poco significativas. En Japón ${ }^{7}$ 
se ha desarrollado una fórmula que permite determinar los cloruros en superficie, en función de la distancia a la costa, a partir de datos tomados entre $1 \mathrm{~m}$ y $5000 \mathrm{~m}$. Según este modelo los cloruros en superficie oscilan entre $0,18 \%$ ( $1 \mathrm{~m}$ de distancia), 0,040\% (500m de distancia) y 0,023\% (5km de distancia). Extrapolando, se obtendría el valor de $0,63 \%$ obtenido en el estudio noruego ${ }^{37}$ para una distancia de $3 \mathrm{~cm}$. Los valores citados que plantea la Instrucción EHE (0,14\% entre 0-500 m y $\quad 0,07 \%$ entre $500-5000 m$ ) resultarían conservadores frente a los valores obtenidos por el modelo de Japón, excepto para estructuras sobre el nivel del mar, en las que el modelo japonés asigna un valor de $0,18 \%$ frente al $0,14 \%$ de la Instrucción EHE, y de acuerdo con el estudio noruego valdría 0,63\%. Se plantea por tanto la incertidumbre sobre el valor de 0,14\% para estructuras en la línea de costa o sobre el mar (pantalanes portuarios).

Por otra parte, el contenido de cloruros debe limitarse en el hormigón. A pesar de que los más peligrosos frente al ataque por corrosión son los cloruros libres, la mayoría de las normativas limitan el contenido de cloruros totales, ya que una simple bajada del pH del hormigón podría liberar cloruros combinados, pasando a ser libres y así susceptibles de producir corrosión².

En el ya citado estudio noruego ${ }^{37}$, se consideró un umbral de cloruros de 0,4 (\%peso de cemento) como la cantidad de cloruros que inicia la corrosión activa (probabilidad mínima) cuando dicha concentración se alcanza dentro del recubrimiento. En el intervalo $(0,4-1,0 \%)$ la probabilidad de corrosión de la armadura se estima posible. La Instrucción $\mathrm{EHE}^{3}$ adopta un valor de 0,6 (\%peso de cemento) para el caso del hormigón armado y 0,3 para el hormigón pretensado. Por tanto también aquí surge la incertidumbre sobre si este valor resultaría conservador aplicado al caso de pantalanes portuarios

En cuanto a los modelos de difusión propuestos en la literatura (determinación del coeficiente de difusión de acuerdo con la calidad del hormigón), en general estos modelos son únicos, cualquiera que sea el ambiente marino considerado. Tan sólo el modelo Bermúdez-Alaejos determina un coeficiente de difusión diferente para ambiente sumergido (mayor velocidad de ingreso de cloruros) y de carrera de mareas (menor velocidad). Se plantea, por tanto, la necesidad de determinar la velocidad de difusión de cloruros en el ambiente marino aéreo, y compararla con la ya obtenida en el resto de ambientes. 


\subsubsection{Aspectos en los que es necesaria la investigación}

De acuerdo con el estudio bibliográfico realizado sobre la corrosión de las armaduras del hormigón en ambiente marino aéreo, se detectan los siguientes campos en los que es necesaria investigación complementaria:

a) Definir subambientes marinos de aplicación a las estructuras situadas sobre el nivel del mar o situadas en la línea de costa, en particular la zona de salpicaduras y zona de spray o niebla salina.

b) Determinar los requisitos del hormigón en estos subambientes (contenido de cemento y relación a/c) y contrastarlos con los actualmente recogidos por la normativa.

c) Establecer requisitos específicos del control de ejecución para estructuras situadas en ambientes agresivos como el ambiente marino.

d) Revisar los parámetros a adoptar en la modelización de cloruros en ambiente marino aéreo, incluyendo zona de salpicaduras y zona de spray: cloruros en superficie y umbral de cloruros.

e) Desarrollar un modelo de difusión específico para predecir el avance de cloruros en ambiente marino aéreo (incluyendo zona de salpicaduras y zona de spray) que represente todos los mecanismos de transporte presentes (coeficiente de difusión aparente). 
ESTADO DEL ARTE 


\section{ESTUDIO EXPERIMENTAL SOBRE DIFUSIÓN DE CLORUROS EN PANTALANES}

\subsection{INTRODUCCIÓN}

El objetivo de la presente tesis doctoral ha sido analizar el comportamiento del hormigón armado empleado en la construcción de pantalanes portuarios (en adelante, pantalanes $A, B, C$ y D) situados en ambiente marino aéreo (este tipo de ambiente, según definición de la EHE-08 afecta a estructuras situadas sobre el mar o en la franja costera hasta $5 \mathrm{~km}$ ). Los hormigones empleados presentan distintas dosificaciones, dado que se han fabricado atendiendo a las distintas normas vigentes en el momento de su construcción. Sus edades también son diferentes (37, 26, 11 y 11 años, respectivamente) y se encuentran ubicados en puertos españoles de ubicación geográfica distinta (Mar Mediterráneo, Océano Atlántico y Mar Cantábrico).

El presente estudio experimental comienza por el análisis de la información correspondiente a la fabricación del hormigón así como los datos recabados del proyecto de construcción del pantalán. A continuación, se realiza una inspección del estado de la estructura para observar el aspecto de hormigón y armaduras así como detectar posibles síntomas de corrosión. Tras la inspección, se ubican los puntos elegidos para la extracción de testigos. En algunos casos, se efectúan medidas de la velocidad de ultrasonidos in situ con el fin de realizar una primera aproximación a los valores de resistencia del hormigón empleado. También se llevan a cabo medidas electroquímicas de la corrosión para conocer el riesgo potencial de corrosión. Con estas medidas in situ, se determinan las zonas que se consideran más idóneas para la extracción de testigos que caracterizarán el muelle. Una vez extraídos los testigos, se procede a su inspección en laboratorio y a su distribución en rodajas para la realización de los ensayos de caracterización del hormigón: contenido de cloruros, resistencia a compresión, velocidad de propagación de ultrasonidos, penetración de agua, porosidad abierta, absorción de agua por inmersión, absorción de agua por capilaridad y permeabilidad al oxígeno, además de la estimación del módulo de elasticidad y de la permeabilidad al agua utilizando los resultados de algunos de los anteriores ensayos. Además, se determina el perfil de cloruros para el cálculo posterior de los coeficientes de difusión y el análisis de su relación con las diferentes propiedades mecánicas y de durabilidad del hormigón ensayadas anteriormente. 
Todo ello con el fin de obtener un ensayo que indirectamente nos permita caracterizar la durabilidad de forma fiable y un modelo D-a/c apto para predecir la vida útil de una estructura de hormigón fabricado con una dosificación determinada y sometido al ambiente IIIa.

\subsection{DESCRIPCIÓN DE LOS PANTALANES OBJETO DE ESTUDIO}

La descripción de los cuatro muelles se realiza a partir de los datos de proyecto recabados en cada caso (dimensiones, tipología, detalles...) así como del hormigón empleado en su fabricación (resistencia característica, relación a/c, etc.). En los casos en los que existen, se aportan datos correspondientes al control de calidad realizado durante la ejecución de los muelles.

\subsubsection{Muelle A}

El muelle A está constituido por un pantalán que da acceso a tres plataformas de operación (plataformas A, B y C) a dos niveles, 17 Duques de Alba (2 junto a la plataforma $A ; 4$ junto a la plataforma $B ; 6$ junto a la plataforma $C ; 3$ junto al acceso principal, entre las plataformas $A$ y $B ; 2$ junto al acceso principal, entre las plataformas $B$ y C), y las correspondientes pasarelas de acceso. En la figura 5.1 se puede observar una vista aérea del pantalán. 


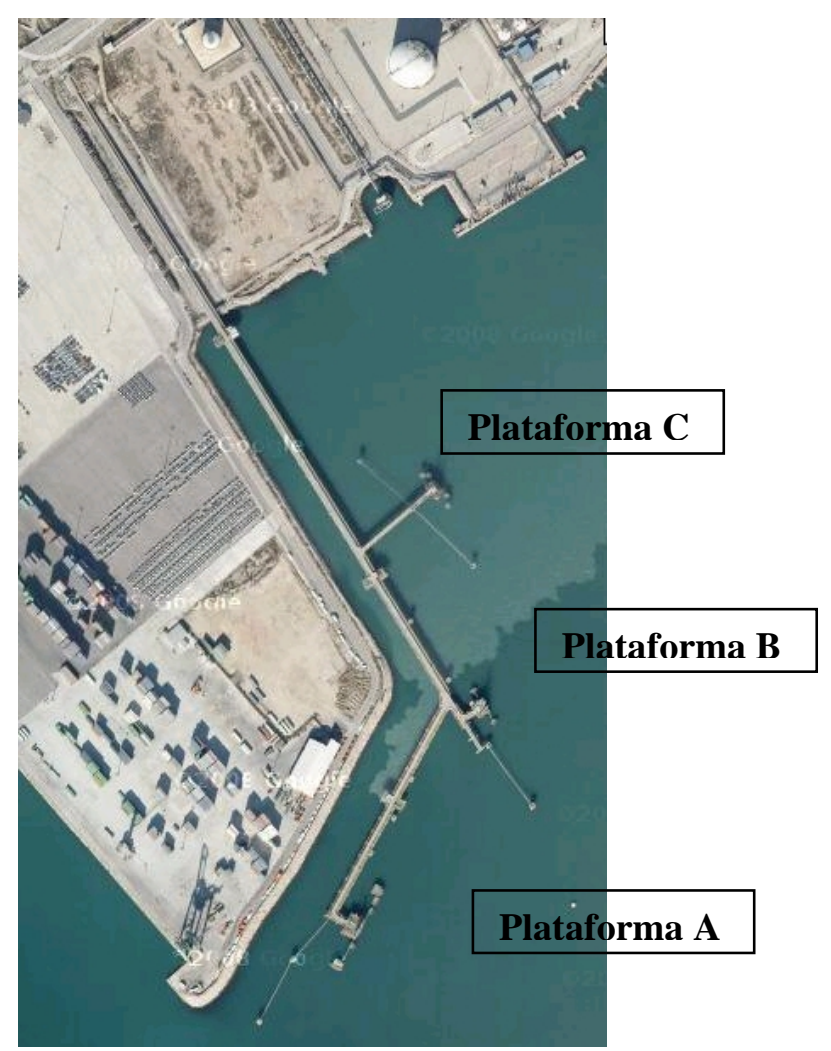

Fig.5.1. Vista aérea del muelle A.

El Proyecto original de construcción del pantalán del Muelle A está visado en el año 1967, aunque existen otros planos del año 1971, que probablemente coincidan con el final de las obras. El acceso principal tiene una longitud de 993,5 m, de los cuales se encuentran sobre tierra firme los primeros $255 \mathrm{~m}$; el acceso a la plataforma A, 25,0 m; el acceso a la plataforma B, 60,0 m; finalmente, el acceso a la plataforma $C$ tiene una longitud de 75,0 m.

Todas las estructuras van apoyadas sobre pilotes metálicos inclinados, con un calado variable de hasta 14,3 m. En la figura 5.2 se adjuntan las dos secciones tipo del pantalán (la general y la de acceso a plataforma), en la figura 5.3 se aporta la sección tipo del pantalán y traviesas normales y por último en la figura 5.4 se aporta el alzado y vista superior de los Duques de Alba. 

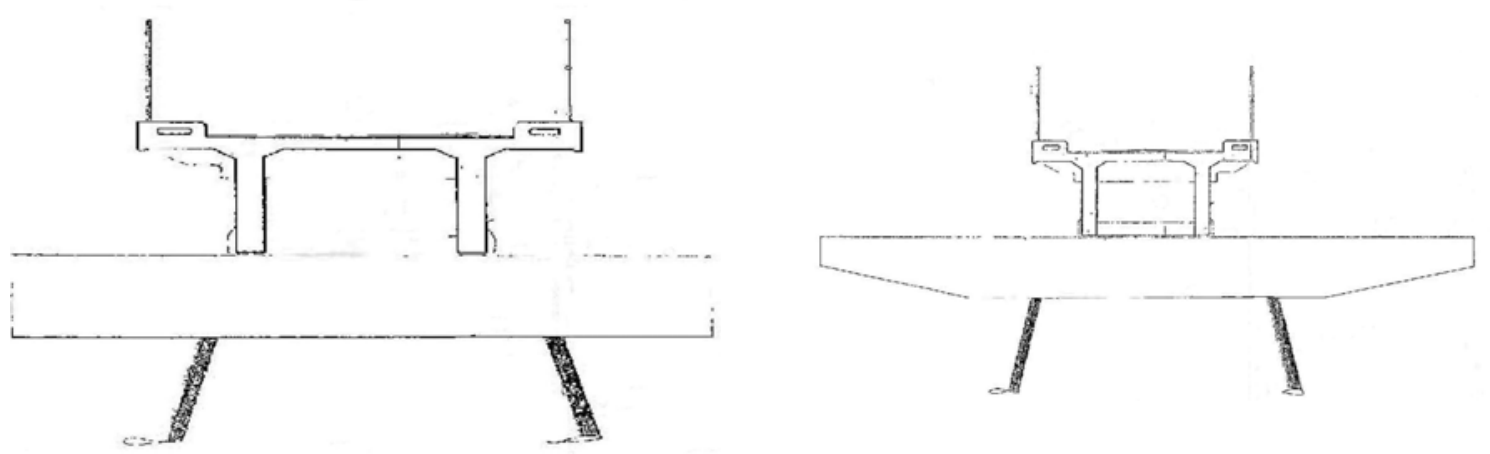

Fig.5.2. Sección tipo del pantalán en su acceso a las plataformas (izquierda) y en caso general (derecha).

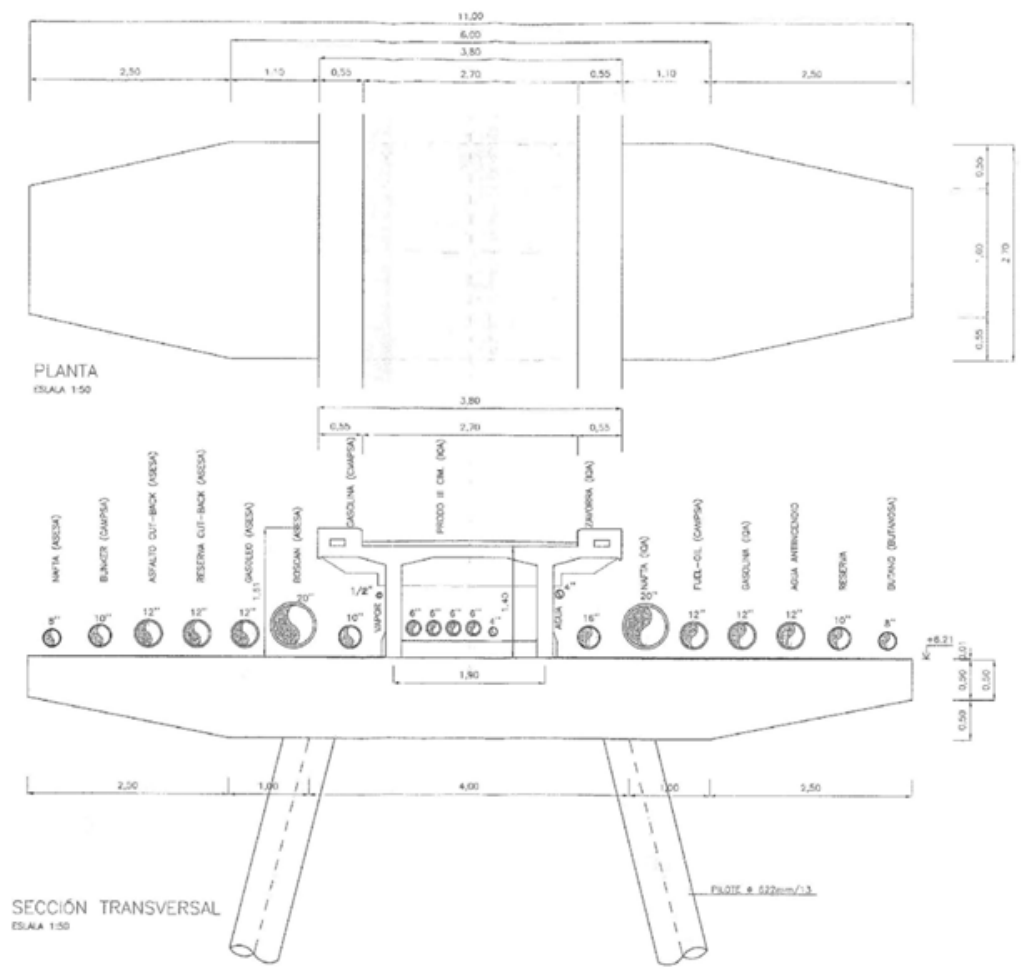

Fig.5.3. Sección tipo del pantalán y traviesas normales. 

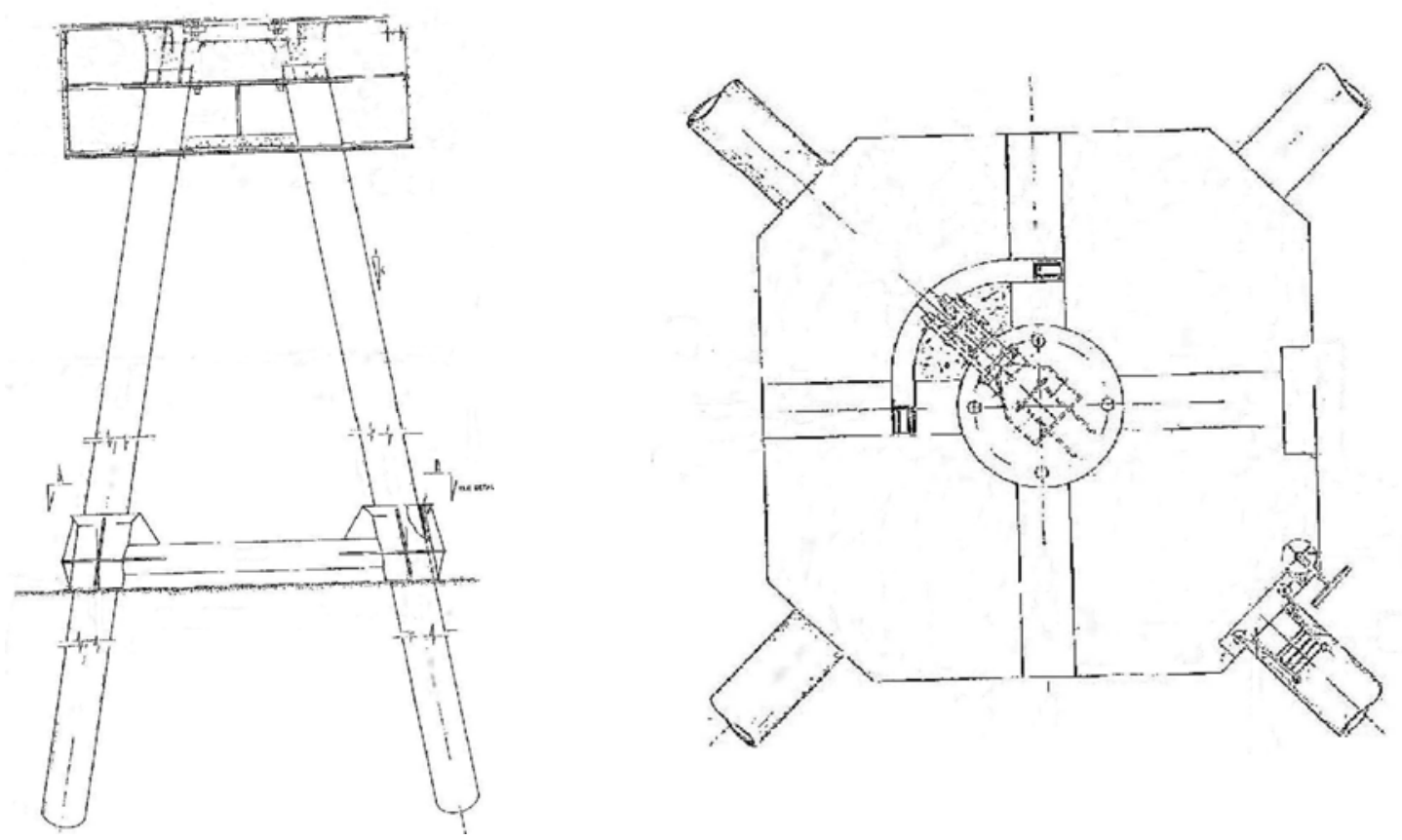

Fig.5.4. Alzado de los Duques de Alba (izquierda). Vista superior (derecha).

Los pilotes metálicos sobre los que apoyan las estructuras no se han inspeccionado por no ser objeto del presente estudio.

No se dispone de la Memoria del Proyecto ni del Pliego de Prescripciones Técnicas Particulares, así que toda la información existente se encuentra en los Planos del pantalán. Los accesos a las plataformas constan de una losa apoyada en forma de "U" invertida, apoyada sobre 80 vigas traviesas pretensadas de $11 \mathrm{~m}$ de longitud, 2,70 $\mathrm{m}$ de anchura máxima y $1 \mathrm{~m}$ de altura (figura 5.3); la localización de los tendones de pretensado no está claramente definida en los planos encontrados. Las plataformas se componen de chapas y perfiles metálicos fundamentalmente, pero también hay losas de hormigón armado.

Finalmente, los Duques de Alba están formados por pilares metálicos sobre los que apoya una losa de planta cuadrada achaflanada, de 3,3m de lado y 2,0 m de altura (figura 5.4).

No existen datos del control de calidad del pantalán.

Respecto a la climatología, el pantalán está prácticamente alineado con la dirección noroeste-sureste y en la zona en la que se encuentra (Mar Mediterráneo), la carrera de marea es prácticamente nula. 


\subsubsection{Muelle B}

El Muelle B se terminó de construir en el año 1981 y tiene una longitud de $902 \mathrm{~m}$. Está formado por 19 módulos, constituido cada uno por una losa de 20,39 metros de ancho (28,50 en los módulos 18 y 19) y $80 \mathrm{~cm}$ de espesor, sobre pilotes de hormigón prefabricados y postesados; sobre estos pilotes apoyan cabeceros continuos de 0,70 m de altura y 2,50 m de sección, sobre las que a su vez apoya la losa. Longitudinalmente se dispone una viga de cantil y tres vigas carril para las grúas, que están embebidas en la losa, por lo que también apoyan directamente sobre las vigas transversales. En la alineación longitudinal correspondiente a la última viga carril, hay un pilote de hormigón intermedio entre cada dos pilotes, con un cabecero aislado cuadrado de 0,70 $\mathrm{m}$ de altura y 2,5 $\mathrm{m}$ de lado sobre el que a su vez apoya la losa (en el caso de los módulos 18 y 19, los pilotes se duplican en las dos últimas alineaciones horizontales). En la figura 5.5 puede verse una sección tipo de la estructura frontal. En la figura 5.6 se aporta una fotografía del pantalán visto desde el módulo 19.

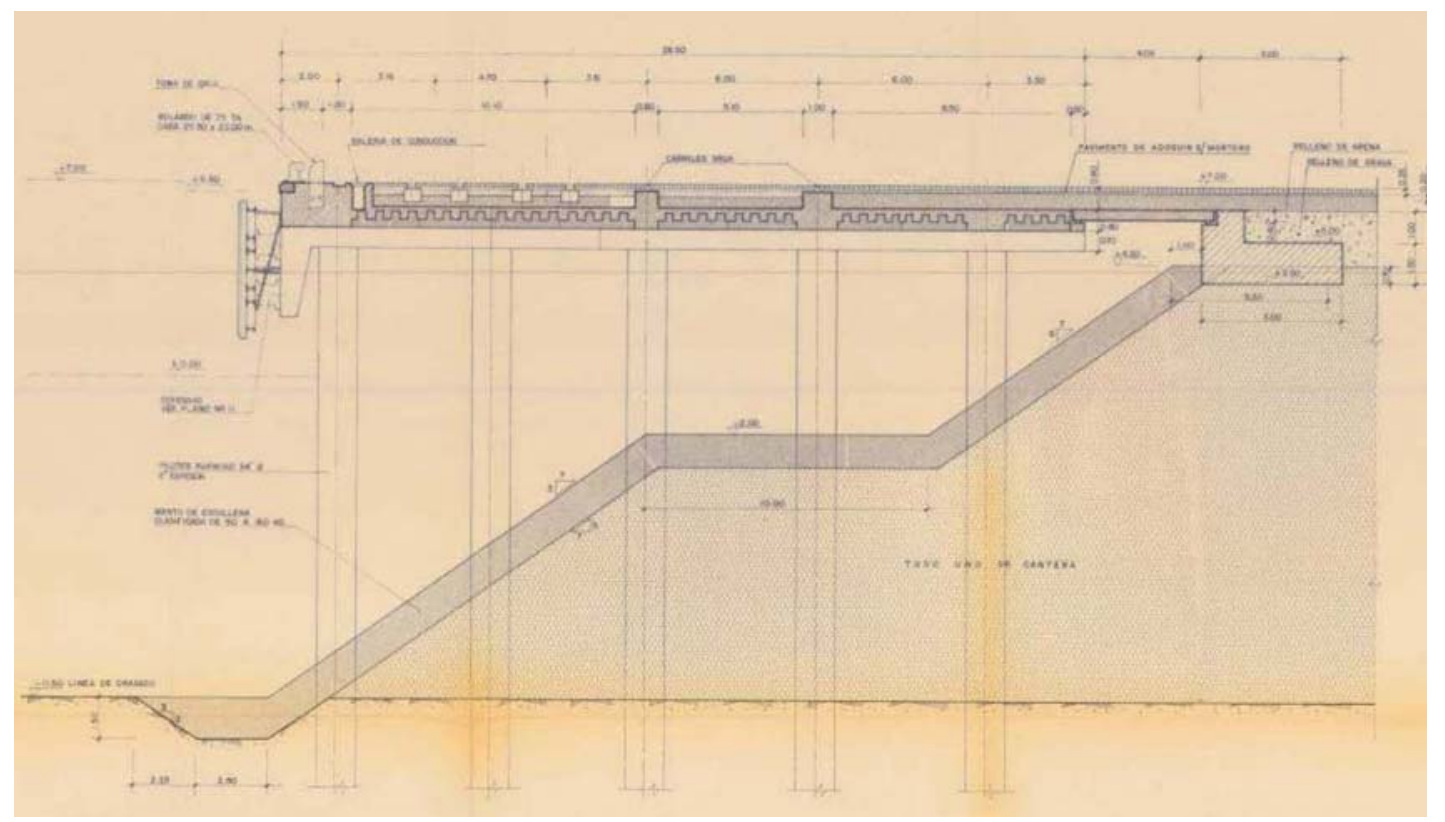

Fig.5.5. Sección tipo del muelle B. 


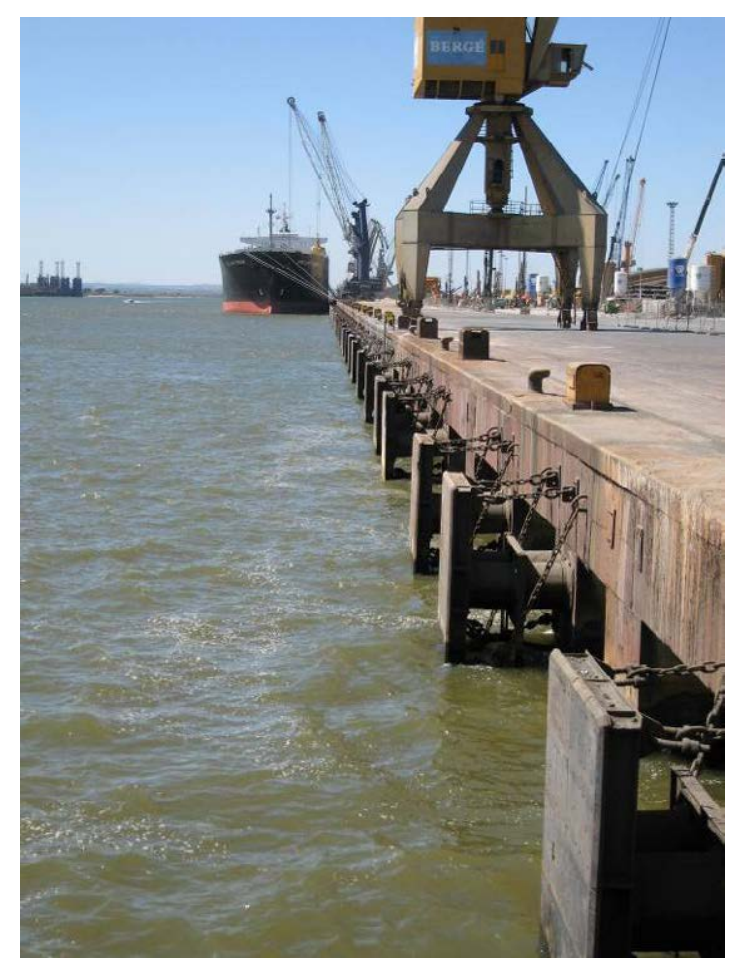

Fig.5.6. Vista frontal del pantalán desde el módulo 19.

Los pilotes prefabricados sobre los que apoyan las estructuras no se han inspeccionado por no ser objeto del presente estudio.

En cuanto a las características del proyecto, el hormigón de los cabeceros y de la losa tiene una resistencia característica de $300 \mathrm{kp} / \mathrm{cm}^{2}$, con un contenido de cemento de $300 \mathrm{~kg} / \mathrm{m}^{3}$, siendo el cemento Pórtland tipo P-350. El recubrimiento es de $5 \mathrm{~cm}$ y el límite elástico del acero corrugado es $4.200 \mathrm{kp} / \mathrm{cm}^{2}$.

La armadura inferior de la losa varía según las zonas entre 6 y 15Ф16/m en sentido longitudinal y entre 6 y $8 \Phi 16 / m$ en sentido transversal.

En los cabeceros aislados, la armadura inferior consta de 8Ф20 en sentido longitudinal y cercos $8 \Phi 10$. En los cabeceros continuos intermedios, la armadura inferior varía entre 16 y 24 Ф25 en sentido longitudinal y cercos de $\Phi 14 c / 0,25$ m y en los cabeceros continuos extremos, la armadura inferior varía entre 14 y 22 Ф25 en sentido longitudinal y cercos de $\Phi 14 \mathrm{c} / 0,25 \mathrm{~m}$.

No existen datos del control de calidad de la ejecución. 
Respecto a la situación y a la climatología, el muelle está prácticamente alineado con la dirección este-oeste y se sitúa en una zona (océano atlántico) con una carrera de marea de $3,70 \mathrm{~m}$.

\subsubsection{Muelle C}

La ampliación del Muelle C, que se construye en el año 1993, consiste en un muelle de pilotes de 12 metros de calado, con una longitud de atraque de $250 \mathrm{~m}$. En el año 1998 se proyecta y en 1999 se ejecuta una segunda ampliación con un muelle de idéntica sección estructural y 130 m de longitud de atraque adicional. Esta segunda ampliación es la estructura objeto del presente estudio.

El muelle objeto de estudio está formado por una plataforma de hormigón armado de 19,72 m de anchura, Además existe una losa de hormigón de 3,20 m de ancho de transición hasta la explanada. La plataforma está dividida en 2 módulos de 65,00 m cada uno. Cada uno de ellos está dispuesto sobre nueve cuchillos transversales de tres pilotes verticales de 1,50 m de diámetro y separados 7,50 m en el sentido longitudinal del muelle, con lo que queda una zona en voladizo en la viga cantil de $2,50 \mathrm{~m}$ respecto al pilote más cercano a la misma.

Sobre las cabezas de los pilotes se disponen vigas de hormigón armado de 1,90 m de canto y de ancho variable entre 1,00 y $1,70 \mathrm{~m}$. Sobre estas vigas se apoyan las losas prefabricadas de hormigón de $0,30 \mathrm{~m}$ de canto, hormigonando "in situ" otros $0,30 \mathrm{~m}$ del conjunto de la plataforma. Así se consigue un canto total de las vigas de $2,50 \mathrm{~m}$ y un espesor de la losa de $0,60 \mathrm{~m}$.

Las vigas que conforman los módulos del tablero son nueve vigas transversales de 1,00 m de ancho, y tres vigas longitudinales. Las vigas longitudinales son:

- viga cantil, donde se aloja una de las vías de la grúa y una galería para conducciones de 0,84 $\mathrm{m}$ de ancho y $1,00 \mathrm{~m}$ de altura

- viga intermedia, de 1,00 m de ancho donde se aloja la otra vía de la grúa

- viga trasera, de 1,70 m de ancho donde se apoya la losa de transición.

La figura 5.7 muestra un croquis de la citada prolongación del muelle. En la figura 5.8 se aportan dos fotografías del frontal del muelle. 


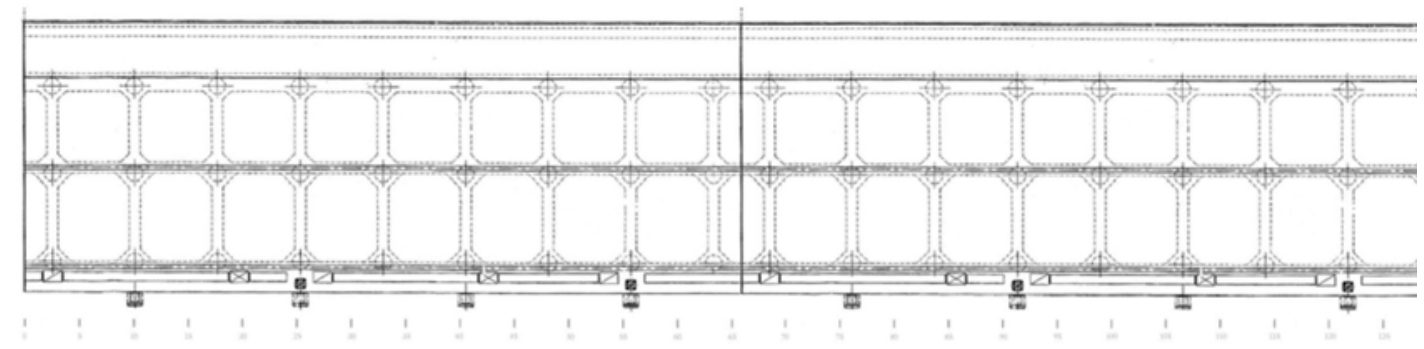

RÍA DE AVILÉS.

Módulo 1. $65 \mathrm{~m}$ de longitud

Módulo 2. $65 \mathrm{~m}$ de longitud

Fig.5.7. Croquis de planta del muelle $C$.
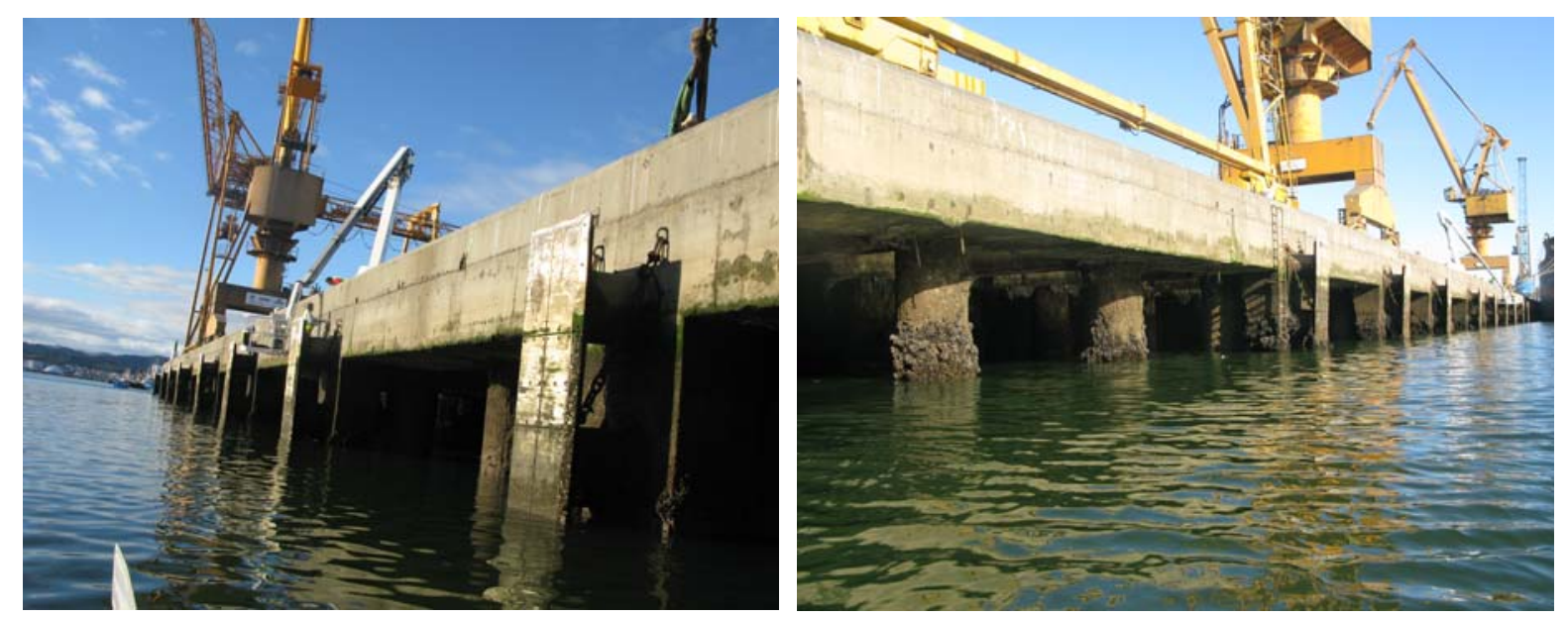

Fig.5.8. Vistas del frontal del muelle C.

Respecto a los materiales, en el pliego de prescripciones técnicas del proyecto se especifica que en lo referente a los hormigones armados, sus componentes (cemento, acero, árido y agua de amasado), manipulación, ensayos, etc. regirá en su plenitud la Instrucción EH-91, Instrucción en vigor en el momento de la construcción del muelle. En el caso del cemento, también deberá cumplir con el Pliego de Prescripciones Técnicas para la Recepción de Cementos RC-93.

A continuación se detallan las características específicas exigidas en el citado Pliego a los diferentes materiales de construcción.

Hormigón.

El hormigón de la losa de compresión, cabeceros, vigas y losa de transición será del tipo H-250, con contenido mínimo de cemento de $350 \mathrm{~kg} / \mathrm{m}^{3}$ de hormigón. El 
hormigón de los pilotes será del tipo H-200, con contenido mínimo de cemento de $300 \mathrm{~kg} / \mathrm{m}^{3}$ de hormigón.

La consistencia de todos los hormigones será plástica.

Acero para armaduras de hormigón.

Los aceros para armaduras empleados son corrugados, con límite elástico 5100 $\mathrm{kp} / \mathrm{cm}^{2}$, y de dureza natural, correspondiéndole la designación AEH $500 \mathrm{~N}$ de la Instrucción EH-91.

En todo momento el recubrimiento de hormigón será de $5 \mathrm{~cm}$, no pudiendo existir ningún elemento metálico a una distancia de los paramentos inferior a ésta.

\section{$\underline{\text { Control de calidad }}$}

Entre los meses de julio y octubre de 1999 se realiza el hormigonado de las vigas. El control de calidad del hormigón refleja las siguientes características de los materiales empleados:

- El cemento empleado es CEM II/BV-32,5 R.

- Se emplea como aditivo "Pozzolith" (plastificante / reductor de agua).

- Tamaño máximo del árido: 30 mm.

- Asiento cono Abrams: 6-9 cm.

Respecto a la situación y a la climatología, el muelle se sitúa en la dirección NS, ligeramente hacia el oeste y sobre el mar Cantábrico con una carrera de marea de $3,80 \mathrm{~m}$.

\subsubsection{Muelle D}

En el año 2004 se construye el recrecido del Muelle D, consistente en un tablero de hormigón armado cimentado sobre pilotes de 23 metros de calado (cota de cimentación a -31m), con una longitud de atraque de 190m.

Dicha ampliación que se construye como un adelantamiento desde el cantil anterior consta de tres módulos de $62,66 \mathrm{~m}$ de longitud y una anchura aproximada de $35 \mathrm{~m}$. Cada uno de estos módulos consta de tres vigas armadas prefabricadas 
in situ de 1,20m de canto en alineaciones paralelas al cantil existente: dos llamadas centrales o intermedias y una exterior o viga cantil. Tales vigas se apoyan sobre cabeceros prefabricados de hormigón armado que recogen las cabezas de los pilotes. Dichos pilotes son metálicos de $1400 \mathrm{~mm}$ de diámetro, $12 \mathrm{~mm}$ de espesor en chapa metálica tipo S235 JRG2 y presentan una distancia entre ejes de $9,75 \mathrm{~m}$.

El hueco entre vigas se salva mediante placas pretensadas aligeradas de $0,40 \mathrm{~m}$ de canto. Sobre las vigas y las placas se ejecuta una losa de hormigón armado de 0,20m para acabar finalmente con el pavimento de hormigón fratasado de espesor variable.

La sección estructural se completa con la ejecución de un estribo de transición entre el tablero y el cantil actual del Muelle D que permite el apoyo de las placas pretensadas interiores y asegura la continuidad del nuevo tablero con la superficie existente.

Las figuras 5.9 y 5.10 muestran vistas lateral y general del recrecido del Muelle D, respectivamente:

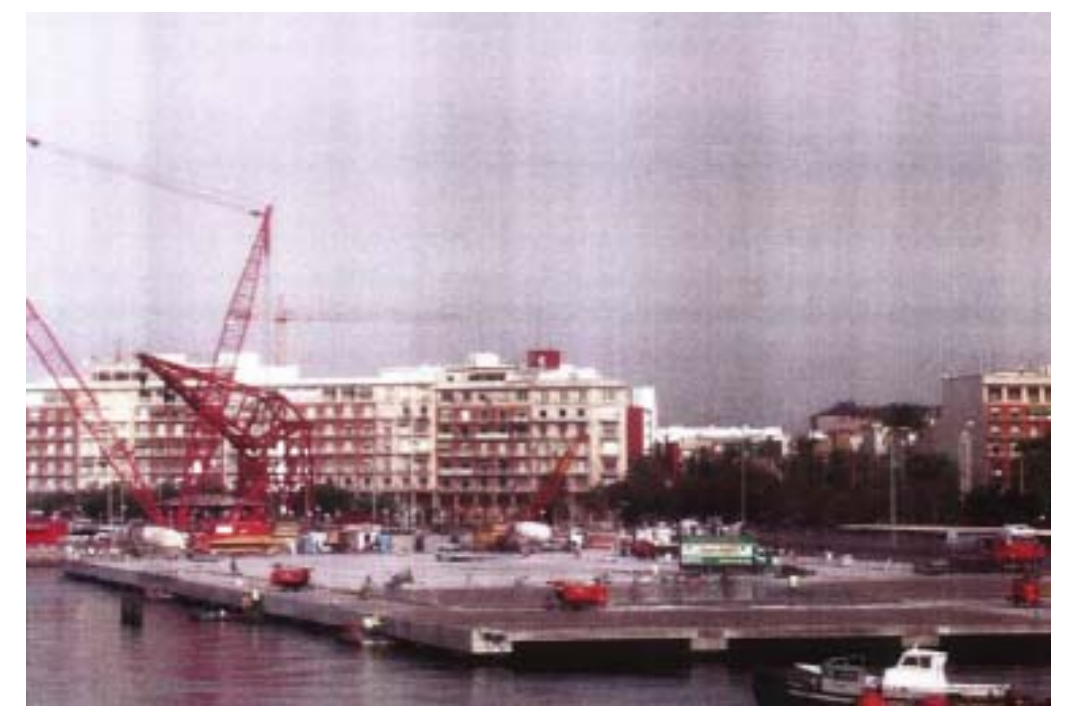

Fig.5.9. Vistas lateral del recrecido del muelle D. 


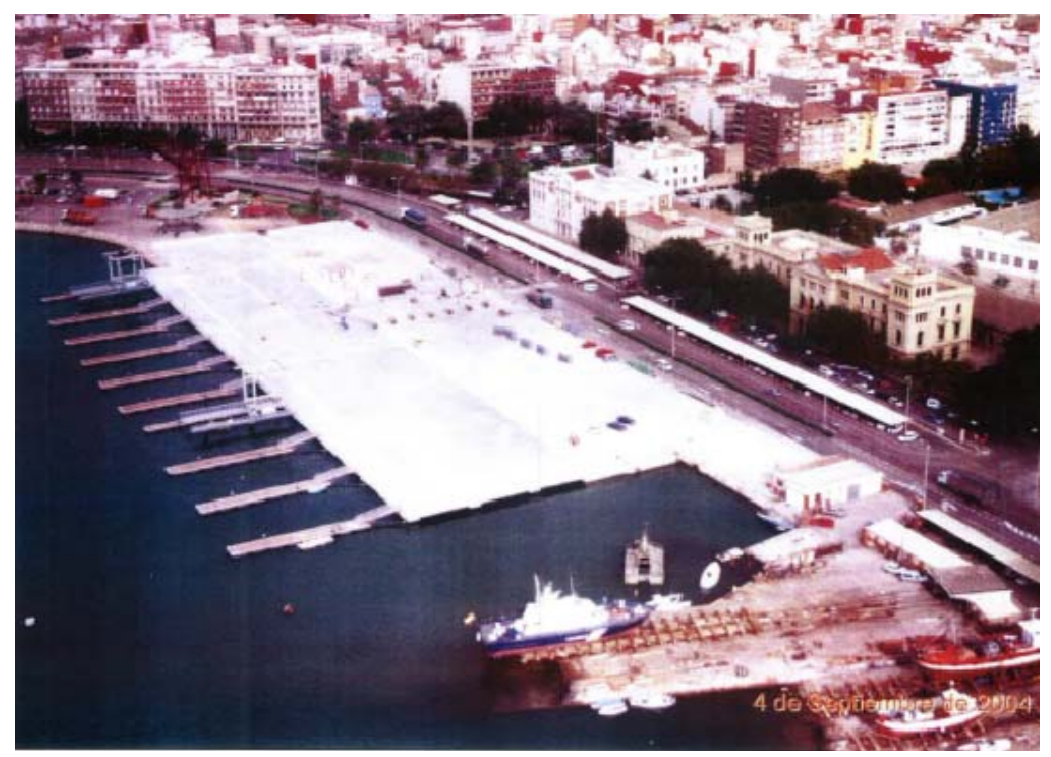

Fig.5.10. Vista general final del recrecido del muelle $D$.

A continuación se incorporan los datos de los materiales utilizados en la obra. Hormigón

El hormigón de las vigas intermedias, cantil y losa superior es un HA35/B/25/IIla.

El hormigón se fabricó en obra y de acuerdo con los partes de toma de muestras el cemento utilizado fue un CEM I 52,5 N/SR y también se utilizó un CEM I 42,5 $\mathrm{R} / \mathrm{SR}$.

No se ha conseguido recabar información sobre la dosificación empleada. De acuerdo con la Instrucción EH-98 en ambiente Illa el hormigón debe llevar un contenido mínimo de cemento de $300 \mathrm{~kg} / \mathrm{m}^{3}$ y una relación agua/cemento de 0,50.

\section{Acero para armaduras del hormigón}

Los aceros para armaduras empleados son de tipo soldable B500S con límite elástico $5100 \mathrm{kp} / \mathrm{cm}^{2}$ y dureza natural. 


\subsubsection{Tabla de Características de los Muelles objeto de estudio}

En la tabla 5.1 se muestra un resumen de las características más importantes de los muelles que se han estudiado:

\begin{tabular}{|c|c|c|c|c|}
\hline Muelle & Muelle A & Muelle B & Muelle C & Muelle D \\
\hline $\begin{array}{l}\text { Edad (año de } \\
\text { construcción) }\end{array}$ & 37 (1971) & 26 (1981) & $11(2000)$ & $11(2004)$ \\
\hline $\begin{array}{c}\text { Normativa vigente } \\
\text { en el momento de la } \\
\text { construcción } \\
\end{array}$ & H.A.61 & $\mathrm{EH}-80$ & EH-91 & EH-98 \\
\hline Localización & Mar Mediterráneo & Océano Atlántico & Mar Cantábrico & Mar Mediterráneo \\
\hline $\begin{array}{c}\text { Distancia B.M.V.E } \\
\text { testigo/carrera } \\
\text { mareas (m) }\end{array}$ & $+6,50 / 0$ & $\begin{array}{c}+5,40(\text { Losas }) / 3,70 \\
+4,70(\text { Cabeceros }) / 3,70\end{array}$ & $+5,90 / 3,80$ & $+1,50 / 0$ \\
\hline $\begin{array}{c}\text { Ambiente } \\
\text { Exposición EHE }\end{array}$ & IIIa Aéreo & IIIa Aéreo & IIIa Aéreo & IIIa Aéreo \\
\hline Subambiente ${ }^{(1)}$ & $\begin{array}{l}\text { Zona IV Spray } \\
\text { (FIB) }\end{array}$ & Zona IV Spray (FIB) & Zona IV Spray (FIB) & $\begin{array}{c}\text { Zona IV } \\
\text { Spray(FIB) }\end{array}$ \\
\hline $\begin{array}{c}\text { Hormigón Proyecto } \\
\left(\mathrm{N} / \mathrm{mm}^{2}\right)\end{array}$ & -- & 30 & 25 & 35 \\
\hline $\begin{array}{c}\text { Resistencia } \\
\text { estimada a } 28 \text { días } \\
\text { según EHE-08(2) }\end{array}$ & 27,07 & $\begin{array}{l}\text { 35,78 (losas)/31,90 } \\
\text { (cabeceros) }\end{array}$ & 38,10 & 25,20 \\
\hline $\begin{array}{c}\text { Hormigón Testigos } \\
\text { (rango/valor medio) } \\
\left(\mathrm{N} / \mathbf{m m}^{2}\right)^{(3)}\end{array}$ & $29,7-45,1 / 38,9$ & $\begin{array}{c}48,0-55,5 / 51,2 \text { (losas) } \\
40,4-50,2 / 45,7 \\
\text { (cabeceros) } \\
\end{array}$ & $42,1-54,3 / 47,9$ & $18,2-33,5 / 30,3$ \\
\hline $\begin{array}{c}\text { Contenido Cemento } \\
\left(\mathrm{kg} / \mathrm{m}^{3}\right)^{(4)}\end{array}$ & 300 & 300 & 350 & 300 \\
\hline Relación a/c ${ }^{(5)}$ & 0,64 & $\begin{array}{l}\text { 0,53 (Losas) } / 0,57 \\
\text { (Cabeceros) }\end{array}$ & 0,53 & 0,58 \\
\hline $\begin{array}{l}\text { Recubrimiento } \\
\text { Proyecto(mm) }\end{array}$ & ----- & 50 & $\geq 50$ & $>45$ \\
\hline $\begin{array}{c}\text { Recubrimiento } \\
\text { medido en campo } \\
(\mathrm{mm})\end{array}$ & $<20$ & $60-65$ & $25-45^{(6)}$ & $\begin{array}{c}23-60 / 51-150 / 28- \\
150\end{array}$ \\
\hline Tipo de Cemento & ---- & P350 & CEM II/BV-32,5 R & $\begin{array}{l}\text { CEM I 52,5N/SR } \\
\text { CEM I 42,5R/SR }\end{array}$ \\
\hline Tipo de Acero & Liso & $\begin{array}{c}\text { B400S (límite elástico } \\
4200 \mathrm{~kg} / \mathrm{cm}^{2} \text { ) }\end{array}$ & AEH500N & B500S \\
\hline $\begin{array}{c}\text { Armadura } \\
\text { horizontal (mm) }\end{array}$ & $\varnothing 14$ & $\begin{array}{c}\varnothing 16 ; \varnothing 12 \text { (losas)/ } \\
\varnothing 25 \text { (cabeceros) }\end{array}$ & Ø25,Ø12 & Ø25,Ø20 \\
\hline $\begin{array}{c}\text { Armadura vertical } \\
(\mathbf{m m})\end{array}$ & ----- & Ø16 (cabeceros) & $\varnothing 14$ & Ø16,Ø12 \\
\hline $\begin{array}{l}\text { Resistencia Control } \\
\text { Calidad durante la } \\
\text { Ejecución }\left(\mathrm{N} / \mathrm{mm}^{2}\right)\end{array}$ & ----- & ----- & $\begin{array}{c}26 \text { (7días)/ } \\
36,5 \text { (28 días) }\end{array}$ & ----- \\
\hline
\end{tabular}

Tabla 5.1. Características fundamentales de los muelles estudiados

(1) Tras la revisión bibliográfica realizada en el Estado del Arte del presente estudio se adopta la siguiente clasificación de subambientes dentro del Ambiente Marino Aéreo: 
Zona I: Estructuras o elementos de ellas que se encuentran a una distancia de la costa $<5 \mathbf{k m}$ (Criterio EHE)

Zona II: Estructuras o elementos de ellas que se encuentran a una distancia de la costa $<\mathbf{5 0 0 m}$ (Criterio EHE para contenido de cloruros en superficie)

Zona III: Estructuras o elementos de ellas que se encuentran a una distancia de la costa $<\mathbf{1 0 0 m}$ (Criterio Japón)

Zona IV: Estructuras o elementos de ellas que se encuentran a una altura sobre el mar $>\mathbf{1 , 5 m}$ (zona de spray según criterio del FIB)

Zona V: Estructuras o elementos de ellas que se encuentran a una altura sobre el mar $<1,5 m$ (zona de salpicaduras según criterio del FIB)

(2) Se ha calculado la resistencia a 28 días según el artículo 31.3 “Características mecánicas” de la Instrucción EHE-08 a partir del valor medio de los resultados de resistencia obtenidos en los ensayos realizados.

(3) Para el cálculo del valor medio de la resistencia de los testigos del muelle D se ha eliminado el valor más bajo por considerarse anómalo.

(4) En el caso del muelle A, se considerado este contenido en cemento, al tratarse de elementos de hormigón estructural armado. Según el documento H.A61 vigente en la época, el mínimo contenido de cemento era $250 \mathrm{~kg} / \mathrm{m} 3$. En el caso del muelle D, por ser un dato desconocido, se considera el mínimo contenido de cemento requerido para el ambiente IIIa por la Instrucción vigente en el momento de la construcción.

(5) El valor de la relación a/c, dado que no es conocida en ninguno de los cuatro muelles, se ha estimado mediante el método de Carlos de la Peña obteniendo el valor de la resistencia a 28 días a partir de la resistencia media calculada mediante los valores de los ensayos.

(6) Este es el rango de recubrimientos medidos, aunque en dos puntos aislados se midieron $7 \mathrm{~mm}$ y $60 \mathrm{~mm}$ de recubrimiento.

\subsection{INSPECCIÓN VISUAL Y EXTRACCIÓN DE TESTIGOS}

\subsubsection{Inspección visual}

El estudio de los muelles se inicia con una inspección visual. Una vez finalizada y considerando los datos de control de calidad, si los hubiere, se procede a la extracción de testigos de hormigón de resistencia baja, alta e intermedia. A continuación se aporta un resumen de cómo se ha procedido en los cuatro muelles:

\subsubsection{Muelle A}

Se ha inspeccionado todo el pantalán incluyendo el camino de acceso sobre las traviesas, las plataformas A, B y C, los Duques de Alba así como las 80 vigas traviesa sobre las que apoya la plataforma del camino de acceso. La figura 5.1. muestra una vista general de la estructura.

En el caso del camino de acceso, la mitad de éste había sido reparada. La mitad no reparada mostraba síntomas de corrosión avanzada, con fisuras, manchas de 
corrosión y múltiples puntos en los que se ha perdido el recubrimiento, quedando la armadura a la vista. Dichos defectos pueden apreciarse en la figura 5.11.
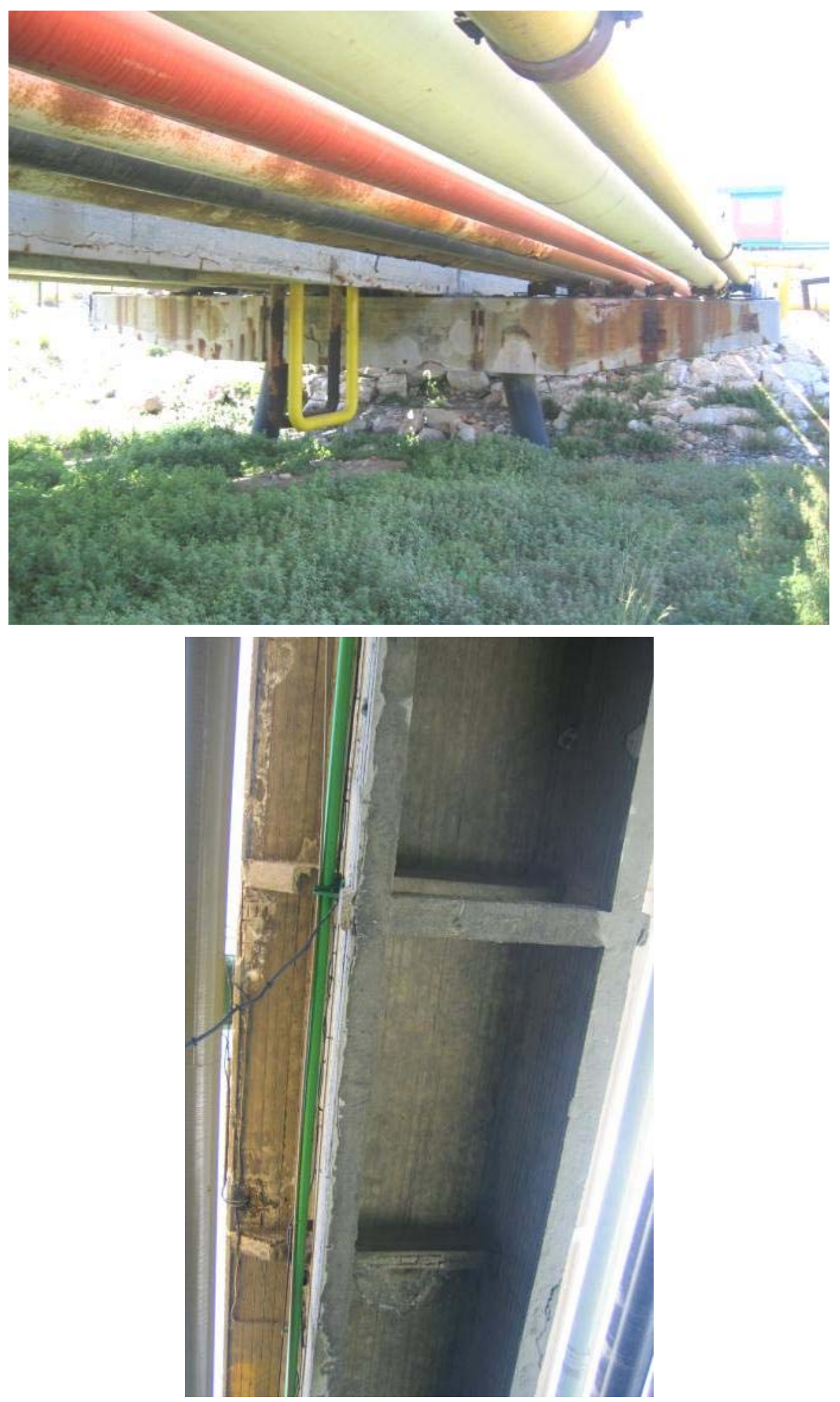

Fig.5.11. Síntomas de corrosión en el camino de acceso. 
Respecto a las plataformas, éstas se componen de chapas y perfiles metálicos, así como de losas de hormigón armado. Estas losas, en general, presentan buen aspecto, con síntomas de corrosión puntuales y eflorescencias (fig.5.12). Sin embargo, en el caso del acceso a la Plataforma A se encuentra una losa con un estado de corrosión muy avanzado, donde pueden observarse fisuras y manchas de corrosión generalizadas (fig. 5.13).

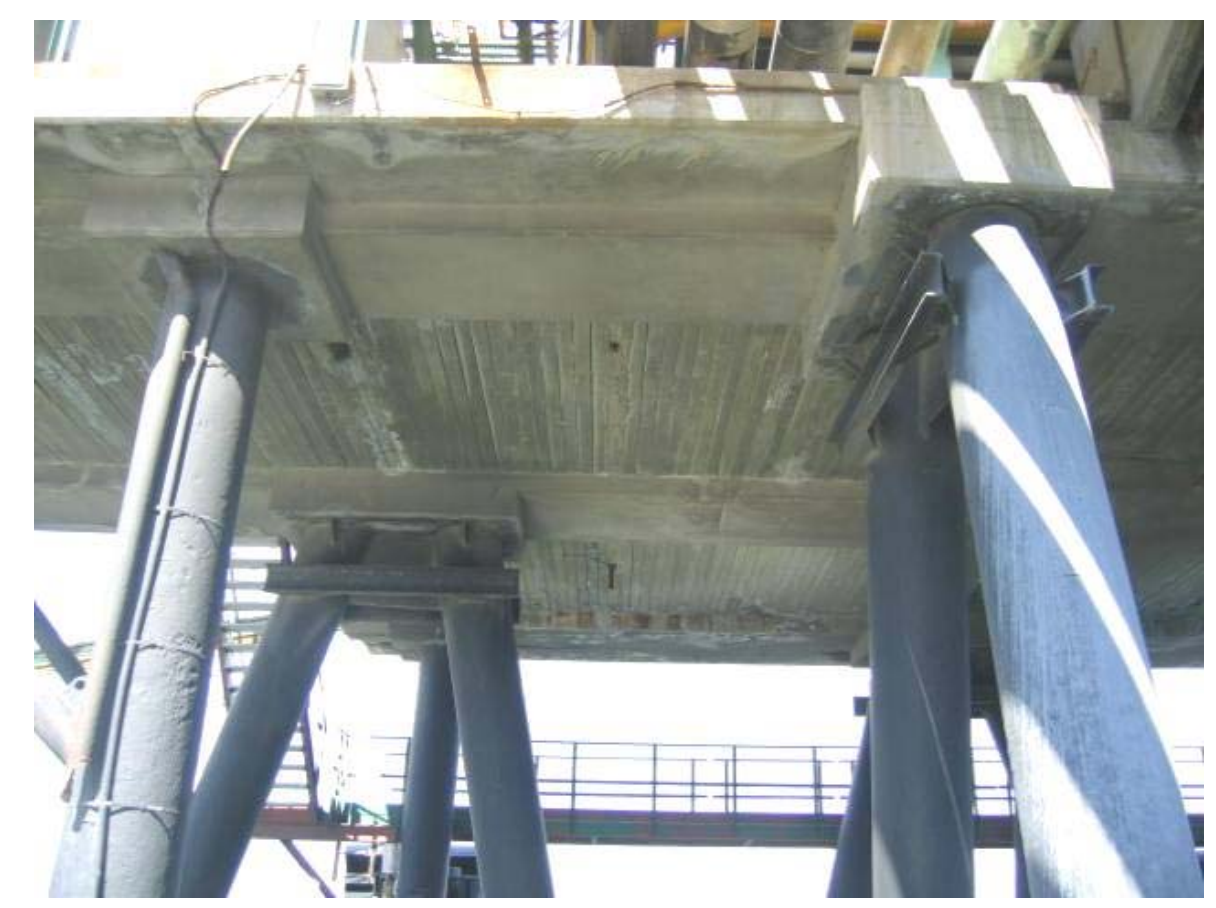

Fig.5.12. Síntomas puntuales de corrosión y eflorescencias en losas.
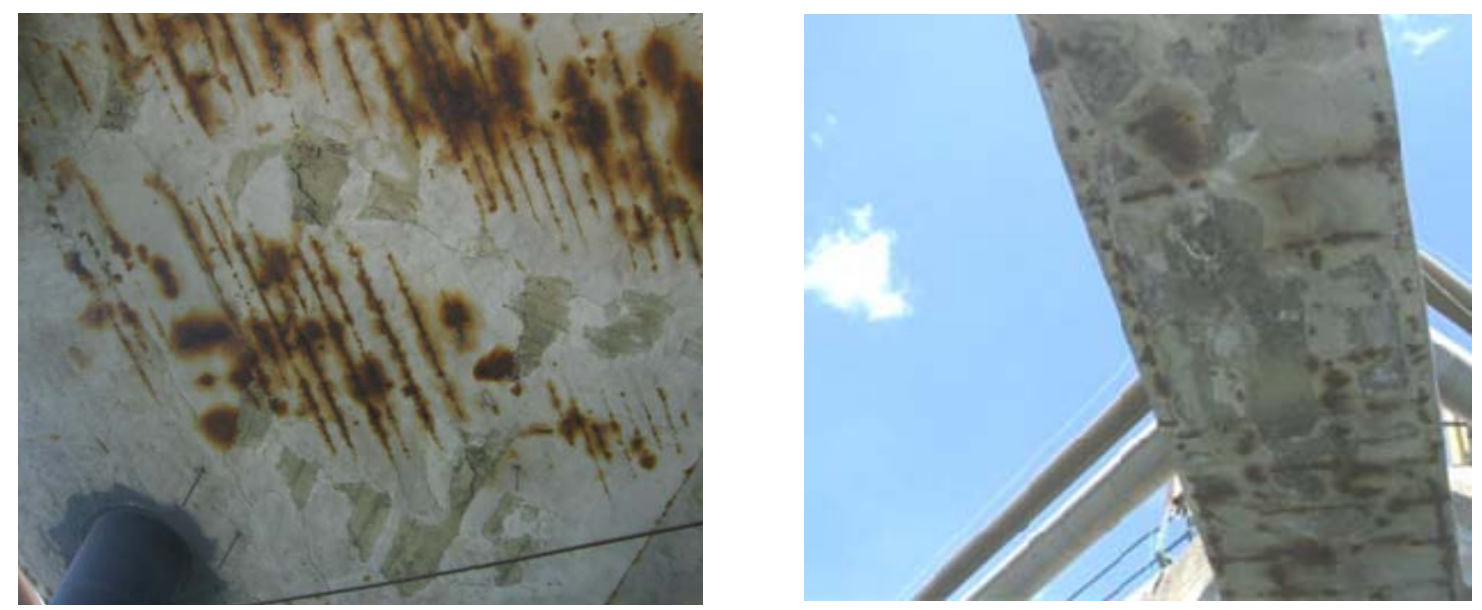

Fig.5.13. Corrosión avanzada en losa de plataforma A.

Del mismo modo, se realizó una inspección general del estado de los Duques de Alba del pantalán. En todos ellos se observan síntomas de corrosión, fundamentalmente en alguna de las superficies laterales, habiéndose perdido en 
alguno de ellos gran parte del recubrimiento (figura 5.14), dejando armadura a la vista y con corrosión. En cambio, las superficies superiores no muestran síntoma alguno de corrosión (figura 5.15).

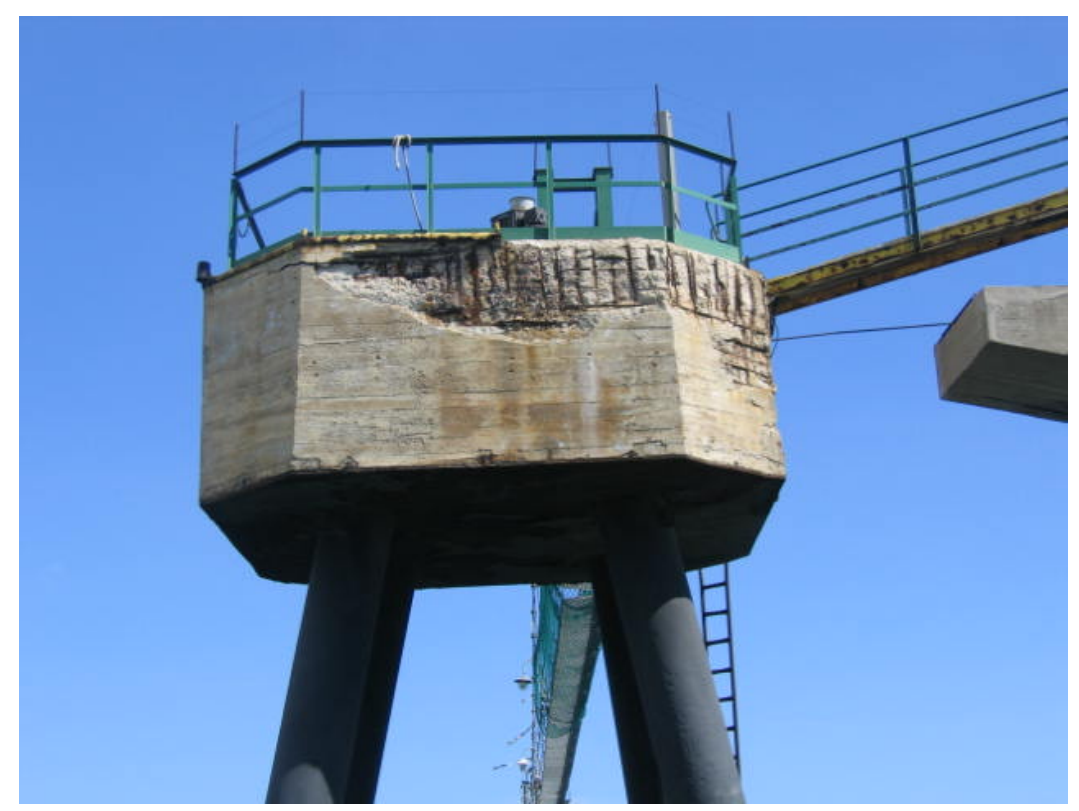

Fig.5.14. Síntomas de corrosión en Duques de Alba

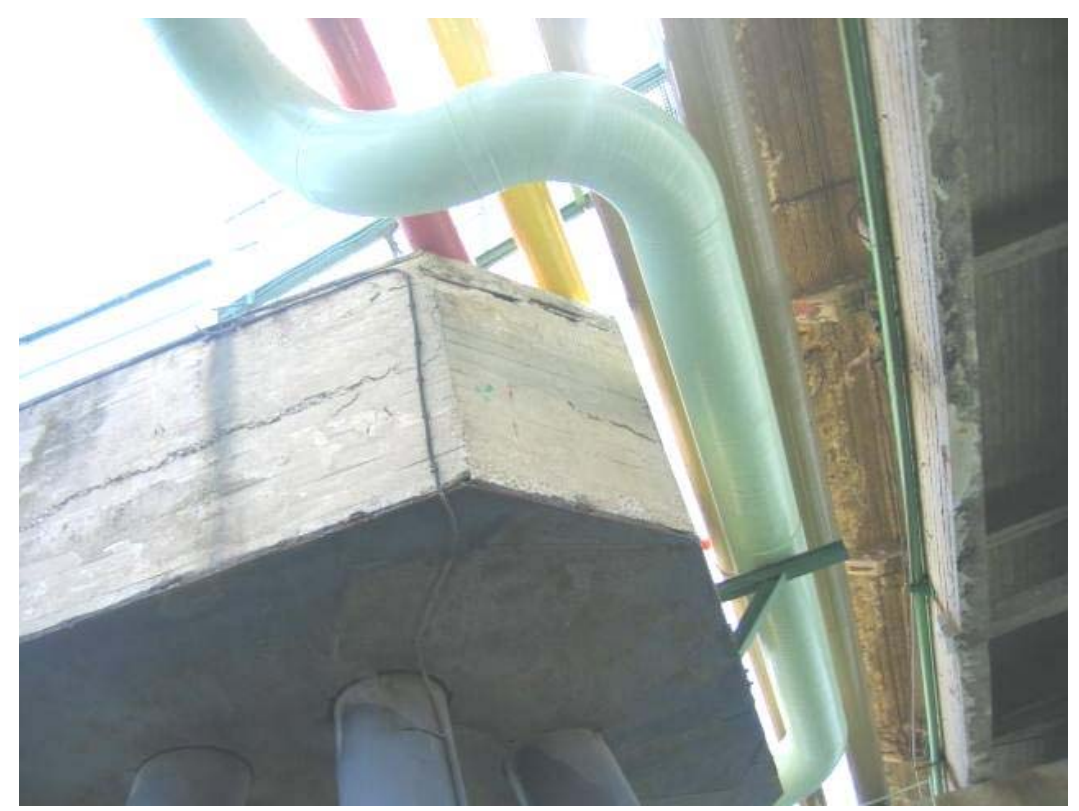

Fig.5.15. Zonas de Duques de Alba con mejor aspecto.

Por último se inspeccionaron las 80 vigas traviesas sobre las que apoya la plataforma del camino de acceso. Prácticamente todas ellas mostraban parches debidos a algún tipo de reparación. Se detectaron los siguientes defectos principales: 
- Fisuras sin manchas de corrosión situadas normalmente en la unión entre los parches y el hormigón antiguo (figura 5.16).
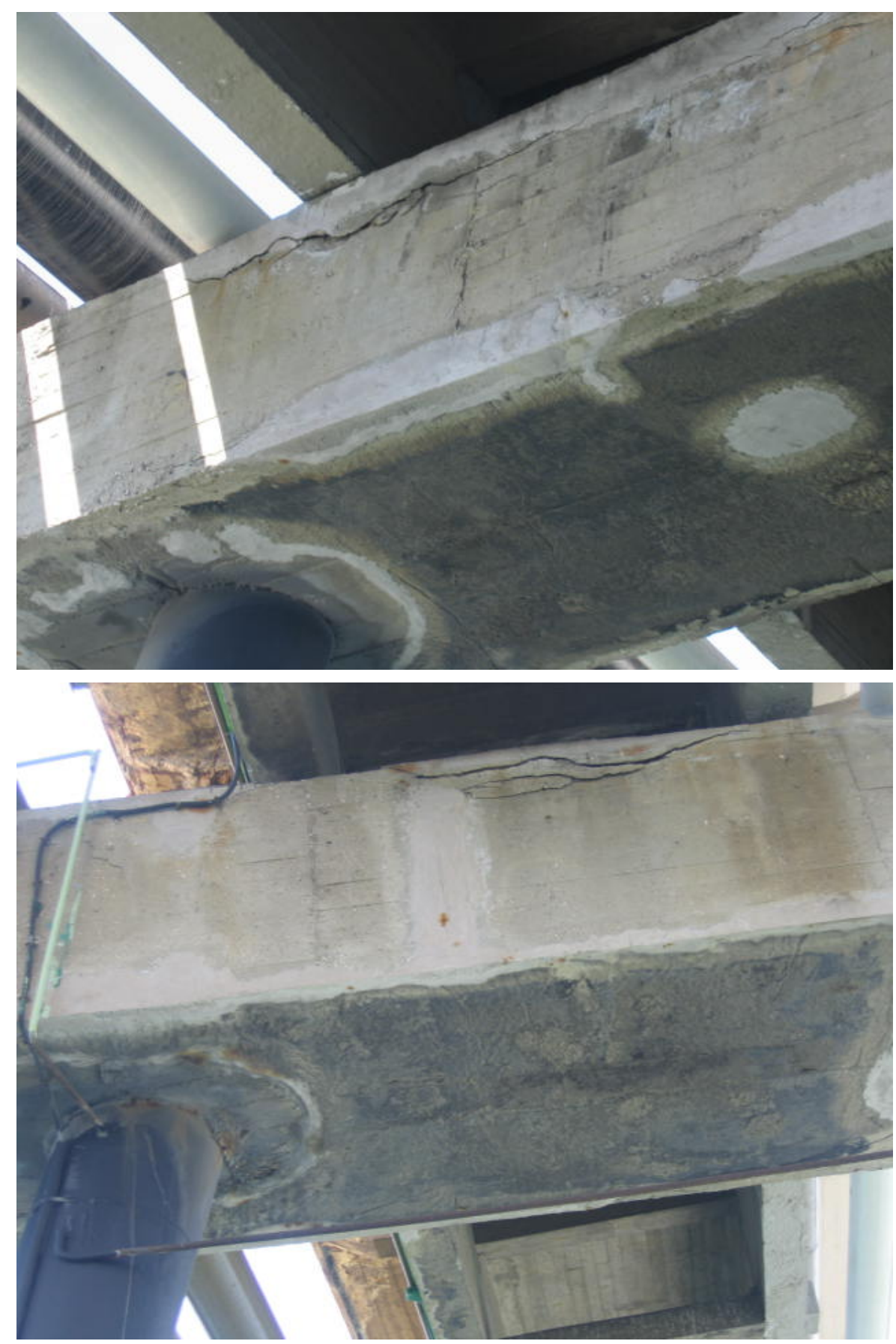

Fig.5.16. Ausencia de corrosión en fisuras. 
- Fisuras con manchas de corrosión. En algunos casos la corrosión se encuentra en un estado temprano, en el que se ven las primeras manchas de corrosión y en otras ocasiones, la corrosión se encuentra más desarrollada (figura 5.17).
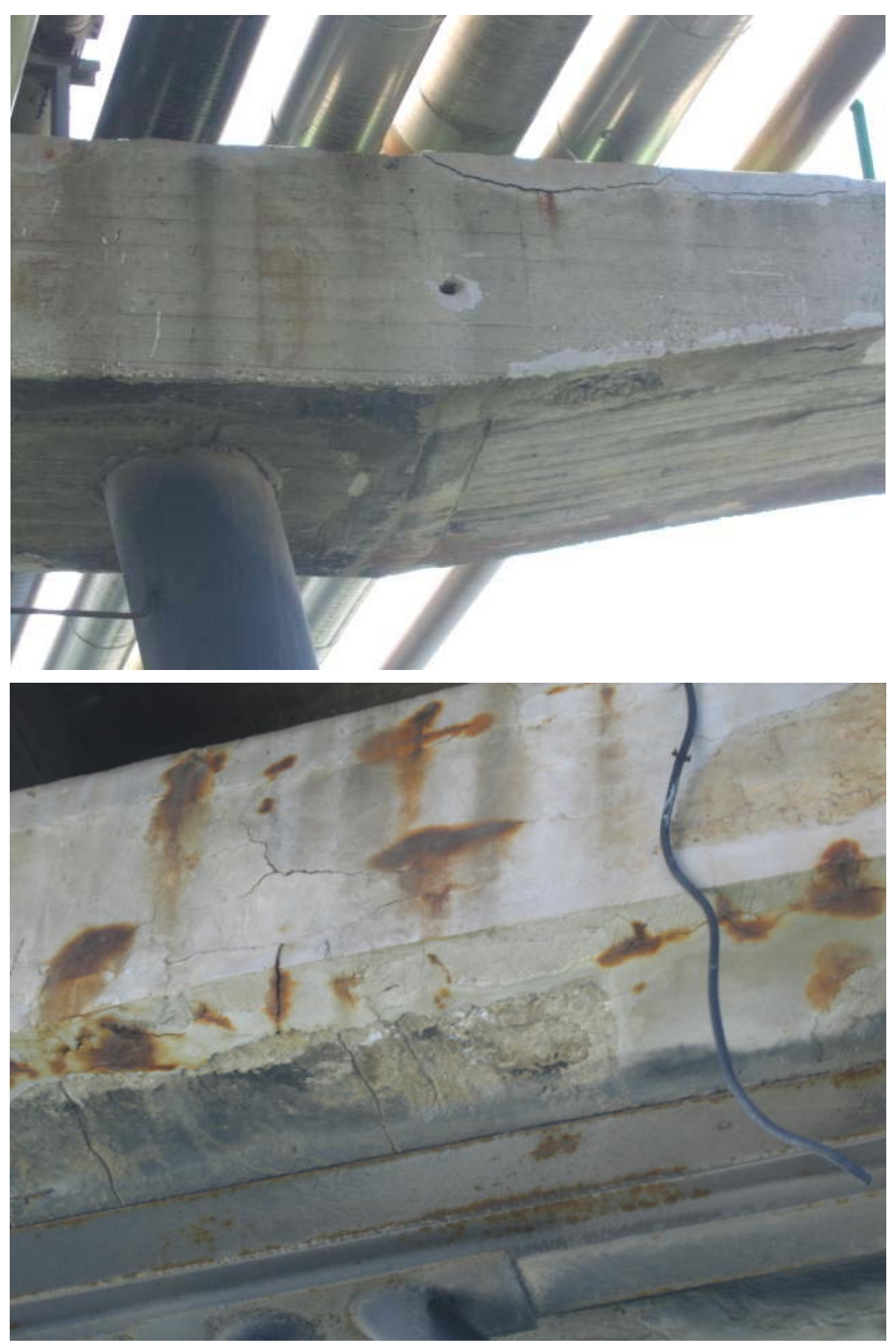

Fig.5.17. Fisuras con manchas de corrosión. 
- Manchas de óxido que se sitúan habitualmente sobre reparaciones, como paso previo a que se origine una fisura de corrosión (figura 5.18).
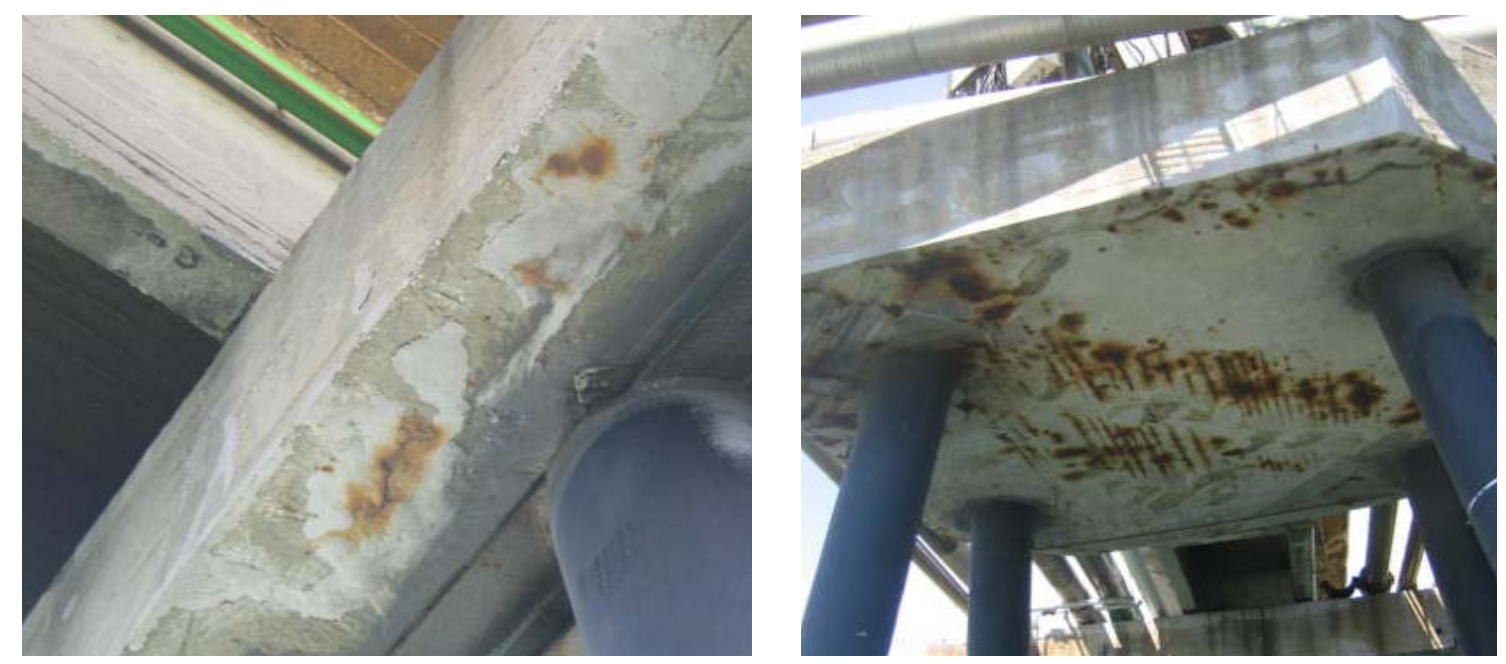

Fig.5.18. Manchas de óxido.

- Ahuecamientos del recubrimiento, previo a su desprendimiento. Se trata de desconchones que no han llegado a eliminar todo el recubrimiento, por lo que no se observan síntomas de corrosión (figura 5.19).

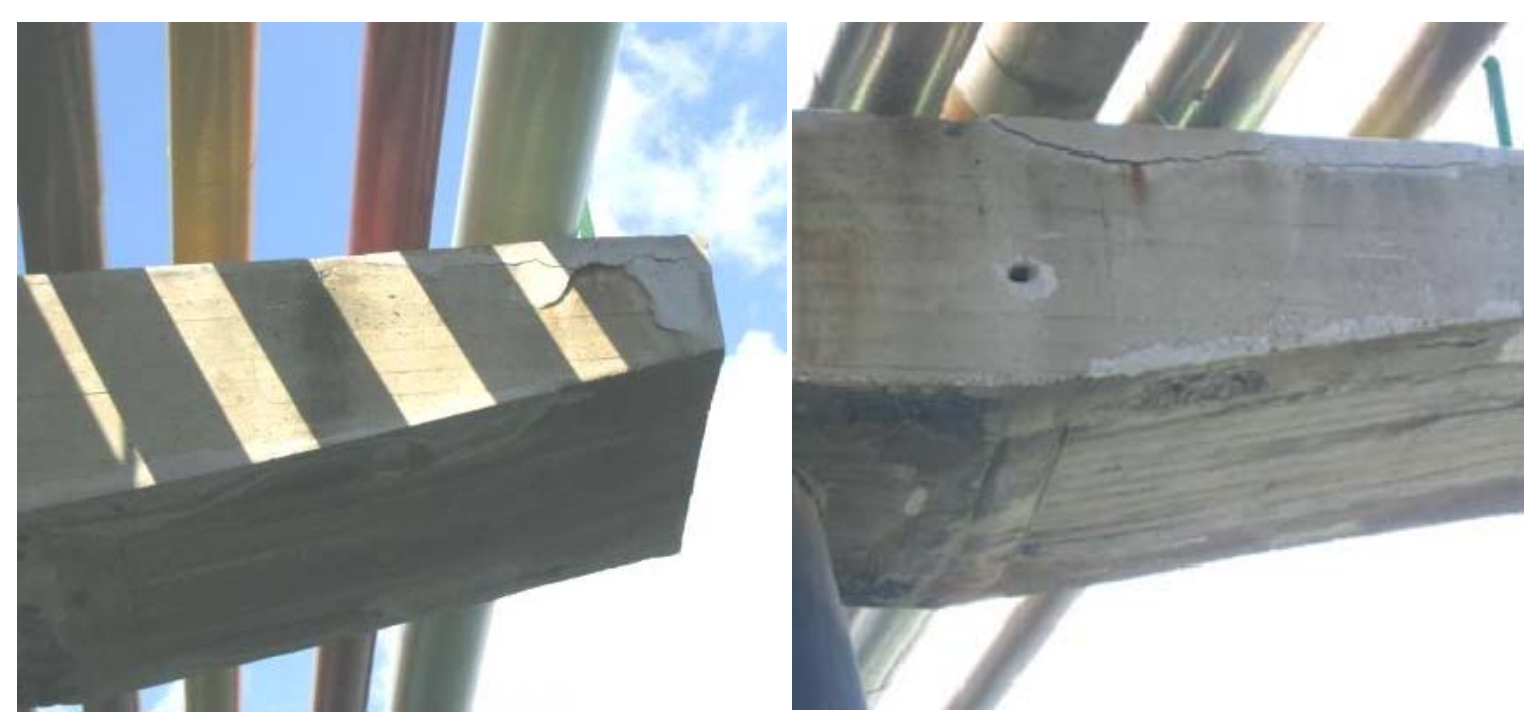

Fig.5.19. Ahuecamientos del recubrimiento 
- Pérdida del recubrimiento de hormigón debido a estados muy avanzados de corrosión de armaduras que han provocado que salte el recubrimiento. Suele estar relacionado con las reparaciones realizadas en las aristas de las superficies laterales o en la superficie inferior (figura 5.20).
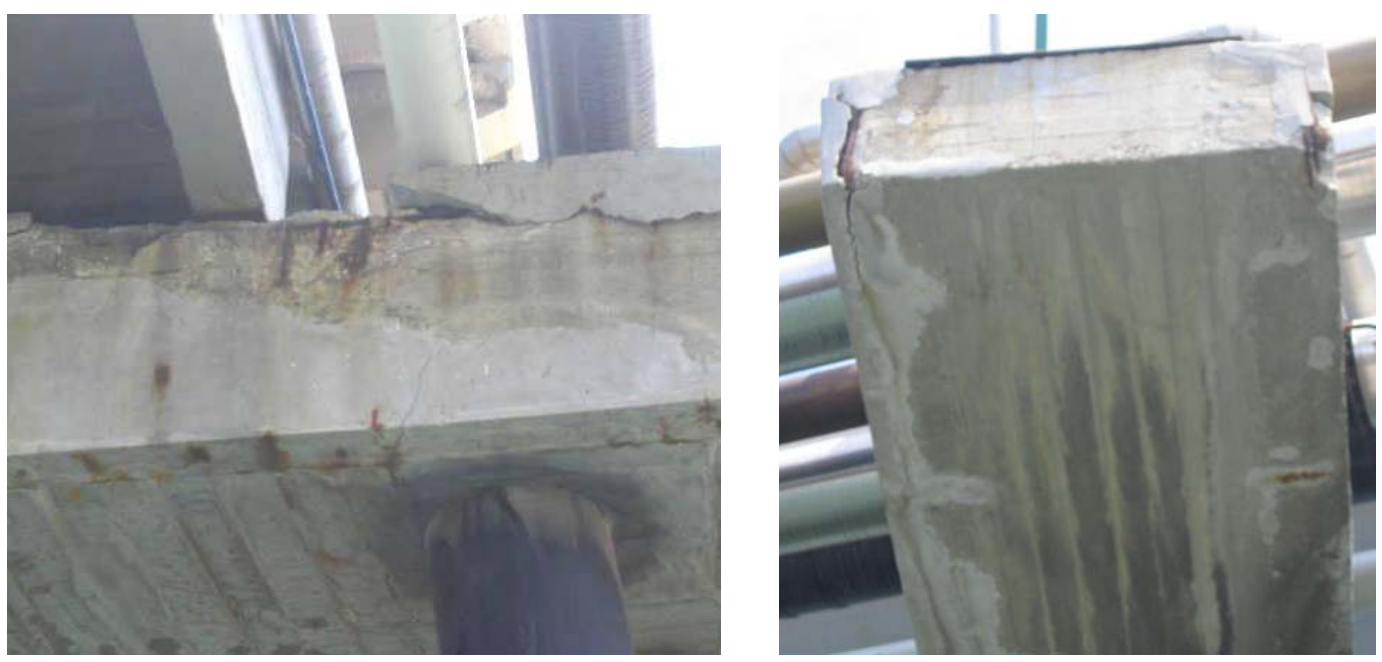

Fig.5.20. Desprendimiento de recubrimiento de hormigón.

- Armaduras vistas localizadas en zonas puntuales con falta de recubrimiento (figura 5.21).
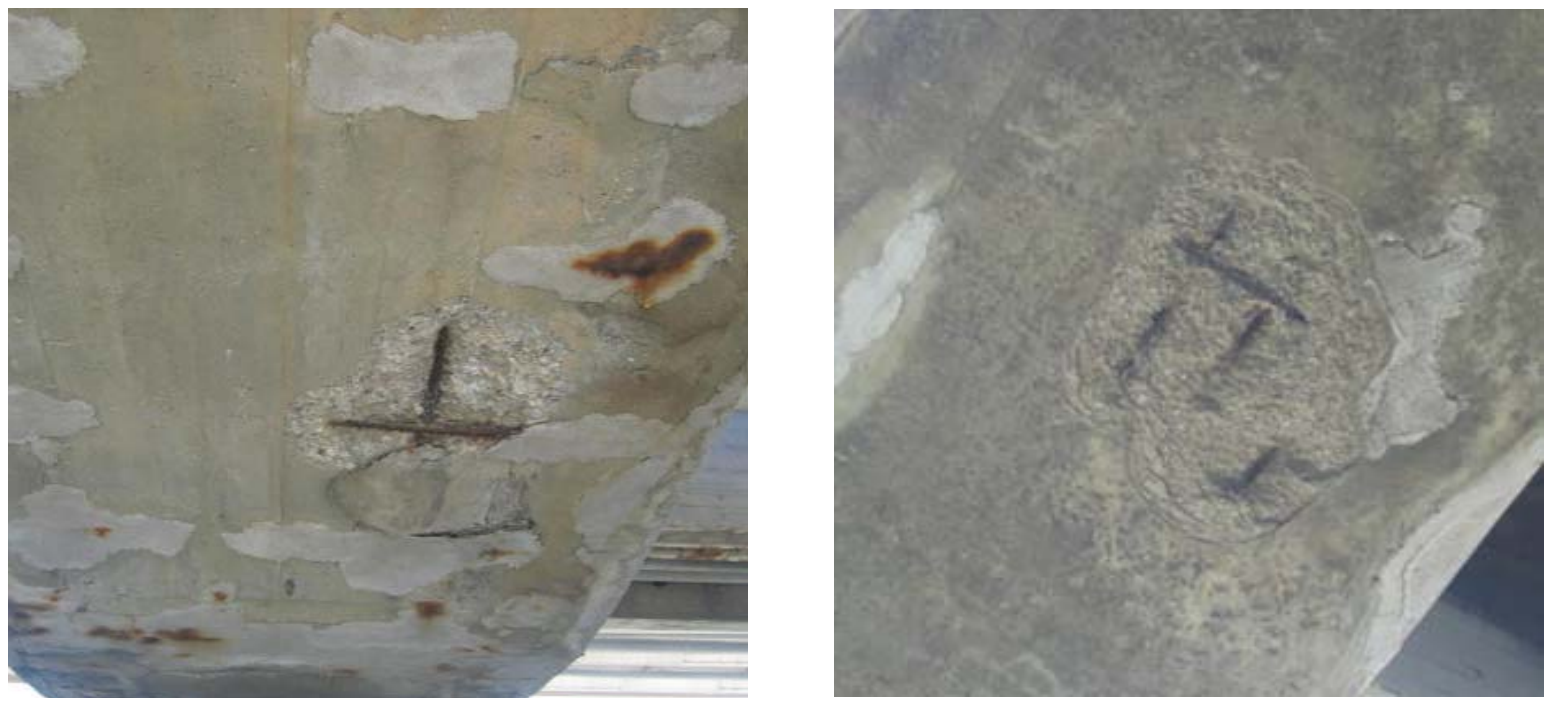

Fig.5.21. Armaduras a la vista. 
- Eflorescencias detectadas en algunas traviesas prismáticas del camino a la plataforma C (figura 5.22).

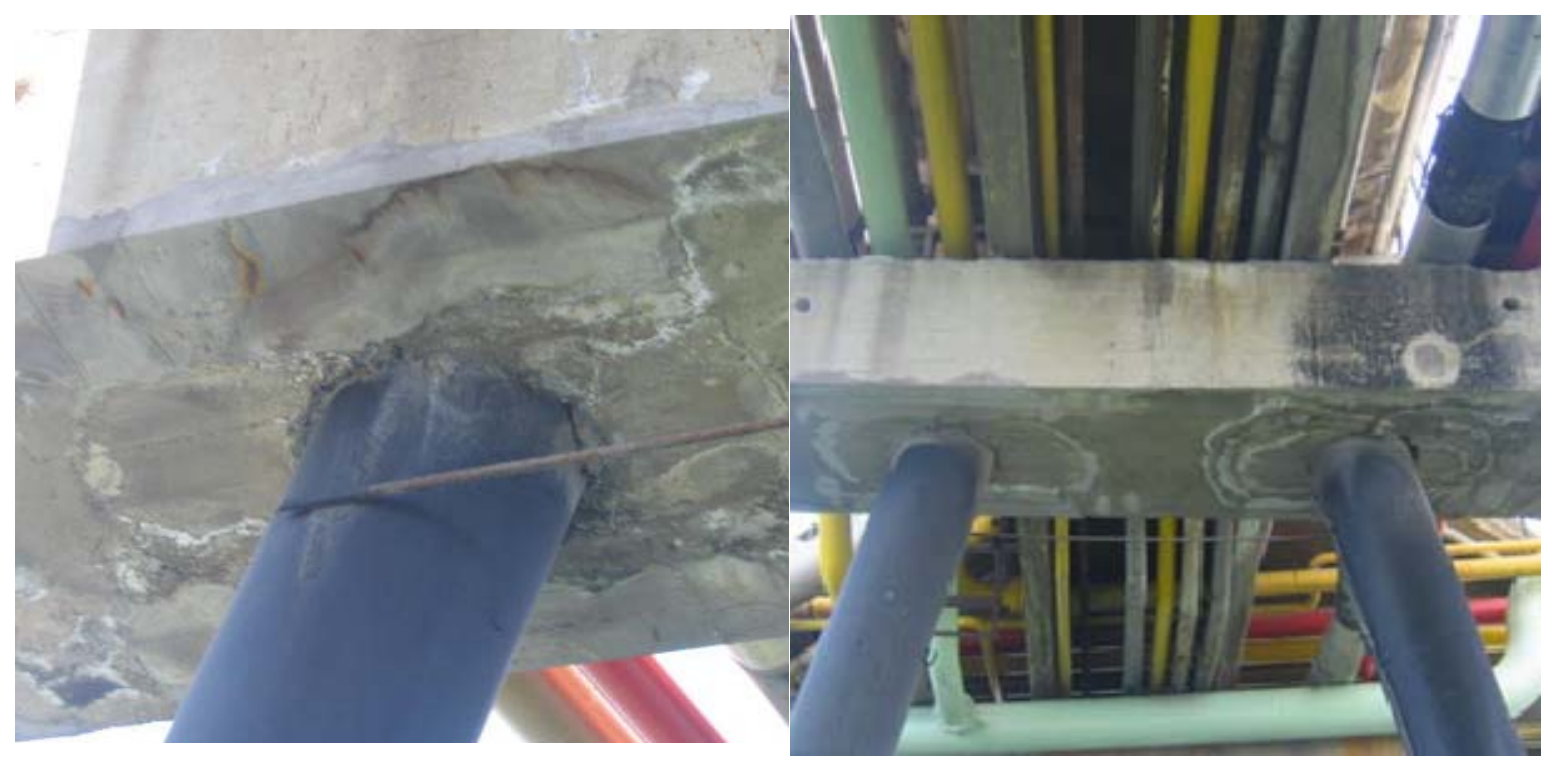

Fig.5.22. Eflorescencias.

- Nidos de grava detectados en algunas traviesas prismáticas del camino a la Plataforma C (figura 5.23).

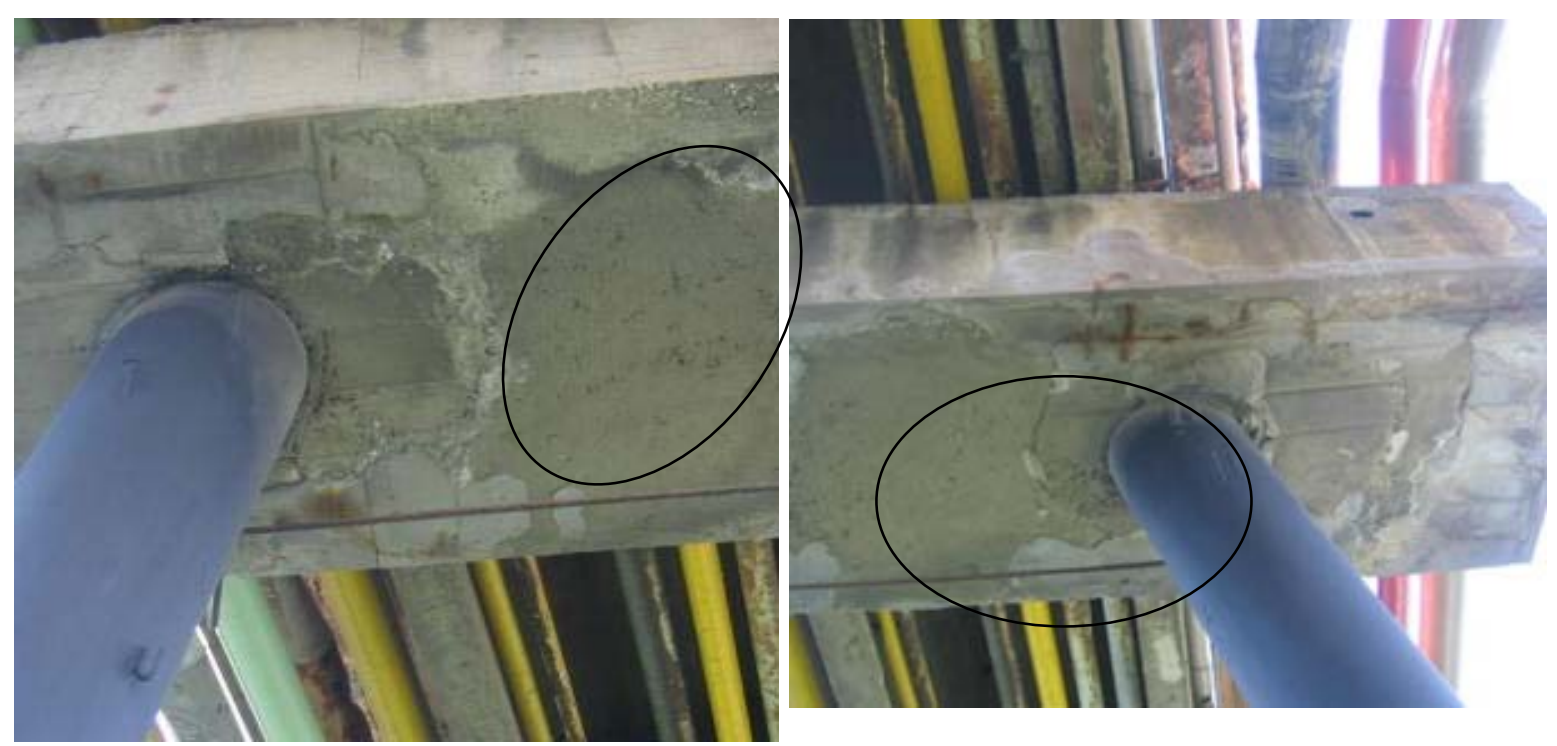

Fig.5.23. Nidos de grava. 
- Montantes metálicos horizontales corroídos situados en apoyos (figura 5.24).

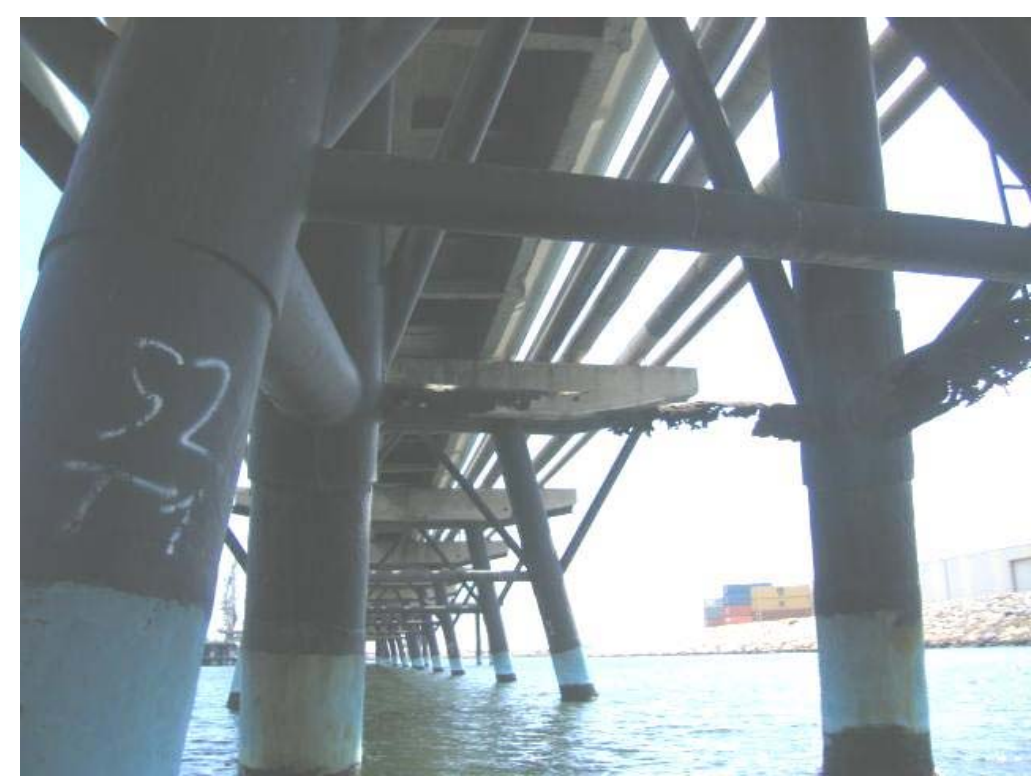

Fig.5.24. Síntomas de corrosión.

Como análisis de la inspección, puede decirse que las traviesas, a pesar de haber sido reparadas, presentan síntomas de corrosión como fisuras entre zona original y reparada, manchas de corrosión y finalmente desprendimiento de recubrimiento en estados de corrosión más avanzada. Esta corrosión observada afecta fundamentalmente a la armadura pasiva, pero su avance podría resultar especialmente peligroso por tratarse de traviesas pretensadas y en el caso de resultar afectados los tendones de pretensado, podrían provocar roturas frágiles del hormigón.

En el caso del camino de acceso, que ha sido reparado parcialmente, es la zona no reparada la que muestra síntomas de corrosión análogos a los de las traviesas.

Las losas de hormigón armado de las plataformas no muestran tantos síntomas de corrosión, salvo la situada en el acceso a la Plataforma A, con manchas de corrosión generalizadas.

En los Duques de Alba, la corrosión afecta fundamentalmente a las superficies laterales, con desprendimiento de recubrimiento.

\subsubsection{Muelle B}

Se han inspeccionado los 19 módulos de los que consta el pantalán. Cada muelle consta de 6 cabeceros continuos y en algunos puntos aparecen cabeceros 
aislados cuadrados. En la inspección se detectaron los siguientes defectos superficiales, tal y como se aprecia en las fotografías:

- Fisuras longitudinales en los laterales de los cabeceros, prácticamente existentes en todos, en mayor o menor cuantía. Las fisuras suelen situarse a unos cinco $\mathrm{cm}$ de altura, coincidiendo con la posición de la parrilla inferior de armado. Presentan manchas de corrosión en la mayoría de los casos (figura 5.25).
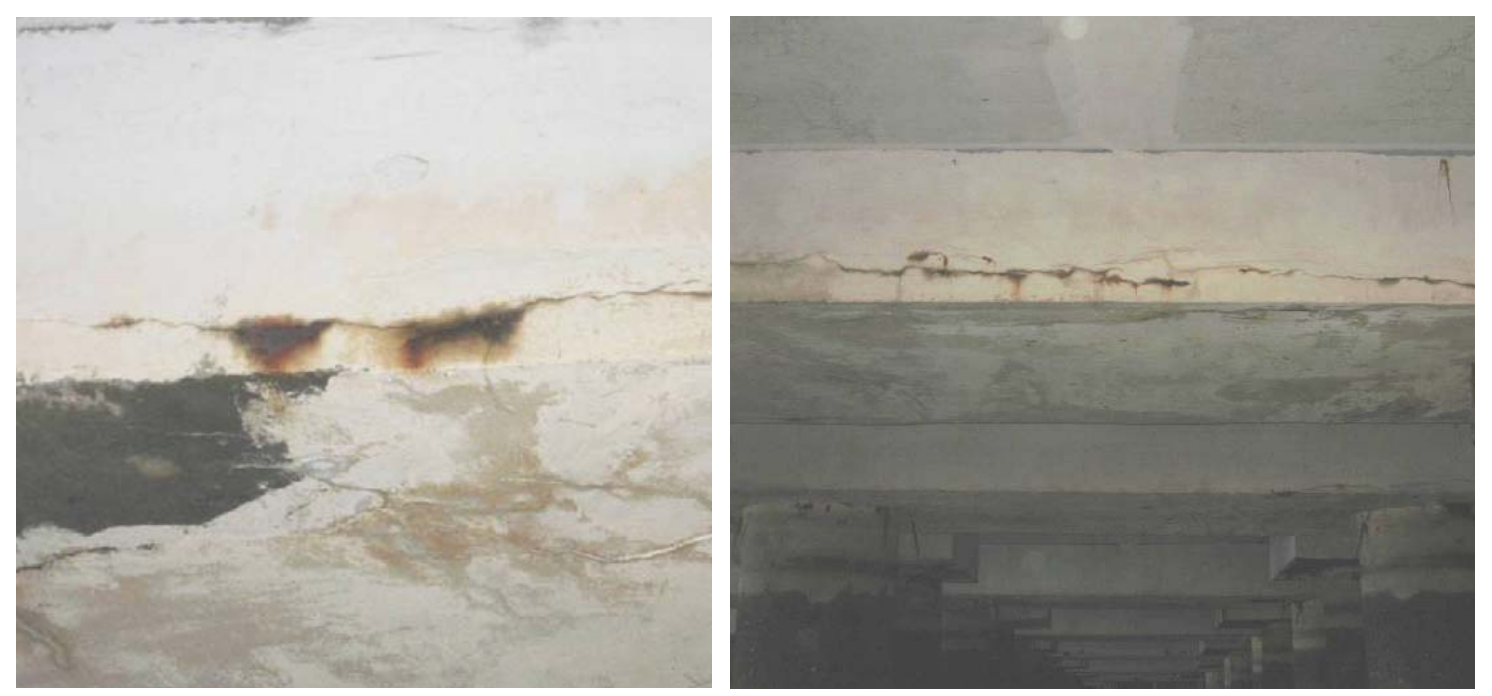

Fig.5.25. Fisuras longitudinales.

- Fisuras en superficie inferior de los cabeceros. Suelen ser longitudinales y situadas a unos cinco $\mathrm{cm}$ del borde; a veces más interiores o no longitudinales (figura 5.26).

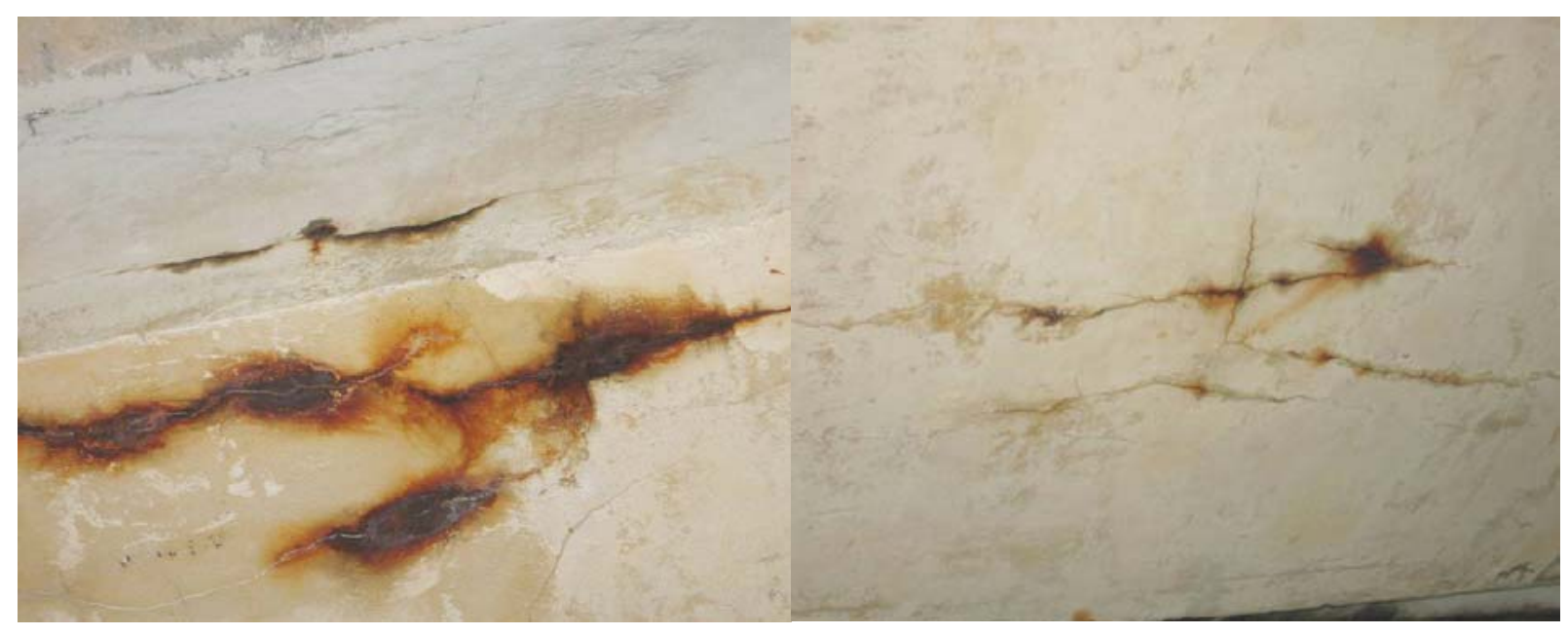

Fig.5.26. Fisuras en cara inferior de cabeceros. 
- Desconchones en superficie inferior de los cabeceros, con armadura a la vista y síntomas de corrosión. En algunos casos la superficie afectada es de más de $1 \mathrm{~m}^{2}$ y en otros afecta a una única barra de armado (figura 5.27).
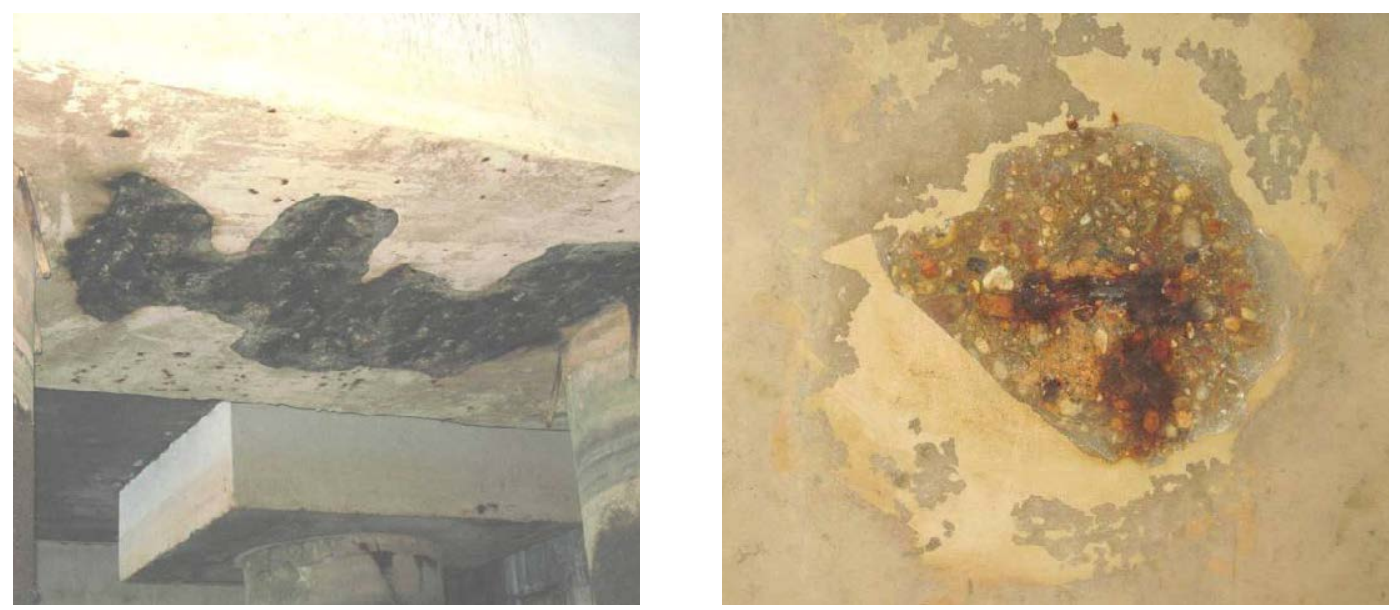

Fig.5.27. Desconchones en cabeceros.

- Puntos de corrosión en superficie inferior de los cabeceros, indicando un estado de corrosión más temprano, sin la cantidad de óxido suficiente como para el desprendimiento del recubrimiento (figura 5.28).
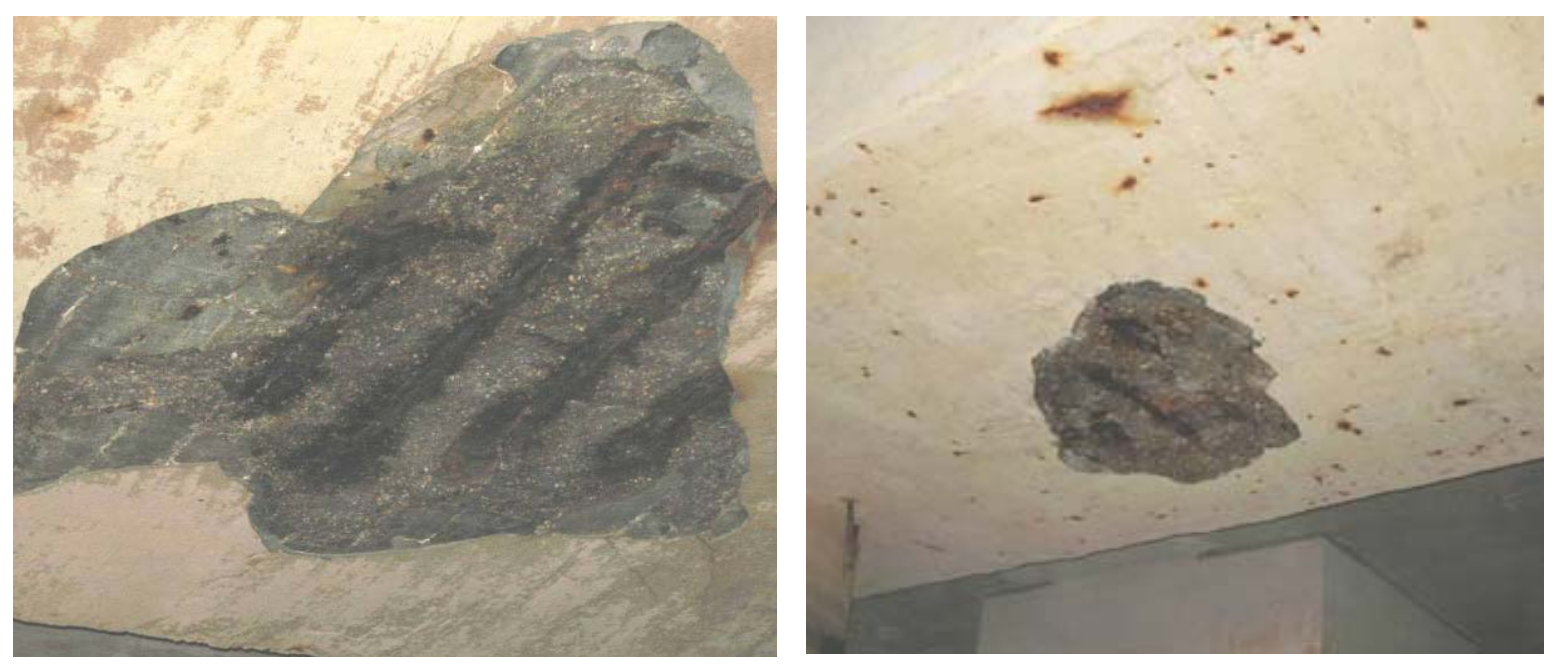

Fig.5.28. Marcas puntuales de corrosión. 
- Desconchones en losa, mucho menos habituales que en el caso de los cabeceros, y ocupando menor superficie. En los puntos en que se producen, la armadura queda a la vista y aparece corroída (figura 5.29).
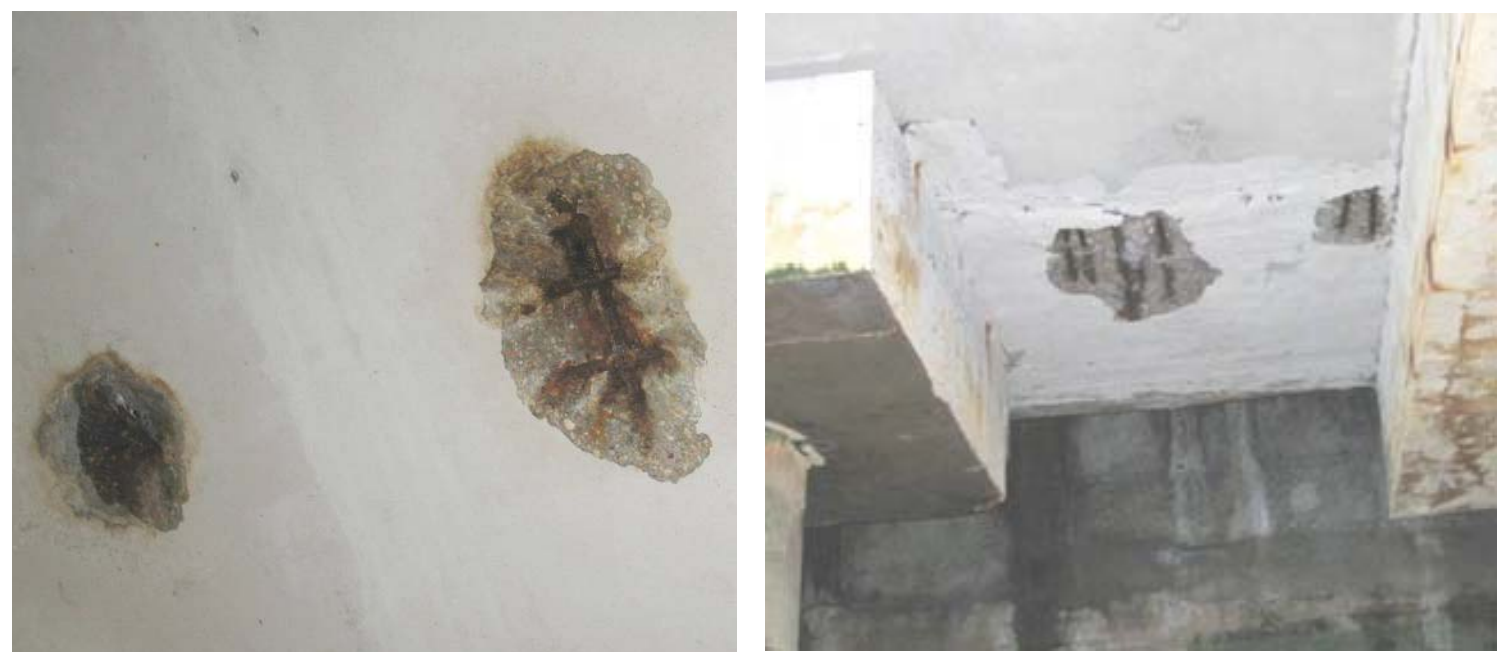

Fig.5.29. Desconchones en losa

- Fisuras transversales en losa, resulta común encontrar una franja de unos $30 \mathrm{~cm}$ con fisuración y hormigón deteriorado en el extremo de la losa más próximo al exterior (figura 5.30).
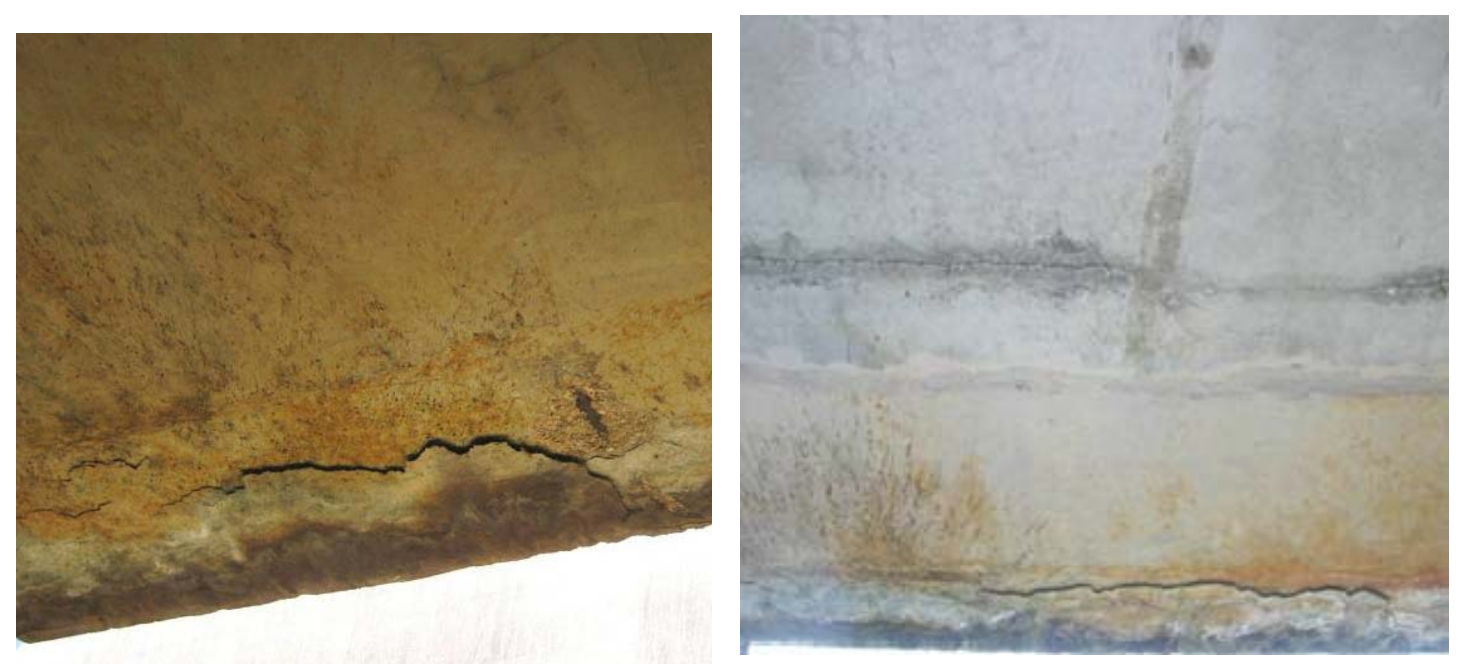

Fig.5.30. Fisuras transversales. 
- Puntos de corrosión en losa, menos abundantes y con menos superficie ocupada (figura 5.31).
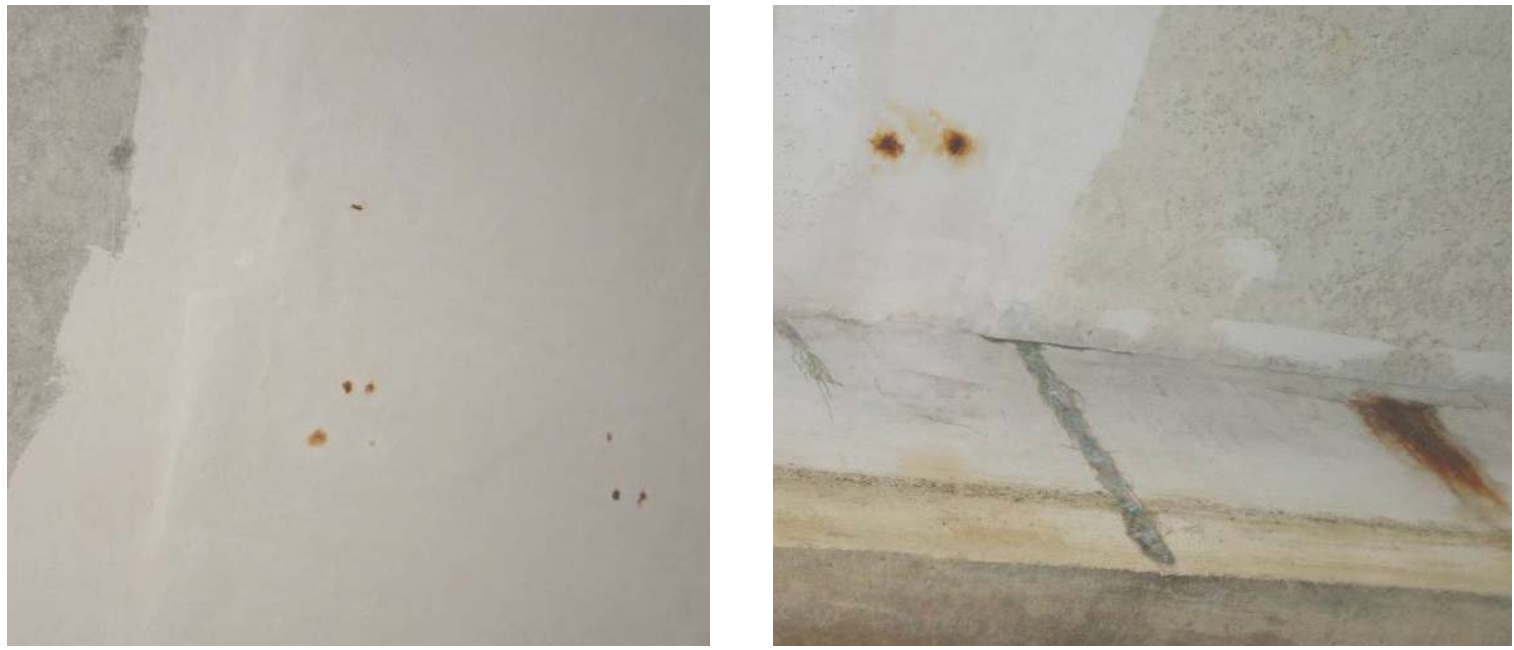

Fig.5.31. Puntos de corrosión.

- Juntas entre módulos en mal estado, que en general presentan manchas de humedad (llegando en algunos casos a gotear) y el hormigón con manchas de óxido (figura 5.32).
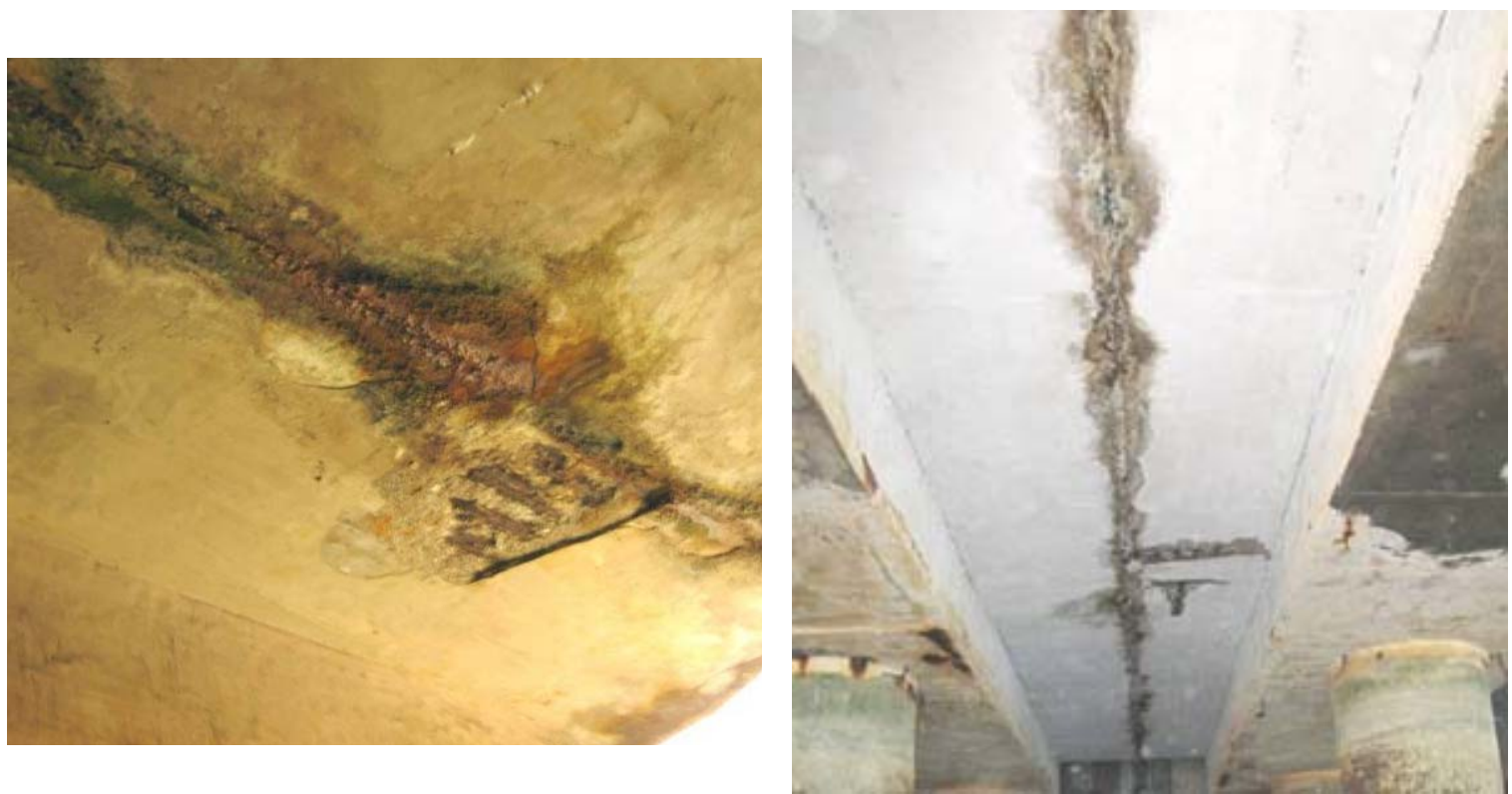

Fig.5.32. Mal estado de juntas. 
- Desconchones en aristas de caberos cuadrados aislados, en algunos casos la arista vertical ha saltado, dejando la armadura vertical vista y con corrosión avanzada (figura 5.33).
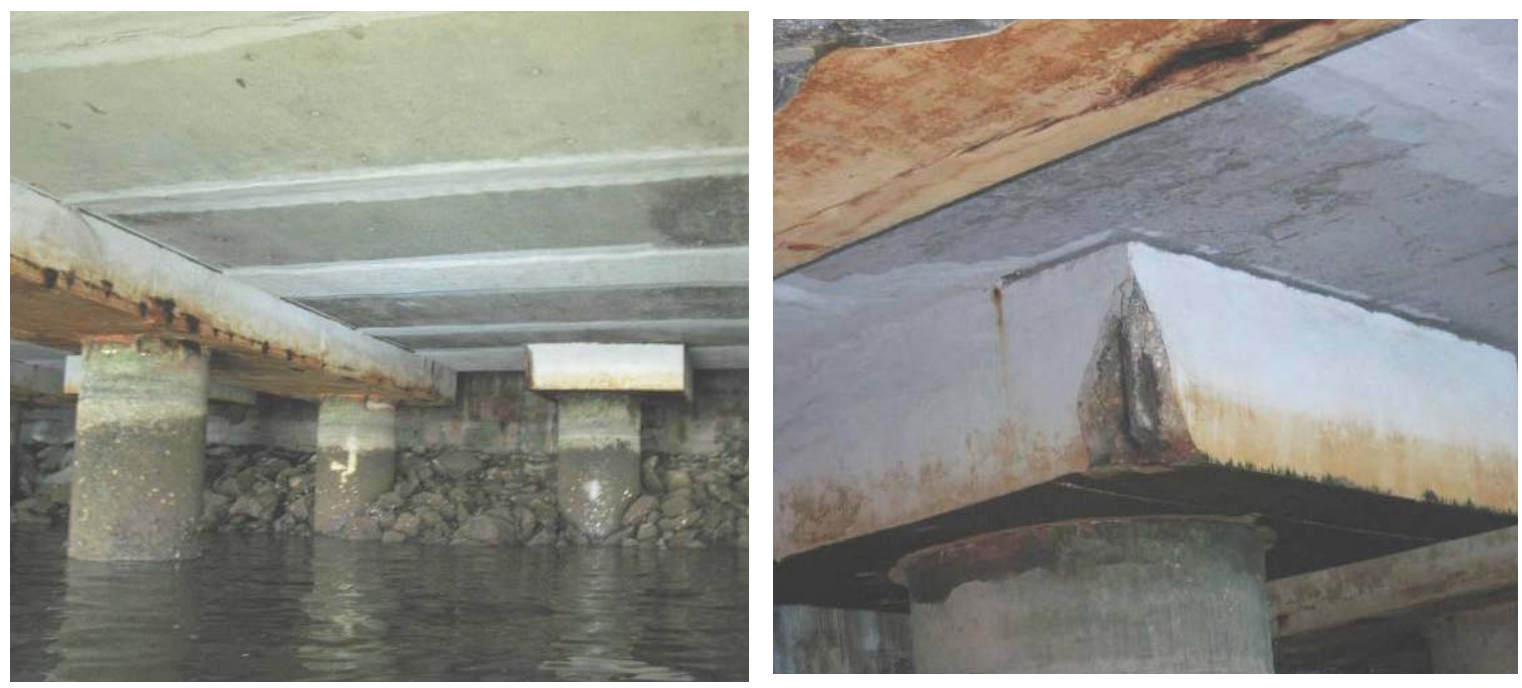

Fig.5.33. Vista frontal de uno de los cabeceros aislados .En la fotografía de detalle, se aprecian desconchón en arista.

- Fisuras en el faldón de los cabeceros, se observan en unos pocos faldones, son de pequeña magnitud y sin manchas de corrosión (figura 5.34).
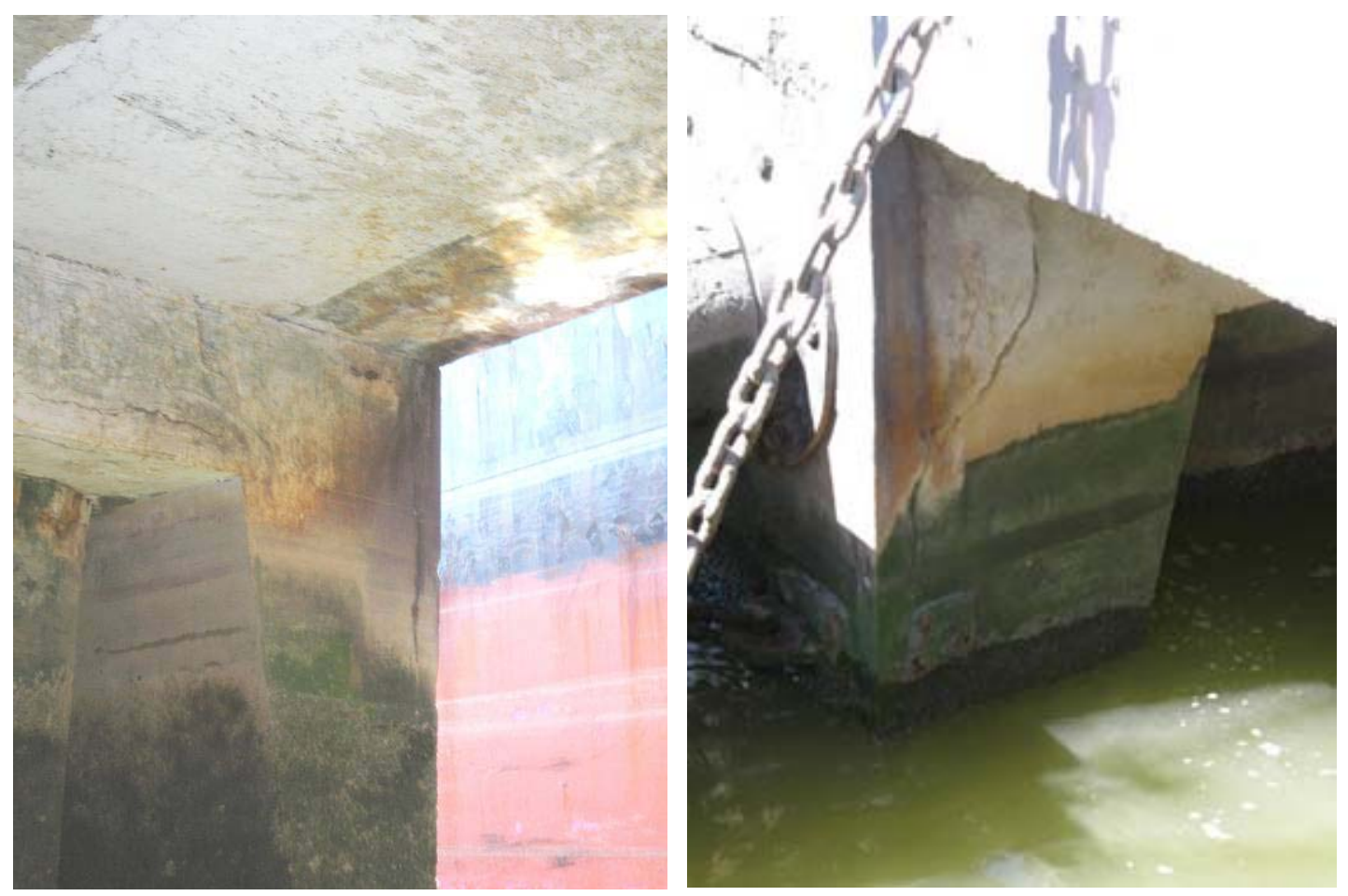

Fig.5.34. Fisuras en faldón de cabeceros. 
- Desconchón en aristas del faldón de los cabeceros, de forma puntual parece este defecto en algún caso y probablemente causado por algún golpe (figura 5.35).
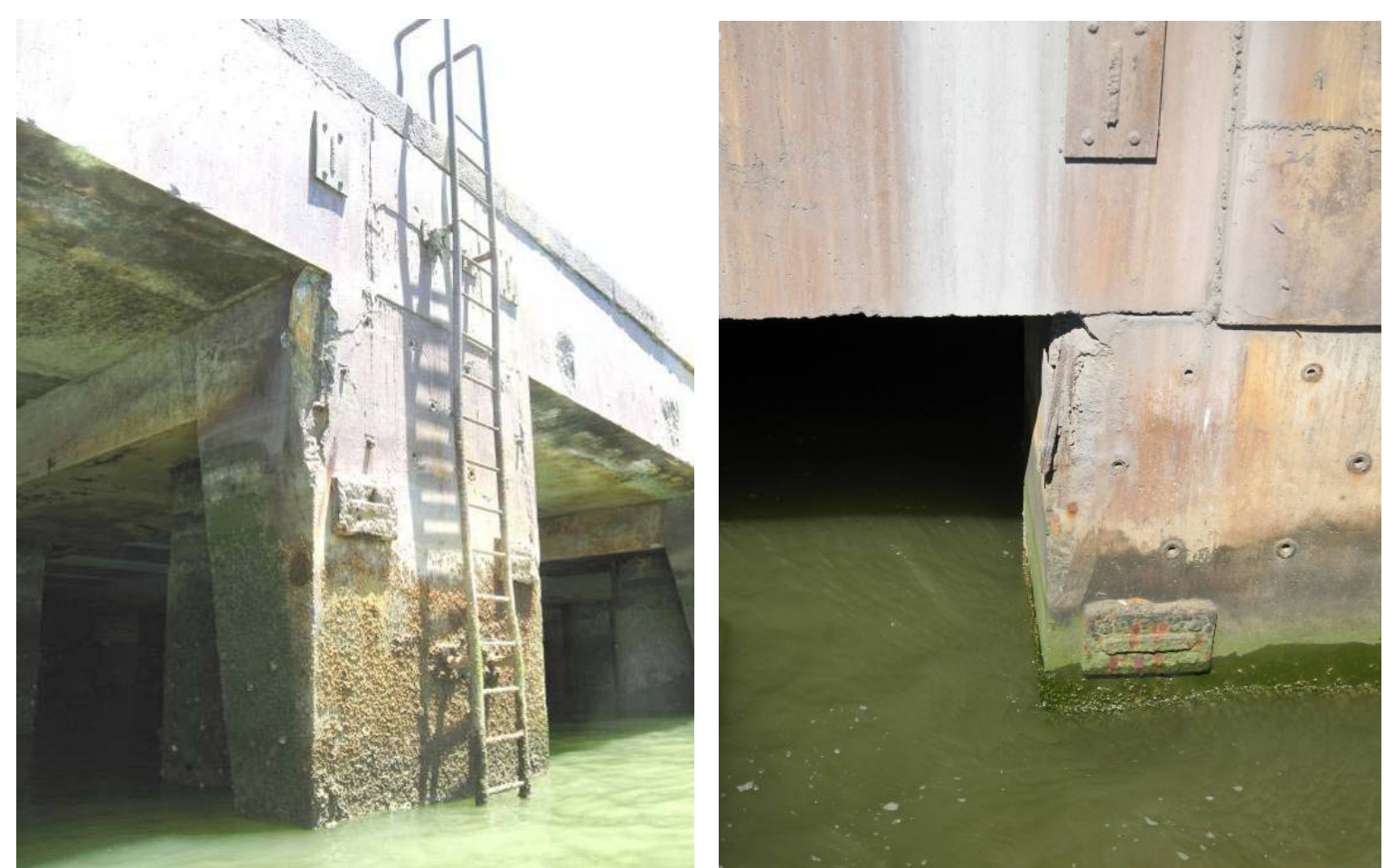

Fig.5.35. Desconchones en aristas.

Tras el análisis de la inspección realizada, el defecto más llamativo de los cabeceros continuos corresponde a la fisuración longitudinal en los paramentos laterales, coincidiendo con la situación de la parrilla inferior de armado del cabecero. También es representativa la pérdida de recubrimiento en zonas del paramento inferior de los mismos, dejando armadura a la vista y con síntomas de corrosión. En dicho paramento inferior se observan fisuras y manchas de corrosión, pero en menor cuantía que en el paramento lateral. Los faldones de los cabeceros presentan en general buen aspecto, con fisuras puntuales y algún desconchón aislado.

En algunos cabeceros aislados se observa que la arista lateral ha saltado, dejando la armadura vista y en un estado muy avanzado de corrosión.

En las losas los síntomas de corrosión son menores, aunque parecen haber sido reparadas recientemente. No se observan fisuras en general, salvo en el extremo de losa más próximo al exterior, donde es habitual que la franja final de $30 \mathrm{~cm}$ esté fisurada y el hormigón deteriorado. En el resto de la losa se observan algunas 
manchas de corrosión puntuales y, sobre todo, pérdidas de recubrimiento, aunque de menor extensión que en los cabeceros. Las juntas entre módulos suelen mostrar manchas de humedad y de corrosión en el hormigón adyacente.

\subsubsection{Muelle C}

Se ha inspeccionado la estructura del muelle con el fin de comprobar el aspecto del hormigón así como detectar los posibles defectos superficiales, revisando fundamentalmente las vigas longitudinales y transversales que unen las cabezas de los pilotes así como el paramento inferior de la losa situada sobre tales vigas. Después se revisa el estado de la viga cantil y del paramento frontal del muelle.

El hormigón de losa y vigas presenta un buen aspecto en general, pese a la existencia de defectos puntuales. A continuación se relacionan los defectos principales observados.

- Manchas de óxido superficial marcando la posición de la armadura (figura 5.36).
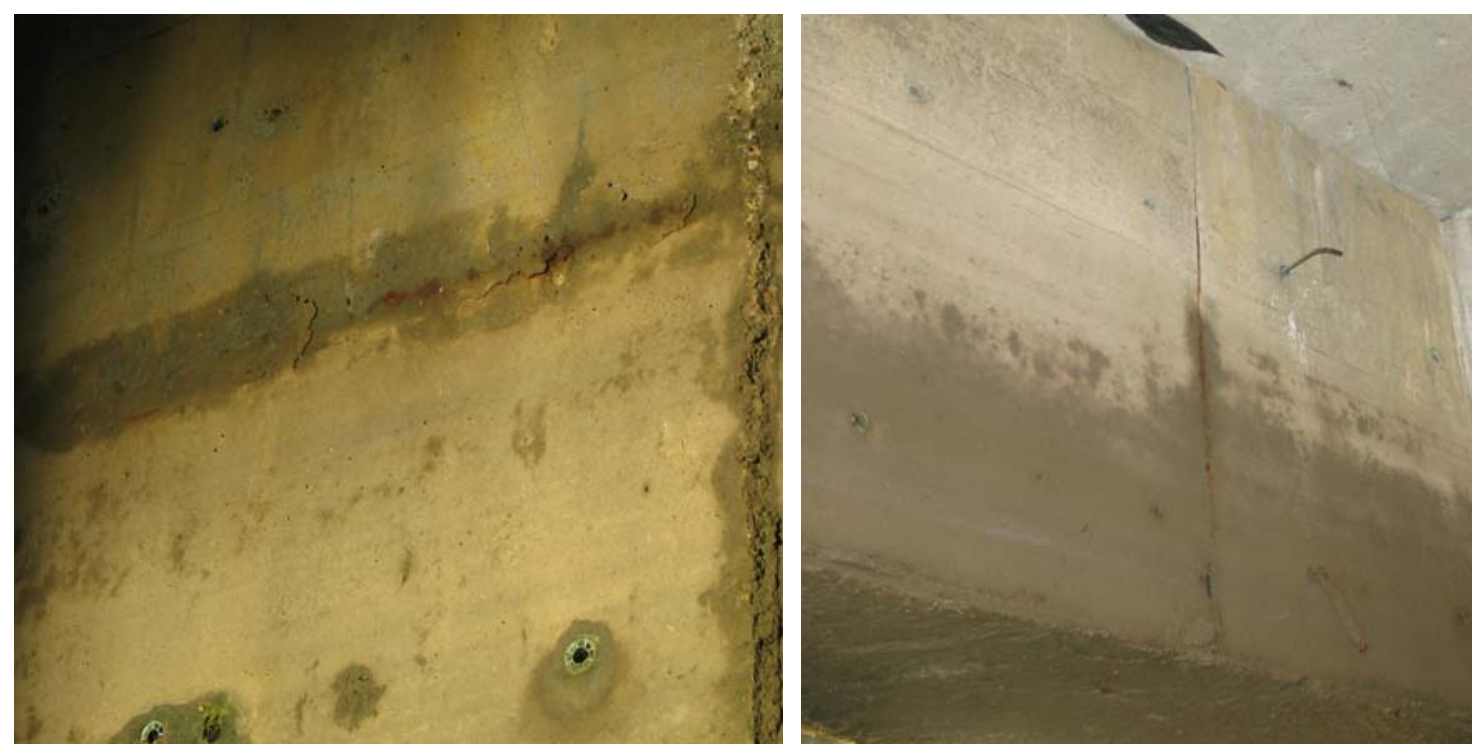

Fig.5.36. Óxido superficial. 
Pequeños puntos de óxido posiblemente asociados a puntos de alambres de atado (figura 5.37).
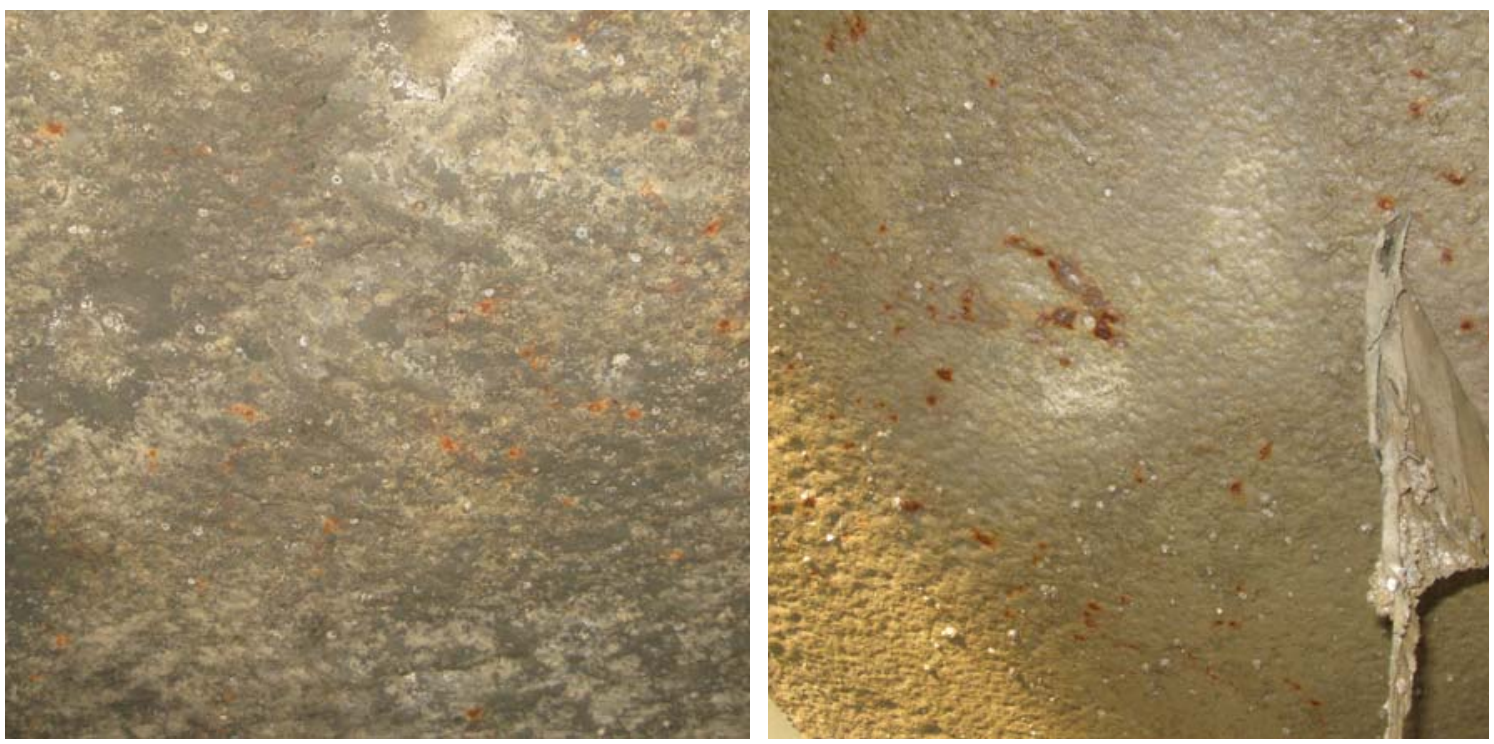

Fig.5.37. Puntos de óxido.

- Armaduras a la vista con síntomas de corrosión y en algunos casos, pérdida de sección de armadura (figura 5.38).

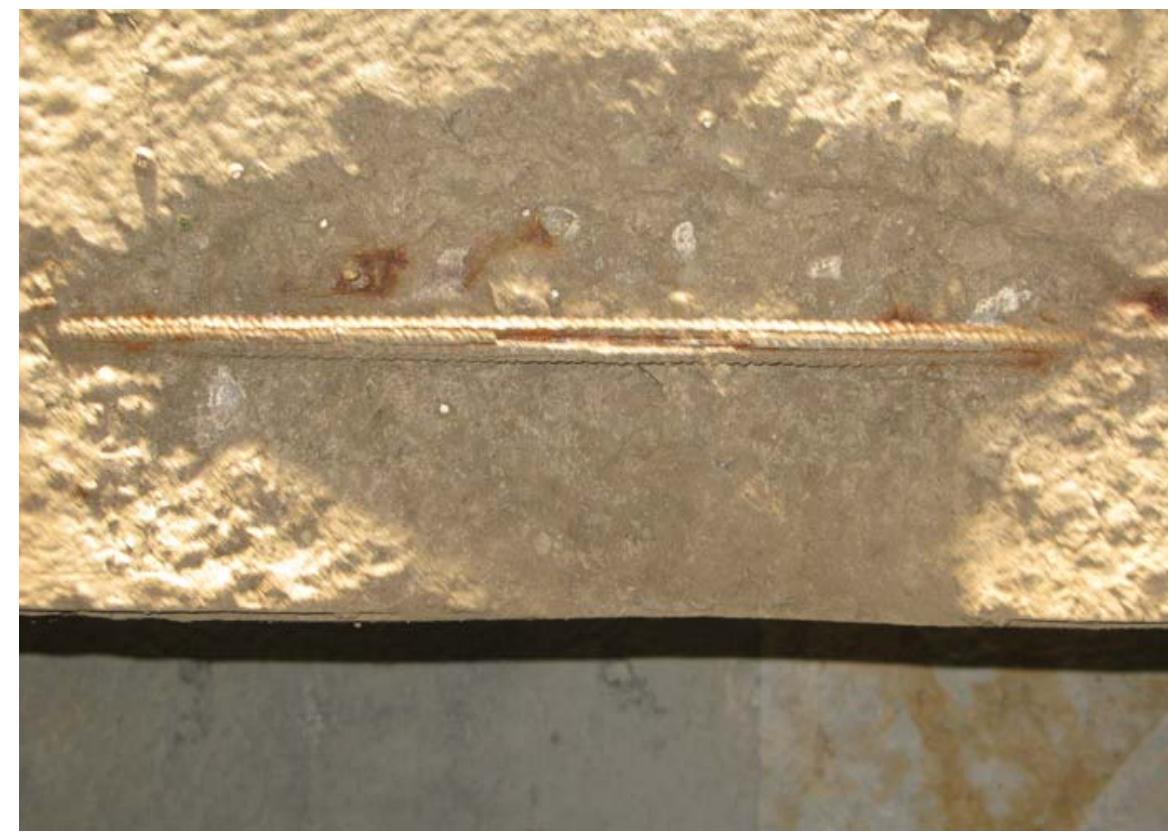

Fig.5.38. Armaduras a la vista. 
- Falta de recubrimiento o merma del mismo en algunos puntos (figura 5.39).
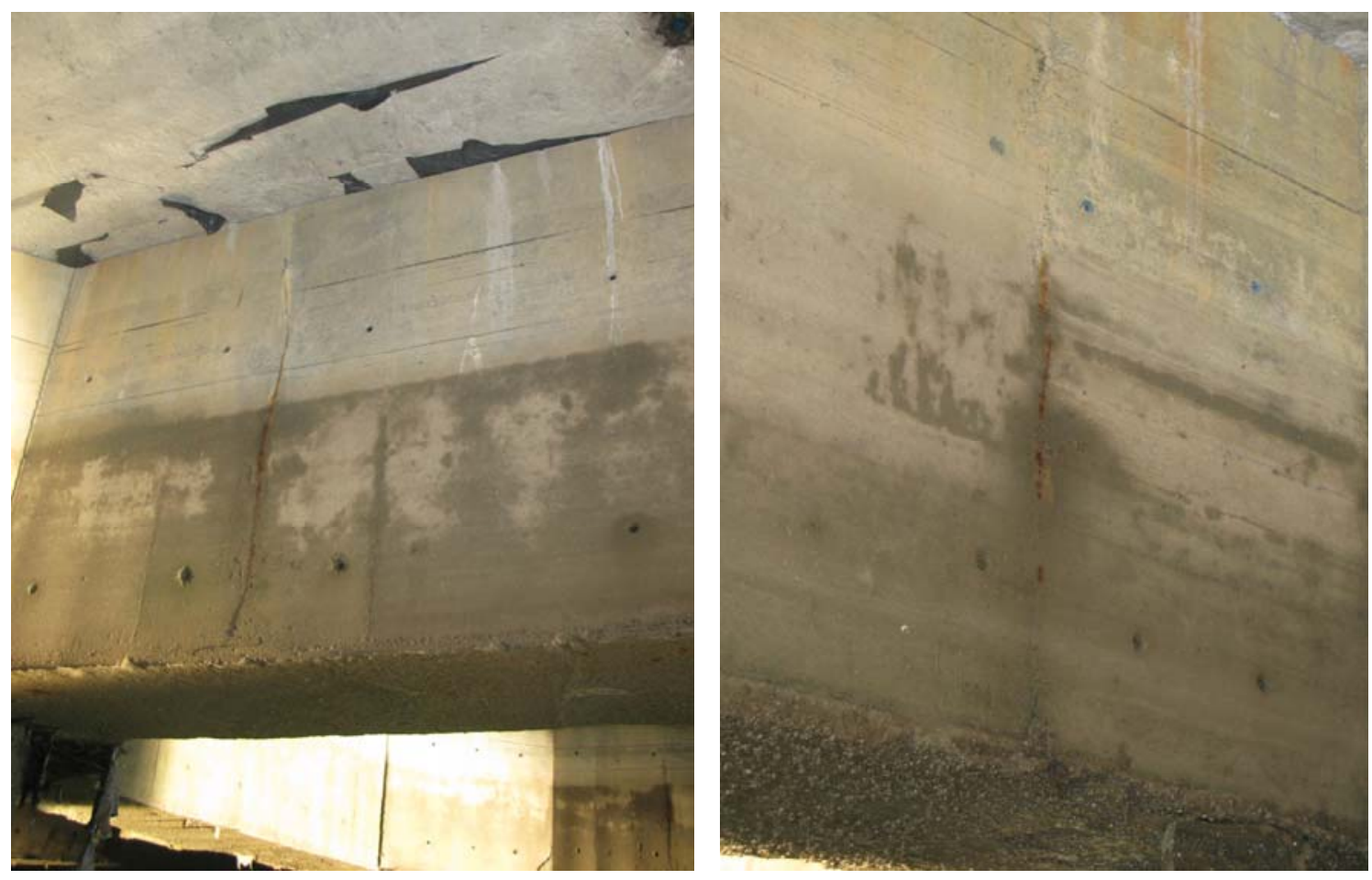

Fig.5.39. Falta de recubrimiento.

- Hormigón sin compactar dejando las armaduras sin recubrimiento (figura 5.40).
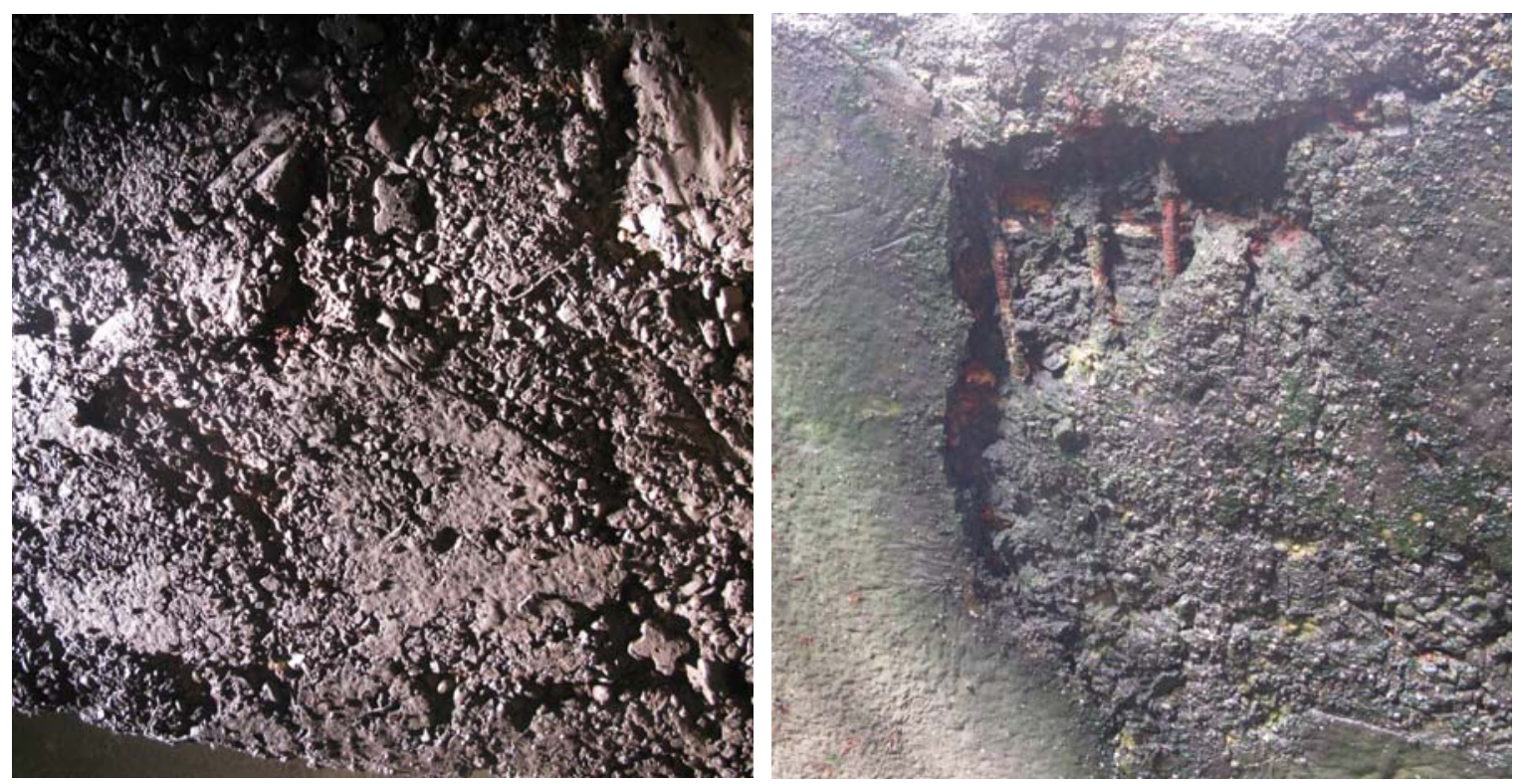

Fig.5.40. Deficiente compactación 
- Descarnado del hormigón en esquinas o bordes, por inadecuada compactación o por golpes (figura 5.41).
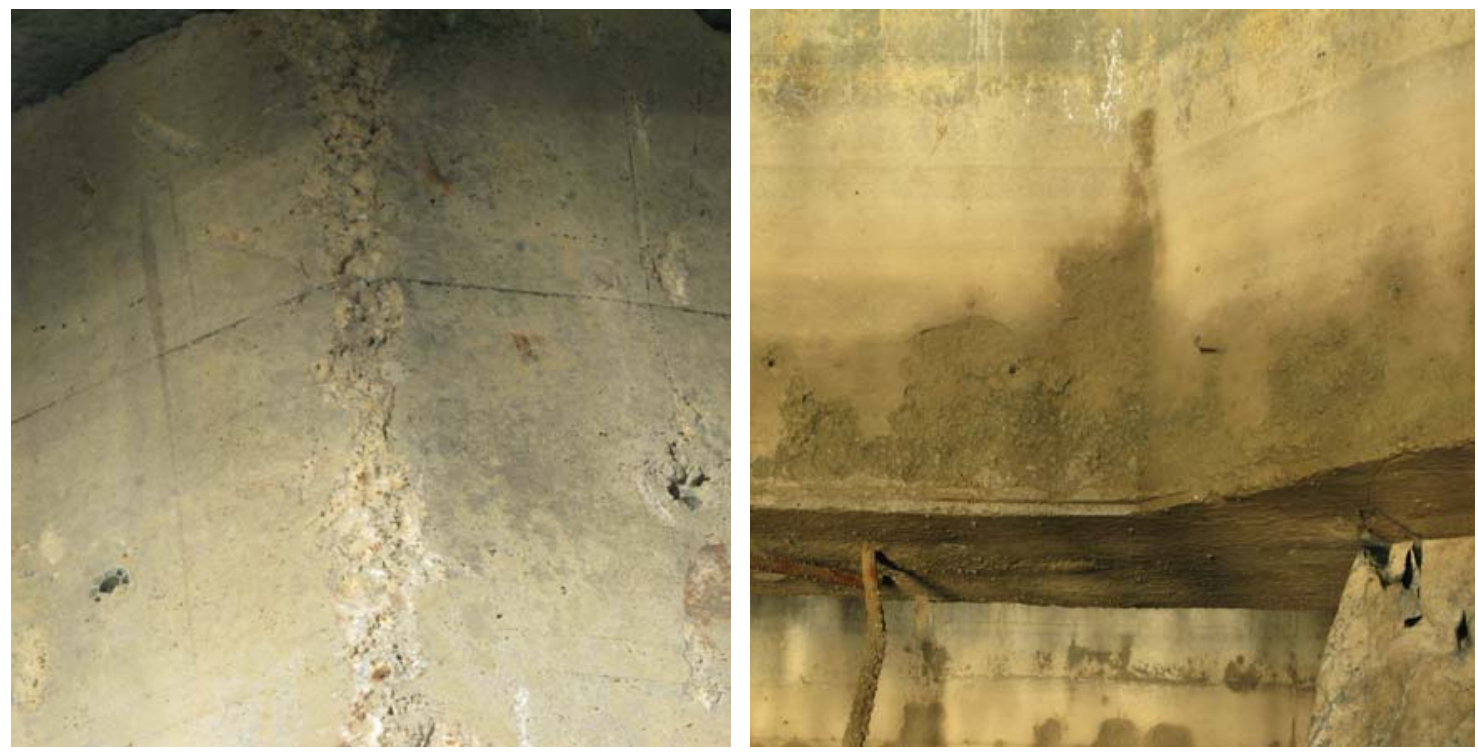

Fig.5.41. Descarnados en el hormigón.

- En algunos casos, coqueras superficiales, pérdida o ausencia de lechada superficial (figura 5.42).
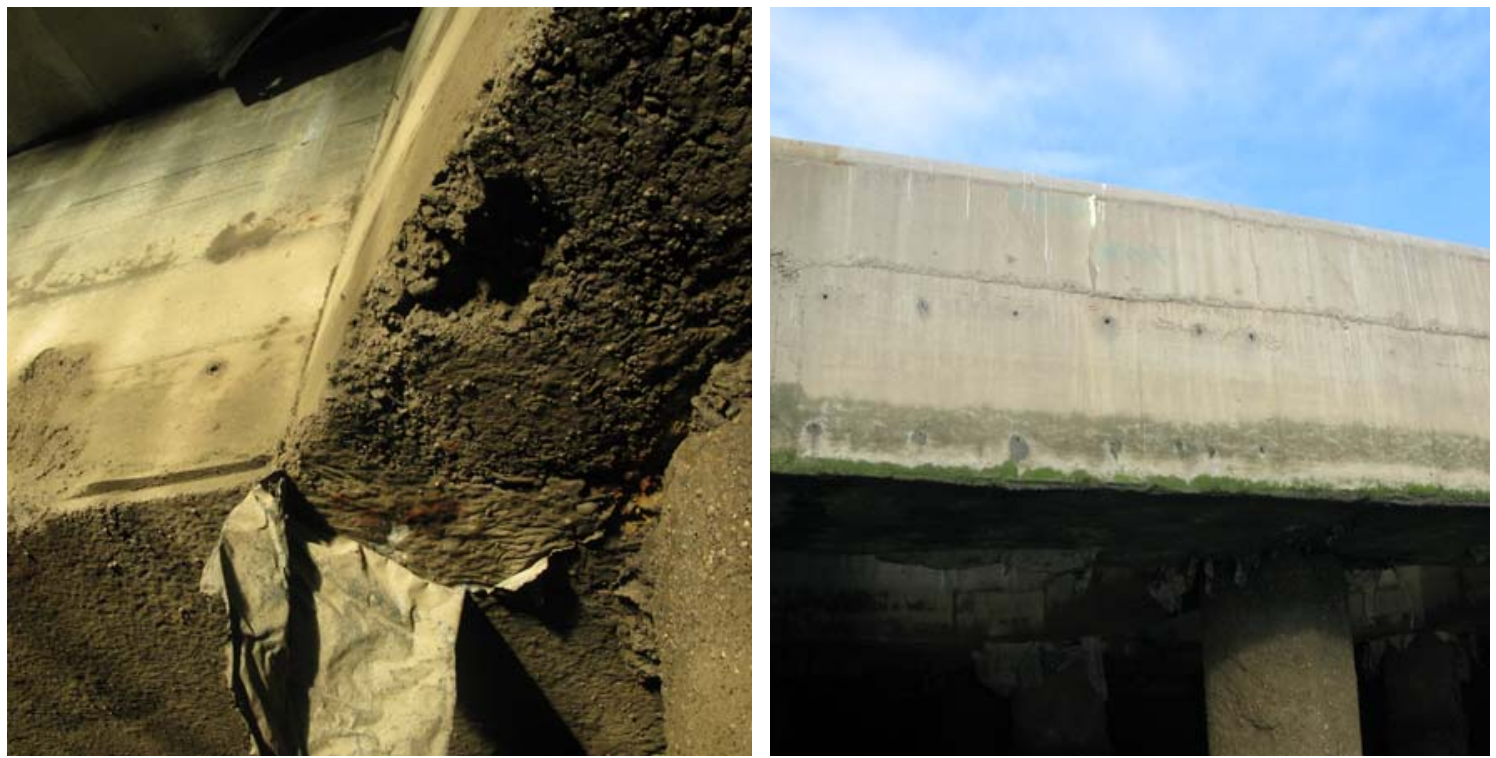

Fig.5.42. Coqueras puntuales 
- Armadura fuera del hormigón y anclajes del encofrado abandonados (figura 5.43).
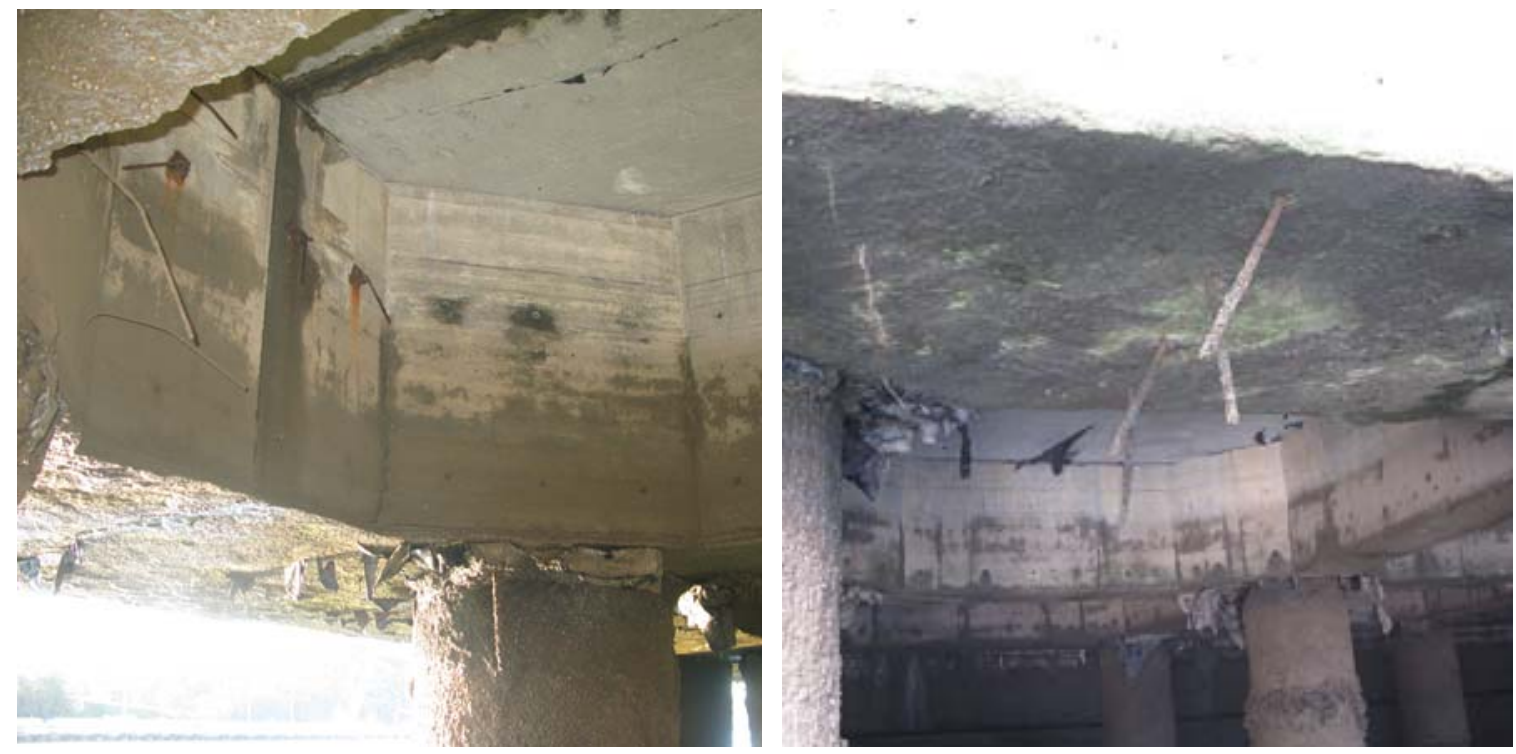

Fig.5.43. Armaduras y anclajes de encofrado a la vista.

- Armaduras expuestas con grado severo de corrosión (figura 5.44).
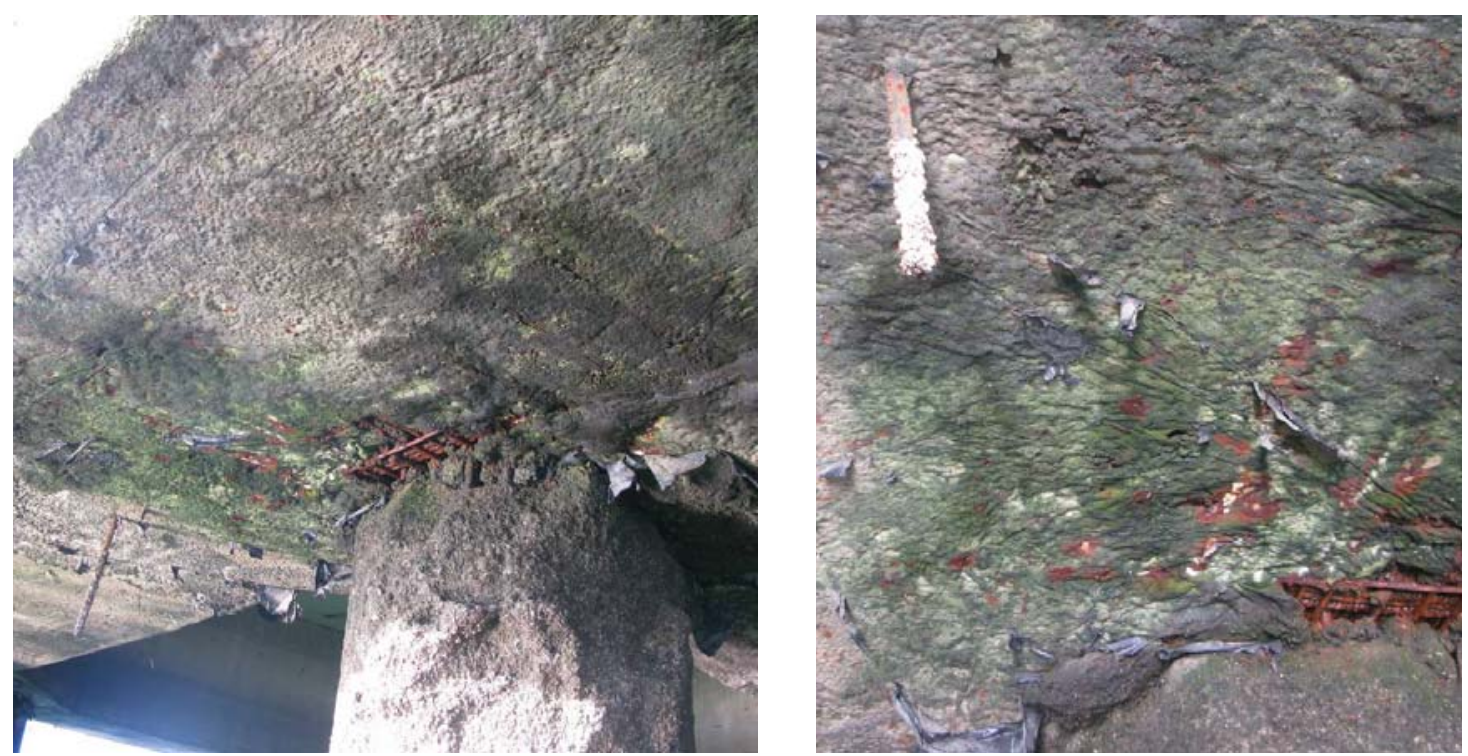

Fig.5.44. Armaduras muy corroídas. 
- Rebabas del hormigón, posible defecto ocasionado por el encofrado o en algún caso durante el desencofrado (figura 5.45).

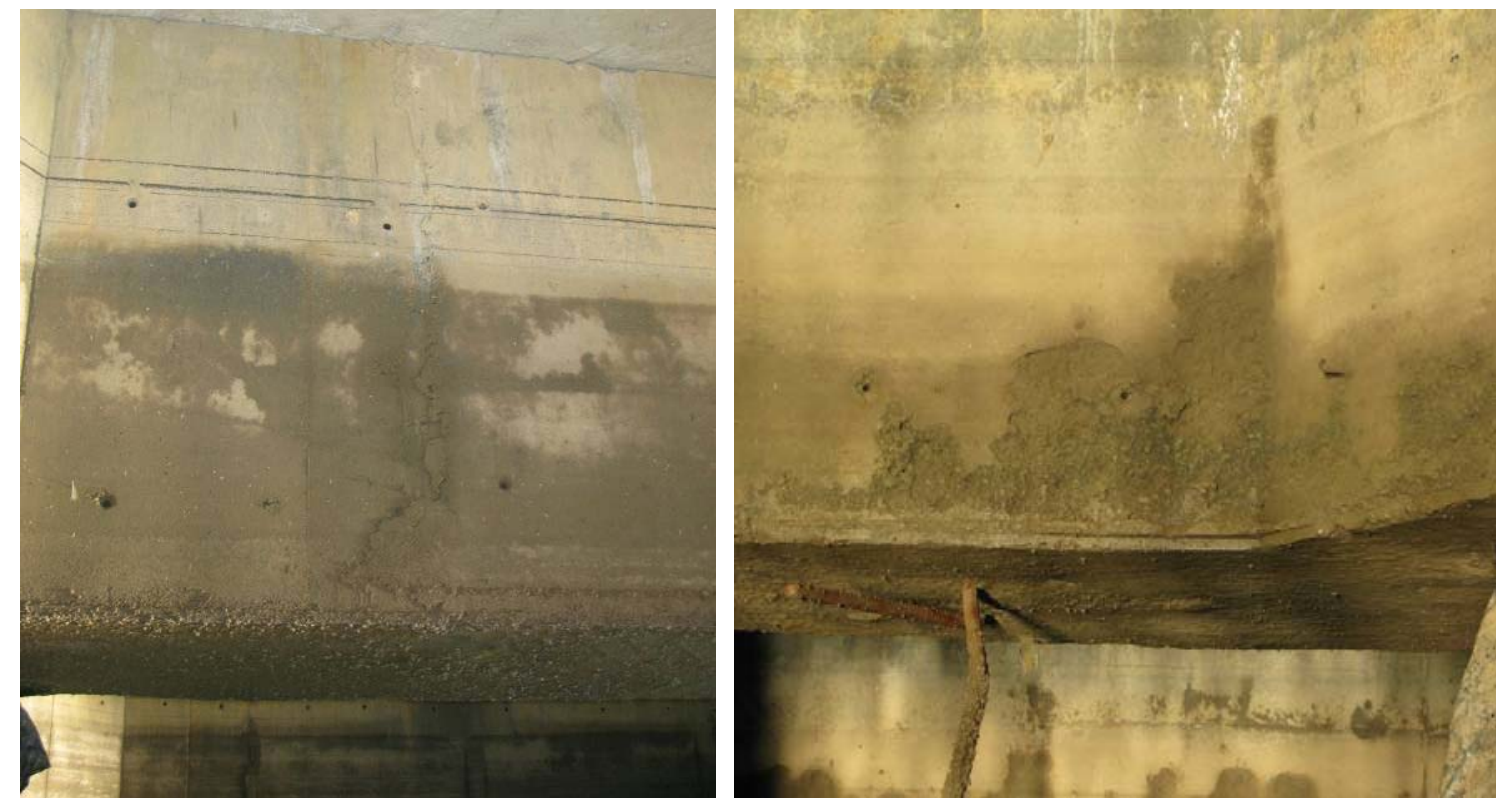

Fig.5.45. Rebabas del hormigón

- Aspecto irregular del hormigón que constituye las pilas-pilote. Pérdida del diámetro (figura 5.46).
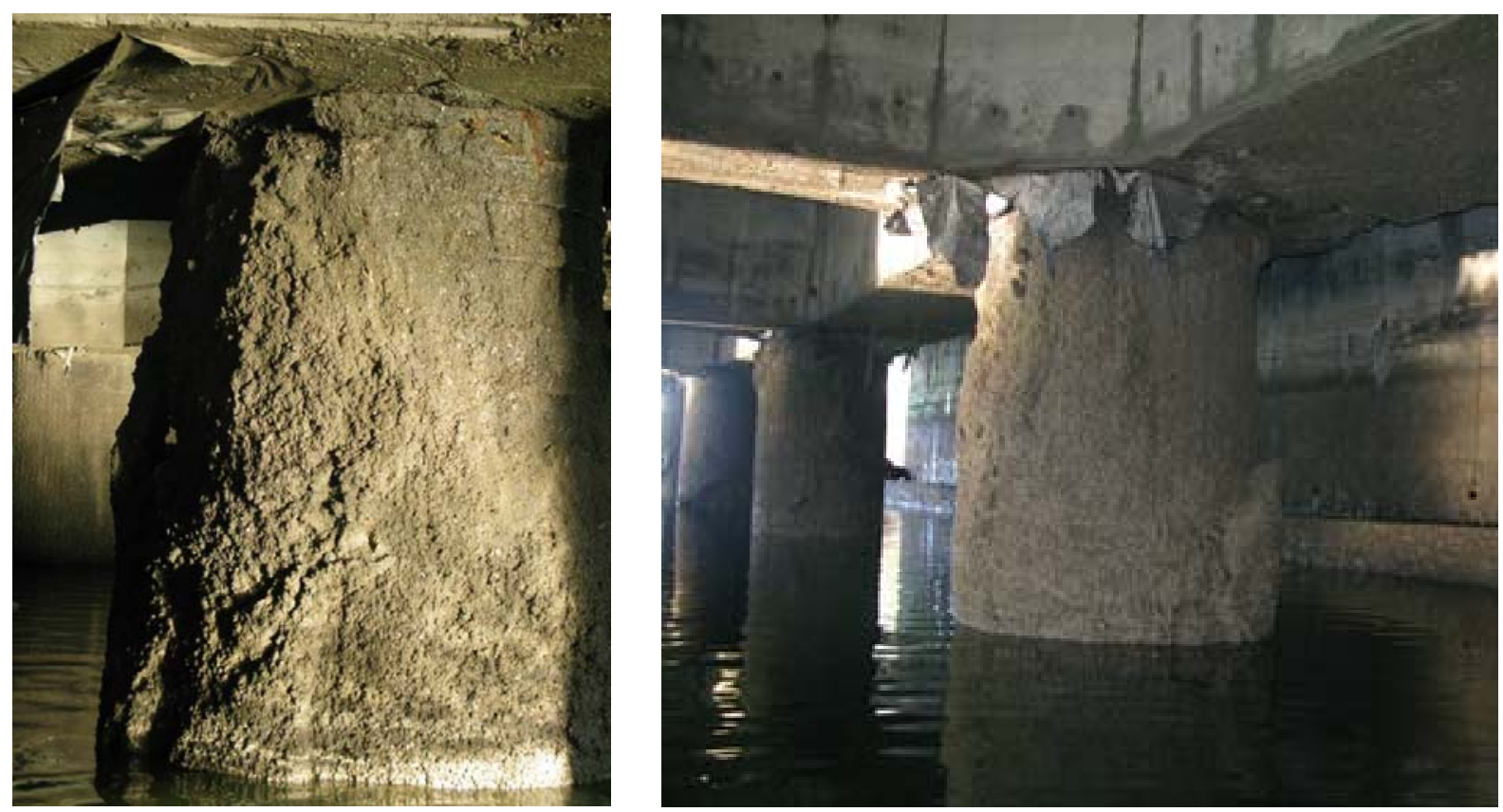

Fig.5.46. Pérdida del diámetro en pilas-pilote. 
- Fisuración puntual del hormigón (figura 5.47).

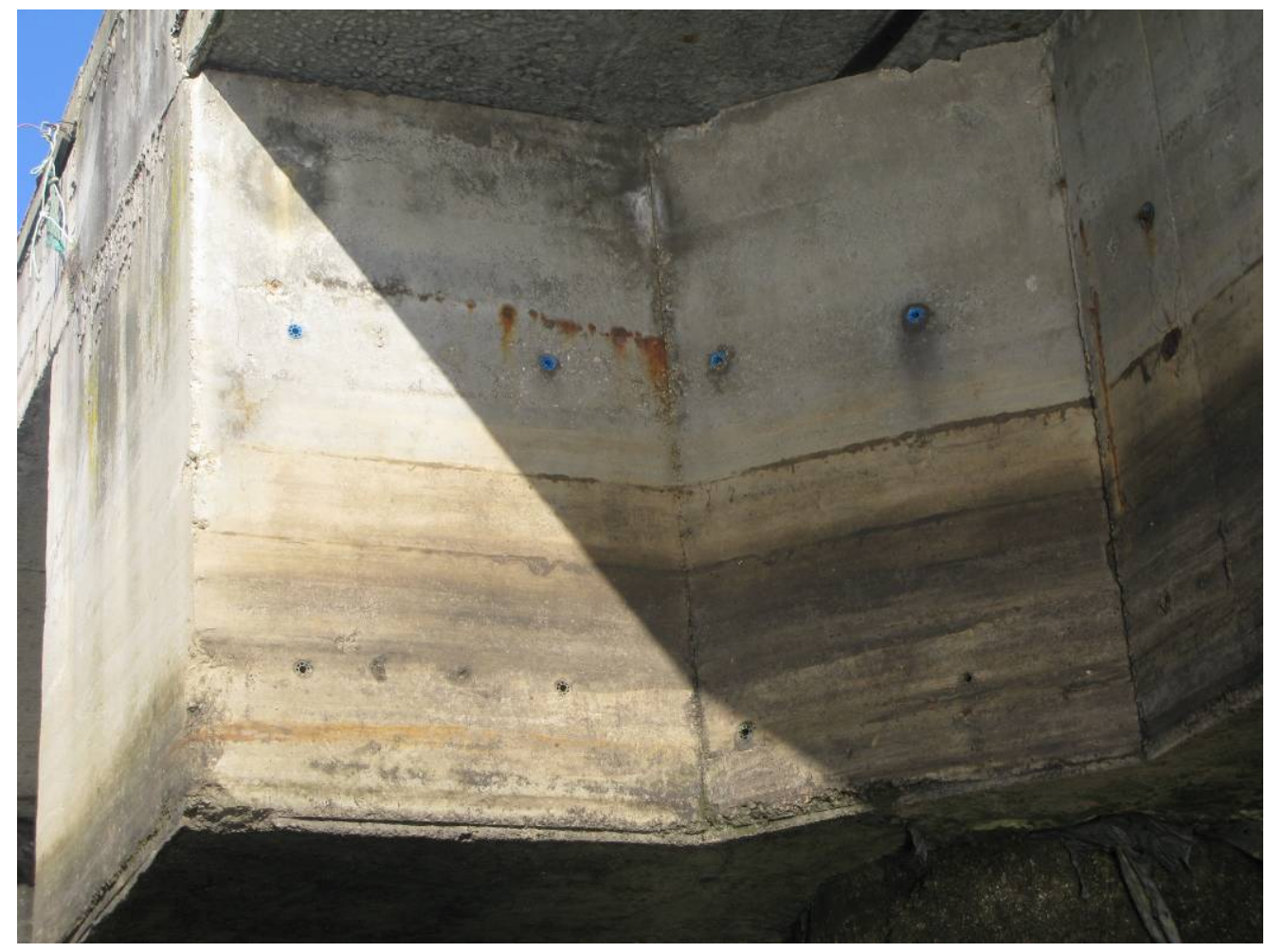

Fig.5.47. Fisuración puntual.

- Desconchones en el hormigón, sin quedar la armadura vista (figura 5.48).
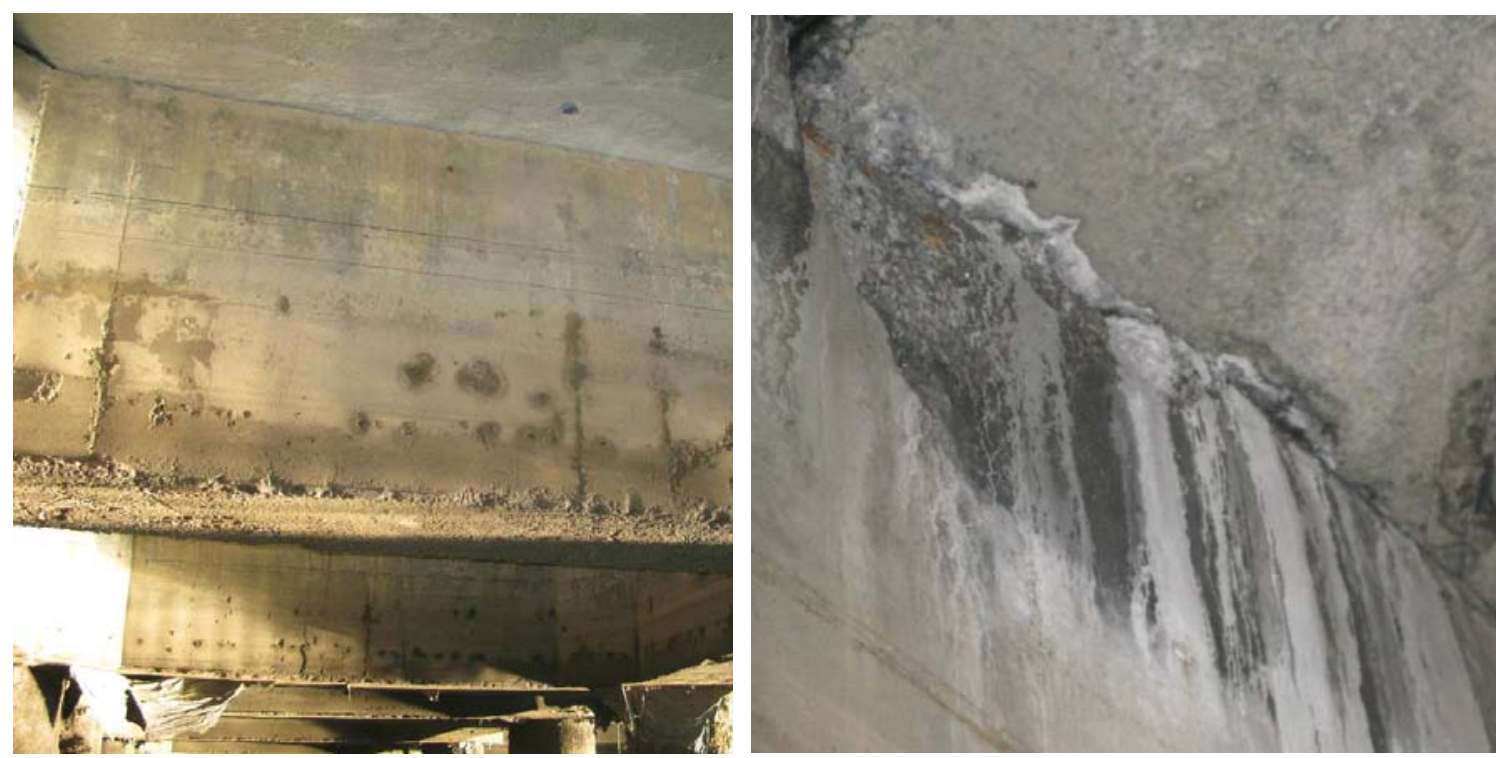

Fig.5.48. Desconchones sin armadura a la vista. 
- Depósitos de cal y manchas de eflorescencias por lixiviación. Filtraciones (figura 5.49).

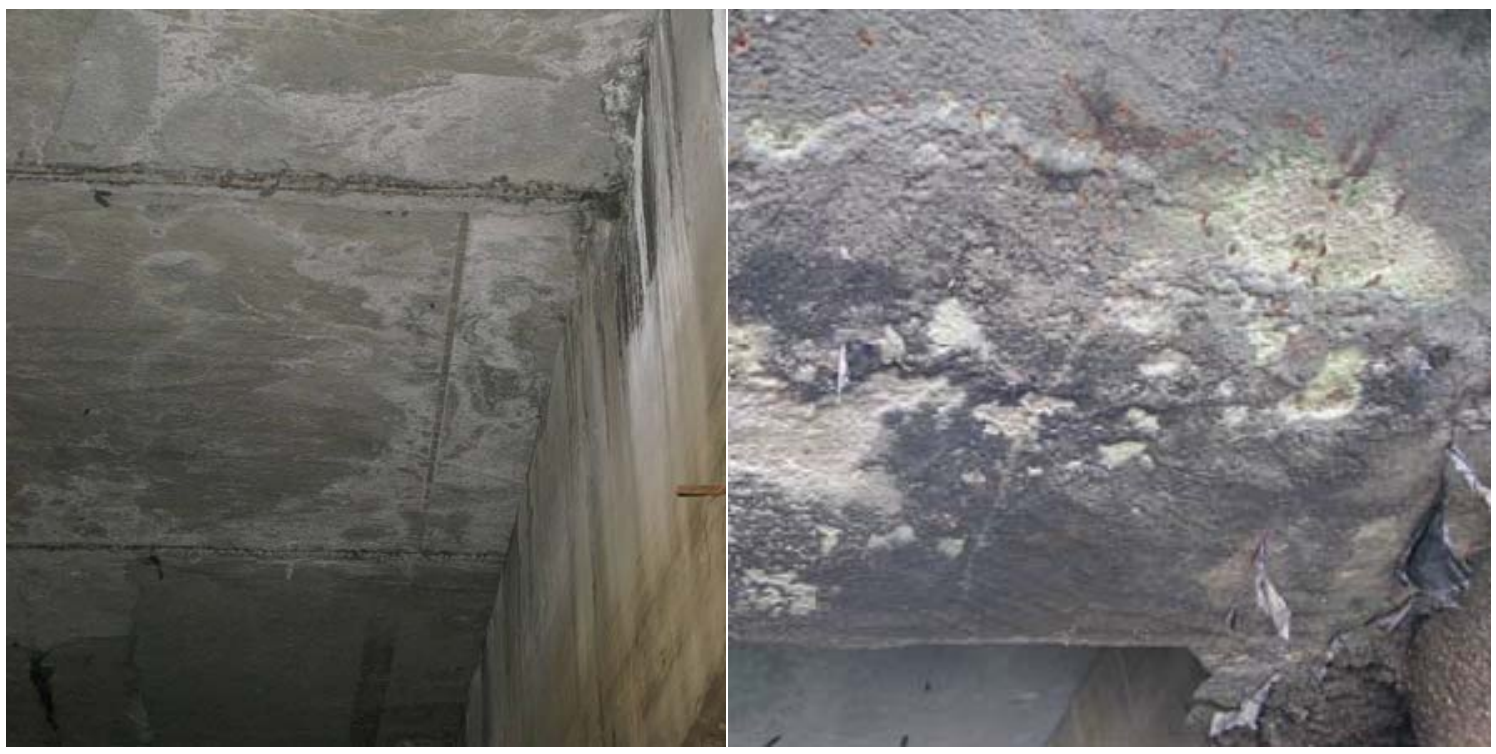

Fig.5.49. Eflorescencias.

- Enmohecido del hormigón (figura 5.50).
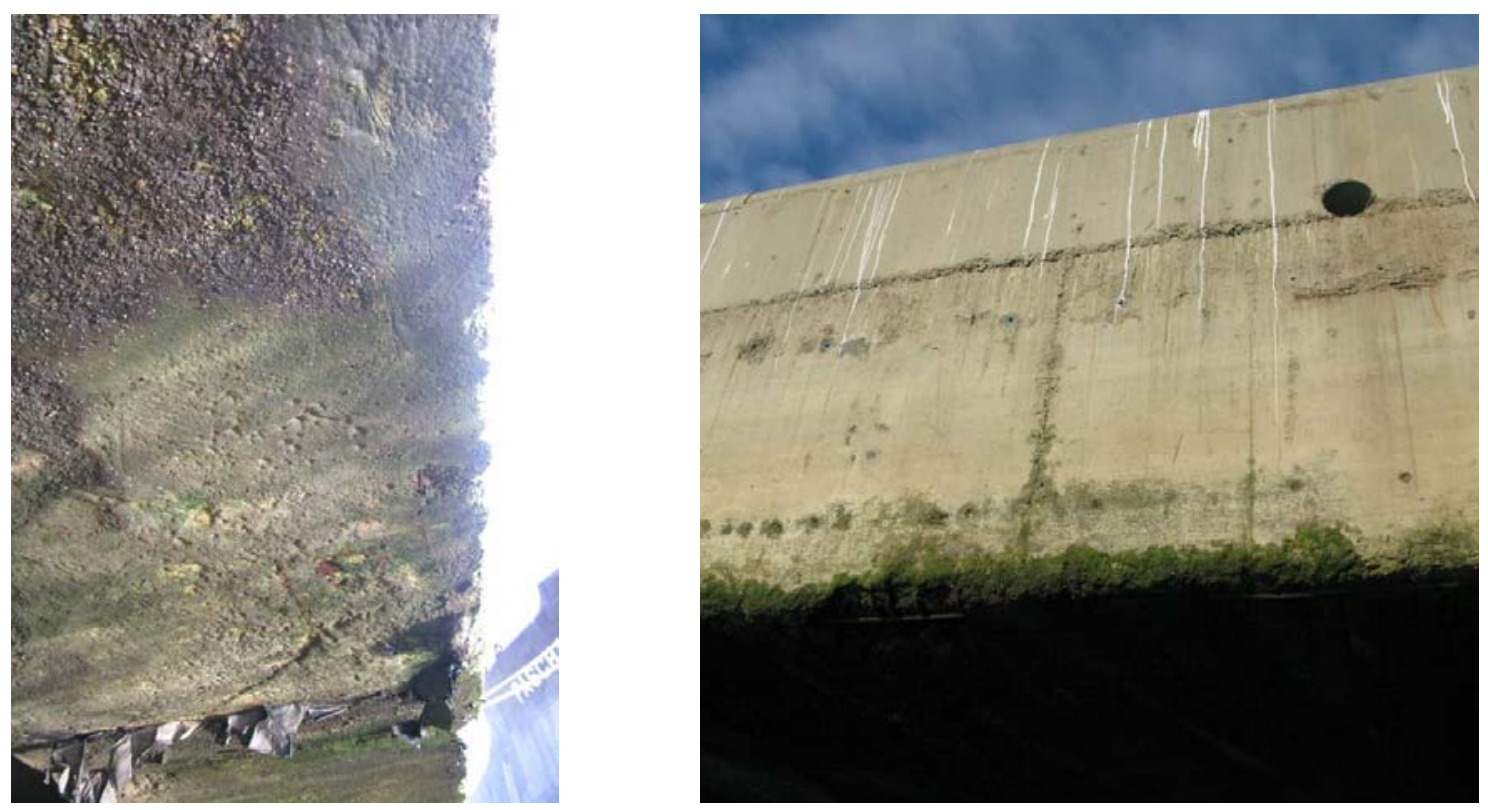

Fig.5.50. Enmohecido del hormigón. 
- Merma del hormigón durante el hormigonado (figura 5.51).
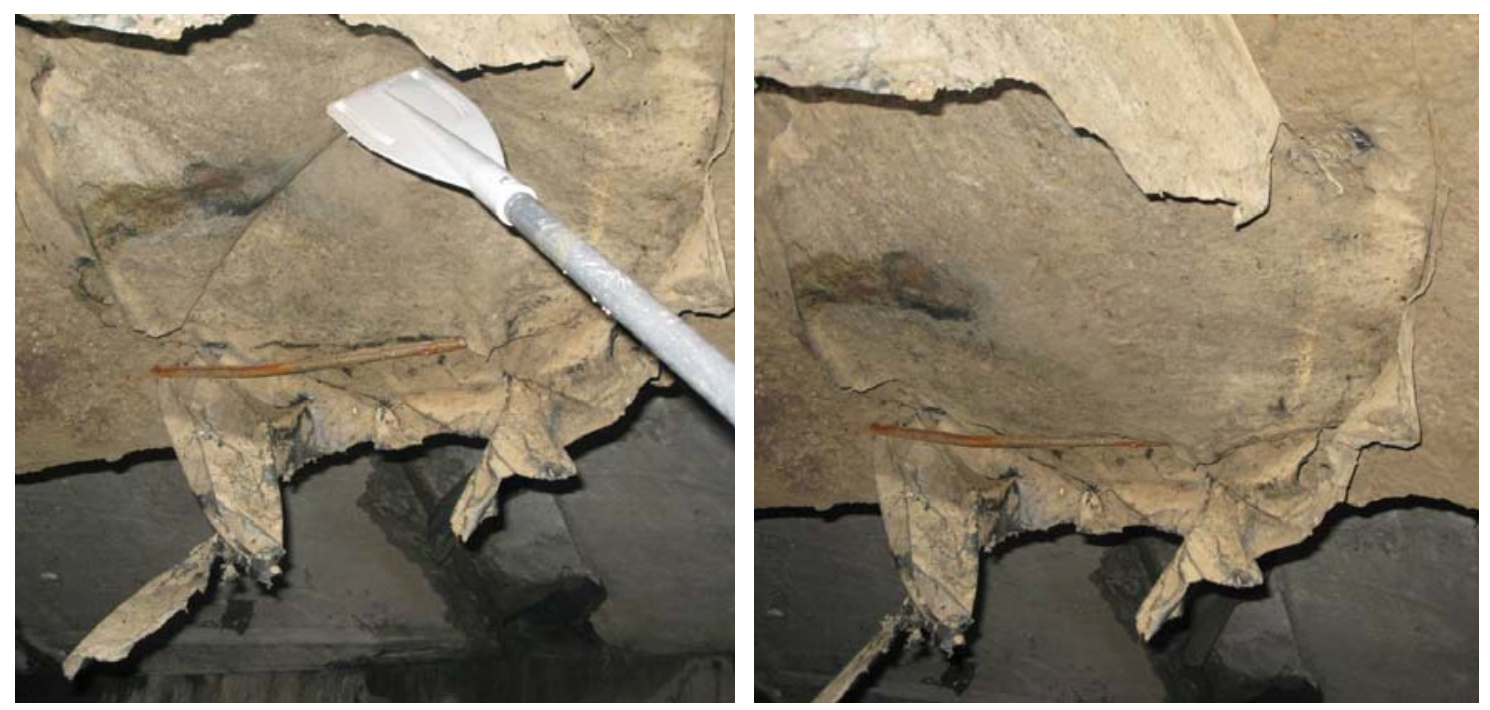

Fig.5.51. Merma en el hormigón.

\subsubsection{Muelle D}

La inspección se restringe a la viga cantil del muelle, única visible debido a la cercanía del tablero al nivel del mar y la reducida carrera de marea en el puerto.

Para facilitar los trabajos de auscultación e inspección, el tramo objeto de estudio se marca a distancias de 5 metros tomando como punto inicial la junta de unión del recrecido con el muelle primitivo (P1) hasta llegar al (P34). La longitud total inspeccionada es de 160 metros.

La inspección se realiza desde barca recorriendo el muelle a lo largo de la viga cantil, comenzando por el módulo 3 del recrecido (desde el P31) y finalizando la inspección en el comienzo del recrecido (módulo 1) en la junta de unión con el muelle antiguo (P1).

En general, el hormigón de la viga cantil presenta un buen estado, observándose un hormigón cerrado y compacto. A continuación se expone de forma resumida los principales defectos observados en la inspección visual:

- Presencia de barras roscadas, clavos y otros elementos metálicos insertados en el hormigón con posterioridad y que han sido utilizados posiblemente como elementos de amarre y sujeción de embarcaciones. En muchos casos estos 
elementos han sido cortados a ras de superficie y abandonados, presentando corrosión (fig 5.52).

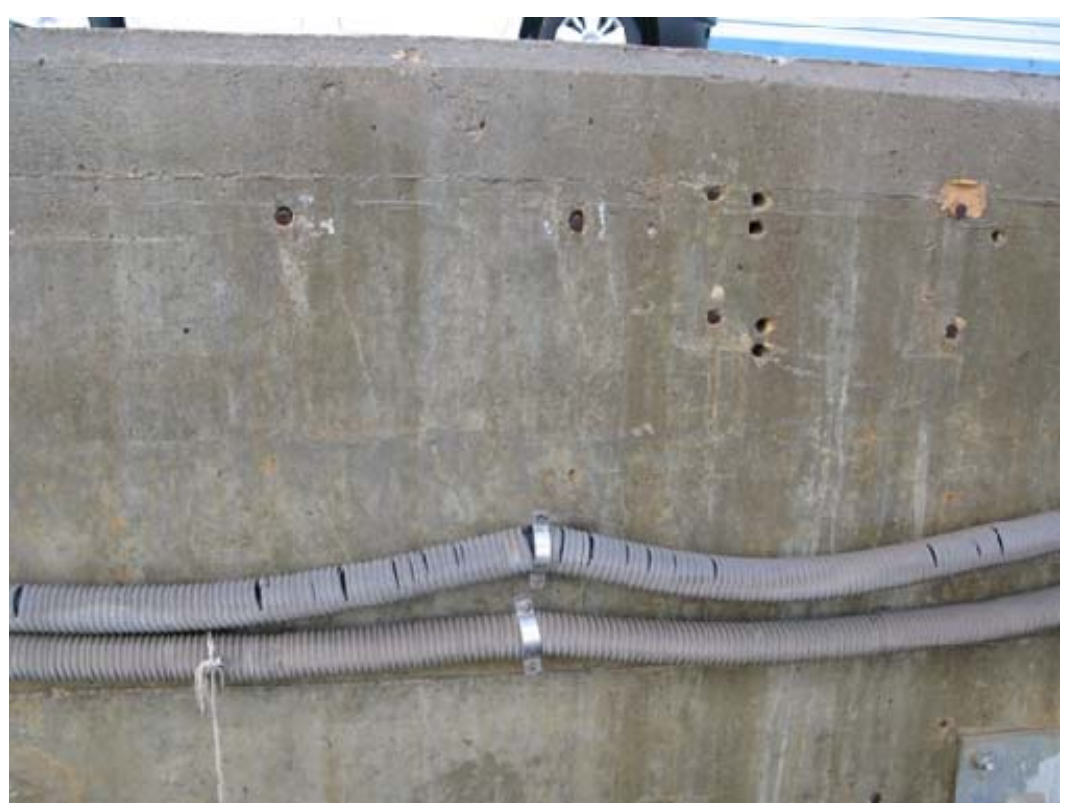

Fig.5.52. Elementos metálicos con síntomas de corrosión.

- En el comienzo del módulo 1 fisuras horizontales y verticales coincidentes con los rehundidos moldeados en la superficie de la viga, que han sido reparados pero se han vuelto a abrir (fig 5.53).

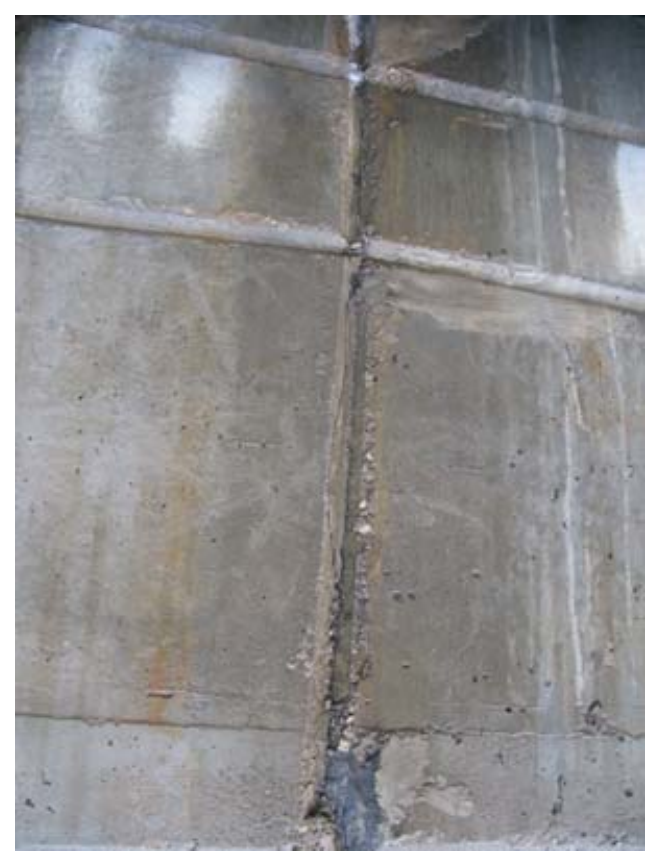

Fig.5.53. Fisuras horizontales y verticales abiertas tras reparación. 
- Juntas de dilatación entre módulos (fig 5.54 izquierda) con fisura abierta (fig 5.54 derecha).
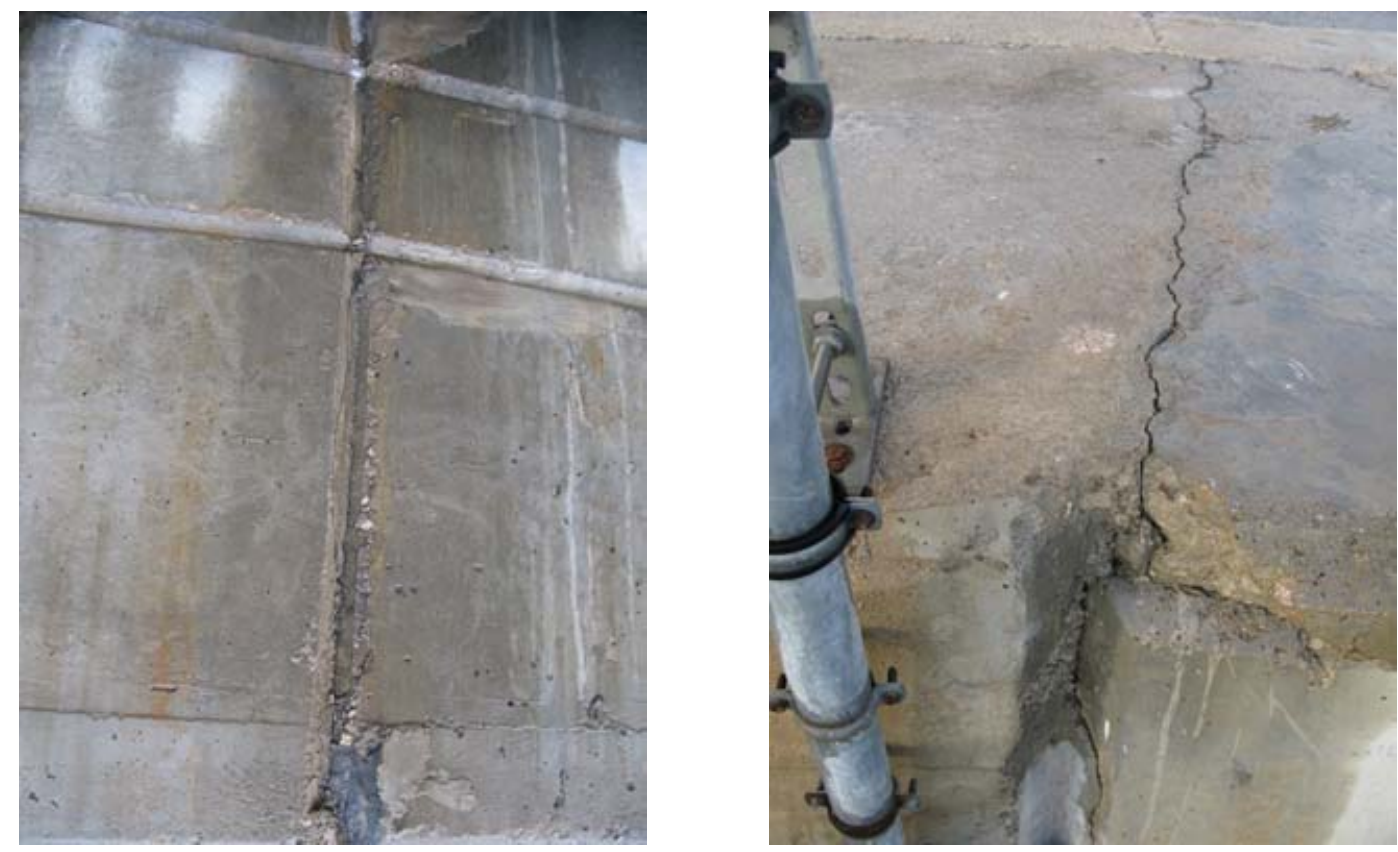

Fig.5.54. Junta dilatación y detalle de fisura.

- De forma puntual la presencia de una fisura longitudinal paralela a la arista inferior (fig 5.55). La fisura no presenta manchas de óxido y su altura es variable aunque siempre cerca de la arista. No parece estar relacionada con fenómenos de corrosión, aunque su presencia puede acortar en estos puntos el período de iniciación de la misma. Podría estar causada por algún defecto en las operaciones de desencofrado.

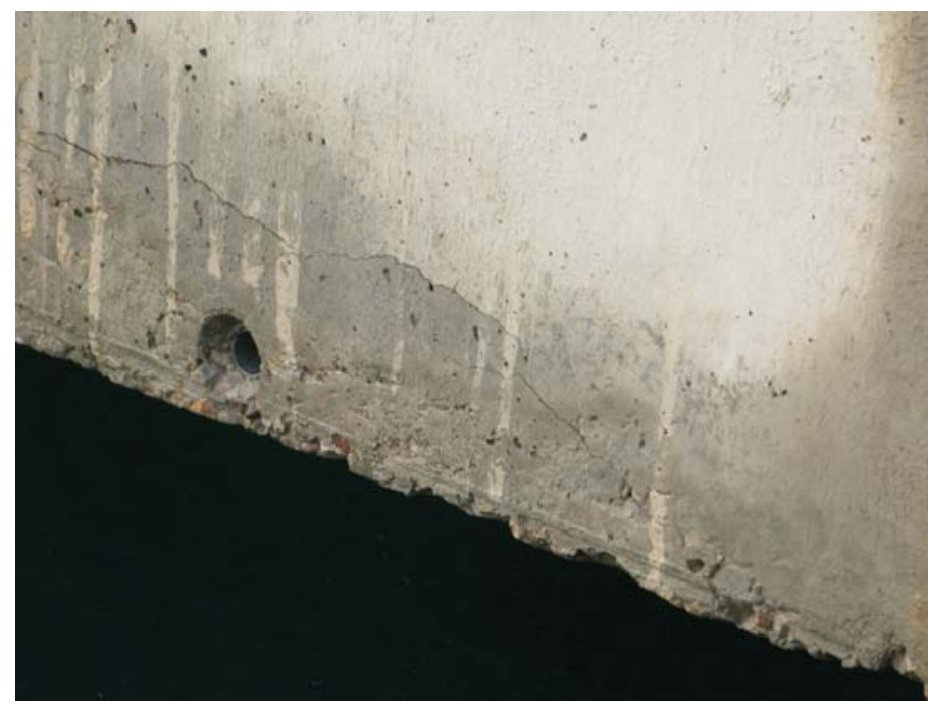

Fig.5.55.Fisura longitudinal sin corrosión paralela a arista inferior. 
- Pequeños desperfectos en la arista inferior y ocasionalmente en la superior de la viga cantil 16 (fig 5.56).

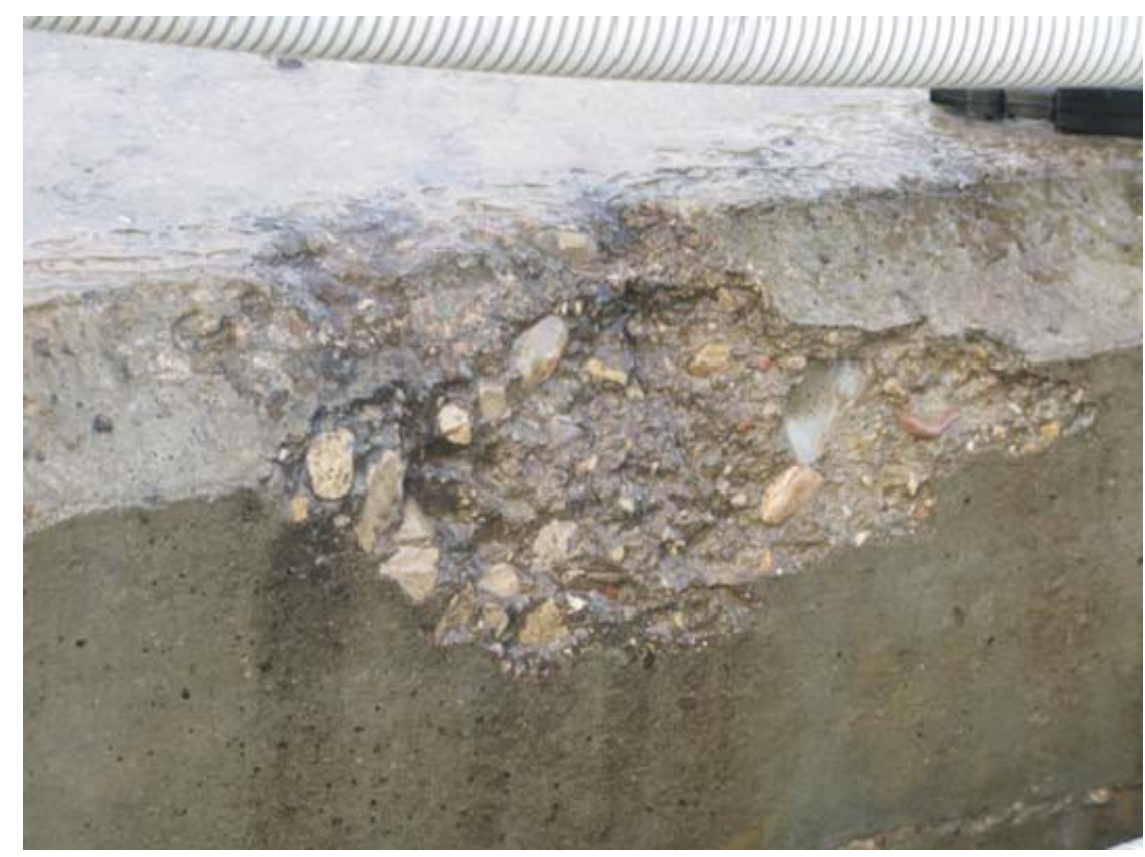

Fig.5.56. Descantillados en aristas.

- Ocasionalmente alguna fisura vertical fina, coincidiendo con los tubos de canalizaciones embebidos en el hormigón (fig 5.57).

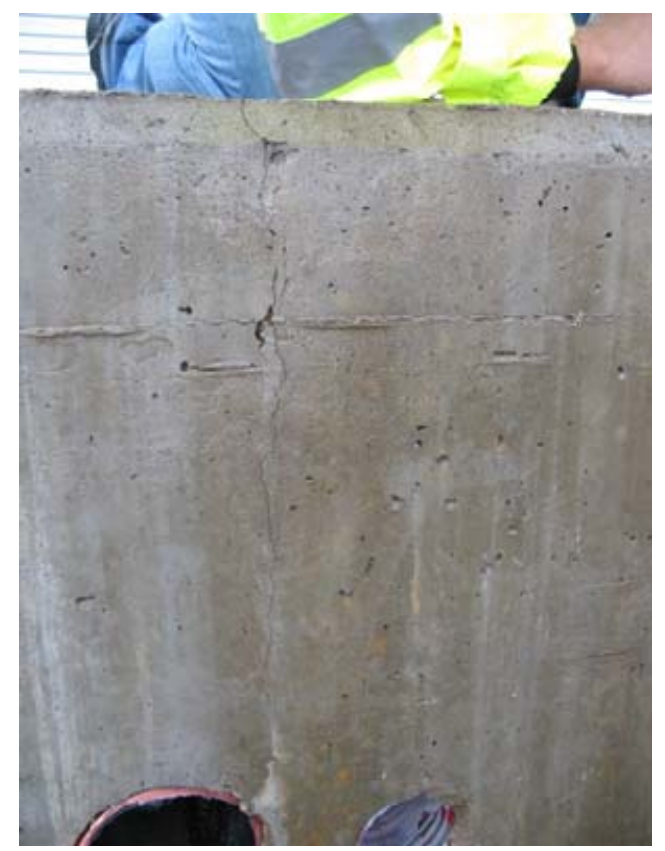

Fig.5.57. Leves fisuras verticales en posición de instalaciones interiores. 


\subsubsection{Medidas in situ y Extracción de testigos}

Finalizada la inspección visual, se procede a la extracción de testigos de hormigón con su correspondiente traslado a laboratorio. A continuación se aporta un resumen del proceso de extracción de testigos así como las descripciones de los mismos para cada muelle.

\subsubsection{Muelle A}

Se han extraído cuatro testigos de $10 \mathrm{~cm}$ de diámetro y $80 \mathrm{~cm}$ de profundidad aproximada en cuatro Duques de Alba. No se han podido extraer testigos en las vigas traviesas ni en la plataforma del camino de acceso por tratarse de estructuras pretensadas y en los planos o bien no se indicaba claramente la ubicación de los tendones, o bien no había espacio para extraer testigos sin cortar alguna vaina de pretensado. Tampoco se han realizado medidas in situ previas a la extracción de testigos. Los testigos han sido extraídos con trépano con corona de diamante y refrigeración de agua. Con estos cuatro testigos, en laboratorio se han realizado ensayos de carbonatación, de penetración de cloruros, de resistencia a compresión, de densidad, de velocidad de transmisión de ultrasonidos, de penetración de agua, de porosidad abierta, de permeabilidad al oxígeno, de absorción y de absorción capilar. 
Se han extraído testigos de los Duques de Alba siguientes:

- Lado derecho de la Plataforma C (figura 5.58).

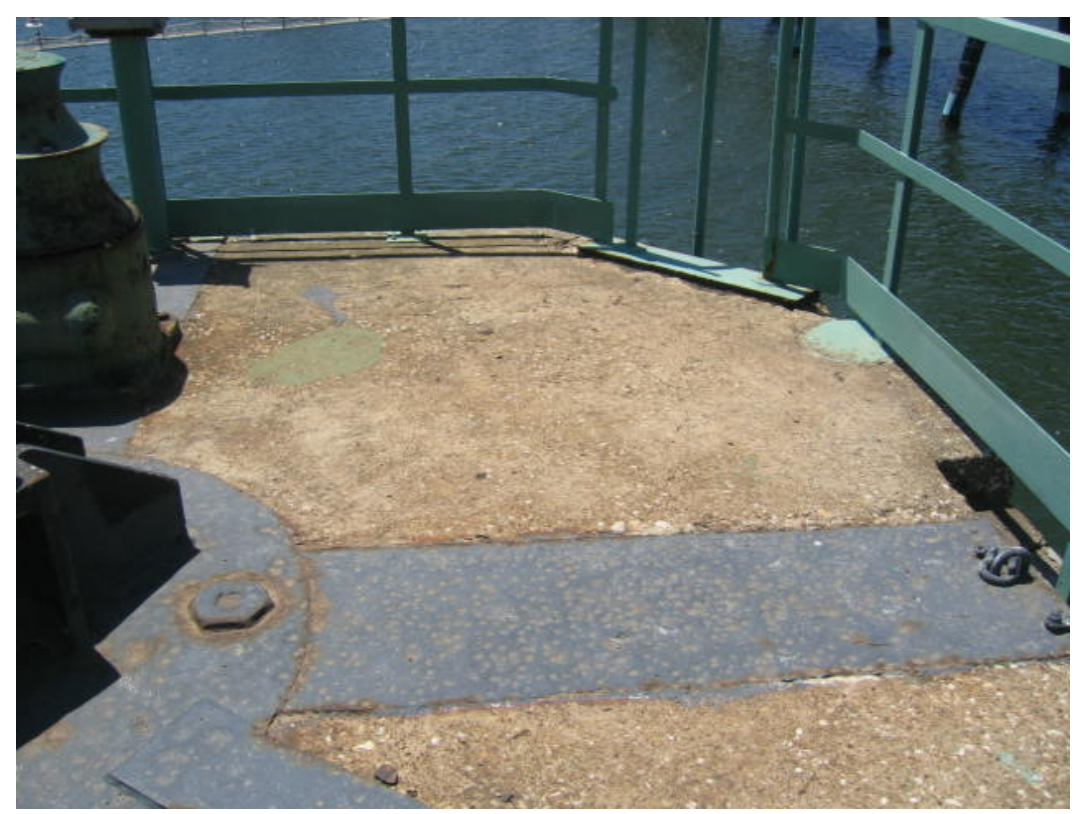

Fig.5.58. Testigo TPS-H1.

- Lado izquierdo de la Plataforma C (figura 5.59).

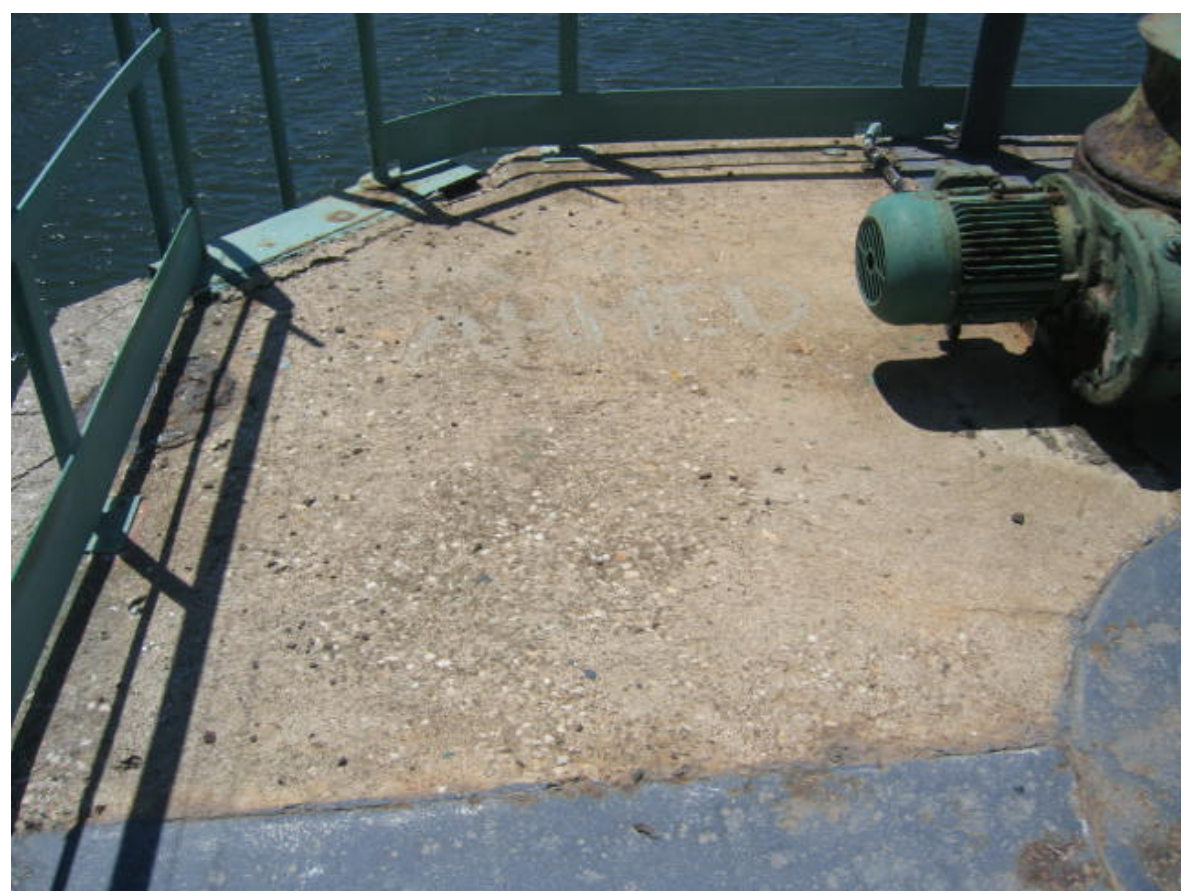

Fig.5.59. Testigo TPS-H2. 
- Primer Duque de Alba situado en el camino de la Plataforma B a la C (figura $5.60)$.

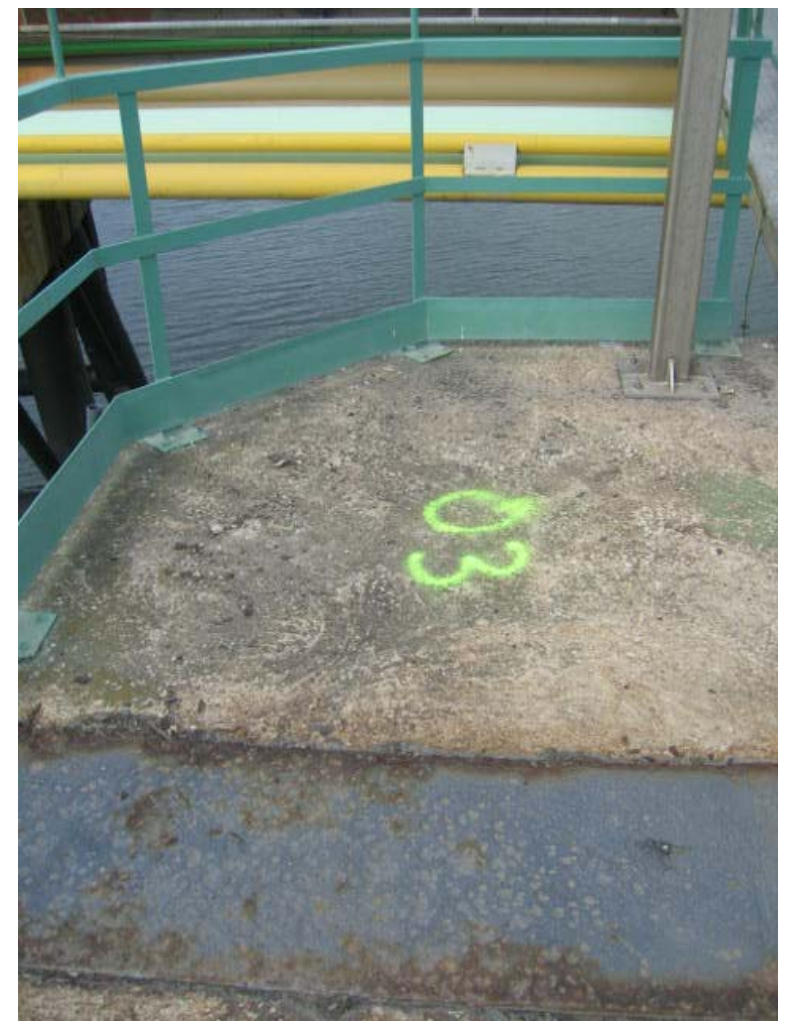

Fig.5.60. TPS-H3.

- Segundo Duque de Alba situado en el camino de la Plataforma B a la C (figura $5.61)$.

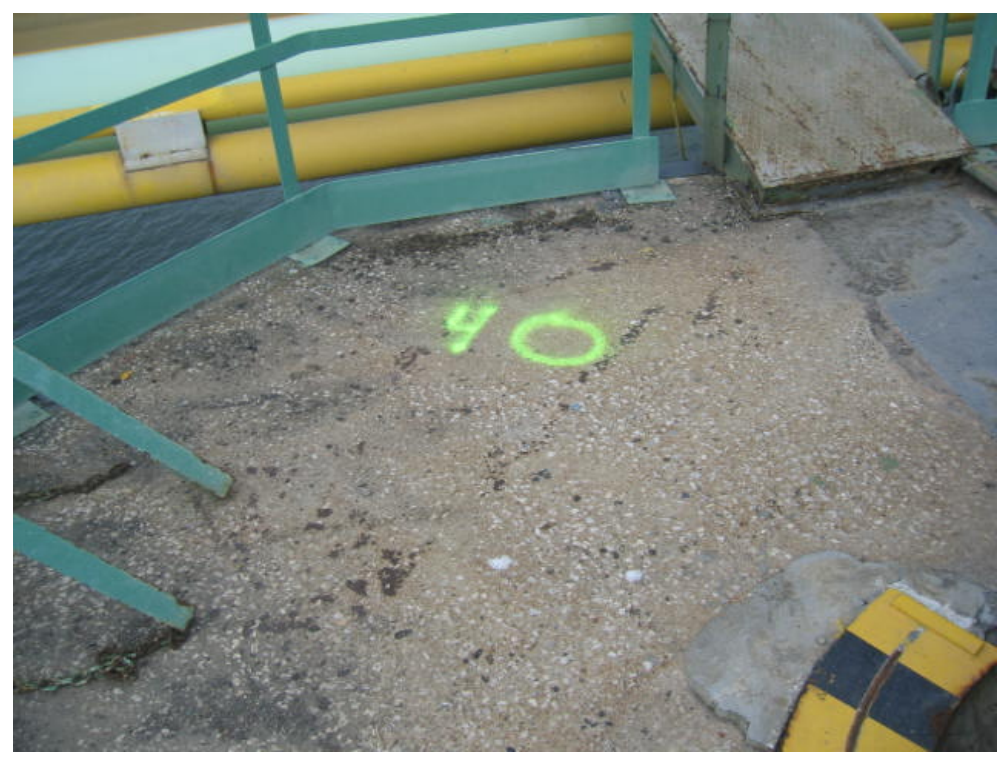

Fig.5.61. TPS-H4. 
Los testigos se han extraído a una altura de $+6,50$ sobre el nivel de B.M.V.E.

Se dispone de cuatro testigos, denominados TPS-H1, TPS-H2, TPS-H3 y TPS-H4, aunque durante su extracción se han partido en diversos fragmentos. Todos ellos tienen un diámetro de $96 \mathrm{~mm}$ y han sido extraídos en sentido vertical desde la superficie superior de los distintos Duques de Alba.

A continuación se describe cada uno de los testigos, aportando fotografías del aspecto de los mismos.

El testigo TPS-H1 pertenece al Duque de Alba situado a la derecha de la Plataforma C; se compone de 4 fragmentos, de longitudes 210 (inicio del testigo y, por lo tanto, parte superior del Duque de Alba), 170, 120 y 160 mm, para una longitud total de $70 \mathrm{~cm}$ aproximadamente. Durante la extracción del testigo no se han cortado armaduras. La figura 5.62 muestras dos fotografías de las vistas laterales del testigo TPS-H1.
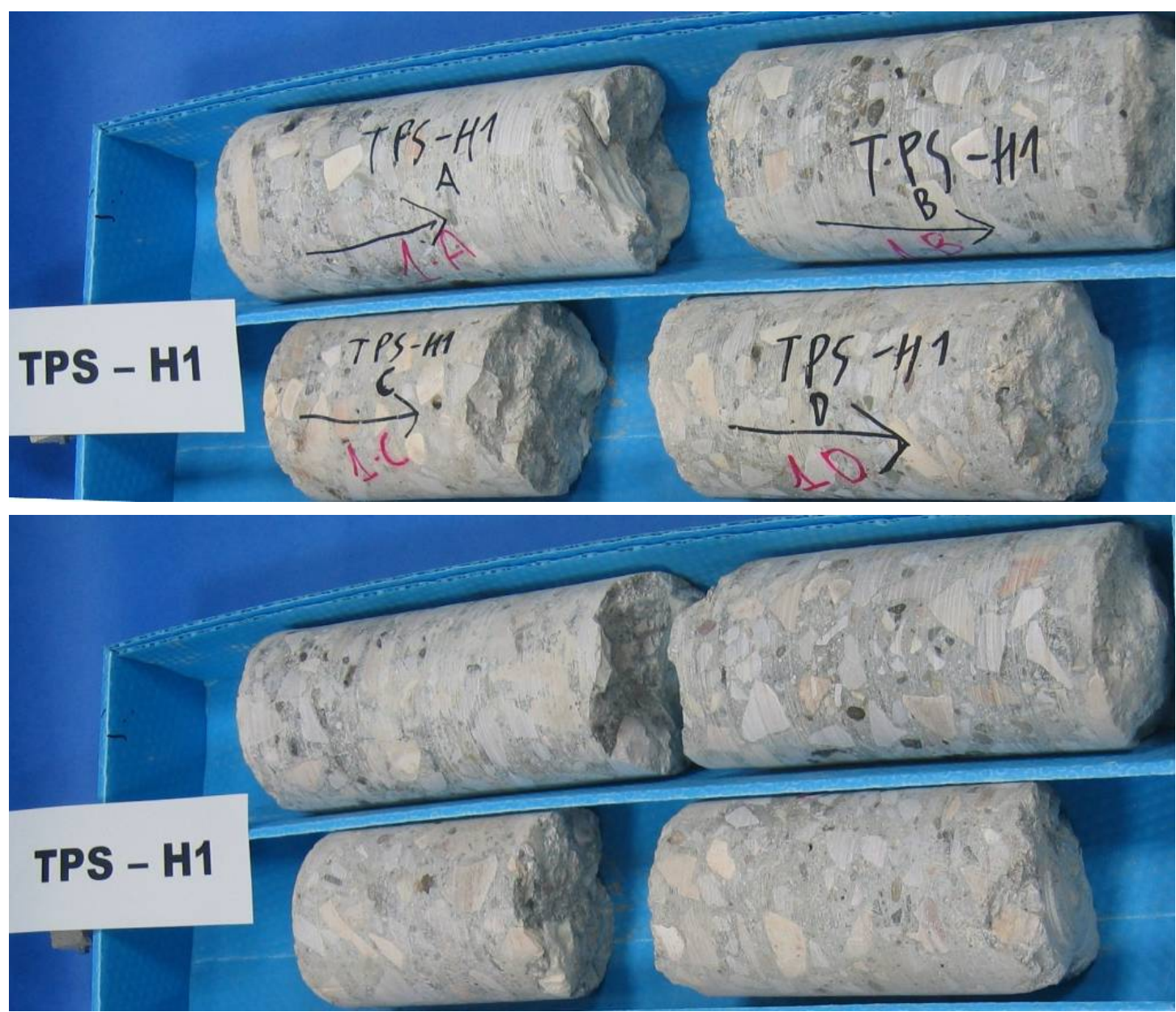

Fig.5.62. TPS-H1.Vistas laterales. 
El testigo TPS-H2 pertenece al Duque de Alba situado a la izquierda de la Plataforma C; se compone de 4 fragmentos, de longitudes 180 (inicio del testigo y, por lo tanto, parte superior del Duque de Alba), 250, 140 y $150 \mathrm{~mm}$, para una longitud total de $75 \mathrm{~cm}$ aproximadamente. Durante la extracción del testigo se han cortado dos armaduras horizontales lisas de $14 \mathrm{~mm}$ de diámetro, con un recubrimiento de $200 \mathrm{~mm}$, y dos alambres de $4 \mathrm{~mm}$ de diámetro, situados a 400 $\mathrm{mm}$ de profundidad. Ninguna de las dos armaduras mostraba síntomas de corrosión. La figura 5.63 muestras dos fotografías de las vistas laterales del testigo TPS-H2 y en la figura 5.64 puede verse una de las armaduras cortadas sin síntomas de corrosión.
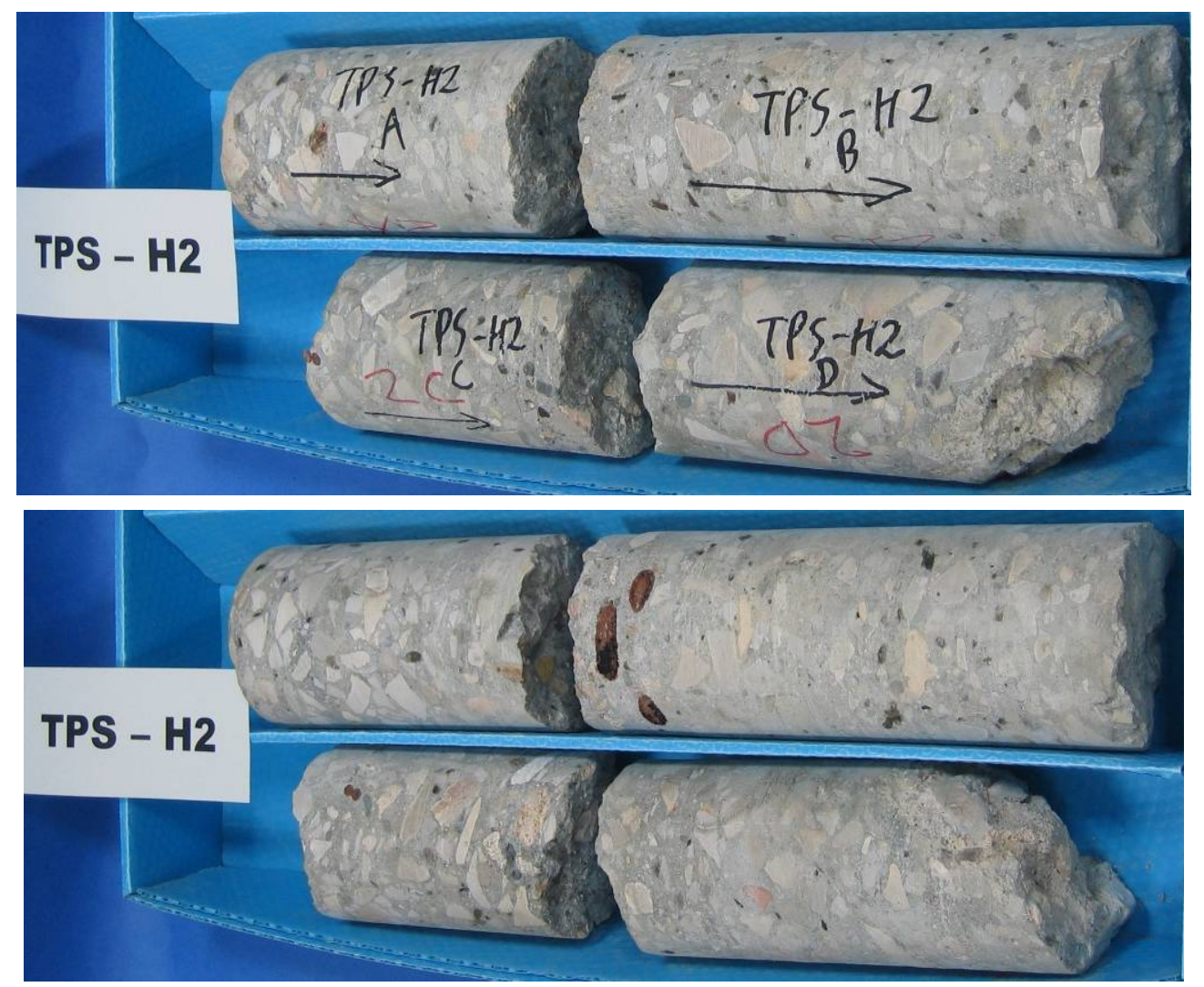

Fig.5.63. TPS-H2.Vistas laterales. 


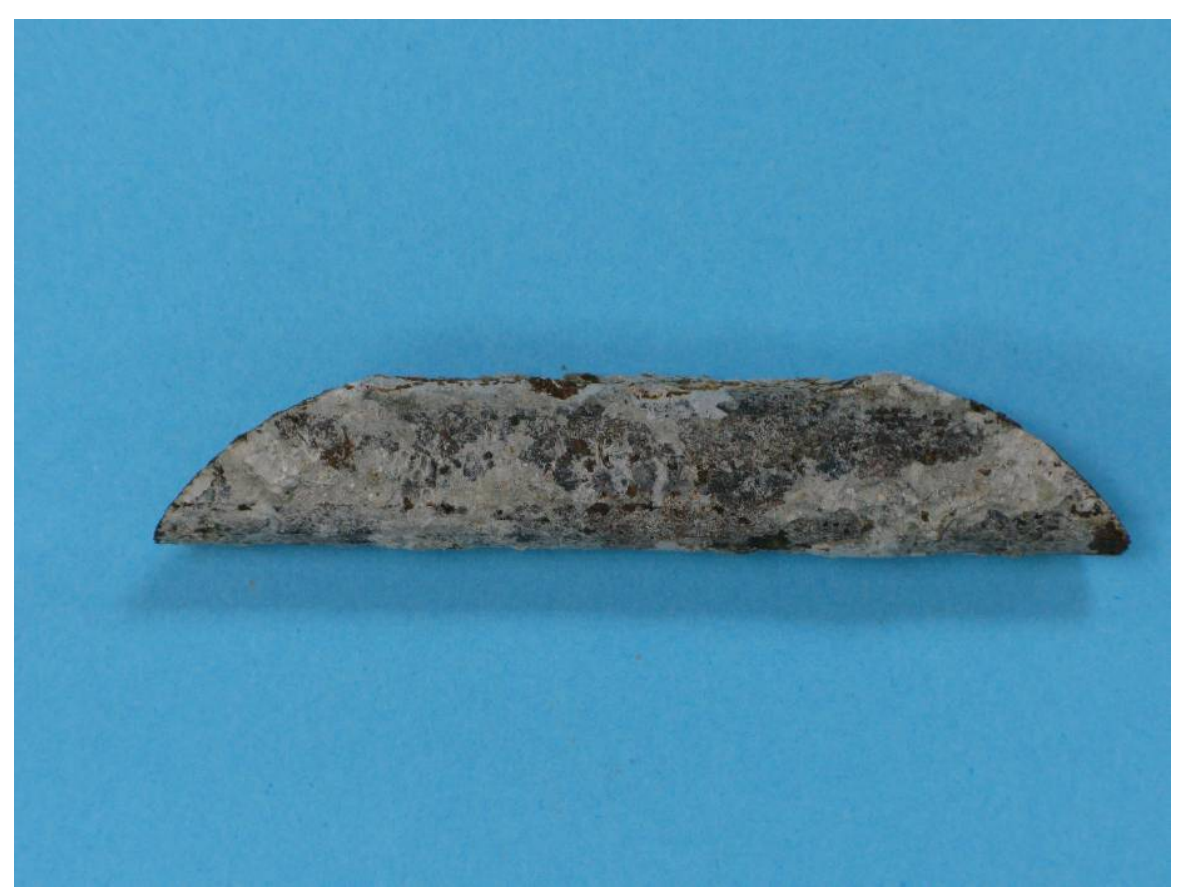

Fig.5.64. Armadura sin síntomas de corrosión.

El testigo TPS-H3 pertenece al primer Duque de Alba situado en el camino de la Plataforma B a la C; se compone de 4 fragmentos, de longitudes 100 (inicio del testigo y, por lo tanto, parte superior del Duque de Alba), 380, 260 y $140 \mathrm{~mm}$, para una longitud total de $90 \mathrm{~cm}$ aproximadamente. Durante la extracción del testigo se han cortado dos armaduras horizontales (en cuadrícula) lisas de $14 \mathrm{~mm}$ de diámetro, con un recubrimiento de $90 \mathrm{~mm}$. Ninguna de las dos mostraba síntomas de corrosión, ni tampoco se observaban manchas de corrosión en el hormigón que las rodeaba. Las figuras 5.65 y 5.66 muestran las vistas laterales del testigo TPSH3 y las armaduras sin síntomas de corrosión cortadas del testigo, respectivamente. 

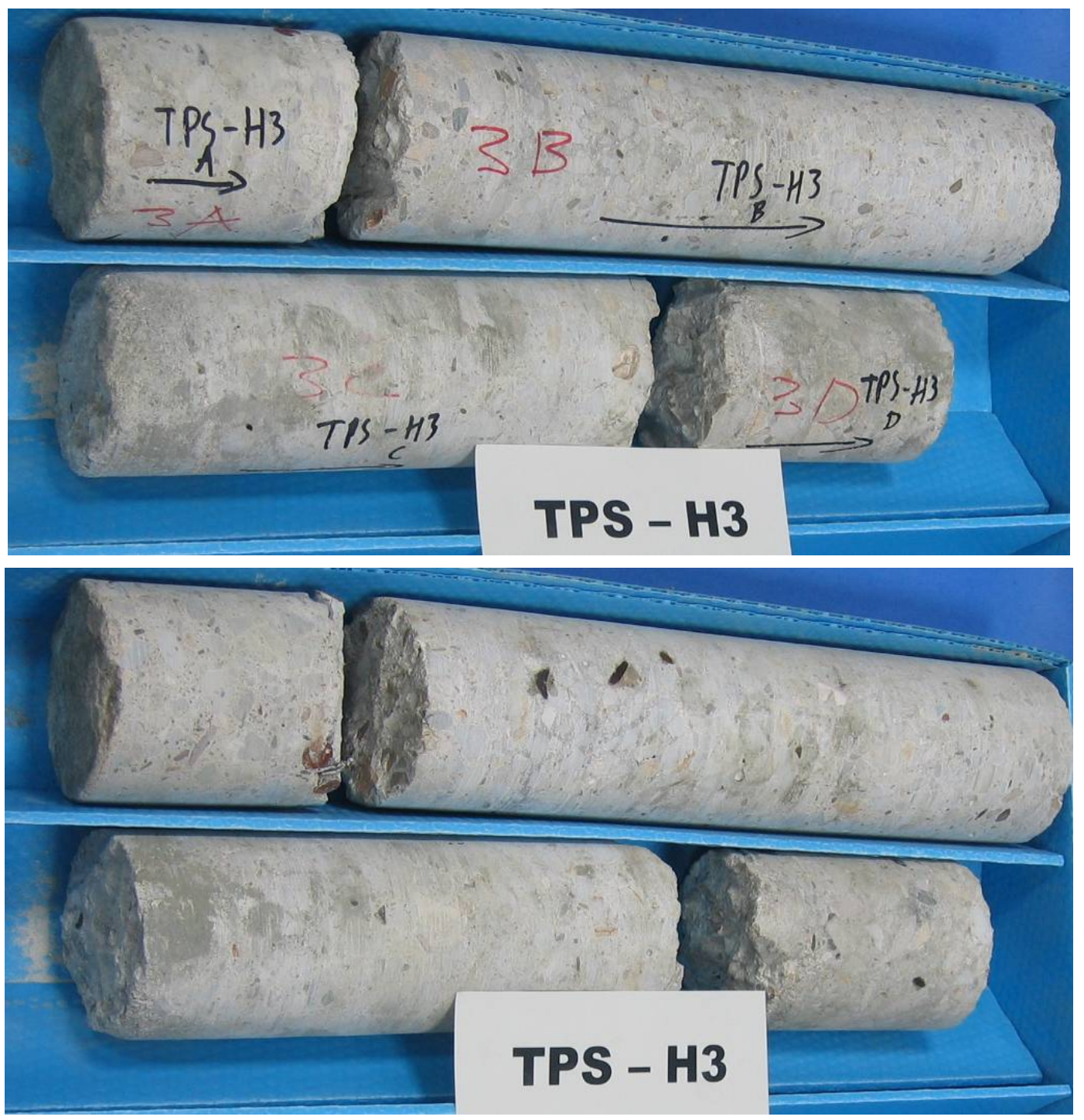

Fig.5.65. TPS-H3. Vistas laterales.
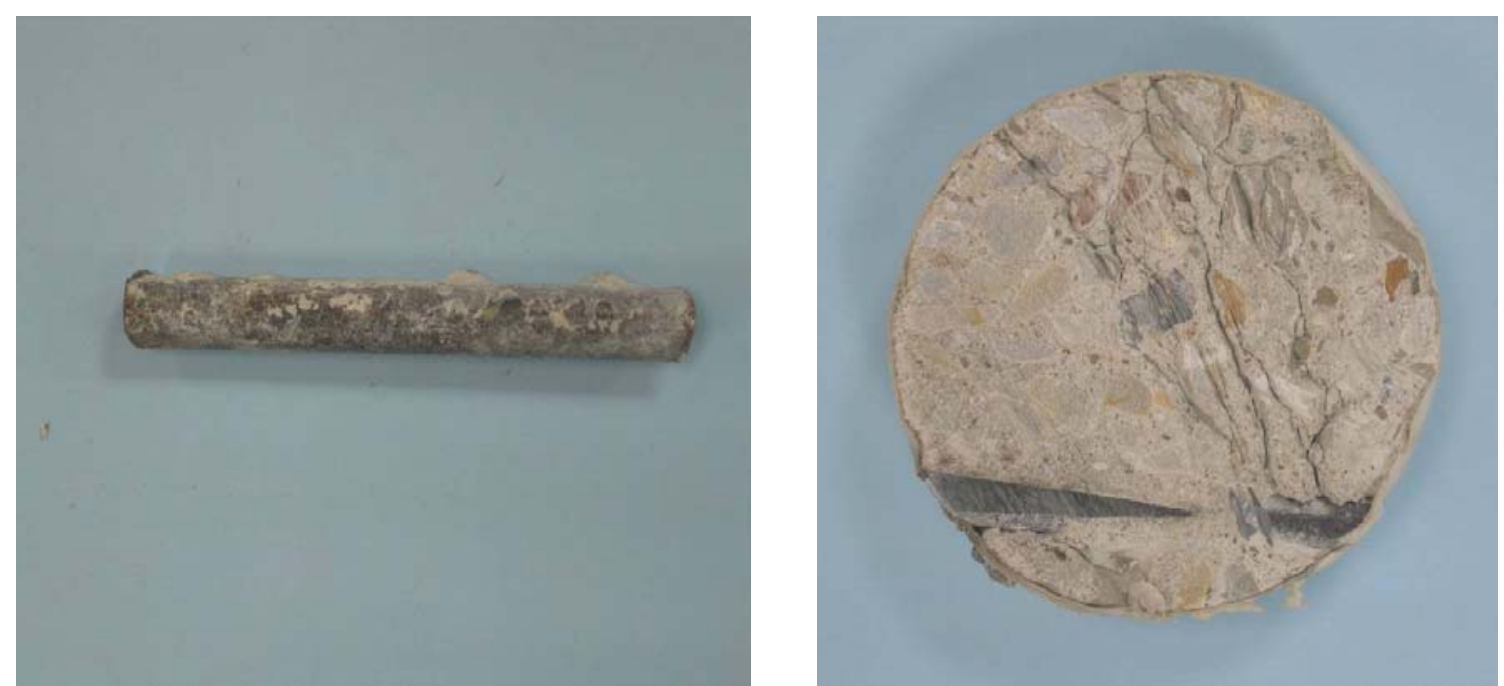

Fig.5.66. Armaduras cortadas sin síntomas de corrosión. 
El testigo TPS-H4 pertenece al segundo Duque de Alba situado en el camino de la Plataforma B a la C; se compone de 2 fragmentos, de longitudes 100 (inicio del testigo y, por lo tanto, parte superior del Duque de Alba) y $310 \mathrm{~mm}$, para una longitud total de $45 \mathrm{~cm}$ aproximadamente. Durante la extracción del testigo se ha cortado una armadura horizontal de $14 \mathrm{~mm}$ de diámetro, con un recubrimiento de $100 \mathrm{~mm}$. No mostraba síntomas de corrosión. La figura 5.67 muestra las vistas laterales del testigo TPS-H4.
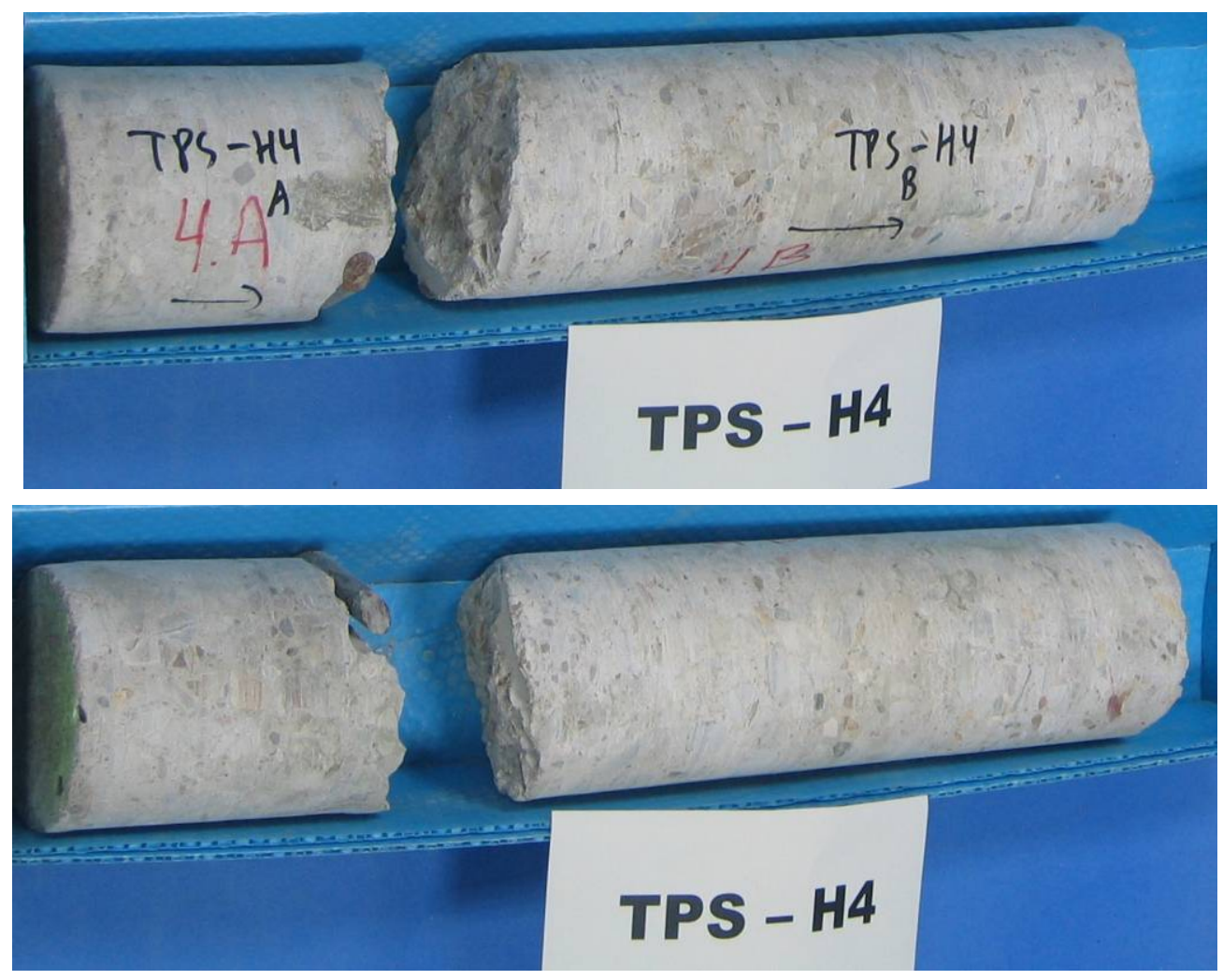

Fig.5.67. TPS-H4. Vistas laterales.

Referente a la inspección realizada a los testigos, el árido observado es de machaqueo, con un tamaño máximo de $30 \mathrm{~mm}$ en el testigo TPS-H3; $40 \mathrm{~mm}$ en el testigo TPS-H4; y 50 mm en los testigos TPS-H1 y TPS-H2.

En los testigos no se aprecian fisuras, juntas, presencia de cuerpos extraños, porosidad elevada ni ningún otro tipo de anomalía destacable, aunque sí se observan pequeñas coqueras. El hormigón tiene un color uniforme, y el árido y la pasta están uniformemente distribuidos. El hormigón no se desmorona con los dedos ni se puede arañar con la uña. 


\subsubsection{Muelle B}

En el caso de este muelle, previo a la extracción de testigos se llevaron a cabo medidas de la velocidad de propagación de ultrasonidos así como medidas electroquímicas de la corrosión con el fin de clasificar la resistencia de varias zonas del muelle y así poder elegir las zonas de extracción de testigos en lugares de resistencia elevada, media y baja a partir de los resultados de la velocidad de ultrasonidos obtenidos.

\subsection{Velocidad de propagación de ultrasonidos}

Se ha realizado una medida indirecta de la velocidad de ultrasonidos en el cabecero continuo, ya que hay demasiada distancia entre las dos caras laterales como para realizar la medida de forma directa. En la cara lateral (de $70 \mathrm{~cm}$ de altura) se dispusieron inicialmente los palpadores separados entre sí $20 \mathrm{~cm}$ en una línea horizontal equidistante de dos barras de la armadura horizontal del cajón (entre la primera y la segunda barras horizontales, por lo que se sitúa dicha línea a unos $20 \mathrm{~cm}$ de la cara superior del cajón). Se realizó una medida de la velocidad de ultrasonidos, y manteniendo fijo un palpador, se realizaron otras tres medidas de la velocidad de ultrasonidos separando cada vez $5 \mathrm{~cm}$ el otro palpador, siguiendo la línea horizontal indicada. Con la media de estas 4 medidas se obtiene la velocidad de ultrasonidos del hormigón del cajón.

Se ha medido la velocidad de ultrasonidos en dos puntos, separados $3 \mathrm{~m}$ aproximadamente, de la superficie lateral del sexto cabecero del módulo 19, tal y como puede verse en las figuras 5.68 y 5.69 , en la misma zona en la que se ha realizado el estudio electroquímico de la corrosión. Se han escogido estos puntos por un criterio de accesibilidad a la estructuras de hormigón. 


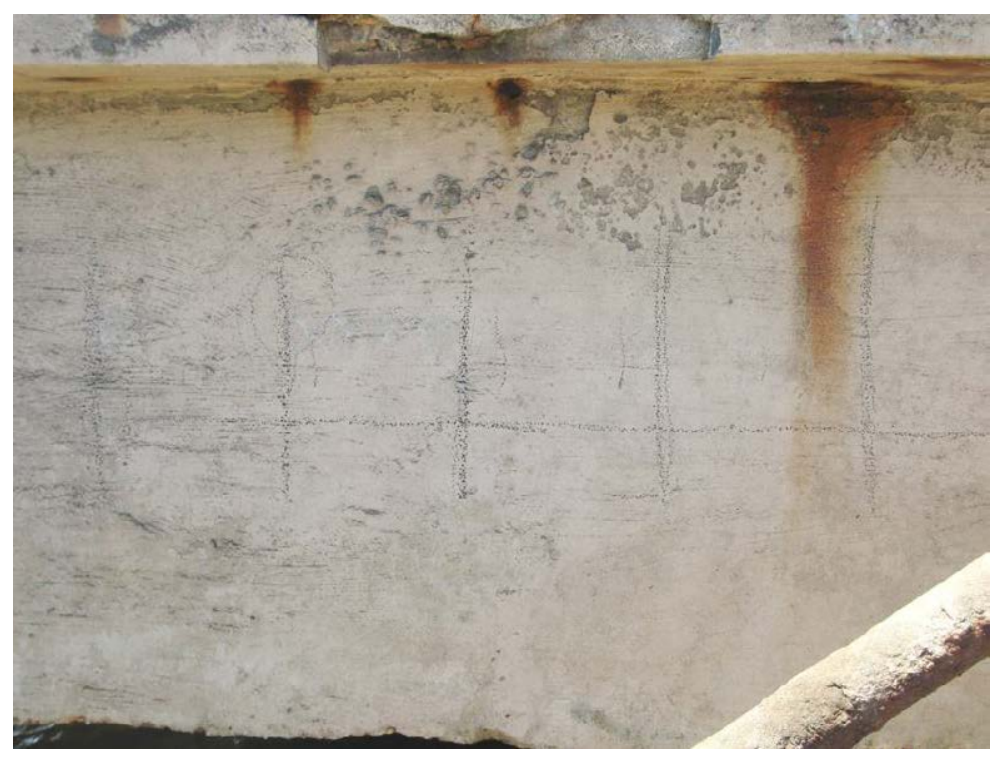

Fig.5.68. Punto 1.

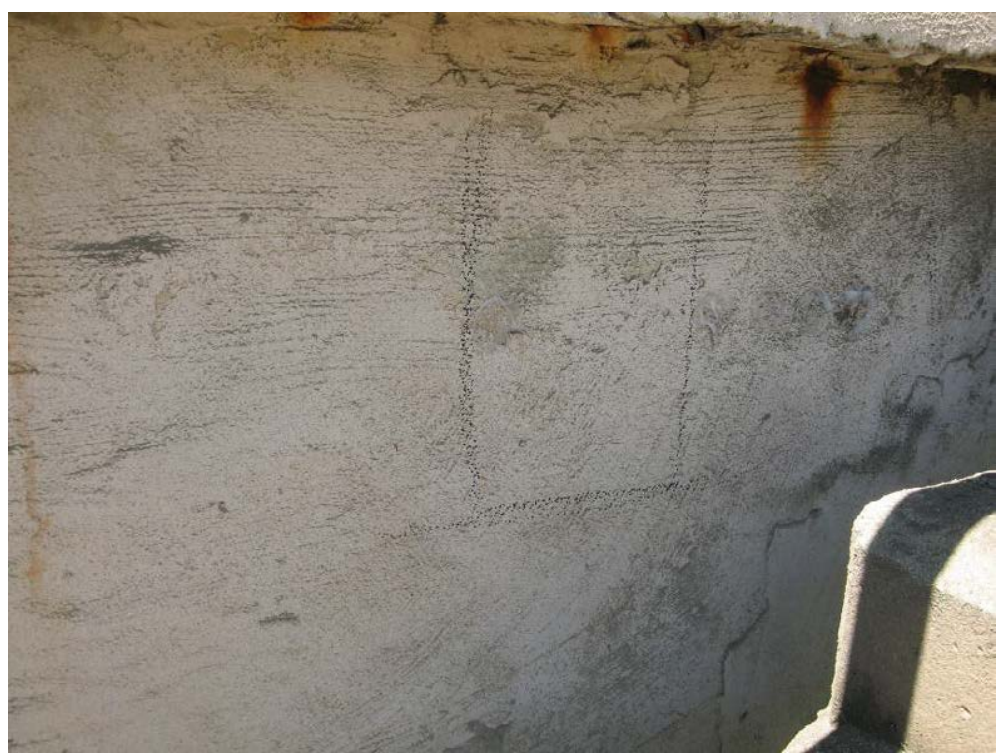

Fig.5.69. Punto 2.

Los resultados de esta medida indirecta de velocidad de ultrasonidos en el hormigón de los cajones se recogen en la siguiente tabla 5.2, así como los recubrimientos medidos con la sonda magnética; la columna "distancia" se refiere a distancia a origen del cabecero (faldón):

\begin{tabular}{|c|c||c||c||}
\cline { 2 - 4 } \multicolumn{1}{c|}{} & Distancia (m) & Recubrimiento (mm) & V. Ultrasonidos (m/s) \\
\hline Punto 1 & 6,30 & 65 & 3.311 \\
\hline Punto 2 & 9,85 & 60 & 3.226 \\
\hline
\end{tabular}

Tabla 5.2. Resultados de la medida indirecta de ultrasonidos 
El hormigón del cabecero se calificaría como de calidad aceptable.

\subsection{Medidas electroquímicas de la corrosión}

El estudio electroquímico de la corrosión se ha realizado en los mismos puntos donde se midió la velocidad de transmisión de ultrasonidos, véase figuras 5.68 y 5.69, midiendo el potencial de media pila, la resistividad y la intensidad de corrosión.

Sobre la superficie de hormigón se pintó una cuadrícula (figura 5.70) con las armaduras contenidas en un metro de longitud aproximadamente, lo que corresponde a cuatro barras verticales ( $\$ 14 \mathrm{c} 25$, cerco exterior) y tres horizontales (1Ф20 en la parrilla superior, 1Ф20 intermedio y 1Ф25 en la parrilla inferior, armadura interior); la superficie inferior del cabecero se encuentra a una altura aproximada de $+5,00 \mathrm{~m}$ sobre el nivel de B.M.V.E. En la cuadrícula correspondiente al PUNTO 1 de medida de velocidad de ultrasonidos, se descubrió un cerco vertical (figura 5.71) y se midió el potencial de media pila y la resistividad en todos los demás cercos verticales, y la intensidad de corrosión sólo en una barra vertical, que son las que tienen mayor peligro de corrosión al estar situadas más cerca de la superficie exterior. En la cuadrícula correspondiente al PUNTO 2 se siguió el mismo procedimiento, pero sin necesidad de descubrir ninguna armadura pues se pudo utilizar como conexión la misma armadura descubierta en el PUNTO 1. En la figura 5.70 se muestran los puntos de medida de la cuadrícula (se empleó el mismo tipo de cuadrícula en ambos puntos):

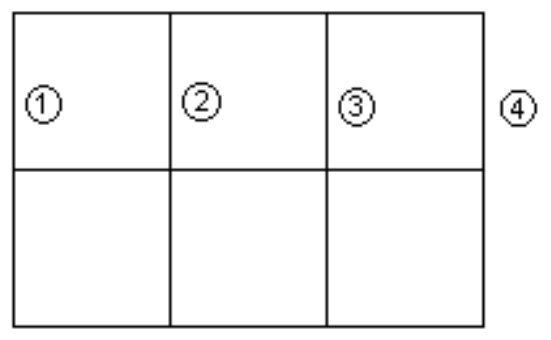

Fig.5.70. Cuadrícula donde se realizaron las medidas electroquímicas en los puntos de medida 


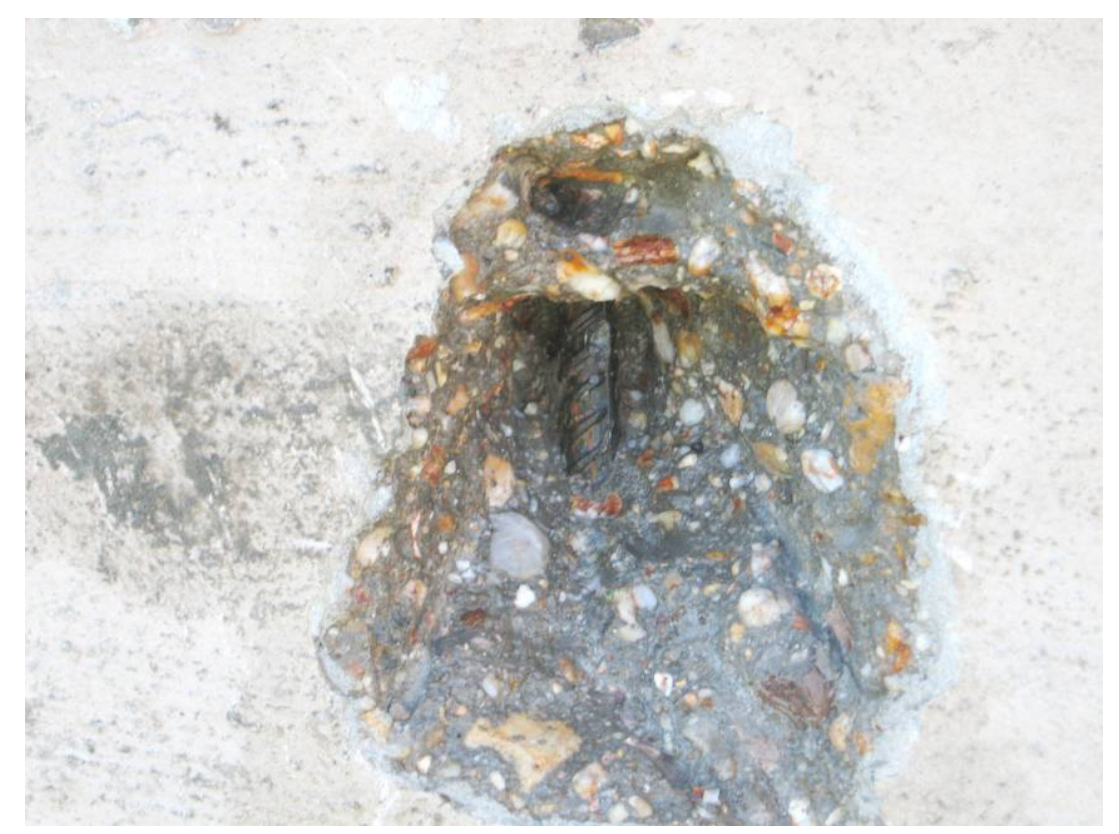

Fig.5.71. Armadura descubierta para conexión de equipos.

\section{Estudio electroquímico de la corrosión realizado en el PUNTO 1.}

En el PUNTO 1 se descubrió la armadura correspondiente al cerco vertical señalado como "1" en la cuadrícula, entre la primera y la segunda barra horizontal. En ese punto, la armadura vertical tenía un recubrimiento de $65 \mathrm{~mm}$. El acero no mostraba síntomas de corrosión. El hormigón también presentaba buen aspecto, sin fisuración aparente (figura 5.71).

Los resultados del potencial de media pila y de la resistividad en la cuadrícula indicada se muestran a continuación en la tabla 5.3:

\begin{tabular}{|c|c|c|c|}
\hline & & Potencial (mV) & Resistividad $(\mathrm{k} \Omega \cdot \mathrm{cm})$ \\
\hline \multirow{3}{*}{$\begin{array}{c}\text { Barras } \\
\text { verticales }\end{array}$} & 2 & -214 & 23 \\
\hline & 3 & -218 & 21 \\
\hline & 4 & -225 & 27 \\
\hline
\end{tabular}

Tabla 5.3. Resultados de potencial de media pila y de resistividad obtenidos en la cuadrícula

Para los electrodos empleados en la medida del potencial de media pila, valores del potencial inferiores a $-300 \mathrm{mV}$ indican una probabilidad de corrosión superior al $90 \%$, mientras que si están comprendidos entre -150 y $-300 \mathrm{mV}$, la probabilidad de corrosión es desconocida (entre un 10 y un 90\%), que es el caso en que nos encontramos. 
Por lo que se refiere a las resistividades, el equipo de medida indica que valores inferiores a $20 \mathrm{k} \Omega$.cm suponen un riesgo alto de corrosión, y entre 20 y $50 \mathrm{k} \Omega . \mathrm{cm}$, un riesgo medio. En todo caso, las zonas con baja resistividad tendrán una mayor velocidad de corrosión tras la despasivación. En el caso del PUNTO 1, todos los puntos de medida presentan resistividades superiores a $20 \mathrm{k} \Omega . \mathrm{cm}$ (el valor medio es $24 \mathrm{k} \Omega . \mathrm{cm}$ ), por lo que el peligro de corrosión se puede considerar medio.

En cuanto a las medidas particulares de cada barra, se observa que en todas las verticales se obtiene un potencial y una resistividad semejantes (están medidas a una misma altura respecto al nivel del mar).

La medida de la intensidad de corrosión se realizó en la barra vertical $n^{\circ} 4$, entre las barras horizontales 1 y 2 . Se obtuvo una intensidad de $0,00 \mu \mathrm{A} / \mathrm{cm}^{2}$, un potencial de $-230 \mathrm{mV}$ y una indicación de exceso de resistividad, por lo que el equipo no era capaz de confinar adecuadamente la señal. Aún teniendo en cuenta esta imposibilidad de obtener una medida totalmente fiable de la intensidad de corrosión por falta de confinamiento de la señal, la obtención de intensidades de corrosión inferiores a $0,20 \mu \mathrm{A} / \mathrm{cm}^{2}$ indica que el acero se encuentra en estado pasivo, esto es, que no se está corroyendo. Este resultado coincide con la superficie limpia de óxido del acero que se observó al descubrir la armadura en las proximidades del punto de medida.

\section{Estudio electroquímico de la corrosión realizado en el PUNTO 2.}

En el PUNTO 2 se aprovechó la armadura descubierta para la realización del estudio electroquímico del punto anterior. El hormigón también presentaba buen aspecto, sin fisuración aparente.

Los resultados del potencial de media pila y de la resistividad en la cuadrícula indicada se muestran en la tabla 5.4:

\begin{tabular}{|c|c|c|c|}
\hline & & Potencial (mV) & Resistividad $(\mathrm{k} \Omega \cdot \mathrm{cm})$ \\
\hline \multirow{3}{*}{$\begin{array}{c}\text { Barras } \\
\text { verticales }\end{array}$} & $\overline{1.1}$ & -242 & 28 \\
\hline & 2 & -242 & 28 \\
\hline & 3 & -247 & 21 \\
\hline
\end{tabular}

Tabla 5.4. Resultados de potencial de media pila y de resistividad obtenidos en la cuadrícula

Al igual que en el caso anterior, se han medido valores del potencial comprendidos entre -150 y $-300 \mathrm{mV}$, rango que supone que la probabilidad de corrosión es desconocida (entre un 10 y un 90\%). 
Por lo que se refiere a las resistividades, también aquí todos los puntos de medida presentan resistividades superiores a $20 \mathrm{k} \Omega . \mathrm{cm}$ (el valor medio es $26 \mathrm{k} \Omega . \mathrm{cm}$ ), por lo que el peligro de corrosión se puede considerar medio.

En cuanto a las medidas particulares de cada barra, se observa que en todas las verticales se obtiene un potencial y una resistividad semejantes (están medidas a una misma altura respecto al nivel del mar).

La medida de la intensidad de corrosión se realizó en la barra vertical $n^{\circ} 3$, entre las barras horizontales 1 y 2 . Se obtuvo una intensidad de $0,03 \mu \mathrm{A} / \mathrm{cm}^{2}$, un potencial de $-234 \mathrm{mV}$ y una resistencia óhmica de $151,88 \mathrm{k} \Omega$, pero una vez más con la indicación del equipo de que no era capaz de confinar adecuadamente la señal. Aun teniendo en cuenta esta imposibilidad de obtener una medida totalmente fiable de la intensidad de corrosión por falta de confinamiento de la señal, la obtención de intensidades de corrosión inferiores a $0,20 \mu \mathrm{A} / \mathrm{cm}^{2}$ indica que el acero se encuentra en estado pasivo, esto es, que no se está corroyendo.

A pesar de los abundantes síntomas de corrosión a todo lo largo del pantalán, en la zona donde se ha realizado la medida electroquímica de la corrosión se observaba un paramento en buen estado, sin fisuras ni manchas de corrosión. Se escogieron estos puntos para determinar la velocidad de corrosión en las zonas en las que aparentemente no hay síntomas de deterioro. El resultado del estudio electroquímico indicaría que el acero de esta zona aún se encuentra en estado pasivo. Para confirmar esta conclusión, se extrajo un testigo en esta misma zona (testigo HU-H5), cuyos resultados en los diferentes ensayos se pueden consultar en el apartado 5.5; en todo caso, el contenido de cloruros medido confirmaría que el acero se encuentra aún en estado pasivo (para $6,5 \mathrm{~cm}$ de recubrimiento medido in situ, el contenido de cloruros es inferior, aunque muy próximo, al 0,4\%).

\subsection{Valoración de los resultados y justificación de los puntos de extracción de testigos}

La medida de la velocidad de ultrasonidos y la realización de medidas electroquímicas sólo se han podido llevar a cabo en dos puntos de los cabeceros del muelle. Los cuatro testigos ( $\mathrm{HU}-\mathrm{H} 1, \mathrm{HU}-\mathrm{H} 2, \mathrm{HU}-\mathrm{H} 3$ y $\mathrm{HU}-\mathrm{H} 4)$ tomados de las losas han sido extraídos por criterios de accesibilidad, ya que son sondeos verticales, y tratando de abarcar distintas zonas del muelle, ya que se han tomado de distintos módulos y a su vez, a distancias longitudinales y transversales diferentes. 
Respecto a las medidas in situ realizadas en los cabeceros, se han llevado a cabo en la superficie lateral del sexto cabecero del módulo 19. Los resultados de la velocidad de ultrasonidos muestran un hormigón de calidad aceptable y las medidas electroquímicas de la corrosión indican un riesgo de corrosión medio (en el caso de la resistividad) y una probabilidad de corrosión desconocida, comprendida entre el 10 y el 90\% (en el caso del potencial). Las medidas de la intensidad de la corrosión, si bien con problemas en su determinación, indicarían que el acero se encuentra aún en estado pasivo. Estas medidas son coherentes con la ausencia de corrosión observada en la armadura vista descubierta. Se extrae el testigo HU-H5 del punto donde se realiza la medida de ultrasonidos en el módulo 19, con el fin de valorar el contenido de cloruros medido en el hormigón. El resto de los testigos se toman de distintos puntos (módulo 19, 16 y 15) con el fin de cubrir la máxima zona posible del muelle, así como a distancias longitudinales diferentes.

\subsection{Extracción de testigos}

En cuatro puntos de la losa del pantalán se han realizado sondeos de $100 \mathrm{~mm}$ de diámetro y 2,00 $\mathrm{m}$ de longitud. Estos sondeos han atravesado una capa de pavimento, una capa de arena de regularización, dos capas de hormigón pobre y, finalmente, la losa de hormigón que está expuesta al ambiente marino; por lo tanto, se dispone de cuatro testigos de hormigón de la losa, de $100 \mathrm{~mm}$ de diámetro y aproximadamente $450 \mathrm{~mm}$ de longitud.

Se han extraído testigos de la losa en los siguientes puntos: 
- Testigo HU-H1: extraído en el módulo 19, a 5,5m del extremo del muelle en sentido longitudinal y a 5,5 m del borde en sentido transversal (figura 5.72).

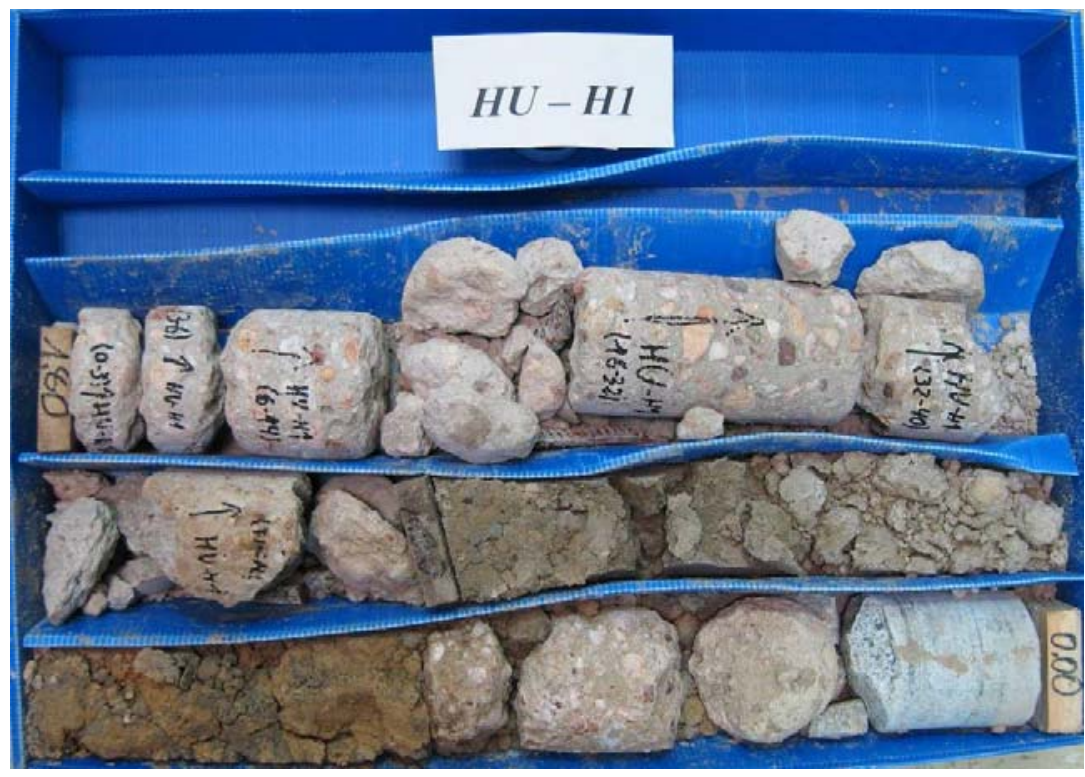

Fig.5.72. Sondeo HU-H1.

- Testigo HU-H2: extraído en el módulo 18, a 54m del extremo del muelle en sentido longitudinal y a $14 \mathrm{~m}$ del borde en sentido transversal (figura 5.73).

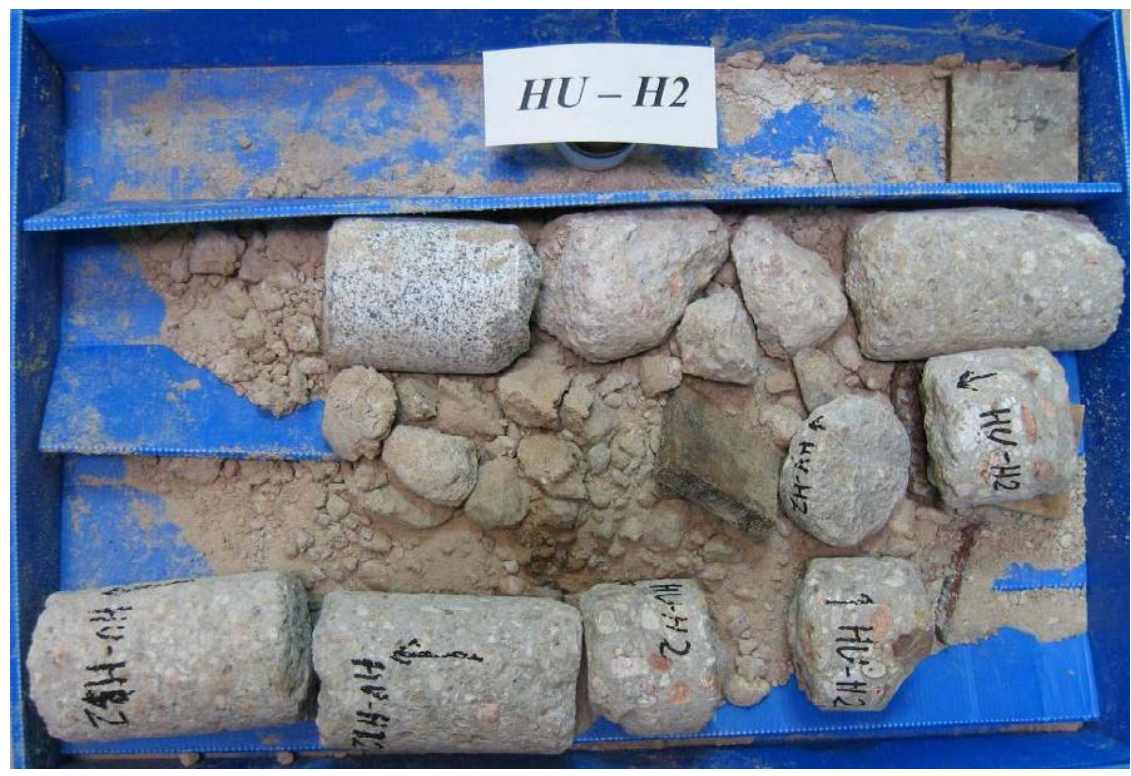

Fig.5.73. Sondeo $\mathrm{HU}-\mathrm{H} 2$. 
- Testigo HU-H3: extraído en el módulo 17, a 102m del extremo del muelle en sentido longitudinal y a $5,5 \mathrm{~m}$ del borde en sentido transversal (figura 5.74).

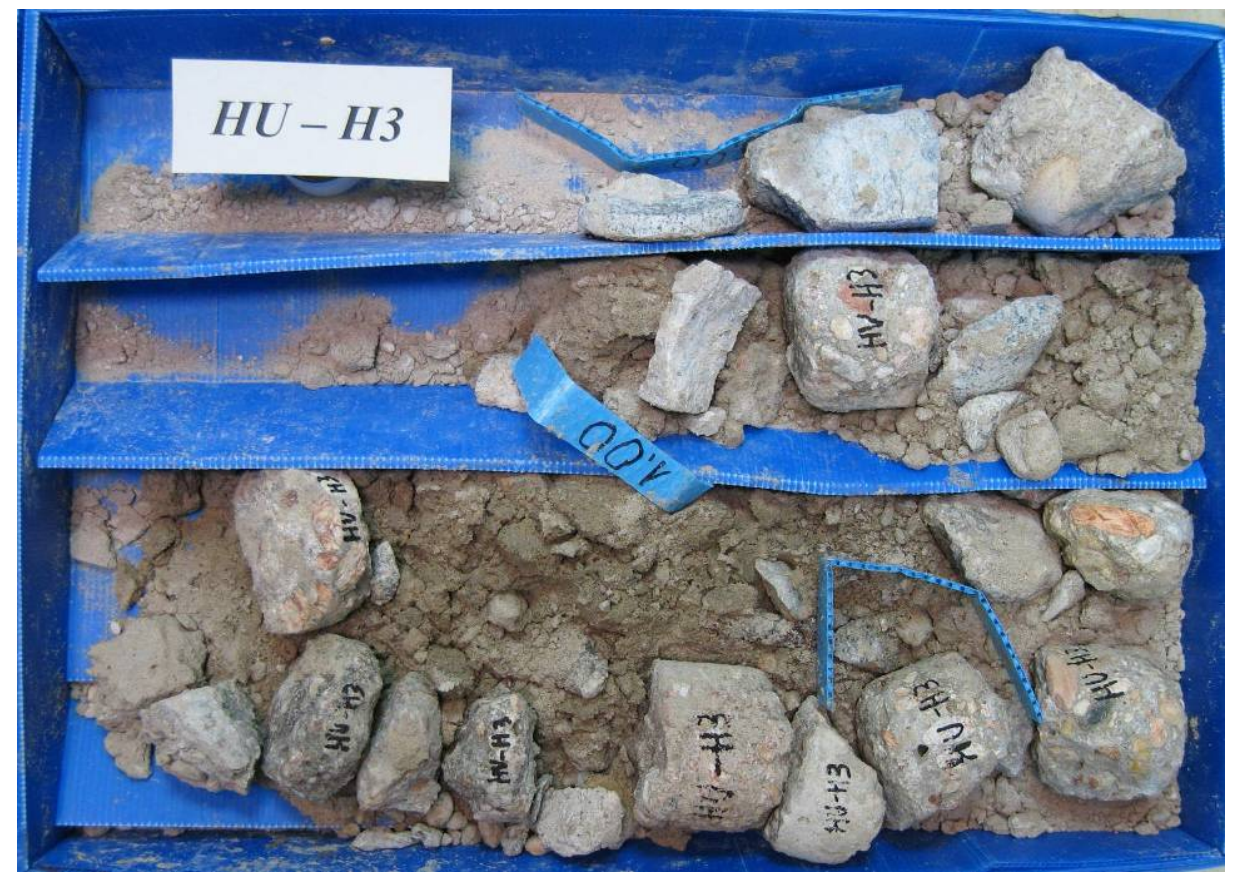

Fig.5.74. Sondeo HU-H3.

- Testigo HU-H4: extraído en el módulo 16, a 149m del extremo del muelle en sentido longitudinal y a $14 \mathrm{~m}$ del borde en sentido transversal (figura 5.75).

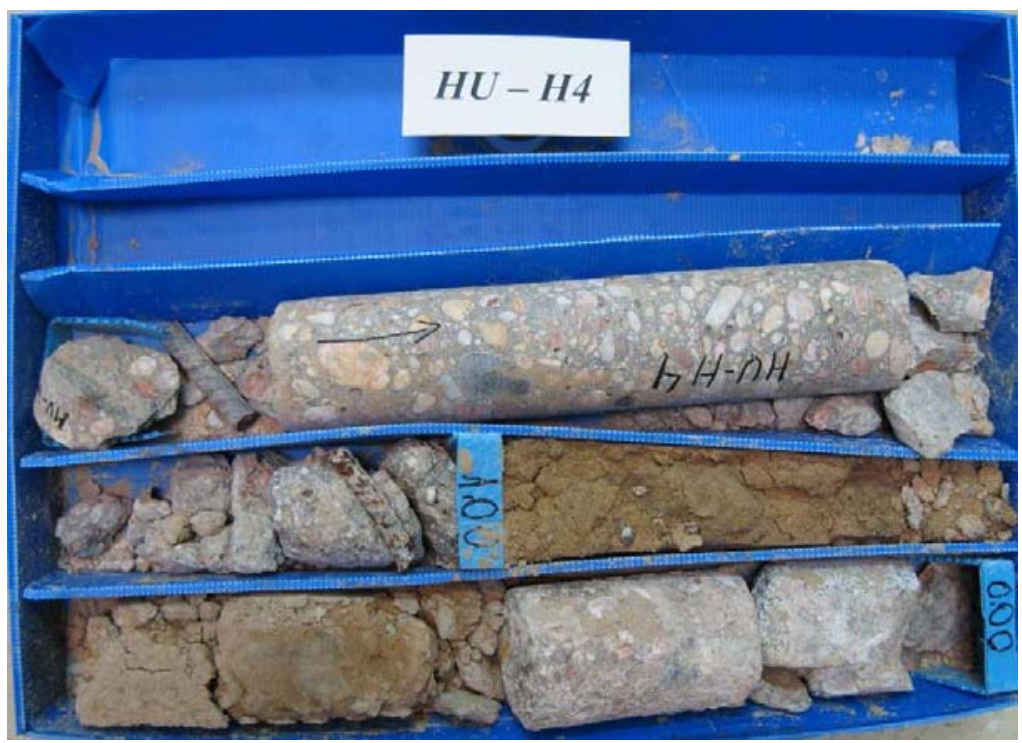

Fig.5.75. Sondeo HU-H4. 
La superficie inferior de la losa se encuentra a una altura de $+5,40$ sobre el nivel de B.M.V.E.

Además se han extraído 4 testigos de los cabeceros, desde la superficie frontal. Son testigos igualmente de $100 \mathrm{~mm}$ de diámetro y unos $40 \mathrm{~cm}$ de longitud, y se han extraído de los siguientes puntos:

- Testigo HU-H5: extraído en el sexto cabecero del módulo 19, en la misma zona donde se realizó la medida de la velocidad de transmisión de ultrasonidos (figura 5.76).

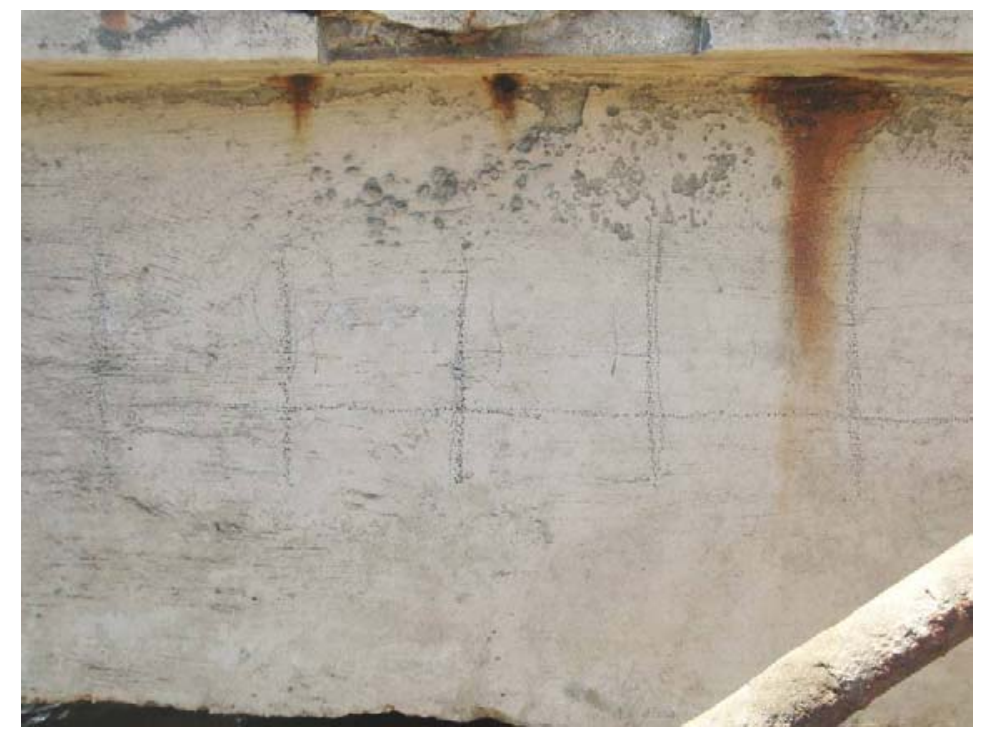

Fig.5.76. Punto de extracción del testigo HU-H5.

- Testigo HU-H6: extraído en el faldón del primer cabecero del módulo 19, a 44 $\mathrm{m}$ del extremo del muelle en sentido longitudinal.

- Testigo HU-H7: extraído en el faldón del quinto cabecero del módulo 16, a 154 $\mathrm{m}$ del extremo del muelle en sentido longitudinal.

- Testigo HU-H8: extraído en el faldón del tercer cabecero del módulo 15, a 216,5 m del extremo del muelle en sentido longitudinal.

Con estos ocho testigos, en laboratorio se han realizado ensayos de carbonatación, de penetración de cloruros, de resistencia a compresión, de penetración de agua, de porosidad abierta, de permeabilidad al oxígeno, de absorción y de absorción capilar. 


\subsection{Descripción de los testigos}

Los testigos extraídos de la losa tienen un diámetro de $9 \mathrm{~cm}$ y una longitud de unos 50,0 cm , aunque fracturados en diferentes trozos: el testigo $\mathrm{HU}-\mathrm{H} 1$ se compone de 7 trozos, el mayor de ellos con una longitud de $16 \mathrm{~cm}$ (figura 5.77); el testigo $\mathrm{HU}-\mathrm{H} 2$ se compone de 6 trozos, con dos trozos de una longitud de $13 \mathrm{~cm}$ (figura 5.77); el testigo $\mathrm{HU}-\mathrm{H} 3$ se ha dividido en 12 trozos de $5 \mathrm{~cm}$ de longitud como máximo (figura 5.78) y el testigo HU-H4 se compone de 2 trozos, uno de 4 $\mathrm{cm}$ y otro de $39 \mathrm{~cm}$ (figura 5.78).
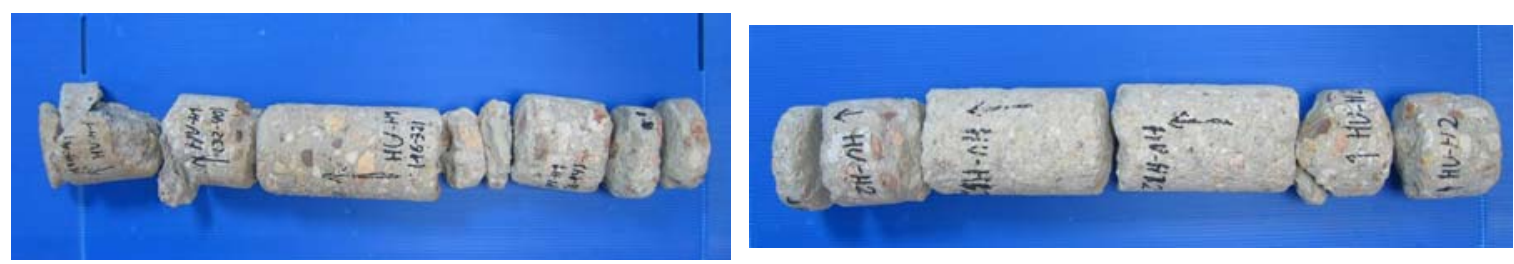

Fig.5.77. Testigo HU-H1 (izquierda) y testigo HU-H2 (derecha).
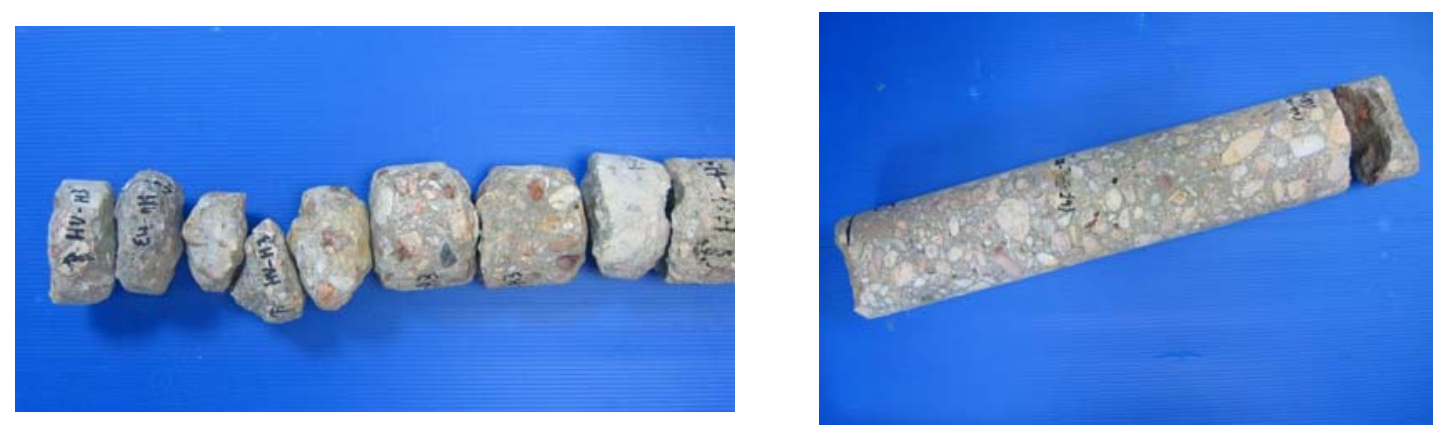

Fig.5.78. Testigo HU-H3 (izquierda) y testigo HU-H4 (derecha).

El árido es rodado, con un tamaño máximo de $45 \mathrm{~mm}$.

En los testigos no se observan coqueras, salvo en un trozo del testigo $\mathrm{HU}-\mathrm{H} 3$ (figura 5.79), fisuras ni ningún otro tipo de anomalía destacable.

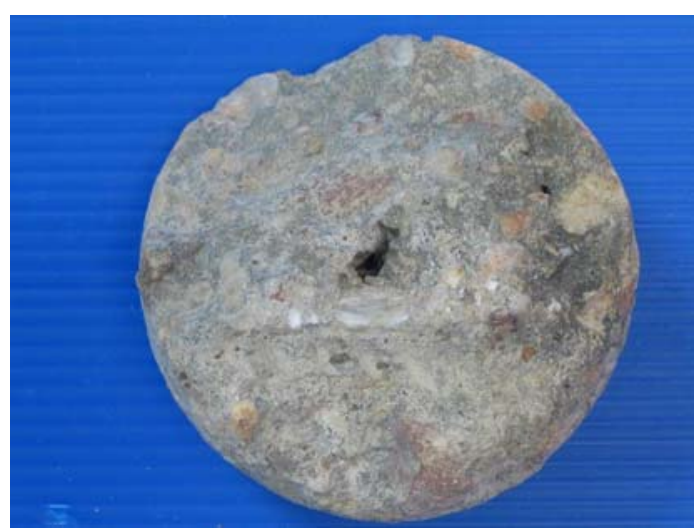

Fig.5.79. Coquera apreciada en la inspección del testigo HU-H3. 
Durante la extracción de los testigos, se ha cortado armadura en todos ellos, aunque en casi todos los casos el testigo ha partido en ese punto, por lo que no es posible conocer si estaban corroídas ni el recubrimiento exacto. En el testigo HU$\mathrm{H} 1$ se han cortado tres barras de $16 \mathrm{~mm}$ de diámetro y otras dos de $12 \mathrm{~mm}$ (figura 5.80); en la sección del sondeo situada a unos $6 \mathrm{~cm}$ del paramento exterior, las corrugas marcadas en el hormigón no presentaban manchas de corrosión (figura 5.80). En el testigo HU-H2 se han cortado una barra de $16 \mathrm{~mm}$ de diámetro y otra de $12 \mathrm{~mm}$, con un recubrimiento de $6,5 \mathrm{~cm}$ (figura 5.81); en el hormigón no se observan manchas de corrosión (figura 5.81). En el testigo HU-H3 se han cortado dos barras de $16 \mathrm{~mm}$ de diámetro y otra de $12 \mathrm{~mm}$ (figura 5.82). Finalmente, en el testigo HU-H4 se han cortado dos barras de $16 \mathrm{~mm}$ de diámetro y otras dos de 12 $\mathrm{mm}$; sólo una de las barras (de $12 \mathrm{~mm}$ de diámetro) ha quedado dentro del hormigón, a una distancia del paramento exterior de aproximadamente $28 \mathrm{~cm}$; al extraerla, no presentaba signos de corrosión. En el hormigón en contacto con las otras dos barras (de 12 y de $16 \mathrm{~mm}$ ) más próximas al paramento expuesto al agua de mar, se observan manchas de corrosión coincidiendo con las marcas de las corrugas (figura 5.83), más acusadas en el hormigón con menos recubrimiento.
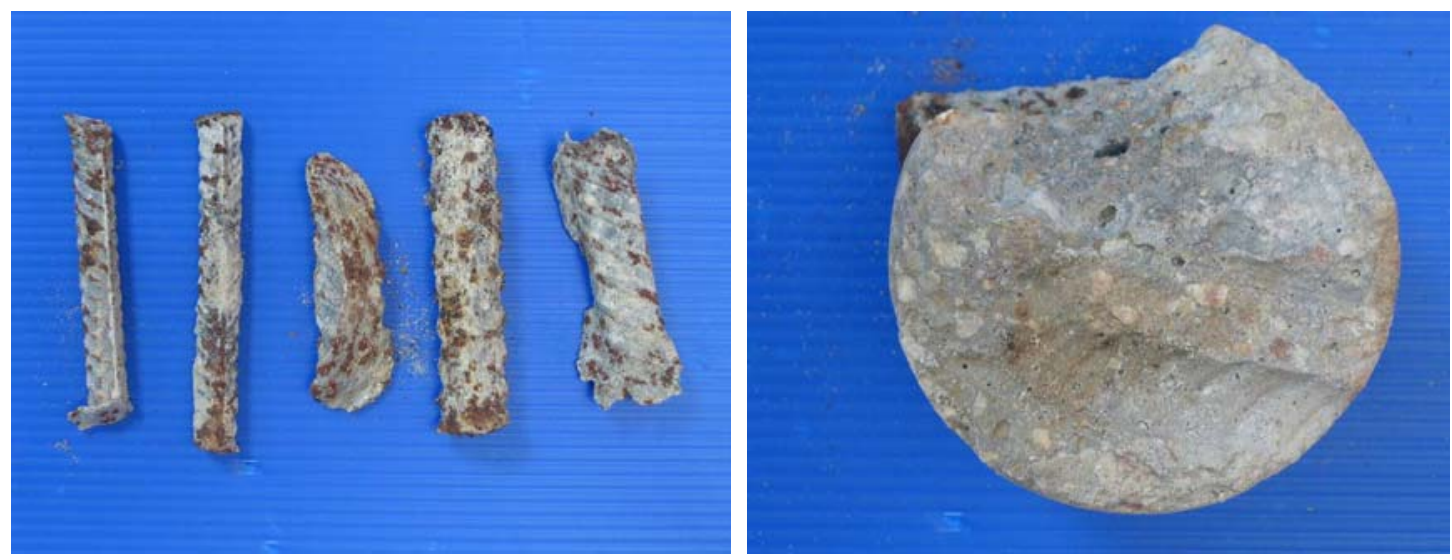

Fig.5.80.Barras cortadas y corrugas marcadas en testigo $\mathrm{HU}-\mathrm{H1}$.
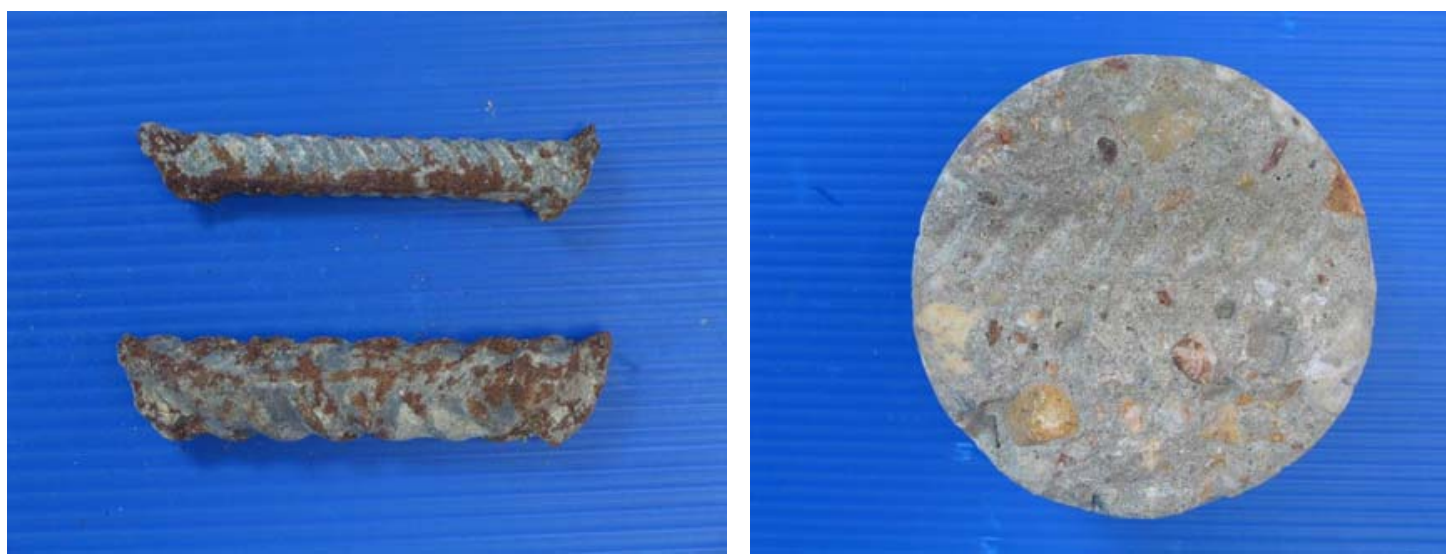

Fig.5.81.Barras cortadas y hormigón sin síntomas de corrosión en testigo HU-H2 


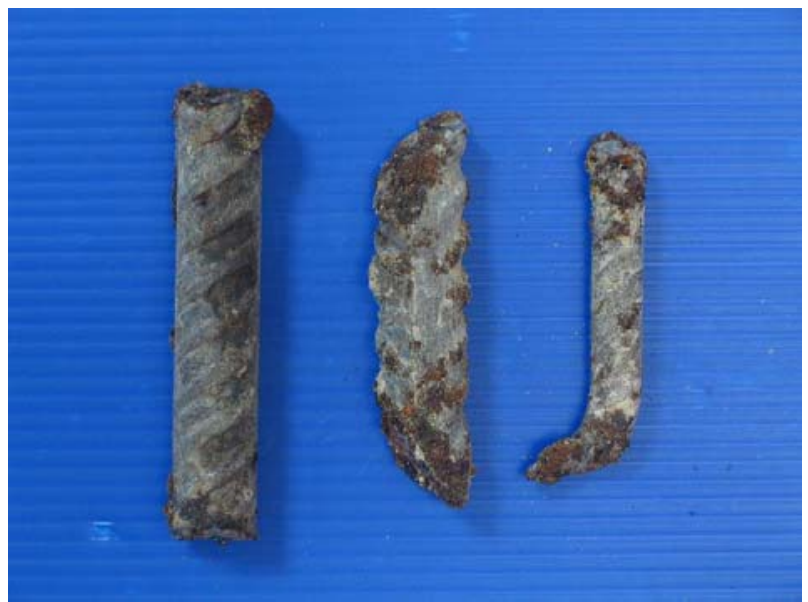

Fig.5.82. Barras cortadas en la extracción del testigo $\mathrm{HU}-\mathrm{H} 3$
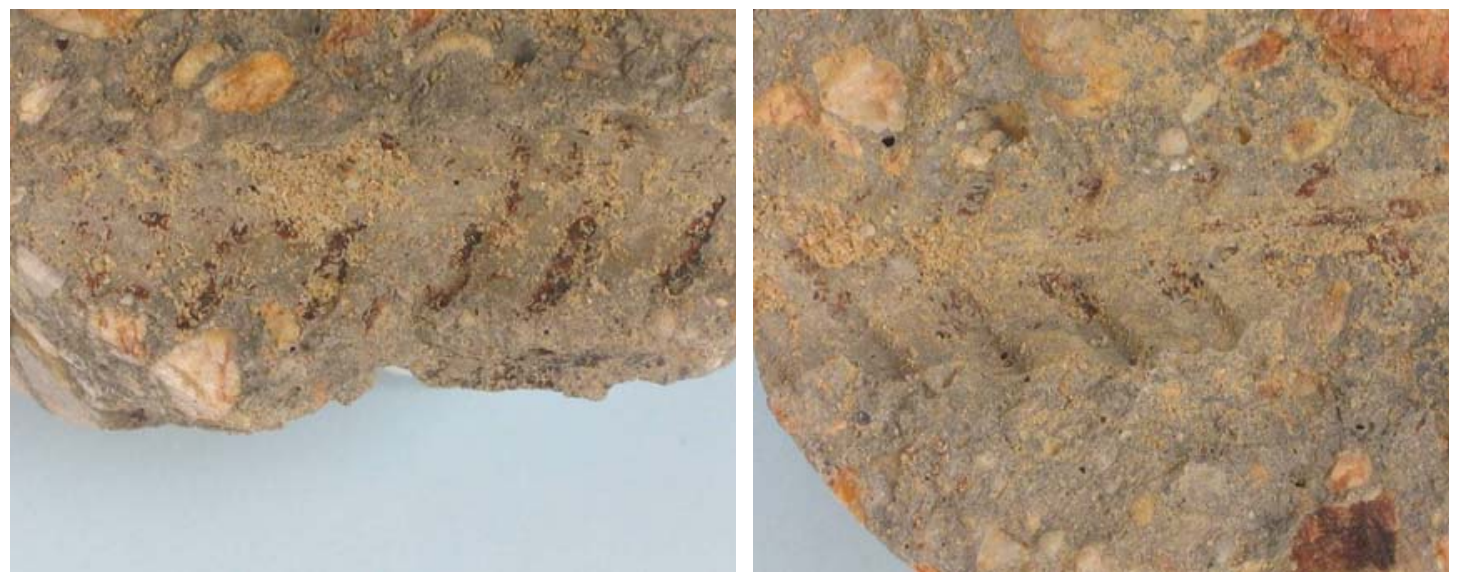

Fig.5.83. Detalle de las manchas de corrosión detectadas en el testigo $\mathrm{HU}-\mathrm{H} 4$, en las corrugas de la armadura más próxima al paramento con el agua de mar

En cuanto a los testigos extraídos de los cabeceros, todos tienen un diámetro de $10 \mathrm{~cm}$ y diferentes longitudes: el testigo HU-H5 mide $41 \mathrm{~cm}$ (figura 5.84); el testigo HU-H6 mide $35 \mathrm{~cm}$, aunque durante su extracción se ha partido en dos fragmentos, de 9 y $26 \mathrm{~cm}$ respectivamente (figura 5.85).
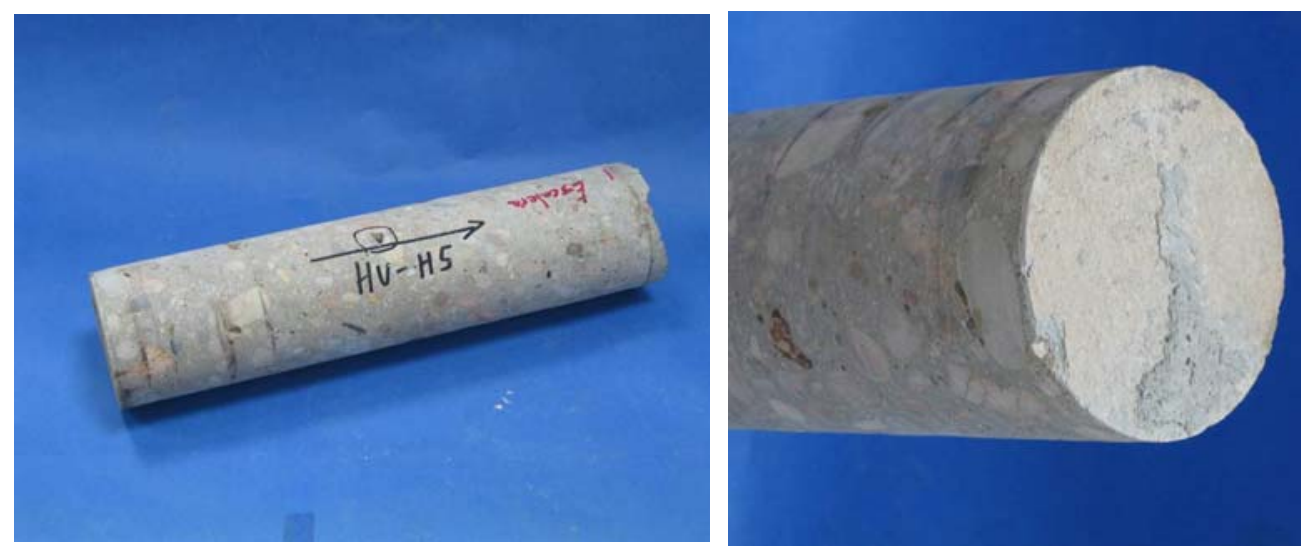

Fig.5.84. Vistas lateral y frontal exterior del testigo $\mathrm{HU}-\mathrm{H} 5$ 

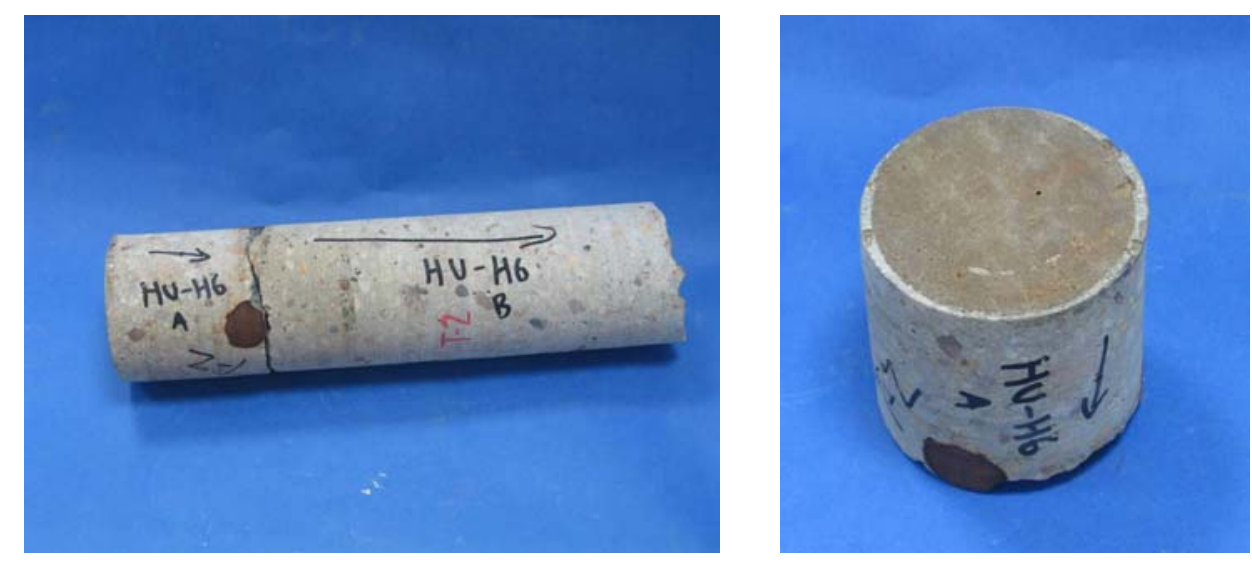

Fig.5.85. Vistas lateral y frontal exterior del testigo $\mathrm{HU}-\mathrm{H} 6$

El testigo HU-H7 mide $41 \mathrm{~cm}$ y está dividido en tres fragmentos, de 8,2 y $31 \mathrm{~cm}$ respectivamente (figura 5.86); finalmente, el testigo $\mathrm{HU}-\mathrm{H} 8$ mide $40 \mathrm{~cm}$ y está dividido en dos fragmentos, de 19 y $21 \mathrm{~cm}$ de longitud respectivamente (figura 5.87).
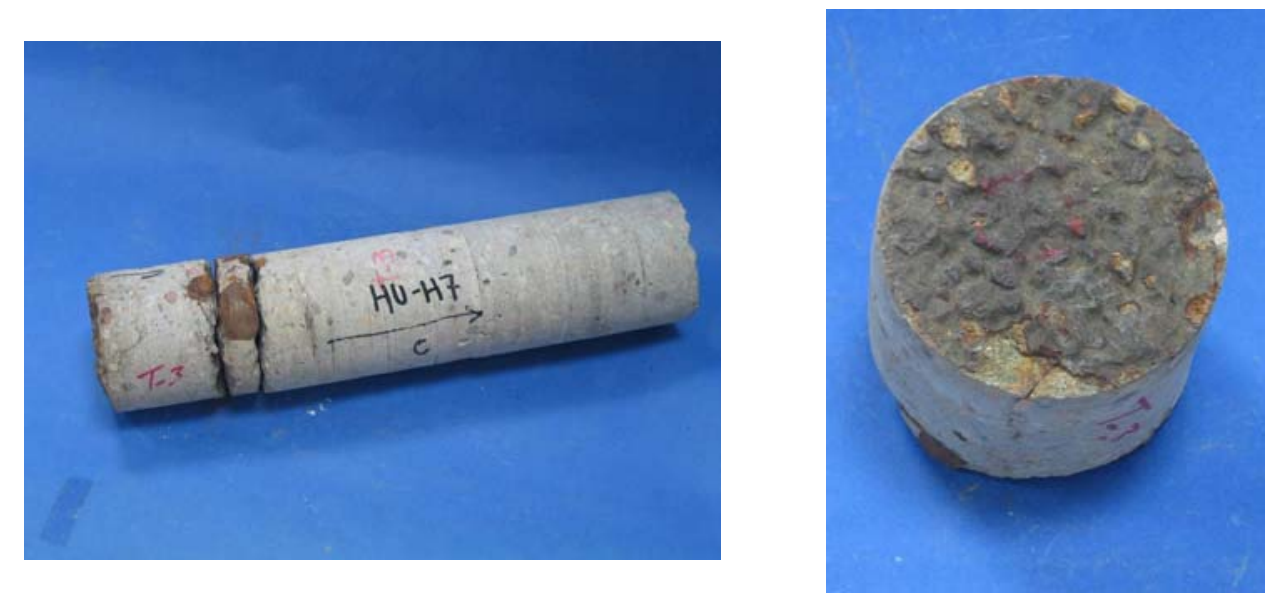

Fig.5.86. Vistas lateral y frontal exterior del testigo $\mathrm{HU}-\mathrm{H} 7$.
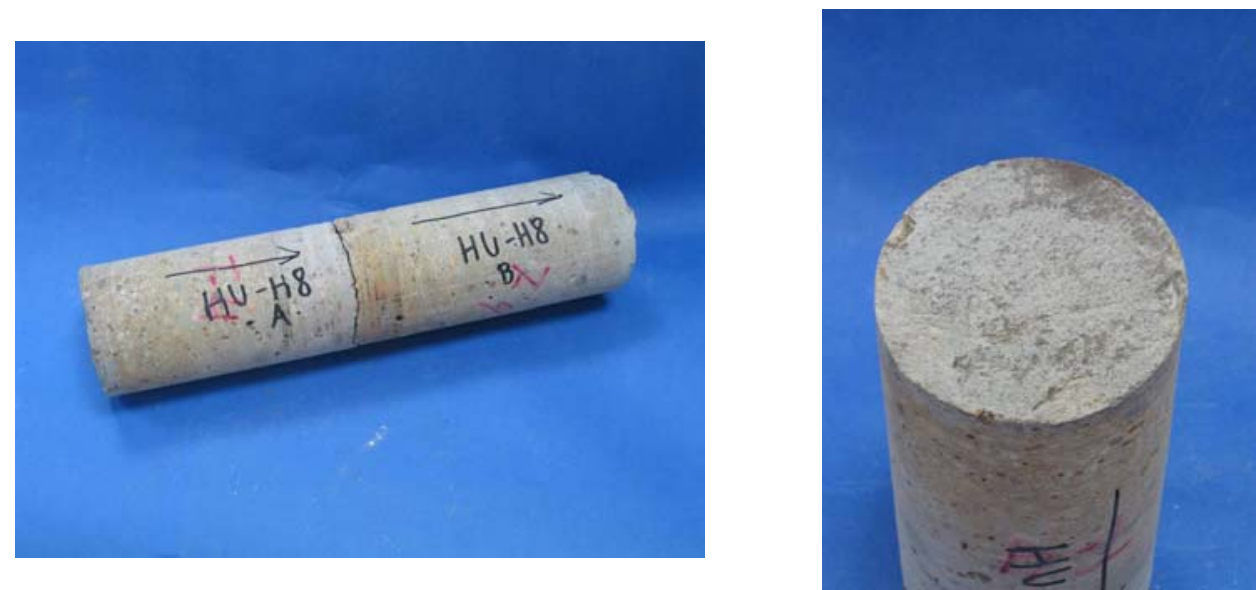

Fig.5.87. Vistas lateral y frontal exterior del testigo $\mathrm{HU}-\mathrm{H} 8$. 
El árido es mezclado, con un tamaño máximo de $15 \mathrm{~mm}$ en los testigos HU-H6 y $\mathrm{HU}-\mathrm{H} 7,25 \mathrm{~mm}$ en el testigo HU-H8 y $50 \mathrm{~mm}$ en el testigo HU-H5.

En los testigos no se observan coqueras (salvo una un poco más grande en el testigo HU-H5), fisuras ni ningún otro tipo de anomalía destacable, excepto en el testigo $\mathrm{HU}-\mathrm{H} 7$, en el que el recubrimiento se encuentra fisurado, debido probablemente a la corrosión de las armaduras (figura 5.88).
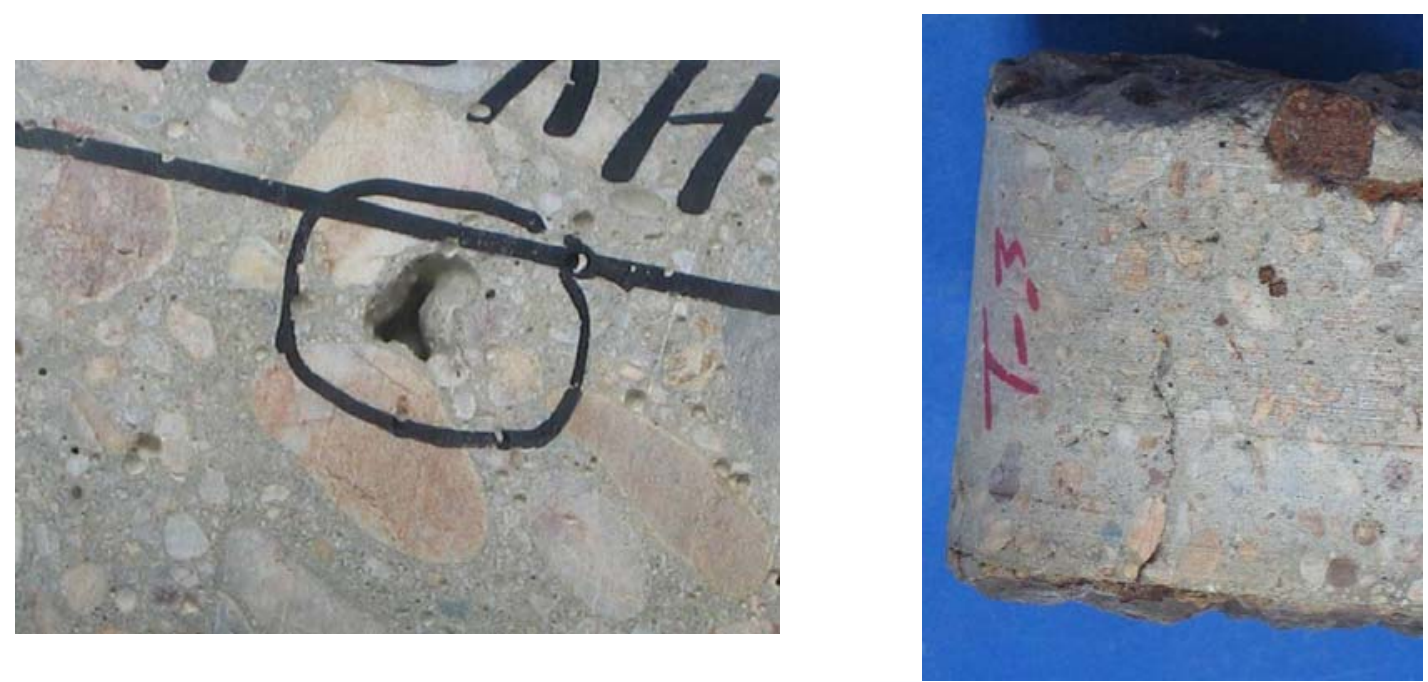

Fig.5.88.Coquera situada en testigo $\mathrm{HU}-\mathrm{H} 5$ y fisuración del recubrimiento en el testigo $\mathrm{HU}-\mathrm{H} 7$.

Durante la extracción de los testigos, se ha cortado armadura en dos testigos. En el testigo HU-H6 se ha cortado una barra de $25 \mathrm{~mm}$ de diámetro, con un recubrimiento de $75 \mathrm{~mm}$; se observan algunos puntos de corrosión, aunque las corrugas marcadas en el hormigón no presentaban manchas de corrosión (figura 5.89). En el testigo $\mathrm{HU}-\mathrm{H} 7$ se han cortado una barra de $16 \mathrm{~mm}$ de diámetro (armadura exterior) y otra de $25 \mathrm{~mm}$, con un recubrimiento de $60 \mathrm{~mm}$; en el hormigón se observan manchas de corrosión y las barras muestran síntomas de un progreso importante de la corrosión (figura 5.90). 

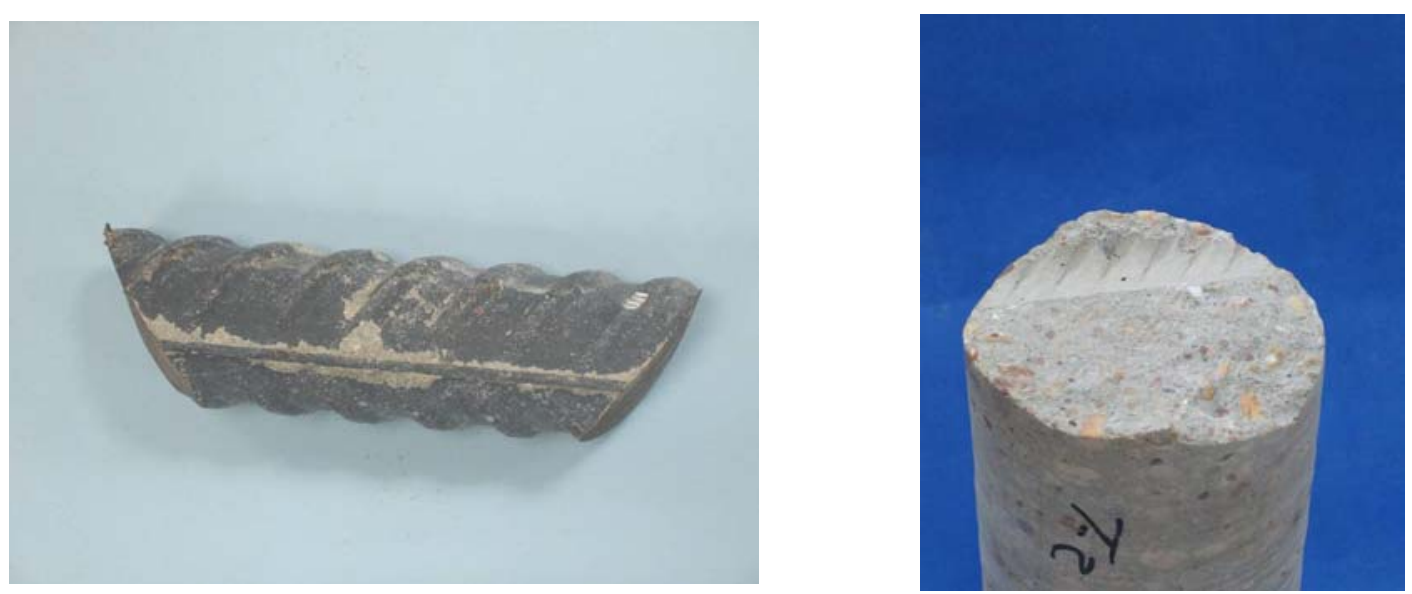

Fig.5.89. Se aprecian leves manchas de óxido en la armadura, pero no en la marca de la corruga en el testigo $\mathrm{HU}-\mathrm{H} 6$.
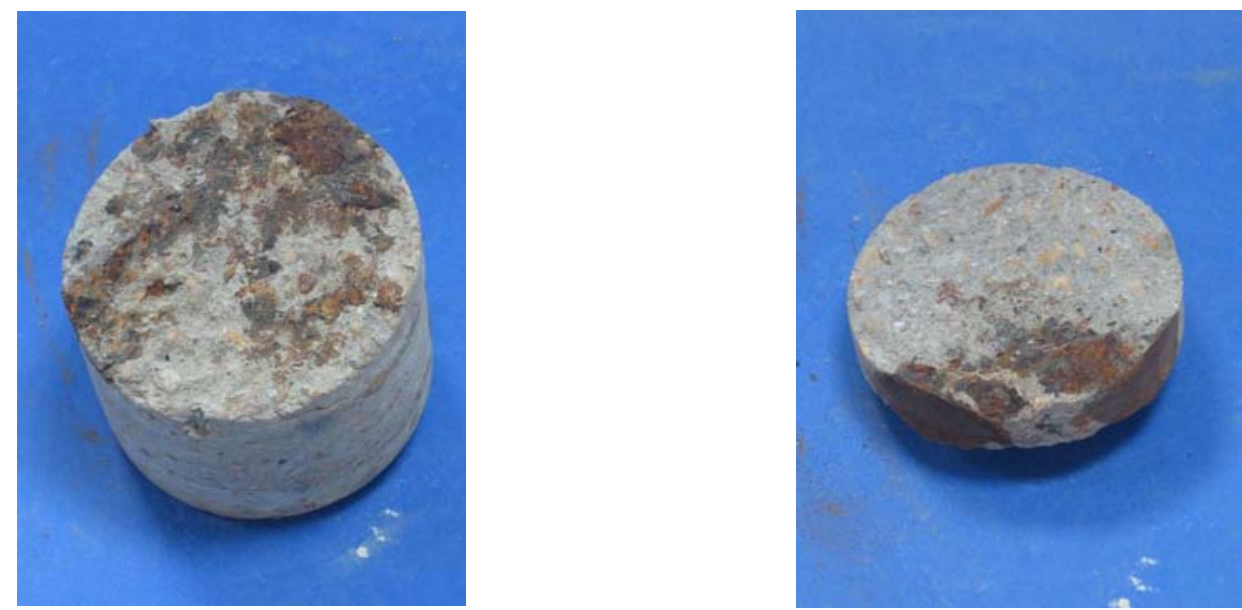

Fig.5.90. Armaduras corroídas y hormigón con manchas de corrosión en el testigo HU-H7.

\subsubsection{Muelle C}

En el caso de este muelle, previo a la extracción de testigos se llevaron a cabo medidas de control de recubrimiento de las armaduras, velocidad de propagación de ultrasonidos así como medidas electroquímicas de la corrosión (resistividad, potencial de media pila e intensidad de la corrosión) con el fin de clasificar la resistencia de varias zonas del muelle y así poder elegir las zonas de extracción de testigos en lugares de resistencia elevada, media y baja a partir de los resultados obtenidos de la medida de velocidad de ultrasonidos.

\subsection{Velocidad de propagación de ultrasonidos}

Se ha realizado una medida indirecta de la velocidad de ultrasonidos en la viga cantil. Se dispusieron inicialmente los palpadores separados entre sí $20 \mathrm{~cm}$ en una 
línea horizontal equidistante de dos barras de la armadura horizontal de la viga (entre la primera y la segunda barras horizontales, por lo que se sitúa dicha línea a unos $20 \mathrm{~cm}$ de la cara superior de la viga). Se realizó una medida de la velocidad de ultrasonidos, y manteniendo fijo un palpador, se realizaron otras tres medidas de la velocidad de ultrasonidos separando cada vez $5 \mathrm{~cm}$ el otro palpador, siguiendo la línea horizontal indicada. Con la media de estas 4 medidas se obtiene la velocidad de ultrasonidos del hormigón de la viga.

Se ha medido la velocidad de ultrasonidos a $5,10,15,20,25,30$ y 35 metros del origen del módulo 1 y en los puntos 70, 91,1, 95, 100, 105, 110, 115 y 119,5 del módulo 2, así como en el lateral del módulo 1, en sus tres vigas. A continuación se aportan las figuras 5.91, 5.92 y 5.93 donde puede verse la situación de tales puntos.

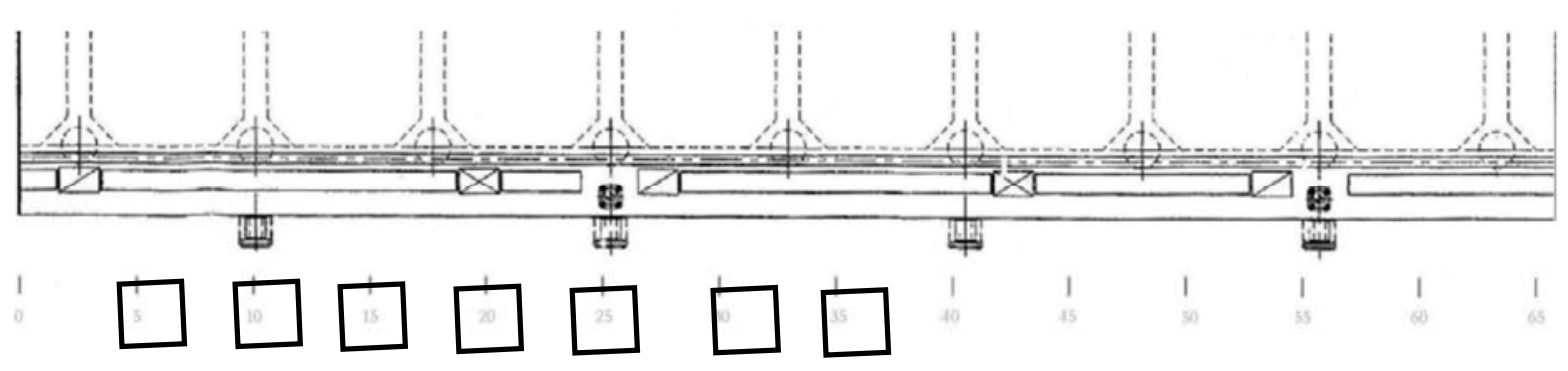

Fig.5.91. Croquis del módulo 1. Puntos de medida de velocidad de ultrasonidos.

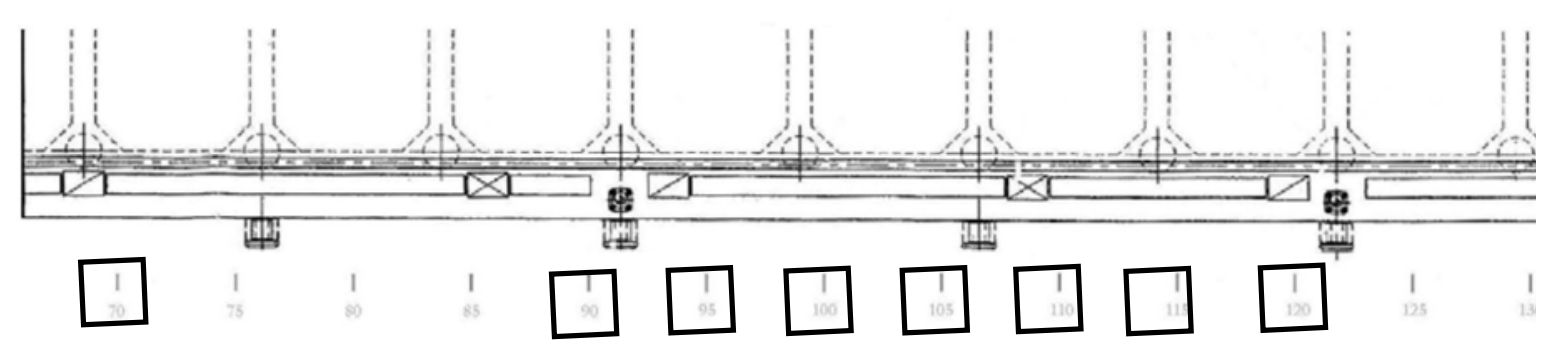

Fig.5.92. Croquis del módulo 2. Puntos de medida de velocidad de ultrasonidos. 


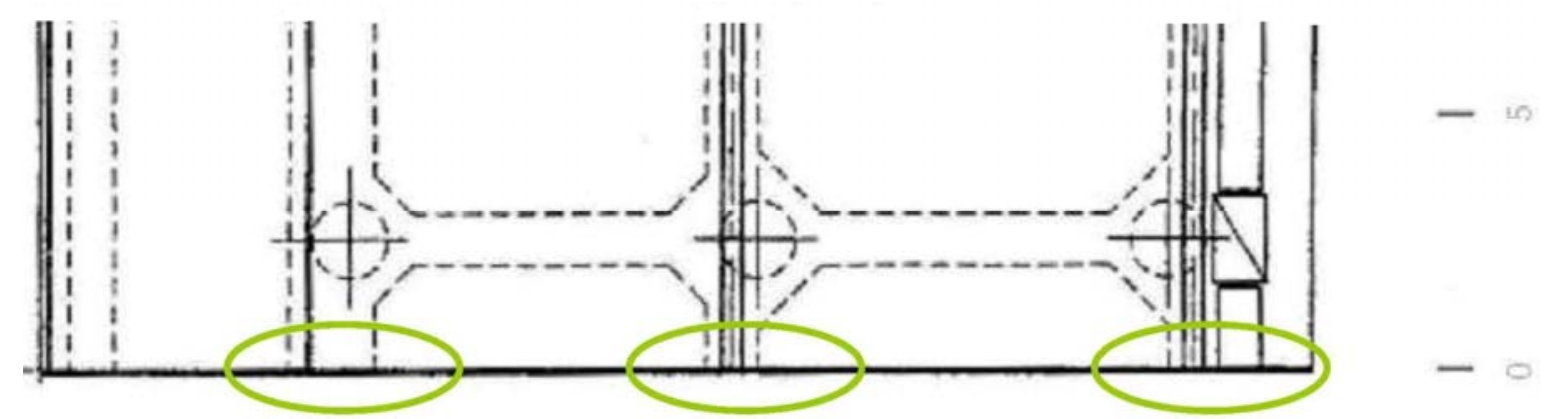

Fig.5.93. Lateral del módulo1. Puntos de medida de velocidad de ultrasonidos.

Los resultados de las medidas obtenidas se aportan en las tablas 5.5, 5.6 y 5.7.

\subsection{Medidas electroquímicas de la corrosión}

El estudio electroquímico de la corrosión se ha realizado en todos los puntos donde se midió la velocidad de transmisión de ultrasonidos y en algún punto más tal y como se muestra en las tablas 5.5, 5.6 y 5.7, midiendo el potencial de media pila, la resistividad y la intensidad de corrosión. Las medidas de potencial de media pila se han tomado a dos alturas diferentes de la viga (a $25-35 \mathrm{~cm}$ y a $60-70 \mathrm{~cm}$ de la fibra superior). 


\begin{tabular}{|c|c|c|c|c|c|c|c|c|c|c|}
\hline \multicolumn{11}{|c|}{ MÓDULO 1} \\
\hline Distancia (m) & 5 & 10 & 15 & 20 & 25 & 30 & 35 & 56 & 60 & 65 \\
\hline $\begin{array}{c}\text { Velocidad } \\
\text { Ultrasonidos }(\mathrm{m} / \mathrm{s})\end{array}$ & 3290 & 3551 & 2594 & 2876 & 3005 & 3053 & 3510 & & & \\
\hline $\begin{array}{c}\text { Potencial Media } \\
\text { Pila (mV) } \\
\text { 25-35 cm. Medida } \\
1\end{array}$ & -187 & -126 & -186 & -159 & -216 & -108 & -179 & -275 & -332 & -326 \\
\hline $\begin{array}{c}\text { Resistividad } \\
(\mathrm{k} \Omega \cdot \mathrm{cm}) \\
25-35 \mathrm{~cm} . \text { Medida } \\
1\end{array}$ & 28 & 29 & 30 & 35 & 20 & 29 & 39 & 22 & 26 & 40 \\
\hline $\begin{array}{c}\text { Potencial Media } \\
\text { Pila (mV) } \\
60-70 \text { cm. Medida } \\
2\end{array}$ & -154 & -146 & -243 & -133 & -221 & -118 & -158 & & & \\
\hline $\begin{array}{c}\text { Resistividad } \\
(\mathrm{k} \Omega \cdot \mathrm{cm}) \\
60-70 \mathrm{~cm} . \text { Medida } \\
2\end{array}$ & 27 & 29 & 34 & 24 & 33 & 35 & 27 & & & \\
\hline $\begin{array}{c}\text { Recubrimiento } \\
\text { (mm) }\end{array}$ & 34 & 60 & 32 & 45 & 36 & 38 & 33 & & & \\
\hline
\end{tabular}

Tabla.5.5. Resultados de las medidas realizadas en el módulo 1. 


\begin{tabular}{|c|c|c|c|c|c|c|c|c|c|c|}
\hline \multicolumn{11}{|c|}{ MÓDULO 2} \\
\hline Distancia (m) & 70 & 74 & 80 & 91,1 & 95 & 100 & 105 & 110 & 115 & 119,5 \\
\hline $\begin{array}{c}\text { Velocidad } \\
\text { Ultrasonidos }(\mathrm{m} / \mathrm{s})\end{array}$ & 3035 & & & 3853 & 3257 & 4000 & 2467 & 3747 & 2985 & 3372 \\
\hline $\begin{array}{c}\text { Potencial Media } \\
\text { Pila (mV) } \\
\text { 25-35 cm. Medida } \\
1\end{array}$ & -177 & -260 & -273 & -227 & -253 & -329 & -325 & -314 & -245 & -210 \\
\hline $\begin{array}{c}\text { Resistividad } \\
(\mathrm{k} \Omega \cdot \mathrm{cm}) \\
25-35 \mathrm{~cm} . \text { Medida } \\
1\end{array}$ & 24 & 23 & 29 & 23 & 56 & 50 & 40 & 81 & 35 & 42 \\
\hline $\begin{array}{c}\text { Potencial Media } \\
\text { Pila (mV) } \\
60-70 \mathrm{~cm} \text {. Medida } \\
2\end{array}$ & -179 & & & -160 & -166 & -266 & -276 & -314 & -306 & -232 \\
\hline $\begin{array}{c}\begin{array}{c}\text { Resistividad } \\
(\mathrm{k} \Omega \cdot \mathrm{cm})\end{array} \\
60-70 \mathrm{~cm} . \text { Medida } \\
2\end{array}$ & 31 & & & 25 & 28 & 24 & 46 & 26 & 21 & 47 \\
\hline $\begin{array}{c}\text { Recubrimiento } \\
\text { (mm) }\end{array}$ & 32 & & & 7 & & 30 & 25 & 25 & 25 & 25 \\
\hline
\end{tabular}

Tabla.5.6. Resultados de las medidas realizadas en el módulo 2.

\begin{tabular}{|c|c|c|c|}
\hline \multicolumn{4}{|c|}{ LATERAL MÓDULO 1} \\
\hline Ubicación & $\begin{array}{c}\text { Viga Longitudinal } \\
\text { Trasera }\end{array}$ & $\begin{array}{l}\text { Viga Longitudinal } \\
\text { Intermedia }\end{array}$ & $\begin{array}{c}\text { Viga Longitudinal } \\
\text { de Cantil }\end{array}$ \\
\hline $\begin{array}{c}\text { Velocidad Ultrasonidos } \\
\text { (m/s) }\end{array}$ & 3945 & 3267 & 3582 \\
\hline
\end{tabular}

Tabla.5.7. Resultados de las medidas realizadas en el lateral del módulo 1.

A continuación, la figura 5.94 aporta un croquis con la ubicación de las medidas realizadas en la viga cantil. En la figura 5.95 se muestra cómo se realizaron las medidas de intensidad de corrosión. 
Parte superior Viga Cantil

VIGA

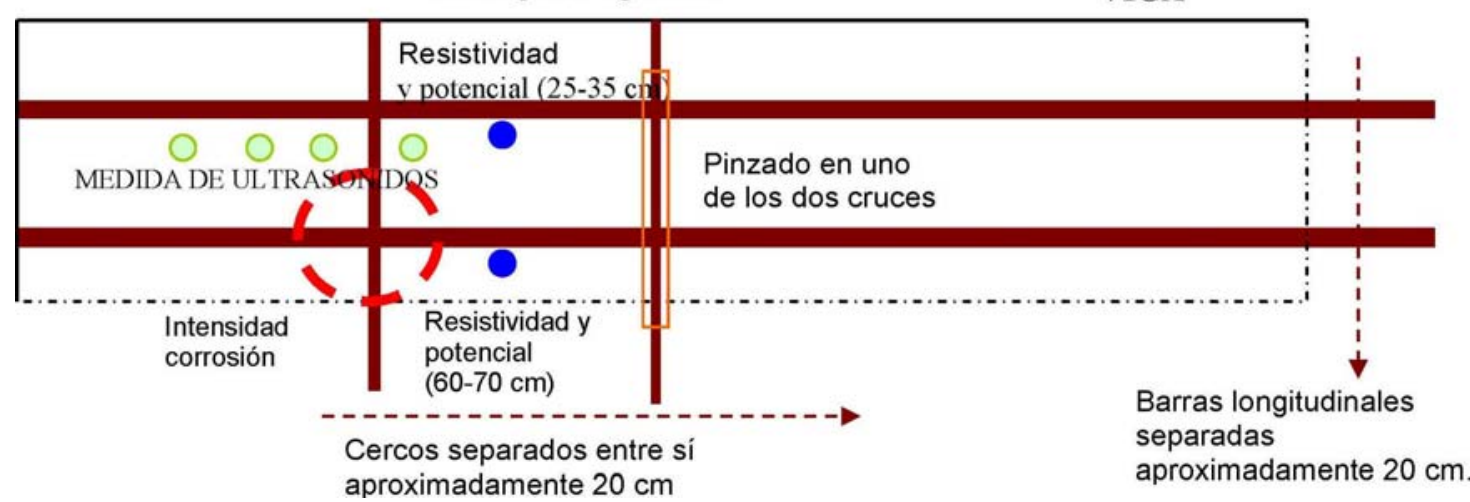

Fig.5.94. Croquis de la ubicación de las medidas en la viga cantil.

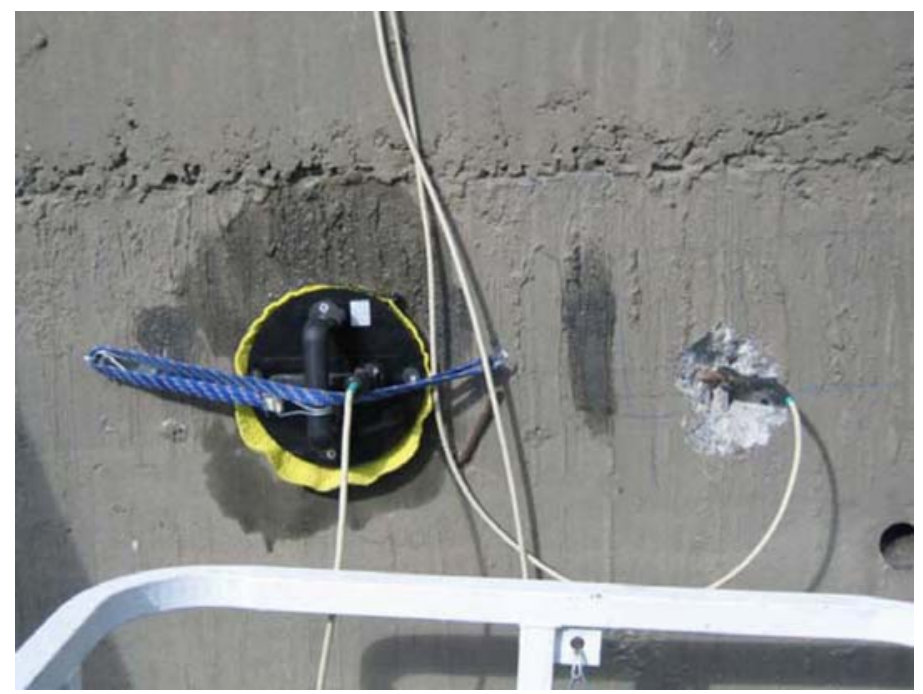

Fig.5.95. Medida de la intensidad de la corrosión.

\subsection{Valoración de los resultados y justificación de los puntos de extracción de testigos}

Las medidas de la velocidad de ultrasonidos son en general dispersas, aunque presentan mayor uniformidad en la zona de la viga cantil próxima a la cabecera del muelle. Hay una tendencia clara al crecimiento de los valores de la velocidad de ultrasonidos a medida que se avanza en el muelle, alejándose de la zona de cabecera. En el caso de las vigas trasera e intermedia del muelle sólo se realizan medidas de ultrasonidos con valores que indican calidad media del hormigón. Los testigos T1 y T2 se extraen de los cabeceros de dichas vigas con el fin de caracterizar su hormigón dada la imposibilidad de extraer los testigos de la cara frontal de las mismas. 
En cuanto a las medidas de resistividad realizadas en diversos puntos de la viga cantil, se han obtenido datos coherentes con los de la velocidad de ultrasonidos, indicando una calidad media del hormigón en los dos primeros tercios de la viga. Se observa que la resistividad disminuye, en general, con la altura en la viga cantil. Las medidas de resistividad tomadas en la parte más inferior de la viga $(60-70 \mathrm{~cm})$ son menores, lo que se justifica debido a que la parte inferior de la viga se encuentra sumergida en agua más tiempo y sus poros más saturados. Por esta razón y dado que se quiere caracterizar el hormigón expuesto a ambiente marino aéreo, los testigos se extraen en todos los casos perpendicularmente al paramento y situados entre el primer y segundo nivel de armaduras.

Las medidas de potencial de media pila se han realizado, como las de resistividad, en dos niveles (superior: $25-35 \mathrm{~cm}$ e inferior: $60-70 \mathrm{~cm}$ ), con resultados más negativos en el primero de los casos. La zona superior, más alejada del nivel del mar, y por tanto con un hormigón menos saturado, registra, sin embargo, valores inferiores del potencial de media pila, que por tanto se relacionan directamente con una mayor probabilidad de sufrir corrosión de la armadura de esta zona.

Las medidas de potencial de media pila indican alta probabilidad de corrosión en el módulo 2. A pesar de que el hormigón presenta mayor resistividad en el tramo final de dicho módulo, no se consigue una protección suficiente de la armadura frente a la corrosión, con valores muy bajos del potencial de media pila. Esto puede deberse a los valores de recubrimiento bajos medidos en esta zona.

Los testigos T3 y T4 se extraen a 5 y 10 m del inicio de la viga cantil ya que presentan valores de potencial de media pila $(-187$ y -126) que indican que el riesgo de sufrir corrosión en tales puntos está por debajo del 10\%. Los testigos T5 y T6 se extraen a 91,5 y 105m del inicio de la viga cantil con valores de potencial de media pila (-227 y -325) lo que muestra un riesgo mayor de sufrir corrosión. Los valores de resistividad medidos en los cuatro casos se sitúan en el entorno de los $30-50 \mathrm{k} \Omega \cdot \mathrm{cm}$, lo que implica que a pesar de ser medio el riesgo de sufrir corrosión, las armaduras se encuentran en estado pasivo, lo que puede corroborarse a la vista del aspecto de la armadura descubierta que aparece en la figura 5.96. 

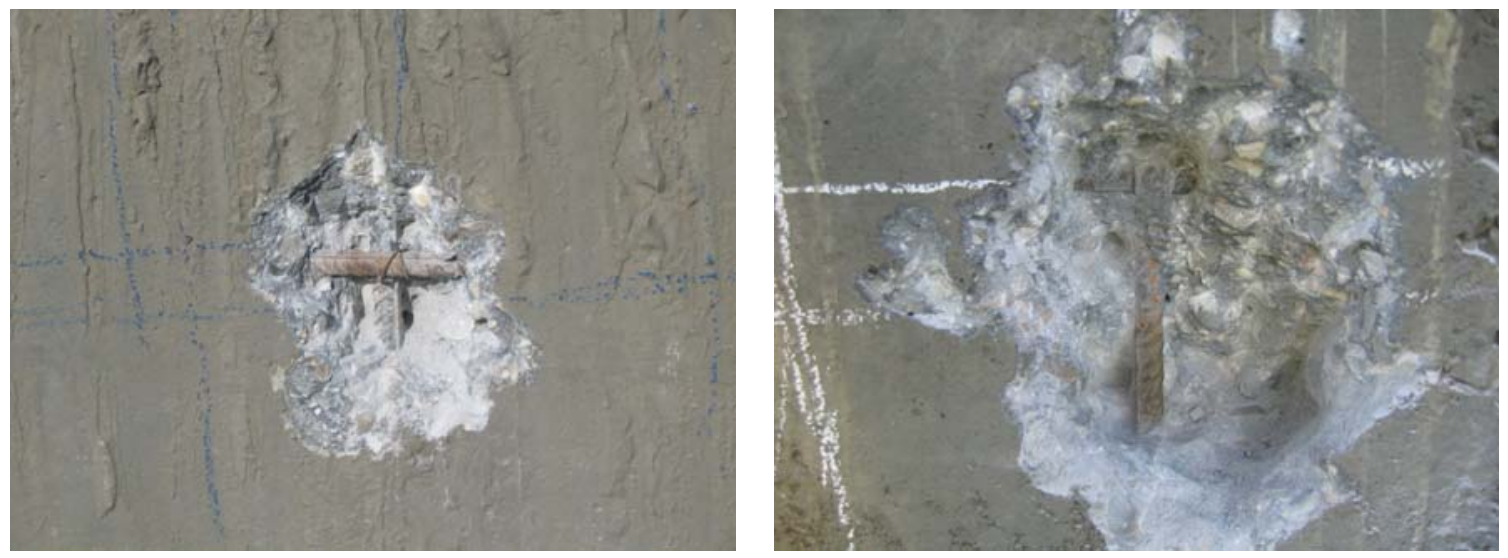

Fig.5.96. Armaduras descubiertas para la realización de las medidas electroquímicas sin síntomas de corrosión.

La figura 5.97 muestra la ubicación en planta de los testigos extraídos.

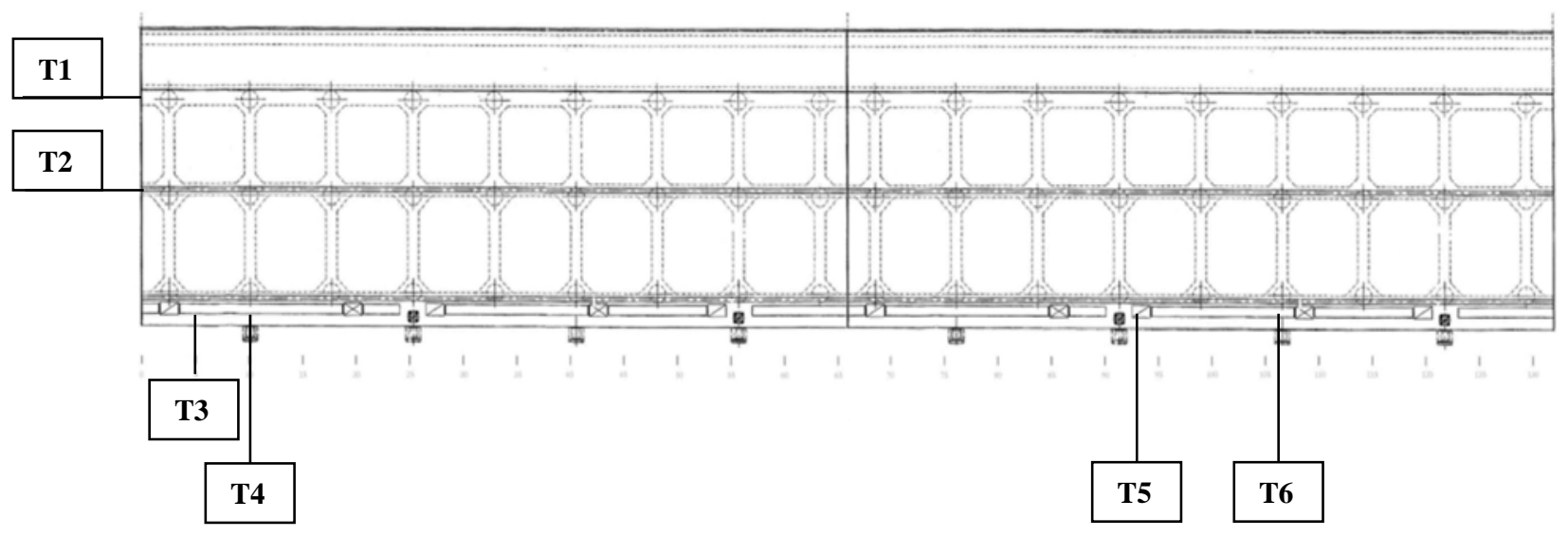

Fig.5.97.Croquis de situación de los testigos extraídos en el muelle C.

\subsection{Extracción de los testigos}

Tras el análisis de los ensayos de campo realizados, se han extraídos seis testigos de $100 \mathrm{~mm}$ de diámetro y $60 \mathrm{~cm}$ aproximadamente de longitud. Cuatro de ellos se han tomado de la zona superior de la viga cantil, extraídos perpendicularmente a su paramento exterior y localizados entre las dos primeras armaduras longitudinales y los dos restantes se extraen del cabecero de la viga trasera e intermedia, tal y como se aprecia en el croquis de la figura 5.97.

Se han extraído testigos en los siguientes puntos del muelle:

- T1: Cabecero de la viga trasera

- T2: Cabecero de la viga intermedia

- T3: Viga Cantil, a 5m del inicio de la viga desde el cabecero del muelle. 
- T4: Viga Cantil, a 10m del inicio de la viga desde el cabecero del muelle.

- T5: Viga Cantil, a 91,5m del inicio de la viga desde el cabecero del muelle.

- T6: Viga Cantil, a 105m del inicio de la viga desde el cabecero del muelle.

La superficie inferior de la losa se encuentra a una altura de $+5,90$ sobre el nivel de B.M.V.E.

\subsection{Descripción de los testigos}

Los testigos extraídos de la losa tienen un diámetro de $9,4 \mathrm{~cm}$ y una longitud de unos $60-65 \mathrm{~cm}$, aunque se presentan fracturados en diferentes fragmentos: el testigo AV-T1 se compone de dos trozos, el primero, con una longitud de $29 \mathrm{~cm}$ y el segundo, de $38 \mathrm{~cm}$ (figura 5.98); el testigo AV-T2 se divide en dos trozos, con una longitud de $30 \mathrm{~cm}$ y $31,5 \mathrm{~cm}$ (figura 5.99); el testigo AV-T3 se compone de tres trozos, de $3,5 \mathrm{~cm}, 22 \mathrm{~cm}$ y $35 \mathrm{~cm}$ (figura 5.100 ); el testigo AV-T4 se divide en dos trozos, de $28 \mathrm{~cm}$ y otro de $30 \mathrm{~cm}$ (figura 5.101); el testigo AV-T5 se compone de dos trozos, de $37 \mathrm{~cm}$ y $24 \mathrm{~cm}$ (figura 5.102 ) y por último, el testigo AV-T6 se divide en dos trozos, de $36 \mathrm{~cm}$ y $30 \mathrm{~cm}$ (figura 5.103 ).
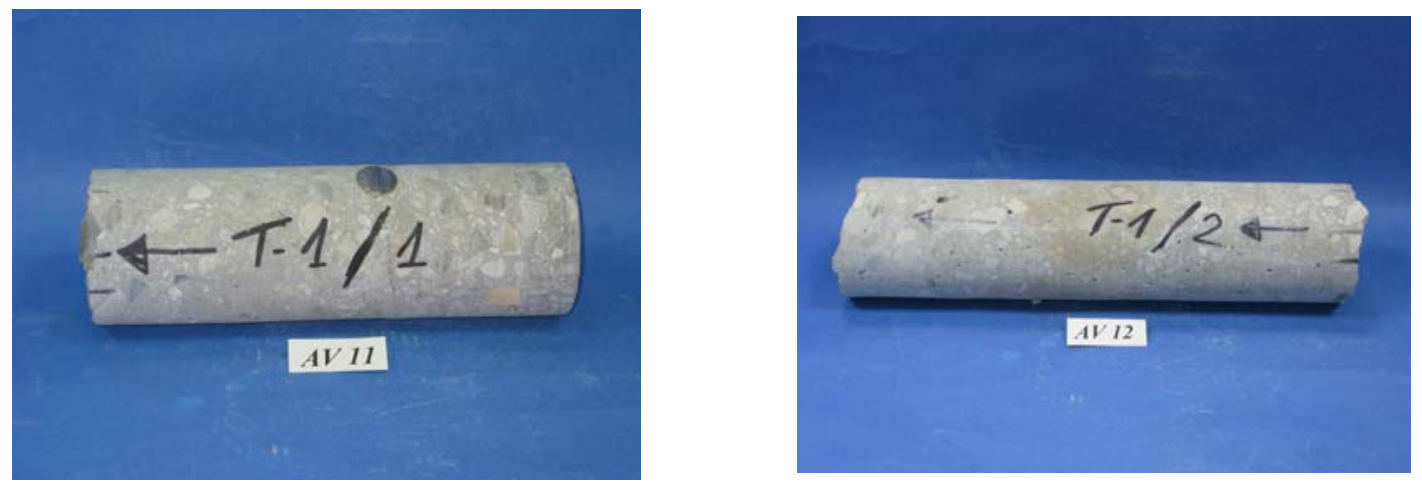

Fig.5.98. AV-T1.
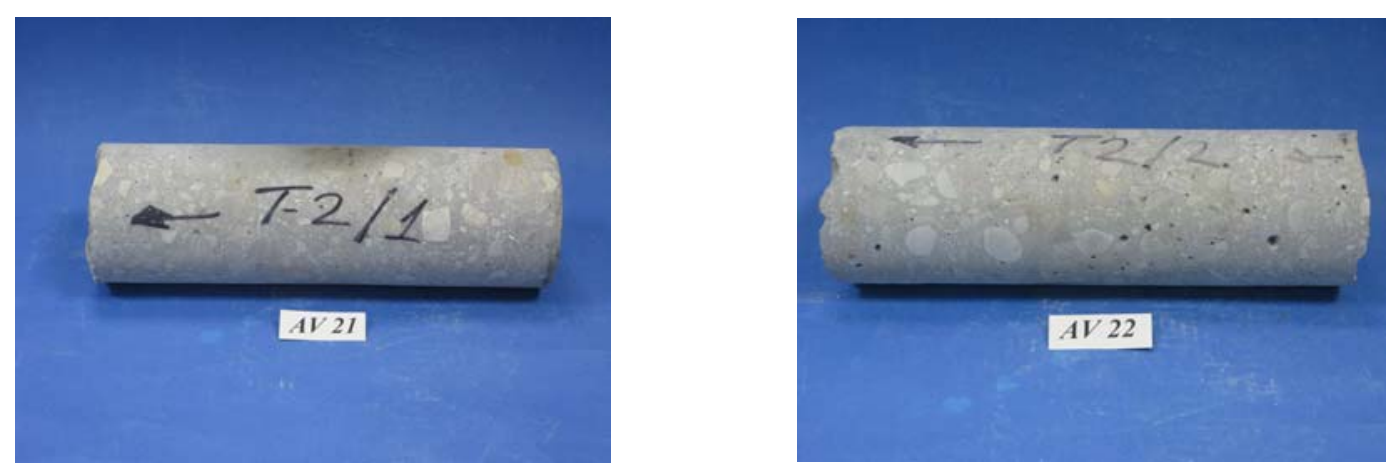

Fig.5.99. AV-T2. 

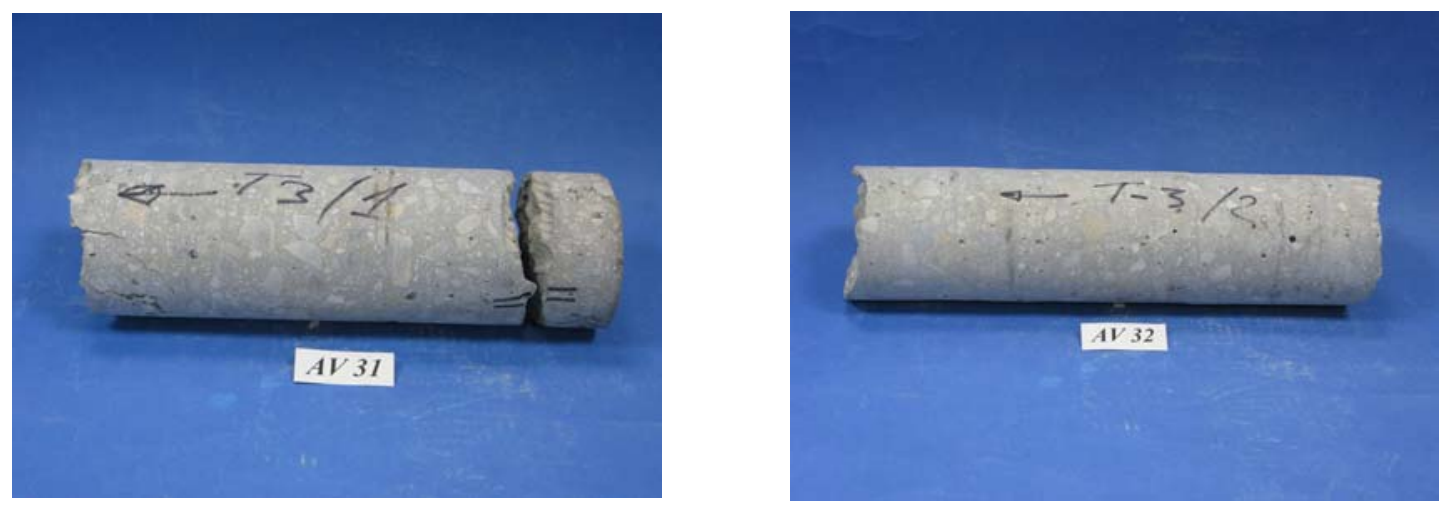

Fig.5.100. $A V-T 3$.
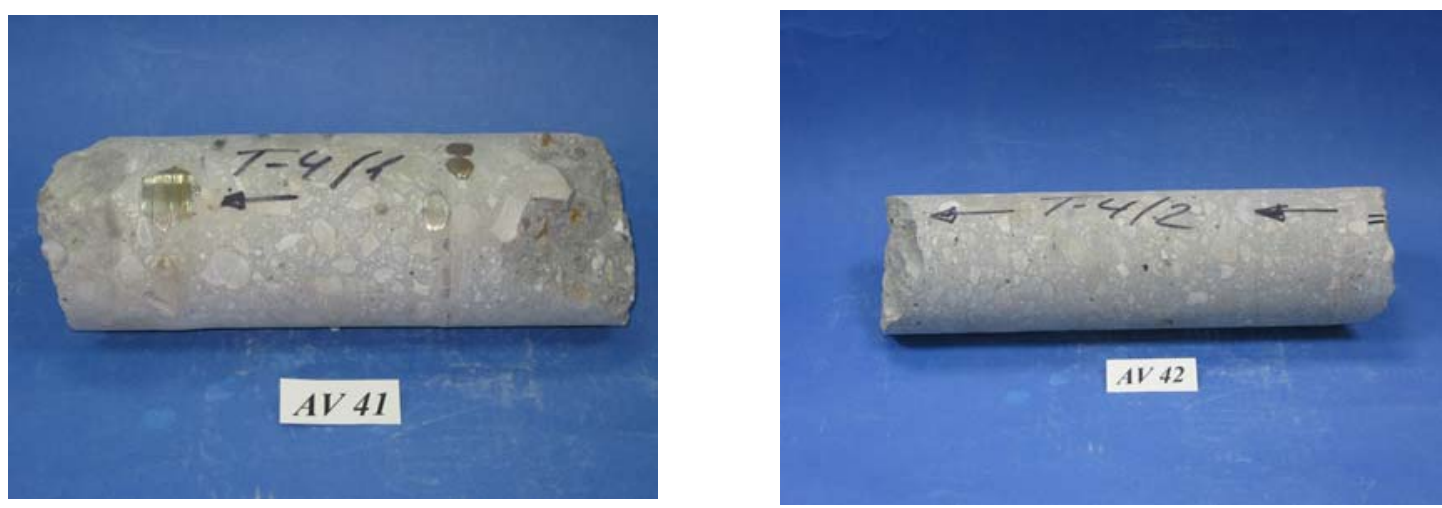

Fig.5.101. $A V$-T4.
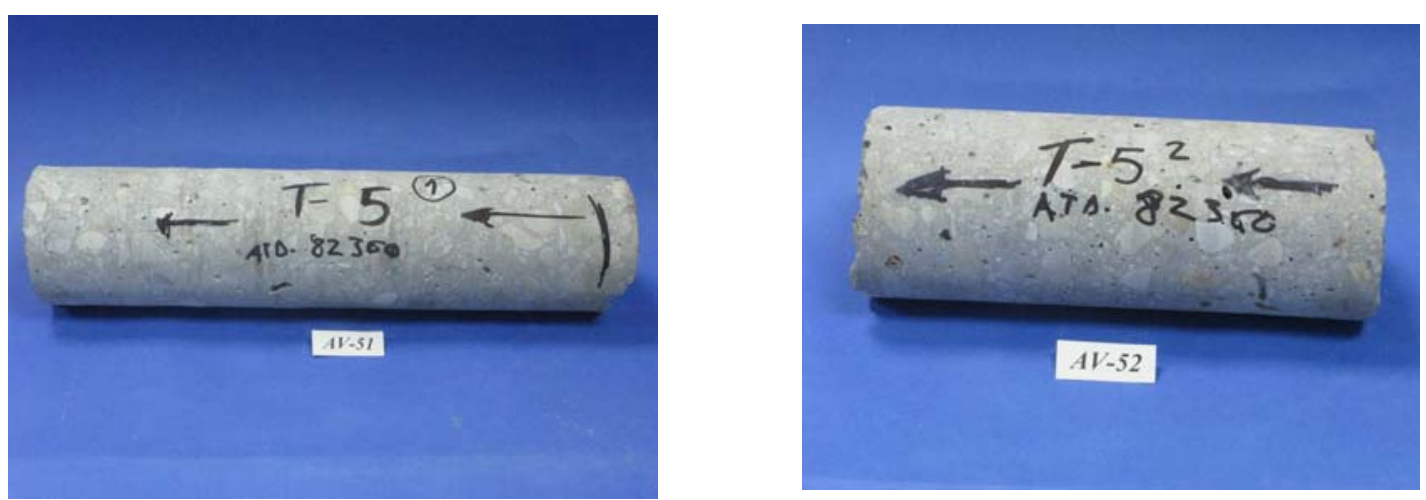

Fig.5.102. AV-T5.
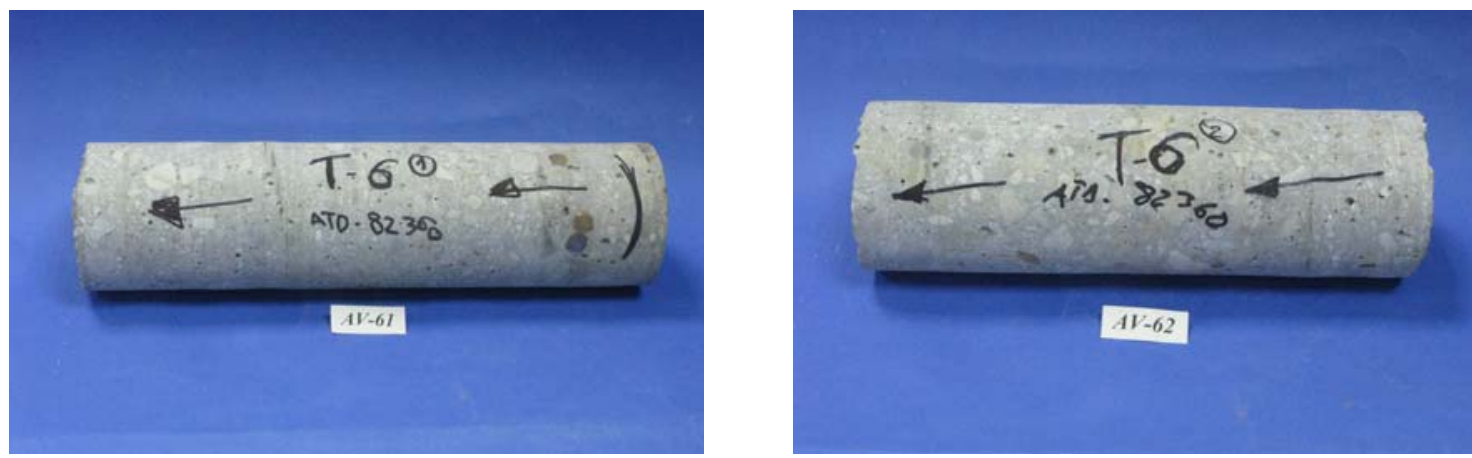

Fig.5.103. $A V$-T6. 
El árido es de machaqueo, con un tamaño máximo de $20 \mathrm{~mm}$.

En los testigos se observan pequeñas coqueras, una ligeramente mayor en el testigo AV-T5 (figura 5.104). En el caso de las fisuras, no aparecen en ninguno de los testigos extraídos salvo en el caso del testigo AV-T3, tal y como se muestra en la figura 5.104 .
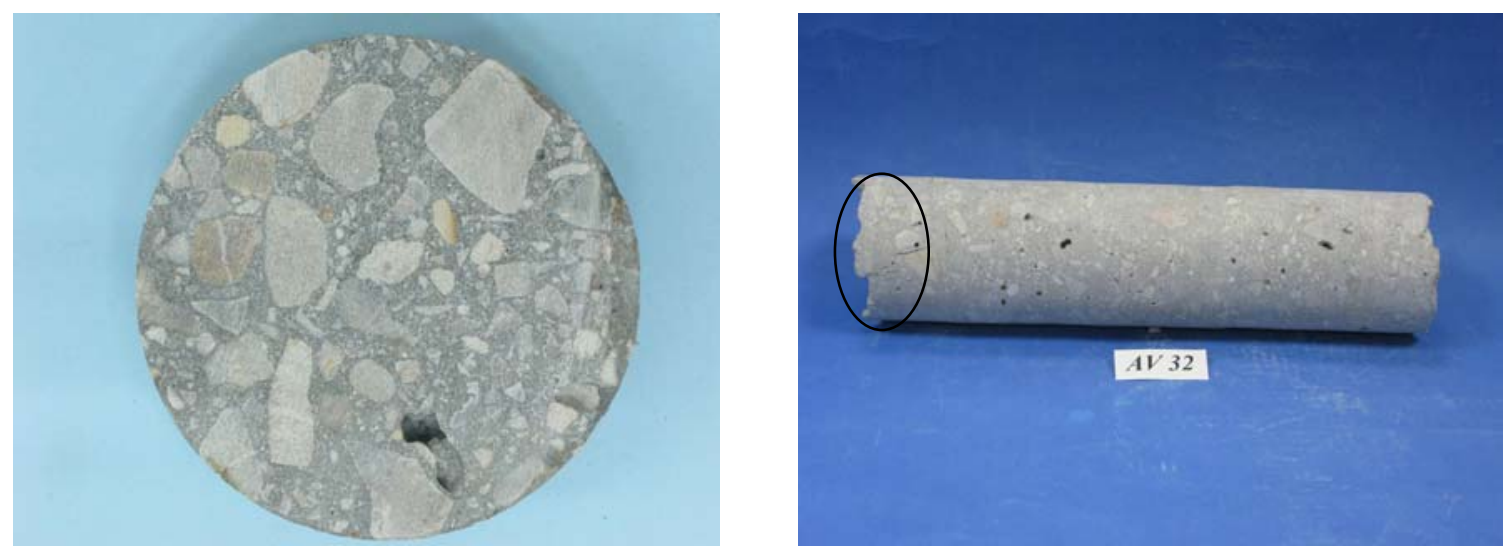

Fig.5.104. Coquera localizada en el testigo AV-T5 y leves fisuras en el extremo de uno de los fragmentos del testigo $\mathrm{AV}$-T3.

Durante la extracción de los testigos, se ha cortado armadura en todos ellos, salvo en el caso del testigo AV-T2. En el testigo AV-T1 se ha cortado una barra de 25 $\mathrm{mm}$ de diámetro (figura 5.105) con un recubrimiento de unos $105 \mathrm{~mm}$. En el testigo AV-T3 no se han cortado armaduras, pero aparecen marcas de dos barras (las barras probablemente se desprenderían durante la extracción del testigo) en el hormigón separadas entre sí a una distancia de $85 \mathrm{~mm}$ con recubrimientos de 40mm y 38mm (figura 5.106). En el testigo AV-T4 se han cortado dos barras de 12 $\mathrm{mm}$ de diámetro, una de $14 \mathrm{~mm}$ y otra de $25 \mathrm{~mm}$, con recubrimientos de $78 \mathrm{~mm}$, $90 \mathrm{~mm}$ y $205 \mathrm{~mm}$ respectivamente (figura 5.107). En el testigo AV-T5 se ha cortado una barra de $14 \mathrm{~mm}$ de diámetro, con recubrimiento de $15 \mathrm{~mm}$ (figura 5.108) en la que se aprecian síntomas de corrosión y por último en el testigo AV-T6 se han cortado tres barras, dos horizontales, de $12 \mathrm{~mm}$ y $14 \mathrm{~mm}$ de diámetro y con recubrimientos de $60 \mathrm{~mm}$ y $50 \mathrm{~mm}$ respectivamente y una vertical de $14 \mathrm{~mm}$ de diámetro con recubrimiento de 50mm (figura 5.109). En ninguno de los casos, salvo en el de AV-T5, aparecen síntomas de corrosión en las armaduras detectadas. 

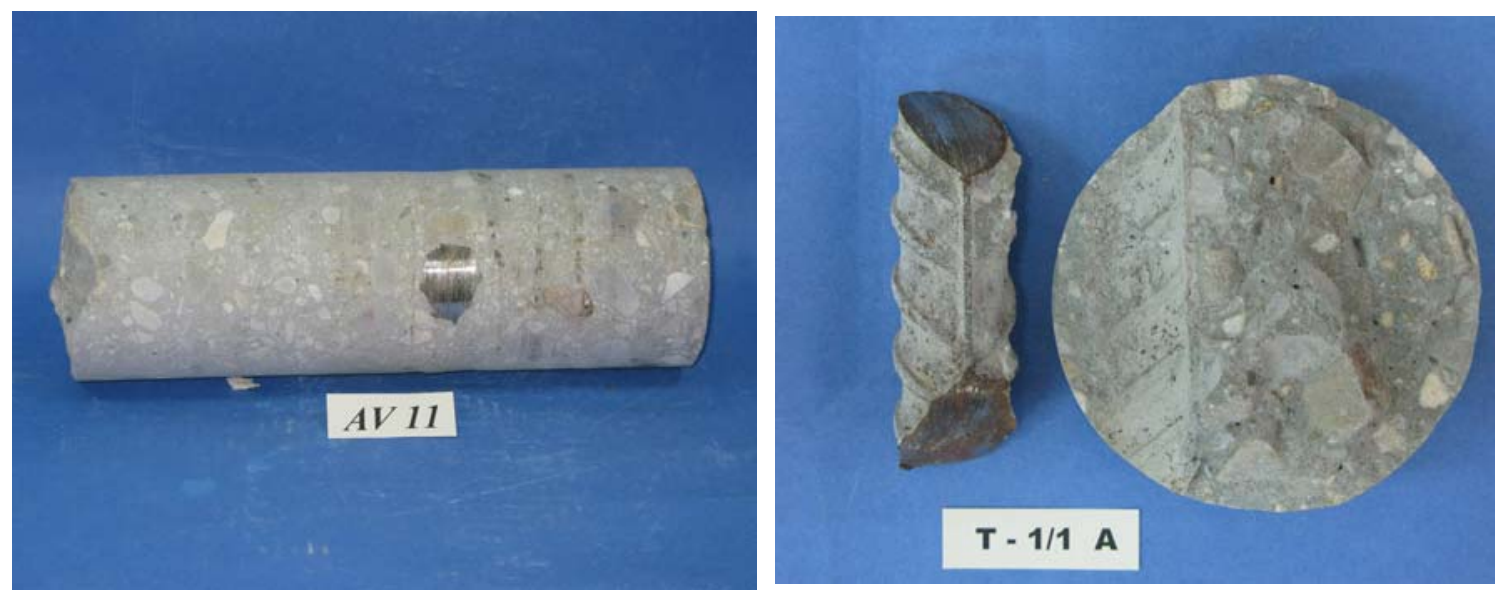

Fig.5.105 Armadura cortada en testigo AV-T1.
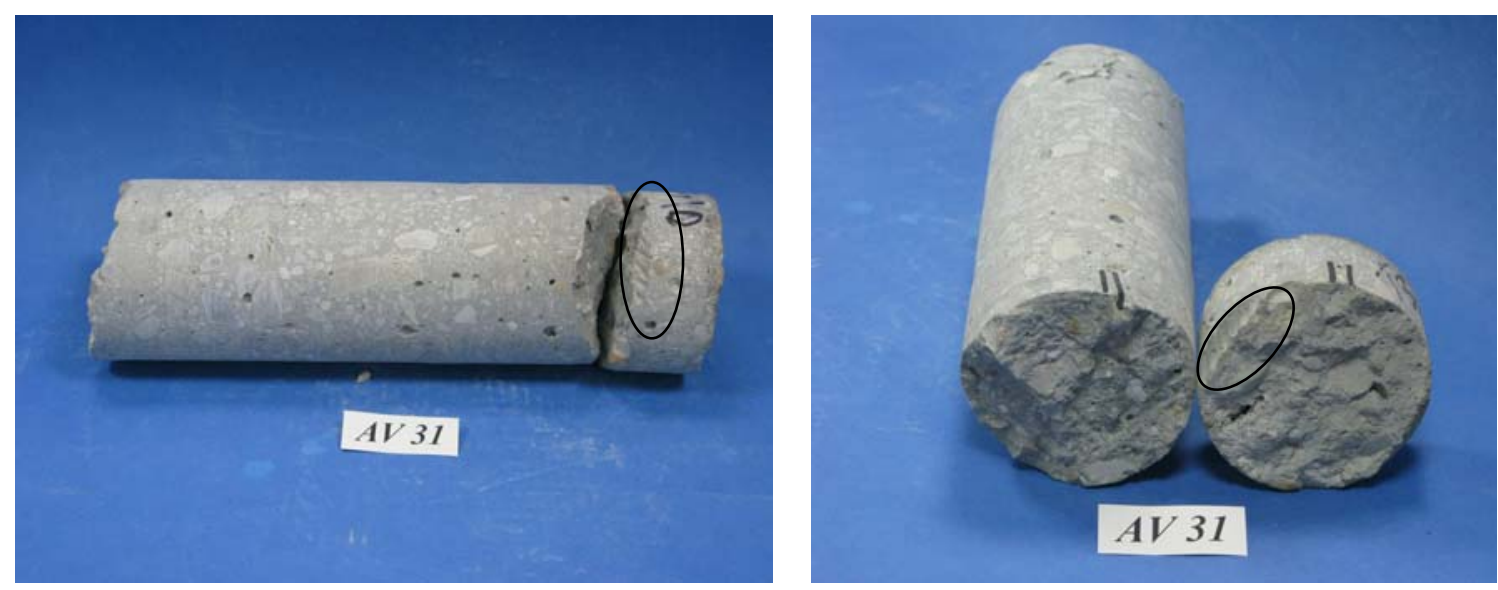

Fig.5.106. Marcas de armaduras en el hormigón del testigo AV-T3.
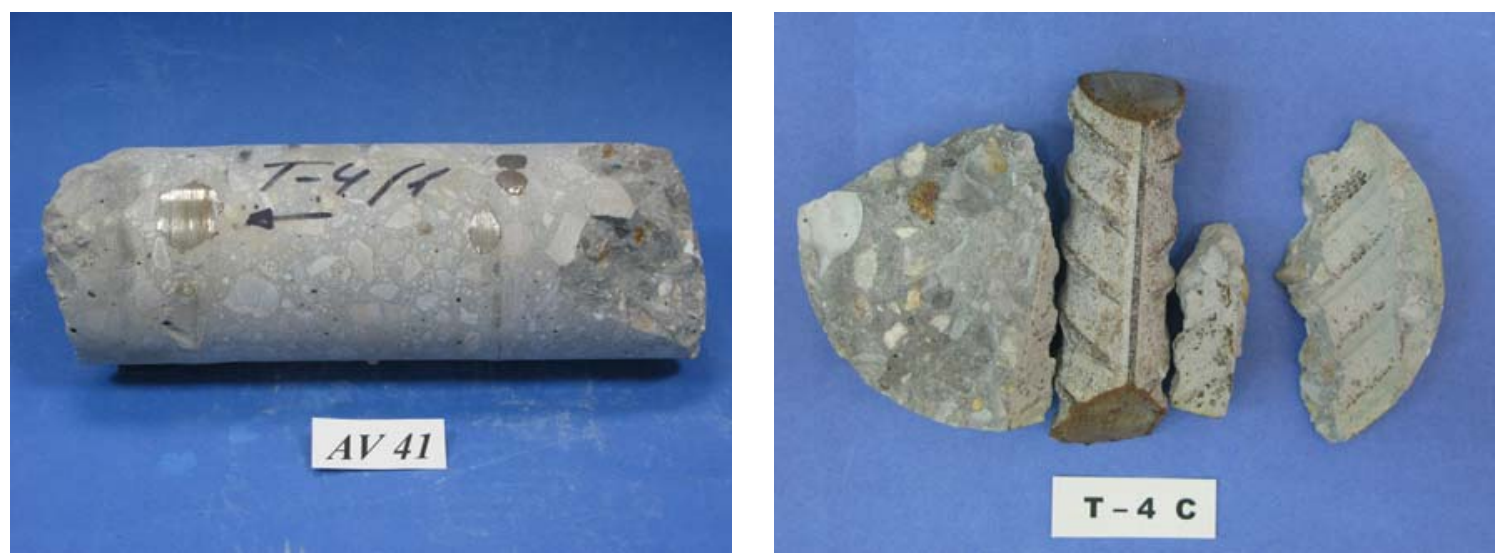

Fig.5.107.Armaduras cortadas en testigo AV-T4. 

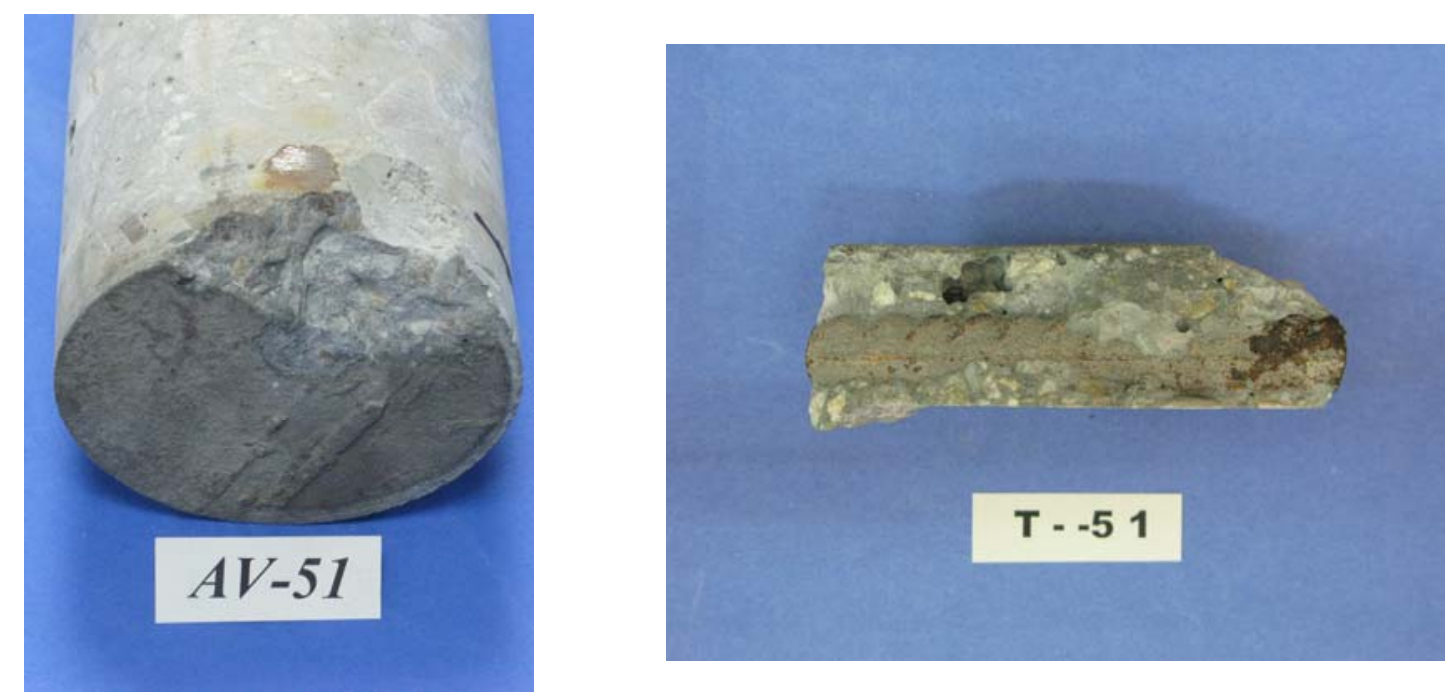

Fig.5.108.Armadura cortada en testigo AV-T5. Se aprecian síntomas de corrosión en el extremo.
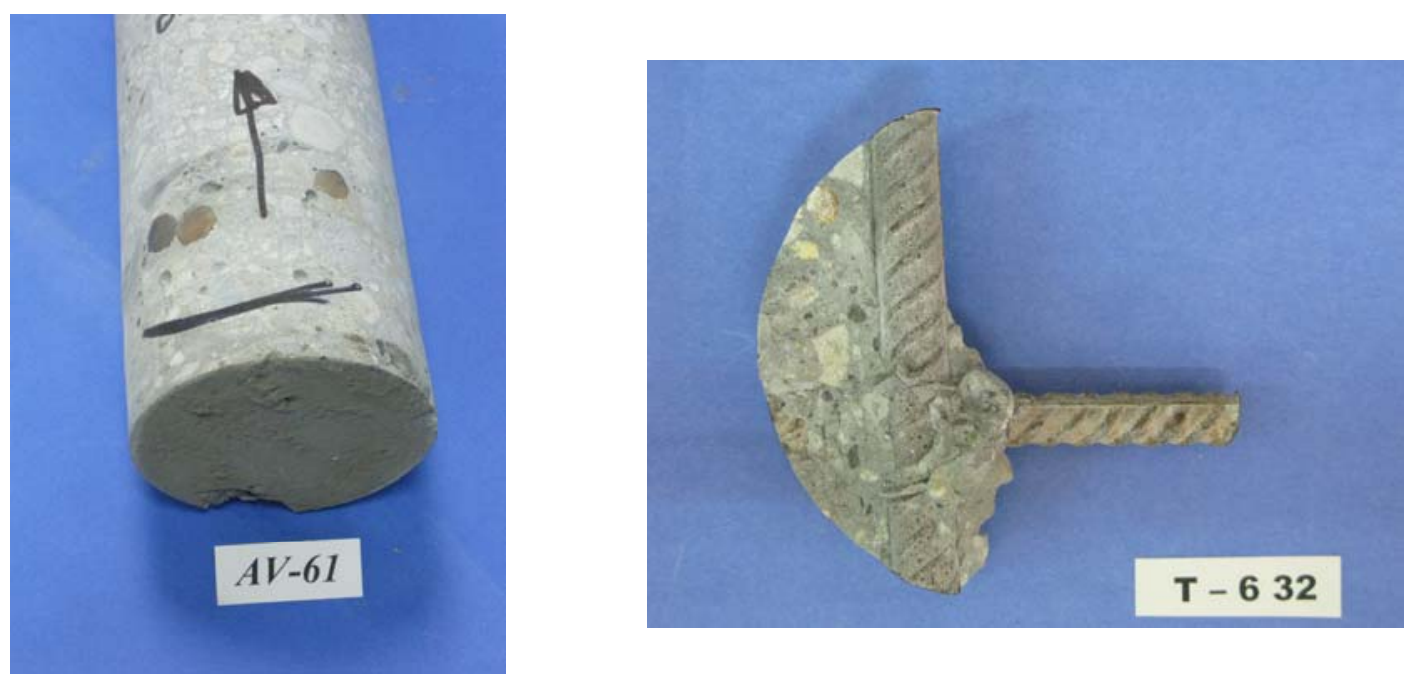

Fig.5.109. Armaduras cortadas en testigo AV-T6.

\subsubsection{Muelle D}

En el caso de este muelle, se ha realizado control de recubrimientos, determinación de velocidad de ultrasonidos, medida de la resistividad, del potencial de media pila y de la intensidad de corrosión.

\subsection{Velocidad de propagación de ultrasonidos}

La medida de la velocidad de ultrasonidos se ha realizado mediante el equipo PROCEQ Tico y de acuerdo con la norma UNE-EN 12504-4 "Ensayos de hormigón en estructuras. Determinación de la velocidad de los impulsos ultrasónicos". Se 
realizan las medidas por transmisión indirecta, colocando el receptor, al menos a 3 distancias diferentes del emisor.

A continuación la figuras 5.110 muestra el croquis de la viga cantil en la que se han realizado las medidas, indicando los puntos en los que se llevan a cabo. (Los puntos correlativos se encuentran a una distancia de $5 \mathrm{~m}$ ).

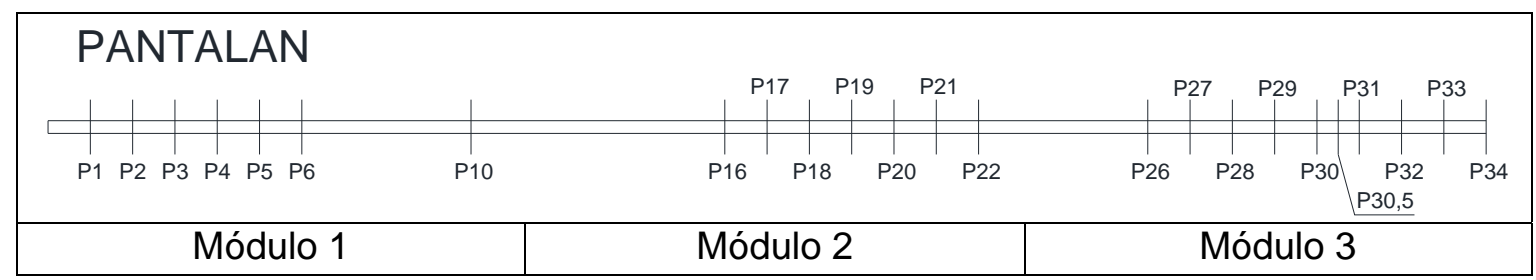

Fig.5.110. Croquis de la viga cantil.

Los resultados de las medidas obtenidas se aportan en las tablas 5.8 (módulo 1), 5.9 (módulo 2) y 5.10 (módulo 3).

\subsection{Medidas electroquímicas de la corrosión}

El estudio electroquímico de la corrosión se ha realizado en los puntos que se recogen en las tablas 5.8 (módulo 1), 5.9 (módulo 2) y 5.10 (módulo 3).

\begin{tabular}{|c|c|c|c|c|c|c|}
\hline \multicolumn{7}{|c|}{ Módulo 1} \\
\hline $\begin{array}{c}\text { Punto de Medida } \\
\text { (identificado en figura } * * \text { ) }\end{array}$ & P1 & P2 & P3 & P4 & P5 & P6 \\
\hline $\begin{array}{l}\text { Distancia al inicio del pantalán } \\
\qquad(\mathrm{m})\end{array}$ & 0 & 5 & 10 & 15 & 20 & 25 \\
\hline $\begin{array}{l}\text { Velocidad de ultrasonidos } \\
\qquad(\mathrm{m} / \mathrm{s})\end{array}$ & 3849 & 4105 & 3731 & 4037 & 3901 & 4068 \\
\hline $\begin{array}{l}\text { Recubrimiento medido con } \\
\text { pachómetro en la parte } \\
\text { superior del estribo }(\mathrm{mm})\end{array}$ & 50 & 51 & 30 & 23 & 60 & 31 \\
\hline Resistividad $(\mathrm{k} \Omega \cdot \mathrm{cm})$ & 200 & 218 & 203 & 262 & 85 & 37 \\
\hline Potencial de media pila (mV) & -503 & -480 & -612 & -559 & -374 & -324 \\
\hline $\begin{array}{l}\text { Intensidad de corrosión } \\
\qquad\left(\mu \mathrm{A} / \mathrm{cm}^{2}\right)\end{array}$ & & & 0,01 & & & \\
\hline
\end{tabular}

Tabla.5.8. Resultados de las medidas realizadas en módulo 1. 


\begin{tabular}{|c|c|c|c|c|c|c|c|}
\hline \multicolumn{8}{|c|}{ Módulo 2} \\
\hline $\begin{array}{c}\text { Punto de medida } \\
\text { (identificado en figura } * \text { ) }\end{array}$ & P16 & P17 & P18 & P19 & P20 & P21 & P22 \\
\hline $\begin{array}{l}\text { Distancia al inicio del pantalán } \\
(\mathrm{m})\end{array}$ & 75 & 80 & 85 & 90 & 95 & 99 & 105 \\
\hline $\begin{array}{l}\text { Velocidad de ultrasonidos } \\
\qquad(\mathrm{m} / \mathrm{s})\end{array}$ & 4646 & 4814 & 4489 & 4424 & 4301 & 3222 & 4442 \\
\hline $\begin{array}{l}\text { Recubrimiento medido con } \\
\text { pachómetro en la parte } \\
\text { superior del estribo }(\mathrm{mm})\end{array}$ & 100 & 51 & 100 & 70 & 78 & 107 & 150 \\
\hline Resistividad $(\mathrm{k} \Omega \cdot \mathrm{cm})$ & 46 & 39 & 48 & 51 & 94 & 67 & 56 \\
\hline Potencial de media pila (mV) & -296 & -205 & -187 & -206 & -117 & -112 & -241 \\
\hline $\begin{array}{l}\text { Intensidad de corrosión } \\
\qquad\left(\mu \mathrm{A} / \mathrm{cm}^{2}\right)\end{array}$ & & & & 4,06 & & & \\
\hline
\end{tabular}

Tabla.5.9. Resultados de las medidas realizadas en módulo 2.

\begin{tabular}{|c|c|c|c|c|c|c|c|}
\hline \multicolumn{8}{|c|}{ Módulo 3} \\
\hline $\begin{array}{c}\text { Punto de medida } \\
\text { (identificado en figura } * \text { ) }\end{array}$ & P27 & P28 & P29 & P30 & P31 & P32 & P33 \\
\hline $\begin{array}{l}\text { Distancia al inicio del } \\
\text { pantalán }(\mathrm{m})\end{array}$ & 131 & 135 & 140 & 146 & 150 & 155 & 160 \\
\hline $\begin{array}{l}\text { Velocidad de } \\
\text { ultrasonidos }(\mathrm{m} / \mathrm{s})\end{array}$ & 4461 & & 4486 & 4439 & 4499 & 4583 & 4300 \\
\hline $\begin{array}{c}\text { Recubrimiento medido } \\
\text { con pachómetro en la } \\
\text { parte superior del estribo } \\
(\mathrm{mm})\end{array}$ & 66 & 78 & 28 & 90 & 68 & 150 & 150 \\
\hline Resistividad $(\mathrm{k} \Omega \cdot \mathrm{cm})$ & 50 & 32 & 24 & 29 & 35 & 27 & 98 \\
\hline $\begin{array}{l}\text { Potencial de media pila } \\
\qquad(\mathrm{mV})\end{array}$ & -216 & -339 & -249 & -233 & -284 & -343 & -197 \\
\hline $\begin{array}{l}\text { Intensidad de corrosión } \\
\left(\mu \mathrm{A} / \mathrm{cm}^{2}\right)\end{array}$ & & & & 8,49 & & & \\
\hline
\end{tabular}

Tabla.5.10. Resultados de las medidas realizadas en módulo 3.

En la fig 5.111 se muestra la realización de una de las medidas de intensidad de corrosión en el módulo 2. 


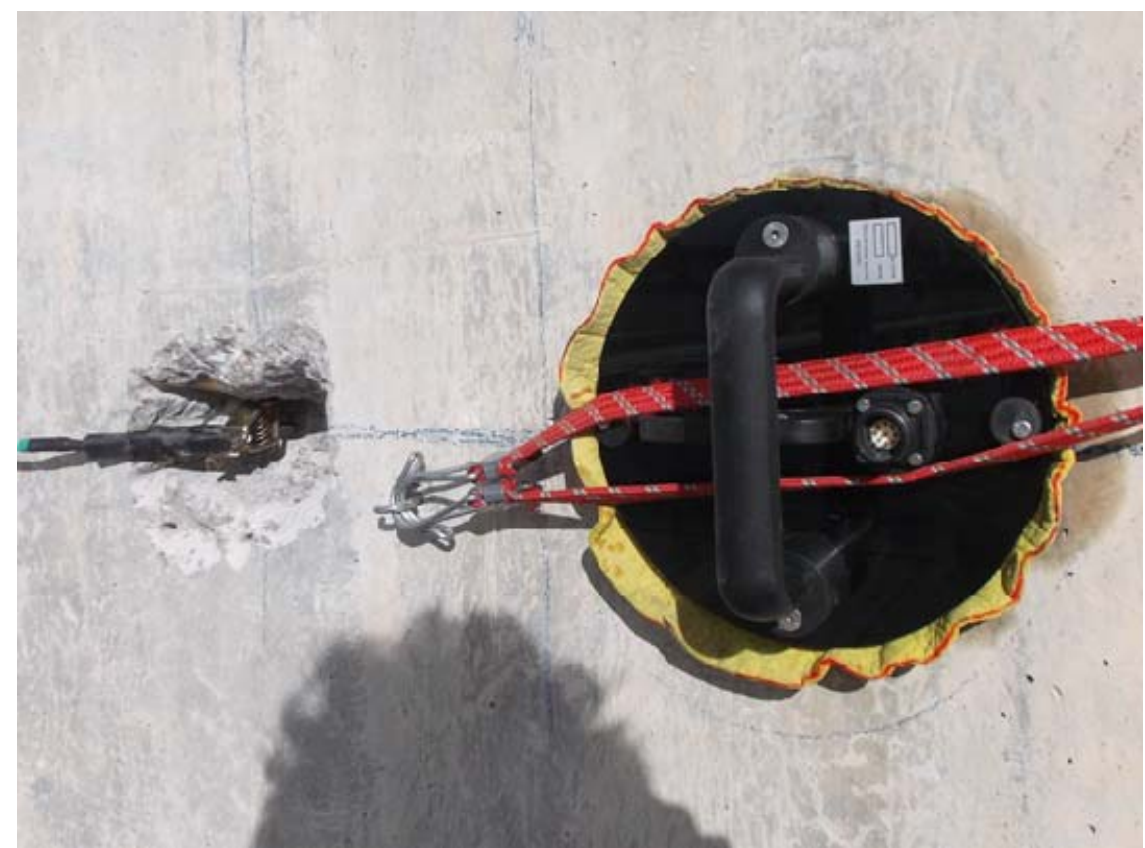

Fig.5.111. Medida de la intensidad de corrosión en módulo 2.

\subsection{Valoración de los resultados y justificación de los puntos de extracción de testigos}

Las medidas de velocidad de ultrasonidos realizadas en el módulo 1 se corresponden con un hormigón de calidad buena próxima al rango de aceptable. En los módulos 2 y 3 el hormigón presenta una mejor calidad, cercana o dentro del rango de excelente. Tan sólo en una de las medidas (P21 a 100 m del comienzo del recrecido), el resultado baja considerablemente, situándose en el rango de hormigón aceptable. Este resultado deberá contrastarse con el valor de resistencia a compresión cuando se proceda a la extracción de los testigos.

En cuanto a los resultados de los recubrimientos medidos, los valores se corresponden con las armaduras verticales (cercos), que de acuerdo con los planos son las más externas y por tanto las que definen el recubrimiento de hormigón.

Se observa que los recubrimientos medidos en el módulo 1 (primeros 60 metros de longitud) son en general inferiores, con tres valores alrededor de los $30 \mathrm{~mm}$. En los otros dos módulos, si bien los recubrimientos se mantienen en general en valores muy próximos a los $70 \mathrm{~mm}$, de forma puntual se han medido valores inferiores (60$50-40 \mathrm{~mm}$ ). No se tiene el dato del recubrimiento exigido en proyecto, aunque sí del cemento utilizado (un CEM I 52,5N/SR y también un CEM I 42,5R/SR). Para el 
caso de un cemento sin adiciones, la Instrucción EHE-08 exige un recubrimiento mínimo de 45 mm (50 años de vida útil) o 65 mm (100 años de vida útil) en ambiente IIla.

Finalmente se realizan las medidas de resistividad, potencial de media pila e intensidad de corrosión con el corrosímetro.

La resistividad mide la capacidad del hormigón de actuar como electrolito y conducir las corrientes de corrosión. En el hormigón de la viga cantil del muelle los resultados obtenidos indican un hormigón con resistividad moderada, salvo en los 15 primeros metros en los que la resistividad es muy superior al resto del muelle.

En general los valores bajos de resistividad se asocian con hormigones de buena calidad, pero en este caso los resultados de la velocidad de ultrasonidos indican precisamente lo contrario: la presencia de un hormigón de menor calidad en este primer módulo del muelle.

Otra explicación posible a los elevados valores de resistividad medidos en los primeros 20 metros del recrecido puede estar relacionada con la humedad presente en el hormigón, ya que la resistividad disminuye de forma importante cuando el hormigón está más seco. Se da la circunstancia de que en la primera parte del muelle se sitúa una plataforma flotante de madera que da acceso a esta zona inicial del módulo 1. Esta plataforma aísla la viga cantil de la superficie del agua, estando menos expuesta a salpicaduras por lo que puede pensarse que el hormigón en este tramo puede encontrarse más seco que en el resto del muelle lo cual justificaría las menores resistividades medidas.

En las resistividades medidas en los módulos 2 y 3 se aprecia que los valores son algo inferiores en este último módulo, lo cual están en consonancia con los valores de ultrasonidos que también son ligeramente inferiores en el módulo 3.

En el caso del potencial de media pila, es una medida de la facilidad de transferencia de electrones entre el metal y el ambiente en que se encuentra. Aunque la interpretación es compleja, potenciales muy negativos son indicativos de que se puede estar produciendo corrosión en esa zona, si bien hay otros factores que pueden influir en la medida de bajos potenciales. Por ello, estos valores bajos deben siempre contrastarse con la medida de la intensidad de corrosión, que da un valor cierto de la degradación que puede estar sufriendo la armadura. En este caso, existen muchos puntos con potenciales muy bajos que podrían indicar riesgo de corrosión, en particular los presentes en el módulo 1. 
Se realizaron tres medidas de la intensidad de corrosión en puntos con bajo potencial, una en cada módulo del muelle. Se descarta que los bajos potenciales del módulo 1 estén relacionados con la corrosión de la armadura (la intensidad medida es nula) mientras que los valores del módulo 2 y 3 parecen indicar que en algún punto de estos módulos la armadura estaría activa y podría estar sufriendo corrosión. En los puntos donde se realizó la cata para pinzar la armadura los recubrimientos eran altos (70 y $90 \mathrm{~mm}$ ) por lo que ésta presentaba buen aspecto sin síntomas de corrosión (fig 5.112). Sin embargo, los puntos de estos dos módulos donde los recubrimientos son menores sí podrían tener algún síntoma incipiente de corrosión.

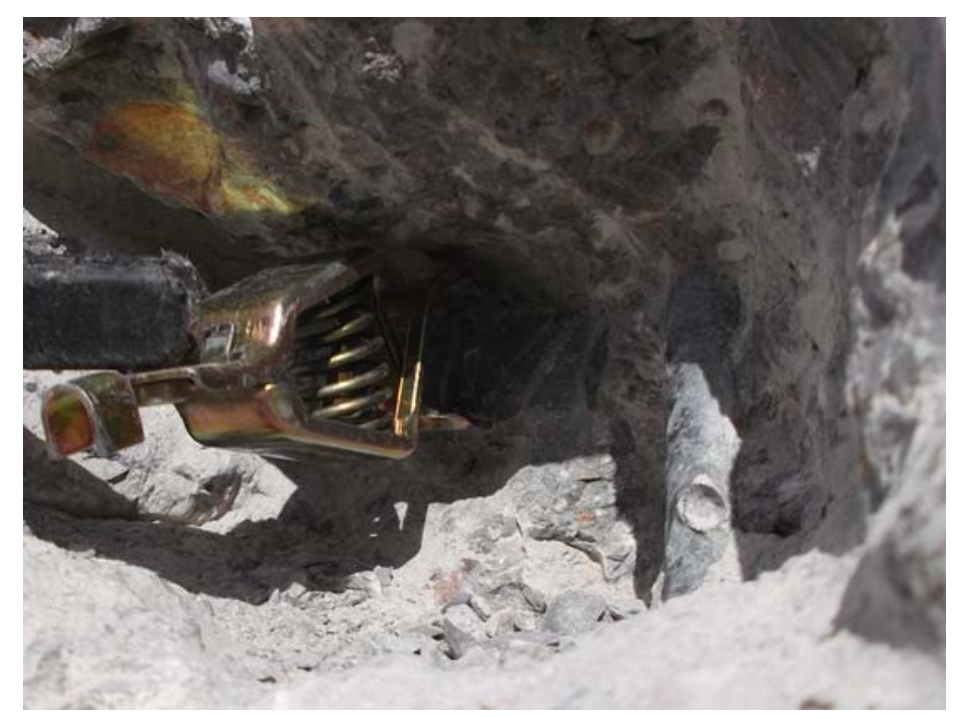

Fig.5.112. Armadura descubierta sin síntomas de corrosión.

La fig 5.113 muestra la ubicación elegida para los testigos en el muelle D. El testigo MAV-1 decide ubicarse en zona de baja velocidad de ultrasonidos, una de las menores de toda la viga y representativa del módulo 1 . Sin embargo, el testigo MAV-2 se localiza en la mejor calidad de hormigón identificada en la viga a la vista de su velocidad de ultrasonidos y los otros 3 testigos se sitúan en zonas de velocidades intermedias. 


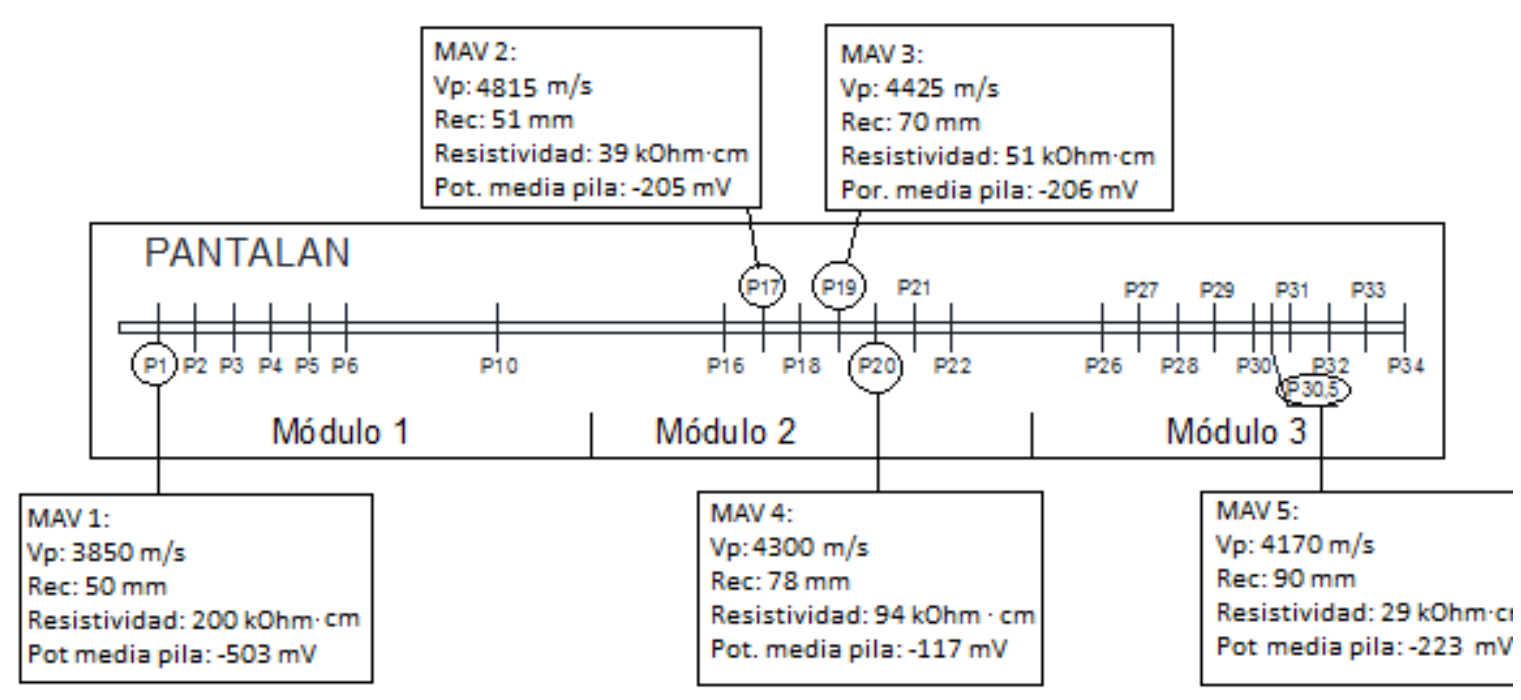

Fig.5.113. Croquis de situación de testigos y resultados de ensayos de campo.

Los 20 primeros metros de la viga han mostrado resultados muy contradictorios con potenciales muy negativos y las mayores resistividades, aunque la velocidad de ultrasonidos identificara esa zona como la de peor calidad de toda la viga. La causa de estos resultados puede deberse a las condiciones ambientales diferentes de esta zona. Por ello, se ha seleccionado el testigo MAV-1 en esta zona del muelle. En los módulos 2 y 3 , la resistividad y el potencial de media pila muestran resultados coherentes entre sí. Así, de los testigos seleccionados en estos módulos, el testigo MAV5 es el de mayor riego de corrosión, MAV-4 el de menor, y MAV2 y MAV3 muestran situaciones intermedias.

Finalmente las medidas de intensidad de corrosión en los bloques 2 y 3 han sido muy elevadas. Estos valores indicarían que existe corrosión en la zona, sin embargo el aspecto de las armaduras descubiertas y los recubrimientos medidos indican que no deberían exitir corrosion. Puesto que estas medidas pueden estar condicionadas por recubrimientos muy elevados, se ha extraído el testigo MAV-3 y MAV-5 de los puntos de medida de la intendidad de corrosión, para tratar de evaluar en laboratorio el riesgo de corrosión real de las armaduras.

\subsection{Extracción de los testigos}

Tras la evaluación en campo del hormigón de la viga cantil del Muelle $D$, se han extraído 5 testigos de hormigón, tratando de ensayar todas las calidades de hormigón determinadas en los diferentes ensayos. Son de diámetro $100 \mathrm{~mm}$ y de longitudes variables entre los 18 y los $33 \mathrm{~cm}$. La extracción es horizontal. 
Su ubicación en la estructura es la siguiente:

- $\quad$ MAV-1: Bloque 1. A un metro del inicio del muelle. (diam 103, 8; L 25)

- MAV-2: Bloque 2. A 80 metros del inicio del muelle (diam 103,8; L 30)

- MAV-3: Bloque 2. A 90 metros del inicio del muelle (diam 104,1; L 33)

- MAV-4: Bloque 2. A 95 metros del inicio del muelle (diam 103,9; L 31)

- MAV-5: Bloque 3. A 146 metros del inicio del muelle (diam 103,8; L 18)

La figura 5.114 muestra la ubicación de los testigos en la estructura, entre dos estribos y por debajo de la barra de armado horizontal situada a $35 \mathrm{~cm}$ del borde superior.

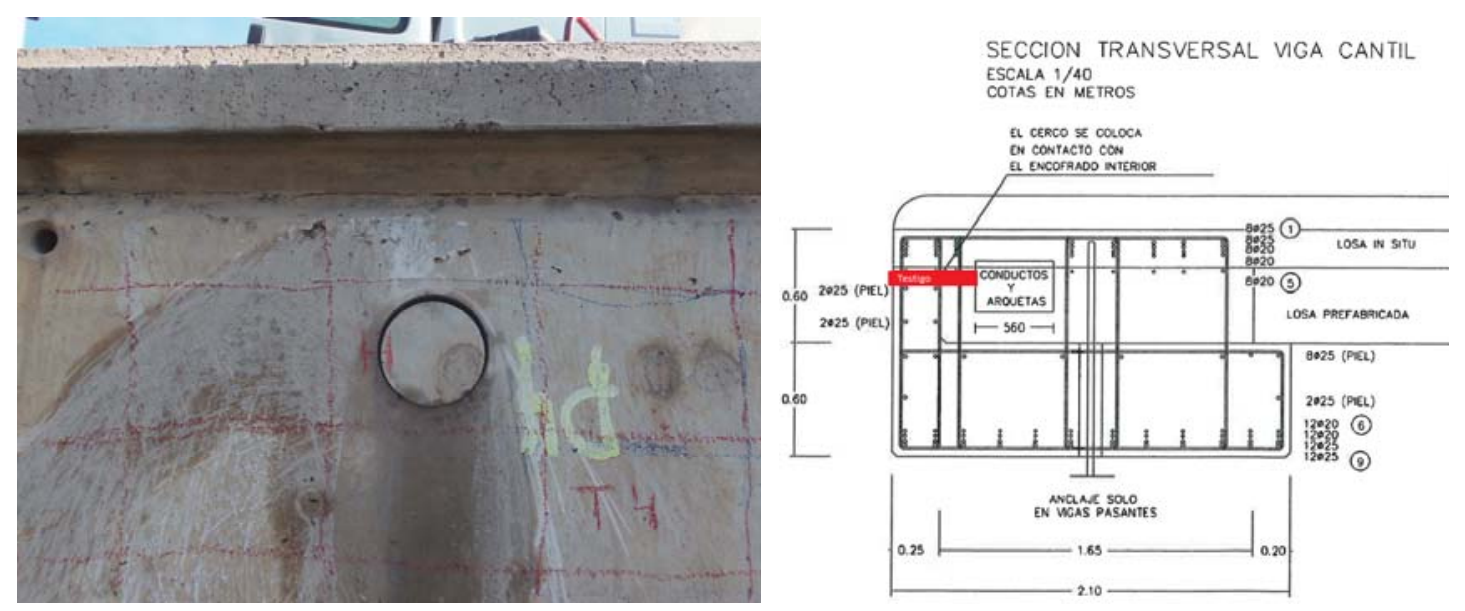

Fig.5.114. Vista frontal de uno de los testigos a extraer (izquierda) y detalle trasnversal de su ubicación en el armado de la viga cantil (derecha).

La superficie inferior de la losa se encuentra a una altura de $+1.50 \mathrm{~m}$ sobre el nivel de B.M.V.E.

\subsection{Descripción de los testigos}

Como ya se ha indicado, los testigos presentan un diámetro de $100 \mathrm{~mm}$ y longitudes variables entre los 18 y los $33 \mathrm{~cm}$. A continuación se indican entre paréntesis las medidas exactas de diámetro y longitud de cada uno de ellos: MAV-1 (103,8 mm; 25 $\mathrm{cm})$, MAV-2 (103,8mm; 30cm), MAV-3 (104,1mm; 33cm), MAV-4 $(103,9 \mathrm{~mm} ; 31 \mathrm{~cm})$ y MAV-5 (103,8mm; 18cm).

El testigo MAV-1 presenta un aspecto general del hormigón bueno, no se desmorona ni se raya con la uña. No presenta fisuras, ni áridos cuyo contorno presente una aureola de otro color. No presenta aspecto poroso. Su color es homogéneo. El árido se encuentra 
uniformemente distribuido y sin una alineación preferente. Presenta una buena adherencia pasta-árido.

La figura 5.115 muestra el aspecto general del testigo MAV-1. En general se observan pocas coqueras en el hormigón y de pequeño tamaño. Aunque son algo mayores en la segunda mitad del testigo, por debajo de la barra de armado, en general el hormigón tiene aspecto de bien compactado.
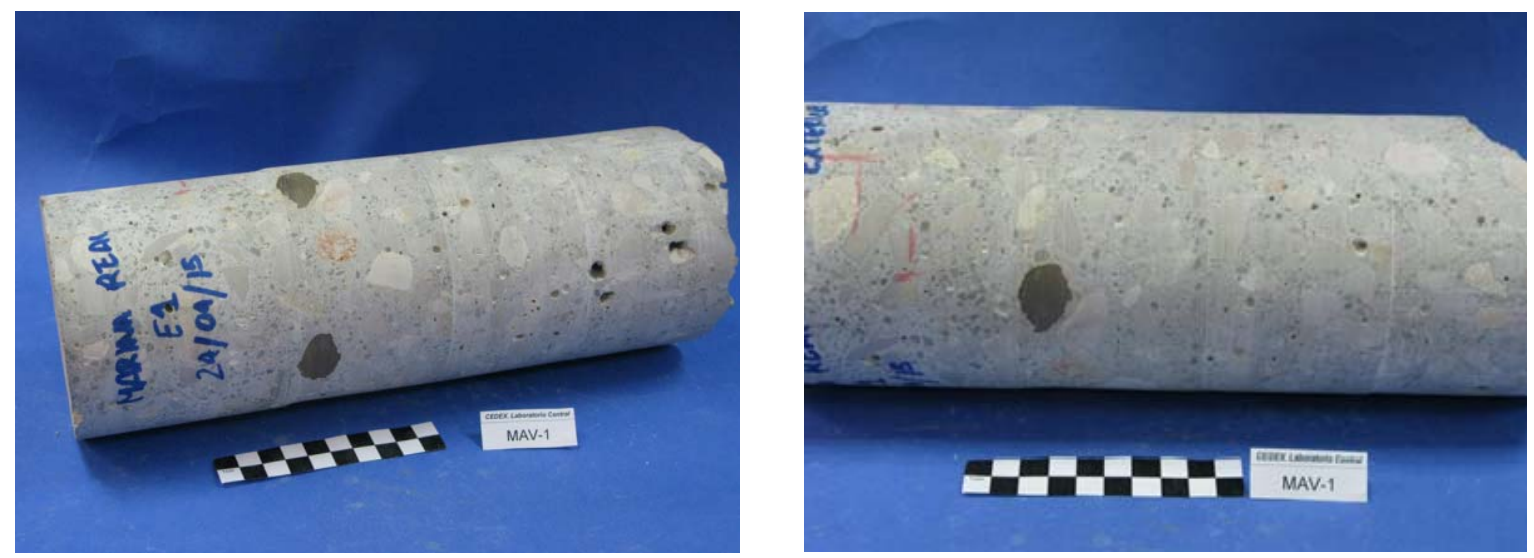

Fig.5.115. Vista general testigo MAV-1 (izquierda). Detalle de coqueras. (derecha).

El árido grueso es mezcla de rodado y machaqueo. El tamaño máximo observado en el testigo es de $16 \mathrm{~mm}$.

El hormigón contiene una barra corrugada de $16 \mathrm{~mm}$, con un recubrimiento de hormigón de $92 \mathrm{~mm}$. No se observa corrosión en la barra (fig 5.116, imagen izquierda). Tras la realización de los ensayos, se extrae la barra corrugada. La fig 5.116 (imagen derecha) corrobora la ausencia de corrosión en la barra.
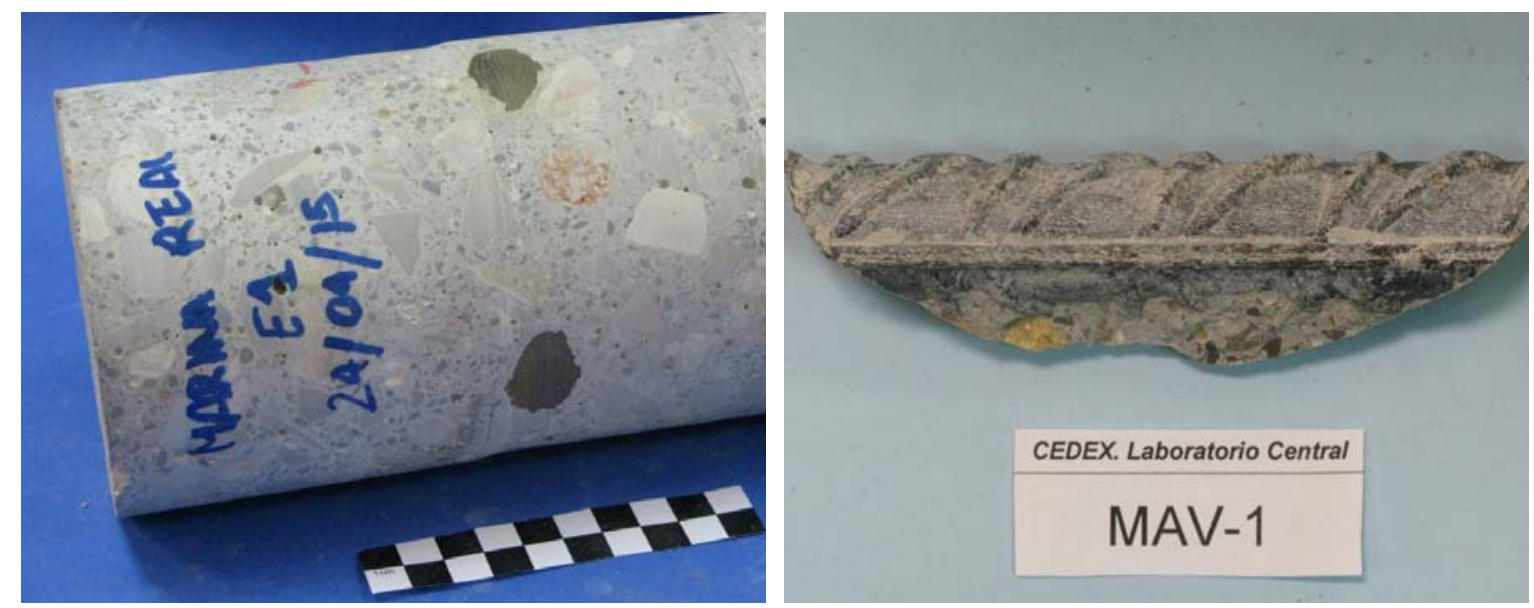

Fig.5.116. Barra 16mm localizada en testigo MAV-1. No muestra síntomas de corrosión. 
El testigo MAV-2 presenta un aspecto general del hormigón bueno, no se desmorona ni se raya con la uña. No presenta fisuras, ni áridos cuyo contorno presente una aureola de otro color. No presenta aspecto poroso. Su color es homogéneo. El árido se encuentra uniformemente distribuido y sin una alineación preferente. Presenta una buena adherencia pasta-árido.

La figura 5.117 muestra el aspecto general del testigo MAV-2. En general se observan pocas coqueras en el hormigón y de pequeño tamaño (fig 5.117 derecha). En general, el hormigón tiene aspecto de bien compactado.
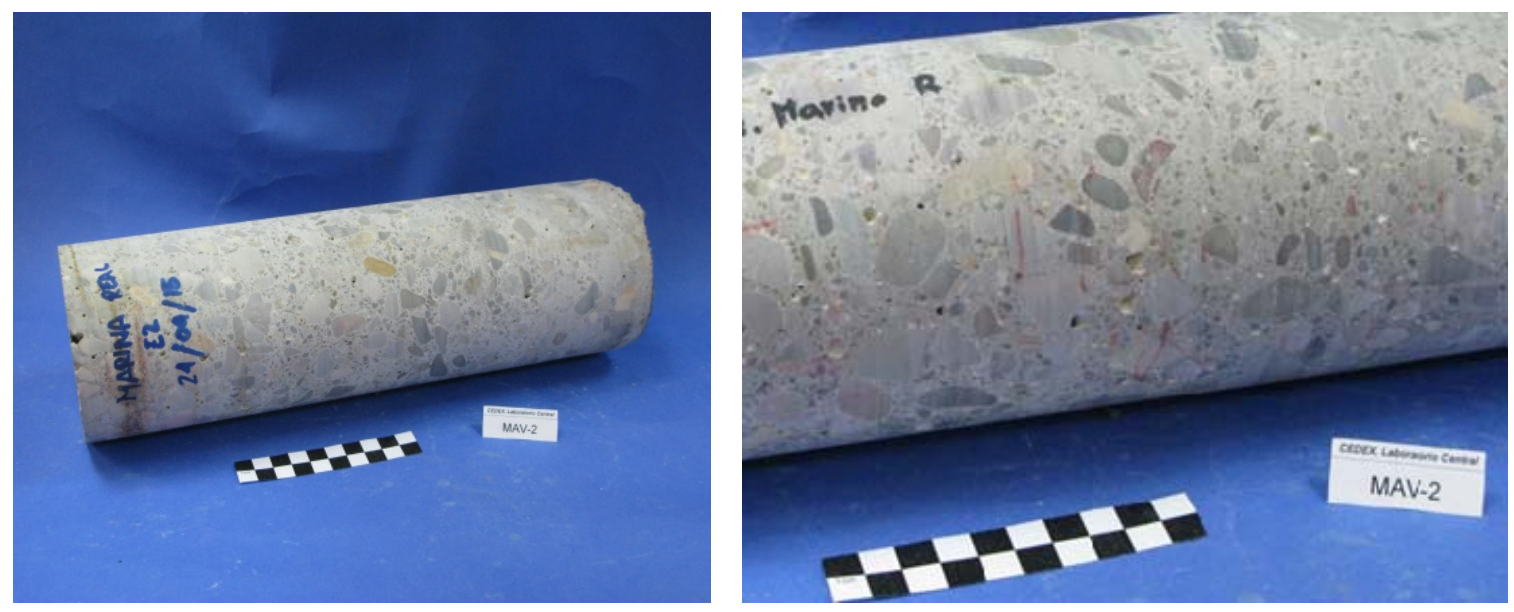

Fig.5.117. Vista general testigo MAV-2 (izquierda). Detalle de coqueras. (derecha).

El árido grueso es mezcla de rodado y machaqueo. El tamaño máximo observado en el testigo es de $16 \mathrm{~mm}$.

El testigo no contiene armaduras, aunque se localiza una malla metálica en la cara interior (fig 5.118), que posiblemente delimite la canaleta de conducciones de servicio que queda dentro de la viga cantil. 


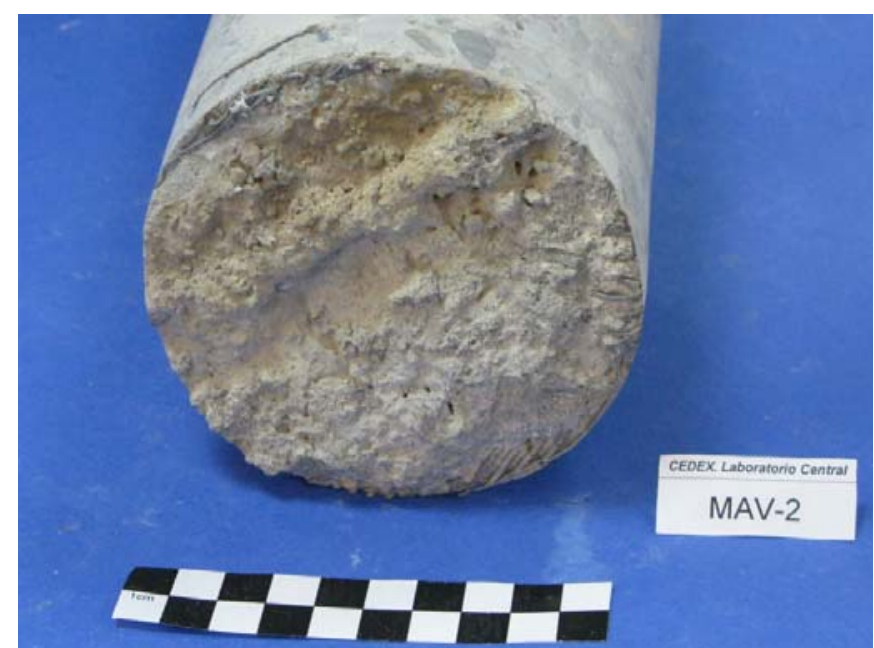

Fig.5.118. Testigo MAV-2. Detalle de malla metálica.

El testigo MAV-3 presenta un aspecto general del hormigón bueno, no se desmorona ni se raya con la uña. No presenta fisuras, ni áridos cuyo contorno presente una aureola de otro color. No presenta aspecto poroso. Su color es homogéneo. El árido se encuentra uniformemente distribuido y sin una alineación preferente. Presenta una buena adherencia pasta-árido.

La figura 5.119 muestra el aspecto general del testigo MAV-3. Se observan algunas coqueras junto a la cara exterior del testigo y a la profundidad de la armadura, quizá por un vibrado menor en la zona de armado y junto al encofrado.

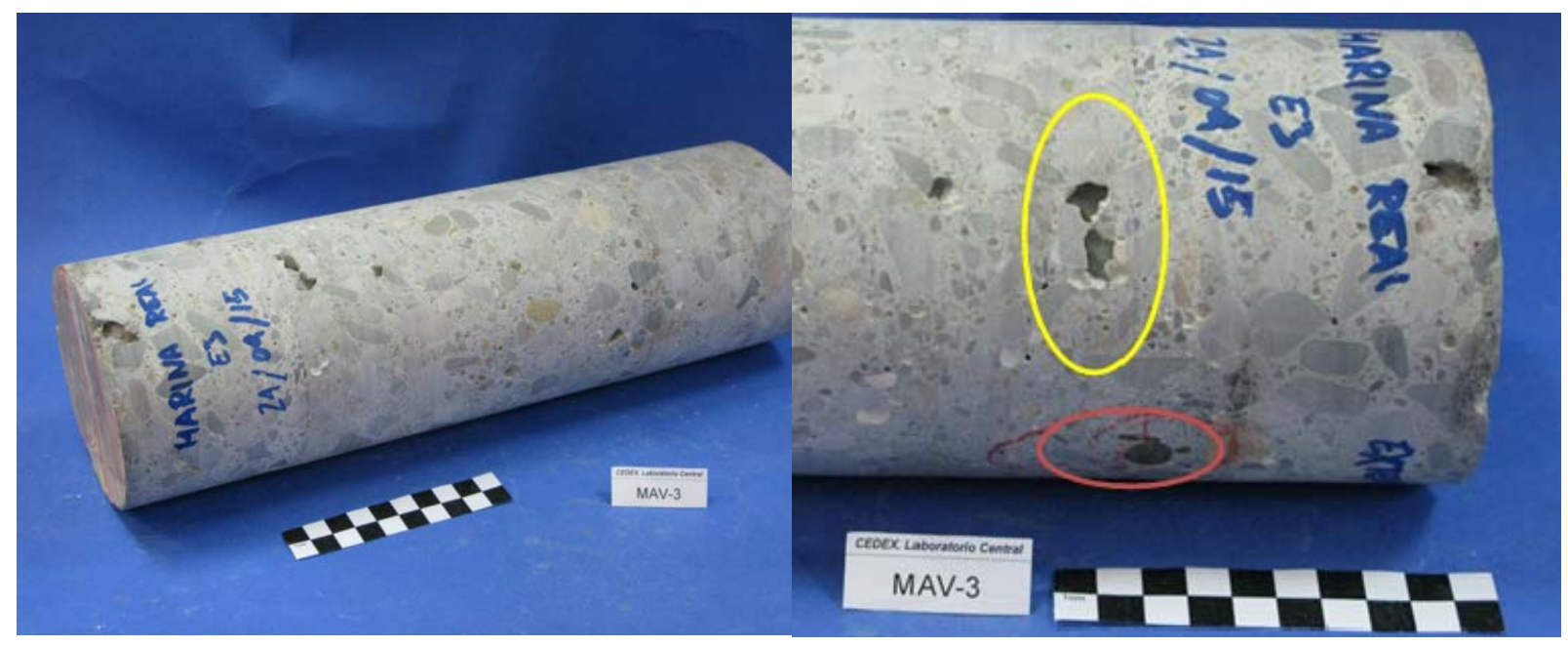

Fig.5.119. Testigo MAV-3. Vista general y detalle de coqueras.

El árido grueso es mezcla de rodado y machaqueo. El tamaño máximo observado en el testigo es de $16 \mathrm{~mm}$. 
El testigo contiene una malla metálica en la cara interior (fig 5.120), que posiblemente delimite la canaleta de conducciones de servicio que queda dentro de la viga cantil.

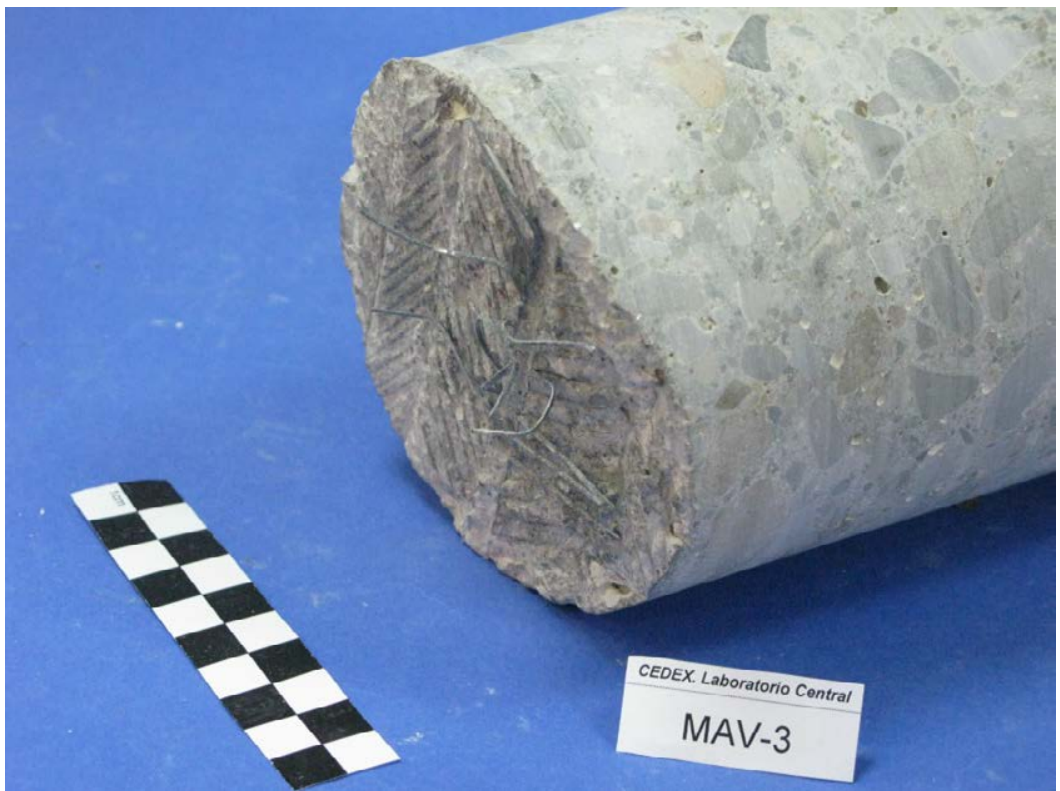

Fig.5.120. Malla metálica localizada en testigo MAV-3.

El testigo además presenta dos barras de armado, como se muestra en la fig 5.121, ambas de diámetro 10mm con recubrimientos de 68 y $235 \mathrm{~mm}$. La barra más profunda incluye en el interior del testigo un solape (fig 5.121 derecha). No se observa corrosión en las barras.
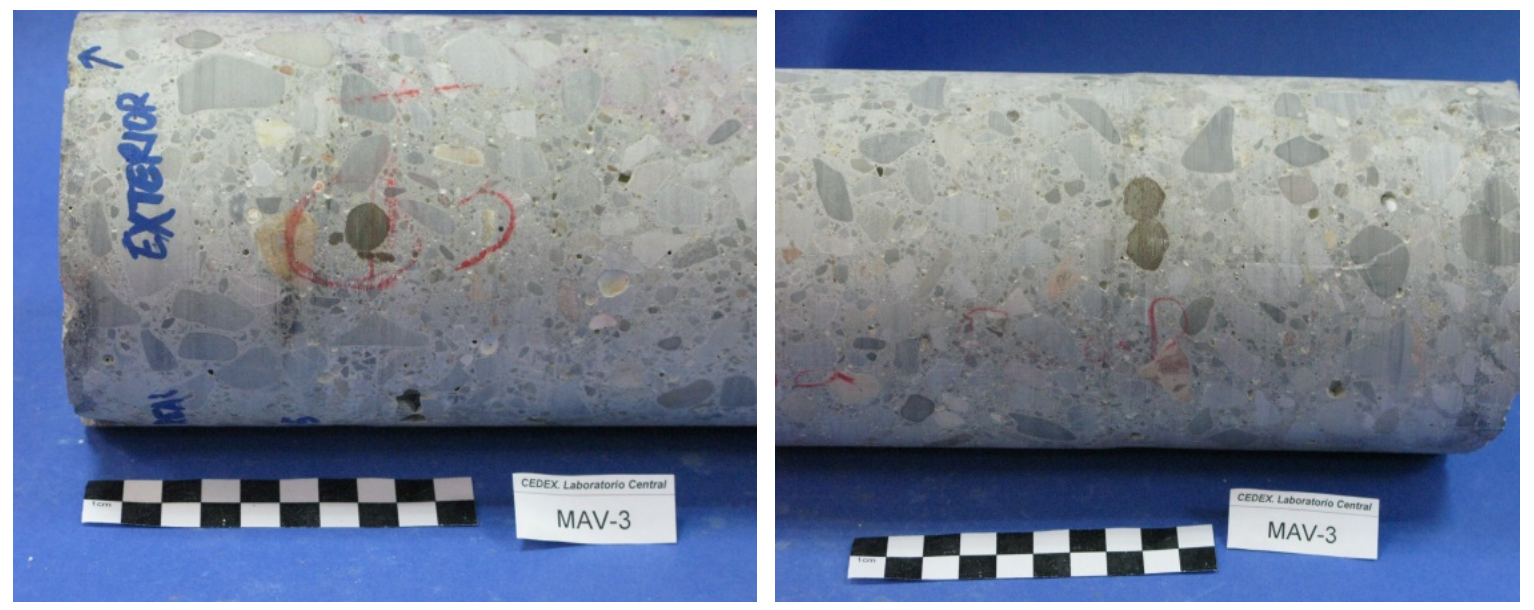

Fig.5.121. Barra Ø10mm (rec=68 $\mathrm{mm})$ y barra Ø10mm $($ rec $=235 \mathrm{~mm})$ con solape en testigo $M A V-3$.

Tras la realización de los ensayos, se extrae dichas barras corrugadas. La fig 5.122 corrobora la ausencia de corrosión en ambas. 

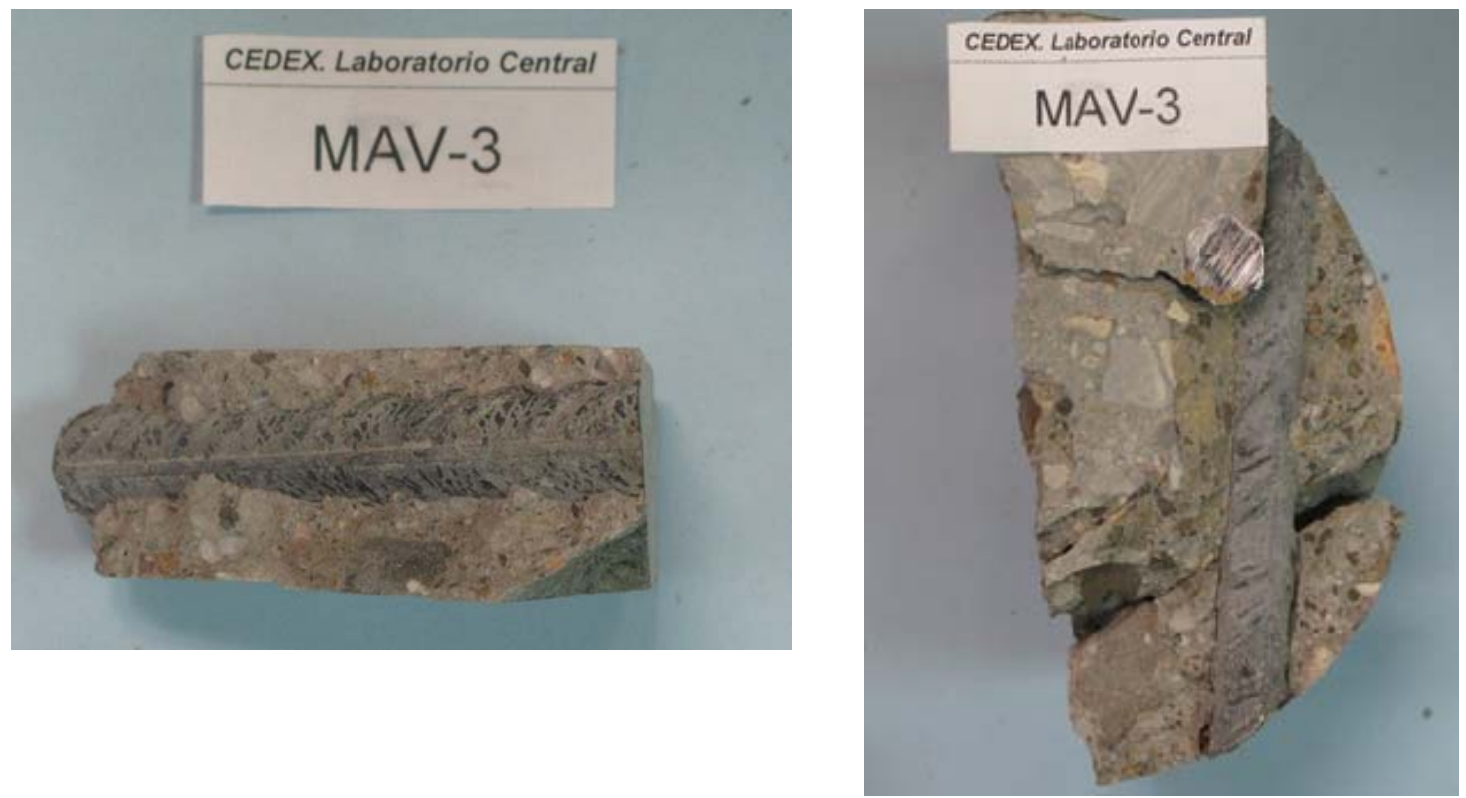

Fig.5.122. Barra $\varnothing 10 \mathrm{~mm}$, rec $=68 \mathrm{~mm}$ (izquierda) y barra $\varnothing 10 \mathrm{~mm}$, rec=235 $\mathrm{mm}$. Se corrobora la ausencia de corrosión en ambas

El testigo MAV-4 presenta un aspecto general del hormigón bueno, no se desmorona ni se raya con la uña. No presenta fisuras, ni áridos cuyo contorno presente una aureola de otro color. No presenta aspecto poroso. Su color es homogéneo. El árido se encuentra uniformemente distribuido y $\sin$ una alineación preferente. Presenta una buena adherencia pasta-árido.

La figura 5.123 muestra el aspecto general del testigo MAV-4. Se observan pocas coqueras y de pequeño tamaño. Alguna de ellas presenta depósitos blancos en su interior (posible presencia de sales).
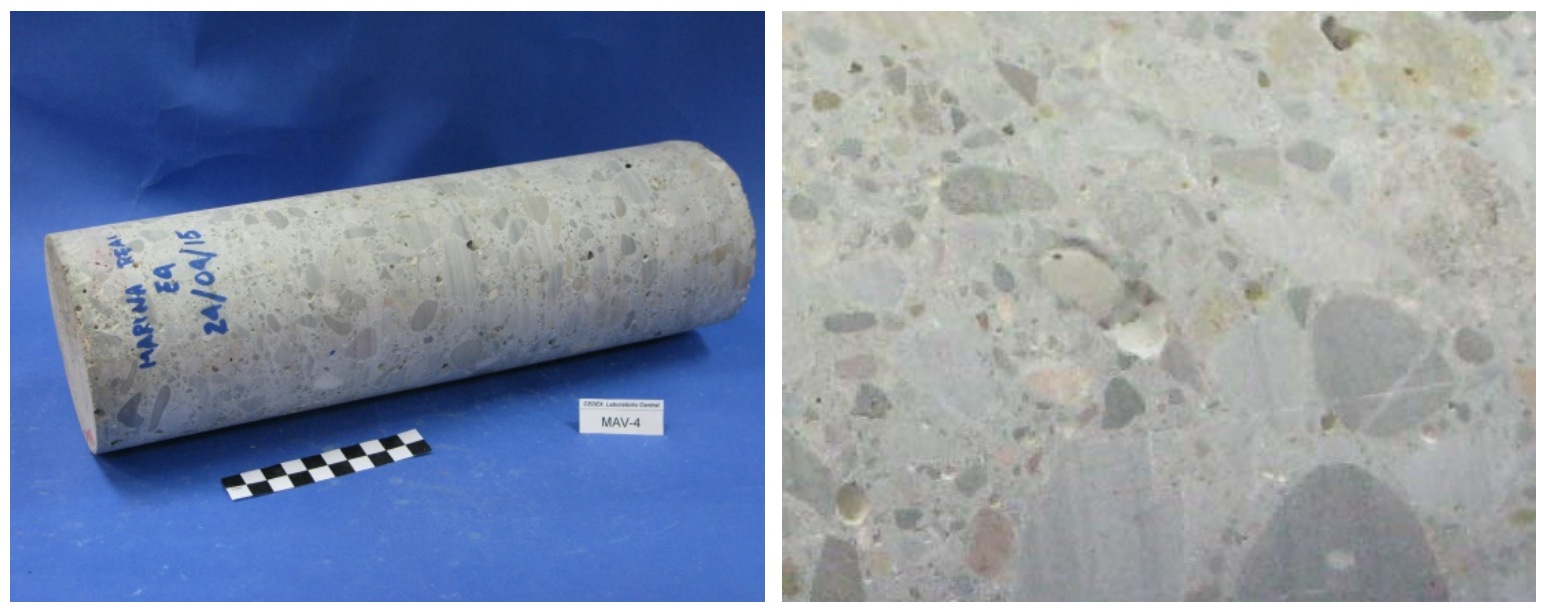

Fig.5.123. Testigo MAV-4. Vista general y detalle de coqueras con depósito blanco. 
El testigo no contiene armaduras, aunque se localiza una malla metálica en la cara interior (fig 5.124), que posiblemente delimite la canaleta de conducciones de servicio que queda dentro de la viga cantil.

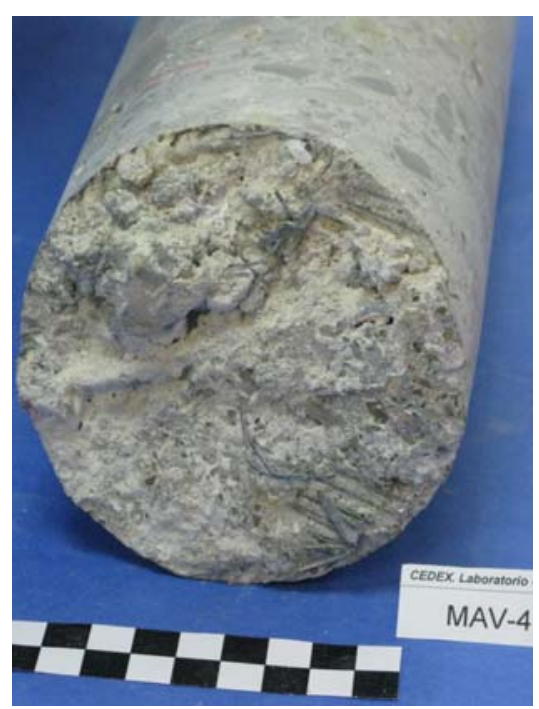

Fig.5.124. Malla metálica localizada en testigo MAV-4.

El árido grueso es mezcla de rodado y machaqueo. El tamaño máximo observado en el testigo es de $16 \mathrm{~mm}$.

El testigo MAV-5 presenta un aspecto general del hormigón bueno (fig 5.125), no se desmorona ni se raya con la uña. No presenta fisuras, ni áridos cuyo contorno presente una aureola de otro color. No presenta aspecto poroso. Su color es homogéneo. El árido se encuentra uniformemente distribuido y sin una alineación preferente. Presenta una buena adherencia pasta-árido. Sin embargo, en la cara interior del testigo aparece una coquera de mayor tamaño que probablemente causa la rotura del testigo durante la extracción. Esta coquera se sitúa sobre una barra de armado (puede apreciarse la huella de la barra en el hormigón), lo cual indica una compactación menor a la altura de las barras. 

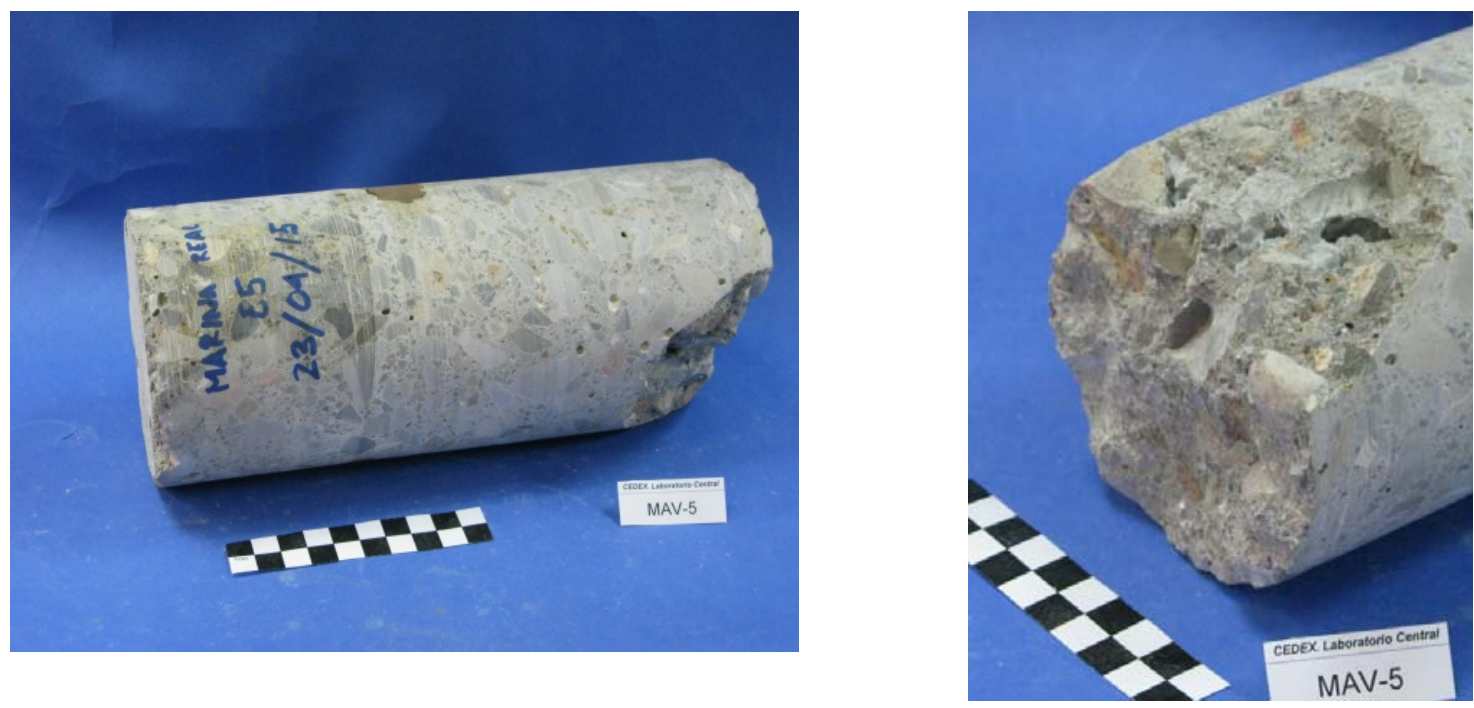

Fig.5.125. Testigo MAV-5. Vista general y detalle de coquera.

El árido grueso es mezcla de rodado y machaqueo. El tamaño máximo observado en el testigo es de $16 \mathrm{~mm}$.

El testigo además presenta dos barras de armado, como se muestra en la fig 5.126, de diámetro $10 \mathrm{~mm}$ y $20 \mathrm{~mm}$ con recubrimientos de 80 y $90 \mathrm{~mm}$, respectivamente.
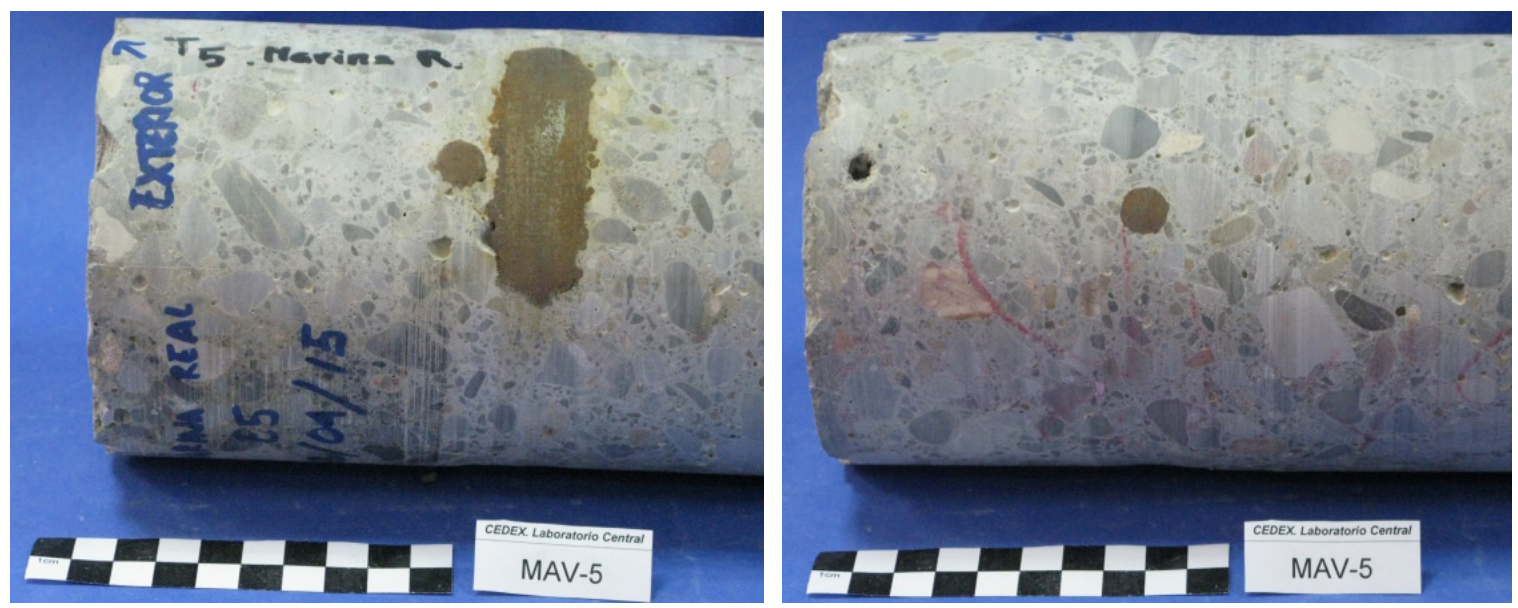

Fig.5.126. Testigo MAV-5. Detalle de barras de armado de Ø10mm y Ø20mm.

Tras la realización de los ensayos, se extraen las barras corrugadas. La fig 5.127 muestra que las barras no presentan corrosión, salvo una pequeña zona en el extremo de la barra de $20 \mathrm{~mm}$, que ha podido producirse durante la extracción del testigo. 


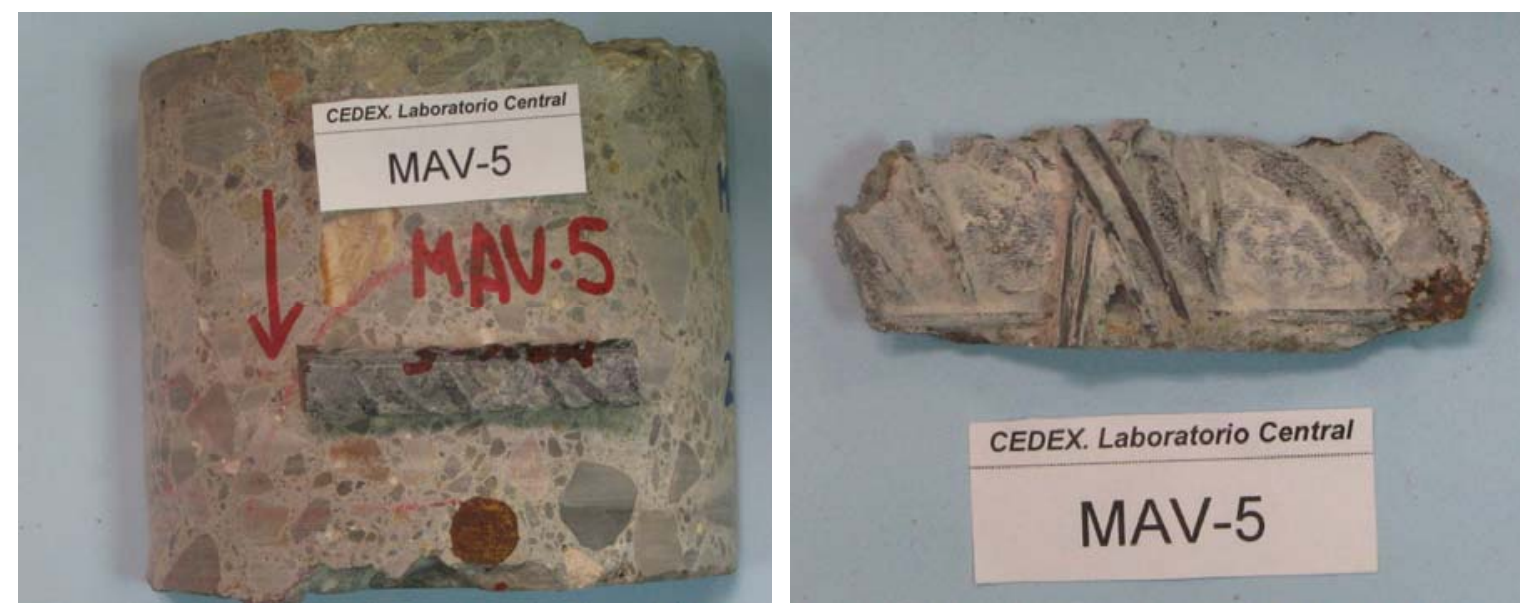

Fig.5.127. Barras de testigo MAV-5. Se corrobora la ausencia de corrosión salvo extremo barra Ø20mm

\subsection{PLANIFICACIÓN DE LOS ENSAYOS}

Los ensayos seleccionados en esta investigación representan diferentes mecanismos de transporte (permeabilidad, capilaridad, absorción y difusión) presentes tanto en la fase de iniciación como en la de propagación de la corrosión de las armaduras en el hormigón. Asimismo, se han utilizado en todos los casos ensayos normalizados.

Así, para caracterizar las propiedades físicas y mecánicas del hormigón de los testigos se ha optado por realizar la siguiente serie de ensayos:

- Resistencia a compresión: norma española UNE-EN 12390-3: "Ensayos de hormigón endurecido. Determinación de la resistencia a compresión de probetas".

- Velocidad de propagación de ultrasonidos: norma UNE-EN 12504-4: "Ensayos de hormigón en estructuras. Determinación de la velocidad de los impulsos sónicos".

- Penetración de agua: norma española UNE 83.309-90: "Ensayos de hormigón. Determinación de la profundidad de penetración de agua" (Muelle A y B). En el muelle C, se ha empleado la norma UNE-EN 12390-8: "Ensayos de hormigón endurecido. Profundidad de penetración de agua bajo presión".

- Porosidad abierta: RILEM CPC 11.3: "Absorption of water by inmersion under vacuum" 
- Absorción de agua por inmersión: BS1881: Part 122.: "Methods of testing concrete. Method for determination of water absorption".

- Absorción de agua por capilaridad: RILEM CPC 11.2.: "Absorption of water by capillarity".

- Permeabilidad al oxígeno: método CEMBUREAU (KOLLEK, J.J. (1989) "La determinación de la permeabilidad del hormigón al oxígeno mediante el método del CEMBUREAU - una recomendación". Materials and Structures, Vol.22). Actualmente dicho método queda recogido en la norma UNE 83981 (2008) "Durabilidad del hormigón. Métodos de ensayo. Determinación de la permeabilidad al oxígeno del hormigón endurecido".

- Estimación de la permeabilidad al agua a partir de los resultados de los ensayos de profundidad de penetración máxima de agua y de porosidad abierta, según la ecuación desarrollada por Valenta (VALENTA, O. (1970) ${ }^{84}$. The permeability and durability of concrete in aggressive conditions. Proceedings of Tenth International Congress on Large Dams. Montreal): $k=$ $P x^{2} / 2 h t$, donde " $k$ " es el coeficiente de permeabilidad; "P" es la porosidad; " $\mathrm{x}$ " es la profundidad de penetración de agua; "h" es la presión hidráulica; y "t" es el tiempo que está actuando la presión.

- Determinación del perfil de penetración de cloruros: mediante el análisis químico de rodajas de hormigón de $1 \mathrm{~cm}$ de espesor aproximadamente, según la norma ASTM C1152 "Standard Test Method for Acid-Soluble Chloride in Mortar and Concrete"

- Profundidad de carbonatación, se ha empleado la norma UNE-EN 13295 (2005) "Productos y sistemas para la protección y reparación de estructuras de hormigón. Métodos de ensayo. Determinación de la resistencia a la carbonatación". En ella se describe un ensayo acelerado en laboratorio para la determinación de la profundidad de carbonatación. Se ha empleado esta norma tan sólo en la parte referente a la lectura del frente.

- Medida de la resistividad del hormigón según la norma UNE 83988-1 (2008) "Durabilidad del hormigón. Métodos de ensayo. Determinación de la resistividad eléctrica. Parte 1: Método directo (método de referencia)".

- El análisis de la penetración de cloruros se ha realizado mediante la determinación del perfil de penetración, que se obtiene analizando químicamente (según la norma ASTM C1152) el contenido de cloruros de 
muestras de hormigón tomadas a diferentes profundidades. No se utilizó la norma española UNE 112-010 porque este método de ensayo introduce en la medida de resultados la dificultad de ver el punto de viraje del sulfato de amonio y hierro-III, que depende en parte de la subjetividad del analista que realiza el ensayo, lo que puede llevar una cierta dispersión en los resultados.

En cada uno de los Muelles los testigos tienen diferente longitud o dirección de ejecución del sondeo, en función de las características de los propios Muelles (tipología de aligeramiento del cajón y espesor de las paredes, etc.), por lo que a continuación se describe individualmente la división de los testigos para la realización de los ensayos.

\subsubsection{Muelle A}

Se han extraído cuatro testigos denominados TPS-H1, TPS-H2, TPS-H3 y TPS-H4 de $10 \mathrm{~cm}$ de diámetro y $80 \mathrm{~cm}$ de profundidad aproximadamente en cuatro Duques de Alba, con los que se han realizado ensayos de carbonatación, de penetración de cloruros, de resistencia a compresión, de densidad, de velocidad de transmisión de ultrasonidos, de penetración de agua, de porosidad abierta, de permeabilidad al oxígeno, de absorción y de absorción capilar.

Partiendo del extremo superior del testigo, en primer lugar se ha determinado hasta qué profundidad han penetrado los cloruros y la carbonatación; con este objetivo se ha cortado una rodaja de $60 \mathrm{~mm}$ de espesor en todos los testigos.

Para realizar los ensayos de determinación de la velocidad de transmisión de ultrasonidos, densidad y resistencia a compresión, se han tallado probetas de 17 $\mathrm{cm}$ de altura en todos los casos salvo en el caso del testigo TPS-H4, donde se talla una probeta de $11 \mathrm{~cm}$ de altura.

En el caso de los ensayos de porosidad y penetración de agua, se tallan probetas de $14 \mathrm{~cm}$ (de $9 \mathrm{~cm}$ para el testigo TPS-H4).

El ensayo de absorción de agua por capilaridad se ha realizado sobre probetas de $10 \mathrm{~cm}$ de longitud ( $5 \mathrm{~cm}$ en el caso del testigo TPS-H4).

Por último, en una probeta de $5 \mathrm{~cm}$ de espesor se han realizado el ensayo de permeabilidad al oxígeno y a continuación el de absorción de agua.

La figura 5.128 indica, a modo de ejemplo, la división del testigo TPS-H1. 


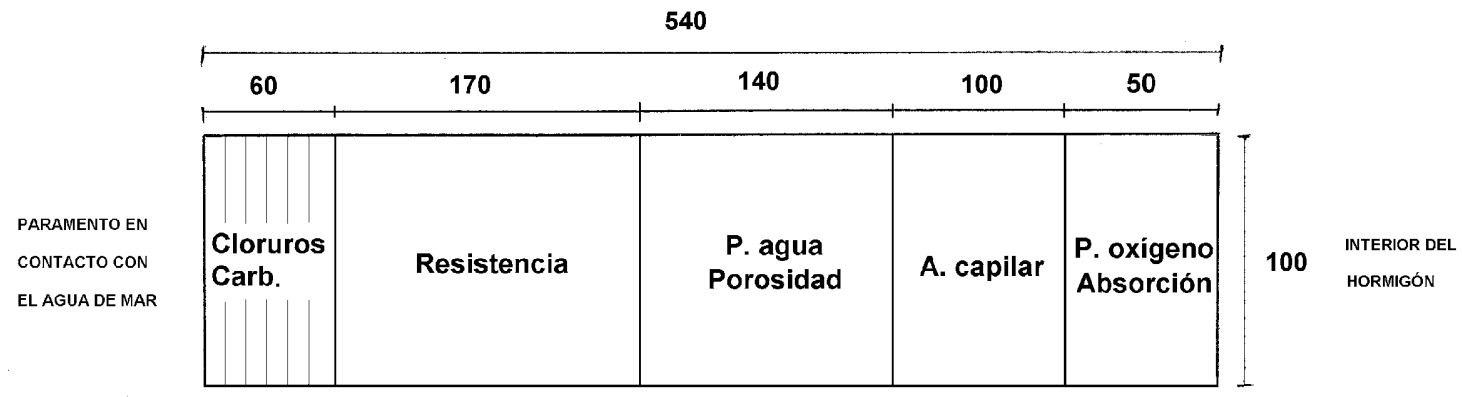

Fig.5.128. Croquis de división del testigo TPS-H1

\subsubsection{Muelle B}

En cuatro puntos de la losa del pantalán se han realizado sondeos de $100 \mathrm{~mm}$ de diámetro y 2,00 m de longitud, por lo tanto, se dispone de cuatro testigos de hormigón de la losa, de $100 \mathrm{~mm}$ de diámetro y aproximadamente $450 \mathrm{~mm}$ de longitud ( $\mathrm{HU}-\mathrm{H} 1, \mathrm{HU}-\mathrm{H} 2, \mathrm{HU}-\mathrm{H} 3$ y $\mathrm{HU}-\mathrm{H} 4)$. Además se han extraído 4 testigos de los cabeceros, desde la superficie frontal. Son testigos igualmente de $100 \mathrm{~mm}$ de diámetro y unos $40 \mathrm{~cm}$ de longitud (HU-H5, HU-H6, HU-H7 y HU-H8). Con todos ellos, en laboratorio se han realizado ensayos de carbonatación, de penetración de cloruros, de resistencia a compresión, de penetración de agua, de porosidad abierta, de permeabilidad al oxígeno, de absorción y de absorción capilar.

Partiendo del extremo del testigo más próximo al mar, en primer lugar se ha determinado hasta qué profundidad han penetrado los cloruros y la carbonatación; con este objetivo se han cortado una serie de rodajas para obtener el perfil de penetración de cloruros en cada testigo.

Los siguientes $10 \mathrm{~cm}$ (en el caso de los testigos de la losa) ó $12 \mathrm{~cm}$ (en los testigos de los cabeceros) del testigo se han reservado para realizar los ensayos de determinación de la velocidad de transmisión de ultrasonidos y de resistencia a compresión, de modo que la altura de la probeta sea al menos 1,1 veces su diámetro.

En los siguientes 9 a $11 \mathrm{~cm}$ del testigo se ha realizado el ensayo de penetración de agua, y posteriormente el ensayo de porosidad.

El ensayo de capilaridad se ha realizado sobre una probeta de aproximadamente 6 cm de longitud.

Por último, en una probeta de $5 \mathrm{~cm}$ de espesor se han realizado el ensayo de permeabilidad al oxígeno y, posteriormente, el de absorción de agua. 
La figura 5.129 muestra el croquis de división de uno de los testigos.

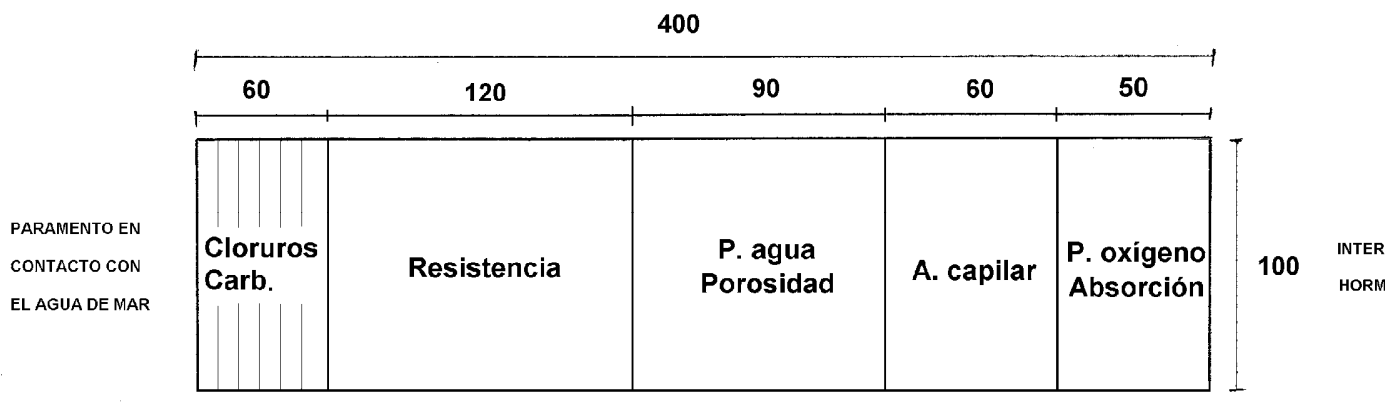

Fig.5.129. Croquis de división del testigo $\mathrm{HU}-\mathrm{H} 8$.

\subsubsection{Muelle C}

Tal y como se expone en el apartado 5.3.2, a partir de los ensayos de campo realizados (medidas de la velocidad de ultrasonidos y medidas electroquímicas de la corrosión), se identificaron las zonas en las que se procedió a extraer 6 testigos de hormigón para su posterior estudio en laboratorio (AV-T1 a AV-T6, de 94mm de diámetro y $60 \mathrm{~cm}$ de longitud aproximadamente).

Cuatro testigos se extrajeron de la parte superior de diferentes zonas de la viga cantil (entre las dos primeras armaduras longitudinales). Los otros dos restantes se extrajeron del cabecero de la viga trasera e intermedia.

Partiendo del extremo del testigo más próximo al mar, en primer lugar se ha determinado hasta qué profundidad han penetrado los cloruros y la carbonatación; con este objetivo se han cortado una serie de rodajas para obtener el perfil de penetración de cloruros en cada testigo.

En las figuras siguientes (fig 5.130 a 5.135) se muestra la división de los seis testigos:

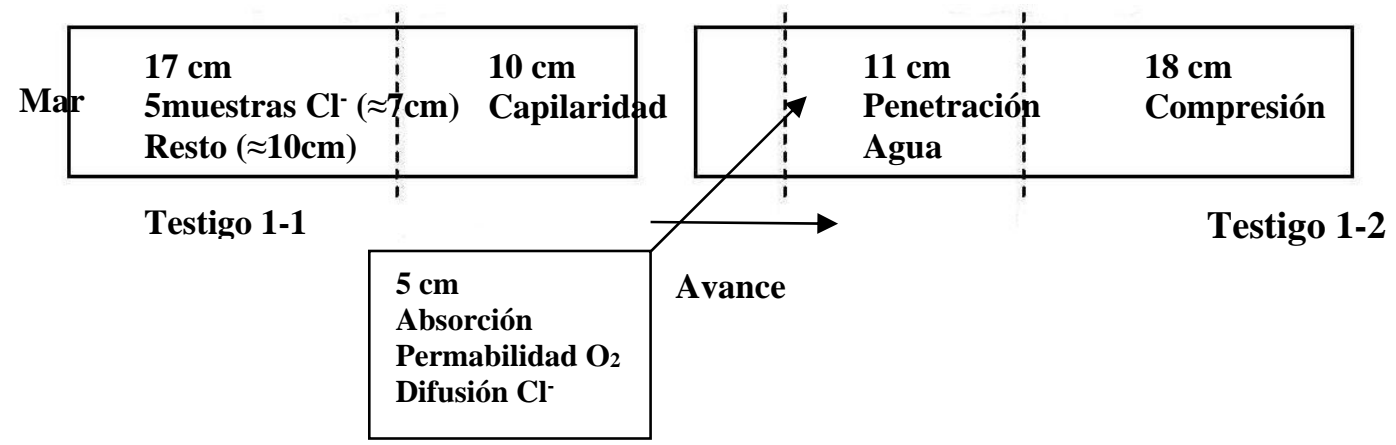

Fig.5.130. Croquis de división del testigo AV-T1. 


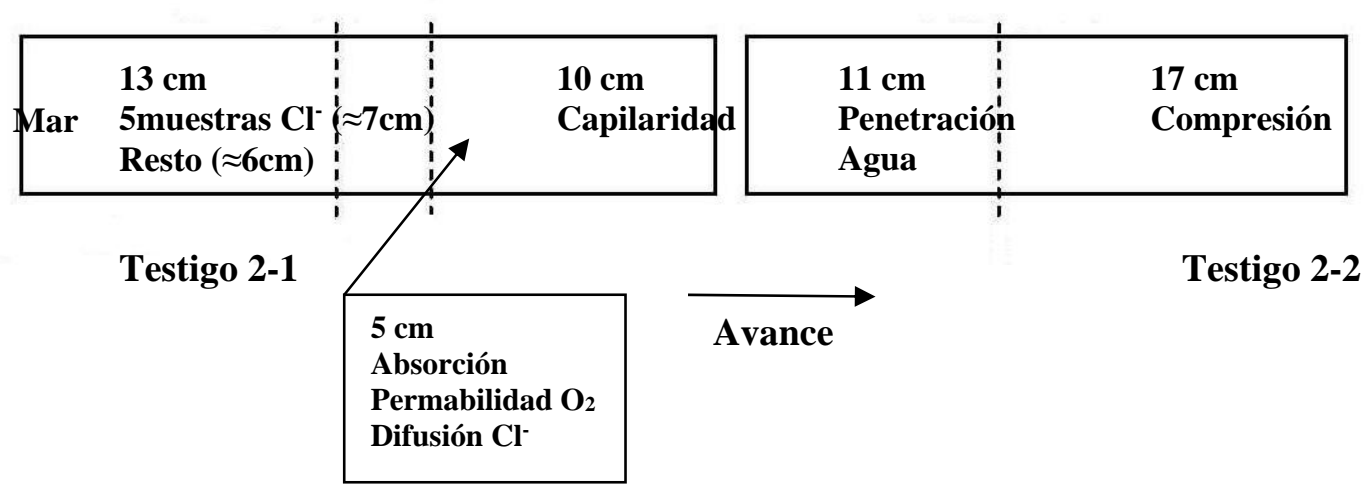

Fig.5.131. Croquis de división del testigo AV-T2.

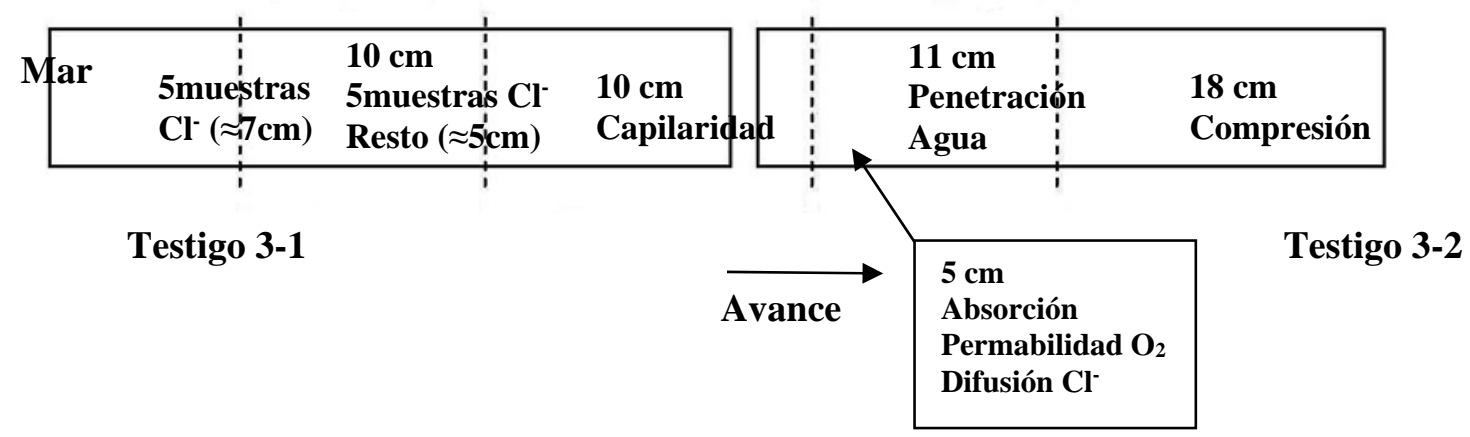

Fig.5.132. Croquis de división del testigo AV-T3.
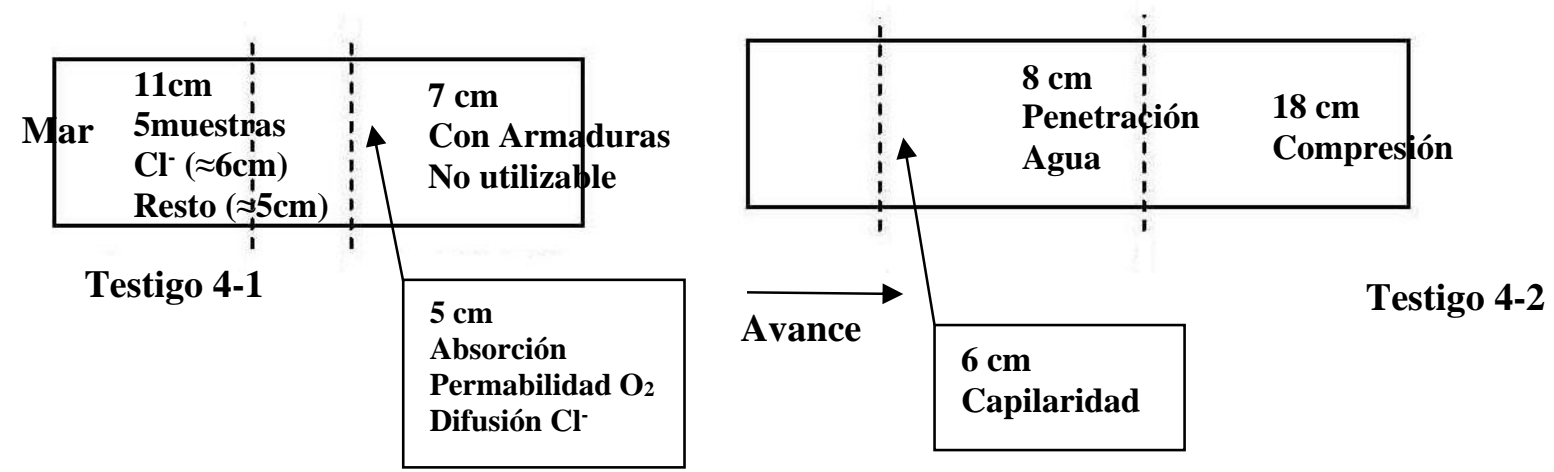

Fig.5.133. Croquis de división del testigo AV-T4. 

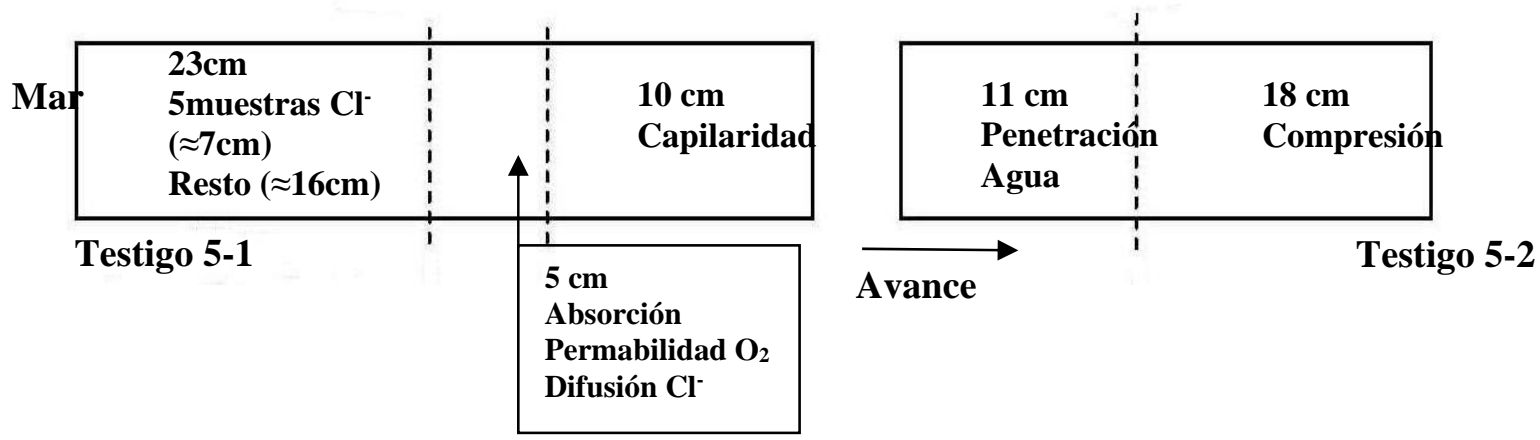

Fig.5.134. Croquis de división del testigo AV-T5.
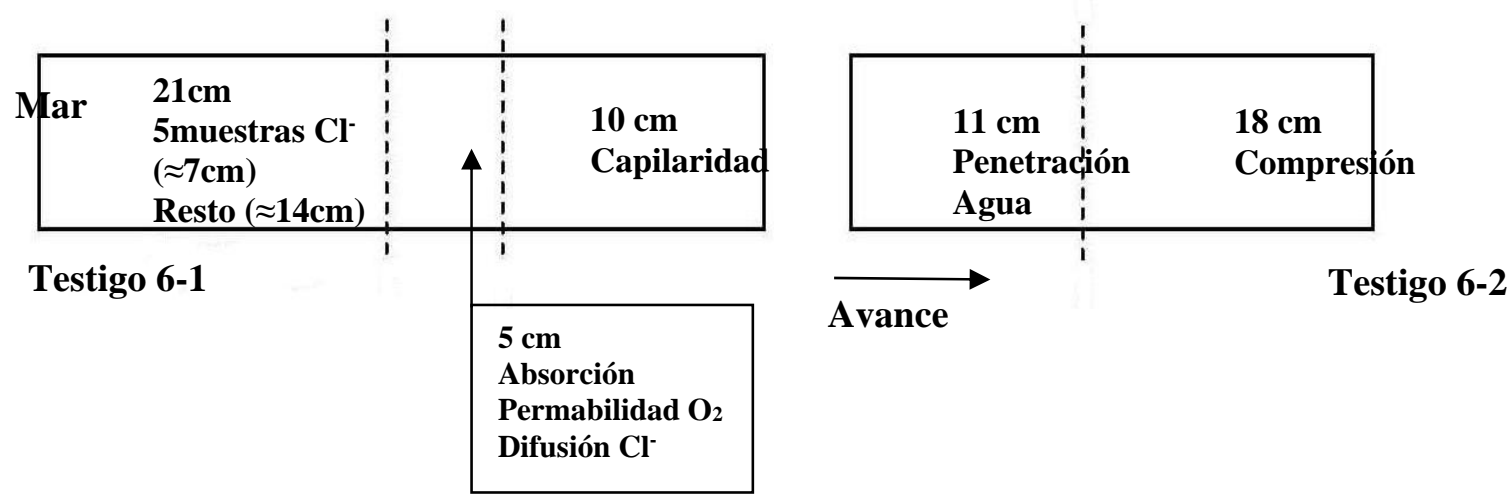

Fig.5.135. Croquis de división del testigo AV-T6.

\subsubsection{Muelle D}

Se han extraído 5 testigos, con dimensiones diferentes y barras en el interior que determinan también la distribución de ensayos.

A continuación las figuras 5.136 a 5.140 muestran la distribución de ensayos de cada testigo. 


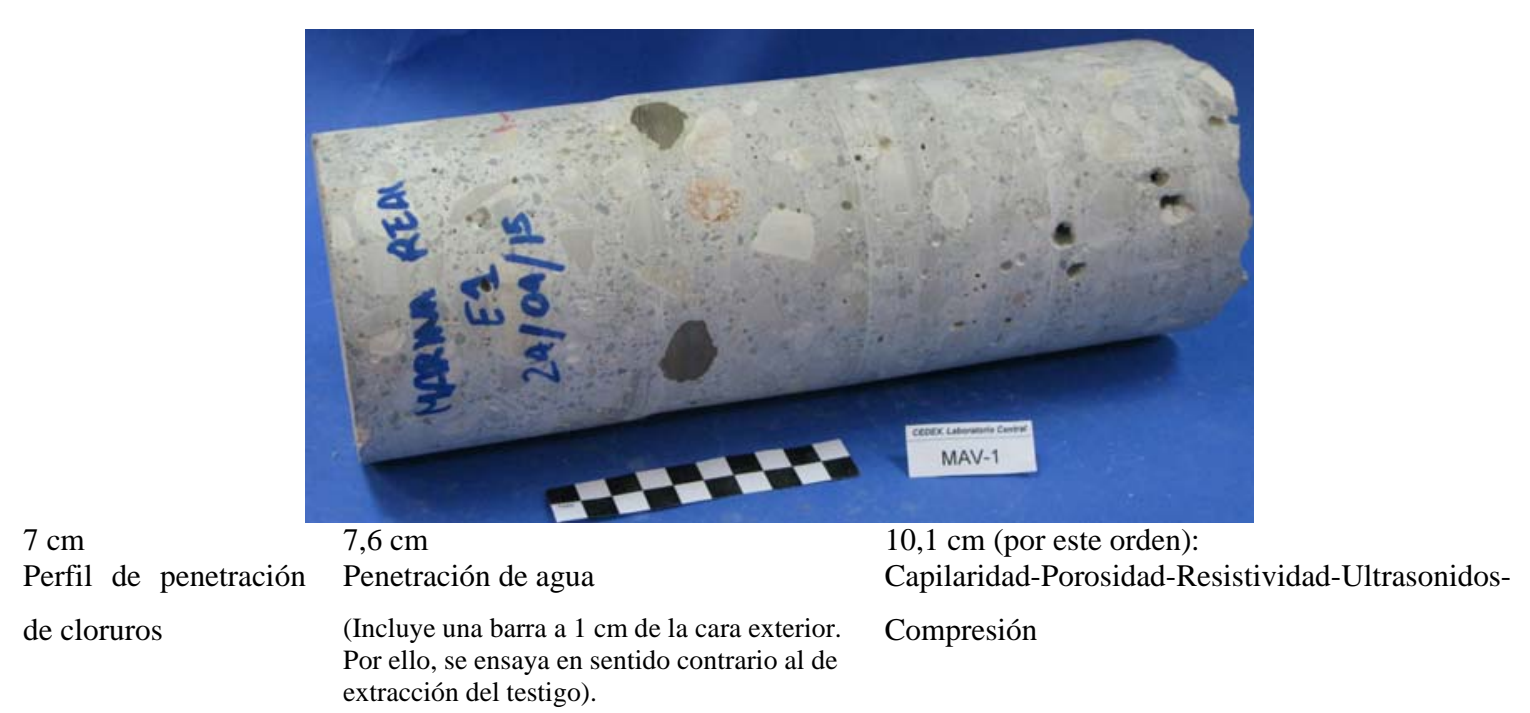

Fig.5.136. Croquis de división del testigo MAV-1.

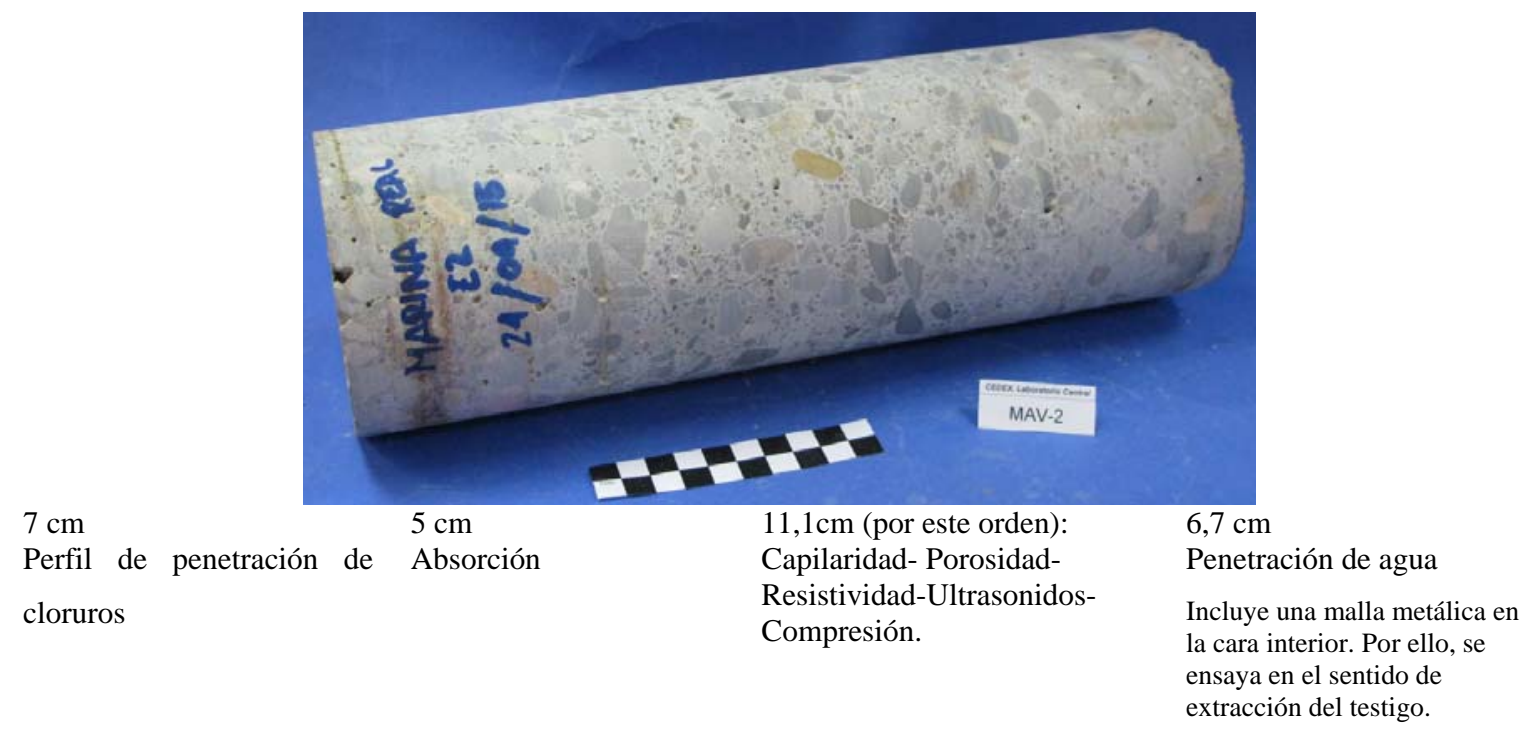

Fig.5.137. Croquis de división del testigo MAV-2. 


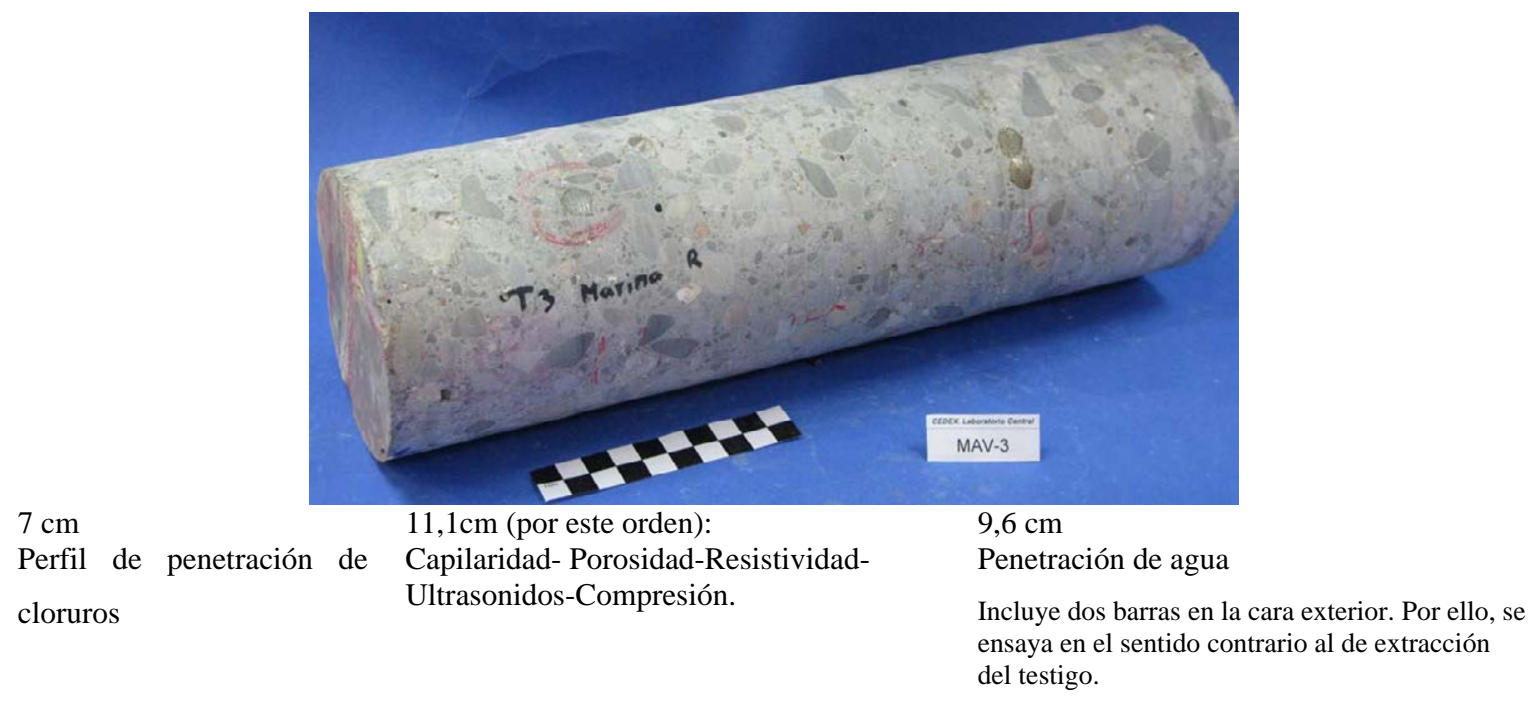

Fig.5.138. Croquis de división del testigo MAV-3.

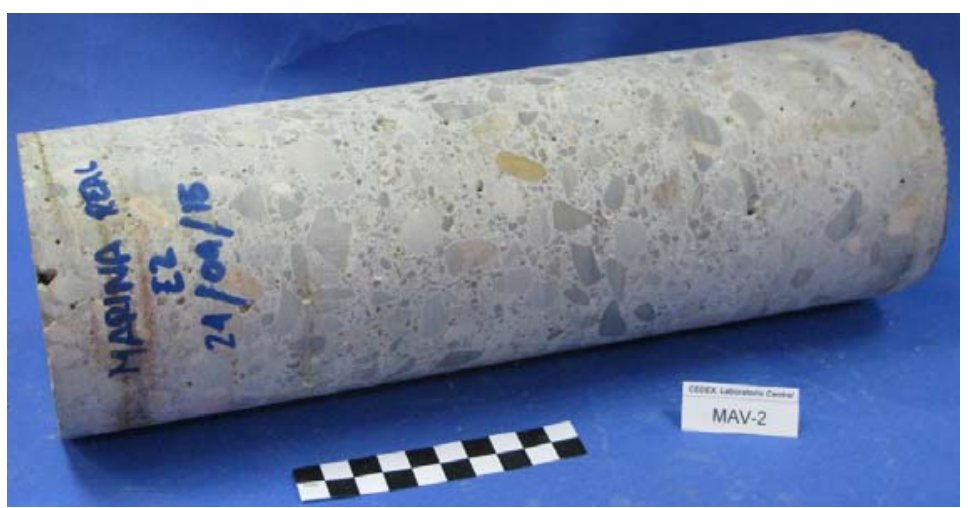

$8 \mathrm{~cm}$

6,6cm

$11,4 \mathrm{~cm}$ (por este orden)

$5 \mathrm{~cm}$

Perfil de penetración de

Penetración de agua

Capilaridad- Porosidad-Resistividad-

Absorción

cloruros

Se ensaya en el sentido Ultrasonidos-Compresión. contrario a la extracción del testigo

Fig.5.139. Croquis de división del testigo MAV-4. 


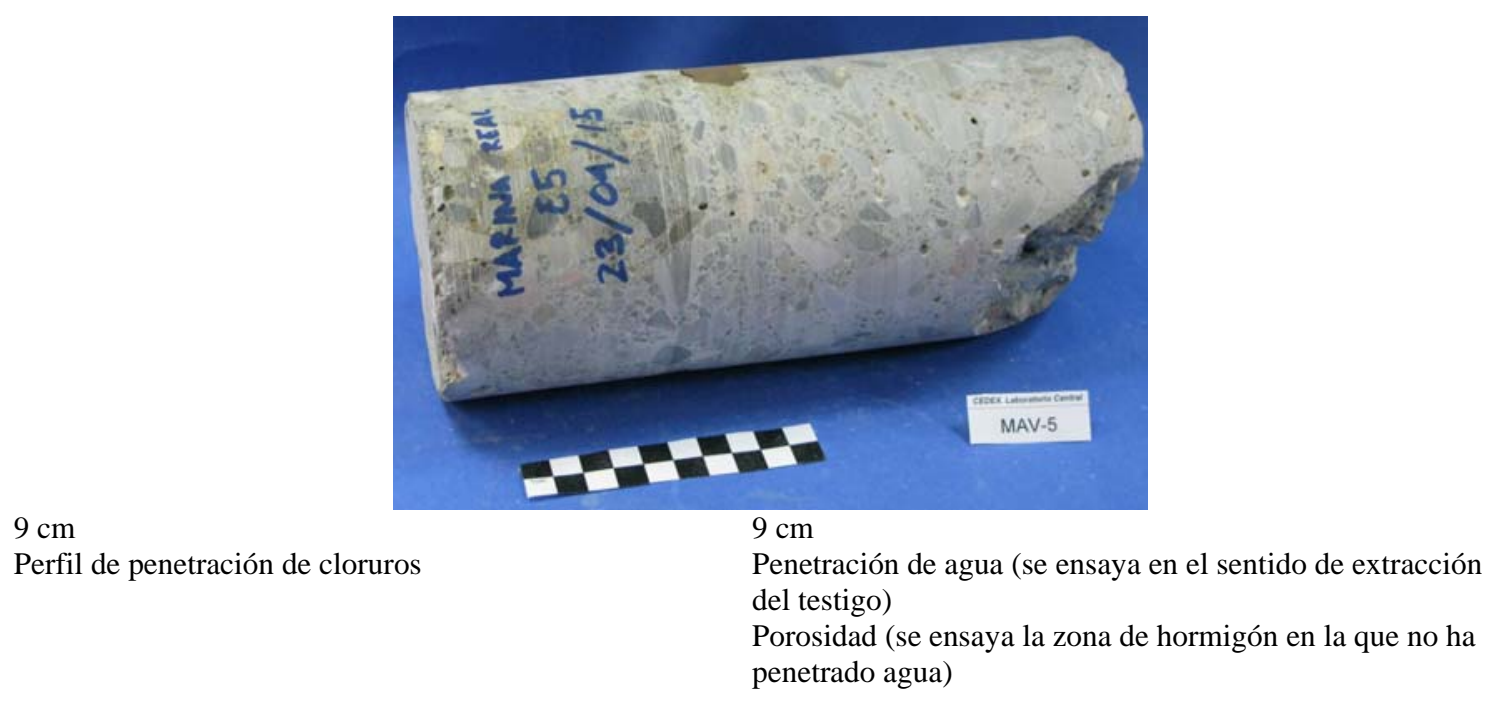

Fig.5.140. Croquis de división del testigo MAV-5.

\subsection{RESULTADOS DE LOS ENSAYOS}

\subsubsection{Ensayos mecánicos. Resistencia a compresión del hormigón y Velocidad de Ultrasonidos}

El procedimiento del ensayo de resistencia a compresión viene recogido en la norma UNE-EN 12390-3 "Ensayos de hormigón endurecido. Determinación de la resistencia a compresión de probetas". La determinación de la velocidad de ultrasonidos se recoge de la Norma UNE-EN 12504-4 "Ensayos de hormigón en estructuras. Determinación de la velocidad de los impulsos ultrasónicos". Los resultados obtenidos se recogen en la tabla 5.11. En la figuras 5.141 se aportan fotografías en las que se observa el dispositivo de realización de los ensayos.
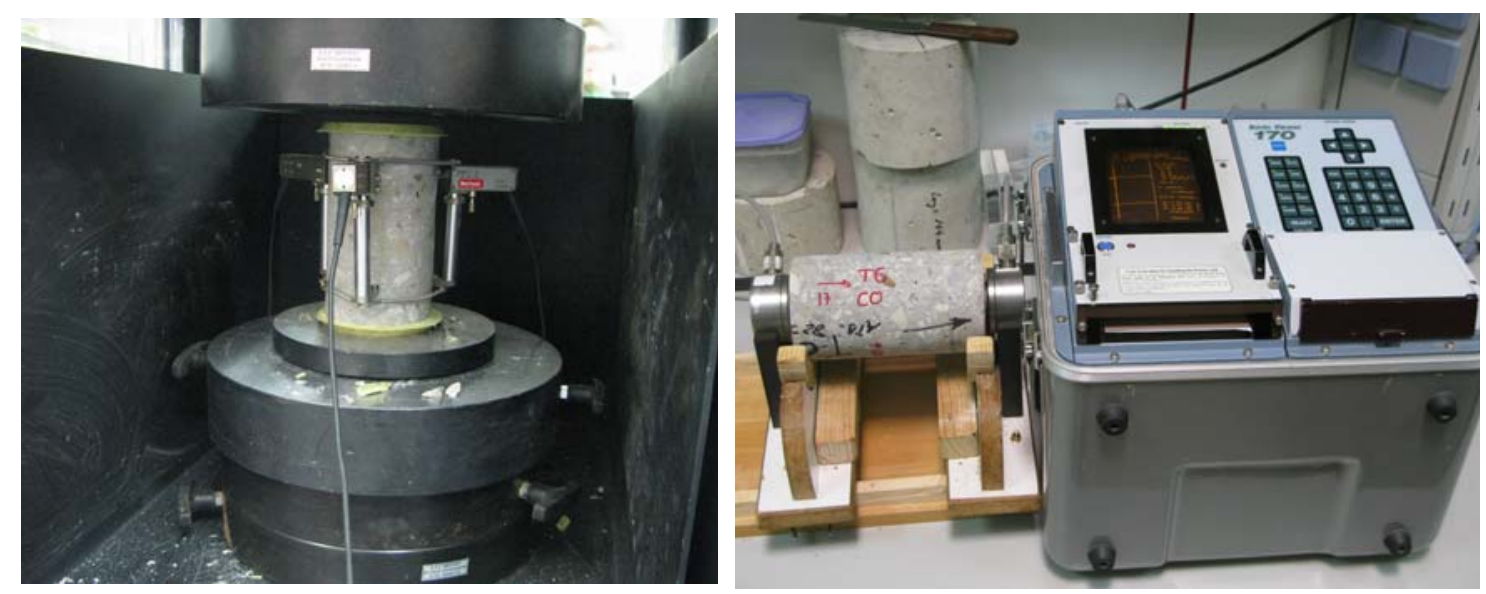

Fig.5.141. Ensayo de resistencia a compresión del hormigón y determinación del módulo de elasticidad (izquierda) y ensayo de determinación de la velocidad de transmisión de ultrasonidos. 
El cálculo del incremento de resistencia se ha realizado comparando los resultados obtenidos en los ensayos de resistencia a compresión con el valor de resistencia de proyecto establecido para cada el hormigón de cada muelle y que se indica en la tabla 5.1.

\begin{tabular}{|c|c|c|c|c|c|}
\hline $\begin{array}{c}\text { Muelle } \\
\text { (Edad en } \\
\text { años) }\end{array}$ & Testigo & $\begin{array}{c}\text { V. Ultrasonidos } \\
(\mathrm{m} / \mathrm{s})\end{array}$ & $\begin{array}{c}\text { Resist. } \\
\text { Compresión } \\
\left(\mathrm{N} / \mathrm{mm}^{2}\right)\end{array}$ & $\Delta \mathrm{R}(\%)$ & $\begin{array}{c}\text { Densidad } \\
\left(\mathbf{k g} / \mathbf{m}^{3}\right)\end{array}$ \\
\hline \multirow{4}{*}{ A (37) } & TPS-H1 & 4.563 & 40,9 & ---- & 2.196 \\
\hline & TPS-H2 & 3.947 & 29,7 & ---- & 2.148 \\
\hline & TPS-H3 & 4.554 & 45,1 & ---- & 2.291 \\
\hline & TPS-H4 & 4.589 & 39,9 & ---- & 2.360 \\
\hline \multirow{7}{*}{ B (26) } & HU-H1 & 4.382 & 50,2 & (67,3 & 2.233 \\
\hline & HU-H2 & 4.439 & 48,0 & 60,0 & 2.205 \\
\hline & HU-H4 & 4.336 & 55,5 & 85,0 & 2.301 \\
\hline & HU-H5 & 4.567 & 47,8 & 59,3 & 2.304 \\
\hline & HU-H6 & 4.418 & 44,3 & 47,7 & 2.273 \\
\hline & HU-H7 & 4.230 & 40,4 & 34,7 & 2.234 \\
\hline & HU-H8 & 4.277 & 50,2 & 67,3 & 2.235 \\
\hline \multirow{6}{*}{ C (11) } & AV-T1 & 4.377 & 46,0 & 84,0 & 2.243 \\
\hline & AV-T2 & 4.479 & 50,4 & 101,6 & 2.292 \\
\hline & AV-T3 & 4.329 & 42,1 & 68,4 & 2.251 \\
\hline & AV-T4 & 4.415 & 47,8 & 91,2 & 2.268 \\
\hline & AV-T5 & 4.475 & 54,3 & 117,2 & 2.294 \\
\hline & AV-T6 & 4.545 & 47,0 & 88,0 & 2.298 \\
\hline \multirow{5}{*}{$D^{*}(11)$} & MAV-1 & 4.370 & 26,5 & $-24,3$ & 2.249 \\
\hline & MAV-2 & 4.720 & 30,8 & $-12,0$ & 2.356 \\
\hline & MAV-3 & 4.780 & 18,2 & $-48,0$ & 2.393 \\
\hline & MAV-4 & 4.560 & 33,5 & $-4,3$ & 2.366 \\
\hline & MAV-5 & --- & --- & --- & 2.389 \\
\hline
\end{tabular}

Tabla .5.11. Resultados obtenidos de los ensayos de velocidad de ultrasonidos y resistencia a compresión.

${ }^{*}$ ) Los testigos del muelle D se han ensayado a compresión saturados de agua, tras la realización del ensayo de resistividad, factor que disminuye la resistencia entre un 10 y $15 \%$. 


\subsubsection{Profundidad de Penetración de Agua, Porosidad y Permeabilidad}

Los ensayos de penetración de agua se realizaron según el procedimiento descrito por la Norma UNE 83.309-90 "Ensayos de hormigón. Determinación de la profundidad de penetración de agua" en el caso de los muelles A y B. En el caso de los muelles C y D, el ensayo se realiza según la norma UNE-EN 12390-8 "Ensayos de hormigón endurecido. Profundidad de penetración de agua bajo presión". Los resultados obtenidos se muestran en la tabla 5.12.

\begin{tabular}{|c|c|c|c|}
\hline Muelle & Testigo & Prof. Máxima (mm) & Prof. Media (mm) \\
\hline \multirow{3}{*}{ A } & TPS-H1 & 44,0 & 38,0 \\
\hline & TPS-H2 & 28,0 & 22,0 \\
\hline & TPS-H3 & 61,0 & 54,5 \\
\hline \multirow{6}{*}{ B } & HU-H2 & 26,0 & 16,5 \\
\hline & HU-H4 & 26,0 & 13,0 \\
\hline & HU-H5 & $>106$ & $>106$ \\
\hline & HU-H6 & 47,0 & 35,5 \\
\hline & HU-H7 & 80,5 & 67,5 \\
\hline & HU-H8 & 42,0 & 32,5 \\
\hline \multirow{6}{*}{ C } & AV-T1 & 25,5 & 17,6 \\
\hline & AV-T2 & 22,0 & 10,9 \\
\hline & AV-T3 & 30,0 & 20,7 \\
\hline & AV-T4 & 27,0 & 17,6 \\
\hline & AV-T5 & 15,5 & 5,8 \\
\hline & AV-T6 & 18,0 & 11,9 \\
\hline \multirow{5}{*}{ D } & MAV-1 & 47,0 & 26,6 \\
\hline & MAV-2 & 28,0 & 14,8 \\
\hline & MAV-3 & 26,0 & 12,6 \\
\hline & MAV-4 & 24,0 & 12,9 \\
\hline & MAV-5 & 30,0 & 18,5 \\
\hline
\end{tabular}

Tabla 5.12. Resultados de los ensayos de determinación de la profundidad de penetración de agua bajo presión.

En la figura 5.142 se observa el dispositivo de ensayo y las figuras 5.143 a 5.149 los resultados del ensayo de penetración de agua de las probetas estudiadas. 

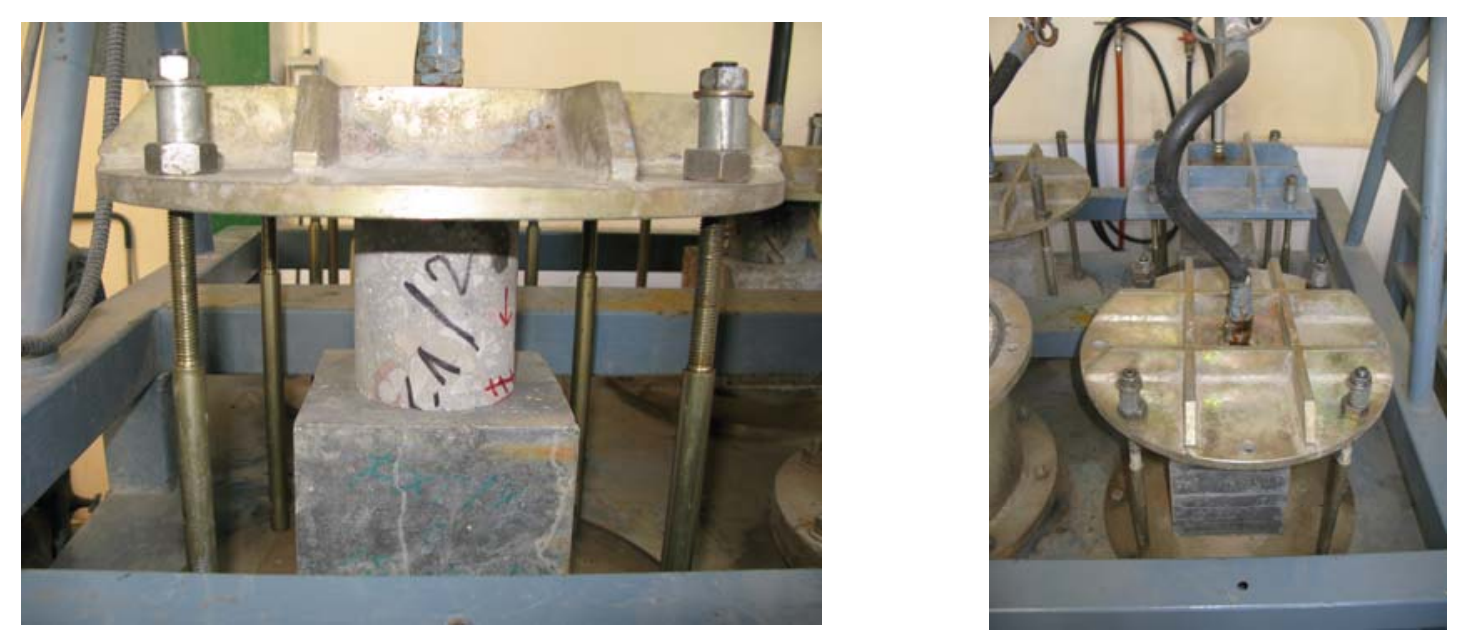

Fig.5.142. Ensayo de penetración de agua bajo presión.
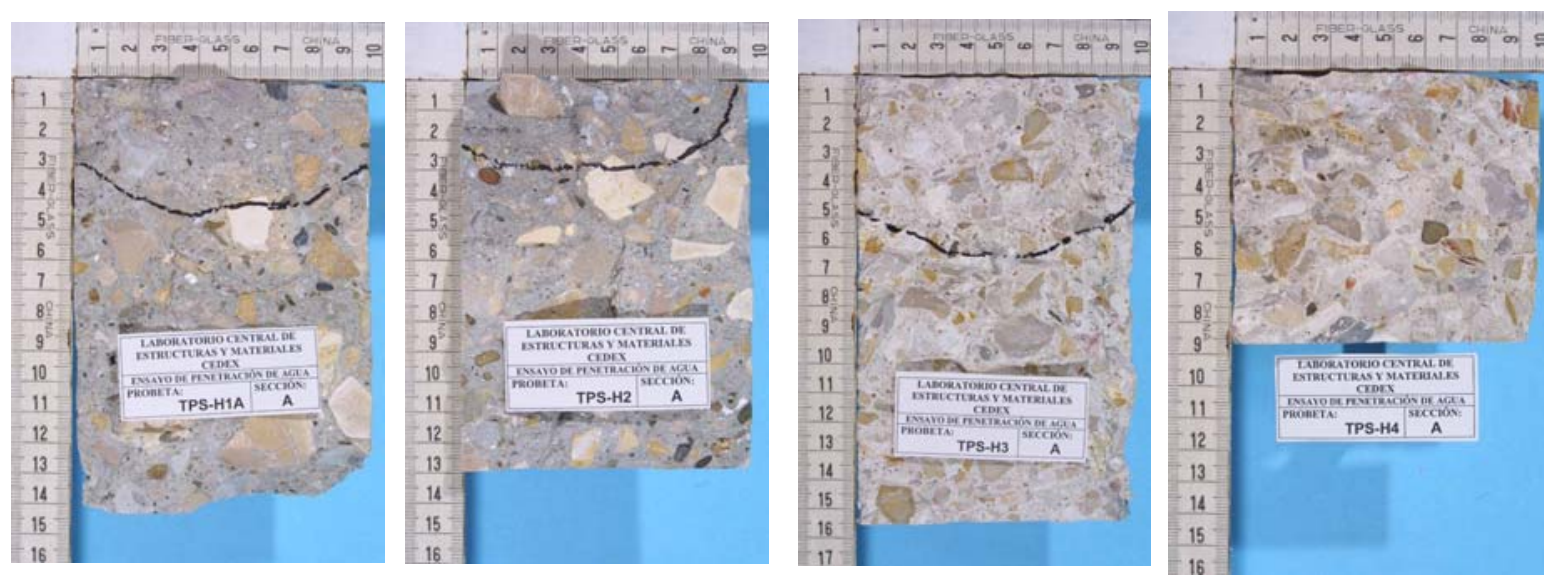

Fig.5.143. Ensayo de penetración de agua bajo presión. Testigos TPS-H1, TS-H2, TPS-H3 y TPS-H4.
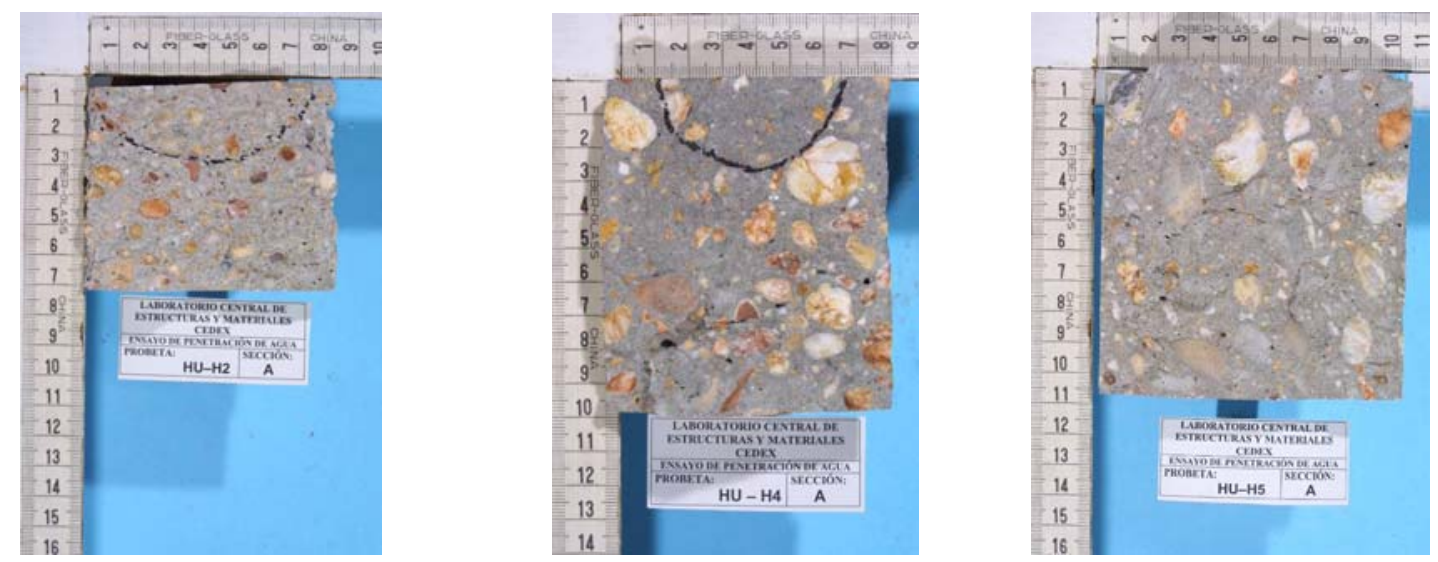

Fig.5.144. Ensayo de penetración de agua bajo presión. Testigos HU-H2, HU-H4 y HU-H5. 

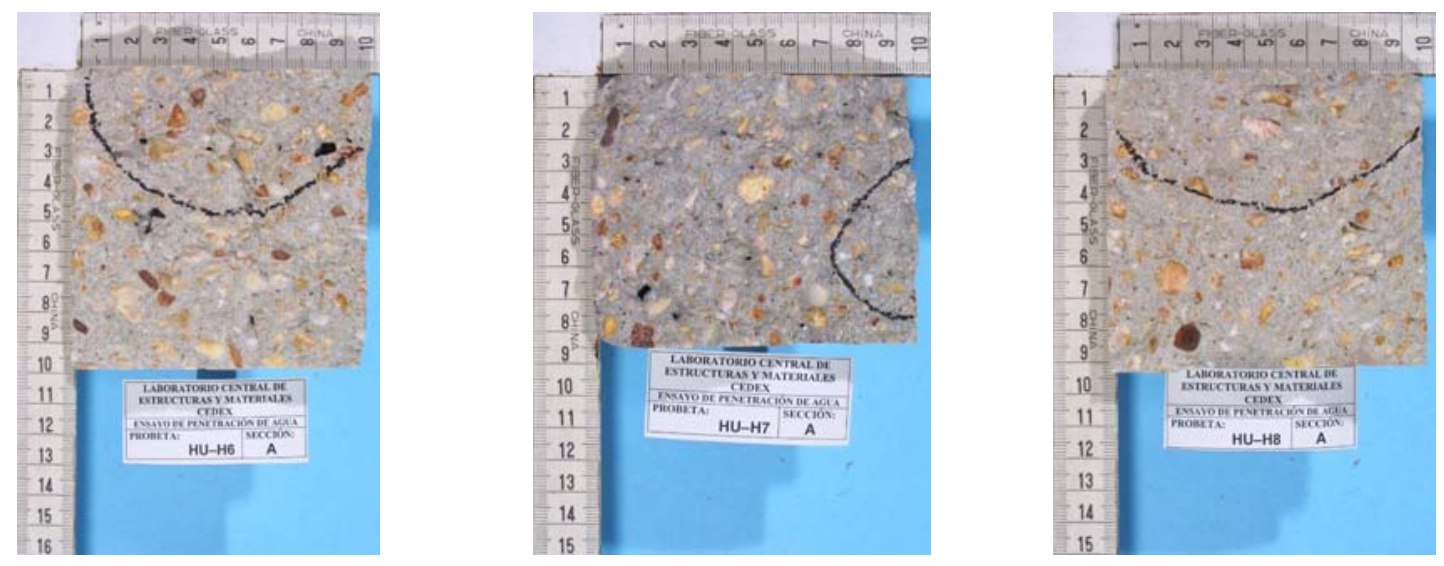

Fig.5.145. Ensayo de penetración de agua bajo presión. Testigos HU-H6, HU-H7 y HU-H8.
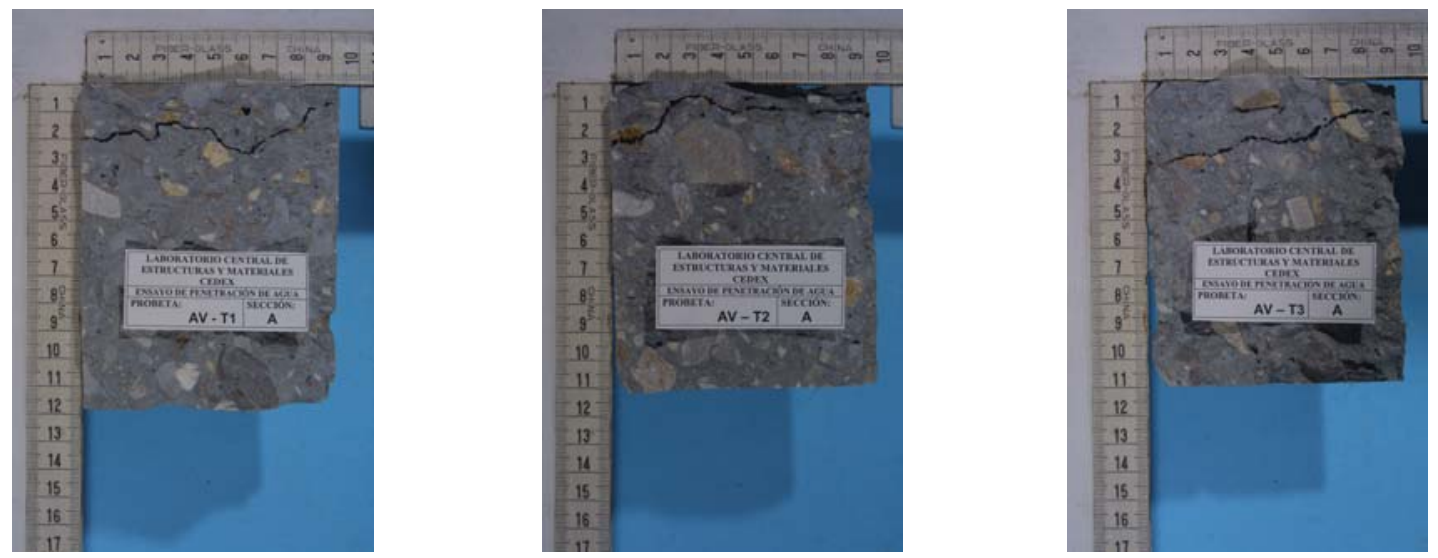

Fig.5.146. Ensayo de penetración de agua bajo presión. Testigos AV-T1, AV-T2 y AV-T3.
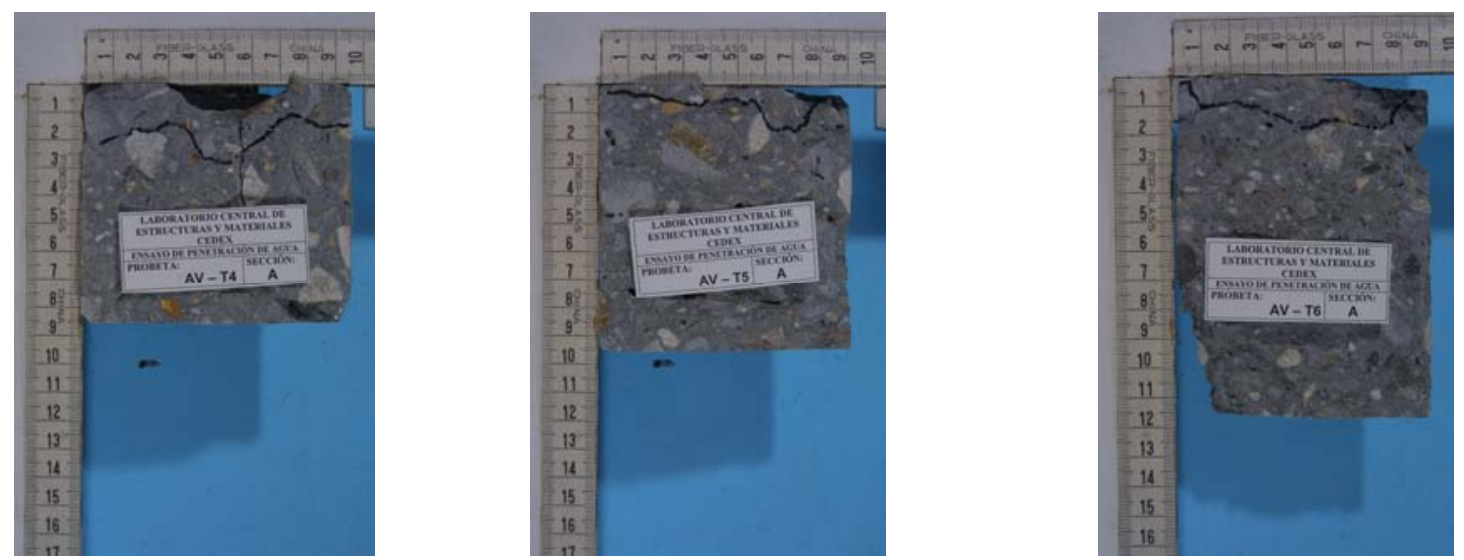

Fig.5.147. Ensayo de penetración de agua bajo presión. Testigos AV-T4, AV-T5 y AV-T6 

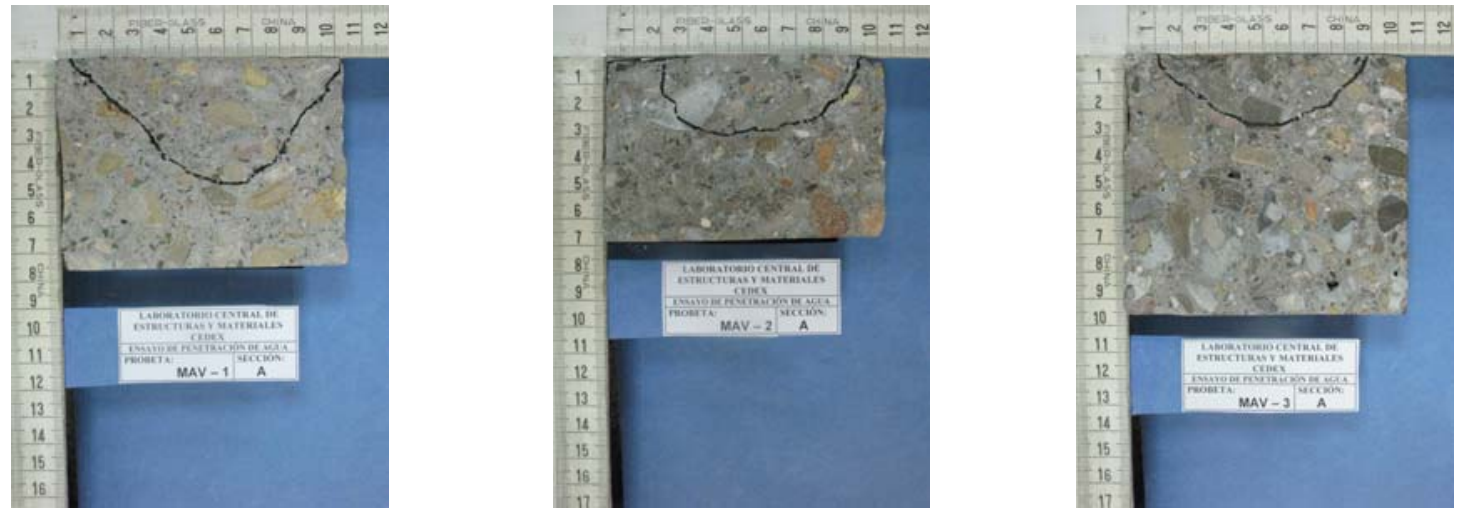

Fig.5.148. Ensayo de penetración de agua bajo presión. Testigos MAV-1, MAV-2 y MAV-3.
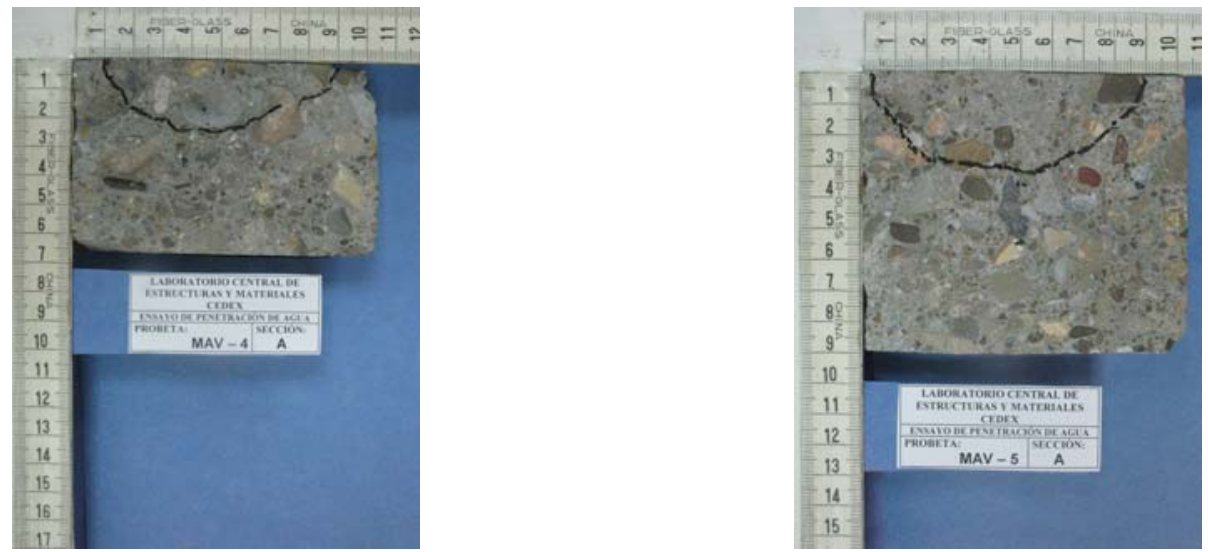

Fig.5.149. Ensayo de penetración de agua bajo presión. Testigos MAV-4 y MAV-5.

\subsubsection{Porosidad Abierta}

La determinación de la porosidad de los hormigones ensayados se realiza de acuerdo a la Recomendación RILEM CPC-11.3 "Absorption of water by inmersion under vacuum".

A partir de los datos de la profundidad de penetración máxima de agua y de la porosidad abierta del hormigón, se realiza una estimación del coeficiente de permeabilidad. Para ello, se sigue el modelo de Valenta ${ }^{84}$ para penetración uniaxial. Los resultados obtenidos se aportan en la tabla 5.13. 


\begin{tabular}{|c|c|c|c|}
\hline Muelle & Testigo & Porosidad (\%) & $K_{\text {est }}(\mathrm{m} / \mathrm{s})\left(\mathrm{x} 10^{-12}\right)$ \\
\hline \multirow{4}{*}{ A } & TPS-H1 & 20,10 & 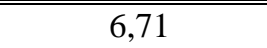 \\
\hline & TPS-H2 & 20,80 & 2,81 \\
\hline & TPS-H3 & 20,70 & 13,29 \\
\hline & TPS-H4 & 16,10 & $>20$ \\
\hline \multirow{8}{*}{ B } & "HU-H1 & 16,40 & "---- \\
\hline & HU-H2 & 15,70 & 1,83 \\
\hline & HU-H3 & 14,00 & $\begin{array}{ll}--- \\
\end{array}$ \\
\hline & HU-H4 & 13,60 & 1,59 \\
\hline & HU-H5 & 8,40 & $>16,22$ \\
\hline & HU-H6 & 9,40 & 3,58 \\
\hline & HU-H7 & 11,00 & 12,23 \\
\hline & HU-H8 & 10,40 & 3,16 \\
\hline \multirow{6}{*}{$\mathbf{C}$} & AV-T1 & 18,90 & 2,12 \\
\hline & AV-T2 & 17,80 & 1,49 \\
\hline & AV-T3 & 19,00 & 2,95 \\
\hline & AV-T4 & 17,70 & 2,23 \\
\hline & AV-T5 & 17,70 & 2,23 \\
\hline & AV-T6 & 18,30 & 2,23 \\
\hline \multirow{5}{*}{ D } & MAV-1 & 16,9 & 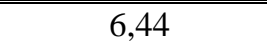 \\
\hline & MAV-2 & 13,6 & 1,84 \\
\hline & MAV-3 & 13,1 & 1,53 \\
\hline & MAV-4 & 13,0 & 1,29 \\
\hline & MAV-5 & 14,4 & 2,24 \\
\hline
\end{tabular}

Tabla 5.13. Resultados de los ensayos de determinación de la porosidad y estimación de la permeabilidad al agua.

\subsubsection{Absorción de Agua y Capilaridad}

La determinación de la absorción de agua de los hormigones ensayados se realiza de acuerdo a la Norma BS1881: Part 122 "Methods of testing concrete. Method for determination of water absorption". La determinación de la absorción capilar de los hormigones ensayados se realiza de acuerdo a la Recomendación RILEM CPC.11.2. "Absorption of water by capillarity". Los resultados obtenidos se indican en la tabla 5.14. 


\begin{tabular}{|c|c|c|c|c|c|}
\hline Muelle & Testigo & Absorción (\%) & $\begin{array}{c}\text { Capilaridad } \\
\left(\mathrm{g} / \mathrm{mm}^{2}\right)\left(\mathrm{x} 10^{-3}\right)\end{array}$ & $\begin{array}{l}\text { Capilaridad } \\
\left(\mathrm{mm} / \sqrt{ }_{\text {min }}\right)\end{array}$ & $\begin{array}{c}\text { Altura Ascensión } \\
\text { (mm) }\end{array}$ \\
\hline \multirow{4}{*}{ A } & TPS-H1 & 4,75 & 7,2 & 0,180 & 44,0 \\
\hline & TPS-H2 & 4,90 & 4,3 & 0,110 & 27,5 \\
\hline & TPS-H3 & 4,94 & 9,0 & 0,210 & 63,0 \\
\hline & TPS-H4 & 3,45 & 4,7 & 0,120 & 43,8 \\
\hline \multirow{7}{*}{ B } & HU-H1 & ---- & $\overline{3,2}$ & 0,090 & $>46$ \\
\hline & HU-H2 & --- & 2,2 & 0,060 & 21,7 \\
\hline & HU-H4 & 1,58 & 2,5 & 0,060 & 40,5 \\
\hline & HU-H5 & 2,21 & 3,0 & 0,080 & 28,9 \\
\hline & HU-H6 & ---- & 2,7 & 0,070 & 30,0 \\
\hline & HU-H7 & 2,81 & 5,7 & 0,120 & $>48$ \\
\hline & HU-H8 & 2,28 & 2,4 & 0,040 & 22,0 \\
\hline \multirow{6}{*}{ C } & AV-T1 & 2,77 & $\overline{3,1}$ & $\overline{0,070}$ & 32 \\
\hline & AV-T2 & 2,13 & 2,6 & 0,060 & 30 \\
\hline & AV-T3 & 3,29 & 3,7 & 0,090 & 34 \\
\hline & AV-T4 & 2,65 & 3,3 & 0,080 & 41 \\
\hline & AV-T5 & 2,11 & 1,7 & 0,040 & 20,5 \\
\hline & AV-T6 & 2,18 & 2,5 & 0,060 & 26 \\
\hline \multirow{5}{*}{ D } & MAV-1 & $\begin{array}{l}-- \\
\end{array}$ & 5,0 & 0,098 & --- \\
\hline & MAV-2 & 2,04 & 2,7 & 0,054 & --- \\
\hline & MAV-3 & --- & 3,1 & 0,064 & --- \\
\hline & MAV-4 & 2,09 & 2,5 & 0,053 & --- \\
\hline & MAV-5 & --- & --- & --- & --- \\
\hline
\end{tabular}

Tabla 5.14. Resultados de los ensayos de determinación de la absorción y de la capilaridad.

En las figuras 5.150 a 5.154 se observan los resultados del ensayo de capilaridad para las probetas ensayadas.
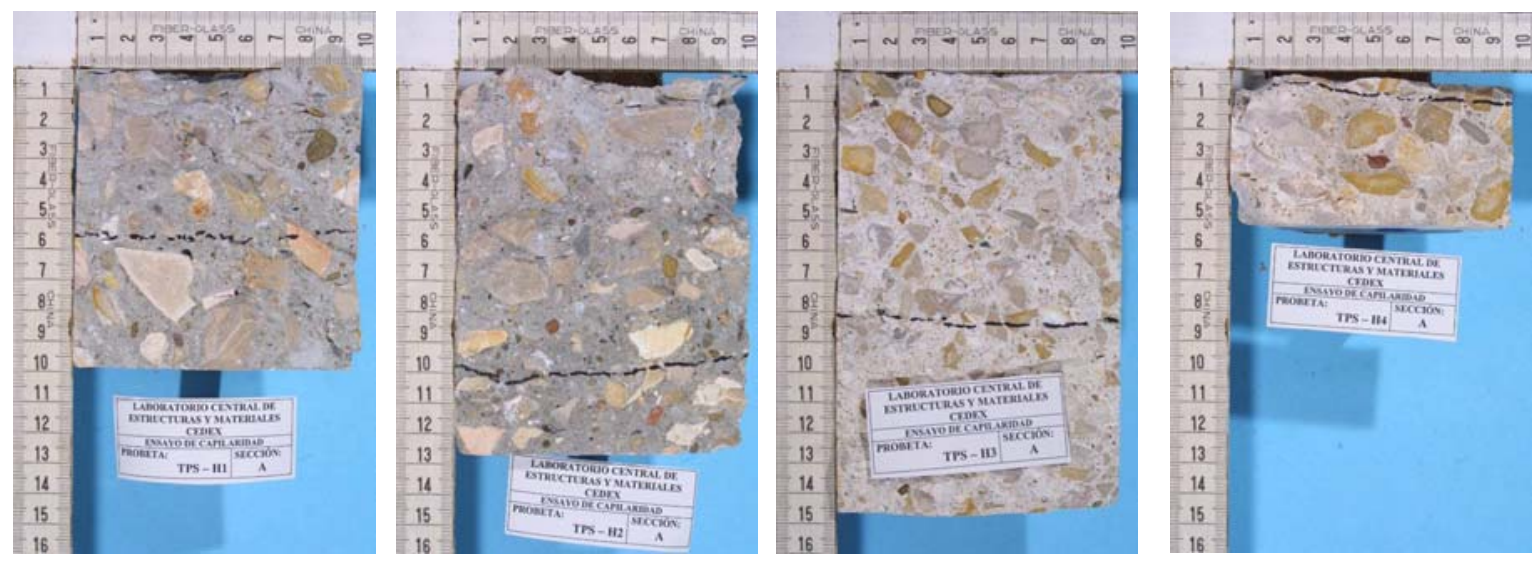

Fig.5.150. Ensayo de absorción de agua por capilaridad. Testigos TPS-H1, TPS-H2, TPS-H3 y TPS-H4. 

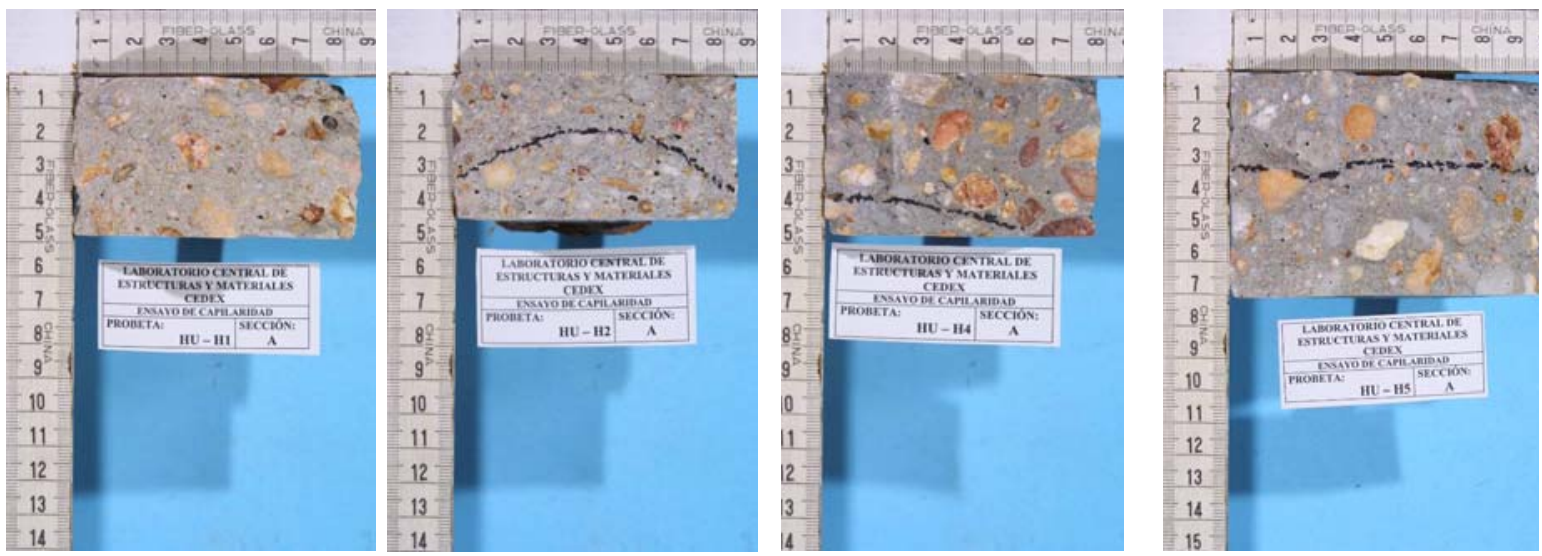

Fig.5.151. Ensayo de absorción de agua por capilaridad. Testigos HU-H1, HU-H2, HU-H4 y HU-H5.
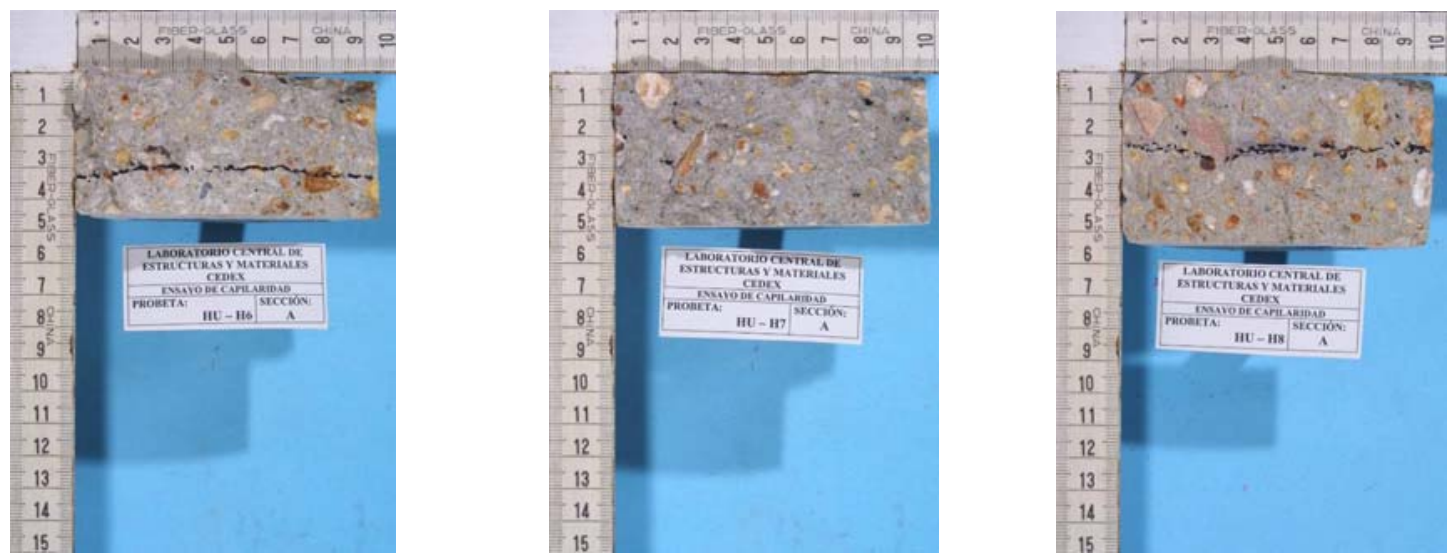

Fig.5.152. Ensayo de absorción de agua por capilaridad. Testigos HU-H6, HU-H7 y HU-H8.
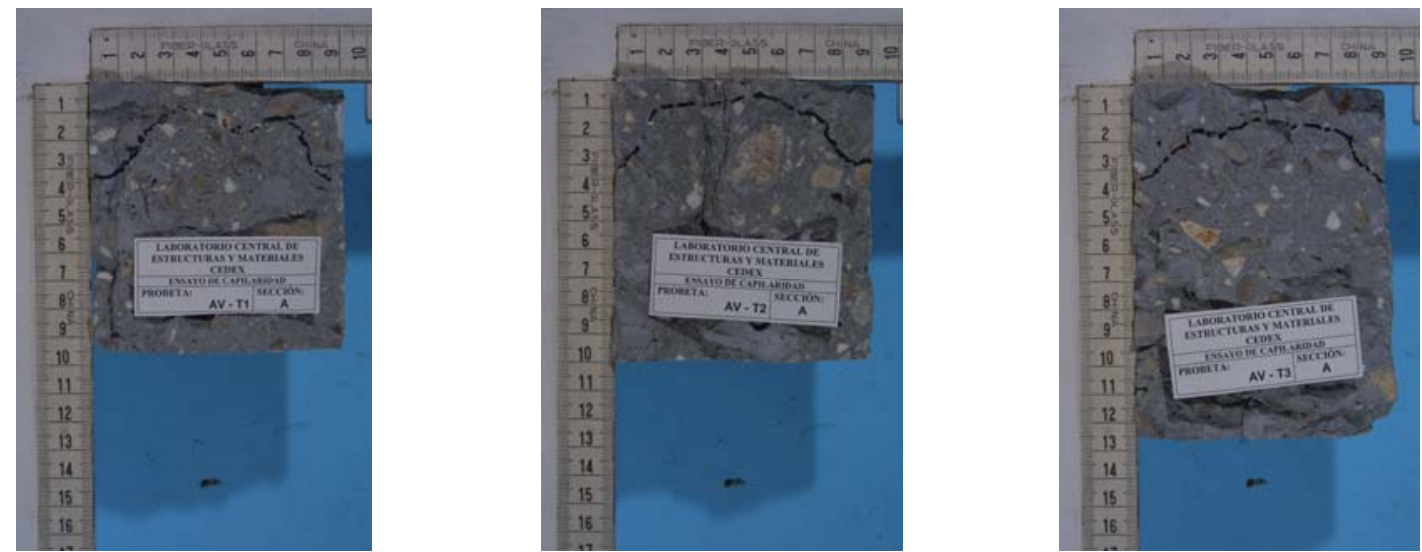

Fig.5.153. Ensayo de absorción de agua por capilaridad. Testigos AV-T1, AV-T2 y AV-T3. 

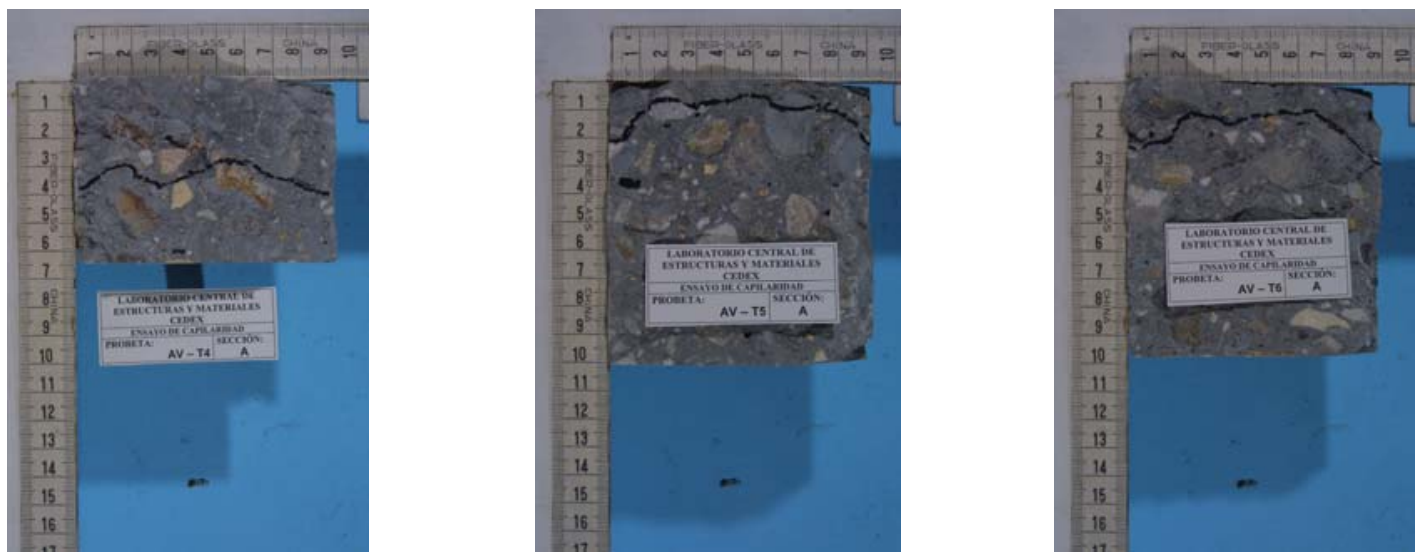

Fig.5.154. Ensayo de absorción de agua por capilaridad. Testigos AV-T4, AV-T5 y AV-T6.

\subsubsection{Permeabilidad al Oxígeno}

La determinación de la permeabilidad al oxígeno de los hormigones ensayados se realiza de acuerdo al método CEMBUREAU ${ }^{85}$. En la actualidad, existe la norma UNE 83981 (2008) "Durabilidad del hormigón. Métodos de ensayo. Determinación de la permeabilidad al oxígeno del hormigón endurecido", que describe el método anteriormente citado. En la figura 5.155 se muestran fotografías del dispositivo de ensayo. En el caso del muelle $D$ no se ha realizado este ensayo. Los resultados obtenidos se recogen en la tabla 5.15. 


\begin{tabular}{|c||c|c||}
\hline Muelle & Testigo & Permeabilidad $\left(\mathbf{m}^{\mathbf{2}} \mathbf{)}\left(\mathbf{x 1 0}^{\mathbf{1 6}}\right)\right.$ \\
\hline \hline \multirow{4}{*}{ A } & TPS-H1 & 0,85 \\
\cline { 2 - 3 } & TPS-H2 & 2,53 \\
\cline { 2 - 3 } & TPS-H3 & 0,64 \\
\cline { 2 - 3 } & TPS-H4 & 0,87 \\
\hline \hline \multirow{4}{*}{ B } & HU-H1 & 1,88 \\
\cline { 2 - 3 } & HU-H2 & 3,42 \\
\cline { 2 - 3 } & HU-H4 & 0,47 \\
\cline { 2 - 3 } & HU-H5 & 0,65 \\
\cline { 2 - 3 } & HU-H6 & 0,71 \\
\cline { 2 - 3 } & HU-H7 & 2,01 \\
\hline \hline \multirow{4}{*}{ C } & HU-H8 & 0,44 \\
\cline { 2 - 3 } & AV-T1 & 4,53 \\
\cline { 2 - 3 } & AV-T2 & 0,29 \\
\cline { 2 - 3 } & AV-T3 & 3,50 \\
\cline { 2 - 3 } & AV-T4 & 1,01 \\
\cline { 2 - 3 } & AV-T5 & 0,09 \\
\hline \hline
\end{tabular}

Tabla 5.15. Resultados de los ensayos de determinación de la permeabilidad al oxígeno.
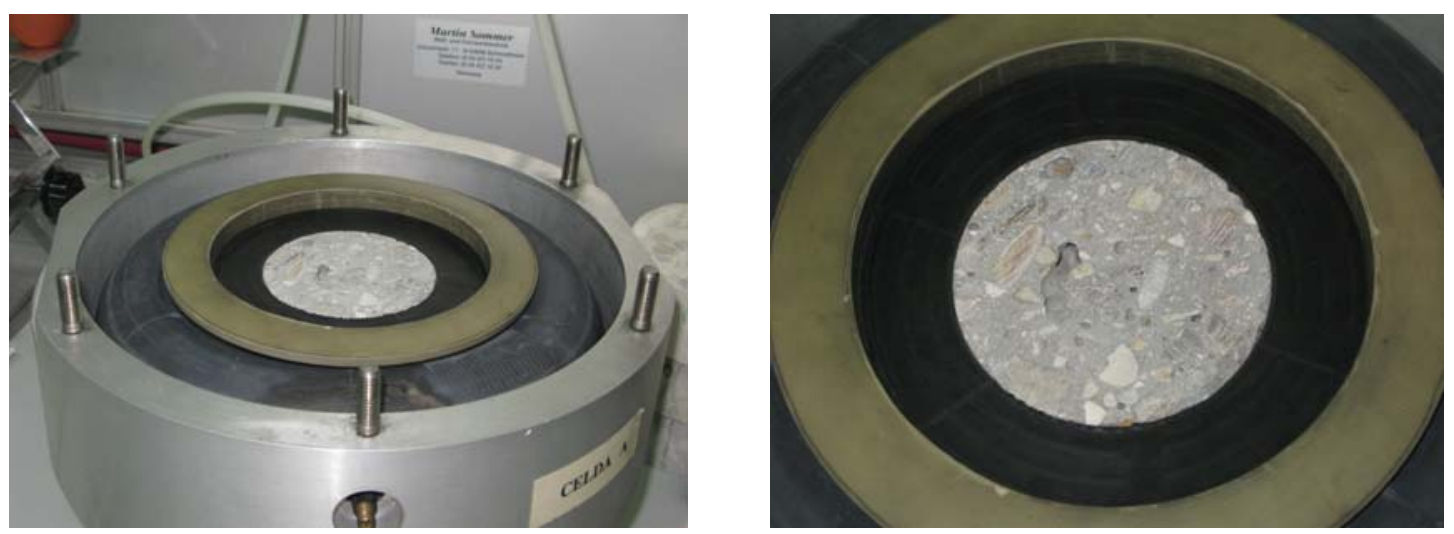

Fig.5.155. Dispositivo de ensayo de permeabilidad al oxígeno.

\subsubsection{Penetración de Cloruros (expresado en \% en peso de hormigón y de cemento)}

El análisis de la penetración de cloruros se ha realizado mediante la determinación del perfil de penetración, que se obtiene analizando químicamente el contenido de cloruros de muestras de hormigón tomadas a diferentes profundidades; en nuestro caso, se han cortado rodajas de espesores en el entorno de $1 \mathrm{~cm}$ de los testigos y 
se han analizado según la norma ASTM C1152 "Standard Test Method for AcidSoluble Chloride in Mortar and Concrete".

La Instrucción EHE-08 en su Anejo n 9 "Consideraciones adicionales sobre durabilidad", artículo 1.2.2.2 "Modelo de penetración de cloruros" dice que la concentración crítica de cloruros deberá ser establecida por el Autor del proyecto de acuerdo con las consideraciones específicas de la estructura. En condiciones normales, puede adoptarse un valor de $0,6 \%$ del peso de cemento para la comprobación del Estado Límite en relación con la corrosión de las armaduras pasivas. En el caso de las armaduras activas pretesas, puede adoptarse un valor límite de 0,3\% del peso de cemento.

Los testigos extraídos en los cuatro muelles tienen un diámetro aproximado de $10 \mathrm{~cm}$. En el caso del muelle A, los cuatro testigos se extrajeron en sentido vertical desde la superficie superior de los Duques de Alba. En el muelle $B$, se extrajeron cuatro testigos en sentido vertical desde la superficie superior de las losas y los cuatro restantes se extrajeron perpendicularmente a la cara frontal de los cabeceros. En el caso del muelle $\mathrm{C}$, en los seis casos se extrajeron perpendicularmente a los paramentos, dos de ellos de los cabeceros de vigas trasera e intermedia y los cuatro restantes de la viga cantil. En el caso del muelle D se extrajeron 5 testigos horizontalmente y perpendiculares a la cara frontal de la viga cantil.

Las tablas 5.16 a 5.19 indican los contenidos $\mathrm{Cl}$ (\% p. hormigón) en muestras analizadas:

\begin{tabular}{|c|c|c|c|c|c|c|c|}
\hline \multirow{2}{*}{ Muelle } & \multirow{2}{*}{ Testigo } & \multicolumn{6}{|c|}{ Contenido de Cloruros en \% en peso de hormigón } \\
\hline & & 0-12mm & 12-24mm & 24-36mm & 36-48mm & 48-60mm & 94-110mm \\
\hline \multirow{4}{*}{ A } & TPS-H1 & 0,1112 & 0,2779 & 0,3367 & 0,3481 & (0,2868 & ---- \\
\hline & TPS-H2 & 0,2411 & 0,4018 & 0,4345 & 0,4617 & 0,3851 & ---- \\
\hline & TPS-H3 & 0,0755 & 0,2798 & 0,2749 & 0,2290 & 0,1528 & 0,0623 \\
\hline & TPS-H4 & 0,1751 & 0,1188 & 0,0621 & 0,0290 & 0,0184 & ---- \\
\hline
\end{tabular}

Tabla 5.16. Cloruros totales expresados en \% en peso de hormigón. 


\begin{tabular}{|c|c|c|c|c|c|c|c|c|}
\hline Muelle & Testigo & & Con & enido de & loruro & $\%$ en peso & hormigón & \\
\hline \multirow{14}{*}{ B } & \multirow{2}{*}{ HU-H1 } & 0-10mm & \multicolumn{3}{|c|}{$10-30 \mathrm{~mm}$} & 30-45mm & 45-60mm & \\
\hline & & "0,004 & \multicolumn{3}{|c|}{0,022} & ב0,033 & 0,018 & \\
\hline & & \multicolumn{2}{|c|}{ 0-20mm } & \multicolumn{3}{|c|}{$20-40 \mathrm{~mm}$} & (40-60mm & \\
\hline & HU-H2 & \multicolumn{2}{|c|}{0,008} & \multicolumn{3}{|c|}{0,011} & 0,008 & \\
\hline & "HU-H3 & \multicolumn{2}{|c|}{0,135} & \multicolumn{3}{|c|}{0,153} & 0,132 & \\
\hline & \multirow{2}{*}{ HU-H4 } & & & \multicolumn{2}{|c|}{ 40-70mm } & 80-90mm & 90-100mm & $100-110 \mathrm{~mm}$ \\
\hline & & & & \multicolumn{2}{|c|}{$\begin{array}{l}0,005 \\
\end{array}$} & 0,002 & 0,004 & 0,002 \\
\hline & \multirow{2}{*}{ HU-H6 } & 0-15mm & $15-30 \mathrm{~mm}$ & \multicolumn{2}{|c|}{ 30-45mm } & "45-60mm & 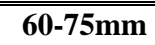 & 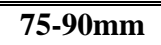 \\
\hline & & 0,127 & 0,167 & \multicolumn{2}{|c|}{0,141} & 0,095 & 0,054 & 0,048 \\
\hline & \multirow{2}{*}{ HU-H7 } & 0-15mm & \multicolumn{3}{|c|}{$15-38 \mathrm{~mm}$} & "38-60mm & (60-75mm & 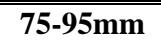 \\
\hline & & 0,441 & \multicolumn{3}{|c|}{0,228} & 0,188 & 0,131 & 0,105 \\
\hline & & 0-12mm & $12-24$ & $24-36$ & $36-48$ & 48-60mm & & \\
\hline & "HU-H5 & 0,479 & 0,186 & 0,132 & 0,132 & 0,091 & & \\
\hline & "HU-H8 & "0,328 & 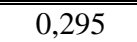 & "0,229 & 0,174 & 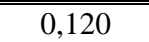 & & \\
\hline
\end{tabular}

Tabla 5.17. Cloruros totales expresados en \% en peso de hormigón

\begin{tabular}{|c|c|c|c|c|c|c|c|c|}
\hline Muelle & Testigo & Conte & o de Clor & s en $\%$ en & $\begin{array}{r}\text { so de horm } \\
\mathrm{mm})\end{array}$ & ón (el espes & de las rodajas & presa en \\
\hline \multirow{12}{*}{ C } & \multirow{2}{*}{ AV-T1 } & 0-10,9 & $14,4-24,2$ & $27,7-40,4$ & 43,9-56,5 & 60-73,1 & $78,1-88,3$ & \\
\hline & & 0,0265 & 0,0639 & 0,0333 & 0,006 & 0,0096 & 0,0051 & \\
\hline & \multirow{2}{*}{ AV-T2 } & $0-14,6$ & $18,1-31,3$ & $34,8-45,9$ & $4049,4-62,9$ & $\begin{array}{l}66,4-79,2 \\
\end{array}$ & $84,2-97,7$ & \\
\hline & & 0,0833 & 0,0586 & 0,0172 & 0,0054 & 0,0087 & 0,0106 & \\
\hline & \multirow{2}{*}{ AV-T3 } & (2-7,0 & $10,5-23,0$ & $26,5-49,1$ & $50,0-66,8$ & $70,3-78,3$ & $83,3-95,2$ & (300-310(F) \\
\hline & & 0,3072 & 0,4185 & 0,1331 & 0,0090 & 0,0117 & 0,0083 & 0,00275 \\
\hline & \multirow{2}{*}{ AV-T4 } & $0-15,2$ & $18,7-34,6$ & $38,1-53,0$ & $56,5-70,7$ & $74,2-83,4$ & $88,4-103,8$ & $108,8 / 120,8$ \\
\hline & & 0,3293 & 0,0636 & 0,0329 & 0,0042 & 0,0145 & 0,0058 & 0,0032 \\
\hline & \multirow[t]{2}{*}{ AV-T5 } & $0-28,4$ & $39,1-47,1$ & $50,6-67,9$ & $71,4-86,5$ & $\begin{array}{l}90,0- \\
106,8\end{array}$ & $380 / 401,4(F)$ & \\
\hline & & 0,2478 & 0,0073 & 0,0048 & 0,0048 & 0,0024 & 0,0032 & \\
\hline & \multirow[t]{2}{*}{ AV-T6 } & $0-18,2$ & $21,7-36,9$ & $40,4-59,8$ & 63,3-82,7 & $\begin{array}{l}86,2- \\
102,3\end{array}$ & 105,8-131,1 & \\
\hline & & 0,3583 & 0,1429 & 0,0323 & 0,0043 & 0,0081 & 0,0051 & \\
\hline
\end{tabular}

Tabla 5.18. Cloruros totales expresados en \% en peso de hormigón. 


\begin{tabular}{|c|c|c|c|c|c|c|c|c|c|c|}
\hline Muelle & Testigo & Conte & ido de Clo & uros en $\%$ & en peso de & hormigón & el espesor & e & Se & en mm). \\
\hline \multirow{10}{*}{ D } & \multirow{2}{*}{ MAV-1 } & $0-6,0$ & $\overline{~ 9,6-15,6}$ & 21,7-27,7 & 35,0-41,0 & 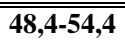 & 64,0-70,0 & & & \\
\hline & & 0,0200 & 0,0564 & 0,0920 & 0,0634 & 0,0296 & 0,0182 & & & \\
\hline & \multirow{2}{*}{ MAV-2 } & $0-6,8$ & $11,2-17,2$ & $23,8-29,8$ & $35,5-41,5$ & $446,6-52,6$ & 61,1-67,1 & & & \\
\hline & & 0,0253 & 0,0563 & 0,0379 & 0,0171 & 0,0142 & 0,0131 & & & \\
\hline & \multirow{2}{*}{ MAV-3 } & 0 & $8,8,2-14,2$ & $1818,3-24,3$ & $29,3-35,3$ & $399,7-45,7$ & 51,6-57,6 & & & \\
\hline & & 0,0493 & 0,0706 & 0,0695 & 0,0475 & 0,0247 & 0,0192 & & & \\
\hline & \multirow{2}{*}{ MAV-4 } & 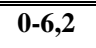 & "9,1-15,1 & $\overline{119,0-25,0}$ & 29,5-35,5 & 42,8-48,8 & 57,2-63,2 & $68,7-74,7$ & & \\
\hline & & 0,0342 & 0,0396 & 0,0493 & 0,0290 & 0,0201 & 0,0102 & 0,0083 & & \\
\hline & \multirow{2}{*}{ MAV-5 } & $0-6,4$ & 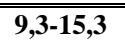 & 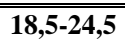 & $\begin{array}{l}27,8-33,8 \\
\end{array}$ & 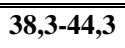 & 40 & $\begin{array}{l}57,9-63,9 \\
\end{array}$ & $69,0-75,0$ & $81,8-87,8$ \\
\hline & & 0,0397 & 0,0463 & 0,0491 & 0,0335 & 0,0197 & 0,0158 & 0,0101 & 0,0088 & 0,0102 \\
\hline
\end{tabular}

Tabla 5.19 Cloruros totales expresados en \% en peso de hormigón.

Se ha considerado que el hormigón tiene un contenido de cemento de $300 \mathrm{~kg} / \mathrm{m}^{3}$ en el muelle A (por encima de la limitación de la normativa vigente en la época HA61 que decía que la dosificación mínima de cemento debía ser $250 \mathrm{~kg}$ por $\mathrm{m}^{3}$ de hormigón), de $300 \mathrm{~kg} / \mathrm{m}^{3}$ en el muelle $B$ (dato de proyecto), de $350 \mathrm{~kg} / \mathrm{m}^{3}$ en el muelle $\mathrm{C}$ (dato de proyecto) y de $300 \mathrm{~kg} / \mathrm{m}^{3}$ en el caso del muelle $\mathrm{D}$ (dato según la limitación de la normativa vigente en la época EHE 98). En la práctica, este dato es relevante únicamente al determinar el umbral de cloruros para el inicio de la corrosión.

También se muestran las densidades medias de los testigos extraídos. En las tablas 5.20 a 5.23 se indican los contenidos de cloruros totales expresados en porcentaje en peso de cemento.

\begin{tabular}{|c|c|c|c|c|c|c|c|c|}
\hline \multirow{2}{*}{ Muelle } & \multirow{2}{*}{ Testigo } & \multirow{2}{*}{$\begin{array}{c}\text { Densidad } \\
\left(\mathrm{kg} / \mathrm{m}^{3}\right)\end{array}$} & \multicolumn{6}{|c|}{ Contenido de Cloruros en \% en peso de cemento } \\
\hline & & & 0-12mm & 12-24mm & 24-36mm & 36-48mm & 48-60mm & 94-110mm \\
\hline \multirow{4}{*}{ A } & TPS-H1 & 2.196 & 0,81 & 2,03 & 2,46 & 2,55 & 2,10 & ---- \\
\hline & TPS-H2 & 2.148 & 1,73 & 2,88 & 3,11 & 3,31 & 2,76 & ---- \\
\hline & TPS-H3 & 2.291 & 0,58 & 2,14 & 2,10 & 1,75 & 1,17 & 0,48 \\
\hline & TPS-H4 & 2.360 & 1,38 & 0,93 & 0,49 & 0,23 & 0,15 & ---- \\
\hline
\end{tabular}

Tabla 5.20. Cloruros totales expresados en \% en peso de cemento. 


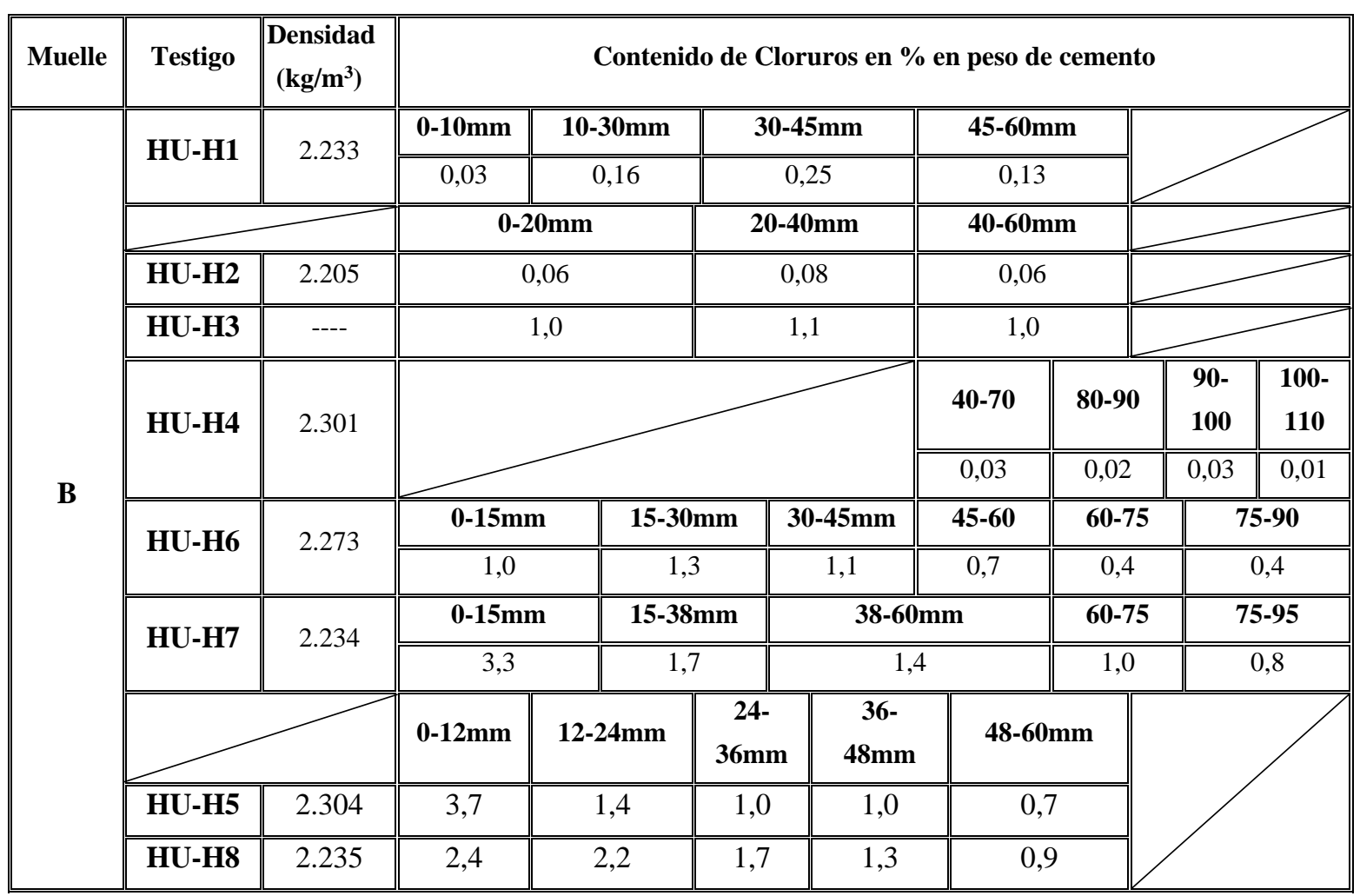

Tabla 5.21. Cloruros totales expresados en \% en peso de cemento.

\begin{tabular}{|c|c|c|c|c|c|c|c|c|c|}
\hline Muelle & Testigo & $\begin{array}{c}\text { Densidad } \\
\left(\mathrm{kg} / \mathrm{m}^{3}\right)\end{array}$ & Conte & o de Cl en & en peso de & $\begin{array}{l}\text { emento (el } \\
\mathrm{mm}) \text {. }\end{array}$ & pesor de las & odajas se ex & esa en \\
\hline \multirow{12}{*}{ C } & \multirow{2}{*}{ AV-T1 } & \multirow{2}{*}{2.243} & "0-10,9 & $14,4-24,2$ & $27,7-40,4$ & 4 & $\bar{~} 60,0-73,1$ & $778,1-88,3$ & \\
\hline & & & 0,1698 & 0,4095 & "0,2134 & 0,0385 & "0,0615 & $\bar{~} 0,0327$ & \\
\hline & \multirow{2}{*}{ AV-T2 } & \multirow{2}{*}{2.292} & "0-14,6 & $18,1-31,3$ & $34,8-45,9$ & $49,4-62,9$ & 6 66,4-79,2 & $84,2-97,7$ & \\
\hline & & & 0,5455 & 0,3837 & 0,1126 & 0,0354 & 0,0570 & 0,0694 & \\
\hline & \multirow[t]{2}{*}{ AV-T3 } & \multirow[t]{2}{*}{2.251} & $0-7,0$ & $10,5-23,0$ & $26,5-49,1$ & $50,0-66,8$ & $70,3-78,3$ & $83,3-95,2$ & $\begin{array}{c}300- \\
310(F)\end{array}$ \\
\hline & & & 1,9757 & 2,6916 & 0,8560 & 0,0579 & 0,0752 & 0,0534 & 0,0177 \\
\hline & \multirow[t]{2}{*}{ AV-T4 } & \multirow[t]{2}{*}{2.268} & $0-15,2$ & $18,7-34,6$ & $38,1-53,0$ & $56,5-70,7$ & $74,2-83,4$ & $\begin{array}{l}88,4- \\
103,8\end{array}$ & $\begin{array}{c}108,8- \\
120,8\end{array}$ \\
\hline & & & 2,1339 & 0,4121 & 0,2132 & "0,0272 & "0,0940 & 0,0376 & "0,0207 \\
\hline & \multirow[t]{2}{*}{ AV-T5 } & \multirow[t]{2}{*}{2.294} & $0-28,4$ & $39,1-47,1$ & $50,6-67,9$ & $71,4-86,5$ & $\begin{array}{l}90,0- \\
106,8\end{array}$ & $\begin{array}{c}380,0 / 401, \\
4(F)\end{array}$ & \\
\hline & & & $\overline{1,6242}$ & 0,0478 & 0,0315 & 0,0315 & 0,0157 & 0,0210 & \\
\hline & \multirow[t]{2}{*}{ AV-T6 } & \multirow[t]{2}{*}{2.298} & $0-18,2$ & $21,7-36,9$ & $40,4-59,8$ & $63,3-82,7$ & $\begin{array}{l}86,2- \\
102,3\end{array}$ & $\begin{array}{l}105,8- \\
131,1\end{array}$ & \\
\hline & & & 2,3525 & 0,9382 & 0,2121 & 0,0282 & 0,0532 & 0,0335 & \\
\hline
\end{tabular}

Tabla 5.22. Cloruros totales expresados en \% en peso de cemento. 


\begin{tabular}{|c|c|c|c|c|c|c|c|c|c|c|c|}
\hline Muelle & Testigo & $\begin{array}{c}\text { Densidad } \\
\left(\mathrm{kg} / \mathrm{m}^{3}\right)\end{array}$ & " Conte & do de $\mathrm{C}$ & en \% en & peso de & $\begin{array}{c}\text { mento } \\
\text { mm). }\end{array}$ & espeso & $\overline{\text { le las ro }}$ & se ex & sa en \\
\hline \multirow{10}{*}{ D } & \multirow{2}{*}{ MAV-1 } & \multirow{2}{*}{2.249} & 0,30 & 1,26 & 2,47 & 3,80 & 5,14 & 6,70 & & & \\
\hline & & & 0,1499 & 0,4228 & 0,6897 & 0,4753 & 0,2219 & 0,1364 & & & \\
\hline & \multirow{2}{*}{ MAV-2 } & \multirow{2}{*}{2.356} & $\overline{0,34}$ & $\overline{11,42}$ & 2,68 & 3,85 & $\begin{array}{l}4,96 \\
\end{array}$ & 6,41 & & & \\
\hline & & & 0,1987 & 0,4421 & 0,2976 & 0,1343 & 0,1115 & 0,1029 & & & \\
\hline & \multirow{2}{*}{ MAV-3 } & \multirow{2}{*}{2.393} & 0,30 & 1,12 & 2,13 & 3,23 & $\begin{array}{l}4,27 \\
\end{array}$ & 25,46 & & & \\
\hline & & & 0,3932 & 0,5632 & 0,5544 & 0,3789 & 0,1970 & 0,1532 & & & \\
\hline & \multirow{2}{*}{ MAV-4 } & \multirow{2}{*}{2.366} & (0,31 & $\overline{1,21}$ & 2,20 & 3,25 & 4,58 & $\begin{array}{l}6,02 \\
\end{array}$ & $\overline{7,17}$ & & \\
\hline & & & 0,2697 & 0,3123 & 0,3888 & 0,2287 & 0,1585 & 0,0804 & 0,0655 & & \\
\hline & \multirow{2}{*}{ MAV-5 } & \multirow{2}{*}{2.389} & 0,32 & $1,1,23$ & 2,15 & ב,08 & 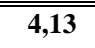 & 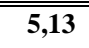 & $6,6,09$ & $\overline{77,20}$ & $8, \overline{8,48}$ \\
\hline & & & 0,3161 & 0,3687 & 0,3910 & 0,2668 & 0,1569 & 0,1258 & 0,0804 & 0,0701 & 0,0812 \\
\hline
\end{tabular}

Tabla 5.23. Cloruros totales expresados en \% en peso de cemento.

\subsubsection{Profundidad de Carbonatación}

Se puede obtener una indicación aproximada de esta profundidad mediante soluciones indicadoras. Se ha empleado la norma UNE-EN 13295 "Productos y sistemas para la protección y reparación de estructuras de hormigón. Métodos de ensayo. Determinación de la resistencia a la carbonatación" para la determinación de la profundidad de carbonatación en lo que se refiere a la forma de lectura.

El ensayo se ha realizado sobre los testigos indicados en la tabla 5.24, algunos de los cuales se muestran en las figuras 5.156 y 5.157, resultando en todos los casos una profundidad de carbonatación muy reducida en comparación con el recubrimiento que tienen las armaduras. Este resultado indica que, en el tipo de ambiente que ocupa nuestro estudio, la carbonatación del hormigón avanza a una velocidad mucho menor que la penetración de cloruros, por lo que en ambiente marino aéreo resulta más agresiva la acción de los cloruros.

\begin{tabular}{|c||c||c|c||c|c||}
\hline \multirow{2}{*}{ Muelle } & Testigo & $\begin{array}{c}\text { Profundidad } \\
\text { Carbonatación } \\
\mathbf{( m m )}\end{array}$ & $\begin{array}{c}\text { Edad } \\
\mathbf{( a n ̃ o s})\end{array}$ & $\begin{array}{c}\text { Rango } \\
\text { Recubrimiento } \\
\mathbf{( m m})\end{array}$ & $\begin{array}{c}\text { Velocidad } \\
\text { Carbonatación } \\
\mathbf{( m m} / \sqrt{\text { año) }}\end{array}$ \\
\hline \hline \multirow{3}{*}{ A } & TPS-H1 & 6,5 & 37 & $<20$ & 1,03 \\
\cline { 2 - 6 } & TPS-H2 & 9,0 & 37 & $<20$ & 1,42 \\
\cline { 2 - 6 } & TPS-H3 & 10,0 & 37 & $<20$ & 1,58 \\
\cline { 2 - 6 } & TPS-H4 & 5,0 & 37 & $<20$ & 0,79 \\
\hline \hline B & HU-H8 & 5,0 & 26 & $60-65$ & 0,91 \\
\hline \hline C & AV-T5 & ---- & 11 & $7-32 / 32-60$ & --- \\
\hline
\end{tabular}

Tabla 5.24. Profundidades de carbonatación obtenidas en algunos testigos de los muelles. 

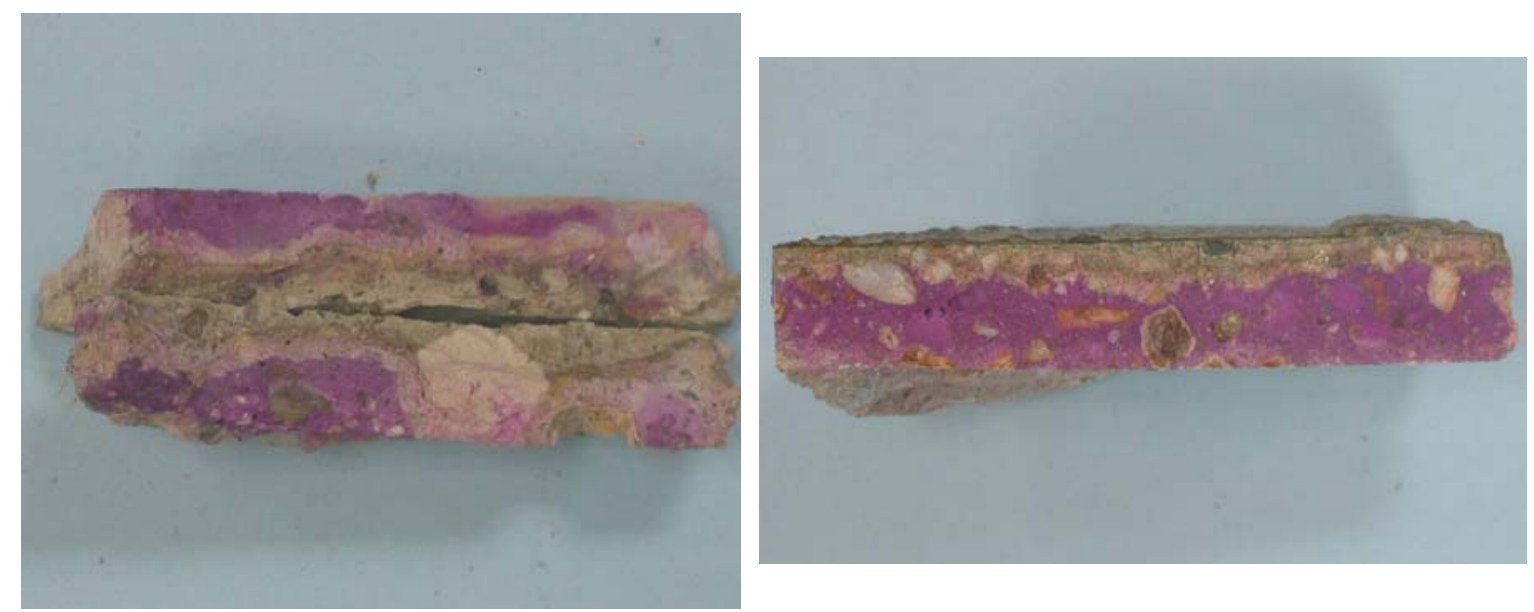

Fig.5.156. Profundidad de carbonatación en testigo TPS-H1(izquierda) y HU-H8 (derecha).

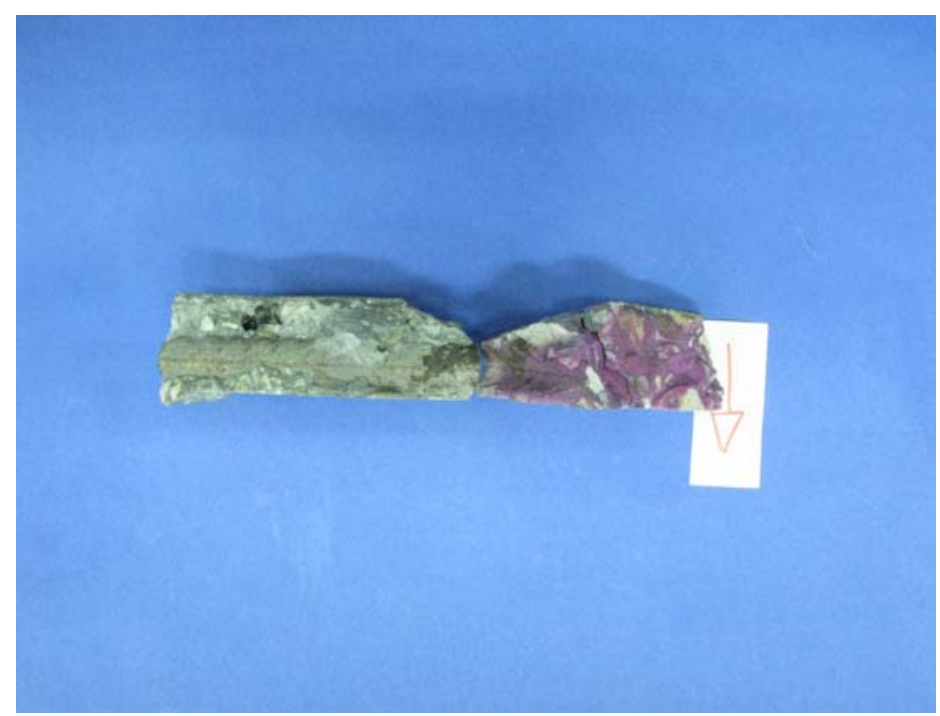

Fig.5.157. Profundidad de carbonatación en testigo AV-T5.

\subsection{VALORACIÓN DE LOS RESULTADOS: CALIDAD DE LOS HORMIGONES UTILIZADOS}

A partir de los resultados obtenidos en los diferentes ensayos de caracterización de las propiedades mecánicas y físicas del hormigón, es posible definir la calidad de los hormigones estudiados mediante las distintas tablas de clasificación cualitativa de las propiedades del hormigón extraídas de la Bibliografía existente del hormigón, como se muestra a continuación. 


\subsubsection{Ensayos Mecánicos}

En este apartado se van a analizar los resultados obtenidos en los ensayos de caracterización de las propiedades mecánicas de los hormigones de los testigos extraídos en los Muelles, cuyos valores se encuentran recogidos en las tablas 5.25 y 5.27 .

Valores típicos de la velocidad de propagación lineal de ultrasonidos en función del estado del hormigón son ${ }^{17}$ :

- Mayor que 4,5 km/s: hormigón excelente.

- 3,6-4,5 km/s: hormigón bueno.

- 3,0-3,6 km/s: hormigón aceptable.

- 2,1-3,0 km/s: hormigón malo.

- Menos de 2,1 km/s: hormigón muy malo

En la tabla 5.25 se muestran los resultados de resistencia obtenidos en los testigos extraídos de los muelles estudiados. En la misma tabla se presentan los valores estadísticos de la población necesarios para analizar si se trata de un hormigón con distintivo de calidad. En la tabla 5.26 se extracta parte del contenido de la tabla de la Instrucción EHE-08 que establece los valores de la desviación típica y el coeficiente de variación para determinadas resistencias del hormigón. 


\begin{tabular}{|c|c|c|c|c|c|}
\hline Muelle & Testigo & $\begin{array}{c}\text { Resistencia } \\
\text { Compresión } \\
\left(\mathrm{N} / \mathbf{m m}^{2}\right)\end{array}$ & $\begin{array}{c}\text { Valor } \\
\text { Medio(N/mm²) }\end{array}$ & $\begin{array}{c}\text { Desviación } \\
\text { Típica } \sigma \\
\left(\mathbf{N} / \mathbf{m m}^{2}\right)\end{array}$ & $\begin{array}{c}\text { Coeficiente } \\
\text { Variación } \\
\delta\end{array}$ \\
\hline \multirow{4}{*}{ A } & TPS-H1 & 40,9 & \multirow{4}{*}{38,90} & \multirow{4}{*}{6,53} & \multirow{4}{*}{0,17} \\
\hline & TPS-H2 & 29,7 & & & \\
\hline & TPS-H3 & 45,1 & & & \\
\hline & TPS-H4 & 39,9 & & & \\
\hline \multirow{7}{*}{ B } & "HU-H1 & $\overline{50,2}$ & \multirow{7}{*}{48,6} & \multirow{7}{*}{4,79} & \multirow{7}{*}{0,10} \\
\hline & HU-H2 & 48,0 & & & \\
\hline & HU-H4 & 55,5 & & & \\
\hline & HU-H5 & 47,8 & & & \\
\hline & HU-H6 & 44,3 & & & \\
\hline & HU-H7 & 40,4 & & & \\
\hline & HU-H8 & 50,2 & & & \\
\hline \multirow{6}{*}{ C } & AV-T1 & $\begin{array}{l}46,0 \\
\end{array}$ & \multirow{6}{*}{47,93} & \multirow{6}{*}{4,13} & \multirow{6}{*}{0,09} \\
\hline & AV-T2 & 50,4 & & & \\
\hline & AV-T3 & 42,1 & & & \\
\hline & AV-T4 & 47,8 & & & \\
\hline & AV-T5 & 54,3 & & & \\
\hline & AV-T6 & 47,0 & & & \\
\hline \multirow{5}{*}{ D } & MAV-1 & 26,5 & \multirow{5}{*}{27,25} & \multirow{5}{*}{6,69} & \multirow{5}{*}{0,25} \\
\hline & MAV-2 & 30,8 & & & \\
\hline & MAV-3 & 18,2 & & & \\
\hline & MAV-4 & 33,5 & & & \\
\hline & MAV-5 & --- & & & \\
\hline
\end{tabular}

Tabla 5.25. Valores de la resistencia de los testigos y análisis estadístico para estimar la calidad del hormigón.

Según el artículo 5.1 del Anejo 19 de la Instrucción EHE-08 referente a distintivos de calidad del hormigón, la tabla 8.2 muestra los valores de desviación típica y coeficiente de variación de una población para aceptar que un hormigón con resistencia característica determinada presenta distintivo de calidad.

\begin{tabular}{|c|c|c|}
\hline $\begin{array}{c}\text { Resistencia especificada para el } \\
\text { hormigón, } \mathbf{f}_{\mathrm{ck}}\left(\mathrm{N} / \mathrm{mm}^{2}\right)\end{array}$ & $\begin{array}{l}\text { Desviación típica de la } \\
\text { población, } \sigma\left(\mathrm{N} / \mathrm{mm}^{2}\right)\end{array}$ & $\begin{array}{c}\text { Coeficiente Variación, } \\
\delta\end{array}$ \\
\hline 25 & 3,6 & $0,0,11$ \\
\hline 30 & 4,2 & 0,11 \\
\hline
\end{tabular}

Tabla 5.26. Extracto de tabla de EHE-08 referente al criterio para otorgar distintivo de calidad a un hormigón. 
De acuerdo con lo expuesto, de los cuatro muelles analizados, el hormigón correspondiente al muelle $\mathrm{C}$, cuya resistencia especificada en proyecto es de 25 $\mathrm{N} / \mathrm{mm}^{2}$, tendría distintivo de calidad según los resultados obtenidos.

En la tabla 5.27 se presentan los resultados de resistencia y velocidad de ultrasonidos obtenidos así como la calidad del hormigón en función del criterio de clasificación del hormigón según la velocidad de ultrasonidos:

\begin{tabular}{|c|c|c|c|c|}
\hline Muelle & Testigo & $\begin{array}{c}\text { Resistencia } \\
\text { Compresión } \\
\left(\mathrm{N} / \mathbf{m m}^{2}\right)\end{array}$ & $\begin{array}{l}\text { V. Ultrasonidos } \\
(\mathbf{m} / \mathbf{s})\end{array}$ & $\begin{array}{l}\text { Calidad } \\
\text { Hormigón }\end{array}$ \\
\hline \multirow{4}{*}{ A } & TPS-H1 & 40,9 & 4.563 & Excelente \\
\hline & TPS-H2 & 29,7 & 3.947 & Buena \\
\hline & TPS-H3 & 45,1 & 4.554 & Excelente \\
\hline & TPS-H4 & 39,9 & 4.589 & Excelente \\
\hline \multirow{7}{*}{ B } & HU-H1 & 50,2 & 4.382 & Buena \\
\hline & HU-H2 & 48,0 & 4.439 & Buena \\
\hline & HU-H4 & 55,5 & 4.336 & Buena \\
\hline & HU-H5 & 47,8 & 4.567 & Excelente \\
\hline & HU-H6 & 44,3 & 4.418 & Buena \\
\hline & HU-H7 & 40,4 & 4.230 & Buena \\
\hline & HU-H8 & 50,2 & 4.277 & Buena \\
\hline \multirow{6}{*}{ C } & AV-T1 & 46,0 & 4.377 & Buena \\
\hline & AV-T2 & 50,4 & 4.479 & Buena \\
\hline & AV-T3 & 42,1 & 4.329 & Buena \\
\hline & AV-T4 & 47,8 & 4.415 & Buena \\
\hline & AV-T5 & 54,3 & 4.475 & Buena \\
\hline & AV-T6 & 47,0 & 4.545 & Excelente \\
\hline \multirow{5}{*}{ D } & MAV-1 & 26,5 & 4.370 & Buena \\
\hline & MAV-2 & 30,8 & 4.720 & Excelente \\
\hline & MAV-3 & 18,2 & 4.780 & Excelente \\
\hline & MAV-4 & 33,5 & 4.560 & Excelente \\
\hline & MAV-5 & --- & --- & --- \\
\hline
\end{tabular}

Tabla 5.27. Calidad del hormigón según los resultados de resistencia y velocidad de ultrasonidos obtenidos

En la figura 5.158 se muestra un gráfico de barras donde se observa el criterio de clasificación de la calidad del hormigón en función de los resultados de velocidad de ultrasonidos obtenidos en los testigos de los muelles estudiados: 


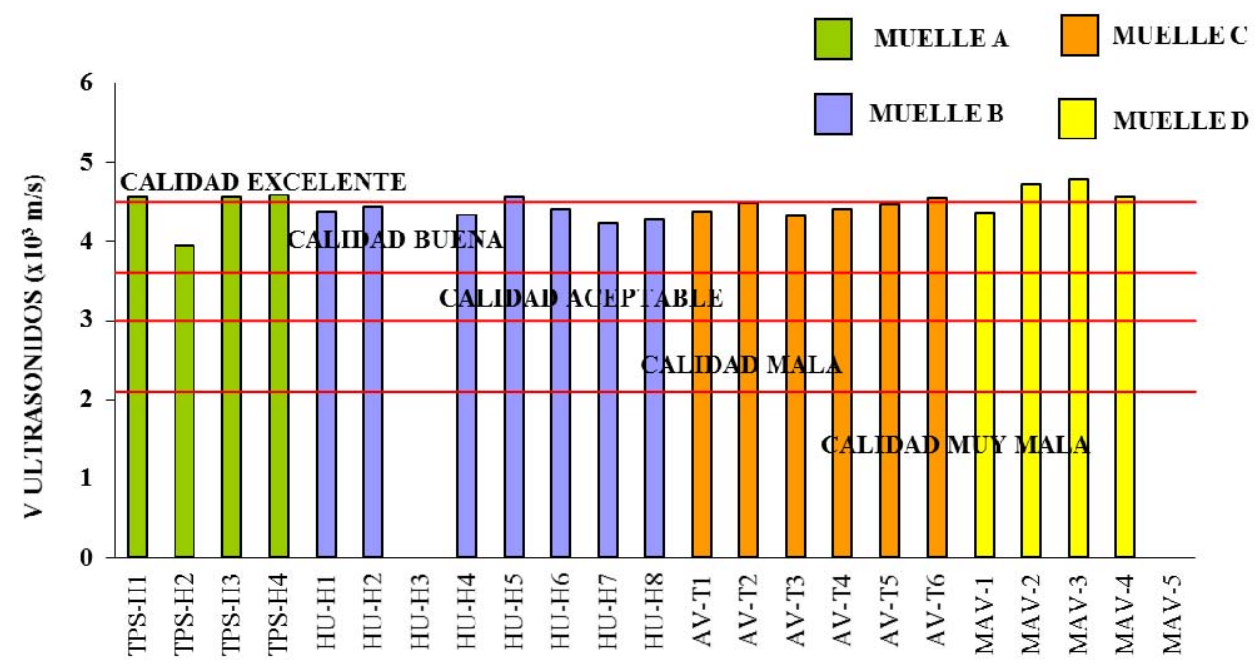

Fig. 5.158.Calidad del hormigón de los testigos según los resultados de la velocidad de ultrasonidos

La figura anterior muestra que la velocidad de ultrasonidos presenta valores similares en los tres muelles analizados y que la calidad del hormigón según el criterio de clasificación de la velocidad de propagación de ultrasonidos resulta buena, rozando incluso en algunos casos la categoría de excelente.

\subsubsection{Penetración de Agua, Porosidad y Permeabilidad}

En este apartado se analizan los resultados obtenidos en los ensayos de caracterización de las propiedades físicas de los hormigones de los testigos extraídos en los Muelles, cuyos valores se encuentran recogidos en las tablas 5.28 y 5.31.

La Instrucción EHE-08, en su artículo 37.3.3. (Impermeabilidad del Hormigón), establece que un hormigón situado en ambiente IIla se considera suficientemente impermeable al agua si los resultados del ensayo de penetración de agua cumplen simultáneamente que:

- La profundidad máxima de penetración de agua es menor o igual que 50 mm.

- La profundidad media de penetración de agua es menor o igual que $30 \mathrm{~mm}$.

En la tabla 5.28 se muestran los valores de penetración media y máxima obtenidos en los testigos de los Muelles estudiados así como si cumplen el criterio de penetración de agua exigido por la Instrucción española EHE-08: 


\begin{tabular}{|c|c|c|c|c|c|}
\hline Muelle & Testigo & $\begin{array}{l}\text { Prof. Máxima } \\
\text { (mm) }\end{array}$ & $\begin{array}{l}\text { Criterio } \\
\text { EHE }\end{array}$ & $\begin{array}{l}\text { Prof. Media } \\
\text { (mm) }\end{array}$ & $\begin{array}{c}\text { Criterio } \\
\text { EHE }\end{array}$ \\
\hline \multirow{3}{*}{ A } & TPS-H1 & 44,0 & Cumple & 38,0 & "No cumple \\
\hline & TPS-H2 & 28,0 & Cumple & 22,0 & Cumple \\
\hline & TPS-H3 & 61,0 & No cumple & 54,5 & No cumple \\
\hline \multirow{6}{*}{ B } & HU-H2 & 26,0 & Cumple & 16,5 & Cumple \\
\hline & HU-H4 & 26,0 & Cumple & 13,0 & Cumple \\
\hline & HU-H5 & $>106$ & No cumple & $>106$ & No cumple \\
\hline & HU-H6 & 47,0 & Cumple & 35,5 & No cumple \\
\hline & HU-H7 & 80,5 & No cumple & 67,5 & No cumple \\
\hline & HU-H8 & 42,0 & Cumple & 32,5 & No cumple \\
\hline \multirow{6}{*}{ C } & $\overline{~ A V-T 1 ~}$ & 25,5 & Cumple & $\overline{17,6}$ & Cumple \\
\hline & AV-T2 & 22,0 & Cumple & 10,9 & Cumple \\
\hline & AV-T3 & 30,0 & Cumple & 20,7 & Cumple \\
\hline & AV-T4 & 27,0 & Cumple & 17,6 & Cumple \\
\hline & AV-T5 & 15,5 & Cumple & 5,8 & Cumple \\
\hline & AV-T6 & 18,0 & Cumple & 11,9 & Cumple \\
\hline \multirow{5}{*}{ D } & MAV-1 & 47,0 & Cumple & 26,6 & Cumple \\
\hline & MAV-2 & 28,0 & Cumple & 14,8 & Cumple \\
\hline & MAV-3 & 26,0 & Cumple & 12,6 & Cumple \\
\hline & MAV-4 & 24,0 & Cumple & 12,9 & Cumple \\
\hline & MAV-5 & 30,0 & Cumple & 18,5 & Cumple \\
\hline
\end{tabular}

Tabla 5.28. Valores de penetración de agua y comprobación de su adecuación a la Instrucción EHE-08.

En las figuras 5.159 y 5.160 se muestran sendos gráficos de barras donde se observan los resultados anteriores:

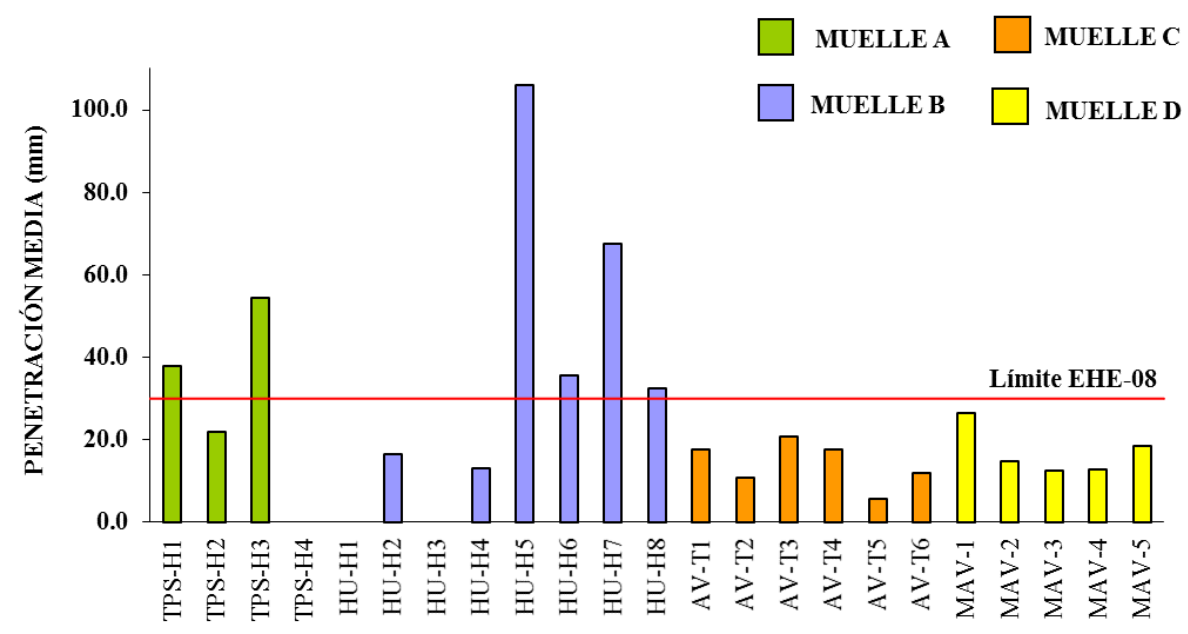

Fig. 5.159. Valores de penetración media obtenidos en los testigos de los muelles. 


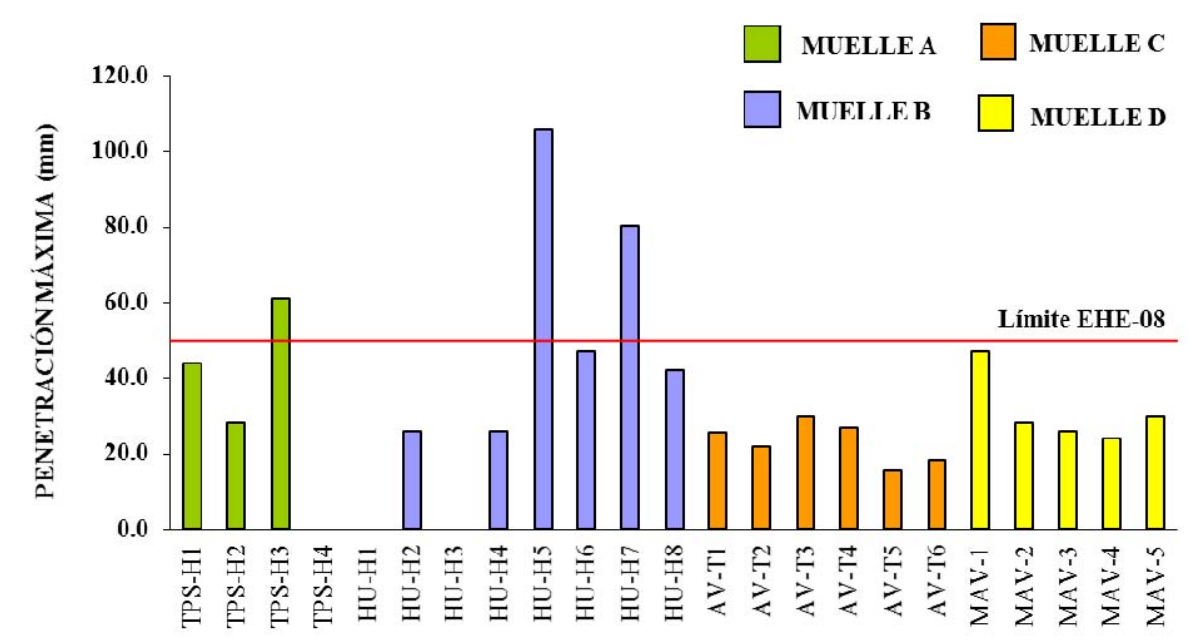

Fig. 5.160. Valores de penetración máxima obtenidos en los testigos de los muelles.

Las figuras anteriores muestran la presencia de un hormigón más impermeable en el muelle $C$, que cumpliría incluso con los requisitos exigidos por la Instrucción EHE-08 para ambiente IIIc (Pmáx $\leq 30 \mathrm{~mm}$; Pmed $\leq 20 \mathrm{~mm}$ ).

Según el Bulletin 243CEB-FIP ${ }^{86}$, se puede estimar la calidad del hormigón a partir de los criterios de porosidad y permeabilidad presentados en las tablas 5.29 y 5.30 .

\begin{tabular}{|c|c|c|}
\hline \multirow{2}{*}{ Calidad del Hormigón } & \multicolumn{2}{|c|}{ Porosidad } \\
\cline { 2 - 3 } & Evaluación & Criterio \\
\hline \hline Buena & Baja & $\mathrm{P}<15 \%$ \\
\hline Media & Media & $15 \%<\mathrm{P}<17 \%$ \\
\hline Mala & Alta & $\mathrm{P}>17 \%$ \\
\hline
\end{tabular}

Tabla 5.29. Criterio de calidad del hormigón en función de los resultados de porosidad.

\begin{tabular}{|c|c|c|}
\hline \multirow{2}{*}{ Calidad del Hormigón } & \multicolumn{2}{|c|}{ Permeabilidad } \\
\hline & Evaluación & Criterio \\
\hline Buena & Baja & $\mathrm{K}<10^{-12} \mathrm{~m} / \mathrm{s}$ \\
\hline Media & Media & $10^{-10} \mathrm{~m} / \mathrm{s}<\mathrm{K}<10^{-12} \mathrm{~m} / \mathrm{s}$ \\
\hline Mala & Alta & $\mathrm{K}>10^{-10} \mathrm{~m} / \mathrm{s}$ \\
\hline
\end{tabular}

Tabla 5.30. Criterio de calidad del hormigón en función de los resultados de permeabilidad.

En la tabla 5.31 se muestran los resultados obtenidos en los testigos de los muelles estudiados así como la calidad del hormigón en función del criterio expuesto: 


\begin{tabular}{|c|c|c|c|c|c|}
\hline Muelle & Testigo & Porosidad (\%) & $\begin{array}{c}\text { Calidad } \\
\text { Hormigón }\end{array}$ & $\begin{array}{c}\text { Permeabilidad } \\
\text { Kest }_{\text {en/s) }}\left(\mathrm{x10}^{-12}\right)\end{array}$ & $\begin{array}{c}\text { Calidad } \\
\text { Hormigón }\end{array}$ \\
\hline \multirow{4}{*}{ A } & TPS-H1 & 20,10 & Mala & $6,6,71$ & Media \\
\hline & TPS-H2 & 20,80 & Mala & 2,81 & Media \\
\hline & TPS-H3 & 20,70 & Mala & 13,29 & Media \\
\hline & TPS-H4 & 16,10 & Media & $>20$ & Media \\
\hline \multirow{8}{*}{ B } & HU-H1 & 16,40 & Media & ---- & ---- \\
\hline & HU-H2 & 15,70 & Media & 1,83 & Media \\
\hline & HU-H3 & 14,00 & Buena & ---- & ---- \\
\hline & HU-H4 & 13,60 & Buena & 1,59 & Media \\
\hline & HU-H5 & 8,40 & Buena & $>16,22$ & Media \\
\hline & HU-H6 & 9,40 & Buena & 3,58 & Media \\
\hline & HU-H7 & 11,00 & Buena & 12,23 & Media \\
\hline & HU-H8 & 10,40 & Buena & 3,16 & Media \\
\hline \multirow{6}{*}{ C } & AV-T1 & 18,90 & Mala & 2,12 & Media \\
\hline & AV-T2 & 17,80 & Mala & 1,49 & Media \\
\hline & AV-T3 & 19,00 & Mala & 2,95 & Media \\
\hline & AV-T4 & 17,70 & Mala & 2,23 & Media \\
\hline & AV-T5 & 17,70 & Mala & 2,23 & Media \\
\hline & AV-T6 & 18,30 & Mala & 2,23 & Media \\
\hline \multirow{5}{*}{ D } & MAV-1 & 16,90 & Media & 6,44 & Media \\
\hline & MAV-2 & 13,60 & Buena & 1,84 & Media \\
\hline & MAV-3 & 13,10 & Buena & 1,53 & Media \\
\hline & MAV-4 & 13,00 & Buena & 1,29 & Media \\
\hline & MAV-5 & 14,40 & Buena & 2,24 & Media \\
\hline
\end{tabular}

Tabla 5.31. Calidad del hormigón según los resultados de porosidad y permeabilidad

En las figuras 5.161 y 5.162 se muestran sendos gráficos de barras donde se representan los resultados anteriores:

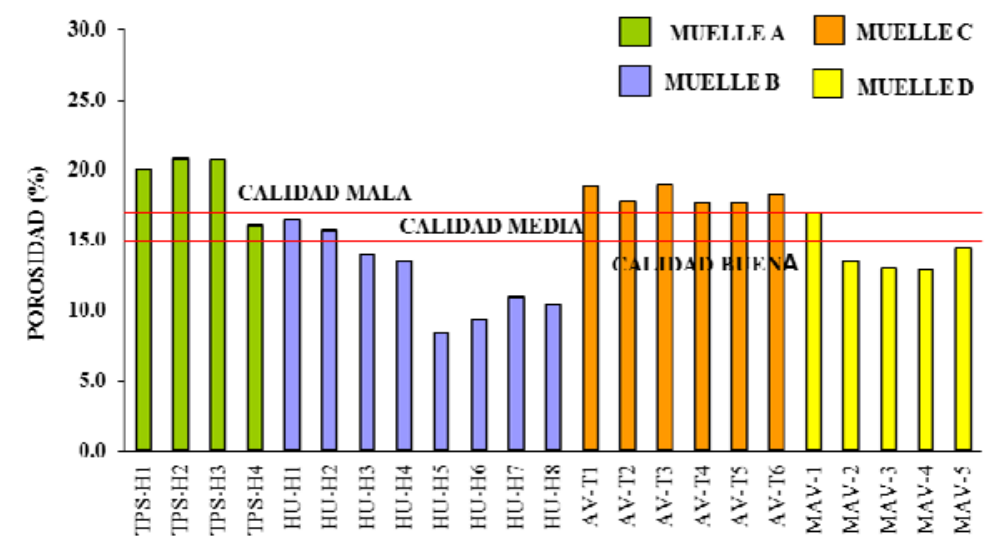

Fig. 5.161. Valores de porosidad obtenidos en los testigos de los muelles. 
A la vista de los resultados representados, la calidad del hormigón atendiendo a este criterio es muy variada, con valores de porosidad que clasificarían el hormigón como malo en el caso de los muelles $\mathrm{A}$ y $\mathrm{C}$ y de medio-bueno en el caso del muelle B y D.

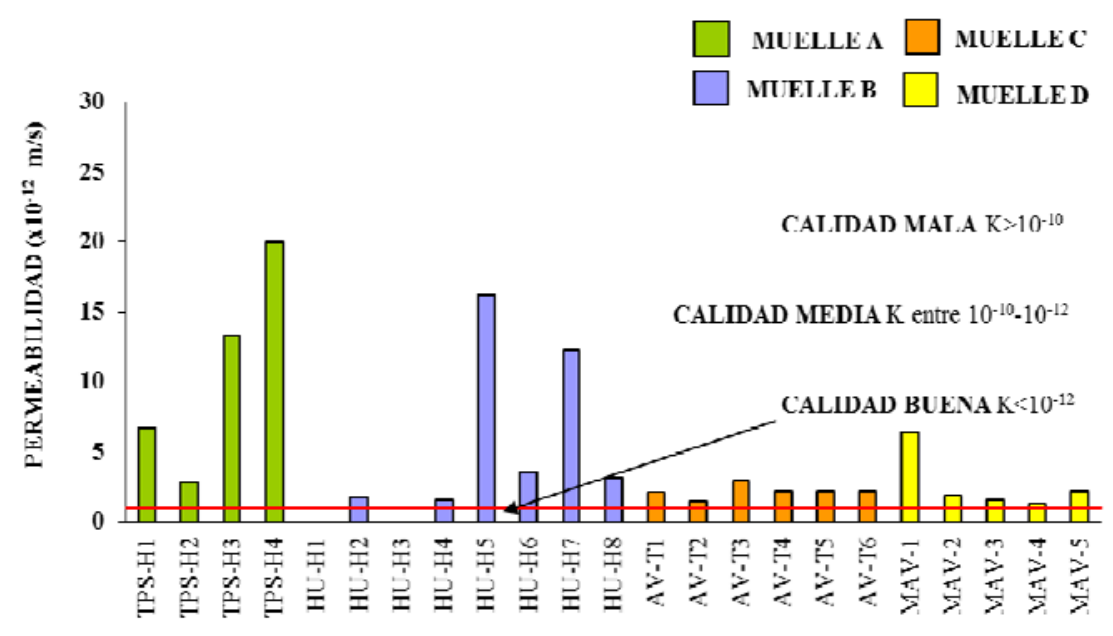

Fig. 5.162. Valores de permeabilidad obtenidos en los testigos de los muelles.

Atendiendo al criterio de calidad según los resultados de permeabilidad obtenidos, los hormigones de los cuatro muelles estudiados serían de calidad media, rozando en algunos casos el límite de calidad buena.

\subsubsection{Absorción de Agua y Capilaridad}

En este apartado se analizan los resultados obtenidos en los ensayos de caracterización de las propiedades físicas de los hormigones de los testigos extraídos en los muelles, cuyos valores se encuentran recogidos en las tablas 5.32 y 5.33.

Según el Bulletin 243 CEB-FIP86, se puede estimar la calidad del hormigón a partir de los resultados del coeficiente de absorción de agua (Ab), de acuerdo con la tabla 5.32. 


\begin{tabular}{|c||c|c|}
\hline \hline \multirow{2}{*}{ Calidad del Hormigón } & \multicolumn{2}{|c|}{ Absorción } \\
\cline { 2 - 3 } & Evaluación & Criterio \\
\hline \hline Buena & Baja & $\mathrm{A}_{\mathrm{b}}<3 \%$ \\
\hline Media & Media & $3 \%<\mathrm{A}_{\mathrm{b}}<4 \%$ \\
\hline Mala & Alta & $\mathrm{A}_{\mathrm{b}}>4 \%$ \\
\hline
\end{tabular}

Tabla 5.32. Criterio de calidad del hormigón en función de la absorción.

En la tabla 5.33 se muestran los resultados obtenidos en los testigos de los muelles estudiados así como la calidad del hormigón en función del criterio expuesto:

\begin{tabular}{|c|c|c|c|}
\hline Muelle & Testigo & Absorción (\%) & Calidad Hormigón \\
\hline \multirow{4}{*}{ A } & TPS-H1 & 4,75 & Mala \\
\hline & TPS-H2 & 4,90 & Mala \\
\hline & TPS-H3 & 4,94 & Mala \\
\hline & TPS-H4 & 3,45 & Media \\
\hline \multirow{8}{*}{ B } & HU-H1 & ---- & ---- \\
\hline & HU-H2 & ---- & ---- \\
\hline & HU-H3 & ---- & ---- \\
\hline & HU-H4 & 1,58 & Buena \\
\hline & HU-H5 & 2,21 & Buena \\
\hline & HU-H6 & ---- & ---- \\
\hline & HU-H7 & 2,81 & Buena \\
\hline & HU-H8 & 2,28 & Buena \\
\hline \multirow{6}{*}{ C } & AV-T1 & 2,77 & Buena \\
\hline & AV-T2 & 2,13 & Buena \\
\hline & AV-T3 & 3,29 & Media \\
\hline & AV-T4 & 2,65 & Buena \\
\hline & AV-T5 & 2,11 & Buena \\
\hline & AV-T6 & 2,18 & Buena \\
\hline \multirow{5}{*}{ D } & MAV-1 & ---- & ---- \\
\hline & MAV-2 & 2,04 & Buena \\
\hline & MAV-3 & ---- & ---- \\
\hline & MAV-4 & 2,09 & Buena \\
\hline & MAV-5 & ---- & ---- \\
\hline
\end{tabular}

Tabla 5.33. Calidad del hormigón según los resultados de absorción. 
En la figura 5.163 se muestra un gráfico de barras donde se observan los resultados anteriores:

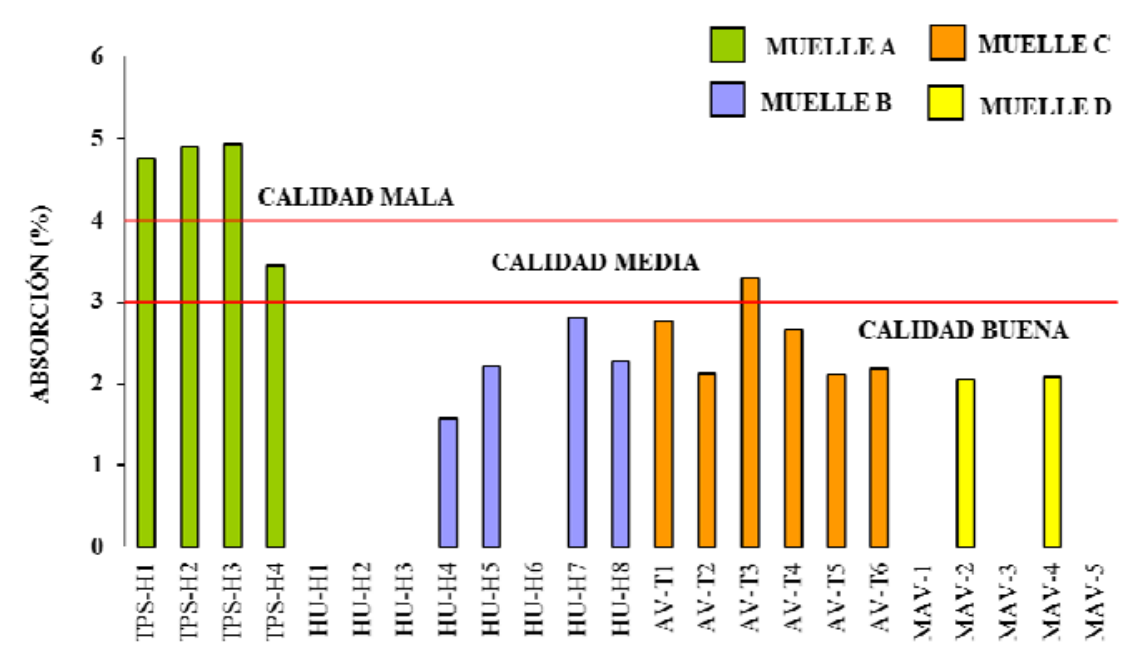

Fig. 5.163. Valores de absorción obtenidos en los testigos de los muelles.

A tenor de los resultados de absorción representados, se aprecia un hormigón de calidad mala-media en el muelle $A$ y en general de calidad buena en los muelles $B$, C y D.

Si se expresa el resultado del ensayo de capilaridad como incremento de peso ( $\mathrm{mm}^{3}$ de agua) por unidad de área de hormigón en contacto con el agua (en $\mathrm{mm}^{2}$ ), dividido por la raíz cuadrada del tiempo (en minutos), se puede estimar la calidad del hormigón según la tabla 5.34 tomada del Bulletin 243 CEB-FIP86.

\begin{tabular}{|c|c|}
\hline Calidad del Hormigón & Capilaridad (mm $/ \sqrt{\text { min) }}$ \\
\hline \hline Buena & $<0,1$ \\
\hline Media & 0,2 a 0,1 \\
\hline Mala & $>0,2$ \\
\hline
\end{tabular}

Tabla 5.34. Criterio de calidad del hormigón en función de los resultados de capilaridad.

Según esta clasificación, el hormigón de los testigos de los Muelles tendría la calidad que se muestra en la tabla 5.35: 


\begin{tabular}{|c|c|c|c|}
\hline Muelle & Testigo & Capilaridad (mm $\sqrt{ }$ min) & $\begin{array}{l}\text { Calidad } \\
\text { Hormigón }\end{array}$ \\
\hline \multirow{4}{*}{ A } & TPS-H1 & 0,180 & Media \\
\hline & TPS-H2 & 0,110 & Media \\
\hline & TPS-H3 & 0,210 & Mala \\
\hline & TPS-H4 & 0,120 & Media \\
\hline \multirow{7}{*}{ B } & "HU-H1 & 0,090 & "Buena \\
\hline & HU-H2 & 0,060 & Buena \\
\hline & HU-H4 & 0,060 & Buena \\
\hline & HU-H5 & 0,080 & Buena \\
\hline & HU-H6 & 0,070 & Buena \\
\hline & HU-H7 & 0,120 & Media \\
\hline & HU-H8 & 0,040 & Buena \\
\hline \multirow{6}{*}{$\mathbf{C}$} & AV-T1 & 0,070 & Buena \\
\hline & AV-T2 & 0,060 & Buena \\
\hline & AV-T3 & 0,090 & Buena \\
\hline & AV-T4 & 0,080 & Buena \\
\hline & AV-T5 & 0,040 & Buena \\
\hline & AV-T6 & 0,060 & Buena \\
\hline \multirow{5}{*}{ D } & MAV-1 & 0,098 & Buena \\
\hline & MAV-2 & 0,054 & Buena \\
\hline & MAV-3 & 0,064 & Buena \\
\hline & MAV-4 & 0,053 & Buena \\
\hline & MAV-5 & ---- & ---- \\
\hline
\end{tabular}

Tabla 5.35. Calidad del hormigón según los resultados de capilaridad.

En la figura 5.164 se muestra un gráfico de barras donde se observan los resultados anteriores:

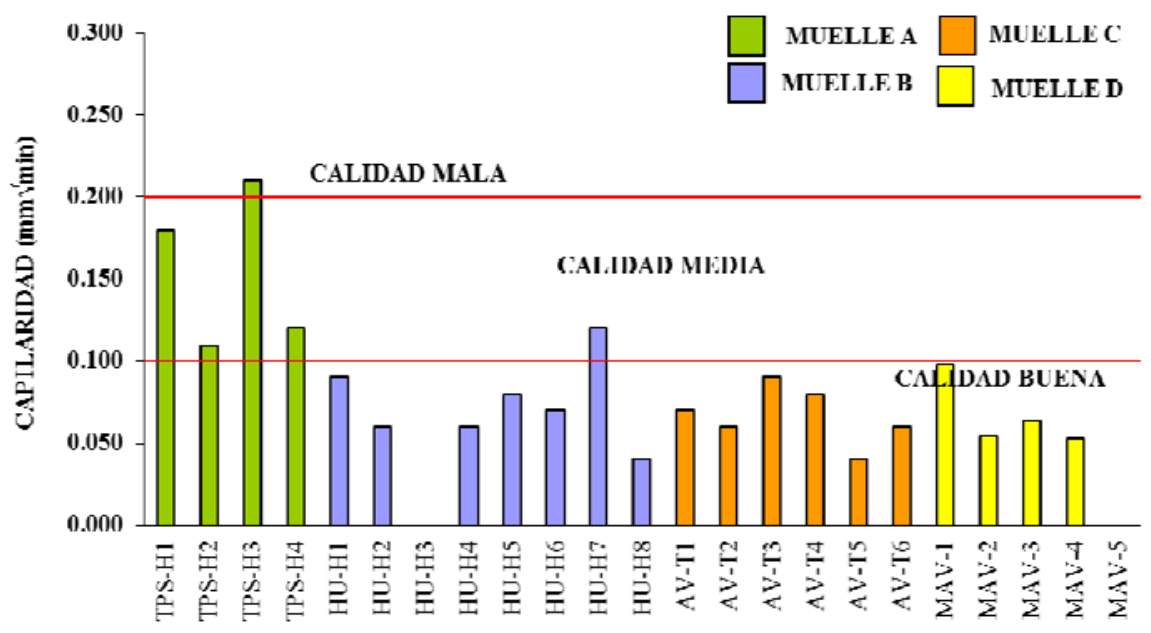

Fig. 5.164. Valores de capilaridad obtenidos en los testigos de los muelles. 
A la vista de los resultados de capilaridad representados, el hormigón del muelle A presenta calidad media en general y el correspondiente a los muelles B, C y D, calidad buena.

\subsubsection{Resumen Cualitativo de la Calidad del Hormigón}

A partir de los resultados obtenidos en los diferentes ensayos de caracterización de las propiedades mecánicas y físicas del hormigón de los testigos extraídos de los cuatro muelles, es posible definir la calidad de los hormigones estudiados considerando los distintos criterios de clasificación cualitativa que se han presentado a lo largo de este apartado (tabla 5.36).

\begin{tabular}{|c|c|c|c|c|c|c|c|c|}
\hline Muelle & Testigo & $\begin{array}{l}\text { Pen. Agua }{ }^{1} \\
\text { (Máx/Med) }\end{array}$ & Ultrasonidos & $\begin{array}{c}\text { Resistencia } \\
\left(\mathbf{N} / \mathbf{m m}^{2}\right)\end{array}$ & Porosidad & Permeabilidad & Absorción & Capilaridad \\
\hline \multirow{4}{*}{ A } & TPS-H1 & SI/NO & Excelente & 40,9 & Mala & Media & Mala & Media \\
\hline & TPS-H2 & SI/SI & Buena & 29,7 & Mala & Media & Mala & Media \\
\hline & TPS-H3 & $\mathrm{NO} / \mathrm{NO}$ & Excelente & 45,1 & Mala & Media & Mala & Mala \\
\hline & \begin{tabular}{|l|} 
TPS-H4 \\
\end{tabular} & ---- & Excelente & 39,9 & Media & Media & Media & Media \\
\hline \multirow{8}{*}{ B } & HU-H1 & ---- & Buena & 50,2 & Media & ---- & ---- & Buena \\
\hline & \begin{tabular}{|l|} 
HU-H2 \\
\end{tabular} & SI/SI & Buena & 48,0 & Media & Media & ---- & Buena \\
\hline & \begin{tabular}{|l|} 
HU-H3 \\
\end{tabular} & ---- & ---- & ---- & Buena & ---- & ---- & ---- \\
\hline & HU-H4 & SI/SI & Buena & 55,5 & Buena & Media & Buena & Buena \\
\hline & \begin{tabular}{|l|} 
HU-H5 \\
\end{tabular} & $\mathrm{NO} / \mathrm{NO}$ & Excelente & 47,8 & Buena & Media & Buena & Buena \\
\hline & \begin{tabular}{|l|} 
HU-H6 \\
\end{tabular} & $\mathrm{SI} / \mathrm{NO}$ & Buena & 44,3 & Buena & Media & $\begin{array}{ll}--- \\
\end{array}$ & Buena \\
\hline & HU-H7 & $\mathrm{NO} / \mathrm{NO}$ & Buena & 40,4 & Buena & Media & Buena & Media \\
\hline & HU-H8 & $\mathrm{SI} / \mathrm{NO}$ & Buena & 50,2 & Buena & Media & Buena & Buena \\
\hline \multirow{6}{*}{ C } & AV-T1 & $\overline{\mathrm{SI} / \mathrm{SI}}$ & "Buena & 46,0 & Mala & Media & "Buena & "Buena \\
\hline & AV-T2 & SI/SI & Buena & 50,4 & Mala & Media & Buena & Buena \\
\hline & AV-T3 & SI/SI & Buena & 42,1 & Mala & Media & Media & Buena \\
\hline & AV-T4 & SI/SI & Buena & 47,8 & Mala & Media & Buena & Buena \\
\hline & AV-T5 & SI/SI & Buena & 54,3 & Mala & Media & Buena & Buena \\
\hline & AV-T6 & SI/SI & Excelente & 47,0 & Mala & Media & Buena & Buena \\
\hline \multirow{5}{*}{ D } & MAV-1 & 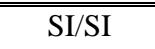 & Buena & 26,5 & Media & Media & "---- & "Buena \\
\hline & MAV-2 & SI/SI & Excelente & 30,8 & Buena & Media & Buena & Buena \\
\hline & MAV-3 & SI/SI & Excelente & 18,2 & Buena & Media & ---- & Buena \\
\hline & \begin{tabular}{|l|} 
MAV-4 \\
\end{tabular} & SI/SI & Excelente & 33,5 & Buena & Media & Buena & Buena \\
\hline & MAV-5 & SI/SI & ---- & ---- & Buena & Media & ---- & ---- \\
\hline
\end{tabular}

Tabla 5.36. Resumen cualitativo de la calidad de los testigos.

${ }^{1}$ Se indica si el testigo correspondiente cumple o no las limitaciones de penetración máxima y media de agua (respectivamente) establecidas por la Instrucción EHE-08 para estructuras situadas en ambiente IIIa. 
Puede observarse que el criterio de clasificación de la calidad varía según las diferentes propiedades analizadas.

En el apartado 5.7 .5 se realiza una comparación de los coeficientes de difusión con los resultados de los ensayos de caracterización realizados. Las regresiones obtenidas en la mayoría de los casos son muy débiles, salvo para el ensayo de penetración de agua, y también demuestran esta falta de uniformidad del criterio de clasificación de la calidad.

\subsection{ANÁLISIS DE RESULTADOS}

\subsubsection{Análisis del perfil de penetración de cloruros}

Para el estudio de la velocidad de penetración de cloruros y el cálculo del coeficiente de difusión, se parte del perfil de cloruros de cada uno de los testigos de los tres muelles analizados, calculado a partir de las concentraciones de cloruros medidas a distintas profundidades (resultados recogidos en el apartado 5.7.2). Con estos datos se representa un gráfico para cada uno de los muelles en el que se relacionan los valores de profundidad media de las muestras y la concentración de cloruros expresada en \% en peso de hormigón (figuras 5.165 a 5.168).

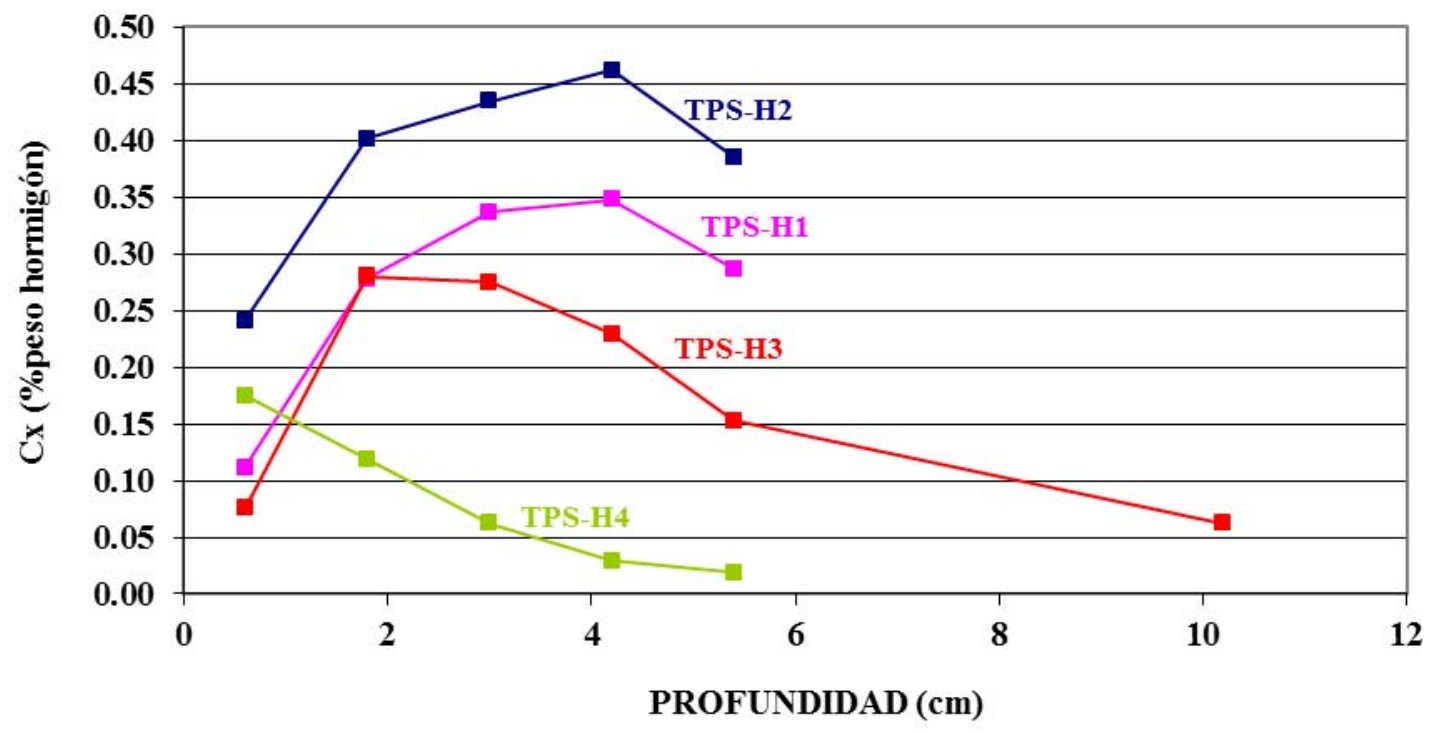

Fig. 5.165. Profundidad media-concentración Cl (en \%peso hormigón) en muelle A. 


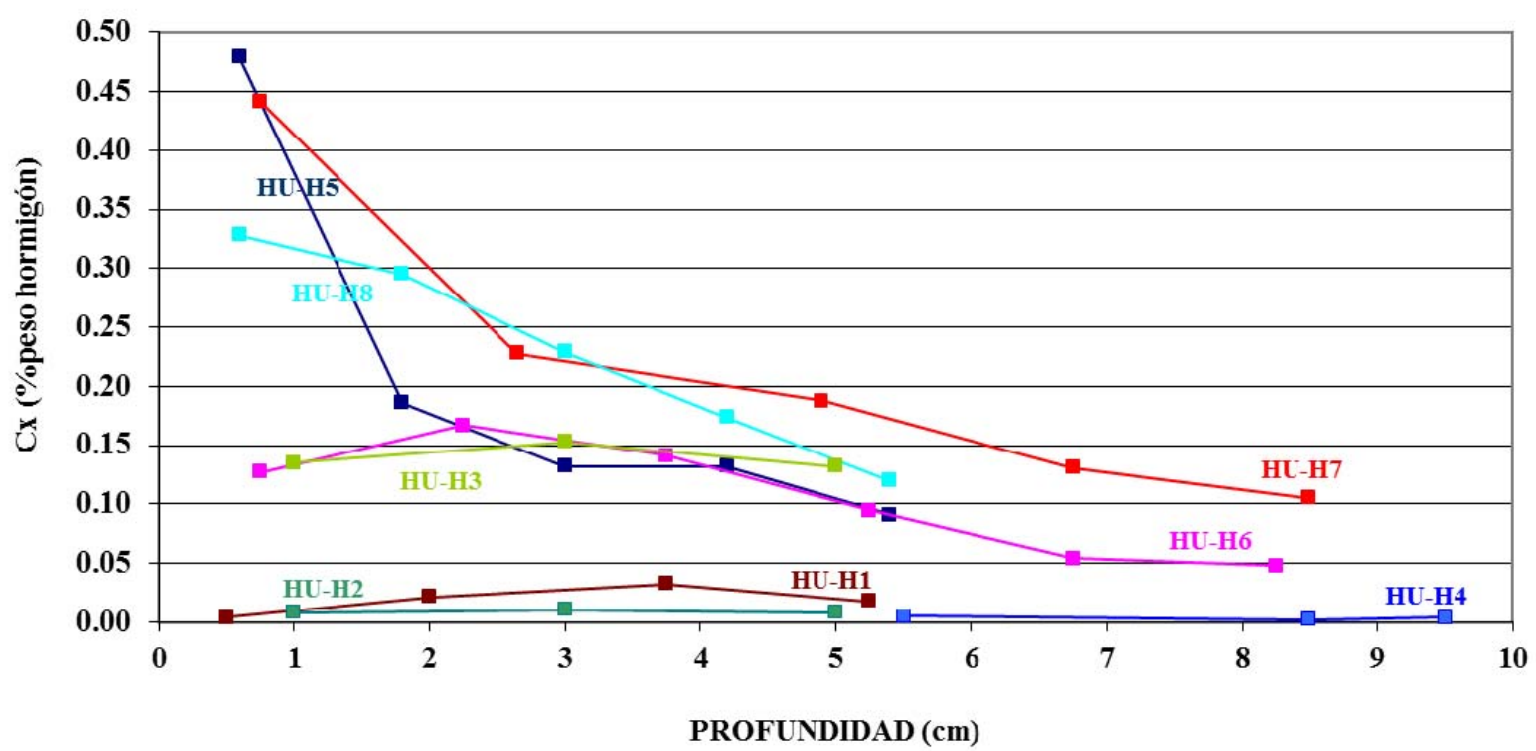

Fig. 5.166. Profundidad media-concentración Cl en \%peso hormigón en muelle B.

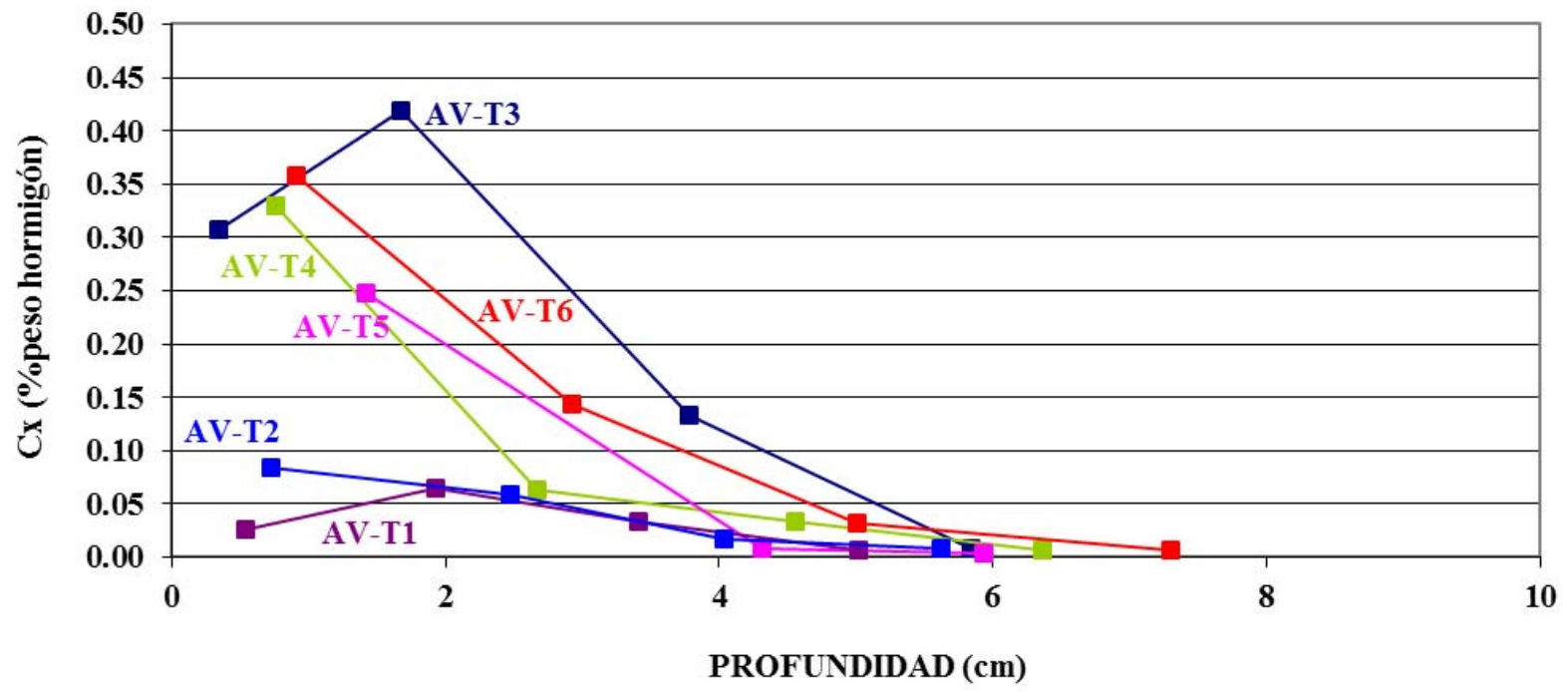

Fig. 5.167. Profundidad media-concentración CI en \%peso hormigón en muelle C. 


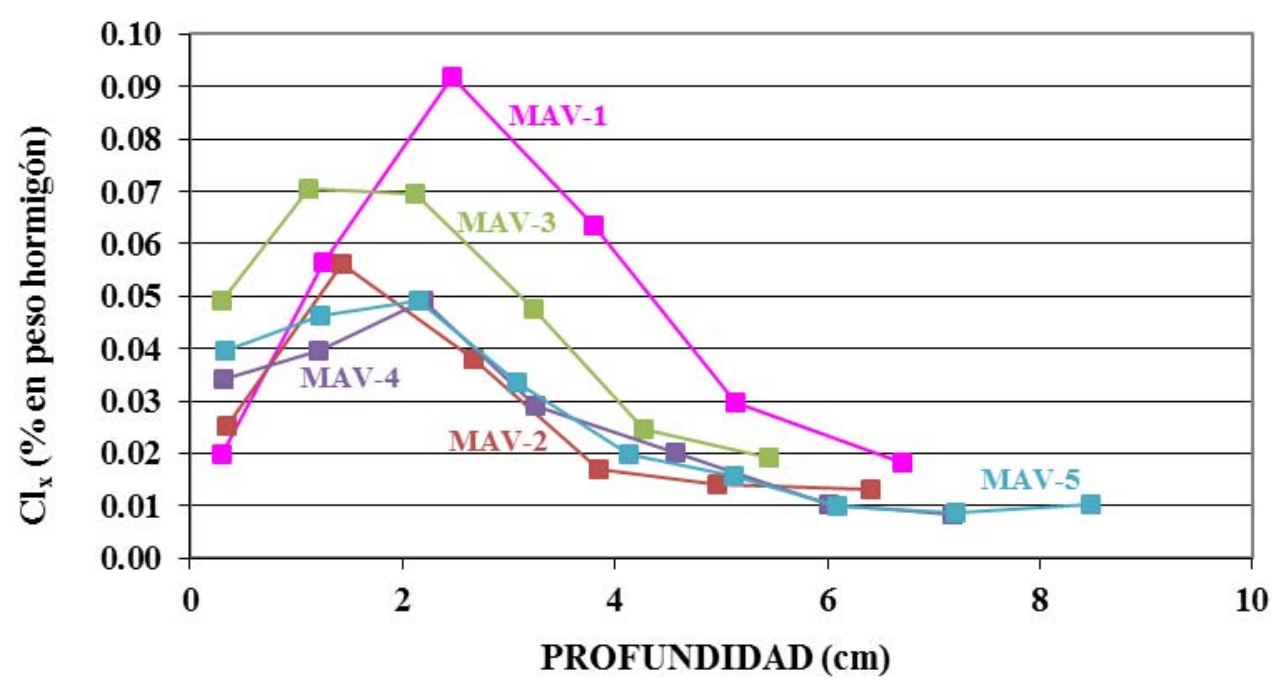

Fig. 5.168. Profundidad media-concentración Cl en \%peso hormigón en muelle D.

\subsubsection{Muelle A}

La figura 5.169 representa la relación entre la profundidad media del testigo y la concentración de cloruros expresada en \% en peso de cemento para el muelle A:

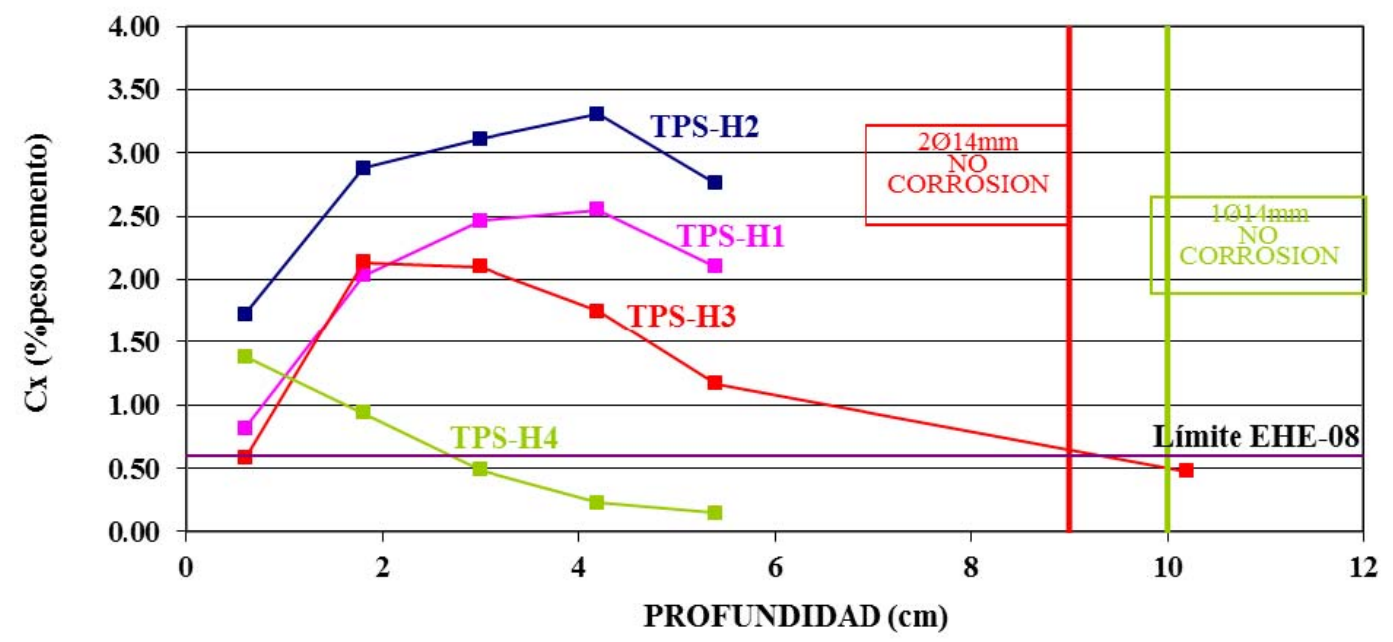

(*) Se han encontrado $2 \varnothing 14 \mathrm{~mm}$ a $20 \mathrm{~cm}$ de profundidad y $2 \varnothing 4 \mathrm{~mm}$ a $40 \mathrm{~cm}$ de profundidad sin síntomas de corrosión. Ambas armaduras quedan fuera del área representada en el gráfico.

Fig. 5.169. Profundidad media-concentración CI (\%peso cemento) en muelle A

En el gráfico puede observarse la variación de resultados que se ha obtenido entre los perfiles de los cuatro testigos. Dado que el hormigón empleado en la construcción de los Duques de Alba de los que se han extraído es el mismo, la variación de los cloruros medidos puede deberse a diferencias en las condiciones de exposición o bien a la 
calidad del hormigón finalmente colocado. En el apartado 5.2.1 se aporta una vista aérea del muelle A. Los perfiles de los testigos TPS-H1 y TPS-H2, situados a derecha e izquierda de la plataforma $C$ respectivamente, presentan una forma muy similar. Dada la situación de ambos, podría ser que el testigo TPS-H2 quedara más expuesto a la acción del viento y por ello, su contenido en cloruros es superior. En el caso de los testigos TPS-H3 y TPS-H4 se encuentran en el camino de acceso entre las plataformas B y C y sus perfiles claramente inferiores podrían justificarse por encontrarse en una zona más abrigada y con menor exposición al viento.

El efecto lavado se refiere al hecho de que el hormigón más superficial queda expuesto al agua de lluvia o de escorrentía, arrastrando de este modo los cloruros depositados en los primeros $\mathrm{cm}$ del hormigón. Por este motivo, los valores iniciales de los perfiles son, en algunas ocasiones, inferiores que los valores más profundos, cuando el contenido de cloruros debería disminuir a medida que se profundiza en la muestra de hormigón presentando su valor máximo al inicio del perfil. Este fenómeno se da en tres de los cuatro testigos, lo que resulta bastante razonable dado que se han extraído de la superficie superior de los Duques de Alba, que es horizontal y favorece el efecto lavado por la lluvia. Se ha producido en los tres perfiles de mayor contenido de cloruros, por lo que no se debe considerar únicamente el dato de los primeros $\mathrm{cm}$, que en este caso sería menor, sino estudiar el perfil lo más completo posible. Debido igualmente a este lavado del hormigón, en dos de los cuatro casos sólo se dispone de dos puntos del perfil a partir de los cuales se podría hacer el ajuste por regresión para el cálculo de la difusión, lo que resulta insuficiente para obtener unos coeficientes de difusión suficientemente fiables.

El caso del testigo TPS-H4 presenta un perfil sensiblemente más bajo que el resto. En este caso no presenta efecto lavado, alcanzando el valor máximo de contenido de cloruros en el primer punto. El perfil llega al límite referido por la Instrucción EHE-08 $(0,6 \%$ peso de cemento) a una profundidad aproximada de $3 \mathrm{~cm}$. A la vista de los resultados de los ensayos (tablas 5.40 y 5.41) la muestra TPS-H4 presenta los valores más bajos de porosidad y absorción de los cuatro perfiles del muelle A. Esto hace pensar en un hormigón con mejor comportamiento ante la penetración de cloruros.

El límite de contenido de cloruros propuesto por la EHE-08 se alcanza por encima de los $5 \mathrm{~cm}$ en los tres casos, pero debe tenerse en cuenta la edad del muelle A que es de 37 años.

Se han encontrado armaduras en todos los testigos, salvo en el caso del TPS-H1. Salvo una de ellas, todas se han encontrado a profundidades elevadas $(>10 \mathrm{~cm})$. En el caso 
del testigo TPS-H3, la armadura representada se corta con el perfil de cloruros por debajo del límite establecido con la EHE-08, lo que resulta coherente con que no presente corrosión puesto que el contenido de cloruros es inferior al límite que establece la Instrucción. En el caso de TPS-H4, el perfil de cloruros llega hasta $5 \mathrm{~cm}$ aproximadamente pero ya en ese punto su valor de concentración es inferior al límite de la EHE-08, por lo que también resulta coherente el estado de no corrosión de la armadura encontrada a $10 \mathrm{~cm}$. En caso de completarse el perfil de TPS-H2 podría corroborarse el estado de la armadura, que tampoco presenta corrosión y por tanto el valor de los cloruros a dicha profundidad no es suficiente para iniciar la corrosión y por tanto, debería estar por debajo del establecido en la norma.

\subsubsection{Muelle B}

La figura 5.170 representa la relación entre la profundidad media del testigo y la concentración de cloruros expresada en \% en peso de cemento para el muelle B. Dado que se han extraído testigos de losas y de cabeceros, distinguimos dos grupos a la hora de realizar el análisis:

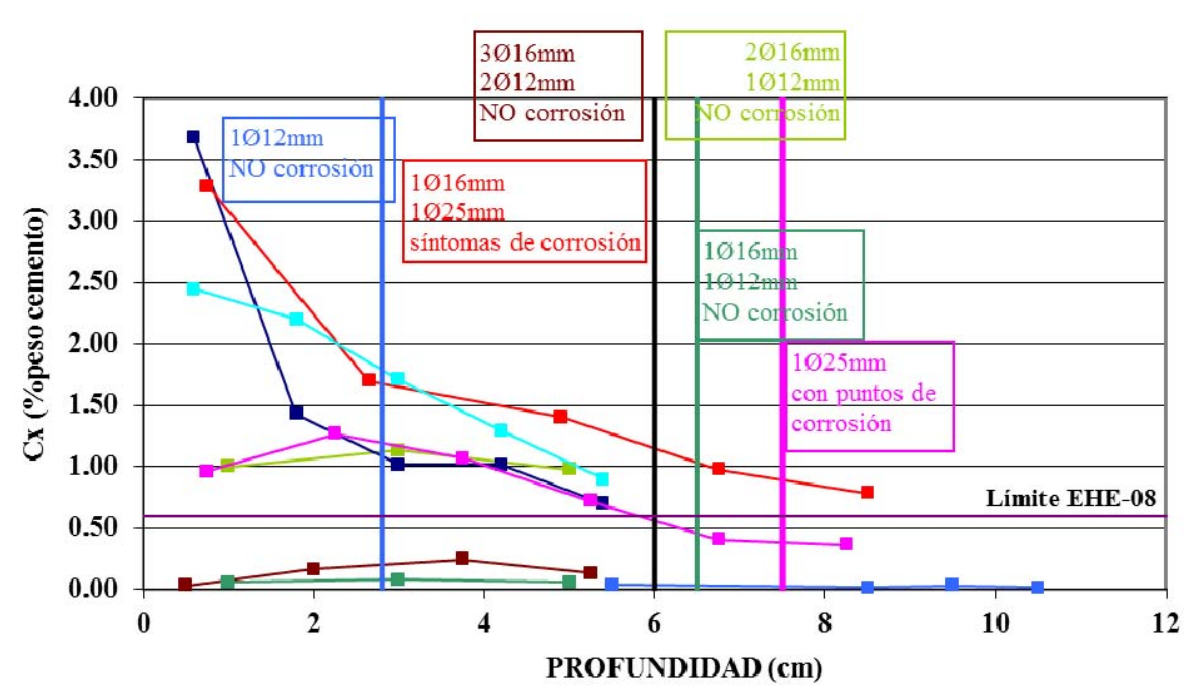

A $6 \mathrm{~cm}$ de recubrimiento se solapa la representación de la armadura (en negro) encontrada en HU-H1,HU-H3 y HU-H7 (ver cuadros en marrón, verde claro y rojo). Sólo en el caso de HU-H7 presenta sintomas de corrosión.

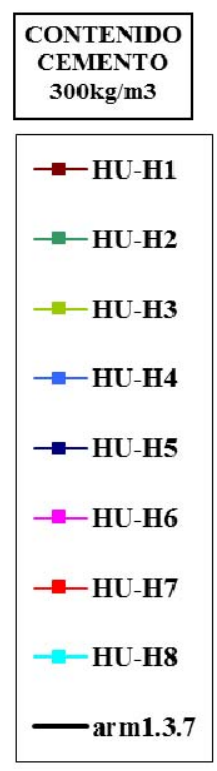

Fig. 5.170. Profundidad media-concentración Cl (\%peso cemento) en muelle B.

\section{Losas}

En el gráfico puede observarse que los testigos $\mathrm{HU}-\mathrm{H} 1$, $\mathrm{HU}-\mathrm{H} 2$ y $\mathrm{HU}-\mathrm{H} 4$ son bastante más tendidos que el correspondiente a HU-H3. Por dificultades en la extracción del testigo y debido a la heterogeneidad de las capas que lo componían (ver fig 5.74), el 
testigo HU-H3 llega al laboratorio bastante dañado y no permite la realización de muchos de los ensayos de caracterización a la vista de los resultados reflejados en las tablas 5.42 y 5.43. Por otro lado, en los otros tres casos, por lo incompleto de sus perfiles y considerando que se necesitan más de dos puntos para ajustar por regresión y obtener el coeficiente de difusión de un modo fiable, se han considerado los tres perfiles como uno único a la vista de la uniformidad de las propiedades de los hormigones que los componen para el cálculo de la difusión, asumiendo como densidad, contenido de cloruros en superficie y contenido inicial de cloruros los valores medios de los tres testigos.

\section{Cabeceros}

En el gráfico puede observarse la variación obtenida entre los perfiles de los cuatro testigos tomados de los cabeceros del muelle (HU-H5 a HU-H8). Así, el más inferior de todos corresponde al testigo $\mathrm{HU}-\mathrm{H} 6$, que se extrajo del faldón del primer cabecero del módulo 19. Dado que la dosificación del hormigón empleado en la construcción de los cabeceros de los muelles de los que se han extraído es el mismo, la variación de los cloruros medidos puede deberse a diferencias en las condiciones de exposición o bien a la calidad final del hormigón colocado. Así los testigos HU-H5 y HU-H7, extraídos de los módulos 19 y 16, presentan los perfiles más elevados y podría explicarse por una exposición más desfavorable al viento o al oleaje.

En cuanto al efecto lavado al que se hacía mención en el anterior apartado, este fenómeno se da en uno de los cuatro testigos extraídos de los cabeceros. En el caso de este muelle, los testigos se tomaron perpendiculares al paramento desde la superficie frontal, por lo que no hay una superficie horizontal que facilite el efecto lavado. Dos de los testigos, el $\mathrm{HU}-\mathrm{H} 5$ y el $\mathrm{HU}-\mathrm{H} 6$ pertenecen al mismo módulo, por tanto las condiciones de exposición en ellos deberían ser similares, sin embargo uno de ellos presenta lavado (el HU-H6) y no en el caso del HU-H5. El testigo HU-H6 se extrae del faldón de un cabecero que puede favorecer que el agua resbale a lo largo suyo procedente de la zona superior y que favorezca el efecto lavado. Es justamente este perfil el que cuenta con menos puntos para el ajuste por regresión para la obtención del coeficiente de difusión.

Los perfiles (salvo el caso de HU-H6 por el efecto de lavado) son muy similares. Los perfiles de $\mathrm{HU}-\mathrm{H} 5$ y $\mathrm{HU}-\mathrm{H} 6$ prácticamente se solapan en un tramo, lo que es bastante coherente dado que pertenecen al mismo módulo, su hormigón es el mismo y las condiciones de exposición son muy similares, por lo que salvando el tramo inicial por el efecto lavado los contenidos de cloruros son semejantes. 
A la vista de la representación de los perfiles $\mathrm{HU}-\mathrm{H} 5, \mathrm{HU}-\mathrm{H} 7$ y HU-H8 se observa que no están completos puesto que no se alcanza el valor del fondo (cloruros iniciales en el hormigón). Si se extrapolan las pendientes de los perfiles en los cuatro casos, el límite de la Instrucción EHE-08 se alcanzaría previsiblemente entre los 5-10 cm de profundidad. La edad del muelle es de 26 años.

Se han encontrado armaduras en dos de los cuatro testigos (HU-H6 y HU-H7), a profundidades de $7,5 \mathrm{~cm}$ y $6,0 \mathrm{~cm}$ respectivamente. En el caso de $\mathrm{HU}-\mathrm{H} 6$ presenta leves puntos de corrosión, pero no manchas de corrosión en los lugares del hormigón marcados por las corrugas, lo que podría justificarse dado que a esa profundidad el perfil del testigo queda por debajo del límite de cloruros fijado por la EHE-08 (0,31\%). Sin embargo en el caso de $\mathrm{HU}-\mathrm{H} 7$, donde se aprecian manchas de corrosión en el hormigón y las barras reflejan un avance importante de la corrosión, su perfil se encuentra por encima del citado límite, lo que resultaría coherente con la presencia de corrosión (1,15\%).

\subsubsection{Muelle C}

La figura 5.171 representa la relación entre la profundidad media del testigo y la concentración de cloruros expresada en \% en peso de cemento para el muelle C:

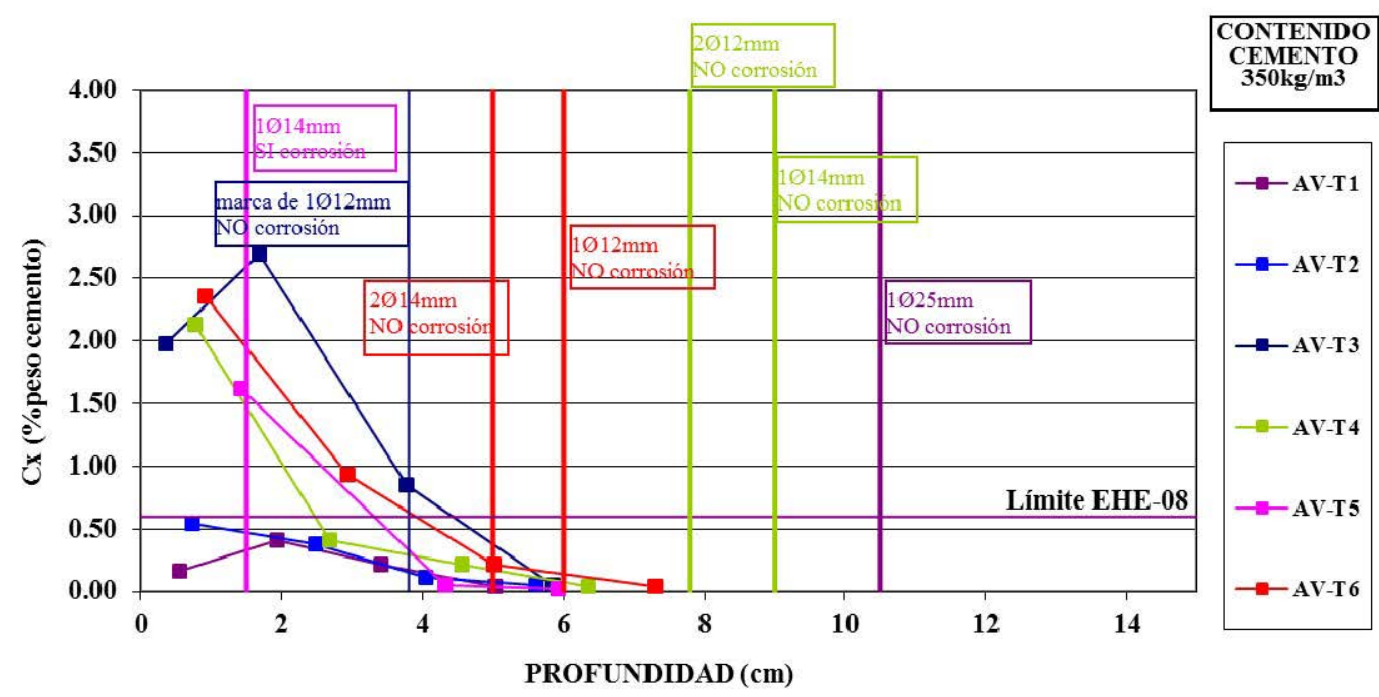

En el testigo AV-T4 se ha encontrado $1 \varnothing 25 \mathrm{~mm}$ a $20,5 \mathrm{~cm}$ de profundidad, que no aparece dentro del área reprensentada en el gráfico.

Fig. 5.171. Profundidad media-concentración Cl en \%peso cemento en muelle C.

En el gráfico puede observarse la variación que se ha obtenido entre los perfiles de los seis testigos extraídos. Así, en el caso de los testigos AV-T1 y AV-T2, que se han 
tomado de los cabeceros de las vigas trasera e intermedia respectivamente (ver croquis situación de testigos fig 5.97), los perfiles son sensiblemente más bajos que en el resto de los casos. En este muelle, la calidad del hormigón es bastante uniforme en todos los testigos por lo que la diferencia en la concentración de cloruros se explica por las condiciones de exposición, al encontrarse dichos testigos en una zona mucho más protegida de la acción del viento y el oleaje que los otros cuatro, que fueron extraídos de la viga cantil a diversas distancias del cabecero del muelle. Los otros cuatro perfiles de testigos extraídos de la viga cantil (AV-T3, AV-T4, AV-T5 y AV-T6) son similares.

En cuanto al efecto lavado al que se hacía mención en los anteriores apartados, este fenómeno se da en dos de los seis testigos. En el caso de este muelle, los testigos se tomaron perpendiculares al paramento, ya sea de los cabeceros de las vigas o bien de la viga cantil, por lo que no hay una superficie horizontal que facilite el efecto lavado. El hecho de que sólo dos de ellos presenten dicho efecto puede asociarse a alguna condición de exposición local como un posible mayor oleaje por situarse próximo al punto de amarre de los barcos que atracan en el muelle. En el caso de este puerto, el efecto lavado no ha evitado que los perfiles sean bastante completos y los coeficientes de difusión han podido obtenerse de un modo fiable, es decir, mediante el ajuste por regresión de varios valores.

Los perfiles correspondientes a AV-T1 y AV-T2, por sus condiciones más protegidas de exposición, no superan el límite de contenido de cloruros (\%peso cemento) establecido por la Instrucción EHE-08 en ningún punto. En el caso del resto de los perfiles, siempre se alcanza dicho límite antes de llegar a los $5 \mathrm{~cm}$ de profundidad en el testigo. La edad del muelle está próxima a los 12 años.

El perfil perteneciente a AV-T3 es algo más elevado, lo que puede explicarse a la vista de los resultados de los ensayos de caracterización que muestran valores de porosidad y de absorción algo mayores que el resto de los perfiles del muelle (ver tablas 5.44 y 5.45). Además este testigo presenta menor resistencia, con lo que es posible que dicho hormigón sea sensiblemente peor, asociado probablemente a unas peores condiciones de ejecución en ese punto.

Se han encontrado armaduras en todos los testigos, salvo en el caso del AV-T2 (ver tabla 5.38).

Las armaduras encontradas en los testigos AV-T1, AV-T4 y AV-T6 se hallaron a profundidades superiores a $5 \mathrm{~cm}$, situándose sus perfiles de cloruros por debajo del límite establecido por la EHE-08 en todos los casos (AV-T1: <0,033\%; AV-T4: <0,027\%; 
AV-T6: 0,22\% (2Ø14mm) y 0,054\% (1Ø12mm)). Esto justifica la ausencia de corrosión de dichas armaduras. En el caso del testigo AV-T3 se detectó una marca de armadura en el hormigón que no reflejaba manchas de corrosión, pero la armadura correspondiente a la marca probablemente se perdió durante el proceso de extracción del testigo. Al no disponer de tal armadura no puede asegurarse el estado de la misma. Por último, en el caso del testigo AV-T5, la armadura se encuentra a una profundidad muy baja $(15 \mathrm{~mm})$ y el perfil en ese punto supera lo establecido por la normativa $(1,575 \%)$, lo que se corresponde con los síntomas de corrosión que aparecen en la armadura (figura 5.108).

\subsubsection{Muelle D}

La figura 5.172 representa la relación entre la profundidad media del testigo y la concentración de cloruros expresada en \% en peso de cemento para el muelle D:

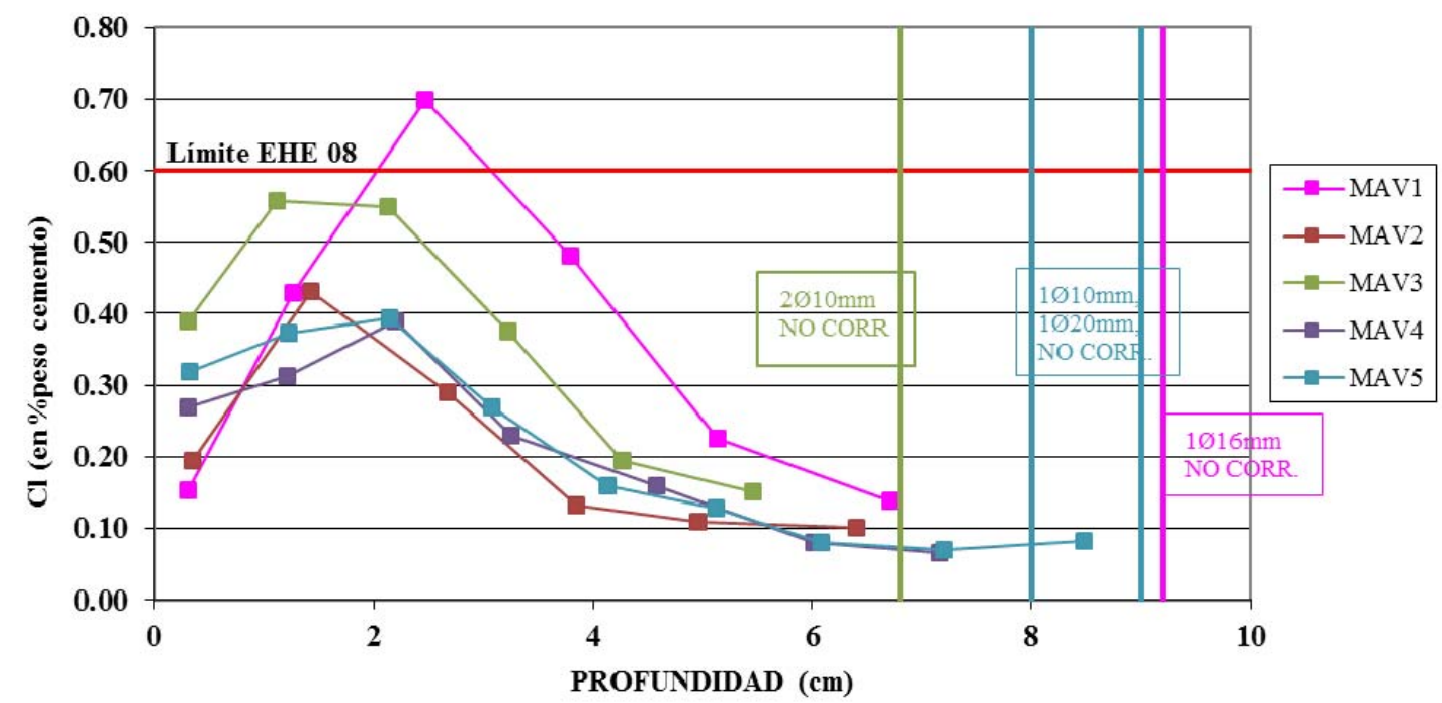

En el caso del testigo MAV3 una de las barras aparece con un recubrimiento de $235 \mathrm{~mm}$, fuera de la zona representada en el gráfico

Fig. 5.172. Profundidad media-concentración Cl en \%peso cemento en muelle $D$.

En el gráfico puede observarse la variación que se ha obtenido entre los perfiles de los cinco testigos extraídos.

Todos los testigos se han extraído perpendicularmente a la viga cantil del muelle.

En cuanto al efecto lavado al que se hacía mención en los anteriores apartados, este fenómeno se da en los cinco testigos. El efecto lavado no ha evitado que los perfiles sean bastante completos y los coeficientes de difusión han podido obtenerse de un modo fiable, es decir, mediante el ajuste por regresión de varios valores. 
Sólo el testigo MAV-1 ha sobrepasado el valor límite a partir del cual, según el anejo 9 de la Instrucción EHE-08, comenzaría la corrosión. En los testigos 2 a 5 no se ha sobrepasado el contenido máximo de cloruros en ninguna medida experimental. La edad del muelle es de 11 años.

Se han encontrado armaduras en tres (MAV1, MAV3 y MAV5) de los cinco los testigos. Ninguna de ellas ha mostrado corrosión. Esto es coherente con los valores experimentales medidos, ya que los cloruros aún no han alcanzado a las barras contenidas en los testigos.

\subsubsection{Cálculo del coeficiente de difusión de cloruros}

Para el cálculo de los coeficientes de difusión, se ha empleado la ley de Fick, cuya expresión simplificada viene dada por la función parábola y es la siguiente:

$$
C_{x}-C_{b}=\left(C_{s}-C_{b}\right) \cdot\{1-x / 2 \sqrt{3} \cdot D \cdot t\}^{2}
$$

Donde " $\mathrm{C}_{\mathrm{x}}$ " es la concentración de cloruros (en \%peso de hormigón o \% peso de cemento) a una profundidad " $\mathrm{x}$ "; " $\mathrm{C}_{\mathrm{s}}$ " es el contenido de cloruros en superficie (en \% peso de hormigón o \% peso de cemento); " $\mathrm{C}_{\mathrm{b}}$ " es la concentración de cloruros inicial de los componentes del hormigón (en \% peso hormigón o \% peso de cemento); "D" es el coeficiente de difusión a la edad del muelle y " $\mathrm{t}$ " es la edad del muelle o periodo de exposición en segundos.

Por ello, a cada valor de la concentración de cloruros (expresada en \% peso de hormigón) en cada punto se le ha restado el contenido de cloruros obtenido en el fondo del testigo (fuera del perfil de penetración), valor que equivale a la concentración de cloruros inicial del hormigón, es decir " $\mathrm{C}_{\mathrm{b}}$ ". Por tanto, las concentraciones empleadas corresponden $a$ " $\mathrm{C}_{\mathrm{x}}-\mathrm{C}_{\mathrm{b}}$ ". Con los puntos representados, se realiza un ajuste por regresión lineal del modo $(y=m x+b)$, siendo el término independiente de la regresión $b=\sqrt{ }\left(C_{s}-C_{b}\right)$ y la pendiente de la recta $m=\sqrt{ }\left(C_{s}-C_{b}\right) / \sqrt{ }(12 \cdot D \cdot t)$, que se emplea para deducir el valor del coeficiente de difusión " $D$ " a la edad del muelle "t". Sólo se han empleado los perfiles que permitían ajustar la regresión lineal al menos con tres puntos.

En el caso del muelle B, en los testigos $\mathrm{HU}-\mathrm{H} 1, \mathrm{HU}-\mathrm{H} 2$ y $\mathrm{HU}-\mathrm{H} 4$ pertenecientes a las losas se ha realizado un ajuste de los puntos de los tres perfiles como si constituyeran un único perfil. En estos casos, sólo se disponía de dos puntos por perfil para su ajuste para el cálculo de la difusión por lo que, debido a la homogeneidad de sus hormigones, 
se ha decidido realizar esta simplificación. Las figuras 5.173 a 5.176 muestran lo expresado anteriormente para los muelles $A, B, C$ y $D$, respectivamente.

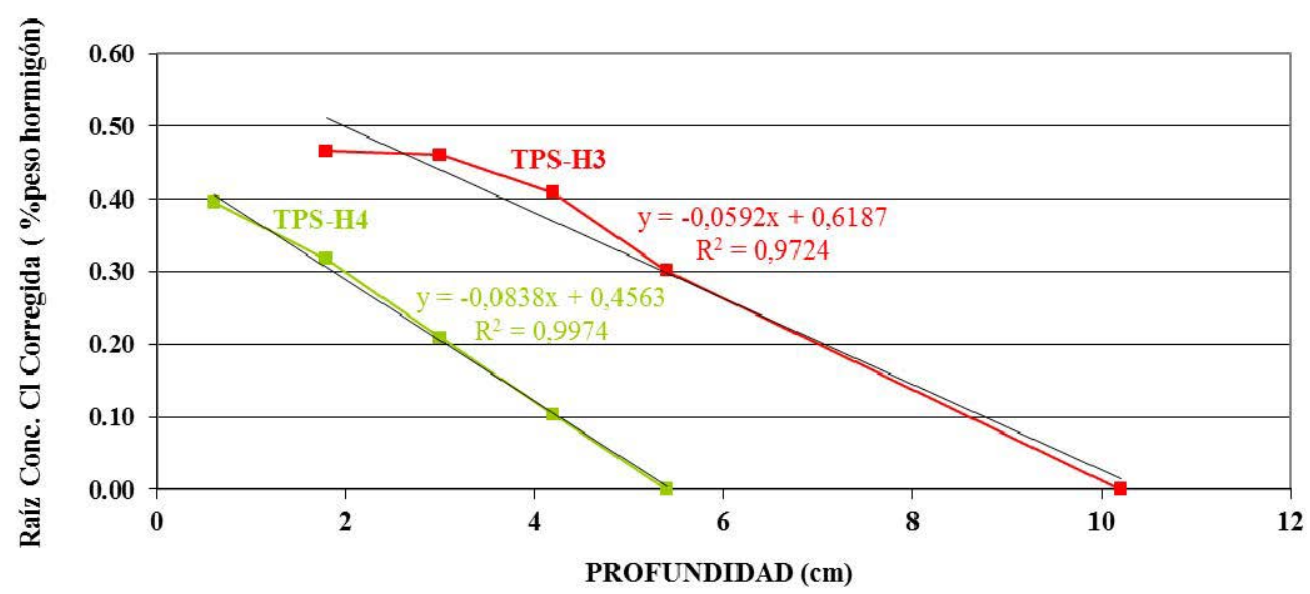

Fig. 5.173. Profundidad media-raíz de la concentración Cl corregida (en \%peso hormigón) en muelle A.

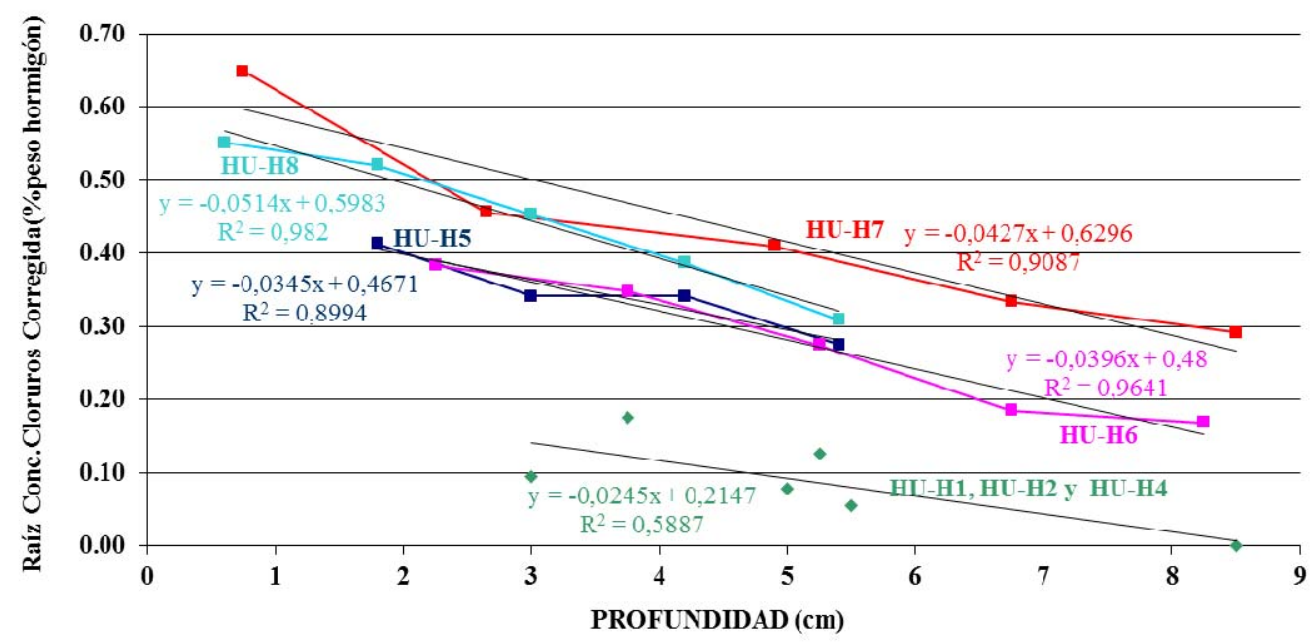

Fig. 5.174. Profundidad media-raíz de la concentración Cl corregida (en \%peso hormigón) en muelle B. 


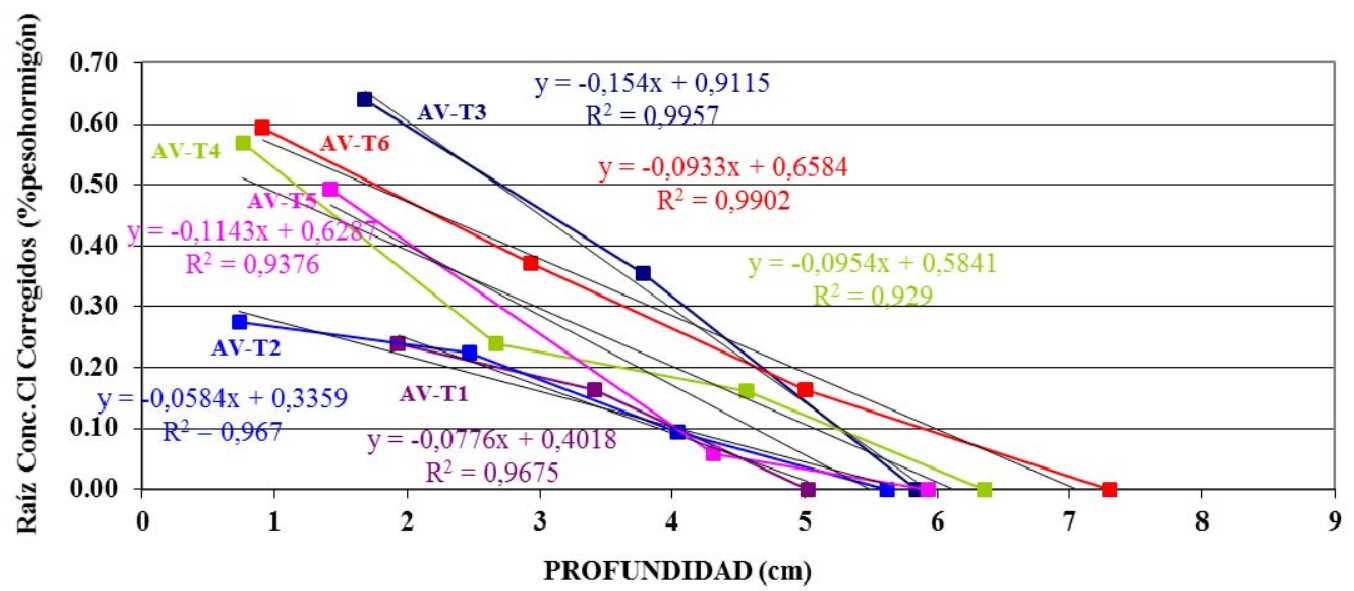

Fig. 5.175. Profundidad media-raíz de la concentración Cl corregida (en \%peso hormigón) en muelle C.

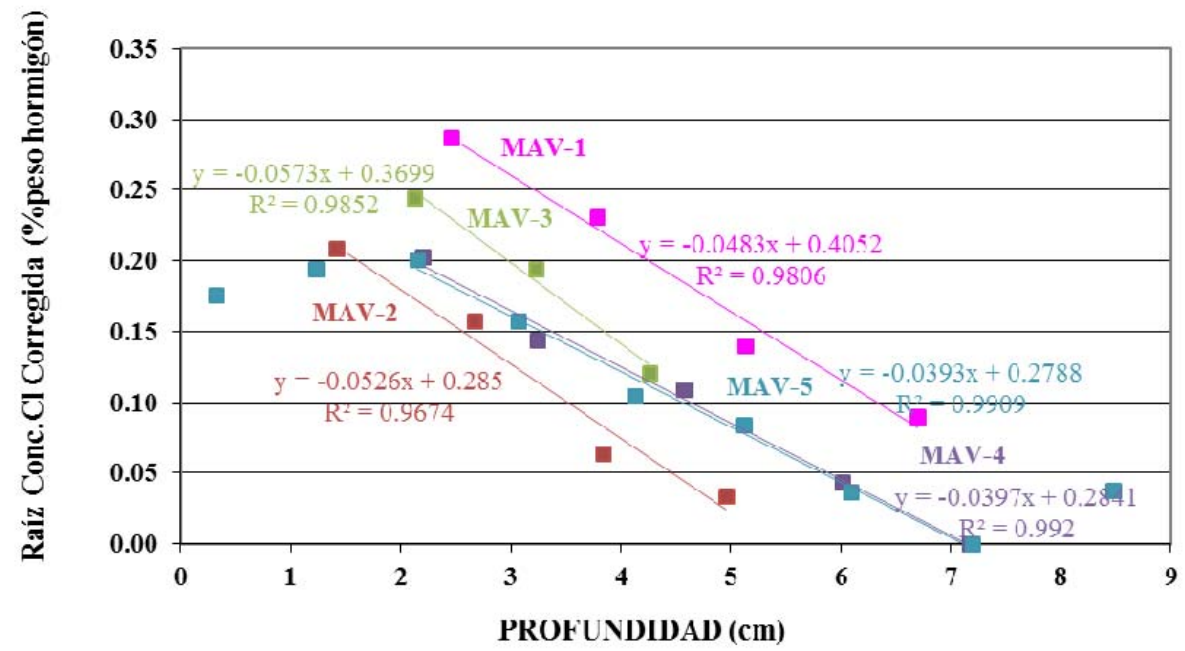

Fig. 5.176. Profundidad media-raíz de la concentración Cl corregida (en \%peso hormigón) en muelle D.

Se pone de manifiesto dentro de un mismo muelle que, con dosificaciones similares de hormigón, se obtienen perfiles de concentración de cloruros diferentes que implican la existencia de otros factores como pueden ser las condiciones de colocación del hormigón en obra o bien factores externos al propio hormigón como las condiciones de exposición (incidencia del viento, Iluvia, niebla salina...) que influyen de manera notable en la penetración de cloruros y por tanto, en la durabilidad del hormigón.

A partir del método anteriormente descrito, se permite obtener los coeficientes de difusión a la edad de cada muelle "D". Para poder realizar un análisis comparativo entre muelles de distintas edades como el caso que nos ocupa, se hace necesario obtener el coeficiente de difusión a 1 año " $\mathrm{D}_{1}$ ". Dado que el coeficiente de difusión varía con el 
tiempo ${ }^{87}$, la expresión siguiente relaciona el valor del coeficiente de difusión " $D$ " a una edad "t" con el valor del coeficiente a 1 año, " $D_{1}$ ":

$$
D(t)=D_{1} \cdot t^{-\alpha}
$$

El coeficiente " $\alpha$ " es el llamado coeficiente de envejecimiento para el que se han encontrado diferentes valores en la bibliografía consultada:

- Un estudio noruego ${ }^{37}$ indica que hay gran variación en los coeficientes de difusión de las estructuras estudiadas y escaso espacio de tiempo transcurrido entre las medidas realizadas como para determinar valores fiables del coeficiente de envejecimiento para estas estructuras. Según experiencias previas emplea $\alpha=0,6$ en sus cálculos.

- Según el Anejo no 9 sobre Durabilidad de la Instrucción EHE 08³ , el factor $n$ de edad puede tomarse, a falta de valores específicos obtenidos mediante ensayos sobre el hormigón de que se trate, igual a 0,5.

- De acuerdo con el Model Code del FIB ${ }^{69}$, el coeficiente de difusión aparente está sometido a una variación considerable y tiende a reducirse con el aumento del tiempo de exposición. Teniendo esto en cuenta al modelizar el período de iniciación, se introduce un parámetro de transferencia " $\mathrm{k}_{\mathrm{t}}$ " en combinación con un coeficiente de envejecimiento "a".

La relación funcional entre el tiempo de exposición t y el coeficiente de difusión aparente $D_{\text {app,c }}$ para tres tipos de cementos distintos se indica en la tabla 5.37. Se deriva de las condiciones de exposición de zona splash, de carrera de mareas y sumergida aunque como consideración del lado de la seguridad también puede aplicarse para zona spray y atmosférica.

\begin{tabular}{|c||c||}
\hline \multicolumn{1}{|c||}{ Hormigón } & Coeficiente de envejecimiento \\
\hline \hline Cemento Portland $(0,40 \leq \mathrm{a} / \mathrm{c} \leq 0,60)$ & Beta $\left(\mathrm{m}^{1}=0,30 ; \mathrm{s}^{2}=0,12 ; \mathrm{a}^{3}=0,0 ; \mathrm{b}^{4}=1,0\right)$ \\
\hline $\begin{array}{c}\text { C. Portland con CV } \\
\left(\mathrm{f} \geq 0,2 \mathrm{z} ; \mathrm{k}=0,5 ; 0,40 \leq \mathrm{a} / \mathrm{c}_{\mathrm{eqv}} \leq 0,62\right.\end{array}$ & Beta $\left(\mathrm{m}^{1}=0,60 ; \mathrm{s}^{2}=0,15 ; \mathrm{a}^{3}=0,0 ; \mathrm{b}^{4}=1,0\right)$ \\
\hline Cemento con escorias $(0,40 \leq \mathrm{a} / \mathrm{c} \leq 0,60)$ & Beta $\left(\mathrm{m}^{1}=0,30 ; \mathrm{s}^{2}=0,20 ; \mathrm{a}^{3}=0,0 ; \mathrm{b}^{4}=1,0\right)$ \\
\hline
\end{tabular}

${ }^{1}$ valor medio, ${ }^{2}$ desviación estándar, ${ }^{3}$ límite superior, ${ }^{4}$ límite inferior.

Tabla 5.37. Valores del coeficiente de envejecimiento según el tipo de hormigón. 
Para llevar a cabo la cuantificación de a, la variable de transferencia kt se fija en 1 (valor constante). El punto de referencia de tiempo escogido t0 $=0,0767$ años (t0=28 días, constante).

La tabla 5.38 muestra los coeficientes de difusión obtenidos a la edad del muelle y a 1 año, $D$ y $D_{1}$ respectivamente. Estos últimos se han calculado empleando los coeficientes de envejecimiento que plantea el FIB y la EHE 08. Asimismo, se presenta para cada muestra el valor de la concentración de cloruros en superficie (valor máximo del perfil), si el perfil refleja o no efecto lavado, la existencia de armadura con o sin corrosión y el recubrimiento de dicha armadura. 


\begin{tabular}{|c|c|c|c|c|c|c|c|c|}
\hline \multirow{3}{*}{$\begin{array}{l}\text { Muelle/ } \\
\text { Edad } \\
\text { (años) }\end{array}$} & \multirow{3}{*}{ Testigo } & \multirow{3}{*}{$\begin{array}{c}\text { Efecto } \\
\text { Lavado }\end{array}$} & \multirow{3}{*}{$\begin{array}{c}\text { Cs (\%p. } \\
\text { hormigón) }\end{array}$} & \multirow{3}{*}{\begin{tabular}{|} 
Coef. Dif. \\
“D” \\
$\left(x 10^{-12}\right.$ \\
$\left.\mathrm{m}^{2} / \mathrm{s}\right)$
\end{tabular}} & \multirow{2}{*}{\multicolumn{2}{|c|}{$\begin{array}{c}\text { Coef. Dif. “ } D_{1} \text { ” } \\
\left(\times 10^{-12} \mathrm{~m}^{2} / \mathrm{s}\right)\end{array}$}} & \multicolumn{2}{|c|}{ Armadura Encontrada } \\
\hline & & & & & & & \multirow{2}{*}{$\begin{array}{c}\text { Corrosión } \\
\text { (Rec.en mm) }\end{array}$} & \multirow{2}{*}{$\begin{array}{c}\mathrm{C}_{\mathrm{x}}(\%) \text { a la } \\
\text { profundidad d } \\
{\text { armadura })^{(1)}}\end{array}$} \\
\hline & & & & & $\boldsymbol{\alpha}_{\text {FIB }}$ & $\boldsymbol{\alpha}_{\mathrm{EHE}}$ & & \\
\hline \multirow{4}{*}{ A (37) } & TPS-H1 & SI & "0,3481 & $1,7,74$ & 5,14 & 10,59 & \multicolumn{2}{|c|}{$\begin{array}{l}--- \\
\end{array}$} \\
\hline & TPS-H2 & SI & 0,4617 & 2,01 & 5,94 & 12,24 & NO (200/400) & -----(2) \\
\hline & TPS-H3 & SI & 0,2798 & 0,78 & 2,30 & 4,74 & NO (90) & 0,65 \\
\hline & TPS-H4 & NO & 0,1751 & 0,21 & 0,63 & 1,29 & NO (100) & $<0,14$ \\
\hline \multirow{9}{*}{ B (26) } & "HU-H1 & $\overline{\mathrm{SI}}$ & "0,0330 & 0,83 & 2,22 & 4 & $\mathrm{NO}(60)$ & $<<0,13$ \\
\hline & HU-H2 & SI & 0,0110 & 1,97 & 5,22 & 10,02 & NO (65) & $<0,06$ \\
\hline & HU-H3 & SI & 0,1530 & 9,61 & 25,55 & 49,02 & NO (60) & -----(2) \\
\hline & HU-H4 & NO & 0,0050 & 0,73 & 1,94 & 3,73 & NO (28) & -----(2) \\
\hline & $\begin{array}{c}\text { H1-H2- } \\
\text { H4 }\end{array}$ & --- & --- & 0,78 & 2,07 & 3,98 & --- & --- \\
\hline & HU-H5 & NO & 0,4790 & 1,86 & 4,95 & 9,50 & \multicolumn{2}{|c|}{---} \\
\hline & HU-H6 & SI & 0,1670 & 1,49 & 3,97 & 7,61 & SI (75) & 0,31 \\
\hline & HU-H7 & NO & 0,4410 & 2,21 & 5,87 & 11,27 & SI (60) & 1,15 \\
\hline & HU-H8 & $\mathrm{NO}$ & 0,3280 & 1,38 & 3,66 & 7,02 & \multicolumn{2}{|c|}{$\begin{array}{ll}--- \\
---\end{array}$} \\
\hline \multirow{6}{*}{ C (11) } & AV-T1 & 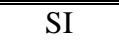 & "0,0639 & 0,64 & 2,71 & 2,14 & NO (105) & 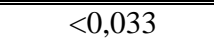 \\
\hline & AV-T2 & $\mathrm{NO}$ & 0,0833 & 0,79 & 3,35 & 2,64 & \multicolumn{2}{|c|}{---} \\
\hline & AV-T3 & SI & 0,4185 & 0,84 & 3,55 & 2,79 & NO (38) & 0,84 \\
\hline & AV-T4 & NO & 0,3293 & 0,90 & 3,80 & 2,99 & $\begin{array}{c}\text { NO } \\
(78 ; 90 ; 205)\end{array}$ & $<0,027$ \\
\hline & AV-T5 & $\mathrm{NO}$ & 0,2478 & 0,73 & 3,06 & 2,41 & SI (15) & 1,575 \\
\hline & AV-T6 & NO & 0,3583 & 1,20 & 5,04 & 3,97 & NO $(50 ; 60)$ & $<0,054$ \\
\hline \multirow{5}{*}{$\mathrm{D}(11)$} & MAV-1 & SI & "0,0920 & $1,1,77$ & 3,59 & 5,75 & NO (92) & $<<0,146$ \\
\hline & MAV-2 & SI & 0,0563 & 0,74 & 1,50 & 2,40 & \multicolumn{2}{|c|}{----} \\
\hline & MAV-3 & SI & 0,0706 & 1,33 & 2,69 & 4,31 & NO $(68 ; 235)$ & $<0,155$ \\
\hline & MAV-4 & SI & 0,0493 & 1,29 & 2,61 & 4,18 & \multicolumn{2}{|c|}{---- } \\
\hline & MAV-5 & SI & 0,0491 & 2,57 & 2,57 & 4,11 & NO $(80 ; 90)$ & $<0,075$ \\
\hline
\end{tabular}

Tabla 5.38. Coeficiente de Difusión de Cloruros a la edad del muelle (D) y a un año $\left(D_{1}\right)$.

(1) Cuando se indica que el valor de la concentración de cloruros en superficie es < que un valor se debe a que no hay corte del perfil de cloruros con la armadura a la profundidad encontrada y se ha indicado el valor más bajo del perfil.

(2) En estos casos los valores disponibles no resultan relevantes por encontrarse muy alejados del valor real de la concentración de cloruros en ese punto.

A la vista de la tabla 5.1 de características de los muelles del punto 5.2.5, el hormigón del muelle $A$ se habría proyectado según la normativa HA-61, el del muelle $B$ según la $E H-80$, el del muelle $C$ según la $E H-91$ y el del muelle $D$ según la $E H-98$, respecto a contenido de cemento y relación a/c empleados. De los cuatro hormigones estudiados, sólo el correspondiente al muelle $\mathrm{C}$ se ha fabricado empleando cemento con adiciones. 
Puede observarse la influencia positiva del empleo de adiciones en la dosificación del hormigón, ya que los coeficientes de difusión obtenidos son, en general, menores. Esto supone que en el hormigón del muelle $C$ se alcanzan velocidades de penetración de cloruros menores que en los muelles A, B y D.

Finalmente, cabe destacar en la Tabla 5.38 las grandes diferencias obtenidas en el valor del coeficiente de difusión al considerar el coeficiente de envejecimiento único que recoge la Instrucción EHE-08 (de valor 0,5$)$ o los dos coeficientes $(0,3$ para portland y 0,6 para cenizas volantes), siendo muy superiores en el primer caso para los casos de cemento portland.

\subsubsection{Análisis de la concentración de cloruros en superficie}

En el Anejo no 1 de la presente tesis doctoral se realiza el "Estudio de la Concentración de $\mathrm{Cl}$ en Superficie". El estudio se ha recogido en un Anejo ya que se han incluido en el mismo no solamente los resultados de los muelles analizados en la presente investigación (ambiente marino aéreo) sino también los obtenidos en el estudio previo de hormigones en ambiente sumergido y carrera de mareas, así como otros datos tomados de la bibliografía.

Como resumen de lo desarrollado en este anejo, se presenta a continuación la propuesta de valores de $\mathrm{C}_{\mathrm{s}}$ planteada así como las conclusiones obtenidas.

\section{Propuesta de valores y comparación con la EHE 08}

Según los resultados analizados (Anejo $n^{0} 1$ ) y tomando como referencia los valores medios de Cs obtenidos en los hormigones situados en los diferentes ambientes marinos, se podrían adoptar los valores planteados en la tabla 5.39 para el cálculo de vida útil. En comparación con lo actualmente recogido en la Instrucción EHE-08 se introduce una zona de spray con un nuevo límite y se rebaja el límite de la zona sumergida.

\begin{tabular}{|c|c|c|c|c|c|}
\hline $\begin{array}{l}\text { Clase General de } \\
\text { Exposición }\end{array}$ & \multicolumn{3}{|c|}{ IIIa } & IIIb & \begin{tabular}{|c|} 
IIIc \\
(incluyendo zona de \\
salpicaduras $h<1,5 \mathrm{~m}$ )
\end{tabular} \\
\hline Distancia a la costa & \begin{tabular}{|}
$\begin{array}{r}\text { Oona de spray } \\
(\mathrm{h}>1,5 \mathrm{~m})\end{array}$ \\
\end{tabular} & Hasta $500 \mathrm{~m}$ & $500 \mathrm{~m}-5000 \mathrm{~m}$ & \multirow{2}{*}{0,35} & \multirow{2}{*}{0,50} \\
\hline Cs(\% p. hormigón) & 0,25 & 0,14 & 0,07 & & \\
\hline
\end{tabular}

Tabla 5.39. Propuesta de valores de concentración de cloruros en superficie. 
En la figura 5.177 se representan los valores medios y característicos obtenidos en los tres ambientes marinos así como los límites que actualmente plantea la normativa EHE08 al tiempo que se incorporan en trazo discontinuo las nuevas propuestas de límites de la tabla anterior, resultado del análisis del estudio realizado.

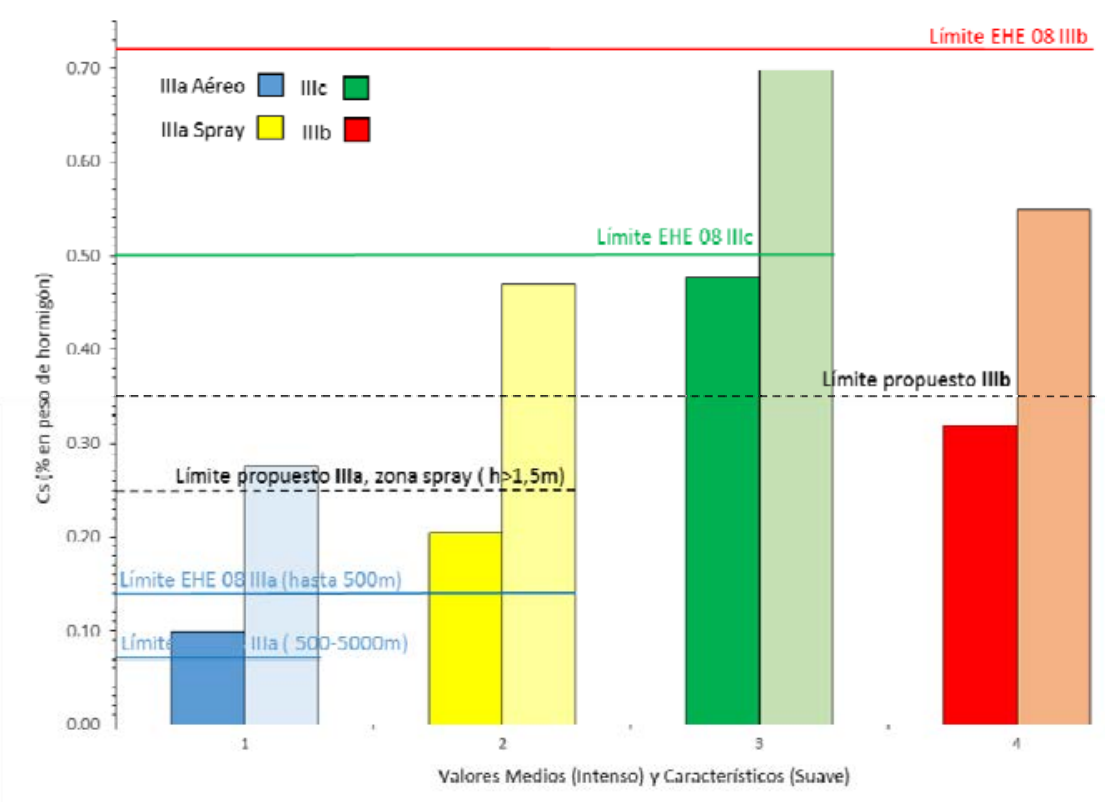

Fig 5.177. Valores medios y característicos de Cs, límites actuales de la normativa EHE08 y nuevas propuestas.

A la vista del gráfico obtenido, puede observarse:

- Los resultados experimentales medidos en estructuras reales indican la necesidad de proponer un nuevo valor de cloruros en superficie para al ambiente IIlb, ya que el actual resulta excesivamente conservador.

- Se considera necesario introducir un nuevo valor de cloruros en superficie, definiendo (de acuerdo con el criterio del $\mathrm{FIB}^{9}$ ) una zona spray en la franja de la estructura que se encuentra a una altura superior a $1,5 \mathrm{~m}$ sobre el nivel del mar.

- Los resultados experimentales analizados en este estudio (valores medios) son coherentes con los recogidos en la Instrucción para el ambiente Illa aéreo y el ambiente IIIc de carrera de mareas.

- Adoptar valores característicos del contenido de Cs supondría elevar notablemente los límites actualmente recogidos por la Instrucción EHE-08 en todos los ambientes, 
salvo en el ambiente sumergido, por lo que los requisitos propuestos corresponden a valores medios.

\section{Conclusiones Obtenidas}

Al término del análisis realizado sobre la concentración de cloruros en superficie en el anejo $n^{\circ} 1$ se alcanzan las siguientes conclusiones:

- Existen diferentes criterios normativos en la clasificación de los ambientes marinos.

- En el ambiente marino aéreo destaca la normativa japonesa, que considera relevantes sólo los primeros $200 \mathrm{~m}$ de costa (700 m en zona de tormentas) y realiza una mayor discretización de esta franja, que eleva notablemente su contenido de cloruros en superficie al acercarse a la línea de mar. El planteamiento es muy diferente a la división simple en dos subzonas de la zona costera que plantea la Instrucción EHE-08.

- El FIB plantea la existencia de una zona de spray en la franja de la estructura situada 1,5m sobre el mar, que no se recoge en la Instrucción EHE-08 y que el presente estudio indica que es necesaria, ya que se diferencia en comportamiento respecto a la de salpicaduras y carrera de mareas.

- Los datos de $\mathrm{C}_{\mathrm{s}}$ recabados en la literatura son muy variables y dispersos dependiendo de la fuente consultada.

- Los resultados obtenidos en este estudio sobre estructuras reales demuestran que el valor de $\boldsymbol{C}_{\mathrm{s}}$ está fundamentalmente influenciado por el tipo de ambiente marino, si bien los datos fluctúan incluso dentro de un mismo puerto y en zonas diferentes de la misma estructura. Esto puede responder a fenómenos locales, por ejemplo zonas de abrigo frente a otras más expuestas o la orientación del paramento frente al viento.

- No existe una influencia determinante de la salinidad puesto que, a pesar de que el mar Mediterráneo tiene un mayor contenido en sales que el mar Cantábrico y el océano Atlántico, los resultados de $\mathrm{C}_{\mathrm{s}}$ obtenidos en los tres casos no difieren entre sí, ni incluso tampoco al incluir datos procedentes de otros países con climatología muy diferente a la nuestra (Noruega o Japón). 
- $\quad$ El lavado en superficie se presenta únicamente en ambiente IIla, al tratarse de un hormigón expuesto al agua de lluvia. Asimismo, el efecto se produce por igual en hormigones con alto y bajo contenido de cloruros en superficie.

- Los resultados experimentales obtenidos en ambiente sumergido indican la necesidad de proponer un nuevo valor de cloruros en superficie para al ambiente sumergido IIlb $(0,35 \%)$, ya que el actual resulta excesivamente conservador $(0,72 \%)$.

- Se considera necesario introducir un nuevo valor de cloruros en superficie igual a $0,25 \%$, definiendo (de acuerdo con el criterio del $\mathrm{FIB}^{9}$ ) una zona spray en la franja de la estructura que se encuentra a una altura superior a $1,5 \mathrm{~m}$ sobre el nivel del mar.

- Los resultados experimentales (valores medios) analizados en este estudio son coherentes con los recogidos en la Instrucción para el ambiente Illa aéreo y el ambiente IIIc de carrera de mareas.

\subsubsection{Análisis de la concentración crítica de cloruros.}

En el anejo $\mathrm{n}^{\circ} 2$ de la presente tesis doctoral se realiza el "Estudio de la Concentración Crítica de $\mathrm{Cl}\left(\mathrm{C}_{\mathrm{th}}\right)$ ". El estudio se ha recogido en un Anejo ya que se han incluido en el mismo no solamente los resultados de los muelles analizados en la presente investigación (ambiente marino aéreo) sino también los obtenidos en el estudio previo de hormigones en ambiente sumergido y carrera de mareas, así como otros datos tomados de la bibliografía. Como resumen de lo desarrollado en este anejo, se presenta a continuación la propuesta de valores de $\mathrm{C}_{\text {th }}$ planteada así como las conclusiones obtenidas.

Las figuras $5.178,5.179$ y 5.180 muestran los umbrales de cloruros para el ambiente IIIa, IIIb y IIIc respectivamente, correspondientes a los estudios realizados en el CEDEX y añadiendo datos adicionales extraídos de estructuras internacionales No se han representado los resultados en los que el umbral de cloruros se encontraba por debajo del $0,4 \%$ en peso de cemento propuesto por la normativa española como contenido límite de cloruros inicial en el hormigón armado, ya que no resulta coherente. 


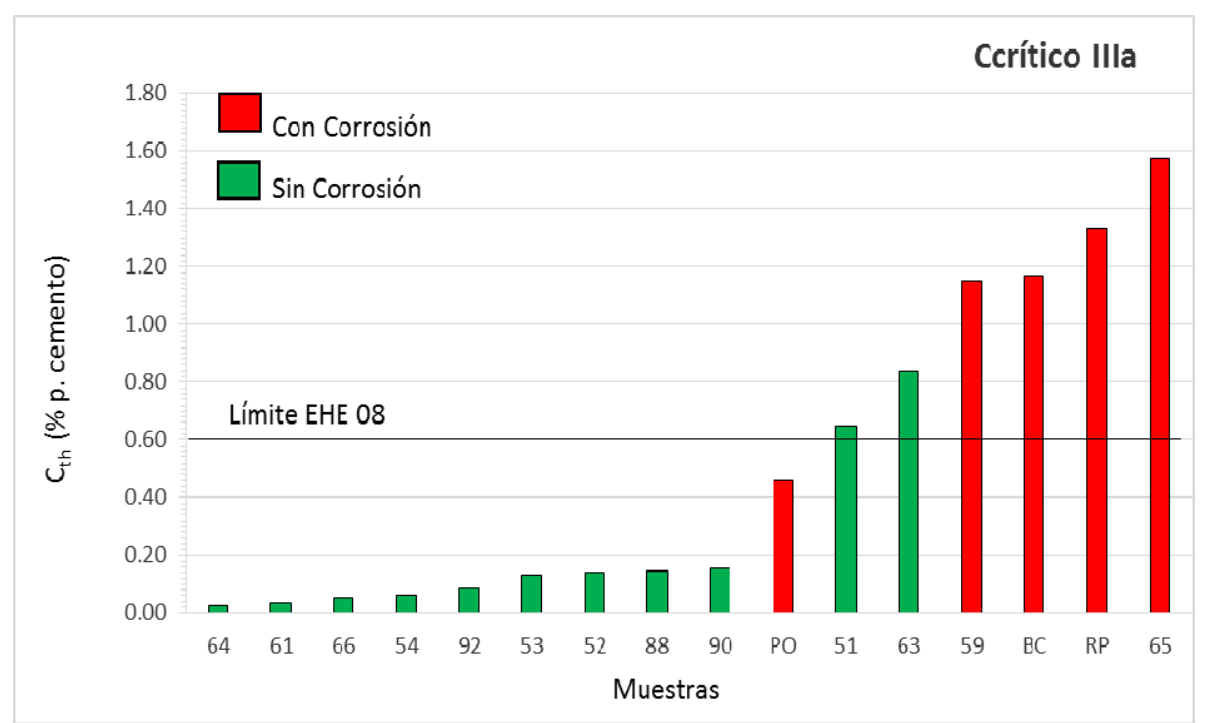

Fig 5.178. Valores $C_{\text {th }}$ experimentales y de bibliografía. Ambiente IIIa.

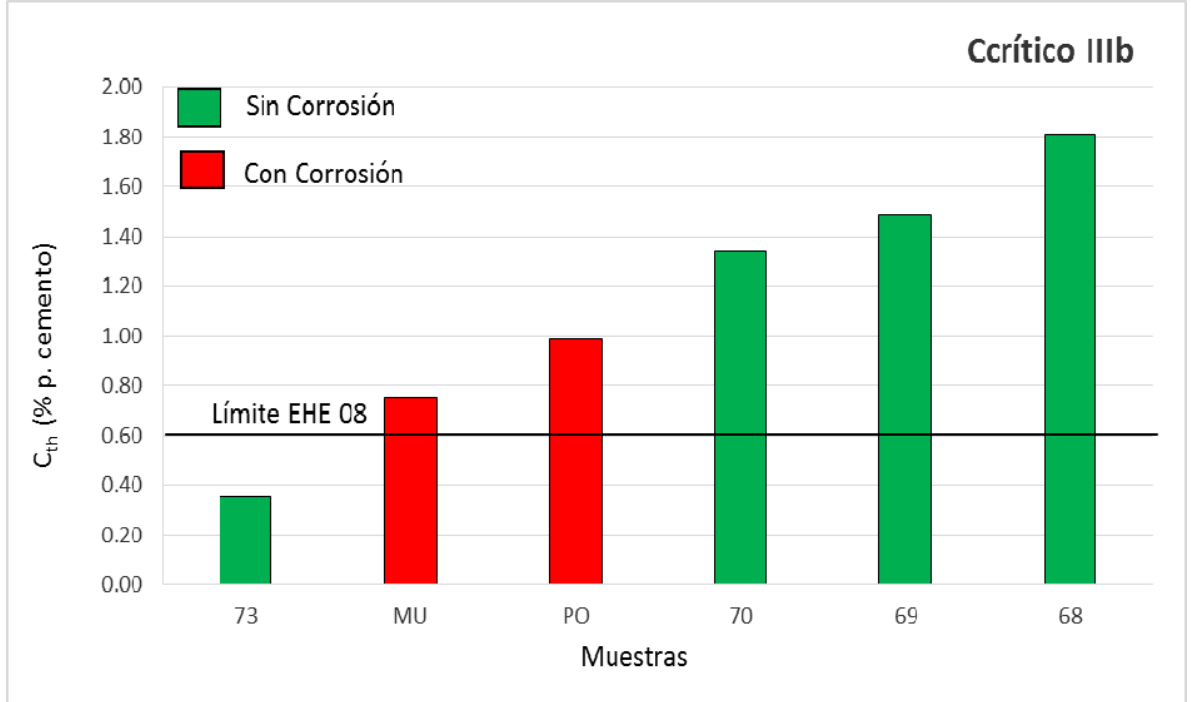

Fig 5.179. Valores $C_{\text {th }}$ experimentales y de bibliografía. Ambiente IIIb.

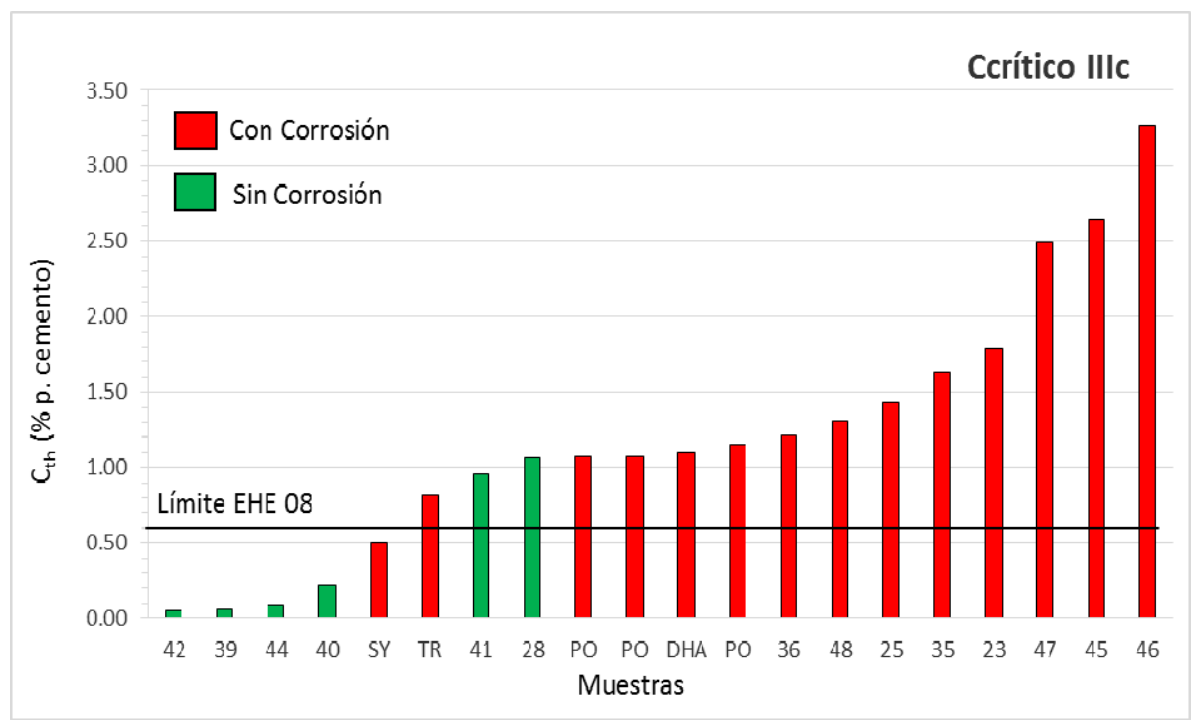

Fig 5.180. Valores $C_{\text {th }}$ experimentales y de bibliografía. Ambiente IIIc. 


\section{Propuesta de valores de $\mathrm{C}_{\mathrm{x}}$}

Los resultados obtenidos aconsejarían mantener el valor de concentración crítica de cloruros del $0,6 \%$ que ha resultado conservador y además también está recogido en otras normativas internacionales.

Sería necesario disponer de un mayor número de resultados experimentales para proponer un cambio de este límite.

\section{Conclusiones obtenidas}

Al término del análisis realizado sobre la concentración crítica de cloruros en el anejo $\mathrm{n}^{\circ}$ 2 se alcanzan las siguientes conclusiones:

- En general, todas las normativas internacionales establecen límites al contenido inicial de cloruros presentes en el hormigón, aunque los valores difieren sustancialmente de unos países a otros, existiendo un número alto de normas que adoptan valores más conservadores al recogido por la Instrucción EHE-08 (0,4\%). En particular, la normativa americana establece límites 0,06\% (hormigón pretensado) y 0,15\% (hormigón armado) para ambiente marino.

- El umbral de cloruros que origina el comienzo de la corrosión de la armadura está muy influenciado por el ambiente marino al que está expuesto el hormigón, si bien la normativa internacional adopta un valor único que oscila del 0,4 al $0,6 \%$ en función de las normas consultadas.

- El límite de la EHE-08 (0,6\%) ha resultado válido, incluso bastante conservador, para los resultados obtenidos en estructuras españolas en los tres ambientes. Así, los casos de corrosión se han presentado con contenidos de cloruros bastante muy por encima del límite actual normativo: 1\% para ambiente IIla y IIIc, 1,8\% para ambiente sumergido.

- Sin embargo, al considerar estudios realizados en estructuras internacionales se registran valores de cloruros que sí han ocasionado corrosión con concentraciones ligeramente superiores al $0,6 \%$ en ambiente IIIb e incluso con valores ligeramente superiores al $0,4 \%$ en los ambientes IIla y IIlc. Estos resultados se han obtenido descartando valores puntuales que resultaban anómalos por su bajo valor para llegar a ocasionar corrosión (entre 0,10 y 0,23\%).

- No se ha observado en los datos analizados una variación en la concentración crítica de cloruros por la utilización de cementos con adiciones o cementos portland. 


\subsubsection{Análisis de los coeficientes de difusión y los resultados de los ensayos de caracterización}

En el apartado 5.7.2. "Cálculo del coeficiente de difusión de cloruros", se obtuvieron los coeficientes de difusión a un año. Se pretende relacionar los resultados de difusión con los resultados de los ensayos de laboratorio realizados para controlar la durabilidad del hormigón. Las tablas 5.40 y 5.41 muestran los valores de los coeficientes de difusión a un año y del resto de los ensayos realizados en los testigos del pantalán $A$, las tablas 5.42 y 5.43 los del B, las tablas 5.44 y 5.45 , los del C y las tablas 5.46 y 5.47 los del D. Los coeficientes de difusión resultan diferentes para la FIB y la Instrucción EHE-08 ya que la primera establece un coeficiente de envejecimiento de valor 0,3 si el hormigón está fabricado con cemento Portland y de valor 0,6 si incorpora cenizas volantes. La Instrucción española adopta un único valor del coeficiente igual a 0,5.

\begin{tabular}{|c|c|c|c|c|c|c|c|c|}
\hline \multirow{2}{*}{ Muelle } & \multirow{2}{*}{ Testigo } & \multicolumn{2}{|c|}{$\mathrm{D}_{1}\left(\cdot 10^{-12} \mathrm{~m}^{2} / \mathrm{s}\right)$} & \multirow{2}{*}{$\begin{array}{c}\text { Resistencia } \\
\left(\mathrm{N} / \mathrm{mm}^{2}\right)\end{array}$} & \multirow{2}{*}{$\begin{array}{c}\text { Porosidad } \\
\text { (\%) }\end{array}$} & \multirow{2}{*}{$\begin{array}{c}\text { Absorción } \\
\text { (\%) }\end{array}$} & \multirow{2}{*}{$\begin{array}{l}\text { P. Máxima } \\
(\mathrm{mm})\end{array}$} & \multirow{2}{*}{$\begin{array}{l}\text { P. Media } \\
\text { (mm) }\end{array}$} \\
\hline & & $\boldsymbol{\alpha}_{\mathrm{FIB}}$ & $\boldsymbol{\alpha}_{\mathrm{EHE}}$ & & & & & \\
\hline \multirow{4}{*}{ A } & "TPS-H1 & 25,14 & 10,59 & 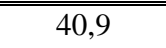 & 20,1 & 24,75 & 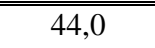 & 38,0 \\
\hline & TPS-H2 & 5,94 & 12,24 & 29,7 & 20,8 & 4,90 & 28,0 & 22,0 \\
\hline & TPS-H3 & 2,30 & 4,74 & 45,1 & 20,7 & 4,94 & 61,0 & 54,5 \\
\hline & TPS-H4 & 0,63 & 1,29 & 39,9 & 16,1 & 3,45 & $* *$ & $* *$ \\
\hline
\end{tabular}

Tabla 5.40. Muelle A. Resumen de resultados de ensayos y coeficientes de difusión $D_{1}$.

\begin{tabular}{|c|c|c|c|c|}
\hline Muelle & Testigo & $\begin{array}{c}\text { Permeabilidad Agua } \\
\left(\cdot 10^{-12} \mathrm{~m} / \mathrm{s}\right)\end{array}$ & Capilaridad (mm/ $/ \sqrt{\min })$ & Permeabilidad $\mathrm{O}_{2}\left(\cdot 10^{-16} \mathrm{~m}^{2}\right)$ \\
\hline \multirow{4}{*}{ A } & "TPS-H1 & 6,71 & 0,18 & 0,85 \\
\hline & TPS-H2 & 2,81 & 0,11 & 2,53 \\
\hline & TPS-H3 & 13,29 & 0,21 & 0,64 \\
\hline & TPS-H4 & 20,00 & 0,12 & 0,87 \\
\hline
\end{tabular}

Tabla 5.41. Muelle A. Resumen de resultados de ensayos de permeabilidad al agua y capilaridad. 


\begin{tabular}{|c|c|c|c|c|c|c|c|c|}
\hline \multirow{2}{*}{ Muelle } & \multirow{2}{*}{ Testigo } & \multicolumn{2}{|c|}{$\mathrm{D}_{1}\left(\cdot 10^{-12} \mathrm{~m}^{2} / \mathrm{s}\right)$} & \multirow{2}{*}{$\begin{array}{c}\text { Resistencia } \\
\left(\mathrm{N} / \mathrm{mm}^{2}\right)\end{array}$} & \multirow{2}{*}{$\begin{array}{c}\text { Porosidad } \\
\text { (\%) }\end{array}$} & \multirow{2}{*}{$\begin{array}{c}\text { Absorción } \\
\text { (\%) }\end{array}$} & \multirow{2}{*}{$\begin{array}{l}\text { Pmax. } \\
(\mathrm{mm})\end{array}$} & \multirow{2}{*}{$\begin{array}{l}\text { P. Media } \\
\text { (mm) }\end{array}$} \\
\hline & & $\alpha_{\text {FIB }}$ & $\boldsymbol{\alpha}_{\mathrm{EHE}}$ & & & & & \\
\hline \multirow{9}{*}{ B } & $\begin{array}{c}\text { HU-H1 } \\
\end{array}$ & 2,22 & 4,26 & $\overline{50,2}$ & $\overline{16,2}$ & *** & *** & *** \\
\hline & HU-H2 & 5,22 & 10,02 & 48,0 & 15,7 & $* *$ & 26,0 & 16,5 \\
\hline & HU-H3 & 25,55 & 49,02 & $* *$ & 14,0 & $* *$ & ** & $* *$ \\
\hline & HU-H4 & 1,94 & 3,73 & 55,5 & 13,6 & 1,58 & 26,0 & 13,0 \\
\hline & H1-H2-H4 & 2,07 & 3,98 & 51,23 & 15,17 & 1,58 & 26,0 & 14,75 \\
\hline & HU-H5 & 4,95 & 9,50 & 47,8 & 8,4 & 2,21 & 106,0 & 106,0 \\
\hline & HU-H6 & 3,97 & 7,61 & 44,3 & 9,4 & $* *$ & 47,0 & 35,5 \\
\hline & HU-H7 & 5,87 & 11,27 & 40,4 & 11,0 & 2,81 & 80,5 & 67,5 \\
\hline & HU-H8 & 3,66 & 7,02 & 50,2 & 10,4 & 2,28 & 42,0 & 32,5 \\
\hline
\end{tabular}

Tabla 5.42. Muelle B. Resumen de resultados de ensayos y coeficientes de difusión $\mathrm{D}_{1}$.

\begin{tabular}{|c|c||c||c||c||}
\hline Muelle & Testigo & $\begin{array}{c}\text { Permeabilidad Agua } \\
\left(\cdot 10^{-12} \mathrm{~m} / \mathrm{s}\right)\end{array}$ & $\begin{array}{c}\text { Capilaridad } \\
(\mathrm{mm} / \sqrt{\mathrm{min}})\end{array}$ & $\begin{array}{c}\text { Permeabilidad } \mathrm{O}_{2}\left(\cdot 10^{-}\right. \\
\left.{ }^{2} \mathrm{~m}^{2}\right)\end{array}$ \\
\hline \hline \multirow{6}{*}{ B } & HU-H1 & $* *$ & 0,09 & 1,88 \\
\cline { 2 - 5 } & HU-H2 & 1,83 & 0,06 & 3,42 \\
\cline { 2 - 5 } & HU-H3 & $* *$ & $* *$ & 0,47 \\
\cline { 2 - 5 } & HU-H4 & 1,59 & 0,06 & 1,92 \\
\cline { 2 - 5 } & H1-H2-H4 & 1,71 & 0,07 & 0,65 \\
\cline { 2 - 5 } & HU-H5 & 16,22 & 0,08 & 0,71 \\
\cline { 2 - 5 } & HU-H6 & 3,58 & 0,07 & 2,01 \\
\cline { 2 - 5 } & HU-H7 & 12,23 & 0,12 & 0,44 \\
\cline { 2 - 5 } & HU-H8 & 3,16 & 0,04 & ${ }^{*}$ \\
\hline \hline
\end{tabular}

Tabla 5.43. Muelle B. Resumen de resultados de ensayos de permeabilidad al agua y capilaridad.

\begin{tabular}{|c|c|c|c|c|c|c|c|c|}
\hline \multirow{2}{*}{ Muelle } & \multirow{2}{*}{ Testigo } & \multicolumn{2}{|c|}{$\overline{\mathrm{D}_{1}\left(\cdot 10^{-12} \mathrm{~m}^{2} / \mathrm{s}\right)}$} & \multirow{2}{*}{$\begin{array}{c}\text { Resistencia } \\
\left(\mathrm{N} / \mathrm{mm}^{2}\right)\end{array}$} & \multirow{2}{*}{$\begin{array}{c}\text { Porosidad } \\
\text { (\%) }\end{array}$} & \multirow{2}{*}{$\begin{array}{c}\text { Absorción } \\
\text { (\%) }\end{array}$} & \multirow{2}{*}{$\begin{array}{l}\text { Pmax. } \\
(\mathrm{mm})\end{array}$} & \multirow{2}{*}{$\begin{array}{l}\text { P. Media } \\
(\mathrm{mm})\end{array}$} \\
\hline & & $\overline{\alpha_{\mathrm{FIB}}}$ & $\overline{\boldsymbol{\alpha}_{\mathrm{EHE}}}$ & & & & & \\
\hline \multirow{6}{*}{ C } & AV-T1 & 2,71 & 2,14 & 46,0 & 18,9 & 2,77 & 25,5 & 17,6 \\
\hline & AV-T2 & 3,35 & 2,64 & 50,4 & 17,8 & 2,13 & 22,0 & 10,9 \\
\hline & AV-T3 & 3,55 & 2,79 & 42,1 & 19,0 & 3,29 & 30,0 & 20,7 \\
\hline & AV-T4 & 3,80 & 2,99 & 47,8 & 17,7 & 2,65 & 27,0 & 17,6 \\
\hline & AV-T5 & 3,06 & 2,41 & 54,3 & 17,7 & 2,11 & 15,5 & 5,8 \\
\hline & AV-T6 & 5,04 & 3,97 & 47,0 & 18,3 & 2,18 & 18,0 & 11,9 \\
\hline
\end{tabular}

Tabla 5.44. Muelle C. Resumen de resultados de ensayos y coeficientes de difusión $\mathrm{D}_{1}$. 


\begin{tabular}{||c|c||c||c|c||}
\hline \multirow{2}{*}{ Muelle } & Testigo & $\begin{array}{c}\text { Permeabilidad Agua } \\
\left(\cdot 10^{-12} \mathrm{~m} / \mathrm{s}\right)\end{array}$ & $\begin{array}{c}\text { Capilaridad } \\
(\mathrm{mm} / \sqrt{ } \mathrm{min})\end{array}$ & $\begin{array}{c}\text { Permeabilidad } \mathrm{O}_{2} \\
\left(\cdot 10^{-16} \mathrm{~m}^{2}\right)\end{array}$ \\
\hline \hline \multirow{6}{*}{$\mathrm{C}$} & AV-T1 & 2,12 & 0,07 & 4,53 \\
\cline { 2 - 5 } & AV-T2 & 1,49 & 0,06 & 0,29 \\
\cline { 2 - 5 } & AV-T3 & 2,95 & 0,08 & 3,50 \\
\cline { 2 - 5 } & AV-T4 & 2,23 & 0,08 & 1,01 \\
\cline { 2 - 5 } & AV-T5 & 2,23 & 0,04 & 0,09 \\
\cline { 2 - 5 } & AV-T6 & 2,23 & 0,06 & 0,23 \\
\hline
\end{tabular}

Tabla 5.45. Muelle C. Resumen de resultados de ensayos de permeabilidad al agua y capilaridad.

\begin{tabular}{|c|c|c|c|c|c|c|c|c|}
\hline \multirow{2}{*}{ Muelle } & \multirow{2}{*}{ Testigo } & \multicolumn{2}{|c|}{$\mathrm{D}_{1}\left(\cdot 10^{-12} \mathrm{~m}^{2} / \mathrm{s}\right)$} & \multirow{2}{*}{$\begin{array}{c}\text { Resistencia } \\
\left(\mathrm{N} / \mathrm{mm}^{2}\right)\end{array}$} & \multirow{2}{*}{$\begin{array}{c}\text { Porosidad } \\
\text { (\%) }\end{array}$} & \multirow{2}{*}{$\begin{array}{c}\text { Absorción } \\
\text { (\%) }\end{array}$} & \multirow{2}{*}{$\begin{array}{l}\text { Pmax } \\
(\mathrm{mm})\end{array}$} & \multirow{2}{*}{$\begin{array}{l}\text { P. Media } \\
(\mathrm{mm})\end{array}$} \\
\hline & & $\overline{\alpha_{\text {FIB }}}$ & $\alpha_{\text {EHE }}$ & & & & & \\
\hline \multirow{5}{*}{ D } & MAV-1 & $3,3,59$ & 25,75 & 26,5 & $\overline{16,9}$ & ב--- & 447,0 & 26,6 \\
\hline & MAV-2 & 1,50 & 2,40 & 30,8 & 13,6 & 2,04 & 28,0 & 14,8 \\
\hline & MAV-3 & 2,69 & 4,31 & 18,2 & 13,1 & --- & 26,0 & 12,6 \\
\hline & MAV-4 & 2,61 & 4,18 & 33,5 & 13,0 & 2,09 & 24,0 & 12,9 \\
\hline & MAV-5 & 2,57 & 4,11 & --- & 14,4 & --- & 30,0 & 18,5 \\
\hline
\end{tabular}

Tabla 5.46. Muelle D. Resumen de resultados de ensayos y coeficientes de difusión $\mathrm{D}_{1}$.

\begin{tabular}{|c|c|c|c|}
\hline Muelle & Testigo & Permeabilidad Agua $\left(\cdot 10^{-12} \mathrm{~m} / \mathrm{s}\right)$ & Capilaridad $(\mathrm{mm} / \sqrt{ } \mathrm{min})$ \\
\hline \hline \multirow{3}{*}{ D } & MAV-1 & 6,44 & 0,098 \\
\cline { 2 - 4 } & MAV-2 & 1,84 & 0,054 \\
\cline { 2 - 4 } & MAV-3 & 1,53 & 0,064 \\
\cline { 2 - 4 } & MAV-4 & 1,29 & 0,053 \\
\cline { 2 - 4 } & MAV-5 & 2,24 & --- \\
\hline
\end{tabular}

Tabla 5.47. Muelle D. Resumen de resultados de ensayos de permeabilidad al agua y capilaridad.

A continuación se analizan por separado los gráficos de correlación obtenidos entre difusión y cada una de las propiedades ensayadas. Se muestran en todos los casos los valores de difusión utilizando el coeficiente de envejecimiento de la Instrucción EHE-08 y de la FIB.

\section{Difusión-Resistencia a Compresión}

La figura 5.181 muestra la representación de las parejas de valores (coeficientes de difusión-resistencia a compresión expresada en $\mathrm{N} / \mathrm{mm}^{2}$ ) para los testigos de los pantalanes analizados: 

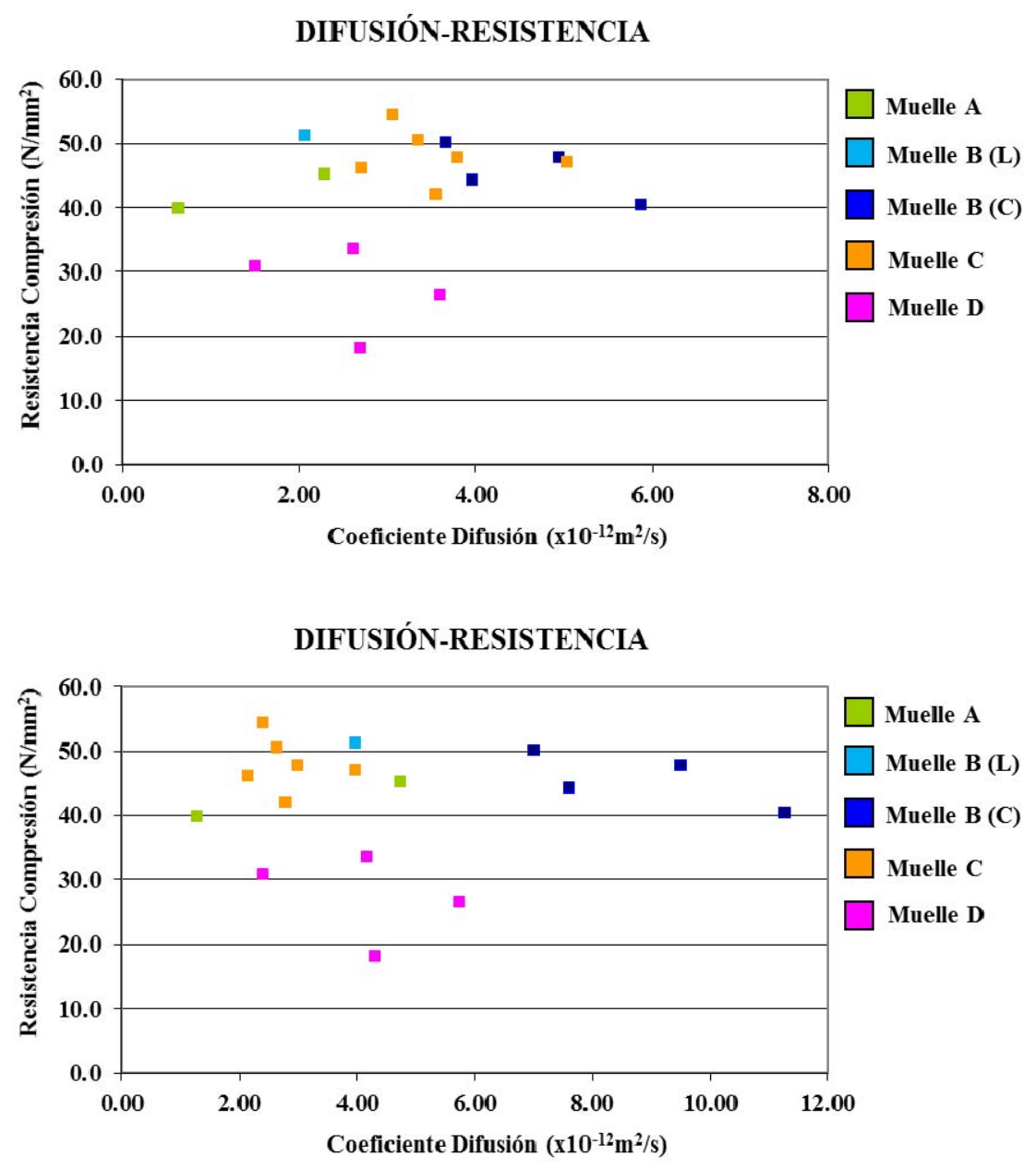

Fig. 5.181. Relación Difusión-Resistencia a Compresión.

Criterio Fib (arriba), Criterio EHE 08 (abajo).

A la vista de los resultados, se observa una gran uniformidad de los valores de resistencia a compresión en todos los muelles, estando comprendidos la gran mayoría de ellos entre $40-50 \mathrm{~N} / \mathrm{mm}^{2}$, salvo en el caso del muelle $D$ en que los valores resultan inferiores. Sin embargo, hay que hacer notar que los testigos de este muelle se ensayaron saturados de agua, ya que procedían del ensayo previamente realizado de resistividad. Este hecho puede ocasionar una reducción de resistencia entorno al 10$15 \%$.

De forma global se observa que existe poca influencia de la resistencia a compresión de los testigos en los valores de los coeficientes de difusión obtenidos, ya que con similares valores de resistencia a compresión, los valores de los coeficientes de difusión presentan grandes variaciones. Sin embargo si se observan los resultados obtenidos de forma individual en cada muelle, sí se aprecia que los testigos de mayor resistencia han 
dado lugar a valores inferiores del coeficiente de difusión (salvo en los dos puntos del Muelle A), si bien el efecto es muy leve.

De todos los datos representados, tan sólo los correspondientes al Muelle C corresponden a un cemento con ceniza volante. Sería de esperar en este caso la obtención de valores de difusión menores gracias al efecto de la adición. Este efecto sólo se refleja en el gráfico que utiliza el Criterio EHE, en el que se aprecia asimismo que el efecto de la adición se acusa en el valor del coeficiente de difusión pero apenas en los valores de resistencia obtenidos.

Por otra parte, los bajos resultados de resistencia obtenidos en el Muelle D contrastan con lo reducido de los coeficientes de difusión registrados en el mismo. Este hecho debe atribuirse a la baja concentración de cloruros en superficie que tiene el hormigón de este muelle en comparación con el resto (Ver tabla 8, anejo n 1), lo cual minimiza la difusión de los cloruros en el interior del hormigón incluso al tratarse de un hormigón de peor calidad.

Puede concluirse que la resistencia a compresión es coherente con los resultados del coeficiente de difusión (mayor resistencia conlleva menor difusión), pero su efecto es muy leve y se manifiesta de forma individual en cada muelle, ya que los coeficientes de difusión están muy influenciados por el tipo de exposición (contenido de cloruros en superficie) que puede ser variable por las condiciones locales en cada caso.

En conclusión, se considera que la resistencia no resulta un ensayo adecuado para controlar la durabilidad dado que hormigones de resistencia similar pueden presentar coeficientes de difusión muy diferentes y la resistencia no refleja el verdadero efecto beneficioso de la adición en el avance de los cloruros.

\section{Difusión-Porosidad}

La figura 5.182 muestra la representación de las parejas de valores (coeficientes de difusión-porosidad expresada en \%) para los testigos de los pantalanes analizados: 

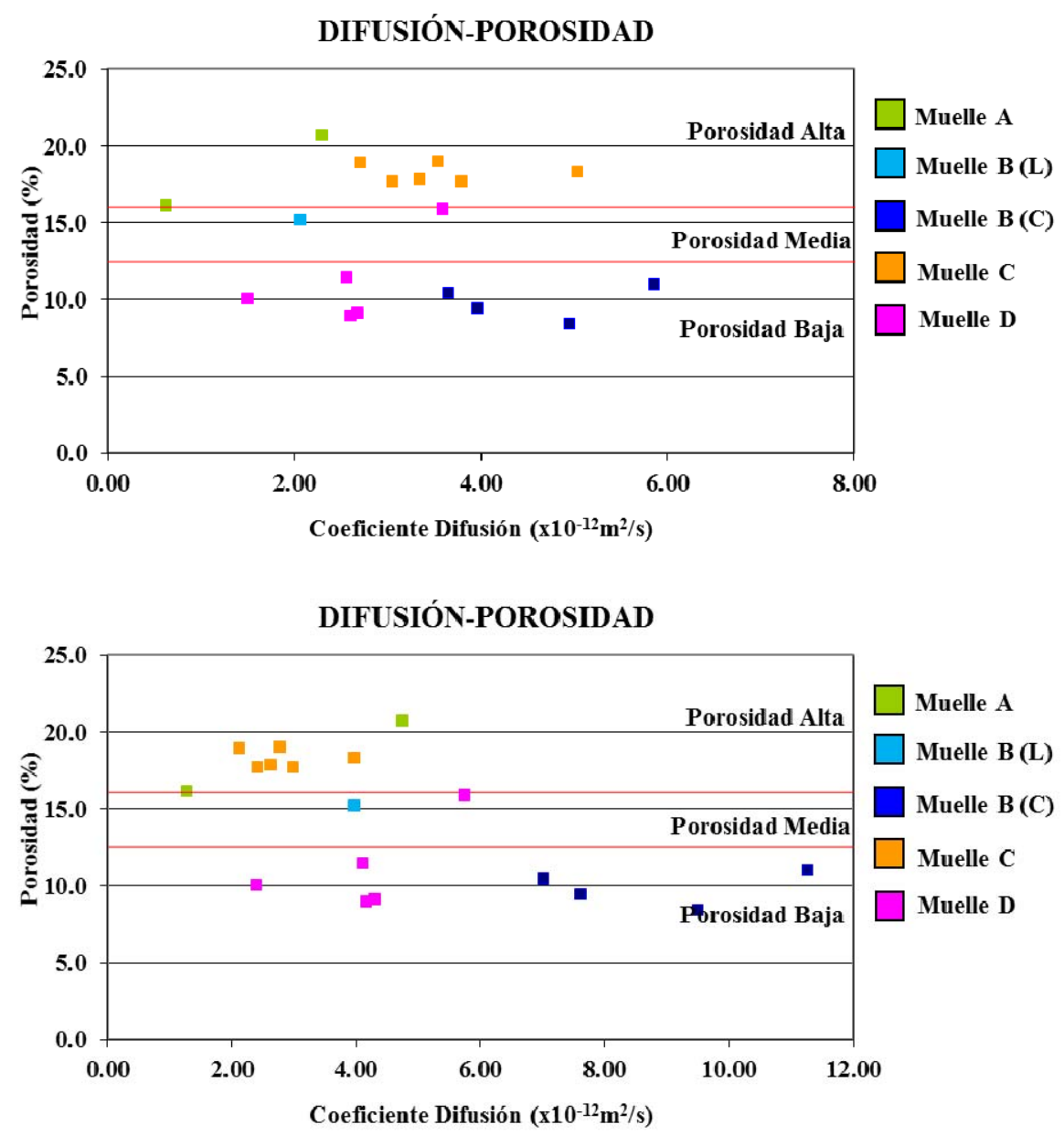

Fig. 5.182. Relación Difusión-Porosidad.

Criterio Fib (arriba), Criterio EHE 08 (abajo).

Los resultados obtenidos no presentan una tendencia clara e incluso en varios de los muelles los valores obtenidos dentro de cada uno de ellos dan porosidades similares cuando los coeficientes de difusión son diferentes.

Cabe decir que el ensayo de porosidad evalúa el contenido de poros totales que existen en el hormigón, sin diferenciar los de mayor tamaño de los más pequeños, por lo que un resultado de porosidad elevado supone un gran número de poros en el seno del hormigón, sin distinguir su tamaño.

Así, la porosidad no refleja adecuadamente el efecto beneficioso de las adiciones sobre la difusión de cloruros: en el caso del muelle C, cuyo hormigón incluye cenizas en su dosificación, las porosidades son mayores y sin embargo, sus coeficientes de difusión resultan muy reducidos. Esto puede deberse al sistema de poros que se crea en los hormigones con adiciones. El efecto de éstas sobre la porosidad no es muy acusado, dado que tal propiedad considera el volumen de poros totales sin diferenciar el tamaño 
pero gracias al uso de las adiciones se puede lograr un refinamiento de la red de poros, disminuyendo los de mayor tamaño.

Por tanto, el ensayo de porosidad proporciona una información parcial de la durabilidad, ya que no valora la distribución de los poros, que es lo que realmente caracteriza el tipo de transporte de los cloruros en el interior del hormigón y permitiría precisar la velocidad real de penetración de cloruros según el mecanismo dominante en cada caso.

Por todo ello, la porosidad no resulta una propiedad adecuada para controlar la durabilidad al no considerar adecuadamente el efecto de las adiciones.

\section{Difusión-Absorción}

La figura 5.183 muestra la representación de las parejas de valores (coeficientes de difusión-absorción de agua por inmersión expresada en \%) para los testigos de los muelles analizados:
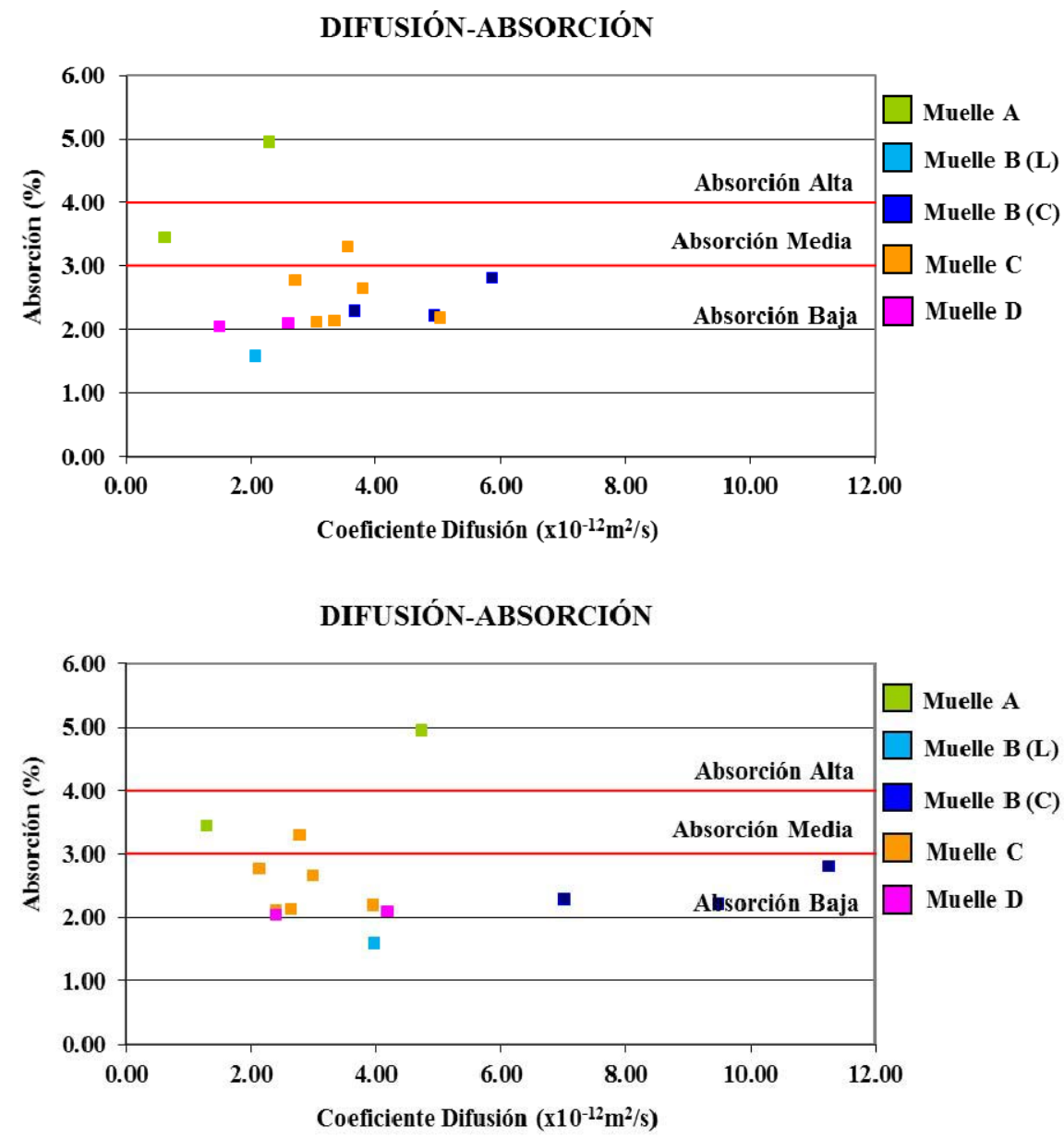

Fig. 5.183. Relación Difusión-Absorción. Criterio Fib (arriba), Criterio EHE 08 (abajo). 
La absorción refleja otro modo de evaluar el contenido total de poros por lo que existe cierta equivalencia con lo planteado en el caso de la porosidad. Análogamente a lo comentado anteriormente, los resultados obtenidos resultan erráticos y no muestran una tendencia clara. En este caso, valores similares de absorción, en unos casos presentan coeficientes de difusión bajos (caso de algunos valores de los muelles C y D y del hormigón de las losas del muelle B) y en el caso del hormigón de los cabeceros del muelle B tienen coeficientes de difusión mayores. Como en el caso de la porosidad, parecería claro asociar una mayor absorción por inmersión con una mayor difusión, sin embargo no se puede concluir esto a partir de los resultados de la figura 5.183, pudiéndose hacer la misma valoración: la porosidad total medida (en este caso por absorción por inmersión) no refleja el tamaño de poros que tiene gran influencia en el coeficiente de difusión.

Por lo tanto, la absorción de agua por inmersión no resulta un ensayo adecuado para valorar la impermeabilidad del hormigón a la penetración de cloruros en ambiente marino aéreo.

A continuación se analizan las correlaciones entre porosidad-absorción, porosidadcapilaridad y porosidad-ascensión capilar máxima con el fin de conocer la correlación entre ellas a la vista de que no están bien correlacionadas con la difusión.

\section{Porosidad-Absorción}

En la figura 5.184 se han representado las parejas de valores (porosidad-absorción, ambas expresadas en \%) con el fin de analizar la relación entre las dos propiedades:

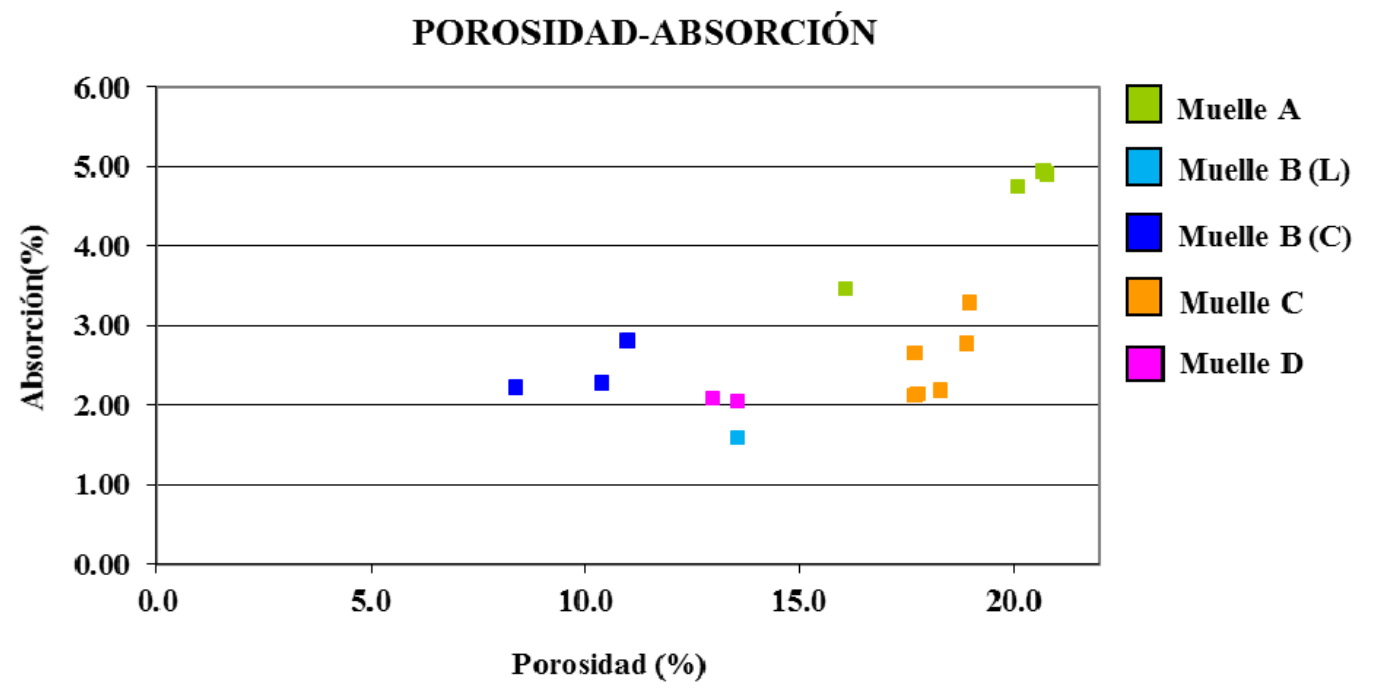

Fig. 5.184. Relación Porosidad-Absorción. 
Puede observarse una tendencia coherente entre los resultados (si bien la correlación es muy pobre), ya que los valores de porosidad menores están, en general, asociados con una absorción por inmersión menor. Resulta coherente dado que ambas propiedades, porosidad y absorción evalúan el volumen total de poros total sin tener en cuenta la distribución de su tamaño.

En términos generales puede decirse que el hormigón menos poroso es el correspondiente a los cabeceros del muelle $B$, seguido del de las losas del mismo muelle, después el muelle $\mathrm{C}$ y el muelle $\mathrm{A}$ resultaría el más poroso de todos.

\section{Porosidad-Capilaridad}

En la figura 5.185 se representan las parejas de valores (porosidad expresada en \%capilaridad expresada en $\mathrm{g} / \mathrm{mm}^{2} \cdot 10^{-3}$ ) con el fin de analizar la relación entre ambas propiedades:

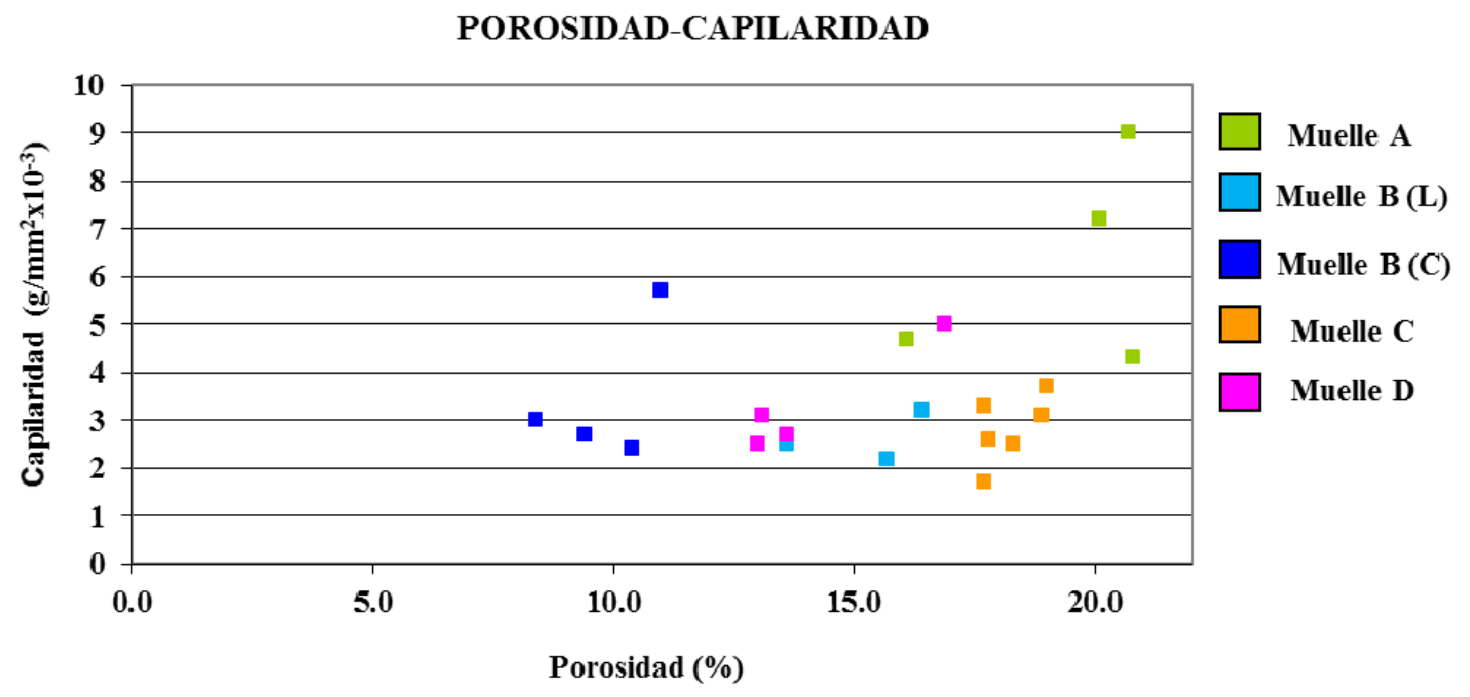

Fig. 5.185. Relación Porosidad-Capilaridad.

En este caso, existe una tendencia a relacionar valores bajos de porosidad con capilaridades bajas (como el caso de cabeceros del muelle B) y valores elevados de porosidad con capilaridades mayores (caso de muelle A). La correlación es muy débil debido a que la absorción por capilaridad está asociada a los poros de menor tamaño de la mezcla y como ya se ha comentado, la porosidad evalúa la cantidad total de poros sin diferenciar los de mayor tamaño de los más pequeños. 


\section{Porosidad-Ascensión Capilar Máxima}

En el gráfico 5.186 se representan las parejas de valores (porosidad-ascensión capilar máxima) con el fin de analizar la relación entre ambas propiedades. En el caso de este gráfico no se dispone del valor de altura de ascensión capilar máxima de los testigos del muelle D por lo que sólo se representan los de los otros tres muelles:

\section{POROSIDAD-ALT.ASCENSIÓN CAPILAR MÁXIMA}

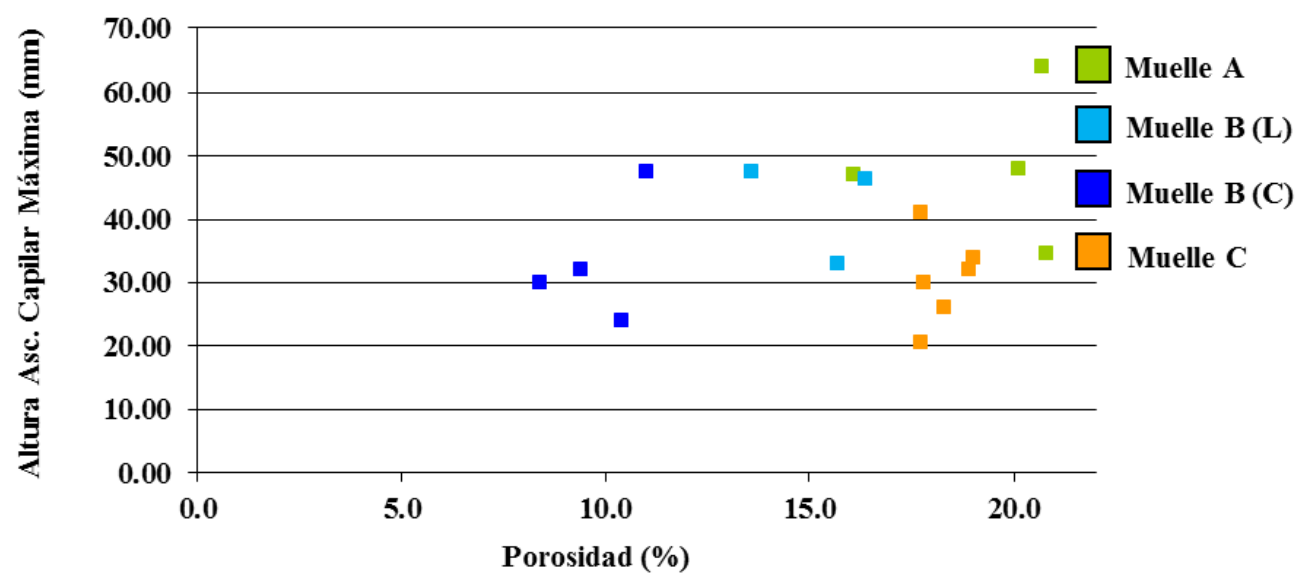

Fig. 5.186. Relación Porosidad-Ascensión Capilar Máxima.

Previamente, se ha analizado la relación entre la porosidad y la capilaridad, concluyendo que en algunos casos no existía una tendencia clara entre ambas propiedades dado que la capilaridad se encuentra más relacionada con los poros de menor tamaño y en cambio, la porosidad valora el total de los poros sin distinguir su tamaño. Ahora se ha evaluado la porosidad con la ascensión capilar máxima y se observa algo parecido al caso anterior, ya que ésta última está directamente relacionada con el radio de poro (ley de Jurin) que no influye en la porosidad total. Lo significativo en el gráfico es que en el hormigón de los cabeceros del muelle B, la altura de ascensión obtenida es baja, lo cual podría indicar la presencia de poros de gran tamaño, que explicarían los coeficientes de difusión altos obtenidos a pesar de su reducido volumen de poros. En el caso del muelle C, la porosidad es mayor que en el muelle B y alcanza en alguno de sus puntos alturas de ascensión capilar mayores, lo que se justificaría porque además de su elevada porosidad (puede haber poros grandes y pequeños), en la dosificación de su hormigón se han empleado cenizas volantes (entre un $20-35 \%$ de contenido en cenizas, según la $\mathrm{RC}$-08 dada la nomenclatura del cemento empleado) que contribuyen al refinamiento de la red de poros y por tanto, favorecen la capilaridad. En el caso del muelle A, hay una correspondencia entre porosidad elevada y altura elevada de ascensión capilar, y aunque se desconoce totalmente el cemento empleado en la dosificación del hormigón, 
su edad elevada (37 años) hace posible el refinamiento de la red capilar por la hidratación del cemento en el tiempo.

\section{Difusión-Profundidad Máxima y Difusión-Profundidad Media}

Las figuras 5.187 y 5.188 relacionan los coeficientes de difusión con las profundidades de penetración de agua máximas y medias expresadas en $\mathrm{mm}$ obtenidas en cada uno de los testigos:
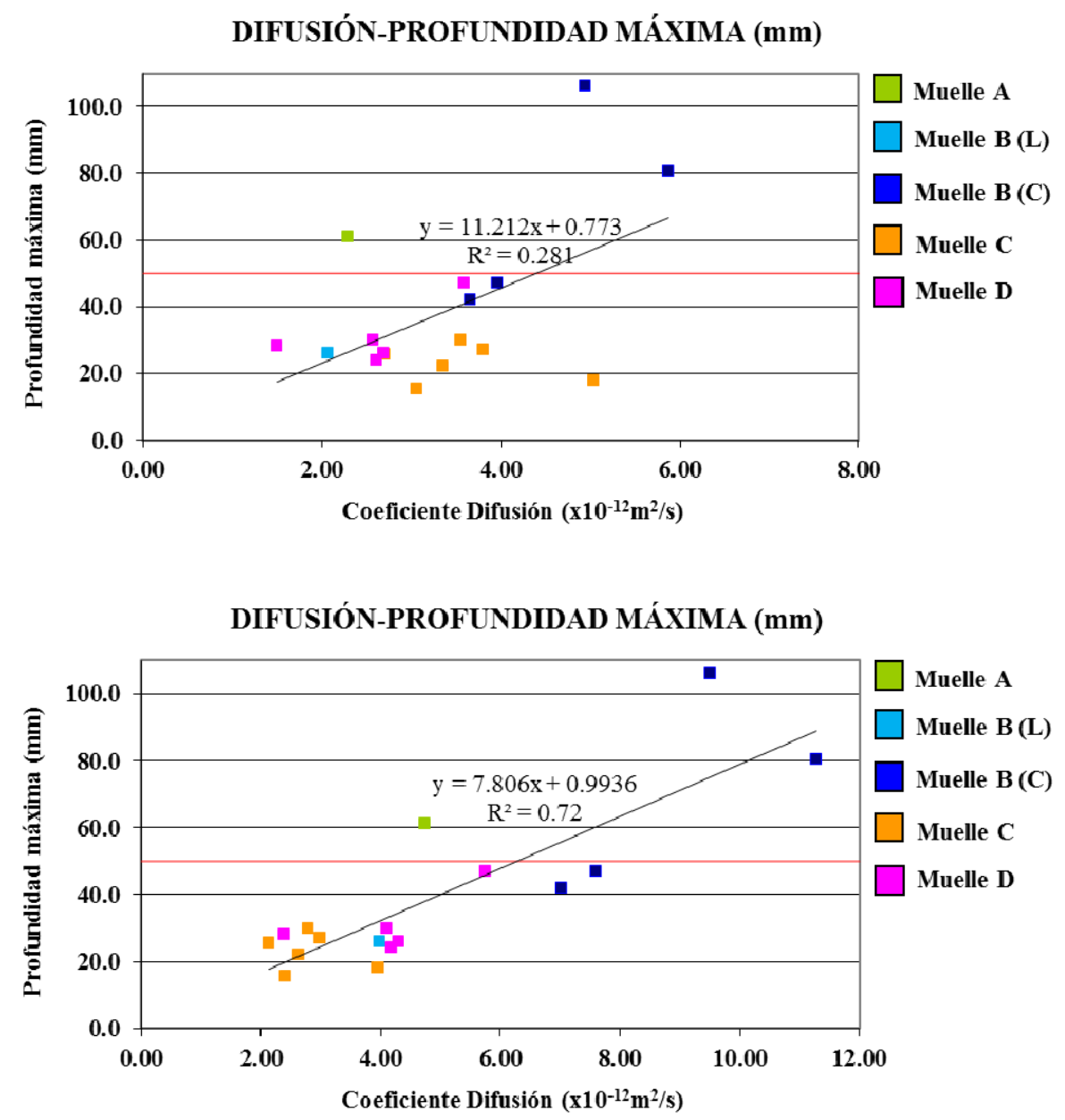

Fig. 5.187. Relación Difusión-Profundidad Máxima.

Criterio FIB (arriba), Criterio EHE (abajo). 

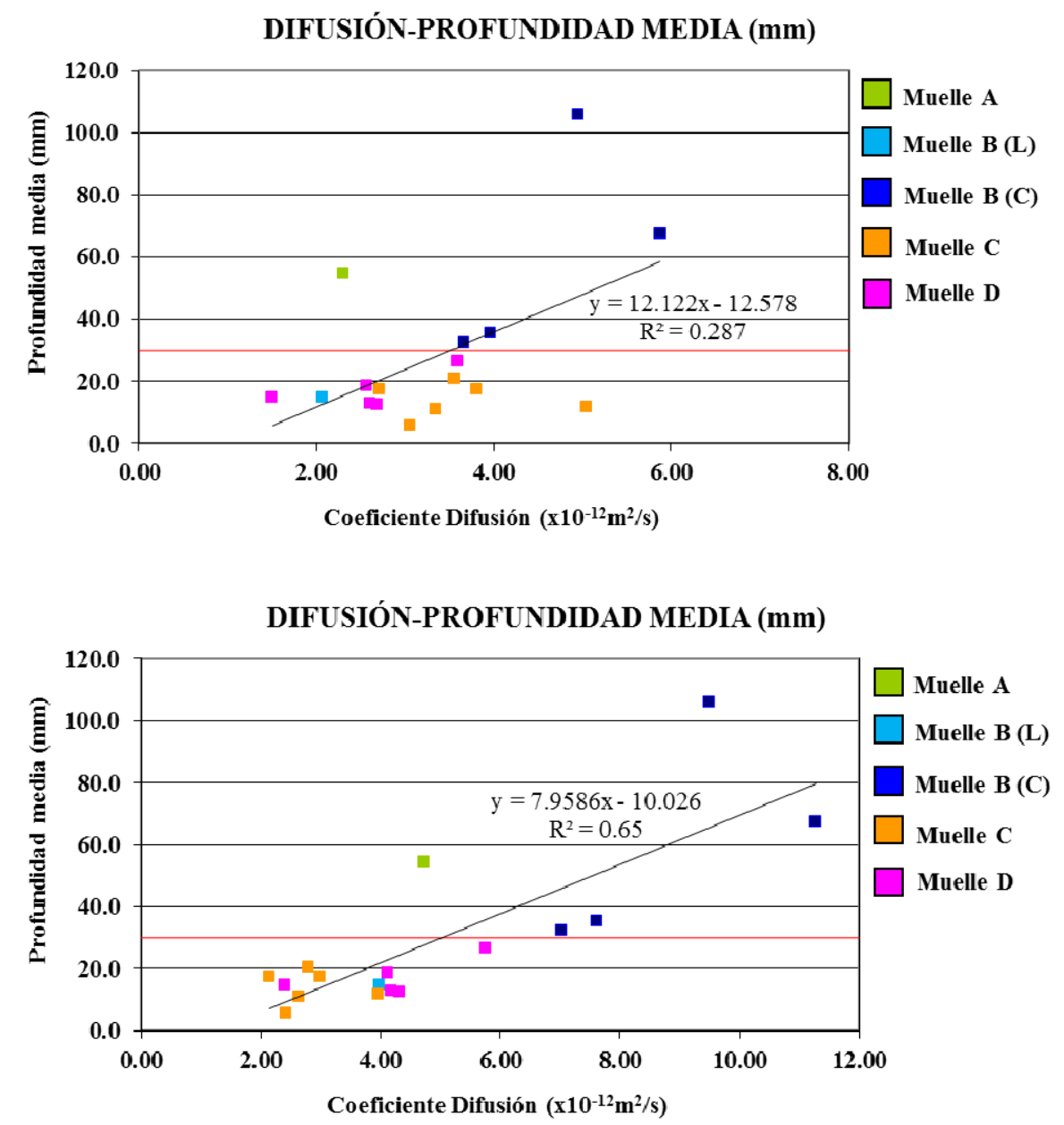

Fig. 5.188. Relación Difusión-Profundidad Media.

Criterio FIB (arriba), Criterio EHE (abajo).

Los resultados de penetración, tanto en el caso de la profundidad máxima como en el de la profundidad media, resultan en general coherentes con la difusión, es decir a menores valores de profundidad de penetración máxima y media, menores valores de coeficiente de difusión. Ambas propiedades, penetración máxima y penetración media, se ven influenciadas por la cantidad de poros así como por su distribución en el hormigón. Sin embargo, la aplicación del criterio FIB de los coeficientes de envejecimiento conlleva una mayor dispersión de los resultados, así como a la obtención de valores del coeficiente de difusión elevados en un hormigón con adiciones (Muelle C) que sin embargo presenta una buena impermeabilidad al agua. El criterio EHE mejora de forma notable la correlación de todos los resultados y es coherente con lo esperable para el hormigón del Muelle C: el efecto beneficioso del uso de adiciones en la dosificación del hormigón, que contribuye a reducir la penetración de agua así como la difusión al refinar la red de poros. 
Si realizamos la intersección de los valores límites establecidos por la Instrucción EHE08 y las regresiones obtenidas en las figuras 5.187 y 5.188 , se obtienen valores más conservadores (mayores coeficientes de difusión asignados) aplicando el criterio EHE, aunque con resultados diferentes a partir de la penetración máxima (valor igual a $4,39 \cdot 10^{-12} \mathrm{~m}^{2} / \mathrm{s}$ según criterio FIB y valor igual a $6,27 \cdot 10^{-12} \mathrm{~m}^{2} / \mathrm{s}$ según criterio EHE 08) y de la penetración media (valor igual a $3,51 \cdot 10^{-12} \mathrm{~m}^{2} / \mathrm{s}$ según criterio FIB y valor igual a $5,03 \cdot 10^{-12} \mathrm{~m}^{2} / \mathrm{s}$ según criterio EHE 08). El valor obtenido según el criterio EHE 08 puede considerarse más adecuado a tenor de la mejor correlación obtenida, además de tratarse de un valor más conservador.

\subsubsection{Contraste de los resultados de penetración de agua (IIla) con los obtenidos en los ambientes IIIb y IIIc.}

Las figuras 5.189 y 5.190 reflejan las regresiones anteriores que corresponden al ambiente de marino aéreo (IIla) y las obtenidas en su día en la investigación precedente a este estudio ${ }^{1,2}$ para los hormigones en ambiente IIIb y IIIc:

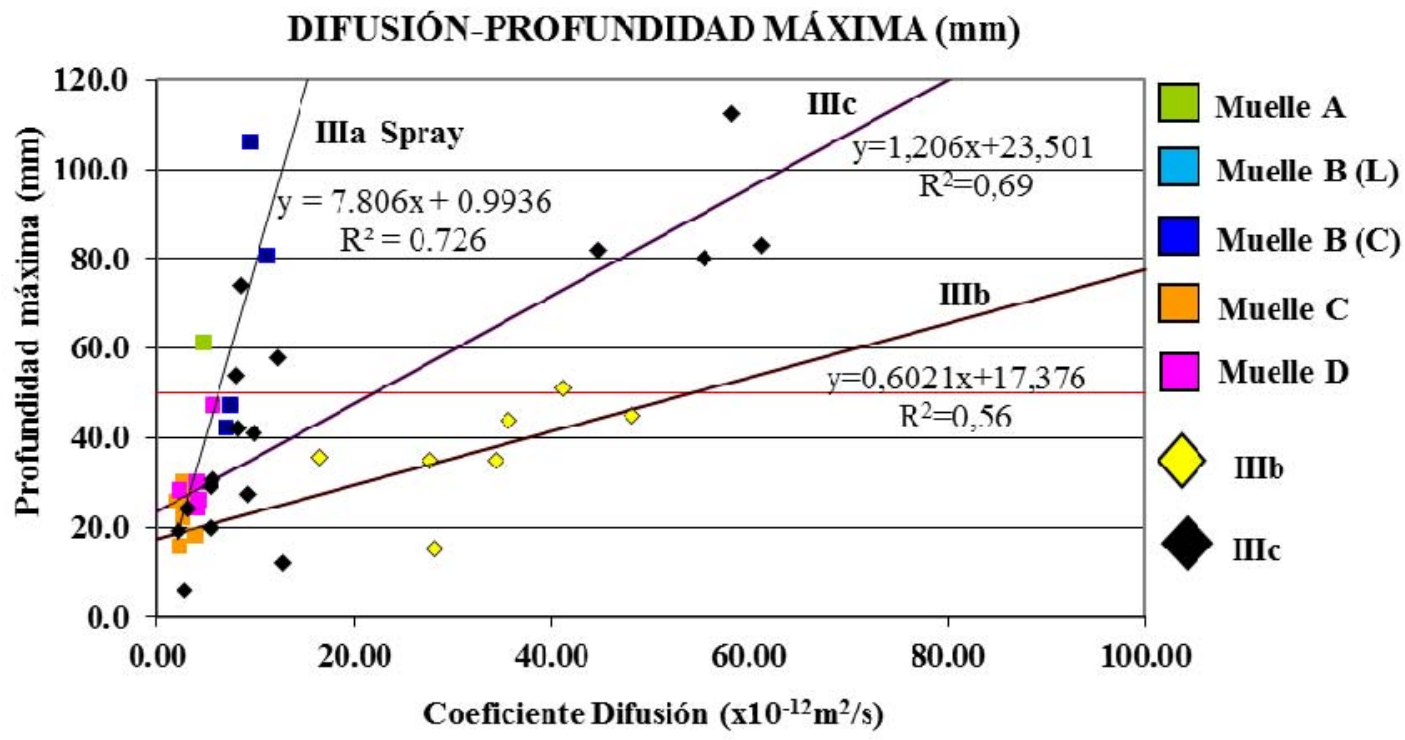

Fig. 5.189. Regresiones Difusión-Profundidad Máxima en ambientes IIIa, IIIb y IIIc. 
DIFUSIÓN-PROFUNDIDAD MEDIA (mm)

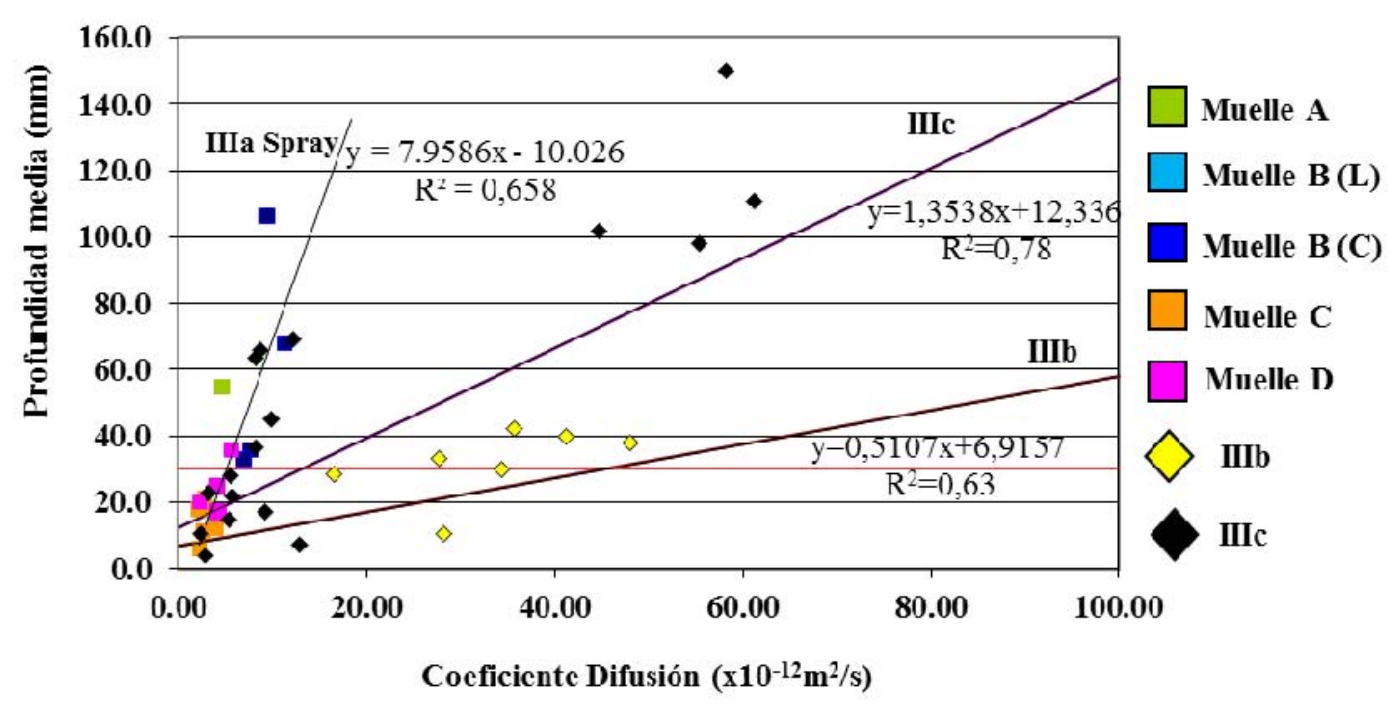

Fig. 5.190. Regresiones Difusión-Profundidad Media en ambientes IIIa, IIIb y IIIc.

Puede observarse en ambos gráficos que los valores de los coeficientes de difusión menores son los correspondientes al ambiente IIla spray, seguidos de los correspondientes al ambiente IIlc y por último, los de mayor difusión son los situados en ambiente IIIb. Esto resulta coherente con los mecanismos de transporte de los cloruros hacia el interior del hormigón. Así en el caso del ambiente Illa (zona spray) el mecanismo predominante sería la difusión pura ya que los poros no aparecen saturados de agua, pero sí tienen un cierto grado de humedad y disponen de oxígeno. Este proceso de difusión pura resulta mucho más lento que en el caso de hormigones sumergidos, (transporte por permeabilidad) y en el caso de hormigones en carrera de mareas (transporte por capilaridad).

\subsubsection{Influencia de la dosificación en el coeficiente de difusión del hormigón}

La velocidad de penetración de cloruros puede verse afectada por numerosos factores, entre los que destacan la dosificación del hormigón (relación a/c, contenido de cemento y adiciones) y el tipo de ambiente (en esta investigación, ambiente marino Illa spray).

En este apartado se va a evaluar el efecto de la relación agua/cemento y de la utilización de adiciones (cenizas volantes el humo de sílice) en el coeficiente de difusión de cloruros. Para ello se han utilizado los resultados obtenidos de los ensayos realizados sobre los testigos extraídos de los cuatro Muelles así como datos recabados 
de la consulta bibliográfica realizada sobre estructuras en ambiente marino spray o atmosférico.

El total de referencias bibliográficas han sido 16 , que corresponden con las fuentes $[1 ; 5 ; 9 ; 10 ; 37,82,97,103,104,105,106,107,108,109,110,111]$.

En la figura 5.191, se representa el gráfico que recoge el conjunto de todos los datos, ya sean de cemento portland (puntos azules), de cemento con ceniza volante (triángulos rojos) o de cemento con humo de sílice (círculos rojos). Todos los datos se encuentran en ambiente IIIa (Instrucción EHE 08) y en la zona spray situada por encima de 1,5m del nivel de pleamar tal y como la define la FIB.

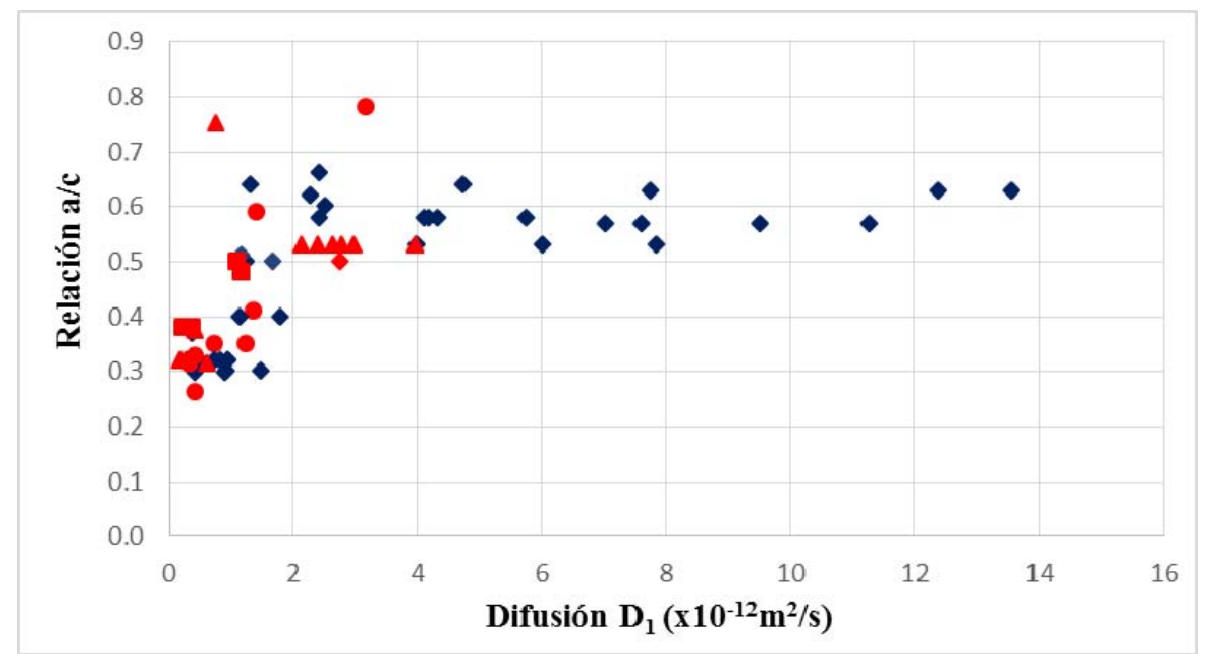

Fig.5.191.Conjunto general de datos procedentes de la experimentación y de las referencias bibliográficas.

Si planteamos el ajuste logarítmico a los datos de hormigón fabricado con cemento Portland, se obtiene una curva que en el gráfico de la fig 5.192 se compara con las obtenidas también para hormigón sin adiciones, en la investigación anterior realizada ${ }^{1,2}$ para Ambiente Sumergido y Carrera de Mareas. 


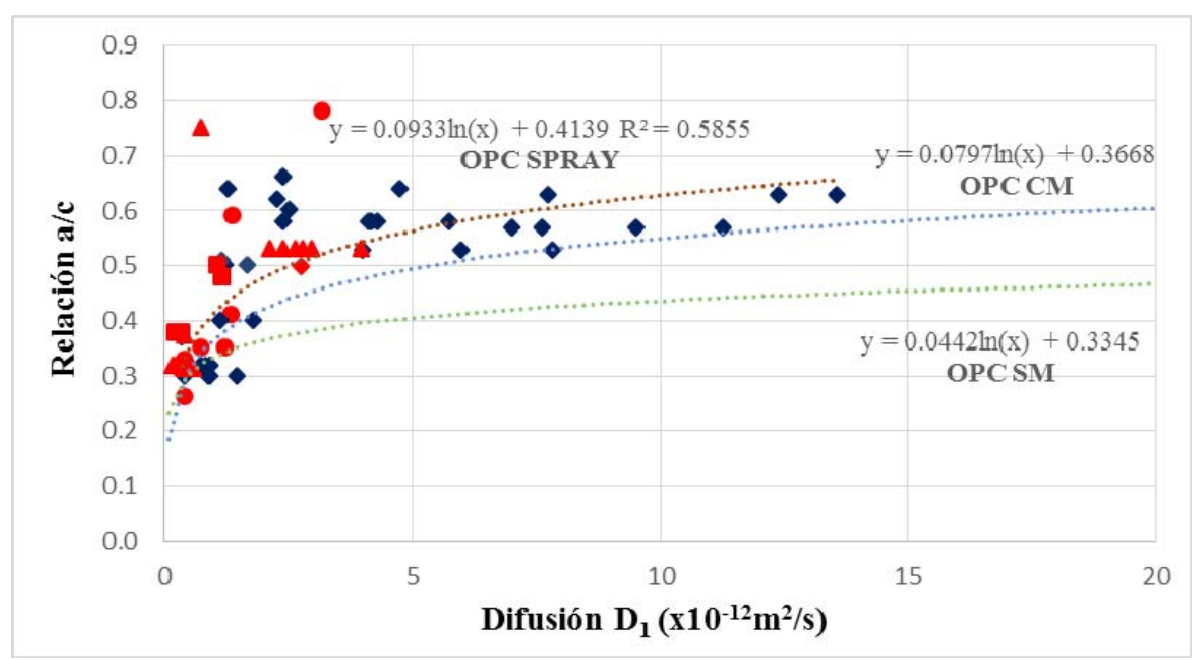

Fig.5.192. Comparativo entre ajustes ambiente sumergido, carrera de mareas y aéreo-spray.

Efecto de la relación a/c. Cálculo del coeficiente de eficacia de adiciones.

Se observa que las velocidades de difusión son inferiores en ambiente IIla spray para hormigones con la misma relación agua/cemento, en comparación con las que se llegan a obtener en los ambientes de carrera de marea IIIc y sumergido IIIb. Tal como se constató ya en la anterior investigación, se observa el claro efecto del tipo de ambiente en la velocidad de penetración de los cloruros, debido a los diferentes mecanismos de transporte existentes en cada caso.

También se observa en la curva anterior correspondiente al ambiente IIla spray, cómo los valores del coeficiente de difusión se disparan para relaciones a/c superiores a 0,55 , valor que no debería superarse en ningún caso para hormigones situados en este ambiente.

Para evaluar la influencia de las adiciones se separan todos los datos en tres gráficos (5.193 a 5.195) individuales mostrando por separado los casos del cemento Portland, cemento con cenizas volantes y cemento con humo de sílice. Se representan ahora los valores en términos del LN D1-a/c, para de esta manera poder comparar ajustes lineales. 


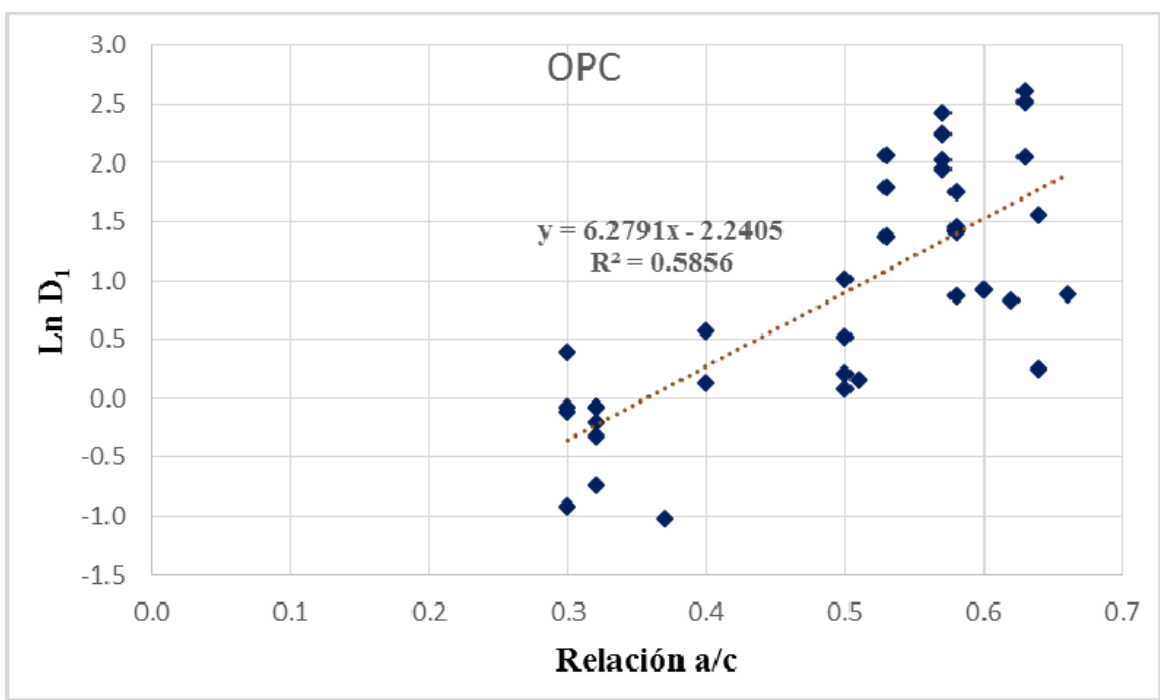

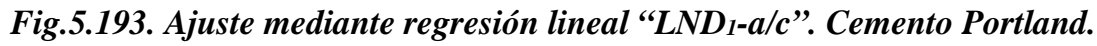

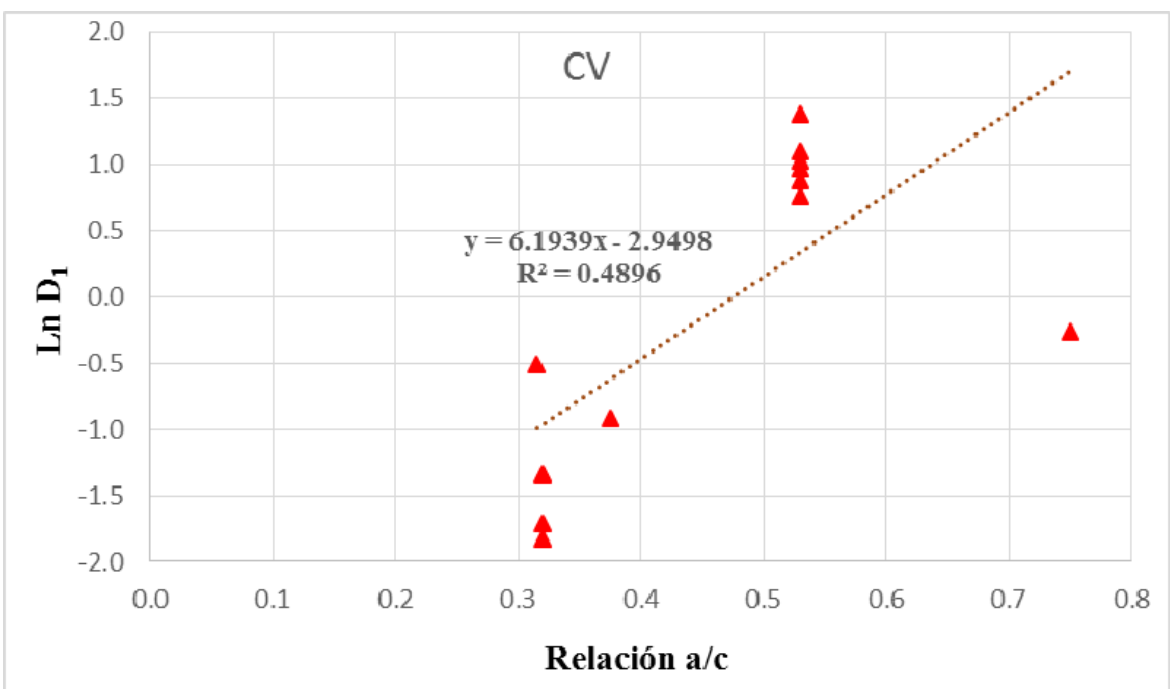

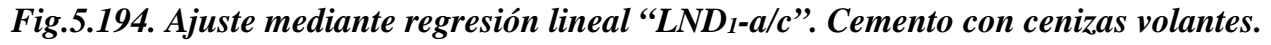

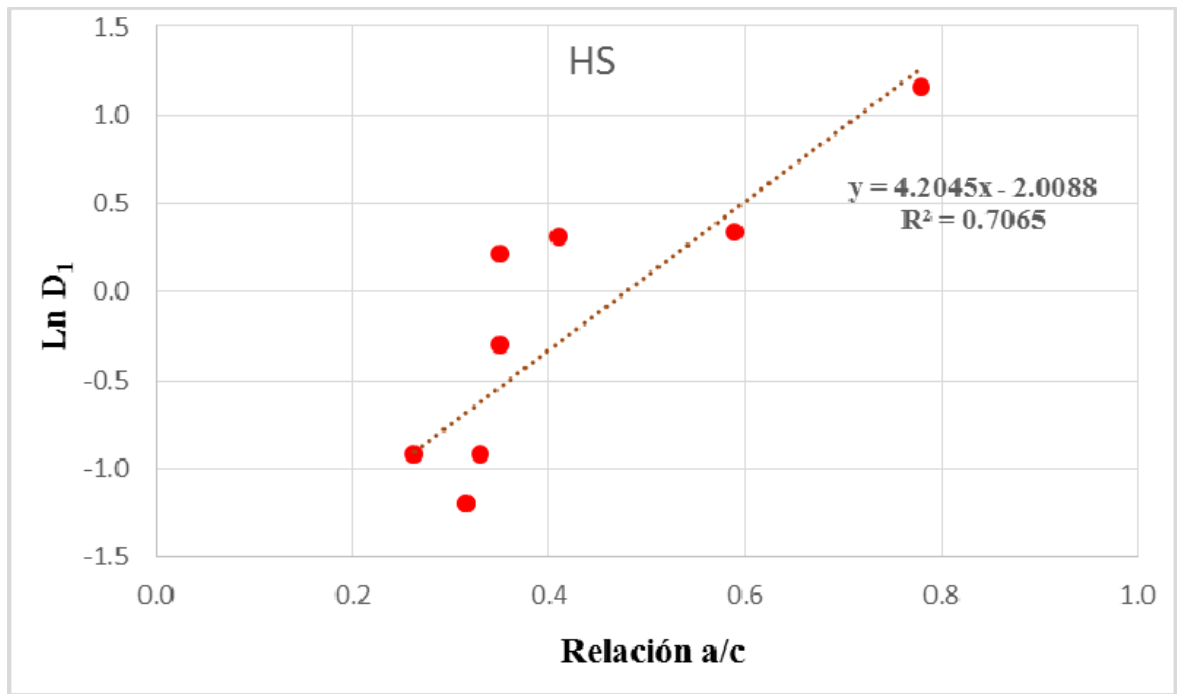

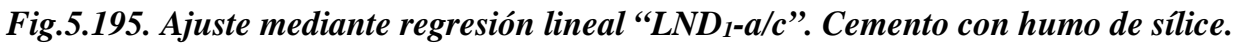


Al objeto de obtener una expresión única válida para hormigones con y sin adiciones, se han modificado las regresiones lineales anteriores recogidas en los gráficos 5.193 a 5.195 de forma que se obtenga un valor igual del término independiente en las tres expresiones, adoptando el valor medio, de forma que tendríamos:

Valor medio del término independiente: $(2,24+2,95+2,00) / 3=2,39$.

Con esta nueva adaptación se modifican ligeramente las regresiones lineales iniciales haciéndolas además pasar por el origen (representación en un segundo eje Y) y se obtienen los gráficos 5.196 a 5.198, en los que los coeficientes de correlación obtenidos con esta modificación disminuyen levemente pero se gana que el efecto de las adiciones sea controlado únicamente por la pendiente de la regresión.

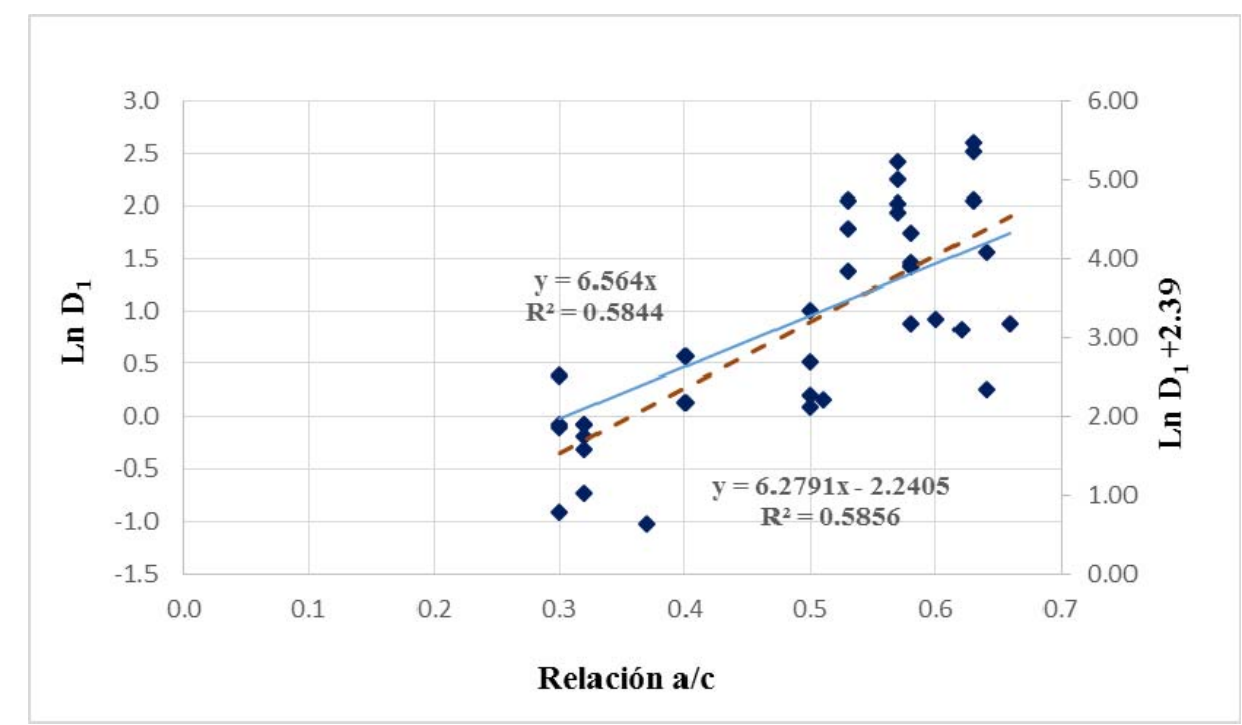

Fig.5.196. Correlación entre “LND 1 -a/c" para hormigones fabricados con OPC. Con trazo discontinuo aparece la regresión del gráfico 5.193. 


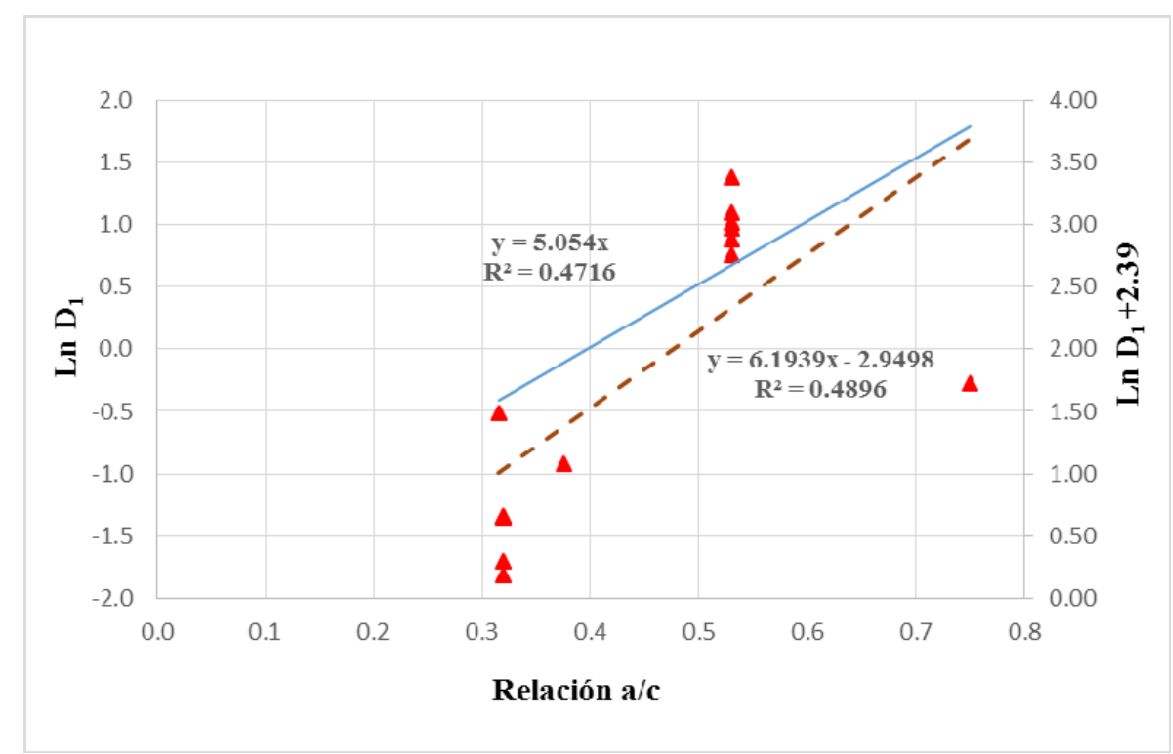

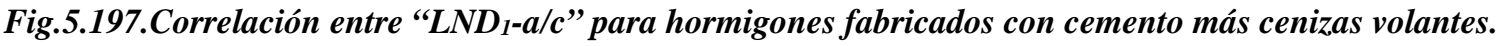
Con trazo discontinuo aparece la regresión del gráfico 5.194.

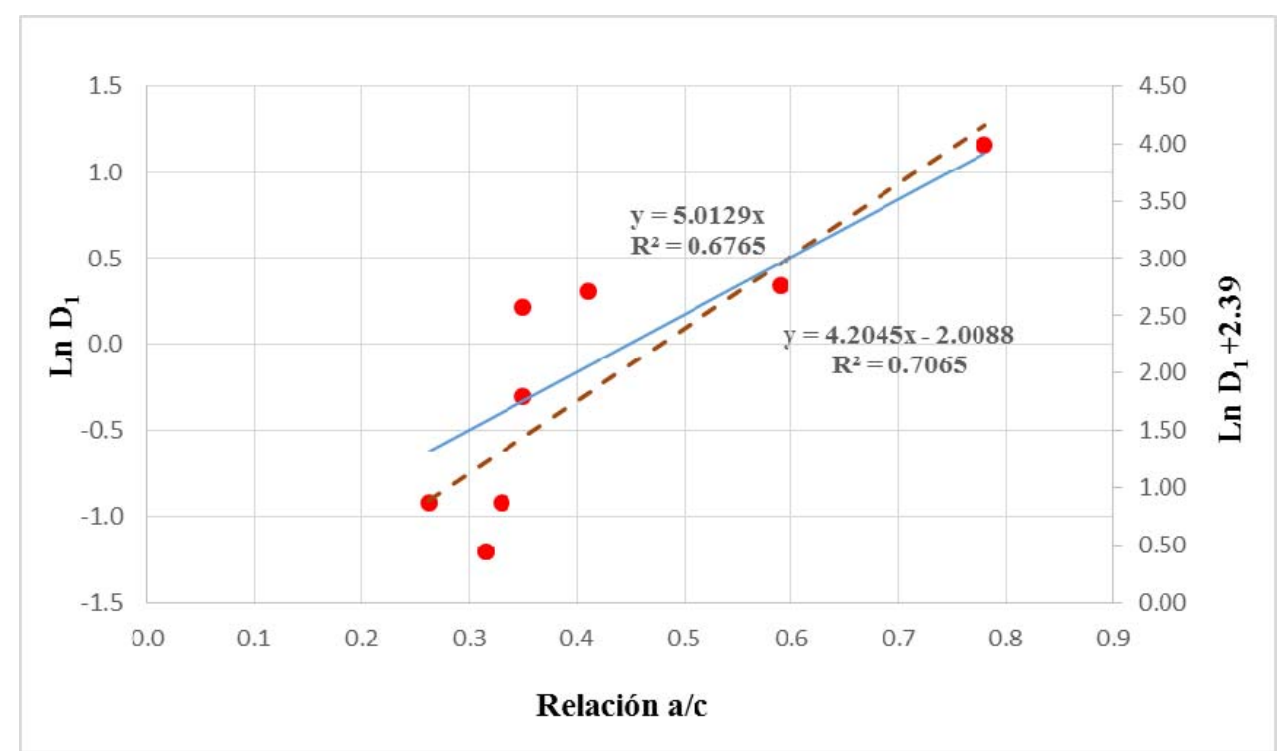

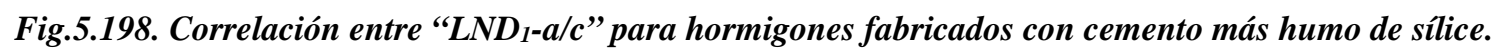
Con trazo discontinuo aparece la regresión del gráfico 5.195.

Se observa que con esta adaptación las correlaciones no empeoran mucho y sin embargo podemos trabajar con todas las gráficas a la vez, y así obtener la expresión general que relacione el coeficiente de difusión de cloruros con la dosificación inicial del hormigón. Además se puede determinar el coeficiente de eficacia, en términos de la penetración de cloruros, tanto de las adiciones de cenizas volantes como de humo de sílice.

Las nuevas expresiones obtenidas en los gráficos 5.196 a 5.198 son: 
- OPC: In $D_{1}+2,39=6,564^{*} a / c$ con lo que $D_{1}=\left(e^{a / c} / e^{0,364}\right)^{6,564} ; R^{2}=0,5844$

- Ceniza Volante: In $D_{1}+2,39=5,054 * a / c$ con lo que $D_{1}=\left(e^{a / c} / e^{0,473}\right)^{5,054} ; R^{2}=0,4716$

- Humo de Sílice: In $D_{1}+2,39=5,013^{*} a / c$ con lo que $D_{1}=\left(e^{a / c} / e^{0,477}\right)^{5,013} ; R^{2}=0,6765$

Partiendo de la expresión para hormigones fabricados con cemento portland sin adiciones, el coeficiente de eficacia de las adiciones $\mathrm{K}_{\mathrm{v}}$ (cenizas volantes) y $\mathrm{K}_{\mathrm{s}}$ (humo de sílice) permitirían transformar el peso de adición mineral en peso de cemento equivalente, en términos de permeabilidad a los cloruros: cemento total=cemento real + $\mathrm{KV}_{\mathrm{V}}{ }^{*} \mathrm{CV}+\mathrm{K}_{\mathrm{S}}{ }^{*} \mathrm{HS}$, siendo $\mathrm{CV}$ el contenido de ceniza volante (el valor medio en los datos analizados es de $22 \%$ ) y HS el contenido de humo de sílice (el valor medio en los datos analizados es de $5,8 \%$ ). Para ello igualamos las expresiones para cementos con cenizas volantes o con humo de sílice con la la correspondiente a OPC, resultando las ecuaciones:

- Cenizas volantes: $6,564 *\left(1 / 1+0,22 * K_{v}\right)=5,054$ con lo que $K_{v}=1,36$

- Humo de sílice: $6,564 *\left(1 / 1+0,058 * K_{s}\right)=5,013$ con lo que $K_{s}=5,33$

Por lo tanto, la fórmula para el cemento Portland podría generalizarse:

$$
D_{1}=\left(\left(e^{\mathrm{a} /(\mathrm{c}+5,35 \mathrm{HS}+1,36 \mathrm{CV})}\right) / \mathrm{e}^{0,36}\right)^{6,564}
$$

siendo "c" el contenido de cemento (en kg), "CV" el contenido de cenizas volantes (en $\mathrm{kg}$ ) y "HS" el contenido de humo de sílice (en kg).

Resulta significativo que los valores de los coeficientes de eficacia obtenidos se asemejan mucho con los que se obtuvieron en la investigación anterior en los ambientes marinos sumergido y de carrera de marea, tal como se recoge en la tabla 5.48 a continuación ${ }^{1,2}$ :

\begin{tabular}{|c||c||c|}
\hline Ambiente & Kv & Ks \\
\hline \hline Illa spray & 1,36 & 5,35 \\
\hline \hline IIIb sumergido & - & 5,56 \\
\hline \hline IIIc carrera de marea & 1,31 & 6,42 \\
\hline Valor medio & $\mathbf{1 , 3 4}$ & $\mathbf{5 , 7 8}$ \\
\hline
\end{tabular}

Tabla 5.48. Valores de Coeficientes de Eficacia de Adiciones obtenidos en los tres ambientes marinos. 


\subsubsection{Valoración de la calidad del hormigón de los pantalanes estudiados}

A la vista de los resultados, los testigos correspondientes al muelle $\mathrm{C}$ han cumplido los requisitos de penetración máxima y media exigidos por la Instrucción (incluso para ambiente IIIc), siendo los resultados de difusión los menores de los cuatro muelles analizados (criterio EHE-08). Este hormigón fue fabricado con una relación a/c estimada igual a 0,53 (ver tabla 5.1), valor que cumple la limitación de relación a/c máxima establecida por la EH-91, Instrucción vigente en el momento de la construcción del muelle. Adicionalmente, el cemento utilizado tenía adiciones, lo cual justifica los bajos coeficientes de difusión obtenidos.

El muelle D cumple asimismo los requisitos de penetración de agua (incluso para ambiente IIIc), si bien su relación a/c estimada es superior $(0,58)$. Este hecho y el que no incorpore adiciones justifica los valores del coeficiente de difusión superiores a los obtenidos en el Muelle C (criterio EHE-08).

En el caso del hormigón de las losas del muelle $B$, las losas cumplen igualmente los requisitos de penetración de ambiente IIla (pero no para ambiente IIIc) siendo en este caso la relación a/c empleada igual a 0,53.

Finalmente, tanto el hormigón de los cabeceros del muelle $\mathrm{B}$ como el único resultado disponible del muelle $A$, proceden de hormigones con elevada relación a/c $(0,57$ y 0,64 respectivamente), por lo que no cumplen las limitaciones de penetración máxima y media exigidas por la instrucción EHE-08 y presentan valores de coeficiente de difusión sensiblemente mayores.

Puede decirse, por tanto, que la relación a/c máxima establecida por la EHE-08 para el caso del ambiente IIla (0,50 para hormigón armado) así como el requisito de penetración de agua resultan coherentes entre sí e incluso algo conservadores (ya que muestras con relaciones a/c ligeramente superiores a la propuesta por la Instrucción aún cumplen el requisito de penetración) para seleccionar hormigones con bajo coeficiente de difusión en ambiente IIIa.

\section{Efecto de la normativa}

En el presente estudio se han analizado hormigones dosificados según cuatro normativas distintas: HA-61 (en este caso no se dispone de información de cómo se realizó la dosificación), EH-80, EH-91 y EH-98. 
Según los datos recopilados de los correspondientes proyectos, el hormigón dosificado según la EH-80 era un H-30, el proyectado según la EH-91 era un H-25 y el dosificado según EH-98 un H35.

En la figura 5.199 se muestran los resultados del ensayo de penetración de agua y del coeficiente de difusión, agrupados según la normativa empleada para proyectar la dosificación del hormigón.

\section{DIFUSIÓN-PROFUNDIDAD MÁXIMA (mm)}

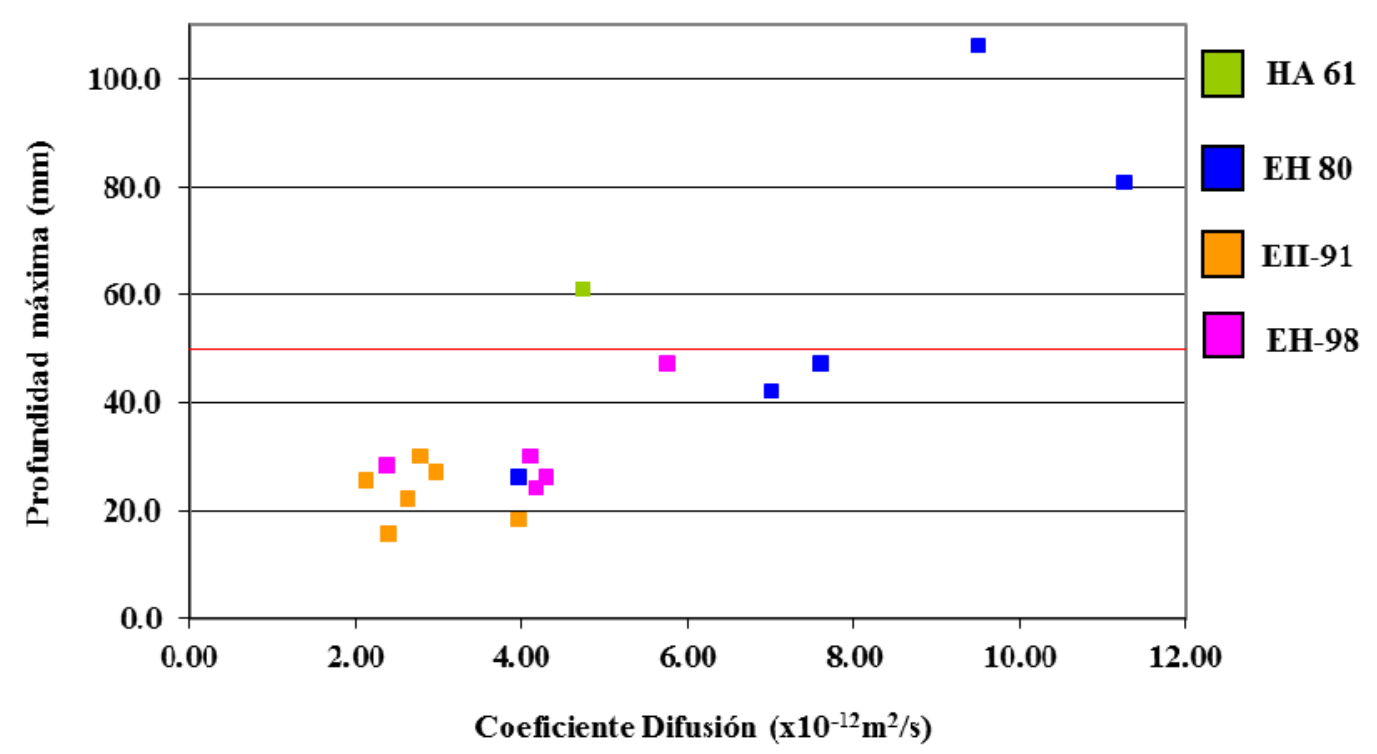

Fig.5.199.Calidad del hormigón según la normativa empleada en su fabricación.

Puede observarse a partir de la figura que los hormigones EH-91 y EH-98 presentan menores coeficientes de difusión y profundidades de penetración de agua que los correspondientes a normativas anteriores (en este caso, HA-61 y EH-80). El gráfico muestra que la evolución de la normativa ha contribuido a la obtención de hormigones de mejor calidad desde el punto de vista de la durabilidad, si bien no se dispone de resultados para verificar el comportamiento de estructuras diseñadas de acuerdo con la vigente instrucción EHE-08.

Efecto de las adiciones en la calidad del hormigón

Entre los hormigones analizados, no se dispone de información correspondiente al cemento con el que se fabricó el perteneciente al muelle $A$, el hormigón correspondiente al muelle $B$ está fabricado con cemento Portland (P350, lo que indica una resistencia a compresión a 28 días en $\mathrm{kp} / \mathrm{cm}^{2}$ de 350 ), el muelle $C$ está elaborado con un cemento mixto CEM II/BV-32,5R que contiene un porcentaje de ceniza volante entre el $21-35 \%$ y 
el hormigón del muelle D se emplearon dos cementos: CEM I 52,5 N/SR y CEM I 42,5 $\mathrm{R} / \mathrm{SR}$. En el resto de los casos, no hay datos de que los cementos fueran MR o SR.

En la figura 5.200 se muestran los resultados del ensayo de penetración de agua y del coeficiente de difusión, agrupados según el cemento empleado para fabricar la dosificación del hormigón.

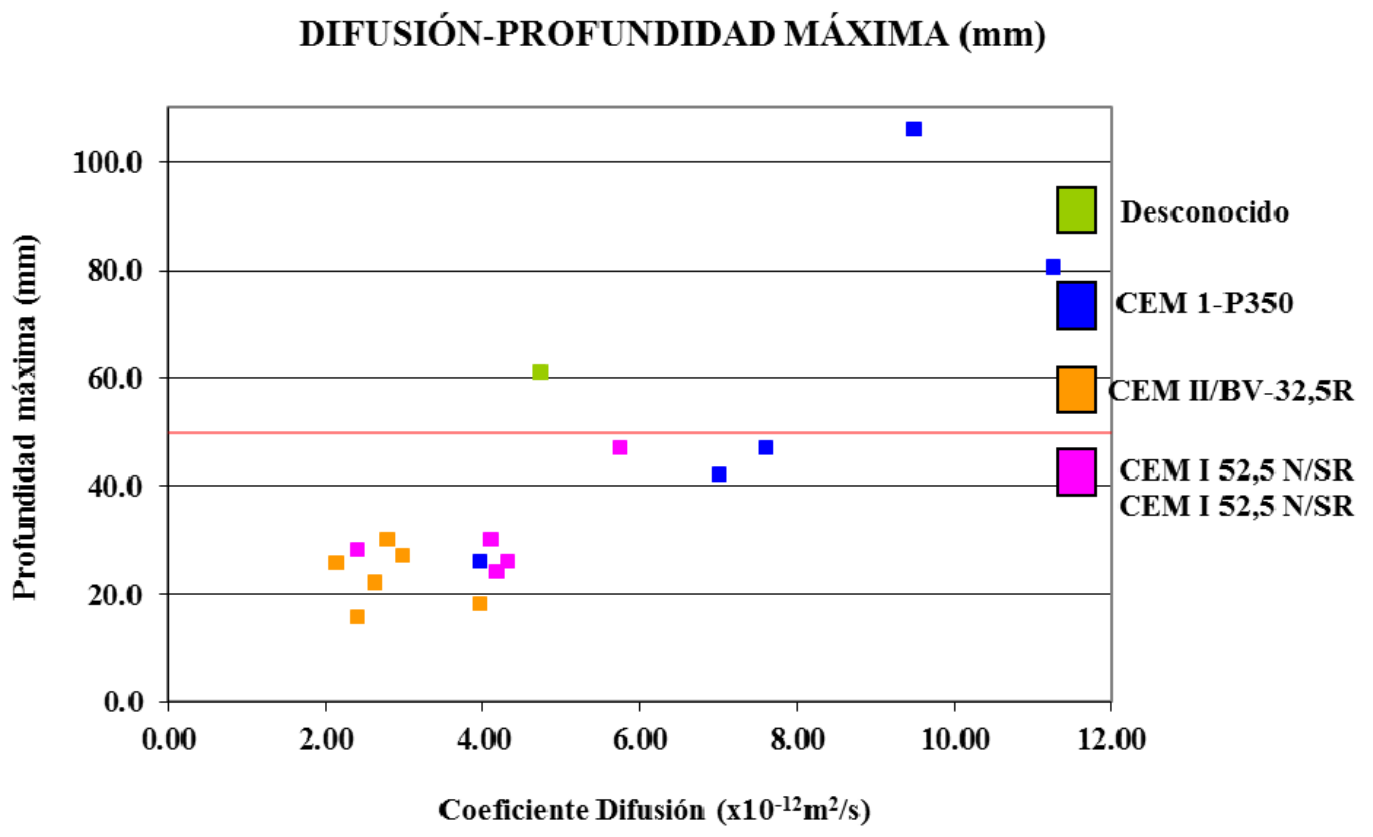

Fig.5.200.Calidad del hormigón según el tipo de cemento empleado en su fabricación.

A la vista de la figura 5.200, puede observarse que de los cuatro hormigones analizados, el que cuenta con cenizas volantes en su dosificación, es decir, el que contiene CEM II/BV 32,5R, es el que presenta menores resultados del coeficiente de difusión así como valores inferiores de penetración de agua frente a los fabricados con cementos Portland convencionales y sin adiciones. Dado que sólo uno de los cuatro hormigones presenta adiciones en su dosificación, sería necesario ampliar la muestra de estudio con hormigones que presenten adiciones, incluso a ser posible adiciones de otro tipo (escorias, humo de sílice...) para poder analizar cuál de ellas resulta más beneficiosa desde el punto de vista de la durabilidad.

\subsubsection{Aplicación del modelo desarrollado en esta investigación}

El modelo desarrollado en esta investigación permite estimar, para garantizar una determinada vida útil de la estructura, los parámetros necesarios en el hormigón si va a 
estar expuesto a un ambiente IIla spray (elementos situados 1,5 $\mathrm{m}$ por encima de la pleamar). El procedimiento consistiría:

- Cálculo del período de propagación de la corrosión, para determinar el período de iniciación.

- Fijar el valor del recubrimiento necesario.

- Fijar el valor del coeficiente de difusión máximo que debe tener el hormigón.

- Fijar la dosificación (contenido de cemento, relación agua/cemento y tipo y contenido de adición) para obtener un hormigón con ese valor del coeficiente de difusión.

- Penetración de agua que debe cumplir ese hormigón para validar de forma experimental esa dosificación.

A continuación se va a mostrar de forma práctica la utilización del modelo desarrollado, para una estructura en zona IIla spray.

a) Datos de partida

Los parámetros adoptados son los siguientes:

Vida útil: 50 años (valor habitual en el cálculo de estructuras portuarias).

Cth $\mathbf{0 , 6 \%}$ en peso de cemento (valor normativo EHE-08 y contrastado experimentalmente en el Anejo 2 de esta tesis).

Cs=0,25\% en peso de hormigón (valor obtenido en el Anejo 1 de esta tesis para el ambiente IIla spray).

d=2300 $\mathrm{kg} / \mathrm{m}^{3}$ (valor normal densidad el hormigón).

b) Cálculo del período de propagación y período de iniciación de la corrosión.

Se adopta como valor de velocidad de corrosión $30 \mu \mathrm{m} / \mathrm{m}$, valor intermedio entre 20 y 50 que son los asignados por la Instrucción EHE-08 a los ambientes IIla y IIIc. Se hará, sin embargo, una comprobación adicional con el valor de $20 \mu \mathrm{m} / \mathrm{m}$.

El período de propagación se estima a partir del recubrimiento de hormigón "d", el

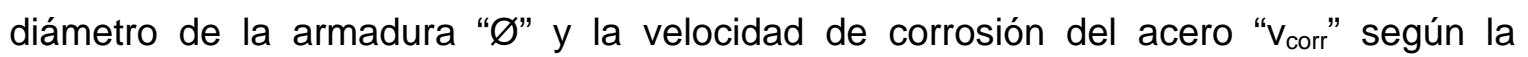
expresión recogida por las fuentes de bibliografía ${ }^{3,36}$. 
Tiempo de propagación $t_{p}=(80 * d) /\left(\varnothing^{*} v_{\text {corr }}\right)$.

Se realizan dos tanteos con dos velocidades distintas y se considera como diámetro de armadura $16 \mathrm{~mm}$ y como recubrimiento $45 \mathrm{~mm}$.

Tiempo propagación $(\mathrm{v}=20 \mu \mathrm{m} / \mathrm{m})=(80 * 45) /(16 * 20)=11,25$ años.

Tiempo propagación $(\mathrm{v}=30 \mu \mathrm{m} / \mathrm{m})=(80 * 45) /(16 * 30)=7,5$ años.

Dado que el periodo de iniciación se obtiene como diferencia entre la vida útil y el periodo de propagación estos valores serían de 38,75 años y de 42,5 años, respectivamente.

c) Valor del recubrimiento necesario

Las Figuras 5.201, 5.202 y 5.203 recogen la evolución de la concentración crítica de cloruros con el tiempo de acuerdo con la Ley de Fick para hormigones con diferentes valores del coeficiente de difusión a 1 año y con 300, 325 y $350 \mathrm{~kg} / \mathrm{m}^{3}$ de cemento (valores exigidos por la Instrucción EHE-08 en ambientes IIla, IIlb y IIIc respectivamente).

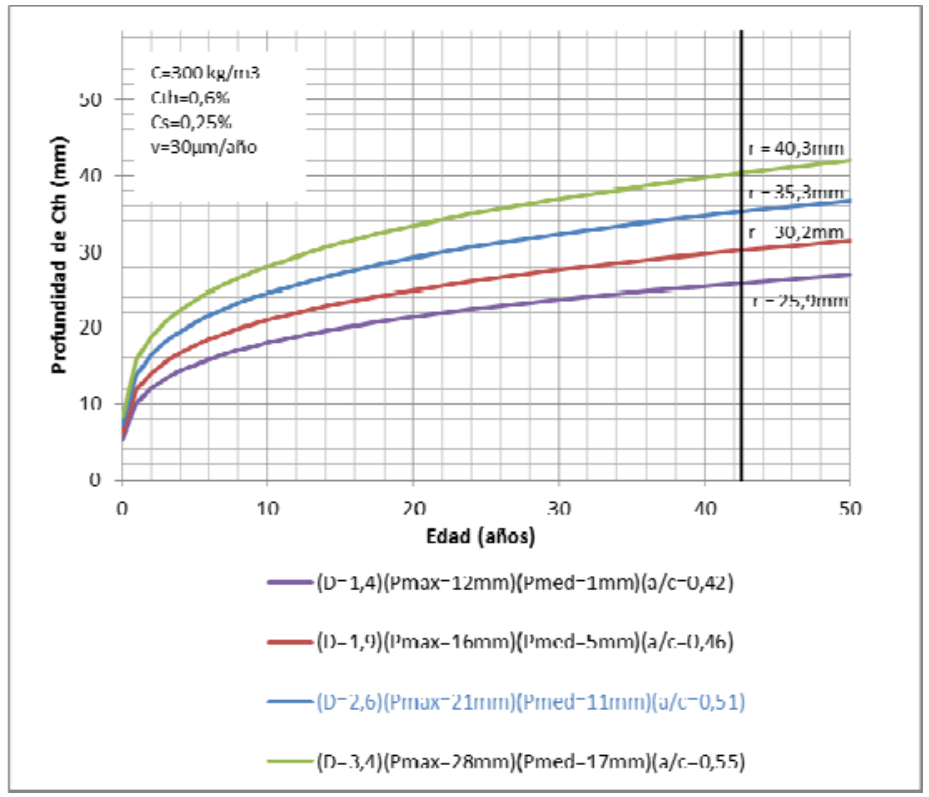

Fig.5.201. Evolución $C_{\text {th }}$ en hormigón situado en ambiente IIIa spray con un contenido de cemento de $300 \mathrm{~kg} / \mathrm{m}^{3}$ 


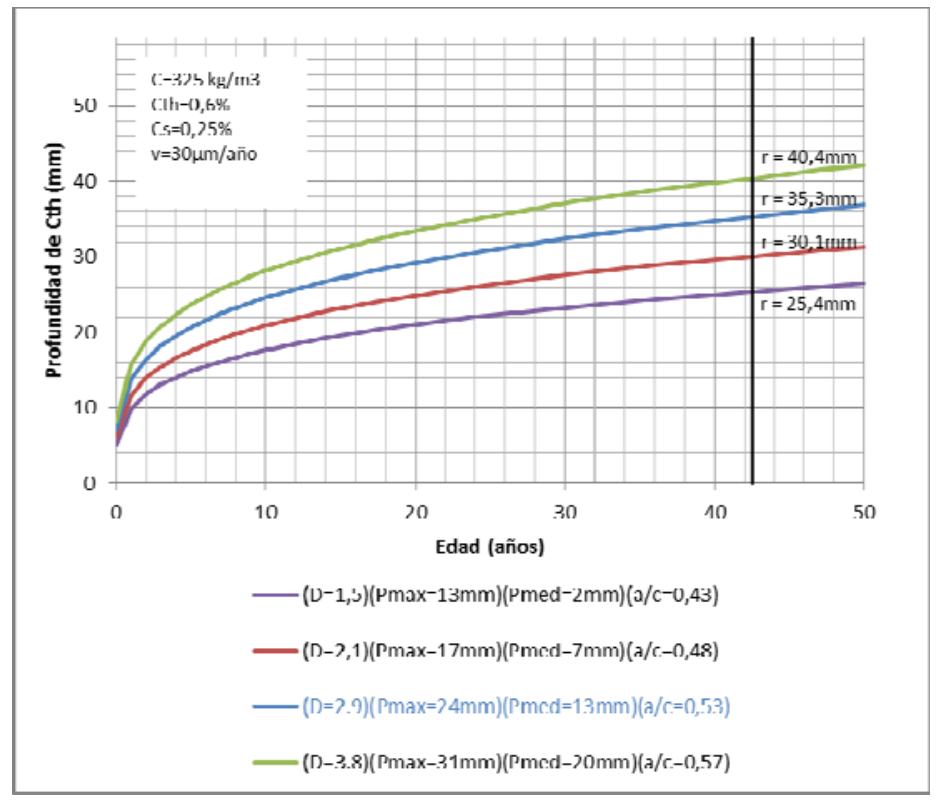

Fig.5.202. Evolución $C_{\text {th }}$ en hormigón situado en ambiente IIIa spray con un contenido de cemento de $325 \mathrm{~kg} / \mathrm{m}^{3}$

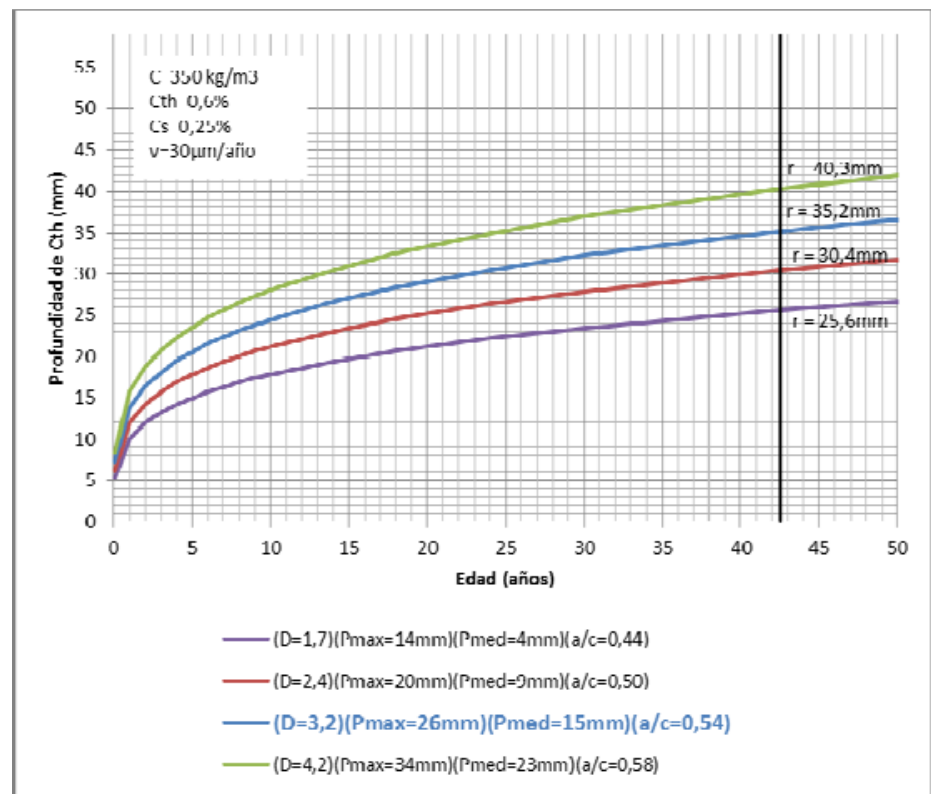

Fig.5.203. Evolución $C_{\text {th }}$ en hormigón situado en ambiente IIIa spray con un contenido de cemento de $350 \mathrm{~kg} / \mathrm{m}^{3}$

Para el período de iniciación antes determinado igual a 42,5 años, el corte con cada curva proporciona el valor de recubrimiento necesario que garantizaría completar la vida útil de 50 años sin problemas de corrosión. Se observa que al considerar hormigones de peor calidad (mayor valor del coeficiente de difusión) se precisan recubrimientos superiores. 
d) Dosificación del hormigón necesaria

Para cada valor del recubrimiento obtenido, la fórmula final obtenida en el apartado 5.7.7 permite calcular a partir del valor del coeficiente de difusión requerido la relación a/c necesaria en la dosificación del hormigón, teniendo también en cuenta si se van a utilizar adiciones (cenizas volantes y humo de sílice). Aplicando dicha fórmula (para el caso de cemento Portland) se han obtenido los valores de la relación a/c para cada coeficiente de difusión, que aparecen recogidas en la leyenda de las Figuras 5.201, 5.202 y 5.203. Se observa que si se utilizan hormigones con menor coeficiente de difusión será necesario reducir la relación a/c en la dosificación.

e) Control del hormigón: ensayo de penetración de agua

Finalmente, la relación establecida entre la penetración de agua y el coeficiente de difusión (Figuras 5.187 y 5.188, criterio EHE-08) permite determinar los requisitos de penetración que debe cumplir el hormigón en cada caso considerado. Se han obtenido los valores de penetración necesarios para cada coeficiente de difusión, que aparecen recogidos en la leyenda de las Figuras 5.201, 5.202 y 5.203. Los requisitos más exigentes del coeficiente de difusión deben validarse con valores en el ensayo de penetración de agua cada vez más reducidos.

f) Posibilidades de aplicación del modelo.

A efectos de diseño de estructuras nuevas el modelo desarrollado permite seleccionar a priori la combinación de variables que se considere más adecuada al caso particular. Así, reduciendo la relación agua/cemento se obtiene un menor recubrimiento o se puede prolongar la vida útil de la estructura, y estos los valores pueden ser fijados en proyecto.

A efectos normativos, las variables, en la medida de lo posible, deben ajustarse a valores habitualmente pedidos en la Instrucción EHE 08 para hormigones expuestos a ambiente marino. Esto es:

- Un recubrimiento entre 25 y $45 \mathrm{~mm}$.

- Unos requisitos de penetración no más exigentes de $P_{\max }=30 \mathrm{~mm}, P_{\operatorname{med}}=20 \mathrm{~mm}$.

- Una relación a/c 0,45 ó 0,50, sin llegar a 0,55.

Con estas premisas, las Figuras 5.201, 5.202 y 5.203 presentan dos posibles combinaciones que aparecen resaltadas en la correspondiente leyenda y que obligarían en los hormigones situados en ambiente IIla spray a adoptar los siguientes requisitos recogidos en la tabla 5.49 : 


\begin{tabular}{|c||c||c||c||c||c|}
\hline AMBIENTE & $\begin{array}{c}\text { Recubrimiento } \\
(\mathrm{mm})\end{array}$ & $\mathrm{a} / \mathrm{c}$ & $\mathrm{c}\left(\mathrm{kg} / \mathrm{m}^{3)}\right.$ & Pmax (mm) & Pmed (mm) \\
\hline \hline IIIa Spray & 35 & 0,50 & 350 & 30 & 20 \\
\hline
\end{tabular}

Tabla 5.49. Requisitos para un hormigón situado en ambiente IIIa Spray.

Se obtiene una dosificación y un recubrimiento similares a los actualmente exigidos en ambiente IIIc, con la salvedad de poderse utilizar una mayor relación a/c.

Finalmente, la Figura 5.204 muestra el resultado que se hubiera obtenido al utilizar una velocidad de propagación algo menor, 20 m/año, indicada por la Instrucción EHE-08 en ambiente IIIa.

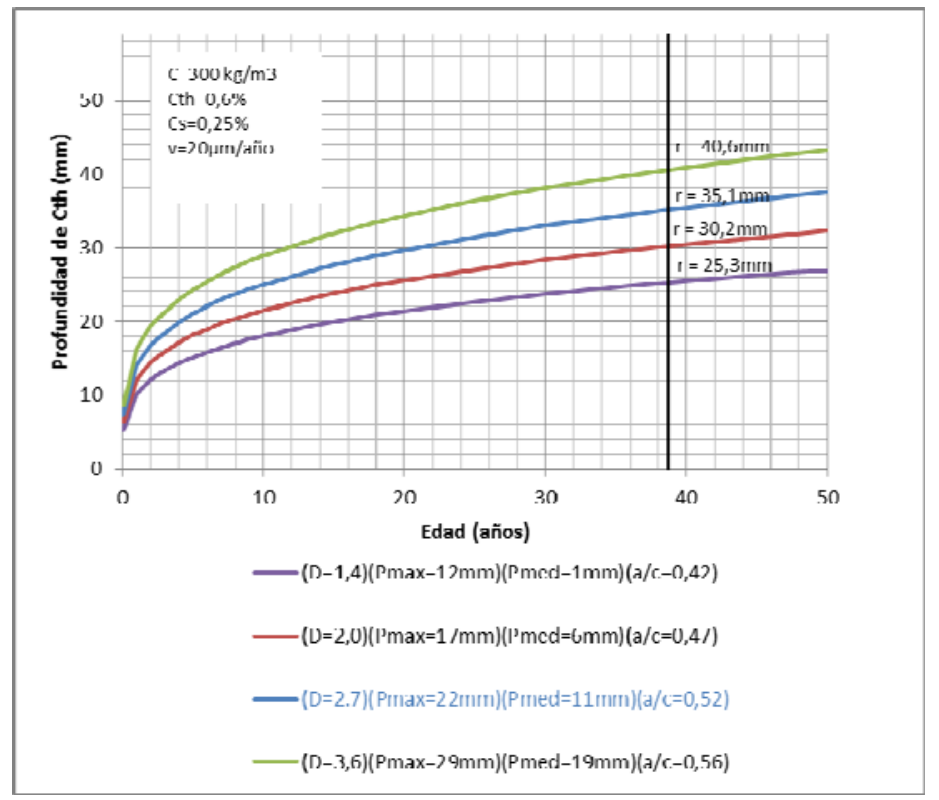

Fig.5.204. Evolución $C_{\text {th }}$ en hormigón situado en ambiente IIIa spray con un contenido cemento de $300 \mathrm{~kg} / \mathrm{m}^{3}$. Velocidad de corrosión= $20 \mu \mathrm{m} / \mathrm{año}$.

Se observa que los valores que se obtienen son muy similares a los anteriores, con una velocidad de $30 \mu \mathrm{m} / a n ̃ o$, siendo ésta más acorde con un ambiente más agresivo (IIla spray) que el ambiente IIla costero. 


\section{ESTUDIO DE LA RESISTIVIDAD COMO ENSAYO DE CONTROL DE LA DURABILIDAD DEL HORMIGÓN}

\subsection{OBJETIVOS}

En esta fase de la tesis doctoral, el objetivo ha sido valorar el ensayo de la resistividad (medida directa) como control de la durabilidad del hormigón en ambiente marino. Se trata de un ensayo no destructivo y de sencilla realización, que mide una propiedad eléctrica del hormigón (resistividad) con influencia en el proceso de corrosión de la armadura.

El trabajo realizado de montaje y puesta a punto del ensayo de resistividad queda recogido en el Anejo nº1.

\subsection{METODOLOGÍA}

Para la realización de este estudio se ha procedido a la medida de resistividad de testigos pertenecientes a muelles ubicados en ambiente IIla, IIlb y IIIc. Se trata de muelles estudiados previamente por el CEDEX cuyas características se indican en el apartado 6.3. En el caso del ambiente Illa se localiza una fuente de bibliografía de la cual también se extrae información de muestras ubicadas en este ambiente.

Con el fin de completar el rango de muestras pertenecientes a muelles situados en ambiente marino se plantea una campaña de fabricación de probetas de hormigón en laboratorio de cementos sin adiciones y con adiciones (cenizas volantes y humo de sílice) y tres relaciones a/c distintas $(0,35 ; 0,45$ y 0,50$)$.

\subsection{MATERIALES ENSAYADOS. RESULTADOS DE RESISTIVIDAD.}

En este apartado se presentan las características geométricas de los testigos ensayados así como los valores de resistividad y penetración obtenidos.

Se han empleado testigos procedentes de puertos localizados en ambiente IIla que han sido estudiados previamente. La descripción de los mismos se encuentra en el apartado 5.2 y la tabla 5.1 resume las características fundamentales de cada uno de ellos 
(Muelles A, B, C y D). La tabla 6.1 recoge las dimensiones de las rodajas de los testigos empleados así como los valores de resistividad y penetración obtenidos:

\begin{tabular}{|c|c|c|c|c|c|}
\hline Rodaja & $\mathrm{e}_{\mathrm{m}}(\mathbf{m m})$ & $\emptyset_{\mathrm{m}}(\mathrm{mm})$ & $\rho \mathrm{H}$ medio $(\Omega \mathrm{m})$ & Pmáx (mm) & Pmed (mm) \\
\hline A-1 & 103,51 & 95,05 & 55,8 & 104,0 & 104,0 \\
\hline A-3 & 102,14 & 95,02 & 76,8 & 47,0 & 39,0 \\
\hline B-C & 104,24 & 86,04 & 88,6 & 53,0 & 39,0 \\
\hline B-D & 102,43 & 86,62 & 48,8 & 104,0 & 92,0 \\
\hline C-3 & 65,90 & 94,30 & 165,5 & 30,0 & 20,7 \\
\hline C-5 & 101,90 & 94,40 & 390,9 & 15,5 & 5,8 \\
\hline C-6 & 76,30 & 94,50 & 241,4 & 18,0 & 11,9 \\
\hline C-2 & 42,90 & 94,40 & 248,9 & 22,0 & 10,9 \\
\hline D-1 & 102,32 & 103,81 & 68,3 & 47,0 & 26,6 \\
\hline D-2 & 114,27 & 103,82 & 73,8 & 28,0 & 14,8 \\
\hline D-3 & 140,50 & 103,81 & 59,4 & 26,0 & 12,6 \\
\hline D-4 & 113,88 & 103,85 & 77,0 & 24,0 & 12,9 \\
\hline
\end{tabular}

Tabla 6.1.Dimensiones de testigos de muelles situados en ambiente IIIa.

Resultados de resistividad y penetración.

Con el fin de completar los testigos analizados en el caso del ambiente IIla y dada la disponibilidad de datos de difusión y penetración de muelles localizados en ambiente IIIb y IIIc, se localizan testigos de esos muelles con el fin de medir su resistividad. En algunos casos se dispone de material suficiente para la realización del ensayo de penetración de agua lo que permite volver a realizarlo con el fin de tener pares de puntos reales de un mismo testigo. En el Anejo $n^{\circ} 1$, la tabla 3 recoge los datos más importantes de los muelles localizados en ambiente IIIb y IIlc. La tabla 6.2 recoge las dimensiones de las rodajas de los testigos empleados así como los valores de resistividad y penetración obtenidos: 


\begin{tabular}{|c||c||c||c|c||c||}
\hline Rodaja & $\mathrm{e}_{\mathrm{m}}(\mathbf{m m})$ & $\boldsymbol{\emptyset}_{\mathrm{m}}(\mathbf{m m})$ & $\boldsymbol{\rho}_{\mathrm{H} \text { medio }}(\mathbf{\Omega m})$ & Pmáx $(\mathbf{m m})$ & Pmed (mm) \\
\hline TMA H4 & 102,50 & 83,30 & $\mathbf{7 2 , 5}$ & $\mathbf{1 0 3 , 0}$ & $\mathbf{1 0 3 , 0}$ \\
\hline TMA H5 & 103,10 & 83,40 & $\mathbf{7 6 , 8}$ & $\mathbf{6 2 , 0}$ & $\mathbf{5 5 , 0}$ \\
\hline ALG-10 & 154,90 & 149,10 & $\mathbf{1 0 8 , 7}$ & $\mathbf{8 2 , 0}$ & $\mathbf{7 9 , 0}$ \\
\hline ALG-11 & 145,80 & 149,30 & $\mathbf{9 3 , 5}$ & $\mathbf{8 9 , 0}$ & $\mathbf{7 5 , 0}$ \\
\hline ALG-12 & 141,70 & 149,30 & $\mathbf{9 6 , 9}$ & $\mathbf{8 5 , 0}$ & $\mathbf{8 1 , 0}$ \\
\hline ALG-13 & 153,30 & 149,40 & $\mathbf{6 2 , 2}$ & $\mathbf{9 0 , 0}$ & $\mathbf{8 3 , 0}$ \\
\hline ALG-14 & 153,00 & 149,60 & $\mathbf{6 1 , 3}$ & $\mathbf{9 9 , 0}$ & $\mathbf{8 4 , 0}$ \\
\hline
\end{tabular}

Tabla 6.2. Dimensiones de testigos de muelles situados en ambiente IIIb y IIIc. Resultados de resistividad y penetración.

También se han empleado muestras procedentes de un estudio realizado por el Instituto Torroja ${ }^{52}$ de probetas localizadas en ambiente IIla. Según se indica en el citado estudio, para la realización de la medida de la resistividad se emplean probetas de $15 \times 30 \mathrm{~cm}$. La tabla 6.3 recoge las dimensiones de las rodajas de los testigos empleados así como los valores de resistividad y penetración obtenidos:

\begin{tabular}{|c|c|c|c|c|c|}
\hline Rodaja & $\mathrm{e}_{\mathrm{m}}(\mathbf{m m})$ & $\emptyset_{\mathrm{m}}(\mathrm{mm})$ & $\rho \mathrm{H}$ medio $(\Omega \mathrm{m})$ & Pmáx (mm) & Pmed (mm) \\
\hline T-1 & 300 & 150 & 65,9 & 83,0 & 61,3 \\
\hline T-2 & 300 & 150 & 71,2 & 32,3 & 14,3 \\
\hline T-3 & 300 & 150 & 87,6 & 18,8 & 7,0 \\
\hline T-4 & 300 & 150 & 108,5 & 30,0 & 14,0 \\
\hline T-5 & 300 & 150 & 77,1 & 119,4 & 89,4 \\
\hline T-6 & 300 & 150 & 46,0 & 62,7 & --- \\
\hline T-7 & 300 & 150 & 157,9 & 22,7 & --- \\
\hline T-8 & 300 & 150 & 471,5 & 18,8 & 7,3 \\
\hline T-9 & 300 & 150 & 107,7 & 33,3 & 16,7 \\
\hline
\end{tabular}

Tabla.6.3. Dimensiones de probetas de Estudio Torroja (IIIa).

Resultados de resistividad y penetración.

En cuanto a valores de laboratorio, se utilizan muestras de una amasada de hormigón H50 con humo de sílice (10\%). La dosificación se encuentra en la tabla 9 del anejo $\mathrm{n}^{\circ} 3$. 
La tabla 6.4 recoge las dimensiones de las rodajas de los testigos empleados así como los valores de resistividad y penetración obtenidos:

\begin{tabular}{|c||c||c|c|c|c||}
\hline Rodaja & $\mathrm{e}_{\mathrm{m}}(\mathbf{m m})$ & $\boldsymbol{\emptyset}_{\mathrm{m}}(\mathbf{m m})$ & $\boldsymbol{\rho}_{\mathrm{H} \text { medio }}(\mathbf{\Omega m})$ & Pmáx $(\mathbf{m m})$ & Pmed (mm) \\
\hline \hline H50-1 & 74,70 & 101,70 & $\mathbf{3 9 6 , 9}$ & $\mathbf{1 1 , 0}$ & $\mathbf{4 , 0}$ \\
\hline H50-2 & 100,90 & 100,50 & $\mathbf{3 6 4 , 5}$ & $\mathbf{1 5 , 0}$ & $\mathbf{7 , 0}$ \\
\hline H50-3 & 75,20 & 100,50 & $\mathbf{3 8 0 , 2}$ & $\mathbf{1 4 , 0}$ & $\mathbf{6 , 0}$ \\
\hline H50-4 & 98,50 & 98,50 & $\mathbf{3 6 8 , 5}$ & $\mathbf{1 3 , 0}$ & $\mathbf{7 , 0}$ \\
\hline
\end{tabular}

Tabla 6.4. Dimensiones de probetas de H50 (10\% HS) fabricadas en laboratorio.

Resultados de resistividad y penetración.

Por último y con el fin de completar los rangos de los resultados anteriores, se lleva a cabo una campaña de amasadas en laboratorio. Se fabrican hormigones de tres relaciones a/c distintas $(0,35,0,45$ y 0,50$)$ empleando a su vez tres tipos distintos de cemento: CEM I, cemento con cenizas volantes y cemento con humo de sílice. A continuación las tablas 6.5 a 6.10 recogen las dimensiones de las rodajas de los testigos empleados así como los valores de resistividad y penetración obtenidos:

\begin{tabular}{|c|c|c|c|c|c|}
\hline Rodaja & $\mathrm{e}_{\mathrm{m}}(\mathbf{m m})$ & $\emptyset_{\mathrm{m}}(\mathrm{mm})$ & $\rho_{\mathrm{H}}$ medio $(\Omega \mathrm{m})$ & Pmáx (mm) & Pmed (mm) \\
\hline 0,35-CEMI4 & 163,65 & 150,04 & 90,5 & 16,0 & 8,0 \\
\hline 0,35-CEMI5 & 164,55 & 149,84 & 86,1 & 14,0 & 6,0 \\
\hline 0,35-CEMI6 & 164,05 & 150,03 & 84,8 & 17,0 & 7,0 \\
\hline 0,45-CEMI4 & 166,49 & 150,04 & 57,3 & 13,0 & 5,0 \\
\hline 0,45-CEMI5 & 164,45 & 149,93 & 63,8 & 16,0 & 8,0 \\
\hline 0,45-CEMI6 & 165,72 & 150,20 & 60,0 & 16,0 & 6,0 \\
\hline 0,50-CEMI4 & 165,53 & 150,44 & 75,9 & 10,0 & 2,0 \\
\hline 0,50-CEMI5 & 165,30 & 150,17 & 78,6 & 19,0 & 5,0 \\
\hline 0,50-CEMI6 & 164,48 & 149,94 & 76,2 & 15,0 & 4,0 \\
\hline
\end{tabular}

Tabla 6.5. Dimensiones de probetas laboratorio (28 días sin adiciones). Resultados de resistividad y penetración. 


\begin{tabular}{|c||c||c|c|c|c||}
\hline Rodaja & $\mathrm{e}_{\mathrm{m}}(\mathbf{m m})$ & $\left.\boldsymbol{\emptyset}_{\mathbf{m}} \mathbf{( m m}\right)$ & $\boldsymbol{\rho}_{\text {H medio }}(\mathbf{\Omega m})$ & Pmáx (mm) & Pmed (mm) \\
\hline \hline $\mathbf{0 , 3 5 - C V 4}$ & 164,35 & 149,80 & $\mathbf{1 2 1 , 7}$ & $\mathbf{2 0 , 0}$ & $\mathbf{9 , 0}$ \\
\hline $\mathbf{0 , 3 5 - C V 5}$ & 163,90 & 149,84 & $\mathbf{1 2 3 , 7}$ & $\mathbf{1 3 , 0}$ & $\mathbf{7 , 0}$ \\
\hline $\mathbf{0 , 3 5 - C V 6}$ & 163,76 & 149,87 & $\mathbf{1 2 2 , 8}$ & $\mathbf{1 7 , 0}$ & $\mathbf{8 , 0}$ \\
\hline $\mathbf{0 , 4 5 - C V 4}$ & 164,12 & 149,69 & $\mathbf{8 5 , 2}$ & $\mathbf{1 0 , 0}$ & $\mathbf{3 , 0}$ \\
\hline $\mathbf{0 , 4 5 - C V 5}$ & 163,91 & 150,18 & $\mathbf{8 8 , 1}$ & $\mathbf{1 3 , 0}$ & $\mathbf{5 , 0}$ \\
\hline $\mathbf{0 , 4 5 - C V 6}$ & 163,96 & 149,82 & $\mathbf{8 8 , 5}$ & $\mathbf{1 5 , 0}$ & $\mathbf{6 , 0}$ \\
\hline $\mathbf{0 , 5 0 - C V 4}$ & 164,86 & 149,97 & $\mathbf{5 6 , 3}$ & $\mathbf{1 2 , 0}$ & $\mathbf{4 , 0}$ \\
\hline $\mathbf{0 , 5 0 - C V 5}$ & 164,14 & 150,21 & $\mathbf{5 2 , 7}$ & $\mathbf{1 3 , 0}$ & $\mathbf{6 , 0}$ \\
\hline $\mathbf{0 , 5 0 - C V 6}$ & 163,70 & 149,94 & $\mathbf{5 3 , 2}$ & $\mathbf{1 4 , 0}$ & $\mathbf{5 , 0}$ \\
\hline
\end{tabular}

Tabla 6.6. Dimensiones de probetas laboratorio (28 días cenizas volantes).

Resultados de resistividad y penetración.

\begin{tabular}{|c|c|c|c|c|c|}
\hline Rodaja & $\mathrm{e}_{\mathrm{m}}(\mathbf{m m})$ & $\emptyset_{\mathrm{m}}(\mathrm{mm})$ & $\rho \mathrm{H}$ medio $(\Omega \mathrm{m})$ & Pmáx (mm) & Pmed (mm) \\
\hline 0,35-HS4 & 163,10 & 149,97 & 381,6 & 16,0 & 6,0 \\
\hline 0,35-HS5 & 164,41 & 149,94 & 386,2 & 14,0 & 6,0 \\
\hline 0,35-HS6 & 164,00 & 150,35 & 390,4 & 16,0 & 7,0 \\
\hline 0,45-HS4 & 163,57 & 149,89 & 278,7 & 17,0 & 7,0 \\
\hline 0,45-HS5 & 165,00 & 149,99 & 276,2 & 11,0 & 4,0 \\
\hline 0,45-HS6 & 162,95 & 149,89 & 267,3 & 7,0 & 1,0 \\
\hline 0,50-HS4 & 163,71 & 150,10 & 245,2 & 12,0 & 2,0 \\
\hline 0,50-HS5 & 164,85 & 150,00 & 234,6 & 10,0 & 3,0 \\
\hline 0,50-HS6 & 164,23 & 149,87 & 237,2 & 13,0 & 5,0 \\
\hline
\end{tabular}

Tabla 6.7. Dimensiones de probetas laboratorio (28 días humo de sílice).

Resultados de resistividad y penetración. 


\begin{tabular}{|c|c|c|c|c|c|}
\hline Rodaja & $\mathrm{e}_{\mathrm{m}}(\mathbf{m m})$ & $\emptyset_{\mathrm{m}}(\mathrm{mm})$ & $\rho_{\mathrm{H}}$ medio $(\Omega \mathrm{m})$ & Pmáx (mm) & Pmed (mm) \\
\hline 0,35-CEMI-1 & 131,25 & 149,70 & 116,0 & 20,0 & 9,0 \\
\hline 0,35-CEMI-2 & 132,50 & 150,00 & 105,2 & 16,0 & 7,0 \\
\hline 0,35-CEMI-3 & 134,04 & 150,10 & 115,2 & 23,0 & 9,0 \\
\hline 0,45-CEMI-1 & 132,91 & 149,99 & 103,4 & 23,0 & 8,0 \\
\hline 0,45-CEMI-2 & 134,58 & 150,18 & 121,3 & 19,0 & 6,0 \\
\hline 0,45-CEMI-3 & 133,07 & 149,85 & 125,9 & 18,0 & 5,0 \\
\hline 0,50-CEMI-1 & 135,04 & 150,17 & 116,1 & 14,0 & 4,0 \\
\hline 0,50-CEMI-2 & 137,10 & 150,19 & 129,7 & 17,0 & 8,0 \\
\hline 0,50-CEMI-3 & 132,93 & 150,19 & 124,1 & 12,0 & 4,0 \\
\hline
\end{tabular}

Tabla 6.8. Dimensiones de probetas laboratorio (90 días sin adiciones). Resultados de resistividad y penetración.

\begin{tabular}{|c|c|c|c|c|c|}
\hline Rodaja & $\mathrm{e}_{\mathrm{m}}(\mathbf{m m})$ & $\varnothing_{\mathrm{m}}(\mathrm{mm})$ & $\rho H$ medio $(\Omega \mathrm{m})$ & Pmáx (mm) & Pmed (mm) \\
\hline 0,35-CV1 & 131,25 & 149,70 & 295,6 & 16,0 & 6,0 \\
\hline $0,35-C V 2$ & 132,50 & 150,00 & 288,3 & 11,0 & 2,0 \\
\hline $0,35-C V 3$ & 134,04 & 150,10 & 288,8 & 14,0 & 4,0 \\
\hline $0,45-C V 1$ & 133,56 & 150,23 & 268,2 & 11,0 & 4,0 \\
\hline $0,45-C V 2$ & 131,96 & 150,52 & 259,7 & 15,0 & 6,0 \\
\hline $0,45-C V 3$ & 131,27 & 150,12 & 264,3 & 11,0 & 4,0 \\
\hline $0,50-C V 1$ & 135,41 & 150,21 & 245,3 & 16,0 & 6,0 \\
\hline $0,50-C V 2$ & 131,70 & 149,95 & 237,5 & 16,0 & 6,0 \\
\hline $0,50-C V 3$ & 134,21 & 150,18 & 237,0 & 17,0 & 5,0 \\
\hline
\end{tabular}

Tabla 6.9. Dimensiones de probetas laboratorio (90 días cenizas volantes).

Resultados de resistividad y penetración. 


\begin{tabular}{|c|c|c|c|c|c|}
\hline Rodaja & $\mathrm{e}_{\mathrm{m}}(\mathbf{m m})$ & $\varnothing_{\mathrm{m}}(\mathrm{mm})$ & $\rho_{\mathrm{H}}$ medio $(\Omega \mathrm{m})$ & Pmáx (mm) & Pmed (mm) \\
\hline 0,35-HS1 & 132,94 & 150,10 & 475,5 & 11,0 & 3,0 \\
\hline 0,35-HS2 & 133,98 & 150,30 & 484,4 & 26,0 & 3,0 \\
\hline 0,35-HS3 & 132,74 & 150,10 & 475,1 & 7,0 & 2,0 \\
\hline 0,45-HS1 & 132,68 & 150,27 & 393,3 & 23,0 & 7,0 \\
\hline 0,45-HS2 & 138,41 & 150,19 & 382,4 & 18,0 & 5,0 \\
\hline 0,45-HS3 & 132,34 & 150,35 & 384,2 & 18,0 & 6,0 \\
\hline 0,50-HS1 & 134,69 & 150,30 & 353,7 & 19,0 & 9,0 \\
\hline 0,50-HS2 & 134,46 & 149,91 & 384,4 & 16,0 & 6,0 \\
\hline 0,50-HS3 & 134,49 & 150,12 & 329,0 & 12,0 & 5,0 \\
\hline
\end{tabular}

Tabla 6.10. Dimensiones de probetas laboratorio (90 días humo de sílice).

Resultados de resistividad y penetración.

\subsection{ANÁLISIS DE RESULTADOS}

Las Figuras 6.1 y 6.2 representan todos los resultados recogidos en las Tablas 6.1 a 6.10, que cubren un amplio rango de valores tanto en penetración de agua (máxima y media) como en resistividad. En los apartados siguientes se analizarán los factores que influyen en los valores obtenidos.

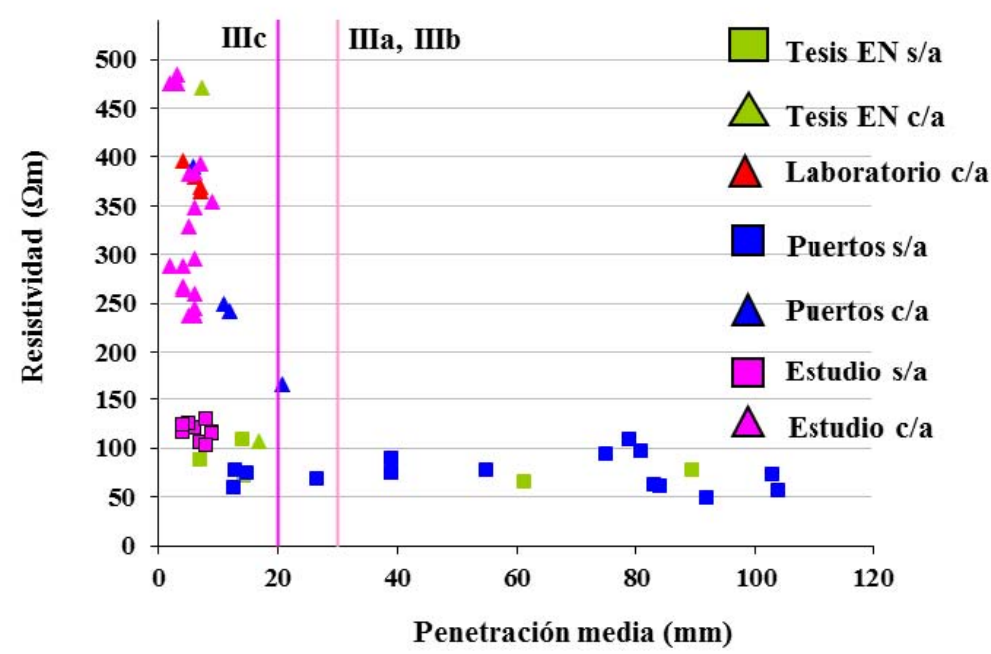

Fig.6.1. Resultados Penetración Media-Resistividad. 


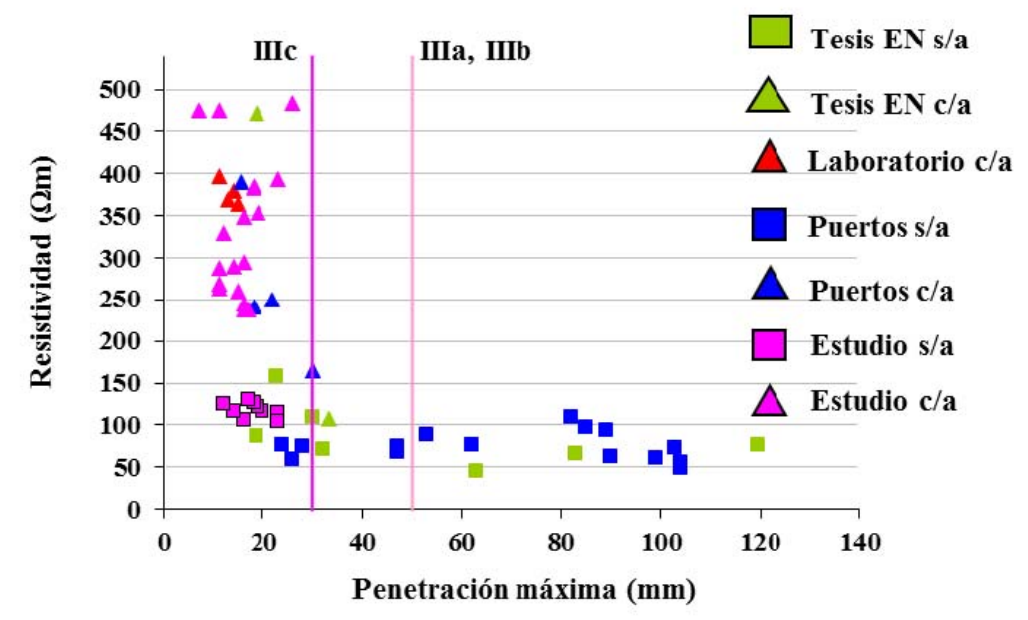

Fig.6.2. Resultados Penetración Máxima-Resistividad.

\subsubsection{Influencia de la presencia de adiciones}

Las Figuras 6.3 y 6.4 diferencian en la muestra global de resultados aquéllos que corresponden a hormigones con adiciones (cenizas y humo de sílice) y sin adiciones.

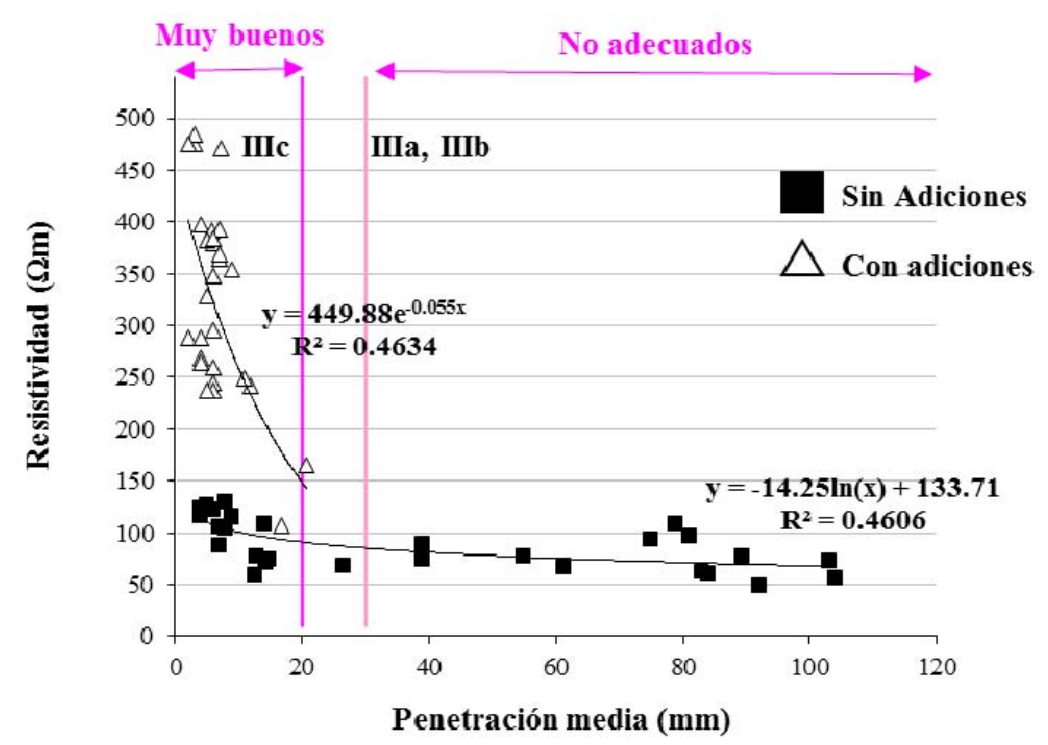

Fig.6.3. Influencia Adiciones en Penetración Media-Resistividad. 


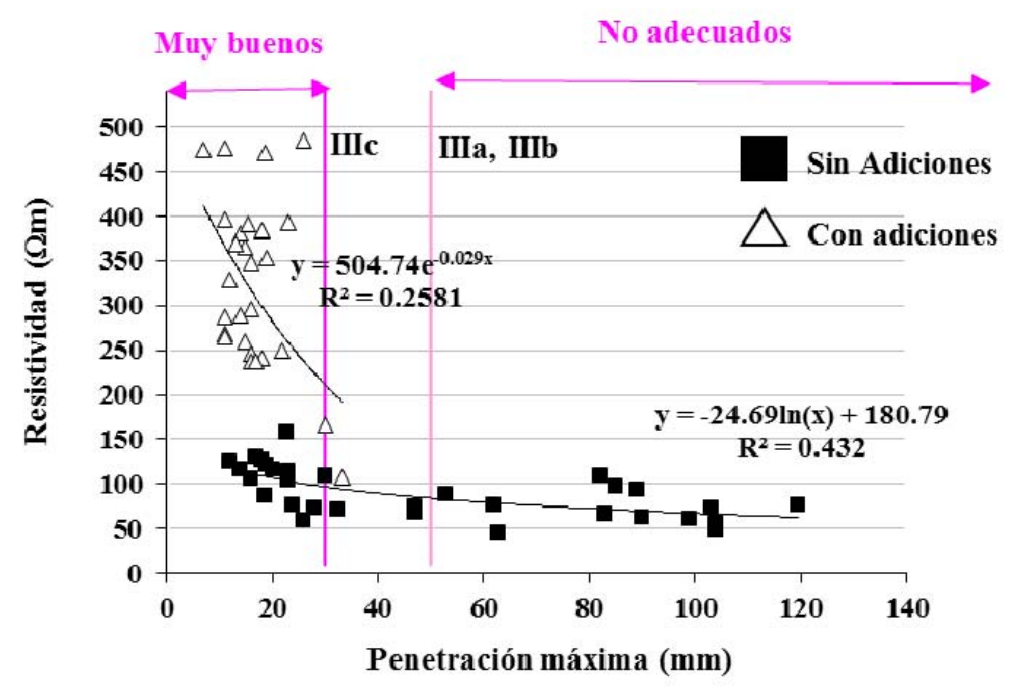

Fig.6.4. Influencia Adiciones en Penetración Máxima-Resistividad.

Se ve un comportamiento muy diferenciado en ambas series de resultados, que se aprecia especialmente en los valores bajos de la penetración de agua correspondientes a hormigones que cumplen los requisitos de penetración de la EHE 08 más exigentes (ambiente IIIc correspondiente a hormigones de muy buena calidad). Hay que indicar que en esta serie de resultados con adiciones hay 4 puntos que corresponden a datos obtenidos en testigos de $10 \mathrm{~cm}$ de diámetro, mientras que el resto corresponde a probetas de $15 \mathrm{~cm}$ de diámetro. Esos 4 puntos, de acuerdo con lo expuesto en el Anejo 3 , podrían estar afectados por un coeficiente de paso a probeta normalizada (que no ha sido posible determinar con precisión) y que haría que los valores definitivos pudieran bajar, pero en cualquier caso se considera que el resultado final no se vería muy afectado, ya que se trata de un número muy limitado de puntos.

En estos hormigones de baja permeabilidad se incrementa notablemente el valor de la resistividad para los hormigones que incorporan adiciones (cenizas o humo de sílice), en relación con los valores correspondientes a hormigones sin adiciones de similar penetración.

El comportamiento puede atribuirse a que en los cementos Portland de baja relación agua/cemento la reducida porosidad disminuye de forma notable el paso del agua bajo presión (penetración de agua) hasta casi llegar a agotar el mecanismo de transporte, pero siendo posible el paso de la corriente eléctrica si existe conexión entre los poros y están saturados de agua. 
Las adiciones, debido a su reacción puzolánica en el tiempo, generan en el hormigón un refinamiento del sistema de poros e incluso un sellado de los mismos que rompe la conexión e impide el paso de la corriente eléctrica, elevándose así de forma notable el valor de la resistividad en estos hormigones.

Se observa además que las curvas presentan dos ramas diferenciadas:

- una rama muy vertical que demuestra la sensibilidad del ensayo de resistividad para detectar hormigones con adiciones, en los que la porosidad accesible interconectada es especialmente baja.

- una rama muy horizontal, correspondiente a hormigones muy permeables (no adecuados en ambientes agresivos) en los que el ensayo de penetración se muestra más sensible para clasificar los hormigones de peor calidad.

Teniendo en cuenta los límites impuestos a la penetración de agua por la Instrucción EHE en los ambientes marinos IIIa, IIIb y IIlc mostrados en la Figura, puede considerarse que este ensayo establece cortes que separan correctamente los hormigones no adecuados, buenos y muy buenos. Establecer esta separación en valores de resistividad supondría excluir los hormigones sin adiciones en el ambiente IIIc, que en todos los casos presentan valores de resistividad muy bajos.

En los hormigones considerados muy buenos que cumplen el límite más restrictivo del ambiente IIIc, el ensayo de resistividad además permite una ordenación en la calidad de los mismos en cuanto a su porosidad accesible. Sin embargo, para los hormigones considerados como no adecuados, la resistividad apenas muestra sensibilidad para diferenciar el grado de calidad del hormigón, mientras que la penetración de agua sí los clasifica correctamente.

En cualquier caso, esta efectividad del ensayo de resistividad para evaluar la especial durabilidad de hormigones de muy buena calidad (obtenidos mediante la incorporación de adiciones), así como la sensibilidad del ensayo de penetración de agua en el rango de hormigones de baja durabilidad, debería también ser coherente con el comportamiento real posterior de estos hormigones expuestos al ambiente marino. En cuanto a la penetración de agua, las Figuras 5.187 y 5.188 sí demuestran la correlación entre el resultado de este ensayo y la difusión de los cloruros en el hormigón expuesto al ambiente marino. Este aspecto será analizado en el apartado siguiente para los resultados de resistividad. 


\subsubsection{Relación de la resistividad con la difusión de cloruros.}

La Figura 6.5 representa los valores de resistividad medidos en los puertos estudiados y el resultado del coeficiente de difusión a 1 año obtenido en cada testigo. Se dispone de un número limitado de resultados, ya que en todos los casos se trata de valores reales de difusión en estructuras. Para ampliar el número de datos se han incluido también los procedentes del estudio Torroja en ambiente IIIa y del estudio CEDEX en ambiente IIIb.

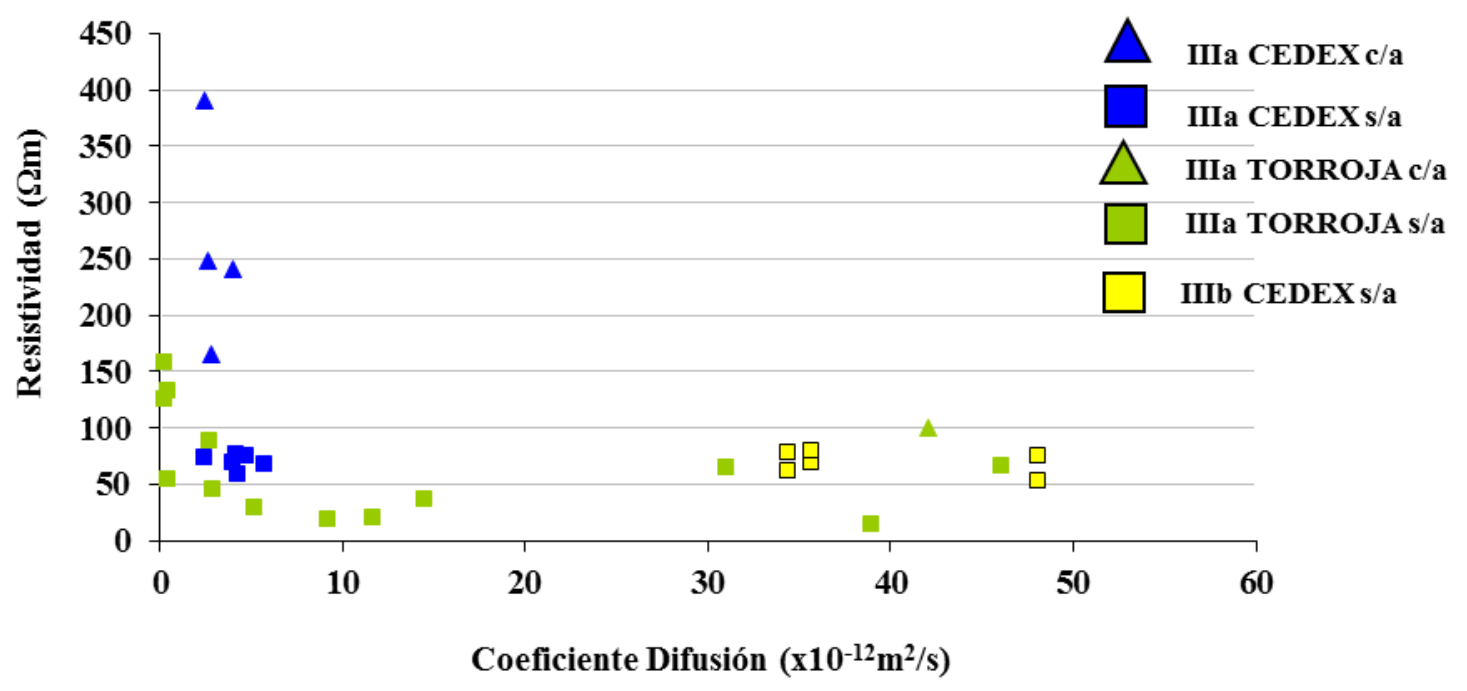

Fig.6.5. Resultados Difusión-Resistividad en ambientes IIIa y IIIb.

Se observa en la Figura 6.5 que los resultados CEDEX en ambiente Illa para hormigones sin adiciones encajan bien en la serie de los resultados del estudio Torroja. Sin embargo, se observan tres puntos de este ambiente de este estudio con valores extremadamente altos. De acuerdo a los estudios CEDEX, los hormigones en el ambiente IIla presentan difusiones que pueden alcanzar hasta $15 \times 10^{-12} \mathrm{~m}^{2} / \mathrm{s}$ (Figura 5.187), mientras que en ambiente IIIb y IIIc los valores pueden llegar a alcanzar hasta 60 $\mathrm{x} 10^{-12} \mathrm{~m}^{2} / \mathrm{s}$ por lo que los tres puntos del estudio Torroja parecen corresponder a hormigones en ambiente de carrera de mareas o sumergido (este aspecto se trata en el Anejo 1, tabla 9, Apartado 5).

Si se excluyen estos puntos y se consideran sólo los que claramente corresponden a un ambiente IIIa, se obtiene la Figura 6.6 que permite ver en detalle estos valores.

Se observa que la serie de puntos correspondiente a hormigones sin adición permite establecer una correlación, si bien la curva resulta poco sensible frente a las variaciones obtenidas en el coeficiente de difusión. 


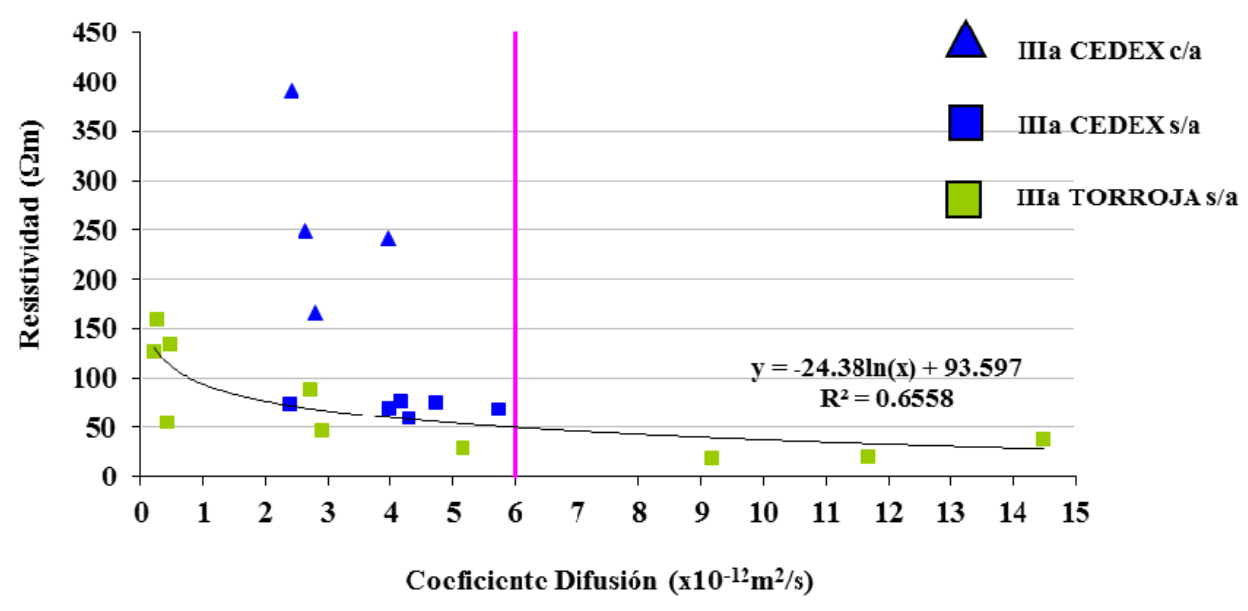

Fig.6.6. Resultados Difusión-Resistividad en ambiente IIIa.

Adicionalmente, se observa en la Figura 6.6 la existencia de hormigones fabricados sin adiciones y que presentaban una resistividad muy inferior a los hormigones con adiciones, pero expuestos al ambiente marino aéreo han presentado una velocidad de penetración de los cloruros similar en ambos casos. Por tanto, el efecto positivo de la adición en la medida de la resistividad no se ha traducido en una mejora del coeficiente de difusión de los cloruros. De hecho, se observa en la figura la presencia de hormigones sin adiciones con un coeficiente de difusión casi nulo, y una resistividad por debajo de la obtenida en los hormigones con adiciones.

El valor del coeficiente de difusión máximo adecuado para este ambiente, según el gráfico de penetración de agua, $\left(6 \times 10^{-12} \mathrm{~m}^{2} / \mathrm{s}\right)$ ha sido cumplido por igual en los hormigones de muy alta (391 $\Omega . m)$ y muy baja resistividad (29 $\Omega$.m).

Por tanto, la resistividad no diferencia correctamente los hormigones que tendrán un mejor comportamiento en cuanto a la difusión, asignando valores muy elevados de resistividad a los hormigones que incorporan adiciones, que no se reflejan luego en un comportamiento mejorado frente a la difusión de cloruros.

\subsubsection{Influencia de la edad}

En la serie de probetas fabricadas en el laboratorio se realizaron los ensayos de penetración de agua y resistividad a la edad de 28 y 90 días para comprobar la evolución y el efecto de las adiciones. En las Figuras 6.7 y 6.8 se muestran los 
resultados para la serie de cemento Portland, cenizas volantes y humo de sílice para 28 días (fig 6.7) y para 90 días (fig. 6.8).

Los resultados de penetración de agua indican en todos los casos que se trata de hormigones que cumplen sobradamente los requisitos exigidos por la Instrucción para el ambiente más exigente (IIIc) por lo que todos ellos pueden considerarse de buena durabilidad, sin que la penetración de agua indique grandes diferencias en su comportamiento.

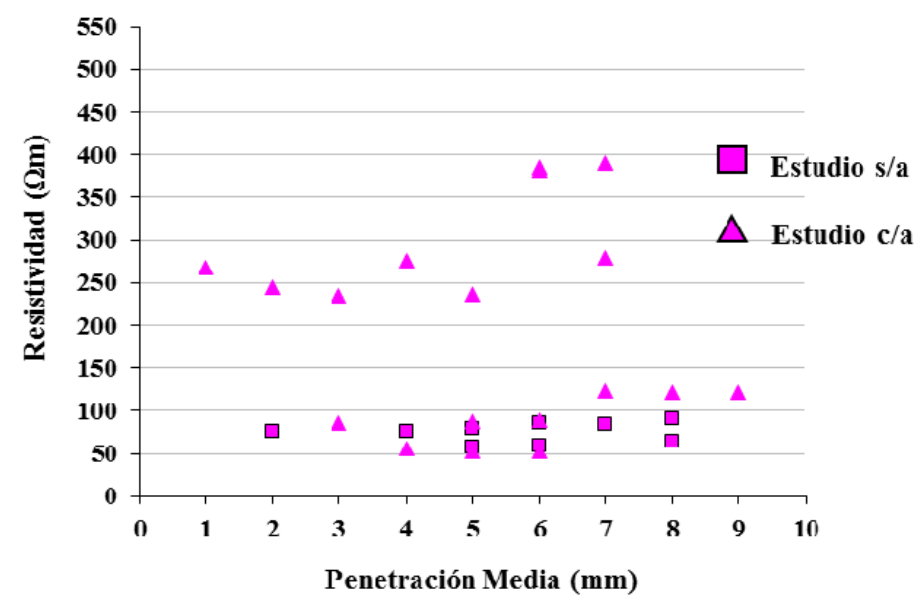

Fig.6.7. Resultados Penetración Media-Resistividad a 28 días.

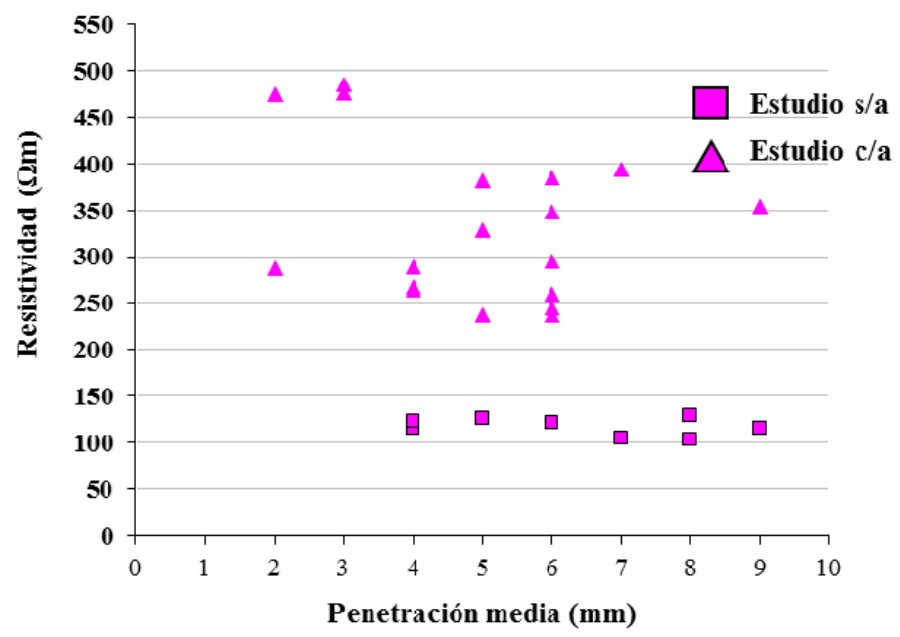

Fig.6.8. Resultados Penetración Media-Resistividad a 90 días.

Se observa en ambas figuras cómo el efecto de la edad es más pronunciado sobre la resistividad que sobre la penetración de agua. En especial los incrementos de 
resistividad se producen en los hormigones con adiciones, que elevan el valor en todos los casos de forma muy notable.

\subsubsection{Influencia del tipo de adición.}

Las Figuras 6.9, 6.10 y 6.11 separan los resultados del apartado anterior en tres series correspondientes a los hormigones fabricados con Cemento Pórtland, con cenizas volantes y con humo de sílice. Se observa el diferente comportamiento en los resultados de resistividad en las tres series ensayadas:

- El hormigón con cemento Pórtland presenta una baja resistividad a los 28 días, que apenas experimenta aumento a los 90 días.

- Los hormigones con ceniza volante presentan a los 28 días valores de resistividad similares a los obtenidos con el cemento Pórtland, pero sin embargo se observa un fuerte aumento a los 90 días. Este comportamiento es coherente con el funcionamiento de la ceniza volante, al tratarse de una adición lenta que manifiesta su efecto fundamentalmente a edades posteriores a los 28 días.

- Los hormigones con humo de sílice presentan ya a 28 días valores de resistividad similares a los conseguidos por las dosificaciones con ceniza volante a los 90 días, y muy superiores a los de las mezclas sin adiciones. El humo de sílice sigue ganando resistividad obteniéndose valores muy elevados a los 90 días. También el resultado es coherente con el funcionamiento esperable, ya que se trata de una adición más activa que la ceniza (mucha más finura) cuyos resultados se aprecian ya a los 28 días y se ven mejorados a edades posteriores.

- Las figuras además muestran que la resistividad proporciona sensibilidad en las medidas sólo en los hormigones con adición y a 90 días de edad (flechas descendentes marcadas). 


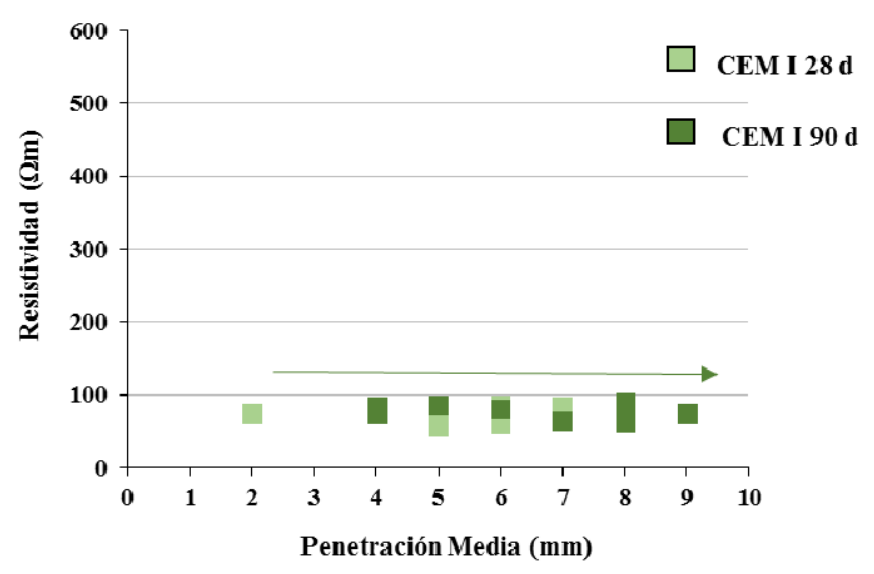

Fig.6.9. Influencia de la edad en muestras de cemento Portland sin adiciones.

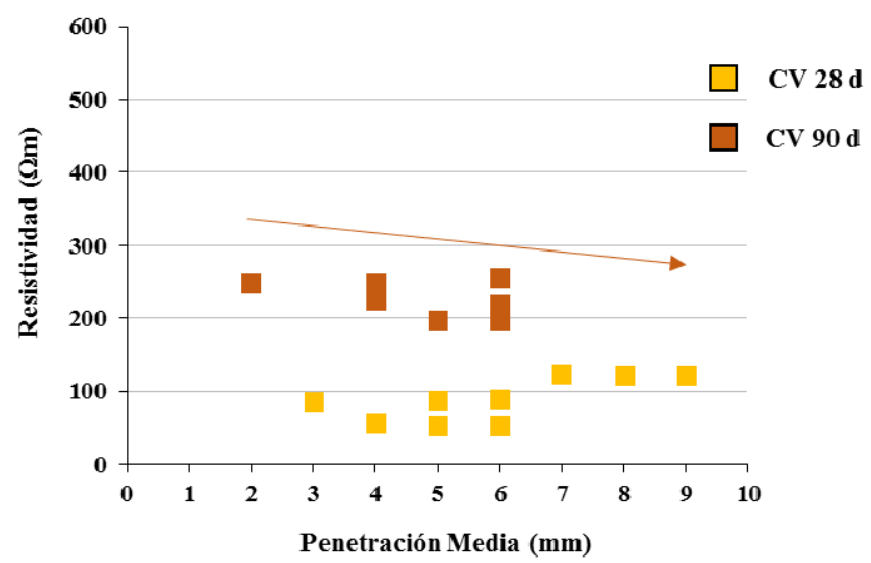

Fig.6.10. Influencia de la edad en muestras de cemento con cenizas volantes.

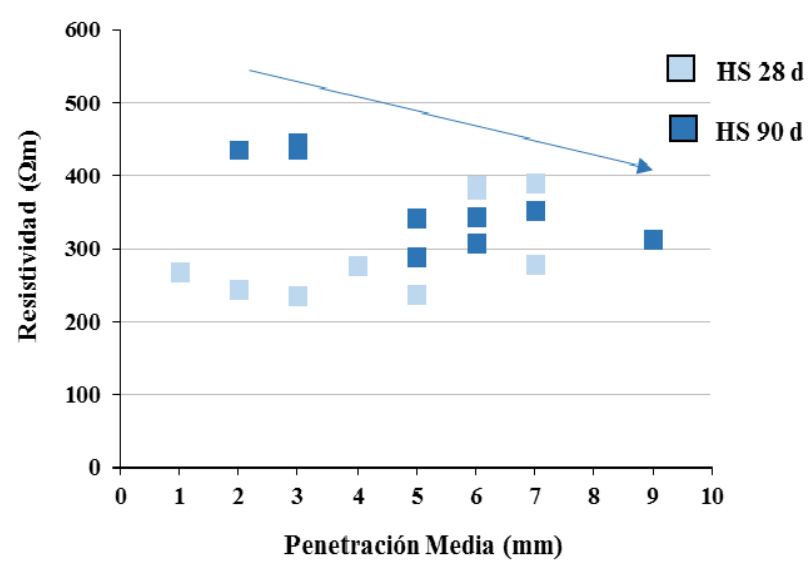

Fig.6.11. Influencia de la edad en muestras de cemento con humo de sílice. 



\section{CONCLUSIONES}

\subsection{CLORUROS EN SUPERFICIE EN HORMIGONES EXPUESTOS A AMBIENTE MARINO}

La concentración de cloruros en superficie $\mathrm{C}_{\mathrm{S}}$ es un factor fundamental en la predicción de la vida útil de las estructuras expuestas al ambiente marino. Los valores de Cs que se encuentran en la literatura son muy variables, por lo que en el seno de la tesis doctoral se ha realizado un estudio específico sobre datos reales de cloruros en estructuras situadas en las diferentes costas españolas, para contrastar estos resultados con los valores límite planteados por la normativa EHE 08 en cada uno los ambientes marinos presentes en la Instrucción.

El estudio se ha recogido en Anejo 1 de la tesis y se ha partido de una revisión bibliográfica de valores de $\mathrm{C}_{\mathrm{s}}$. Se han analizado los resultados obtenidos en estudios experimentales sobre estructuras en España ubicadas en ambiente marino Illa (aéreo), IIIb (sumergido) y IIIc (carrera de mareas).

Las principales conclusiones alcanzadas se resumen a continuación

- Existen diferentes criterios en la clasificación de los ambientes marinos en la normativa internacional, siendo las diferencias más relevantes frente a lo planteado por la Instrucción EHE-08 las siguientes:

- En el ambiente marino aéreo destaca la normativa japonesa, que considera relevantes sólo los primeros $200 \mathrm{~m}$ de costa (700 m en zona de tormentas) y realiza una mayor discretización de esta franja, que eleva notablemente su contenido de cloruros en superficie al acercarse a la línea de mar. El planteamiento es muy diferente a la división simple en dos subzonas de la zona costera que plantea la Instrucción EHE-08.

- EI FIB plantea la existencia de una zona de spray en la franja de la estructura situada a una altura superior a $1,5 \mathrm{~m}$ sobre la pleamar, que no se recoge en la Instrucción EHE-08 y que el presente estudio indica que es necesaria, ya que se diferencia en comportamiento respecto a la de salpicaduras y carrera de mareas. 
- Los datos de $\mathbf{C}_{\mathbf{s}}$ recabados en la literatura pertenecientes a estructuras reales son muy variables y dispersos dependiendo de la fuente consultada. Los resultados obtenidos en este estudio sobre estructuras reales españolas demuestran:

- El valor de $C_{s}$ está fundamentalmente influenciado por el tipo de ambiente marino, si bien los datos fluctúan incluso dentro de un mismo puerto y en zonas diferentes de la misma estructura. Esto puede responder a fenómenos locales, por ejemplo zonas de abrigo frente a otras más expuestas o a la orientación del paramento frente al viento.

- No existe una influencia determinante de la salinidad del agua del mar puesto que, a pesar de que el mar Mediterráneo tiene un mayor contenido en sales que el mar Cantábrico y el océano Atlántico, los resultados de $C_{s}$ obtenidos en los tres casos no difieren entre sí, tampoco al incluir datos procedentes de otros países con climatología muy diferente a la nuestra (Noruega o Japón).

- El lavado en superficie se presenta únicamente en ambiente IIIa, al tratarse de un hormigón expuesto al agua de lluvia. Asimismo, el efecto se produce por igual en hormigones con alto y bajo contenido de cloruros en superficie.

- El análisis de los resultados en los tres ambientes marinos para estructuras españolas ha permitido introducir las siguientes propuestas de variación de los requisitos actualmente recogidos por la Instrucción EHE-08:

- Los resultados experimentales obtenidos en ambiente sumergido indican la necesidad de proponer un nuevo valor de cloruros en superficie para al ambiente sumergido IIIb (0,35\%), ya que el actual resulta excesivamente conservador $(0,72 \%)$.

- Debe introducirse un ambiente específico para estructuras situadas en ambiente Illa sobre el mar, ya que las condiciones son muy diferentes a las que pueda presentar un hormigón situado en zona costera. La Instrucción EHE-08 establece un único valor de concentración de cloruros en superficie en el caso de ambiente IIla (fijando una distancia a la costa entre $0-500 m$ ) de 0,14\%. Los resultados demuestran que es necesario introducir un nuevo valor de cloruros en superficie igual a $\mathbf{0 , 2 5 \%}$, definiendo (de acuerdo con el criterio del FIB) una zona spray en la franja de la estructura que se encuentra a una altura superior a 1,5m sobre la pleamar. 
- Los resultados experimentales (valores medios) analizados en este estudio son coherentes con los recogidos en la Instrucción para el ambiente Illa aéreo en la costa y el ambiente IIIc de carrera de mareas.

\subsection{ESTUDIO SOBRE LA CONCENTRACIÓN CRÍTICA DE CLORUROS PARA EL INICIO DE LA CORROSIÓN.}

La concentración crítica de cloruros para el inicio de la corrosión presenta valores muy variables tanto en la literatura como en diferentes normativas internacionales consultadas, por lo que en el seno de la tesis doctoral se ha realizado un estudio específico sobre datos reales de cloruros en estructuras situadas en las diferentes costas españolas, para contrastar estos resultados con los valores límite planteados por la normativa EHE 08 en cada uno de los ambientes marinos recogidos en la Instrucción.

Las principales conclusiones alcanzadas se resumen a continuación:

- En general, todas las normativas internacionales establecen límites al contenido inicial de cloruros presentes en el hormigón, aunque los valores difieren sustancialmente de unos países a otros, existiendo un número alto de normas que adoptan valores más reducidos al recogido por la Instrucción EHE-08 (0,4\%). En particular, la normativa americana establece límites 0,06\% (hormigón pretensado) y 0,15\% (hormigón armado) para ambiente marino.

- La concentración crítica de cloruros que origina el comienzo de la corrosión de la armadura está muy influenciada por el ambiente marino al que está expuesto el hormigón, si bien la normativa internacional adopta un valor único que oscila del 0,4 al $0,6 \%$ en función de las normas consultadas.

- El estudio realizado concluye que el límite de la concentración crítica de cloruros que recoge la Instrucción EHE-08 (0,6\%) ha resultado válido, incluso bastante conservador, para los resultados obtenidos en estructuras españolas situadas en los tres ambientes marinos. Así, los casos de corrosión se han presentado con contenidos de cloruros bastante muy por encima del límite actual normativo: 1\% para ambiente IIIa y IIIc, 1,8\% para ambiente sumergido.

- Sin embargo, al considerar estudios realizados en estructuras internacionales se registran valores de cloruros que sí han ocasionado corrosión con concentraciones 
ligeramente superiores al $0,6 \%$ en ambiente IIIb e incluso con valores ligeramente superiores al $0,4 \%$ en los ambientes IIla y IIlc. Estos resultados se han obtenido descartando valores puntuales que resultaban anómalos por su bajo valor para llegar a ocasionar corrosión (entre 0,10 y 0,23\%).

Como medida conservadora y teniendo en cuenta lo recogido en la normativa internacional, se considera adecuado mantener el límite del $0,6 \%$ de la concentración crítica de cloruros que indica la Instrucción EHE-08.

- No se ha observado en los datos analizados una variación en la concentración crítica de cloruros por la utilización de cementos con adiciones o cementos portland.

\subsection{DIFUSIÓN DE CLORUROS EN AMBIENTE MARINO AÉREO (ZONA SPRAY)}

\subsection{1.- Control de la calidad del hormigón en ambiente marino}

A lo largo del presente estudio se han analizado datos procedentes de testigos que fueron extraídos de muelles de edades diferentes (Muelle $A: 37$ años, Muelle $B$ : 26 años, Muelle $C: 11$ años y Muelle D: 11 años) así como fabricados con hormigones de dosificación distinta (Muelle A: a/c =0,64; Muelle B (losas) a/c $=0,53$; Muelle B (cabeceros) $a / c=0,57$, Muelle $C$ : $a / c=0,53$ y Muelle $D$ : $a / c=0,58$ ) con el fin de estudiar el comportamiento de tales hormigones frente a la difusión en ambiente Illa tratándose de hormigones que se sitúan sobre el mar, en concreto en la zona Spray (por encima de $1,5 \mathrm{~m})$.

Los testigos se han caracterizado en laboratorio utilizando diferentes ensayos relacionados con la durabilidad del hormigón, al objeto de determinar el ensayo que mejor refleja el comportamiento posterior del hormigón expuesto al ambiente marino (difusión de cloruros).

Las principales conclusiones extraídas son:

- En el análisis de la difusión junto con los resultados de los ensayos de caracterización, puede decirse que la resistencia a la compresión no resulta un ensayo adecuado para controlar la durabilidad dado que hormigones de resistencia similar pueden presentar coeficientes de difusión muy diferentes. Sin embargo, si analizamos de forma individual cada muelle, si resulta coherente la 
resistencia a compresión con la difusión (mayor resistencia conlleva menor difusión), pero su efecto es muy leve, ya que los coeficientes de difusión están muy influenciados por el tipo de exposición (contenido de cloruros en superficie) que puede ser variable en cada muelle. Por otro lado, la resistencia no refleja el verdadero efecto beneficioso de la adición en el avance de los cloruros.

- Respecto a la porosidad, no resulta un ensayo adecuado para caracterizar la durabilidad del hormigón en ambiente Illa, ya que valores de porosidad similares presentan coeficientes de difusión diferentes. Esto puede deberse a que la porosidad evalúa el contenido de poros totales en el seno del hormigón sin distinguir su tamaño ni tener en cuenta la distribución de poros que es lo que caracteriza el tipo de transporte de cloruros en el interior. Tampoco refleja de forma adecuada el efecto de las adiciones, ya que éstas refinan el tamaño de la red de poros disminuyendo los de menor tamaño, aunque su efecto sobre la porosidad total no es tan notable.

- De forma similar, la absorción tampoco es un ensayo adecuado para valorar la impermeabilidad del hormigón a la penetración de cloruros en ambiente Illa puesto que valores de absorción similares presentan coeficientes de difusión distintos. La absorción por inmersión refleja el contenido total de poros, de forma análoga a la porosidad, sin considerar el tamaño de poros, aspecto que resulta de principal influencia en el coeficiente de difusión.

- A partir del análisis de las correlaciones entre porosidad-absorción, porosidadcapilaridad y porosidad-ascensión capilar máxima se demuestra la coherencia existente entre tales propiedades, a pesar de que no existe buena correlación entre ellas y el coeficiente de difusión.

- La dispersión obtenida en las correlaciones con el coeficiente de difusión está influenciada por la gran variación encontrada en el valor de contenido de cloruros en superficie en los muelles expuestos a este ambiente, función de las condiciones locales en cada caso.

- A la vista de las regresiones planteadas entre la difusión y la penetración máxima y media en los ambientes de exposición Illa (spray), existe una buena correlación entre difusión y penetración de agua en este ambiente, por lo que el ensayo de penetración de agua se considera un ensayo adecuado para controlar la durabilidad del hormigón en ambiente Illa spray (al igual que ya 
había sucedido en los ambientes IIlb y IIlc en una investigación previa). El cumplimiento del ensayo de penetración garantiza que el hormigón presentará un bajo coeficiente de difusión en ambiente IIla spray.

- Estas conclusiones obtenidas son coincidentes con los resultados que se alcanzaron en testigos extraídos de hormigón expuesto al ambiente marino sumergido y de carrera de mareas.

\subsection{2.- Modelo de difusión de cloruros en ambiente marino Illa spray}

En la investigación realizada se ha evaluado el efecto de la relación agua/cemento y de la utilización de adiciones (cenizas volantes y humo de sílice) en el coeficiente de difusión de cloruros. Para ello, se han utilizado los resultados obtenidos de los ensayos realizados sobre los testigos extraídos de los cuatro Muelles estudiados, así como datos recabados de la consulta bibliográfica realizada sobre estructuras en ambiente marino spray o atmosférico. El total de referencias bibliográficas consultadas ha sido 16.

Los principales resultados alcanzados han sido los siguientes:

- El valor del coeficiente de difusión del hormigón varía con el tipo de ambiente marino. Se comprueba que los valores son menores en el ambiente Illa spray, seguidos del ambiente IIlc y por último, los de mayor difusión son los situados en ambiente IIIb. Esto resulta coherente con los mecanismos de transporte de los cloruros hacia el interior del hormigón. Así, en el caso del ambiente Illa spray, el mecanismo predominante sería la difusión pura, ya que los poros no aparecen saturados de agua pero sí tienen un cierto grado de humedad y disponen de oxígeno. Este proceso de difusión pura resulta mucho más lento que en el caso de hormigones sumergidos (transporte por permeabilidad) y en el caso de hormigones en carrera de mareas (transporte por capilaridad).

- El análisis de los resultados obtenidos en estructuras reales sometidas al ambiente marino Illa spray ha permitido desarrollar un modelo con el que se puede determinar la relación agual cemento y la cantidad y tipo de adición, en su caso, para obtener un hormigón con un coeficiente de difusión determinado. Se observa que a partir de una relación a/c de 0,55 el valor del coeficiente de difusión del hormigón se dispara en este ambiente, por lo que éste debe ser un límite superior a considerar. Este modelo se completa con la relación experimental obtenida entre la difusión y el resultado del ensayo de penetración de agua, que permite validar 
la dosificación adoptada en laboratorio para garantizar un determinado coeficiente de difusión.

- La influencia de las adiciones puzolánicas en el coeficiente de difusión del hormigón es extremadamente elevada, habiéndose obtenido valores del coeficiente de eficacia de 1,36 y 5,35 para la ceniza volante y el humo de sílice respectivamente. Estos resultados son muy similares a los que ya se obtuvieron en el estudio previo realizado sobre hormigones en ambiente sumergido y carrera de mareas, lo cual ratifica aún más los resultados alcanzados.

- A efectos normativos, los resultados de aplicación del modelo exigirían en ambiente Illa spray la utilización de un hormigón con los mismos requisitos en cuanto a dosificación y recubrimiento que en el ambiente IIIc, con la salvedad de poder utilizar una relación a/c igual a 0,50.

\subsection{ESTUDIO DE LA RESISTIVIDAD COMO ENSAYO DE CONTROL DE LA DURABILIDAD DEL HORMIGÓN}

\subsubsection{Medida de la Resistividad del Hormigón}

El Anejo 3 recoge los resultados obtenidos al aplicar la norma UNE 83988-1 de medida directa de la resistividad a testigos y probetas de hormigón. Los resultados indican que es necesaria una revisión de la norma al no estar completamente definidos algunos de los parámetros en la descripción del método de ensayo, con influencia en el resultado final de la medida:

- Para conseguir el rango de intensidad (30-50mA) exigido por norma se debe utilizar corriente alterna, aspecto que sólo se recomienda en ella.

- Se observa en las medidas realizadas que las rodajas de pequeño espesor (25-50 $\mathrm{mm}$ ) se ven influenciadas por la utilización de diferentes equipos de medida. Deben emplearse, en la realización del ensayo, probetas de espesor igual o superior a 3 veces el Dmax del árido, aspecto que no se indica en la norma.

- La medida de resistividad es muy sensible a las condiciones de saturación, aspecto que puede tener importancia cuando se ensayan probetas testigo, que deben saturarse previamente. 
- El diámetro de la probeta ensayada tiene influencia en el resultado obtenido. Las probetas de $15 \mathrm{~cm}$ dan un valor de resistividad superior a las de $10 \mathrm{~cm}$ de diámetro, en especial en hormigones de menor calidad. Este aspecto no queda recogido en la norma y obliga a ajustar coeficientes de paso si se utilizan ambos tipos de probetas o comparar medidas de resistividad procedentes de muestras de mismo diámetro.

\subsubsection{Influencia de la Resistividad en la Durabilidad del Hormigón en Ambiente Marino}

El estudio de la resistividad realizado permite apuntar en el ensayo de resistividad las siguientes ventajas para evaluar la durabilidad del hormigón en ambiente marino:

- Presenta una gran sensibilidad para detectar la presencia de adiciones en el cemento en hormigones de muy buena calidad con baja penetración de agua, obteniéndose en estos casos valores muy por encima de los logrados con cementos Portland de la misma calidad.

- En estos hormigones que presentan muy baja penetración de agua, la resistividad resulta muy sensible para clasificar la calidad del hormigón.

- El ensayo de resistividad además proporciona una buena información sobre la actuación de la adición en el tiempo mejorando el resultado de la resistividad del hormigón a largo plazo (90 días) al utilizar adiciones puzolánicas.

Sin embargo, el ensayo de resistividad presenta asimismo los siguientes inconvenientes:

- En hormigones de baja calidad (muy permeables) la resistividad no presenta sensibilidad siendo más adecuado el ensayo de penetración de agua para clasificar los hormigones de peor calidad.

- El más importante de los inconvenientes encontrados es que el valor real del resultado del ensayo de resistividad no se corrobora al estudiar el comportamiento de los hormigones expuestos al ambiente marino Illa spray. Así, hormigones con cemento Pórtland con valores de resistividad bajos y que han sido expuestos a este ambiente en la vida de la estructura, han presentado un coeficiente de difusión similar a hormigones con adiciones que presentaban un valor de la resistividad muy superior. Por consiguiente, los valores tan elevados de la 
resistividad medidos no se han traducido en una mejora especial en cuanto a la velocidad de penetración de cloruros en ambiente IIla en esos hormigones, lo cual le resta utilidad práctica al ensayo. 
CONCLUSIONES 


\section{FUTURAS LÍNEAS DE INVESTIGACIÓN.}

El trabajo de investigación realizado ha permitido comprobar la eficacia de las medidas recogidas (relativas a dosificación y penetración de agua) por la Instrucción EHE-08 para prevenir la corrosión de las armaduras localizadas en hormigón expuesto a ambiente IIla. Sin embargo, de cara a establecer conclusiones más determinantes, el número de resultados evaluados es reducido (se han estudiado cuatro puertos, pero sólo dos de ellos se ajusta a las actuales especificaciones de la Instrucción y sólo uno lleva adiciones de ceniza volante) por lo que se plantean a continuación las líneas futuras en que deberá desarrollarse la investigación:

- Dado que sólo uno de los puertos analizados presentaba hormigón con adiciones, sería necesario ampliar la muestra de hormigones analizados que contengan adiciones en su dosificación con el fin de corroborar la reducción de los valores de la difusión que se obtiene de forma más fiable. También se obtendrían valores adicionales de resistividad que corroborasen los elevados resultados obtenidos en el muelle analizado.

- Se ha observado que la utilización del coeficiente de envejecimiento específico para hormigones con cenizas volantes indicado por el FIB da lugar a valores del coeficiente de difusión a 1 año excesivamente elevados, por lo que podría ser conveniente un estudio específico sobre este aspecto.

- Los resultados obtenidos en esta investigación indican que el valor de la concentración crítica de cloruros actualmente recogida en la Instrucción EHE0,8 , igual al $0,6 \%$ en peso de cemento es un valor conservador que podría quizás ser elevado si se dispusiera de un mayor volumen de resultados procedentes de obras reales.

- Ampliar el estudio a los hormigones que la Instrucción EHE-08 clasifica en Ambiente Marino Aéreo (IIla), dentro de la primera zona $(0-500 \mathrm{~m})$ o de la segunda (500-5000m). En particular sería conveniente disponer de mayor volumen de resultados de perfiles y de cloruros en superficie.

- Comprobar la efectividad del ensayo de resistividad en más estructuras reales, de todos los ambientes marinos. 
- Comprobar con un mayor volumen de resultados las diferencias encontradas en el resultado de resistividad utilizando probetas de diferente diámetro.

- Realizar estudios específicos para determinar la influencia de la ejecución en la durabilidad del hormigón en ambiente marino, con el objetivo de establecer requisitos específicos del control de ejecución para estructuras situadas en este ambiente. 


\section{BIBLIOGRAFÍA CONSULTADA.}

1. Bermúdez, M. A., Alaejos, M. P., (2009). "Estudio experimental de la durabilidad del hormigón armado en ambiente marino. Zonas sumergida y de carrera de mareas". Monografía 103, CEDEX, Madrid.

2. Alaejos, M. P., Bermúdez, M. A. (2008). "Corrosión de las armaduras en el hormigón situado en ambiente marino". Monografía 96, CEDEX, Madrid.

3. Ministerio de la Presidencia (2008). "Instrucción de Hormigón Estructural (EHE-08), Madrid.

4. Wood, J. G. M, Crerar, J. (1997). "Tay Road Bridge: Analysis of Chloride Ingress Variability and Prediction of Long Term Deterioration". UK.

5. Costa, A., Appleton, J. (2002). "Case studies of concrete deterioration in a marine environment in Portugal". Lisbon.

6. Koga, H., Watanabe, H. y otros (2007). "The distribution of chloride ions in the concrete bridges located near the coastline in Japan" Tsukuba e Hiroshima, Japan.

7. Tanaka. Y, Kawano. H y otros (2001). "Study on required cover depth of concrete highways bridges in coastal environment". Tsukuba, Japan.

8. ACl Committee 222 (2001). "Protection of metals in Concrete against Corrosion".

9. Sagües, A., Kranc, S.C. y otros (2001). "Corrosion forecasting for 75-year durability design of reinforced concrete". Florida, USA.

10. Cramer, S. D., Covino, B. S. y otros (2002). "Corrosion prevention and remediation strategies for reinforced concrete coastal bridges". Cement and Concrete Composites 24.

11. Melchers, R. E, Li, C. Q. y otros (2009). "Observation and Analysis of a 63year-old reinforced concrete promenade mailing exposed to the North Sea". Magazine of Concrete Research, 2009, 61, № 4, May 233-243.

12. Tanaka. Y., Kawano. H. y otros (2001). "Chloride-induced deterioration and its influence on load carrying capacity of post-tensioned concrete bridges". 
Proceedings of the Third CONSEC. Public Works Research Institute, Ministry of Construction, Japan.

13. Kirpatrick. T. J, Weyers. R. E. y otros (2002). "Impact of specification changes on chloride-induced corrosion service life of bridge decks". Cement and Concrete Research 32 (2002) 1189-1197.

14. Williamson. G. S, Weyers. R. E y otros (2009). "Concrete and Steel Type Influence on Probabilistic Corrosion Service Life". ACI Materials Journal, n 106M11.

15. Williamson. G. (2007). "Service Life Modeling of Virginia Bridge Decks". Tesis Doctoral. Virginia Polytechnic Institute. Blacksburg, Virginia.

16. Rodriguez. F. (1998). "La microestructura del hormigón y su influencia en la durabilidad". Curso sobre durabilidad y reparación de estructuras de hormigón. CEDEX.

17. Fernández Cánovas, M. (2007). “Hormigón”. Colegio de Ingenieros de Caminos, Canales y Puertos, Colección Escuelas.

18. ASTM (2002) "Standard test method for acid soluble chloride in mortar and concrete. Standard C 1152-97". En Annual book of ASTM Standards, Vol.04.02. Philadelphia: Ed. American Society for Testing and Materials.

19. ASTM (2002) "Standard test method for water soluble chloride in mortar and concrete. Standard C 1218-99". En Annual book of ASTM Standards, Vol.04.02. Philadelphia: Ed. American Society for Testing and Materials.

20. ACI 318-95/ACI 318R-95."Building Code Requirements for Structural Concrete and Commentary".

21. British Standards Institution, CP110. The structural use of concrete. Part I. Design, materials and workmanship. London 1972.

22. ACI 201.2R-08 (2008). "Guide to Durable Concrete".

23. Mangat, P.S. y Molloy, B.T. (1994). "Prediction of long term chloride concentration in concrete". Materials and Structures, Vol.27. pp. 338-346. 
24. Maheswaran, T. y Sanjayan, A. (2004). "A semi-closed form solution for chloride diffusion in concrete with time-varying parameters". Magazine and Concrete Reserch, Vol.56, Nº6, pp. 359-366

25. Bamforth, P.B. (1999). "The derivation of input data for modelling chloride ingress from eight year UK coastal exposure trials", Magazine of Concrete Research, Vol. 51, Nº 2, pp. 87-96.

26. Helland, S. (1995). "Service Life prediction of marine structures" proceedings of the FIP Symposium concrete 95. Brisbane, Australia, pp.243-250.

27. Maage, $\mathbf{M}$ et al. (1996). "Service Life prediction of existing concrete structures exposed to marine environment." ACI Journal 93 (6), pp. 602-608.

28. ACI (2002) Fixed Offshore Concrete Structures. ACI 357 R. En "ACI Manual of Concrete Practice 2002 Part 5. Design and Construction Practices". Detroit: Ed. American Concrete Institute.

29. Bureau of Ports and Harbours (2002). "Technical Standards for Port and Harbour Facilities in Japan". Ministry of Transports. Tokio.

30. Miyagawa, T. (1991). "Durability Design and Repair of Concrete Structures: Chloride Corrosion of Reinforcing Steel and Alkali-Aggregate Reaction". Magazine of Concrete Research, Vol.43, № 156, 155-170.

31. Yeomans, S.R. (2004). "Galvanized Steel Reinforcement in Concrete:Galvanized Steel in Concrete: An Overview. Elsevier, NY.

32. Clemena, G.C. (2003). "Investigation ot the resistance of several new metallic reinforcing bars ti chloride induced corrosion in concrete". Virginia Transportation Research Council, Report VTRC 04-R7, Dec 2003.

33. Trejo, D (2002). "Evaluation of the Critical Chloride Thershold and Corrosion Rate for Different Steel Reinforcement Types" Texas,, A\&M University, July 2002.

34. U.S. ARMY COASTAL ENGINEERING RESEARCH CENTER (1984)."Shore Protection Manual".

35. FIP (1985). "Design and Construction of Concrete Structures" FIP Recommendations. Thomas Telford LTD, Londres. 
36. RILEM (1996). "Durability Design of Concrete Structures". RILEM Report 14. A. Sarja; E. Vesikari.

37. Helland. S, Aarstein. R and Maage. M, (2010). "In-field performance of North Sea offshore platforms with regard to chloride resistance". Structural Concrete, 2010, 11 Nº1, Thomas Telford and fib.

38. Torres Acosta. A.A, Backhoff. M.A, Núñez. G, Martínez. M. (2002). "Aplicación de un sistema de información geoestadística para la evaluación de los agentes corrosivos del medio ambiente en la degradación de la infraestructura de puentes de México". Colloquia 2002, Maracaibo, Venezuela 710 julio 2002.

39. Andrade. C, Castellote. M, D’Andréa. R, Picón. J.M, Sanjuán. M.A. (2009). "Difusión de Cloruros en Hormigones expuestos a Ambientes Marinos. Estudio de 15 años de exposición".

40. Torres Acosta. A. A, Martínez. M. (2003). "Residual Life of Corroding Reinforced Concrete Structures in Marine Environment". Journal of Materials in Civil Engineering, ASCE, Julio-Agosto 2003.

41. Darmawan. M.S, (2010). "Pitting corrosion model for reinforced concrete structures in a chloride environment". Magazine of Concrete Research, 62, n², Febrero 2010.

42. Torres Acosta. A.A, Martínez. M. et al. (2007). "Corrosion damage evaluation and diagnosis of bridges in the Mexican highway network". Proceedings of the $3^{\text {rd }}$ International Conference on Structural Health Monitoring and Intelligent Infrastructure: Structural Health Monitoring and Intelligent Infrastructure, Julio 2007.

43. Torres Acosta. A.A, Castro-Borges. P. et al. (2010). "New Technologies to rehabilitate an old Mexican pier in a harsh environment". Bridge maintenance, Safety, management and Life-Cycle Optimization. México, 2010.

44. Aenor, Asociación Española de Normalización y Certificación (2010). "Eurocódigo 2. Proyecto de estructuras de hormigón. Parte 1-1. Reglas generales y reglas para edificación". 
45. Aenor, Asociación Española de Normalización y Certificación (2008). "UNE-EN 206-1. Hormigón. Parte 1: Especificaciones, prestaciones, producción y conformidad".

46. Costa. A, Appleton. J. (2001). "Concrete carbonation and chloride penetration in a marine environment". Concrete Science and Engineering, vol. 3, Diciembre 2001, pp 242-249.

47. ARGO (2010). "Sistemas de protección catódica".

48. ARGO (2010). "Protección catódica en estructuras de hormigón".

49. Lim. Y.C, Noguchi. T., Shin. S.W. (2010). "Corrosion Evaluation by Estimating the Surface Resistivity of Reinforcing Bar". Journal of Advanced Concrete Technology, vol. 8, n² 2, pp 113-119, Junio 2010.

50. Miyazato. S., Otsuki. N. (2010). "Steel Corrosion Induced by Chloride or carbonation in Mortar with Bending Cracks or Joints". Journal of Advanced Concrete Technology, vol. 8 n² 2, pp 135-144, Junio 2010.

51. CEDEX, Laboratorio Central de Estructuras (2015) "Puerto de Valencia. Estudio del hormigón del Muelle de la Aduana".

52. D’Andrea, R. (2010). "Predicción de la durabilidad del hormigón armado a partir de indicadores de corrosión: aplicación de la resistividad eléctrica". Tesis doctoral, ETSICCP, Universidad Politécnica de Madrid.

53. ACI 365.1R-00. "Service-Life Prediction-State of the Art Report". (2000).

54. Hwan OH, B y Seok Jang, B. (2003). "Chloride diffusion analysis of concrete structures considering effects of reinforcements". ACI Materials Journal, MarzoAbril, 143-149.

55. Izquierdo, D. (2003) "Bases de diseño para un tratamiento probabilista de los procesos de corrosion de armaduras en el hormigón”. Tesis Doctoral. E.T.S. Ingenieros de Caminos, Canales y Puertos, Madrid.

56. Browne, RD (1980). "Marine durability survey of the Tongue Sands Tower", In Concrete in the Oceans. Cement and Concrete Association, Wexham Springs, technical report 5 .

57. Thomas, M. (1996). "Chloride thresholds in marine concrete" Cement and Concrete Research, Vol.26, no 4, 513-519. 
58. Alonso, MC (2008). "Chloride threshold values in literature" Proceedings of the COIN Workshop on Critical Chloride Contents in Concrete, Trondheim, Norway, 5-6 June 2008.

59. BRE CENTRE FOR CONCRETE CONSTRUCTION (2000). Corrosion of Steel in concrete. Digest 444 (parts 1 to 3). Londres: CRC.

60. Castellote, M; Andrade, C y Alonso, C. (2002). "Standardization, to a reference of $25^{\circ} \mathrm{C}$, of electrical resistivity for mortar and concretes in saturated or isolated conditions" ACI Materials Journal, Vol 99, No 2, March-April, 119-128.

61. Polder, R. B. (2001). "Test methods for on site measurement of resistivity of concrete"-A RILEM TC-154 Technical Recommendation" Construction and Building Materials, vol. 15, 125-131.

62. BRE CENTRE FOR CONCRETE CONSTRUCTION (1998). Corrosion of reinforcement in concrete: electrochemical monitoring. Digest 434 . Londres: CRC.

63. ASTM G1-03 (2003). "Standard practice for preparing, cleaning and evaluating corrosion test specimens". ASTM International, Estados Unidos.

64. BS 6349. Parte 1 (1984) "British Standard Code of Practice for Maritime Structures. Part 1. General Criteria".

65. BS Addenda no 4 AMD 6159 (1989) Publicada el 31 de Julio de 1989 como Addenda al documento $n^{\circ} 64$.

66. Bermúdez M.A., Alaejos P. (2010). "Models for Chloride Diffusion Coefficients of Concrete in Tidal Zone". ACl Materials Journal, title $n^{\circ} 107$, M01, EneroFebrero 2010.

67. Lindvall A. (2002). "Influence of temperature and salinity on the chloride ingress into concrete exposed in marine environments". Third RILEM workshop on Testing and Modelling the Chloride Ingress into Concrete, 9-10 Septiembre 2002, Madrid, España.

68. Ferreira R.M. (2004). "Probability-based durability analysis of concrete structures in marine environment". Escola de Engenharia, Universidade do Minho. 
69. FIB (2006). "Model Code for Service Life Design". Bulletin 34. Lausanne, Switzerland.

70. ACI 318-08

71. Weyers R.E. y otros (1994) "Concrete Bridge Protection and Rehabilitation: Chemical and Physical Techniques. Service Life Estimates.

72. Florida Department of Transportation (2011). "Structures Design Guidelines. FDOT Structures Manual, Volume 1."

73. Stewart, M.G, Rosowsky D.V (1998). "Structural Safety and Serviceability of Concrete Bridges subject to Corrosion" Journal of Infrastructure Systems, Vol.4 No 4, December 1998.(ASCE)

74. Shafiq, $\mathbf{N}$ (2004). "Effects of Fly Ash on Chloride Migration in Concrete and Calculation of Cover Depth required against the Corrosion of Embedded Steel Reinforcement" Structural Concrete, Vol 4, 2004. Thomas Telford.

75. Berke, N.S, Hicks, M.C. (1992). "Estimating the Life Cycle of Reinforced Concrete Decks and Marine Piles using Laboratory Diffusion and Corrosion Data" Corrosion Forms and Control for Infrastructure, ASTM STP 1137, Victor Chaker, ED. American Society for Testing and Materials, Philadelphia, 1992.

76. Fukui J., Shirato M. (2005). "Performanced-based specifications for Japanese highway bridges" Proceedings ICOSSAR 2005 "Safety and Reliability of Engineering Systems and Structures", Millpress, Rotterdam.

77. Tanaka Y., Kawano H., Watanabe H, Nakajo T. (2002). "Improving Durability by using HSC/HPC for Highway Bridges in Coastal Areas" Sixth International symposium on high strength/high performance concrete, Junio 2002, Leipzig, Alemania)

78. Tanaka Y., Kawano H., Watanabe H, Nakajo T. (2006). "Study on cover depth for prestressed concrete bridges in airborne-chloride environments" PCl Journal, 2006.

79. Ozaki S, Sugata N. (1988). "Sixty-year-old concrete in a marine environment" SP 109-26 AMERICAN CONCRETE INSTITUTE Concrete in marine 
environment. Second International Conference. ACI SP 109. Detroit: Ed. V.M. Malhotra.

80. Roper H, Heiman JL, Baweja D. (1988) "Site and laboratory evaluation of repairs to marine concrete structures and maintenance methodologies. Two case studies" SP 109-25 AMERICAN CONCRETE INSTITUTE Concrete in marine environment. Second International Conference. ACI SP 109. Detroit: Ed. V.M. Malhotra.

81. Cui F, Sagüés AA. (2006) "Exploratory assessment of corrosion behaviour of stainless steel clad rebar: part 1-experimental".CORROSION, vol.62 $n^{\circ} 9$, septiembre 2006.

82. Costa A, Appleton J. (1999) "Chloride penetration into concrete in marine environment. Part I: Main parameters affecting chloride penetration".

83. Costa A, Appleton J. (1999) "Chloride penetration into concrete in marine environment. Part II: Prediction of long term chloride penetration".

84. Valenta, O (1970) "The permeability and durability of concrete in aggressive conditions" Proceedings of Tenth International Congress on Large Dams. Montreal ]

85. Kollek, J.J (1989) "La determinación de la permeabilidad del hormigón al oxígeno mediante el método del CEMBUREAU: una recomendación" Materials and Structures, vol.22.

86. CEB (1998) "Strategies for testing and assessment of concrete structures". Guidance Report. Bulletin CEB n 243. Lausanne, Suiza. Ed.CEB.

87. Goltermann, P (2003) "Chloride ingress in concrete structures: extrapolation of observations". ACI Materials Journal, March-April 2003.

88. JSCE (2002) "Standard Specifications for Concrete Structures-2002. Materials and Construction" JSCE Guidelines for concrete $n^{\circ} 6$, Japan Society of Civil Engineers. 
89. JSCE (2001) "Standard Specifications for Concrete Structures-2001. Maintenance" JSCE Guidelines for concrete $n^{\circ} 4$, Japan Society of Civil Engineers.

90. Ahmad S et al (2008) "Correlations between depth of water penetration, chloride permeability and coefficient of diffusion in plain, silica fume, and fly ash cement concretes" Journal of Testing and Evaluation, vol. 36, n 2.

91. UNE-EN 83988-1 (2008) "Durabilidad del hormigón. Métodos de ensayo. Determinación de la resistividad eléctrica. Parte 1: Método directo (método de referencia)".

92. UNE-EN 83988-2 (2014) "Durabilidad del hormigón. Métodos de ensayo. Determinación de la resistividad eléctrica. Parte 2: Método de cuatro puntas o de Wenner".

93. UNE-EN 14617-13 (2013) "Piedra aglomerada. Métodos de ensayo. Parte 13: Determinación de la resistividad eléctrica".

94. RILEM TC 154-EMC (2000) "Electrochemical techniques for measuring metallic corrosion. Test methods for on site measurement of resistivity of concrete".

95. Andrade C., Gulikers J. (2012) "Advances in Modeling Concrete Service Life". Proceedings of $4^{\text {th }}$ International RILEM PhD Workshop held in Madrid (Spain), Noviembre 2010.

96. Metha P.K. (1996) "Odd E. Gjørv Symposium on Concrete for Marine Structures". Third CANMET/ACI International Conference on Performance of Concrete in Marine Environment, Canada, Agosto 1996.

97. Gjørv O.E. (2009) "Durability design of concrete structures in severe environments", Taylor and Francis (Estados Unidos).

98. UNE 83-309-90 (1990) “Ensayos de hormigón. Determinación de la profundidad de penetración de agua bajo presión".

99. UNE-EN 12390-8 (2009) "Ensayos de hormigón endurecido. Parte 8: Profundidad de penetración de agua bajo presión". 
100. Polder, R. B. (2000) "Test methods for on site measurement of resistivity of concrete" Recommendation of RILEM TC-154 EMC:"Electrochemical techniques for measuring metallic corrosion" Materials and Structures, vol. 33, December, 603-611.

101. RILEM. Corrosion of Steel in concrete. Report of the Technical Committee 60-CSC. P. Schiessl.

102. Song, G. y Shayan, A. (1998). "Corrosion of Steel in concrete: causes, detection and prediction. State of the art review. ARRB Transport Research Ltd, Review Report 4.

103. Bamforth, P.B. y Chapman- Andrews, J.F. (1994) "Long term performance of R.C. elements under UK coastal exposure conditions". En Swamy. Proceedings of International Conference on Corrosion and Corrosion Protection of Steel in concrete. Sheffield, pp. 139-156.

104. McCarter, W.J., Finnegan, L., Linfoot, B.T., Basheer, P.A.M. y Chrisp, T.M. (2006) "Performance of treated and untreated concrete in marine environment. SP 234-5. En AMERICAN CONCRETE INSTITUTE. $7^{\text {th }}$ CANMET/ACI International Conference on Durability of Concrete. ACI SP 234. Detroit: Ed.V.M. Malhotra, pp. 71-86.

105. Bamforth, P.B., Price, W.F. y Emerson, M. (1997) "An International Review of Chloride ingress into structural concrete". Scotland. Contractor Report 359. Transport Research Laboratory (TRL).

106. Sakoda, S., Takeda, N. y Sogo, S. (1992) "Influence of various cement types on concrete durability in marine environment". 9 $9^{\text {th }}$ International Congress on Chemistry of Cement, New Delhi, India. Vol. VI, 1992, pp. 175-181.

107. Takeda, N., Sogo, S. , Sakoda, S., Idemitsu, T. (1999) "An experimental study on penetration of chloride ions into concrete and corrosion of reinforcing bars in various marine environments". Concrete Library of JSCE, $n^{\circ} 34$, dic. 1999, pp.89-108.

108. Thomas, M.D.A. (1990) "A comparison of the properties of PC and PFA concrete in 30 year old mass concrete structures. Proc. of $5^{\text {th }}$ Int. Conf. on Durability of Building Materials and Components, Brighton, Nov. 1990. 
109. Sorensen, B. y Maahn, E (1982). "Penetration of chloride in marine concrete structures". Nordic Concrete Research, Publication no 1 , Oslo, Nordic Concrete Federation, 1982, pp. 24.1-24.18.

110. Sandberg, P. (1998). "Chloride initiated reinforcement corrosion in marine concrete". Report TVBM-1015. Lund, Suecia: Lund Institute of Technology, Division of Building Materials.

111. Holst, J. y Buhr, B. (2003). "The Langeland bridge, Denmark. Pilot Project using cathodic protection as basis for overall repair strategy". 
BIBLIOGRAFÍA CONSULTADA 


\section{ANEJO 1: ESTUDIO DE LA CONCENTRACIÓN DE CLORUROS EN SUPERFICIE.}

\section{1.- ANTECEDENTES}

La corrosión por cloruros es la principal causa de deterioro en estructuras costeras de hormigón armado y pretensado, aspecto de especial importancia en países con una gran longitud de costa, como es el caso de España ${ }^{1}$.Dado que los costes de reparación o rehabilitación de estas estructuras son elevados, se han desarrollado métodos específicos para prevenir el inicio de la corrosión, asignando una vida útil en función de su relevancia ${ }^{1,4}$.

Los cloruros pueden encontrarse dentro del propio hormigón o penetrar desde el exterior a través de su superficie, como en el caso de las estructuras expuestas al ambiente marino. El avance de los cloruros puede simularse mediante modelos de difusión con el fin de estimar la vida útil y comprobar que se cumplen los requisitos de proyecto. Estos modelos pueden ser fickianos, probabilísticos, desarrollados mediante elementos finitos o con programas comerciales ${ }^{1,4}$, siendo los primeros, de carácter más sencillo, frecuentemente utilizados en la fase de proyecto para prevenir la corrosión $n^{1,5}$.

La segunda ley de Fick de difusión permite determinar el tiempo de iniciación de la corrosión, es decir, el tiempo requerido para alcanzar una concentración límite de cloruros en el nivel de las armaduras, tiempo que se asociaría a la vida útil de la estructura ${ }^{1,5}$. Así, para una losa de profundidad infinita, concentración de cloruros en superficie constante y coeficiente de difusión constante, la expresión de la ley de Fick, según Crack (1975) es la siguiente ${ }^{1,3,5}$ :

$$
\mathrm{C}_{\mathrm{x}}-\mathrm{C}_{\mathrm{b}}=\left(\mathrm{C}_{\mathrm{s}}-\mathrm{Cb}_{\mathrm{b}}\right) *\{1-\operatorname{erf}(\mathrm{x} / 2 * \sqrt{\mathrm{D}} * \mathrm{t})\}
$$

en la que Cx es la concentración de cloruros a una profundidad " $x$ "

Cs es la concentración de cloruros en superficie

$\mathrm{Cb}$ es la concentración de cloruros inicial del hormigón

D es el coeficiente de difusión efectiva de los cloruros

t es el periodo de exposición

erf es la función error

La concentración de cloruros en superficie, $\mathbf{C}_{\mathbf{s}}$, es un factor fundamental en la estimación de la vida útil de la estructura ya que representa la carga ambiental. Su valor depende del tipo de ambiente marino al que está expuesta la estructura y si se 
encuentra en contacto con el agua, de su concentración de sales, del tiempo de exposición a los cloruros y de la dosificación del hormigón (contenido y tipo de cemento, relación a/c...).

Debido al elevado número de factores que influyen, en la revisión de la bibliografía ${ }^{1}$ se constata que la concentración de cloruros en superficie presenta valores muy dispersos.

Así, los valores obtenidos en estudios realizados en EEUU $1,16,17$ se encuentran comprendidos entre 1,2 y $8,2 \mathrm{~kg} / \mathrm{m}^{3} \quad(0,05 \%-0,35 \%$ en peso de hormigón si consideramos una densidad del hormigón de $2300 \mathrm{~kg} / \mathrm{m}^{3}$ ). En un estudio realizado en Noruega $^{6}$ en plataformas situadas en alta mar, analizando el efecto de la altura y factores locales como la orientación del viento dominante, el valor medio de $\mathrm{C}_{\mathrm{s}}$ de un total de 137 resultados es de $0,63 \%$ en peso de hormigón con una desviación típica de 0,43 .

Otros autores ${ }^{1,7,8}$ plantean $\mathrm{C}_{\mathrm{S}=17,8 \mathrm{~kg} / \mathrm{m}^{3}}(0,77 \%$ peso de hormigón) en el caso del ambiente de carrera de mareas o salpicaduras, y en atmósfera salina, $C_{s=15} \mathrm{~kg} / \mathrm{m}^{3}$ (0,65\% p.h).

El valor que se asigne a $\mathbf{C}_{\mathbf{s}}$ en los modelos de estimación de vida útil, tiene una influencia importante en los resultados que se obtengan. Así, la figura 1 representa la relación a/c del hormigón necesaria para alcanzar una vida útil de 50 años, cuando el umbral de cloruros y el contenido de cloruros en superficie varían en el rango recogido por la literatura, así como cuando el recubrimiento varía entre 30 y $70 \mathrm{~mm}$, tanto para los ambientes de carrera de mareas como sumergido. Las condiciones generales de aplicación del modelo (basado en la ley de Fick) se recogen en la tabla 1.

Condiciones generales de aplicación del modelo ${ }^{2,3}$

\begin{tabular}{||c|c|c|}
\cline { 2 - 3 } \multicolumn{1}{c|}{} & Carrera Mareas & Zona Sumergida \\
\hline \hline Recubrimiento (mm) & 40 & 30 \\
\hline C $_{\mathbf{S}}$ (\% p.hormigón) & \multicolumn{2}{c|}{0,70} \\
\hline C $_{\mathbf{X}}$ (\% p.cemento) & 1,0 & 1,8 \\
\hline \hline Contenido cemento (kg/m ${ }^{\mathbf{3}}$ hormigón) & 350 & 325 \\
\hline Tipo de cemento & \multicolumn{2}{|c|}{ OPC } \\
\hline Vida útil (años) & \multicolumn{2}{|c|}{} \\
\hline
\end{tabular}

Tabla 1. Condiciones generales de aplicación del modelo de cálculo del coeficiente de difusión. 

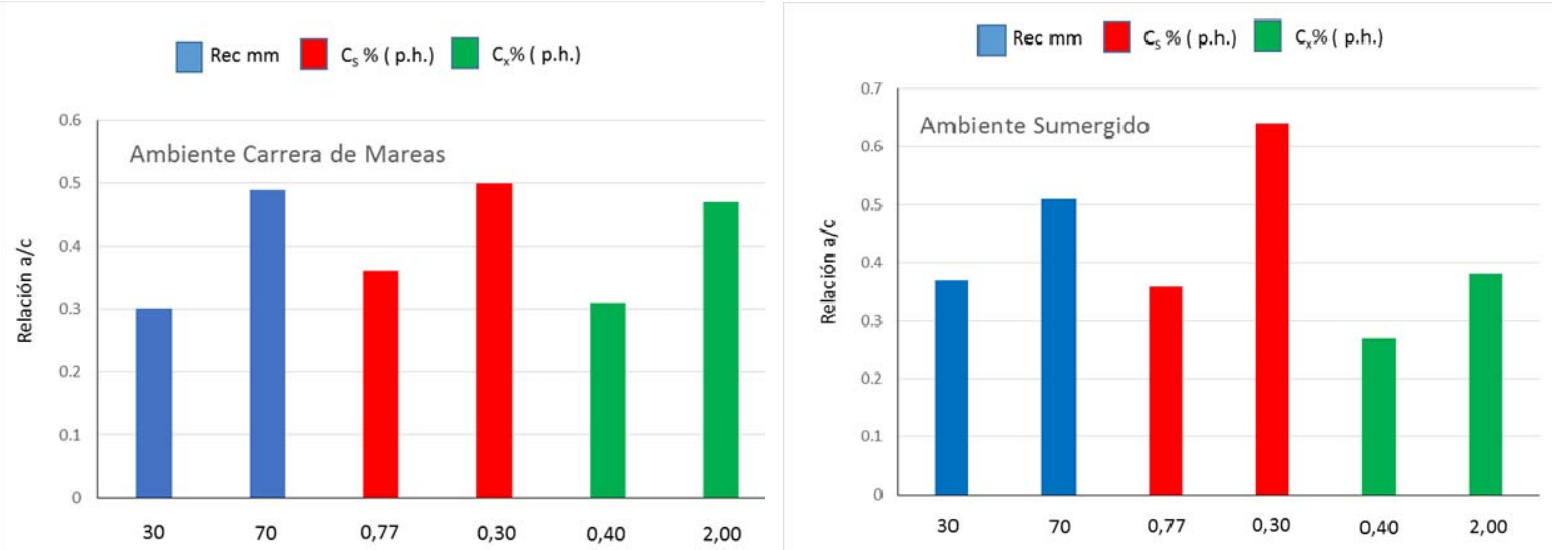

Fig. 1. Relación a/c respecto a recubrimiento, Cs y Cx. Ambiente Carrera de Mareas y Sumergido.

Se observa que la relación agua cemento necesaria en el hormigón, de acuerdo con el modelo utilizado, es sensible a las variaciones de los tres parámetros considerados. En especial se observa la influencia sobre la relación agua/cemento que tiene el contenido de cloruros en superficie que se considere en el cálculo con el modelo.

Tal como se ha comentado anteriormente, la gran dispersión de resultados de Cs encontrados en la literatura puede explicarse por los diversos factores que influyen en su valor.

La salinidad del agua del mar $^{1}$ puede tener influencia en los cloruros que se acumulen en superficie. En el caso particular de los mares que afectan a las costas españolas, el mar Mediterráneo tiene una concentración de sales mayor que el océano Atlántico y el mar Cantábrico, aunque la diferencia es pequeña.

En cuanto a la influencia del tiempo de exposición ${ }^{3}$, suele expresarse esta dependencia mediante la expresión $n^{3,19}: \mathrm{C}_{\mathrm{S}}(\mathrm{t})=\mathrm{C}_{1} \cdot \mathrm{t}^{\mathrm{n}}$, asignándose valores diferentes al coeficiente de envejecimiento $n$, según las fuentes. También el $A C l 3651 R^{21}$ señala que no hay conclusiones definitivas para fijar de forma inequívoca una evolución del valor de cloruros en superficie con el tiempo, planteándose soluciones que van desde la progresión lineal hasta la raíz cuadrada.

En particular, el FIB ${ }^{9}$ indica que, aunque $\mathrm{C}_{\mathrm{S}}$ varía con el tiempo, en un periodo corto se llega a un valor máximo estable, por lo que para predicciones a largo plazo no es necesario considerar esta dependencia del tiempo.

En el caso del estudio realizado en Noruega ${ }^{6}$ sobre plataformas situadas en alta mar, con datos recogidos de nueve estructuras distintas, analizando el efecto de la altura y 
factores locales, se obtiene la figura 2, que relaciona la edad de la estructura con el contenido de cloruros en superficie en ese momento.

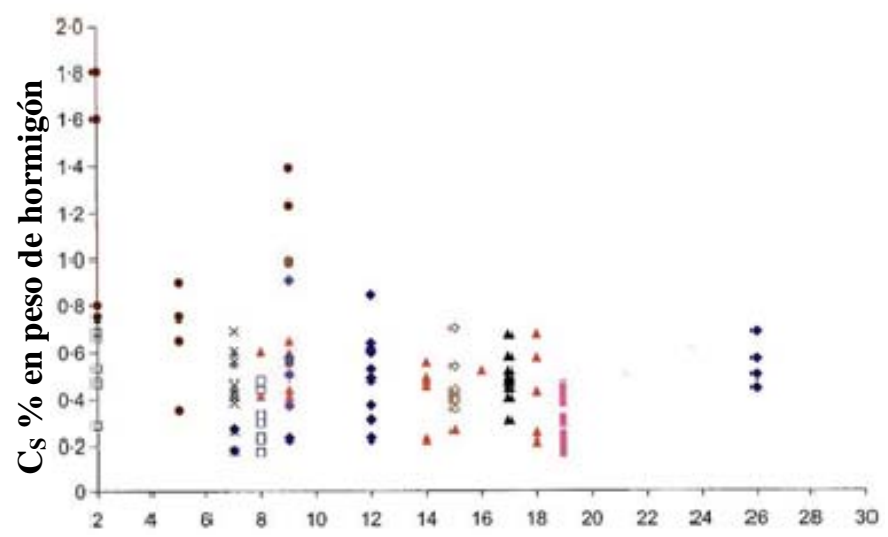

Años

Fig.2. Cloruros en superficie-tiempo. Datos recogidos de nueve estructuras noruegas

A la vista de los valores representados, las concentraciones de cloruros en superficie que proceden de testigos con edades diferentes pero siempre con más de dos años de exposición, presentan valores similares por lo que el estudio concluye que a esta edad han alcanzado un nivel estable.

En cambio, otros estudios realizados en España ${ }^{20}$ sobre hormigones situados en carrera de marea (línea de playa) constatan que los valores de Cs siguen aumentando al menos hasta los 15 años de edad, con valores entre el 0,1\% a los 2 años y 0,4\% a los 15 años (con picos puntuales que alcanzan el 0,6\%).

También a la hora de determinar el valor de $\mathrm{C}_{\mathrm{S}}$ hay que tener en cuenta que, en la capa superficial del hormigón, puede ser menor el contenido de cloruros por el efecto de la lixiviación ${ }^{1}$ o de la carbonatación por lo que dicho valor debe descartarse.

Por encima de todos los factores anteriormente citados, el tipo de ambiente marino tiene una influencia determinante en la concentración de cloruros en superficie. En particular, en el ambiente marino aéreo, la distancia a la costa es fundamental. Así, en Japón ${ }^{10}$ durante la década de los 80 se llevó a cabo un estudio con el fin de determinar la relación entre la cantidad de cloruros disponible en el aire y la distancia a la costa, así como la relación entre la concentración de cloruros en superficie y en el aire. Se recogieron más de 200 datos dentro de los $10 \mathrm{~km}$ más próximos al mar y a partir de ellos se pudo establecer una relación entre $\mathrm{C}_{\text {air }}$ (masa media de iones cloruro medidos en un año) y la distancia a la costa d:

$$
\mathrm{C}_{\text {air }}=\mathrm{C}_{1} \cdot \mathrm{d}^{-0.6}
$$


donde $C_{\text {air }}$ es el nivel de cloruros en el aire ( $\left.m d d=m g / d^{2} / d i ́ a\right), C_{1}$ es el nivel de cloruros equivalente al valor a distancia de $1 \mathrm{~km}(\mathrm{mdd})$ y $\mathrm{d}$ es la distancia a la costa $(\mathrm{km}) . \mathrm{C}_{1}$ expresa el nivel de cloruros en el aire de cada región según condiciones de viento, oleaje, variaciones estacionales...Así $\mathrm{C}_{1 \mathrm{~A}}=\mathrm{C}_{1 \mathrm{~B}}=0,6$ y $\mathrm{C}_{1 \mathrm{C}}=0,2$.

En el mismo estudio, la expresión que permite relacionar $\mathrm{C}_{0}$ (cloruros en superficie de hormigón) y $\mathrm{C}_{\text {air }}$ es la siguiente:

$$
\mathrm{C}_{0}=1,5 \cdot\left(\mathrm{C}_{\text {air }}\right)^{0,4}
$$

Desde el punto de vista normativo, la Instrucción EHE-08 ${ }^{11}$ plantea valores límite de $\mathrm{C}_{\mathrm{S}}$ en función del ambiente de exposición así como de la distancia a la costa (en el caso del ambiente marino aéreo), tal y como indica la tabla 2 :

\begin{tabular}{|c|c|c|c|c|c|}
\hline $\begin{array}{c}\text { Clase General de } \\
\text { Exposición }\end{array}$ & \multicolumn{2}{|c|}{ IIIa } & IIIb & IIIC & IV \\
\hline Distancia a la costa & Hasta 500m & $500 \mathrm{~m}-5000 \mathrm{~m}$ & \multirow{2}{*}{0,72} & \multirow{2}{*}{0,50} & \multirow{2}{*}{0,50} \\
\hline Cs (\%p.hormigón) & 0,14 & 0,07 & & & \\
\hline
\end{tabular}

Tabla 2. Concentración de cloruros en superficie según ambiente de exposición EHE-08

\section{2.- OBJETIVOS}

En el presente anejo se pretende analizar los valores experimentales obtenidos en muelles localizados en las costas españolas en los distintos ambientes marinos que plantea la Instrucción EHE 08: IIla (Aéreo), IIIb (Sumergido) y IIIc (Carrera de Mareas y Salpicaduras) y compararlos con los límites de $\mathrm{C}_{\mathrm{s}}$ propuestos, para establecer si resultan acordes.

\section{3.- METODOLOGÍA}

Para la realización del presente análisis de la concentración de cloruros en superficie se ha llevado a cabo una labor de recopilación de datos procedentes de estructuras ubicadas en los tres ambientes marinos que recoge la Instrucción EHE-08. Dicha tarea corresponde a parte de los trabajos previos realizados por el CEDEX ${ }^{1,2,3,12}$ con el fin de caracterizar la durabilidad de diversos puertos españoles.

A continuación se plantean las tablas 3 y 4 donde se resumen la mayoría de los datos de interés para el análisis de Cs de los puertos estudiados. 


\begin{tabular}{|c|c|c|c|c|c|c|c|c|c|}
\hline & Muelle A & Muelle B & Muelle C & Muelle D & Muelle E & Muelle F & Muelle G & Muelle H & Muelle I \\
\hline Edad (años) $)^{(1)}$ & 4,5 & 6,5 & 30 & 7,5 & 5 & 18 & 2 & 2 & 31 \\
\hline $\begin{array}{l}\text { Normativa } \\
\text { vigente en el } \\
\text { momento de } \\
\text { construcción } \\
\end{array}$ & EH 98 & ЕH 98 & HA 61 & ЕH 98 & EH 98 & EH 80 & ЕH 98 & EH 98 & HA 61 \\
\hline Localización & Mediterráneo & Mediterráneo & Mediterráneo & Mediterráneo & Atlántico & Atlántico & Cantábrico & Cantábrico & Cantábrico \\
\hline $\begin{array}{l}\text { Distancia a } \\
\text { B.M.V.E. del } \\
\text { testigo/carrera } \\
\text { de mareas (m) }\end{array}$ & $-0,1 / 0,8$ & $-0,1 / 0,4$ & $-0,1 / 0$ & $+0,5 / 0,7$ & $+2,5 / 4,0$ & $+1,6 / 4,0$ & $+3,5 / 4,5$ & $\begin{array}{c}+2,0-3,5 \\
\quad / 5,4\end{array}$ & $+1,3 / 4,5$ \\
\hline $\begin{array}{l}\text { Ambiente de } \\
\text { exposición }\end{array}$ & Sumergido & Sumergido & Sumergido & $\begin{array}{c}\text { Carrera de } \\
\text { marea }\end{array}$ & $\begin{array}{c}\text { Carrera } \\
\text { de marea }\end{array}$ & $\begin{array}{c}\text { Carrera } \\
\text { de marea }\end{array}$ & $\begin{array}{c}\text { Carrera de } \\
\text { mareas }\end{array}$ & $\begin{array}{c}\text { Carrera de } \\
\text { mareas }\end{array}$ & $\begin{array}{c}\text { Carrera de } \\
\text { mareas }\end{array}$ \\
\hline $\begin{array}{l}\text { Hormigón } \\
\text { proyecto } \\
\left(\mathrm{N} / \mathrm{mm}^{2}\right) \\
\end{array}$ & H-25 & H-25 & HA- 17,5 & $\mathrm{H}-25$ & H-25 & $\mathrm{H}-25$ & HA-30 & HA-30 & - \\
\hline $\begin{array}{l}\text { Penetración } \\
\text { Máxima (mm) }\end{array}$ & $35-45$ & 51 & $8-48$ & 27,5 & $80-112,5$ & $54-135,5$ & $6-24$ & $20-42$ & $24-74$ \\
\hline
\end{tabular}

Tabla 3. Tabla resumen datos significativos puertos estudio CEDEX ambiente sumergido y carrera de mareas.

(1) Edad del muelle en el momento de la realización del estudio. 


\begin{tabular}{|c|c|c|c|c|}
\hline Muelle & Muelle A & Muelle B & Muelle C & Muelle D \\
\hline $\begin{array}{l}\text { Edad (año de } \\
\text { construcción) }\end{array}$ & 37 & 26 & 11 & 11 \\
\hline $\begin{array}{l}\text { Normativa vigente } \\
\text { en el momento de } \\
\text { la construcción }\end{array}$ & H.A.61 & EH-80 & EH-91 & EH-98 \\
\hline Localización & Mediterráneo & Atlántico & Cantábrico & Mediterráneo \\
\hline $\begin{array}{c}\text { Distancia B.M.V.E } \\
\text { testigo/carrera } \\
\text { mareas (m) }\end{array}$ & $+6,50 / 0$ & $\begin{array}{c}+5,40 \text { (losas) } / 3,70 \\
+4,70(\text { Cabeceros }) / 3,70\end{array}$ & $+5,90 / 3,80$ & $+1,50 / 0$ \\
\hline $\begin{array}{c}\text { Ambiente } \\
\text { Exposición EHE }\end{array}$ & IIIa Aéreo & IIIa Aéreo & IIIa Aéreo & IIIa Aéreo \\
\hline Subambiente ${ }^{(*)}$ & $\begin{array}{l}\text { Zona Spray } \\
\text { (FIB) }\end{array}$ & Zona Spray (FIB) & $\begin{array}{c}\text { Zona Spray } \\
\text { (FIB) }\end{array}$ & $\begin{array}{c}\text { Zona Spray } \\
\text { (FIB) }\end{array}$ \\
\hline $\begin{array}{c}\text { Hormigón } \\
\text { Proyecto }\left(\mathbf{N} / \mathbf{m m}^{2}\right)\end{array}$ & -- & 30 & 25 & 35 \\
\hline $\begin{array}{c}\text { Penetración } \\
\text { Máxima (mm) }\end{array}$ & $28-61$ & 26-106 & $15,5-30$ & $24-47$ \\
\hline
\end{tabular}

Tabla 4. Tabla resumen datos significativos puertos CEDEX ambiente aéreo.

(1) Edad del muelle en el momento de la realización del estudio.

En todos los puertos se ha procedido a la extracción de testigos con su posterior envío a laboratorio para determinar el perfil de cloruros, considerando el valor de la concentración de cloruros en superficie como punto más alto del perfil obtenido. El perfil de cloruros se obtiene cortando lonchas de un espesor variable entre 1-2 cm a lo largo de los 15-30 primeros $\mathrm{cm}$ del testigo, pulverizándolas y realizando el análisis químico del contenido de cloruros solubles en ácido de acuerdo con ASTM (2012) C1152 "Standard Test method for Acid Soluble Chloride in Mortar and Concrete". En la tablas 5, 6, 7 y 8 se recogen los resultados de Cs obtenidos para cada uno de los puertos analizados.

Al objeto de ampliar los datos de estudio, se han considerado también los resultados obtenidos en otro estudio realizado en España ${ }^{13}$, que emplea probetas de laboratorio con exposición natural en ambiente marino aéreo Illa, así como varios estudios realizados en distintos países (Japón ${ }^{14}$, Portugal ${ }^{15}$ y Noruega ${ }^{6}$ ) donde se emplean muestras situadas en ambiente sumergido IIIb. Estos datos se recogen en la Tabla 5 y 6 respectivamente. 


\section{4.- RESULTADOS}

A continuación se muestran los resultados de concentración de cloruros en superficie considerados en el estudio realizado.

\begin{tabular}{|c||c||c||}
\hline $\begin{array}{c}\text { CCAA } \\
\text { Exposición }\end{array}$ & Designación & Cs (\%p. hormigón) \\
\hline \hline Andalucía & 1 & 0,0812 \\
\hline Cantabria & 2 & 0,1450 \\
\hline Andalucía & 3 & 0,0186 \\
\hline Andalucía & 4 & 0,0774 \\
\hline Andalucía & 5 & 0,1036 \\
\hline Andalucía & 6 & 0,0557 \\
\hline \hline Galicia & 20 & 0,0200 \\
\hline Galicia & 21 & 0,3550 \\
\hline \hline Cantabria & 22 & 0,0900 \\
\hline \hline Andalucía & 7 & 0,0731 \\
\hline Andalucía & 8 & 0,1137 \\
\hline Canarias & 9 & 0,2610 \\
\hline Canarias & 10 & 0,1100 \\
\hline Canarias & 11 & 0,1000 \\
\hline Canarias & 12 & 0,0000 \\
\hline Canarias & 13 & 0,0390 \\
\hline Galicia & 14 & 0,0100 \\
\hline Galicia & 15 & 0,4000 \\
\hline Galicia & 16 & 0,0270 \\
\hline Canarias & 17 & 0,0000 \\
\hline Valencia & 18 & 0,0320 \\
\hline Valencia & 19 & 0,0600 \\
\hline
\end{tabular}

Tabla 5. Valores $C_{S}$ muestras estudio Torroja ${ }^{13}$. Ambiente marino aéreo. 


\begin{tabular}{|c|c|c|}
\hline Muelles & Designación & Cs(\%p.hormigón) \\
\hline \multirow{3}{*}{ A-Su (IIIb) } & 67 & 0,2932 \\
\hline & 68 & 0,1802 \\
\hline & 69 & 0,0881 \\
\hline \multirow{3}{*}{ B-Su (IIIb) } & 70 & 0,3257 \\
\hline & 71 & 0,6498 \\
\hline & 72 & 0,4566 \\
\hline \multirow{3}{*}{ C-Su (IIIb) } & 73 & 0,2533 \\
\hline & 74 & 0,0893 \\
\hline & 75 & 0,5426 \\
\hline \multirow{5}{*}{$\begin{array}{l}\text { Noruega }^{6} \\
\text { (7 años) }\end{array}$} & 76 & 0,1740 \\
\hline & 77 & 0,2230 \\
\hline & 78 & 0,2850 \\
\hline & 79 & 0,3030 \\
\hline & 80 & 0,3180 \\
\hline $\begin{array}{l}\text { Portugal }^{15} \\
\text { (16 años) }\end{array}$ & 81 & 0,2400 \\
\hline \multirow{6}{*}{$\begin{array}{l}\text { Muroran }^{14} \\
\text { (60 años) }\end{array}$} & 82 & 0,2660 \\
\hline & 83 & 0,4630 \\
\hline & 84 & 0,3410 \\
\hline & 85 & 0,3710 \\
\hline & 86 & 0,3960 \\
\hline & 87 & 0,4360 \\
\hline
\end{tabular}

Tabla 6. Valores Cs muestras CEDEX $X^{* 2}$ y bibliografía ${ }^{6,14,15}$. Ambiente Sumergido. 


\begin{tabular}{|c|c|c|}
\hline Muelles & Designación & Cs(\%p. hormigón) \\
\hline \multirow{3}{*}{ D-Cm (IIIc) } & 23 & 0,4842 \\
\hline & 24 & 0,4807 \\
\hline & 25 & 0,4944 \\
\hline \multirow{4}{*}{ E-Cm (IIIc) } & 26 & 0,3258 \\
\hline & 27 & 0,2034 \\
\hline & 28 & 0,4343 \\
\hline & 29 & 0,2471 \\
\hline \multirow{7}{*}{ F-Cm (IIIc) } & 30 & 0,6620 \\
\hline & 31 & 0,5803 \\
\hline & 32 & 0,4514 \\
\hline & 33 & 0,4679 \\
\hline & 34 & 0,5948 \\
\hline & 35 & 0,6500 \\
\hline & 36 & 0,7340 \\
\hline \multirow{4}{*}{ G-Cm (IIIc) } & 37 & 0,3577 \\
\hline & 38 & 0,5945 \\
\hline & 39 & 0,5064 \\
\hline & 40 & 0,4195 \\
\hline \multirow{4}{*}{ H-Cm (IIIc) } & 41 & 0,6152 \\
\hline & 42 & 0,3483 \\
\hline & 43 & 0,5271 \\
\hline & 44 & 0,2910 \\
\hline \multirow{4}{*}{ I-Cm (IIIc) } & 45 & 0,5010 \\
\hline & 46 & 0,6244 \\
\hline & 47 & 0,3604 \\
\hline & 48 & 0,4493 \\
\hline
\end{tabular}

Tabla 7. Valores Cs muestras CEDEX ${ }^{2}$. Ambiente Carrera de Mareas. 


\begin{tabular}{|c|c|c|}
\hline Muelles & Designación & Cs (\%p. hormigón) \\
\hline \multirow{4}{*}{ A-Ae } & 49 & 0,3481 \\
\hline & 50 & 0,4617 \\
\hline & 51 & 0,2798 \\
\hline & 52 & 0,1751 \\
\hline \multirow{8}{*}{ B-Ae } & $\overline{53}$ & $0,0,0330$ \\
\hline & 54 & 0,0110 \\
\hline & 55 & 0,1530 \\
\hline & 56 & 0,0050 \\
\hline & 57 & 0,4790 \\
\hline & 58 & 0,1670 \\
\hline & 59 & 0,4410 \\
\hline & 60 & 0,3280 \\
\hline \multirow{6}{*}{ C-Ae } & 61 & 0,0639 \\
\hline & 62 & 0,0833 \\
\hline & 63 & 0,4185 \\
\hline & 64 & 0,3293 \\
\hline & 65 & 0,2478 \\
\hline & 66 & 0,3583 \\
\hline \multirow{5}{*}{ D-Ae } & 88 & 0,0920 \\
\hline & 89 & 0,0563 \\
\hline & 90 & 0,0706 \\
\hline & 91 & 0,0493 \\
\hline & 92 & 0,0491 \\
\hline
\end{tabular}

Tabla 8. Valores Cs muestras CEDEX ${ }^{1,12}$. Ambiente Aéreo.

En la figura 3 se representan los valores de Cs obtenidos para los tres ambientes recogidos en las tablas anteriores. Se han considerado como ambiente IIla Aéreo, los valores del estudio Torroja puesto que pertenecen a muestras situadas hasta $1000 \mathrm{~m}$ de la costa. Sin embargo, los datos del estudio CEDEX se han considerado como ambiente IIla Spray, ya que corresponden a muestras tomadas sobre el nivel del mar y acordes con el criterio planteado por el fib ${ }^{9}$ (el fib considera zona de salpicaduras hasta $1,5 \mathrm{~m}$ sobre la pleamar y la zona spray es la situada a partir de esta altura). Se han ordenado los cuatro grupos de datos de menor a mayor agresividad desde el punto de vista del ambiente de exposición y dentro de cada uno de ellos, los valores se ordenan también de menor a mayor. Asimismo, se representan los límites del contenido de cloruros en superficie establecidos por la Instrucción EHE-08 para cada ambiente de exposición. 


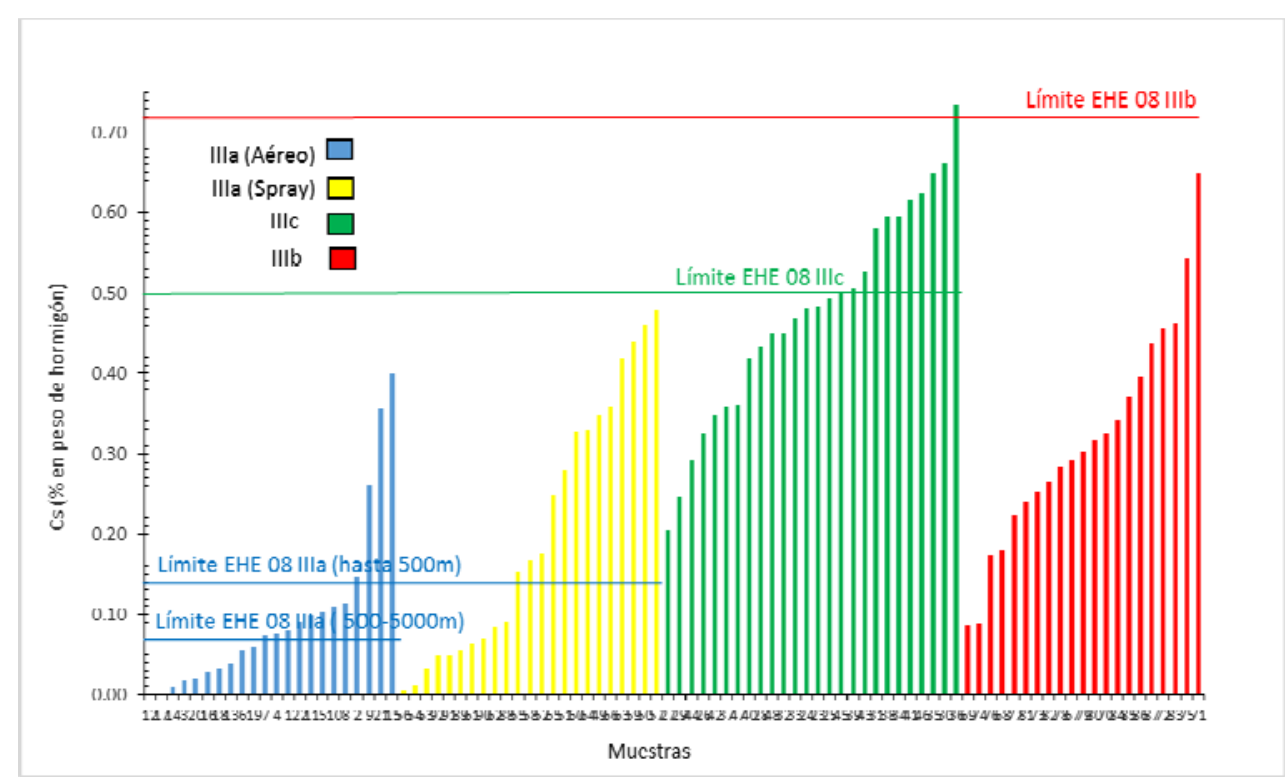

Fig 3. Concentración de cloruros en superficie en ambiente IIIa, IIIb y IIIc.

\section{5.- ANÁLISIS DE RESULTADOS}

A continuación se analizan los resultados de la concentración de cloruros en superficie obtenidos teniendo en cuenta la influencia que ejerce el ambiente de exposición en el que se encuentra la muestra, el mar en el que se localiza la estructura y la presencia o no de lavado de la superficie del hormigón.

Finalmente se comparan los valores obtenidos con los que actualmente recoge la normativa EHE-08, proponiendo algunas modificaciones.

\subsection{INFLUENCIA DE LA EDAD}

En la fig. 4 se representan los valores medios e individuales de Cs de los muelles del estudio CEDEX ${ }^{2,3}$ en carrera de mareas, ordenados por edad. Se observa en la figura que el contenido de cloruros en superficie analizado en ambiente carrera de mareas ${ }^{2}$ no experimenta un incremento más allá de los 2 años, tal como se observa en la Fig.4 (tanto en los valores medios de cada muelle como en el rango de los valores individuales), obteniéndose valores que fluctúan alrededor del valor medio total representado en las figuras. 

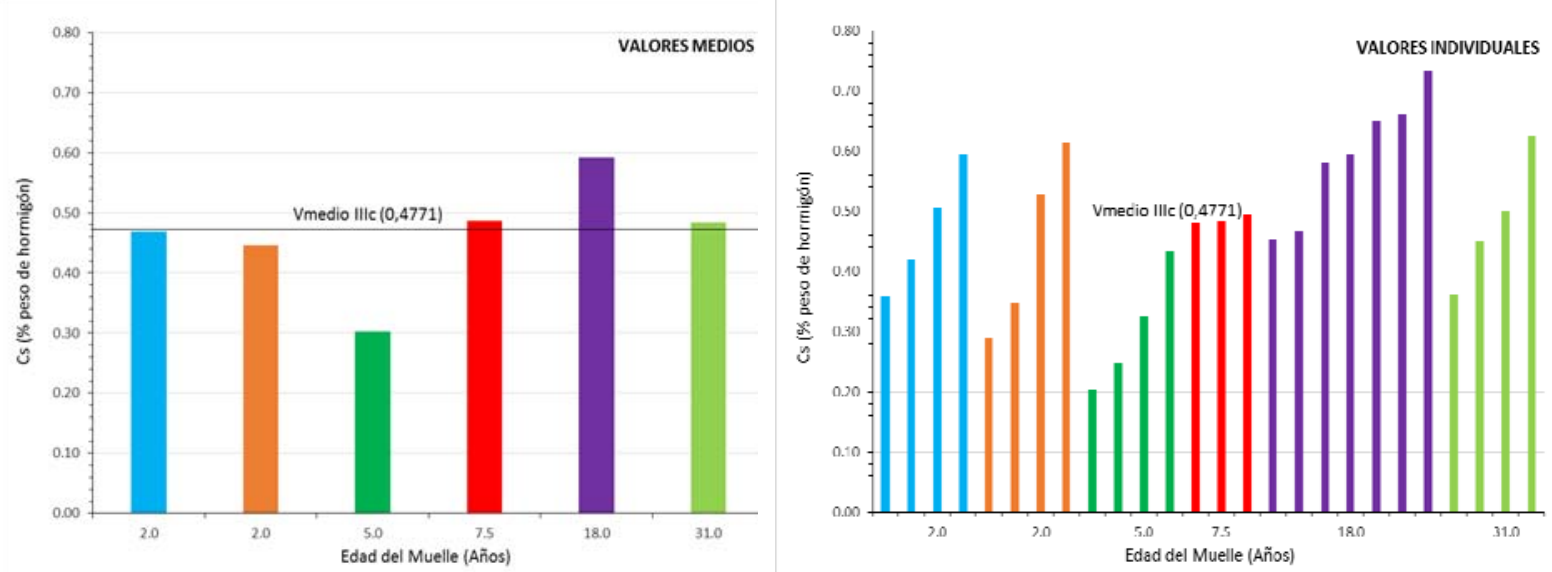

Fig.4. Valores medios e individuales Cs según edad de cada muelle. Ambiente Carrera de Mareas.

Hay que señalar que otra investigación realizada en España ${ }^{20}$ sobre probetas de hormigón colocadas en línea de playa y sometidas a carrera de marea, sí constata un incremento creciente del valor de cloruros en superficie durante 15 años, aunque con fuertes oscilaciones y acercándose progresivamente a un valor muy similar al obtenido en los puertos analizados en este estudio, si bien en la presente investigación el valor se alcanza en tan sólo 2 años.

En la fig. 5 se representan los valores medios e individuales de Cs de los tres muelles españoles ${ }^{2,3}$ en ambiente sumergido ordenados por edad (4,5-6,5 y 30 años de edad cuando se realizó el estudio). Al objeto de ampliar la muestra, se han incorporado también los datos de las estructuras internacionales tomados de la Tabla 6.
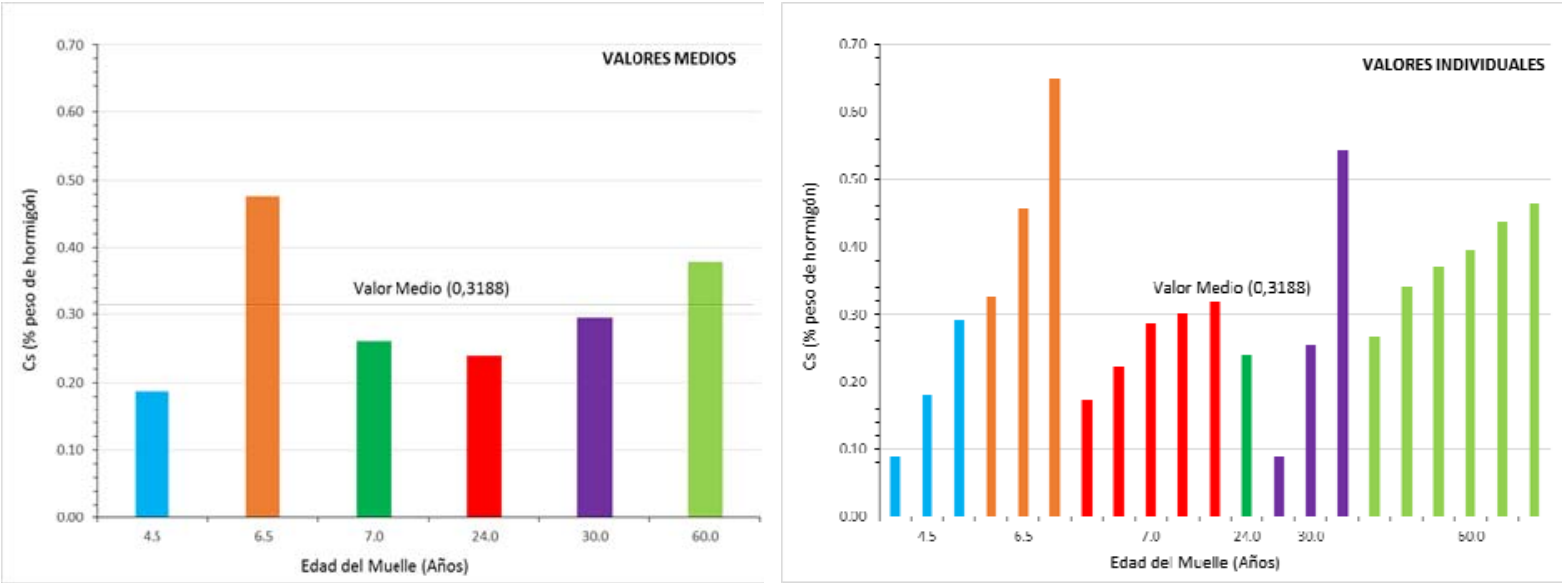

Fig.5. Valores medios e individuales de Cs según edad de cada muelle. Ambiente Sumergido

Se observa, como en el ambiente de carrera de marea, que no existe una evolución con el tiempo de los valores de Cs, que fluctúan alrededor del valor medio total de los resultados mostrados en la figura. 
En el estudio realizado en la presente investigación para ambiente marino aéreo $0^{1,12}$, la figura 6 muestra las edades de los cuatro muelles estudiados así como los cloruros en superficie obtenidos en cada caso, tanto valores medios por muelle como los valores individuales. Se observa que tres de los cuatro muelles presentan valores uniformes a pesar de tener un intervalo de edades entre 11 y 37 años. En el muelle D con 11 años de edad los resultados de todos los testigos son similares y de reducido valor. Estos valores bajos también se encuentran de forma puntual en los otros muelles, en las zonas más resguardadas de los mismos. En el caso del Muelle D se trata de una estructura muy al abrigo del puerto lo cual podría justificar los valores tan bajos de cloruros en superficie (habituales en estructuras en tierra y muy alejadas del mar) y que en principio no deberían ser atribuidos a un efecto de la edad más temprana del muelle.
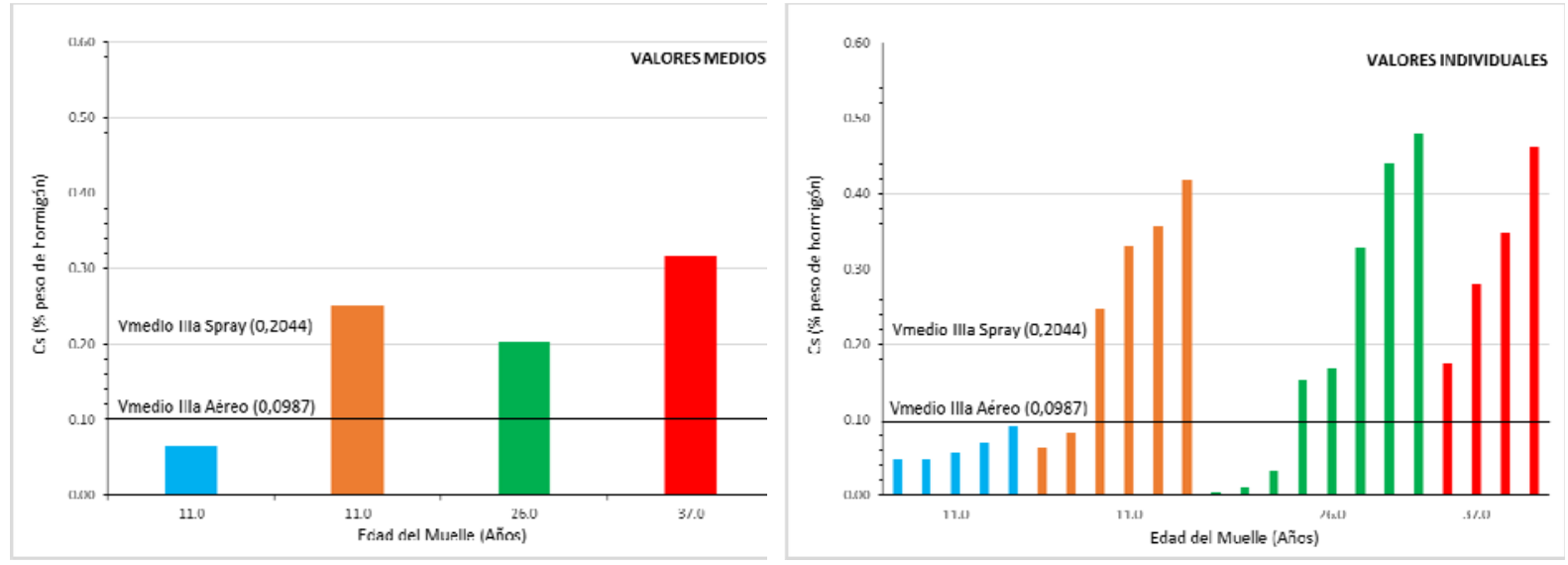

Fig.6. Valores medios e individuales de Cs según edad de cada muelle. Ambiente Aéreo.

Por tanto, en los tres ambientes marinos estudiados, con estructuras entre 2 y 60 años de antigüedad no se observa una tendencia creciente de los valores de cloruros en superficie del hormigón. Los resultados parecen indicar que el hormigón de la superficie se carga con un contenido de cloruros que crece hasta alcanzar el equilibrio con el ambiente de exposición, lo cual se produce en un corto período de tiempo (alrededor de dos años, en coherencia con lo recogido en la literatura). A partir de ese momento el valor de los cloruros en superficie se mantiene estable, aunque con fluctuaciones alrededor del valor medio que pueden llegar a ser importantes (gran dispersión de resultados) y podrían ser atribuidas a las diferentes condiciones ambientales locales en cada muelle (orientación, viento, etc).

\subsection{INFLUENCIA DEL TIPO DE AMBIENTE}

La figura 3 muestra de forma clara la gran influencia del tipo de ambiente marino en el valor de cloruros acumulados en superficie. 
En particular se observa que los valores de Cs correspondientes al ambiente IIla aéreo ${ }^{13}$ en general son mayoritariamente inferiores a los valores de Cs del ambiente IIla Spray ${ }^{1,12}$, lo cual es coherente ya que en el caso de los primeros, los resultados proceden de muestras que se colocaron en puntos situados a menos de 1000m de la línea de costa en distintas comunidades autónomas de la geografía española mientras que en el caso de los segundos, los valores siempre se tomaron de muelles portuarios en hormigones sobre el mar.

No obstante, destacan los tres valores mayores del rango Illa aéreo que sobresalen de la horquilla general. La tabla 9 muestra los valores del coeficiente de difusión para estos datos, observándose que para el caso particular de la muestra 9 el hormigón presenta un coeficiente de difusión extremadamente elevado, más coherente con una exposición al ambiente IIIb ó IIIc. En el caso de las muestras 15 y 21, el valor del coeficiente de difusión es bajo, por lo que sí podrían corresponder a zonas de ambiente Illa Aéreo, aunque los valores de Cs tan elevados, similares al grupo de barras correspondientes a los datos CEDEX ${ }^{1,12}$ procedentes de la zona de Illa Spray, inducen a pensar que podría tratarse de muestras justo en la costa $(0 \mathrm{~m})$. En cualquier caso, al no quedar estas hipótesis confirmadas en la fuente ${ }^{13}$ de donde se han tomado los datos (situación de 0 a $1000 \mathrm{~m}$ sin datos adicionales), se ha optado por mantenerlos en el ambiente Illa Aéreo.

\begin{tabular}{||c||c||c||}
\hline Muestras & C $_{\mathbf{S}} \mathbf{( \%}$ peso hormigón) & $\mathbf{D}_{\mathbf{1}}\left(\mathbf{\cdot 1 0}^{\mathbf{- 8}} \mathbf{c m}^{\mathbf{2}} \mathbf{s}\right)$ \\
\hline $\mathbf{9}$ & 0,261 & 39,00 \\
\hline $\mathbf{1 5}$ & 0,400 & 2,91 \\
\hline $\mathbf{2 1}$ & 0,355 & 0,21 \\
\hline
\end{tabular}

Tabla 9. Valores de Cs y $D_{1}$ que sobresalen de la horquilla general de resultados.

Los datos experimentales del ambiente IIla aéreo recopilados ${ }^{13}$ presentan un valor medio próximo a 0,1\% e intermedio entre los dos límites de la Instrucción EHE-08 en ambiente aéreo $(0,14 / 0,07)$. Este resultado puede considerarse razonable, ya que como se ha indicado son muestras de varias estructuras situadas a distancias variables hasta $1000 \mathrm{~m}$ de la costa (sin precisar más en la fuente consultada) y la Instrucción EHE-08 establece la subdivisión de ambos ambientes a la distancia de 500m. Puede pensarse que los valores mayores de la serie podrían corresponder a estructuras situadas dentro de esta franja de distancia y que elevan el valor medio de todos los resultados. En particular, si se recalcula la media de los datos eliminando los tres valores superiores (muy dispares del resto) el resultado es 0,061, coherente con el límite inferior de la Instrucción correspondiente a estructuras de 500 a 5000m (0,07). Por tanto, los datos disponibles no son suficientes para precisar más pero sí parece que podrían ajustarse razonablemente a lo recogido por la Instrucción EHE-08 en este ambiente. 
Sin embargo, un porcentaje muy alto de las muestras analizadas en el presente estudio en ambiente Illa Spray superan el límite para el ambiente IIla de la Instrucción EHE-08, incluso el valor más estricto planteado hasta los $500 \mathrm{~m}(0,14 \%)$ resulta claramente superado

En el caso del ambiente marino Illc, el valor límite planteado por la Instrucción apenas es superado por algunos de los resultados obtenidos mientras que en el caso del ambiente IIIb, el límite planteado por la normativa es claramente alto a la vista de los valores representados.

La tabla 10 recoge los valores medios y característicos de los datos representados en la figura 3, el número de muestras empleadas y los límites actualmente establecidos por la normativa EHE-08 ${ }^{11}$. Para calcular el valor característico de cada serie se supone que se trata de variables aleatorias normales.

\begin{tabular}{||c||c|c||c||c||}
\hline Valores Cs & Valor Medio & Valor Característico & Datos Empleados & Límite EHE-08 \\
\hline IIIa Aéreo & 0,0987 & 0,2758 & 22 & $0,14 / 0,07^{(1)}$ \\
\hline IIIa Spray & 0,2044 & 0,4698 & 23 & $-{ }^{(2)}$ \\
\hline IIIc & 0,4771 & 0,6978 & 26 & 0,50 \\
\hline IIIb & 0,3188 & 0,5494 & 21 & 0,72 \\
\hline
\end{tabular}

Tabla 10. Relación de valores medios y característicos de las series anteriores.

(1) 0,14 para estructuras hasta $500 \mathrm{~m}$ de la costa y 0,07 para aquéllas situadas entre los 500m y los 5000m.

(2) No se recoge este subambiente en la actual normativa EHE-08: dentro del ambiente IIIc sí se recoge la zona de salpicaduras (sin precisar altura), pero no zona de spray.

Para el caso del ambiente IIIb, los valores de la tabla 10 se han calculado considerando también los datos extraídos de la bibliografía. Sin embargo, si los parámetros se determinan utilizando únicamente los datos de puertos españoles (9 datos), los resultados que se obtienen son muy similares: valor medio $=0,3199$, valor característico $=0,6430$.

Los valores medio y característico correspondientes al rango de valores IIla Aéreo ${ }^{13}$ se han calculado sin eliminar los tres datos más elevados, tal como se ha comentado anteriormente, lo cual da lugar a un resultado más conservador.

En un apartado posterior se analizan en mayor profundidad los resultados experimentales obtenidos en los diferentes ambientes en comparación con los límites normativos, realizando una propuesta de modificación. 


\subsection{INFLUENCIA DE LA SALINIDAD DEL MAR}

En la figura 7 se representan los datos de cada muelle ordenados de menor a mayor, tanto de los procedentes de la bibliografía ${ }^{13}$ como de los muelles estudiados por el CEDEX $X^{1,2,3,12}$ para comprobar la posible influencia de aspectos locales de cada muelle.

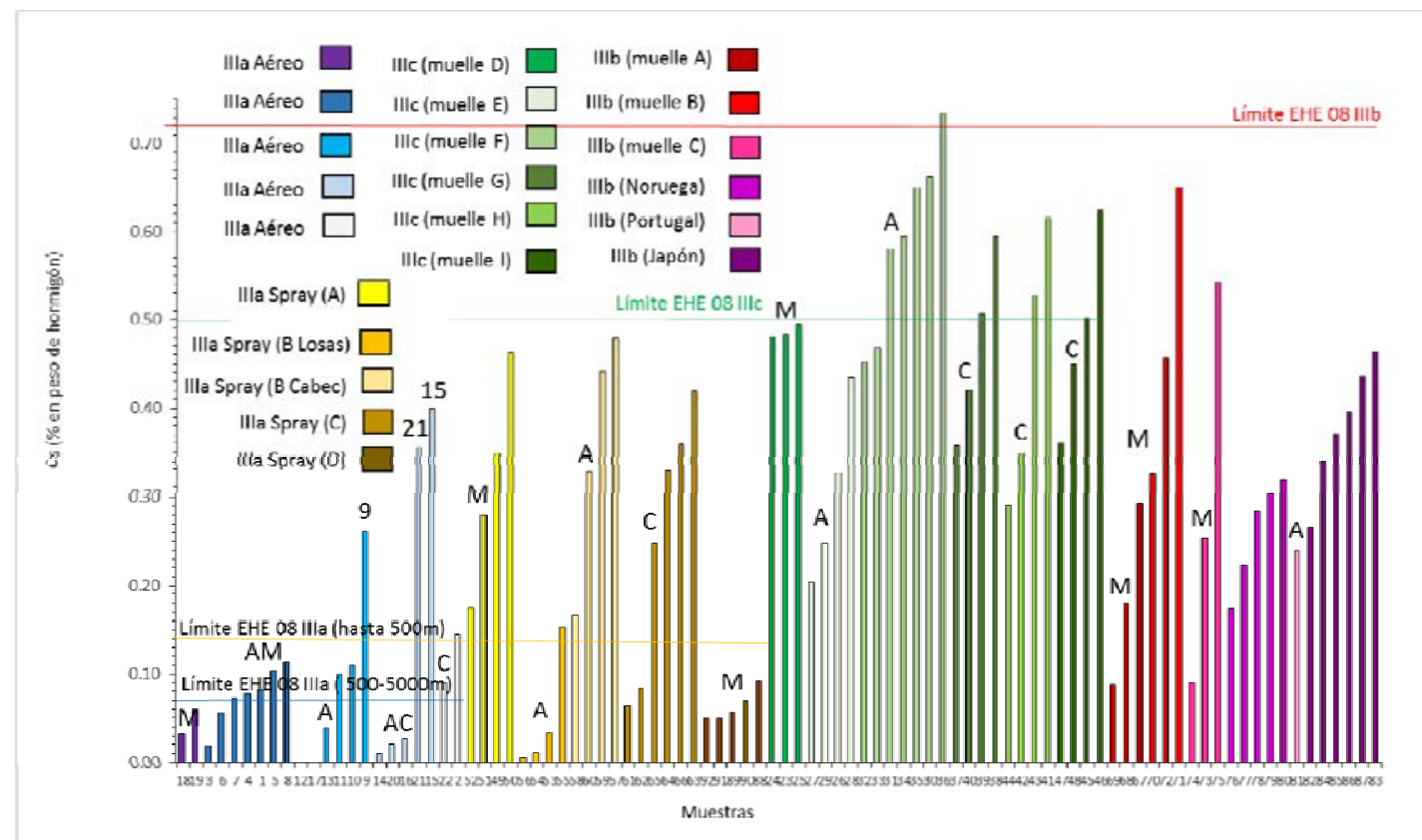

Fig 7. Cloruros en superficie en ambiente IIIa, IIIb y IIIc ordenados por ambientes y por muelles. Las letras entre paréntesis indican la nomenclatura para designar a los muelles en cada estudio. Las letras M, A, C, AC y AM que se superponen sobre las barras indican el mar en el que se sitúa cada muelle: Mediterráneo, Atlántico, Cantábrico, costa Gallega y costa Andaluza respectivamente.

Se observa en la figura la poca influencia de la zona costera en la que se encuentra el hormigón, obteniendo una variación de resultados similares en los hormigones expuestos a las tres costas españolas: Mediterránea, Atlántica y Cantábrica, dentro del mismo tipo de ambiente marino. Incluso para los casos tomados de la bibliografía de hormigones en una climatología muy diferente a la de nuestro país (Noruega ${ }^{6}$ y Japón $\left.{ }^{14}\right)$, los resultados son también comparables a los obtenidos en costas españolas.

\subsection{INFLUENCIA DEL LAVADO EN SUPERFICIE}

El efecto lavado en superficie se refiere al hecho de que el hormigón más superficial de las muestras analizadas queda expuesto al agua de lluvia o de escorrentía, arrastrando así los cloruros depositados en los primeros centímetros. Por este motivo, los valores iniciales de los perfiles son, en algunas ocasiones, inferiores que los valores más profundos, cuando el contenido de cloruros debería disminuir a medida que se profundiza en la muestra de hormigón presentando su valor máximo al inicio del perfil. En la figura 8 se representan las muestras ordenadas de menor a mayor valor de Cs 
resaltando aquellas que presentan perfiles de hormigón con efecto lavado en superficie. Se han eliminado los valores correspondientes al estudio de Noruega puesto que no se dispone de su perfil de cloruros y sí han podido considerarse los resultados de la tesis consultada en la bibliografía ${ }^{13}$ ya que en ellos se señala la aparición de los casos con lavado, designados como "efecto piel".

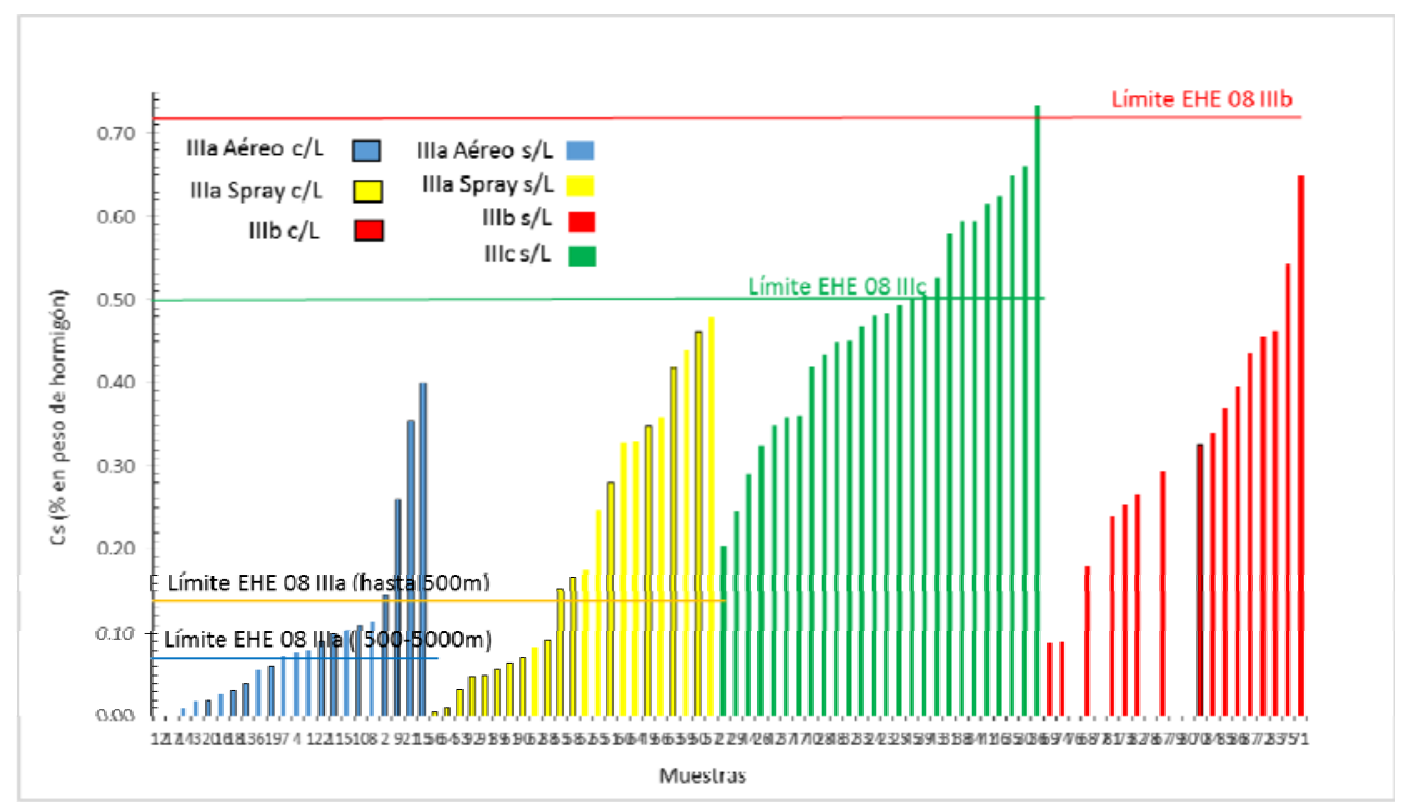

Fig 8. Representación de muestras con efecto de lavado en superficie sobre el gráfico general de valores de Cs. Los valores remarcados corresponden a aquellas muestras con efecto lavado.

Se observa en la figura que el efecto lavado aparece de forma exclusiva en los perfiles correspondientes al ambiente IIla, ya que es el ambiente en el que el hormigón puede verse más afectado por el agua de lluvia. No se observan perfiles con lavado en ninguna de las muestras tomadas en ambiente de carrera de mareas (IIIC) y aunque hay un caso en ambiente sumergido (IIIb), se trata de un perfil con una tenue curva inicial que podría estar ocasionada por algún efecto puntual del hormigón.

Por otra parte, en la figura se observa cómo el lavado afecta por igual a hormigones con fuerte concentración de cloruros en superficie como a aquéllos con menor cantidad.

\subsection{INFLUENCIA DE LA DISTANCIA A LA COSTA}

La normativa japonesa es la que más importancia da a la distancia a la costa de las estructuras afectadas por el ambiente marino aéreo, entre las estudiadas. Así, Japón divide su zona costera en tres regiones ( $\mathrm{A}, \mathrm{B}$ y $\mathrm{C}$ ) de acuerdo con las condiciones climatológicas que aparecen en la Tabla $11^{18}$. La región $\mathrm{C}$ se considera como zona más afín al ambiente de exposición Illa puesto que en nuestro país no se producen de manera habitual fenómenos meteorológicos extremos como tifones o vientos de 
tormenta. Se observa en la Tabla 11 que para la Zona C se consideran relevantes sólo los $200 \mathrm{~m}$ de franja costera, estableciendo una mayor discretización de la misma en comparación con la división simple en dos subzonas del ambiente Illa en la Instrucción EHE-08.

En el apartado de antecedentes se ha hecho referencia a un estudio realizado en Japón ${ }^{10}$ sobre estructuras costeras que permitía obtener una relación entre el contenido de cloruros en superficie y la distancia a la costa. Si se aplica dicho estudio a las distancias recogidas en la tabla 11 se obtienen los valores de Cs (cloruros en superficie) que se muestran en la misma tabla.

\begin{tabular}{|c|c|c|c|c|}
\hline Zona & Distancia costa $(\mathrm{km})$ & $\mathrm{C}_{1}$ & $\mathrm{C}_{\text {air }}$ & $\mathrm{C}_{\mathrm{s}}(\% \mathrm{ph})$ \\
\hline \multirow{2}{*}{$\begin{array}{c}\text { A } \\
\text { (ruta de tifones) }\end{array}$} & 0,1 & \multirow{2}{*}{0,6} & 2,389 & 0,092 \\
\hline & 0,3 & & 1,236 & 0,071 \\
\hline \multirow{4}{*}{$\begin{array}{c}\text { B } \\
\text { (Viento de } \\
\text { tormenta en } \\
\text { invierno) }\end{array}$} & 0,1 & \multirow{4}{*}{0,6} & 2,389 & 0,092 \\
\hline & 0,3 & & 1,236 & 0,071 \\
\hline & 0,5 & & 0,909 & 0,063 \\
\hline & 0,7 & & 0,743 & 0,058 \\
\hline \multirow{4}{*}{$\mathrm{C}$} & 0,02 & \multirow{4}{*}{0,2} & 2,091 & 0,088 \\
\hline & 0,05 & & 1,207 & 0,070 \\
\hline & 0,1 & & 0,796 & 0,060 \\
\hline & 0,2 & & 0,525 & 0,050 \\
\hline
\end{tabular}

Tabla 11. Discretización de ambientes marinos en la normativa japonesa ${ }^{18}$ y contenidos de cloruros en superficie asociados, de acuerdo con el modelo japonés ${ }^{10}$.

El estudio japonés aplicado a distancias lejanas de la costa (de 500m a 5km) proporciona contenidos de cloruros en superficie muy similares entre sí y muy inferiores a los recogidos en la Instrucción EHE-08 (Fig.9), siendo estos últimos más acordes con los resultados experimentales obtenidos en la costa española ${ }^{13}$. 


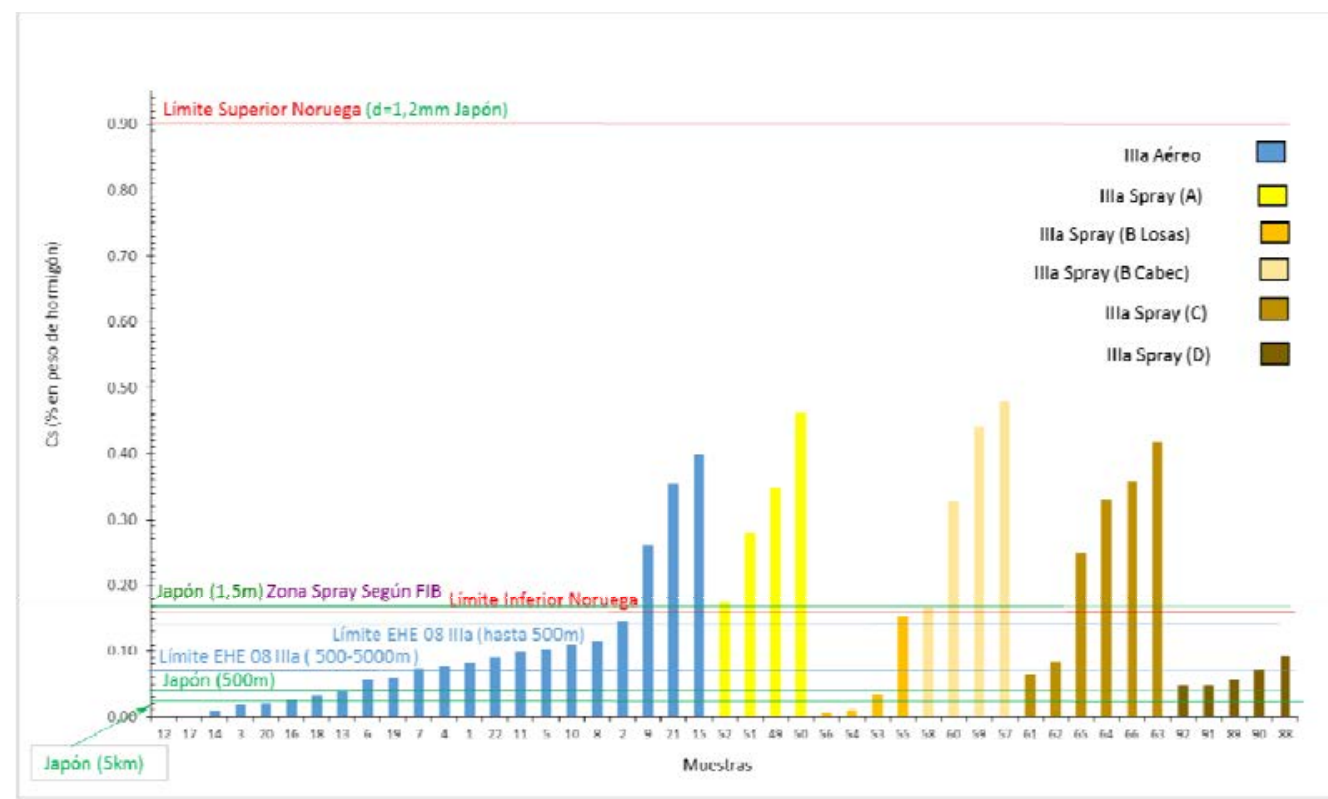

Fig 9. Cs en ambiente IIIa recogidos en la experimentación.

Representación de límites españoles, japoneses y noruegos.

Según nos acercamos a la línea de la costa (franja de 200 a 20 m), en la propuesta japonesa los valores de $C_{s}$ se elevan de forma notable, tal como se observa en la Tabla 11. Esto concuerda con la posible necesidad de una mayor discretización del ambiente Illa en su zona más próxima a la costa para el caso español, ya que actualmente se introducen en el mismo grupo estructuras situadas en la propia costa o sobre el mar, con otras situadas a medio kilómetro de distancia.

Finalmente, si se extrapola el modelo japonés ${ }^{10}$ a la zona de spray $(1,5 \mathrm{~m})$ se obtiene un valor ajustado a los obtenidos en los puertos españoles situados en esta zona y también en coherencia con el límite inferior de resultados en las plataformas noruegas correspondiente a hormigones situados a nivel del mar( Fig.9). Si se extrapolara aún más la propuesta japonesa (1,2 mm representado en la Fig.9) los valores de cloruros se disparan y se corresponderían con los límites superiores obtenidos en hormigones de estructuras noruegas al nivel de la superficie del mar. Estos resultados tan elevados quedan muy por encima de los obtenidos en los puertos españoles, lo cual puede atribuirse a que se trata de estructuras que se encuentran en alta mar y en el Mar del Norte, con poca similitud al que pudiera encontrarse en los puertos en España.

\subsection{INFLUENCIA DE LA CALIDAD DEL HORMIGÓN}

Finalmente, se analiza la posible influencia de la calidad del hormigón en los cloruros acumulados en superficie, valorada a partir de los datos de penetración de agua. Así, en la figura 10 se representan los resultados de penetración de agua (estudio CEDEX y estudio Torroja) y cloruros en superficie medidos en todos los testigos para los diferentes ambientes. Pese a la dispersión de resultados sí se observa que en general 
se registran, para cada ambiente, mayores valores de cloruros en superficies en los hormigones de peor calidad (mayor penetración de agua). Descartando los valores erráticos, la envolvente de todos los resultados es ascendente.

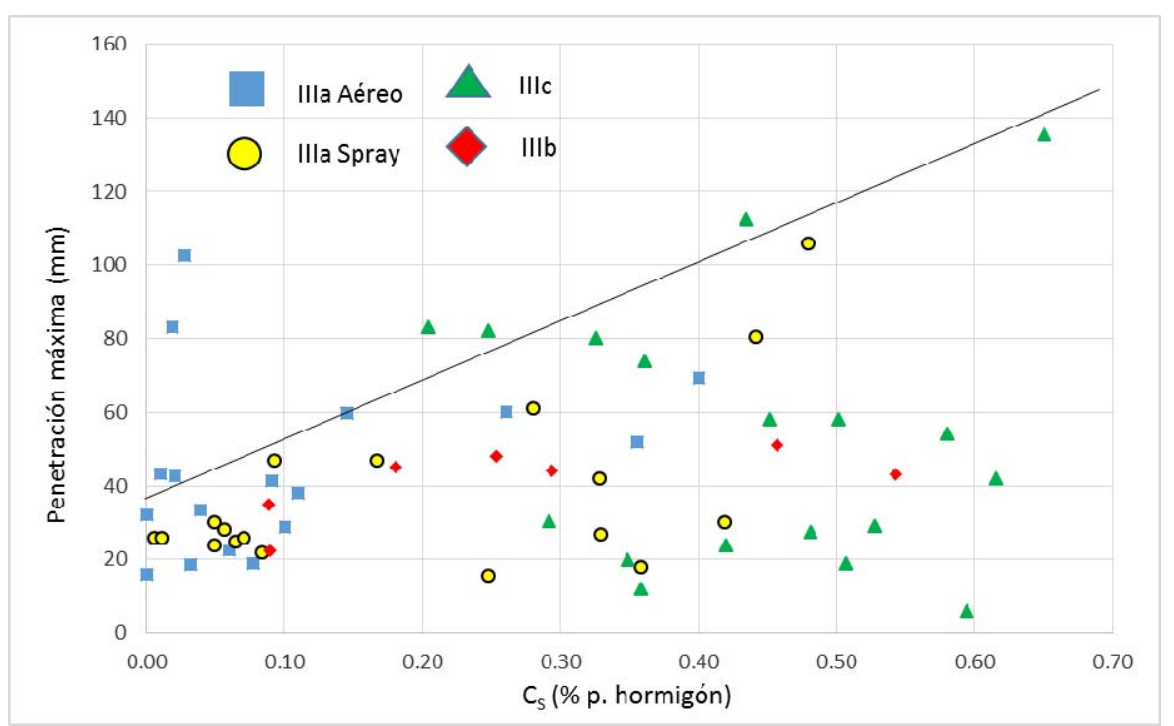

Fig 10. Penetración máxima de agua en IIIa, IIIb y IIIc según el orden de menor a mayor Cs.

Muchas de las estructuras representadas en el gráfico anterior son antiguas y la calidad del hormigón no cumple los requisitos de penetración de agua actualmente exigidos por la Instrucción EHE-08. Si se aplican estos parámetros a los resultados que se están analizando, considerando únicamente aquéllos que cumplen el requisito de penetración máxima $<50 \mathrm{~mm}$, se obtiene la tabla 12 .

\begin{tabular}{|c||c||c|c|c||}
\hline Valores Cs & Valor Medio & $\begin{array}{c}\text { Valor } \\
\text { Característico }\end{array}$ & $\begin{array}{c}\text { Datos } \\
\text { Empleados }\end{array}$ & $\begin{array}{c}\text { Límite } \\
\text { EHE-08 }\end{array}$ \\
\hline \hline IIIa Aéreo & 0,0490 & 0,1157 & 11 & $0,14 / 0,07^{(1)}$ \\
\hline IIIa Spray & 0,1553 & 0,3878 & 15 & $--^{(2)}$ \\
\hline IIIc & 0,4600 & 0,6462 & 9 & 0,50 \\
\hline IIIb & 0,2411 & 0,5202 & 6 & 0,72 \\
\hline
\end{tabular}

Tabla 12. Relación de valores medios y característicos de muestras con Pmax<50mm.

Salvo para el caso de ambiente de carrera de mareas, el resto de valores medios se reduce. Esto significaría que para hormigones de buena calidad que cumplen los actuales requisitos de durabilidad de la Instrucción EHE-08 sería de esperar un contenido inferior de cloruros en superficie, lo cual si se mantienen los valores normativos actuales queda del lado de la seguridad. 


\subsection{PROPUESTA DE VALORES Y COMPARACIÓN CON LA EHE 08}

De acuerdo con los resultados analizados y tomando como referencia los valores medios de Cs obtenidos en los hormigones situados en los diferentes ambientes marinos (redondeados al alza) de la tabla 10, se podrían adoptar los valores planteados en la tabla 13 para el cálculo de vida útil. En comparación con lo recogido en la Instrucción EHE-08 se introduce una zona de spray con un nuevo límite y se rebaja el límite de la zona sumergida.

\begin{tabular}{|c|c|c|c|c|c|}
\hline $\begin{array}{l}\text { Clase General } \\
\text { de Exposición }\end{array}$ & \multicolumn{3}{|c|}{ IIIa } & IIIb & \begin{tabular}{|c} 
IIIc \\
(incluyendo zona de \\
salpicaduras $h<1,5 \mathrm{~m}$ )
\end{tabular} \\
\hline $\begin{array}{c}\text { Distancia a la } \\
\text { costa }\end{array}$ & $\begin{array}{r}\text { Zona de spray } \\
(\mathrm{h}>1,5 \mathrm{~m})\end{array}$ & Hasta $500 \mathrm{~m}$ & $500 \mathrm{~m}-5000 \mathrm{~m}$ & \multirow{2}{*}{0,35} & \multirow{2}{*}{0,50} \\
\hline $\begin{array}{l}\text { Cs(\% p. } \\
\text { hormigón) }\end{array}$ & 0,25 & 0,14 & 0,07 & & \\
\hline
\end{tabular}

Tabla 13. Propuesta de valores de concentración de cloruros en superficie

En la figura 11 se representan los valores medios y característicos obtenidos en los tres ambientes marinos así como los límites que actualmente plantea la normativa EHE-08 al tiempo que se incorporan en trazo discontinuo las nuevas propuestas de límites de la tabla anterior, resultado del análisis del estudio realizado.

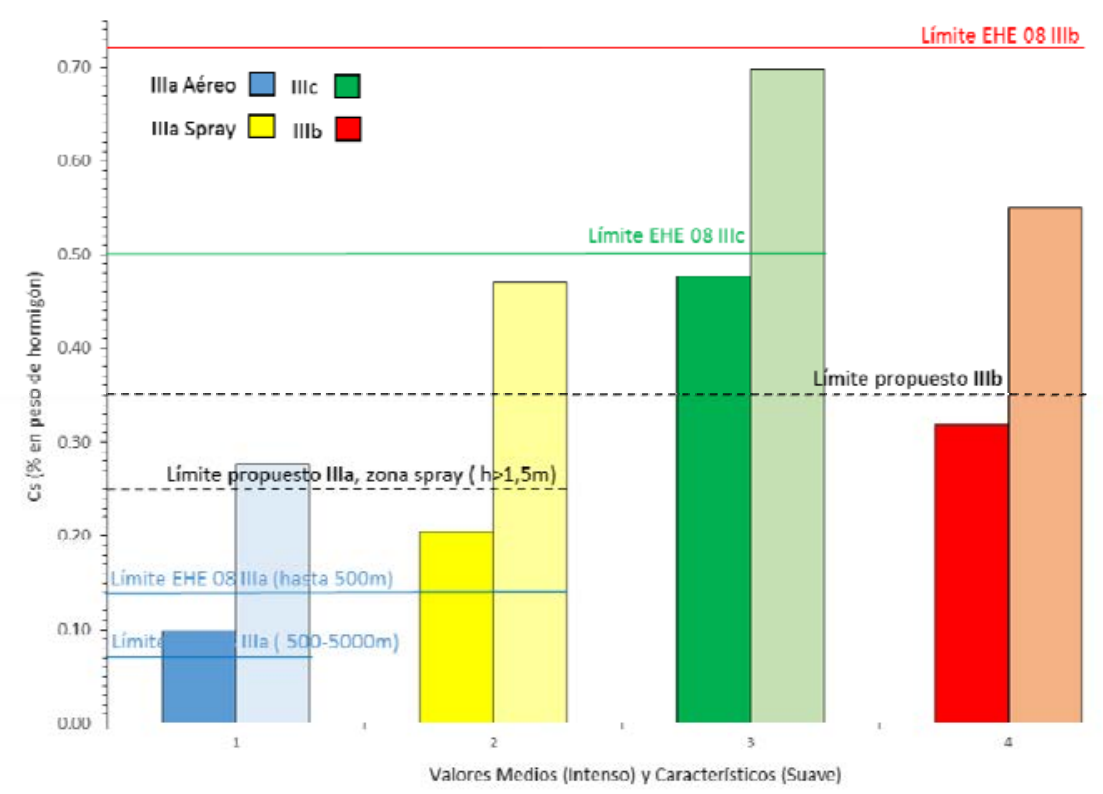

Fig 11. Valores medios y característicos de $C_{S}$, límites actuales de la normativa EHE08 y nuevas propuestas.

A la vista del gráfico obtenido, puede observarse: 
- Los resultados experimentales medidos en estructuras reales indican la necesidad de proponer un nuevo valor de cloruros en superficie para al ambiente IIIb, ya que el actual resulta excesivamente conservador.

- Se considera necesario introducir un nuevo valor de cloruros en superficie, definiendo (de acuerdo con el criterio del $\mathrm{FIB}^{9}$ ) una zona spray en la franja de la estructura que se encuentra a una altura superior a $1,5 \mathrm{~m}$ sobre el nivel del mar.

- Los resultados experimentales analizados en este estudio (valores medios) son coherentes con los recogidos en la Instrucción para el ambiente Illa aéreo y el ambiente IIIc de carrera de mareas.

- Adoptar valores característicos del contenido de Cs supondría elevar notablemente los límites actualmente recogidos por la Instrucción EHE-08 en todos los ambientes, salvo en el ambiente sumergido. 


\section{6.-CONCLUSIONES}

Al término del análisis realizado sobre la concentración de cloruros en superficie puede concluirse:

- Existen diferentes criterios normativos en la clasificación de los ambientes marinos.

- En el ambiente marino aéreo destaca la normativa japonesa, que considera relevantes sólo los primeros $200 \mathrm{~m}$ de costa (700 m en zona de tormentas) y realiza una mayor discretización de esta franja, que eleva notablemente su contenido de cloruros en superficie al acercarse a la línea de mar. El planteamiento es muy diferente a la división simple en dos subzonas de la zona costera que plantea la Instrucción EHE-08.

- El FIB plantea la existencia de una zona de spray en la franja de la estructura situada 1,5m sobre el mar, que no se recoge en la Instrucción EHE-08 y que el presente estudio indica que es necesaria, ya que se diferencia en comportamiento respecto a la de salpicaduras y carrera de mareas.

- Los datos de $\mathrm{Cs}_{\mathrm{s}}$ recabados en la literatura son muy variables y dispersos dependiendo de la fuente consultada.

- Los resultados obtenidos en este estudio sobre estructuras reales demuestran que el valor de $\boldsymbol{C}_{\mathrm{s}}$ está fundamentalmente influenciado por el tipo de ambiente marino, si bien los datos fluctúan incluso dentro de un mismo puerto y en zonas diferentes de la misma estructura. Esto puede responder a fenómenos locales, por ejemplo zonas de abrigo frente a otras más expuestas o la orientación del paramento frente al viento.

- No existe una influencia determinante de la salinidad puesto que, a pesar de que el mar Mediterráneo tiene un mayor contenido en sales que el mar Cantábrico y el océano Atlántico, los resultados de $\mathrm{C}_{\mathrm{S}}$ obtenidos en los tres casos no difieren entre sí, ni incluso tampoco al incluir datos procedentes de otros países con climatología muy diferente a la nuestra (Noruega o Japón).

- $\quad$ El lavado en superficie se presenta únicamente en ambiente IIla, al tratarse de un hormigón expuesto al agua de lluvia. Asimismo, el efecto se produce por igual en hormigones con alto y bajo contenido de cloruros en superficie.

- Los resultados experimentales obtenidos en ambiente sumergido indican la necesidad de proponer un nuevo valor de cloruros en superficie para al ambiente sumergido IIIb (0,35\%), ya que el actual resulta excesivamente conservador $(0,72 \%)$. 
- Se considera necesario introducir un nuevo valor de cloruros en superficie igual a $0,25 \%$, definiendo (de acuerdo con el criterio del FIB ${ }^{9}$ ) una zona spray en la franja de la estructura que se encuentra a una altura superior a $1,5 \mathrm{~m}$ sobre el nivel del mar.

- Los resultados experimentales (valores medios) analizados en este estudio son coherentes con los recogidos en la Instrucción para el ambiente Illa aéreo y el ambiente IIlc de carrera de mareas.

\section{7.-BIBLIOGRAFÍA CONSULTADA}

Para la elaboración del presente anejo se han consultado las siguientes fuentes bibliográficas a las que se hace referencia durante el documento:

1. Fernández, S. (2011). "Corrosión de armaduras en el hormigón armado en ambiente marino aéreo". Suficiencia investigadora, ETSICCP, Universidad Politécnica de Madrid.

2. Bermúdez, M.A; Alaejos, M.P. (2009). "Estudio experimental de la durabilidad del hormigón armado en ambiente marino. Zonas sumergida y de carrera de mareas" Monografía 103, CEDEX. Madrid.

3. Alaejos, M. P; Bermúdez, M.A. (2008). "Corrosión de las armaduras en el hormigón situado en ambiente marino". Monografía 96, CEDEX. Madrid.

4. Williamson. G. S, Weyers. R. E y otros (2009). "Concrete and Steel Type Influence on Probabilistic Corrosion Service Life". ACI Materials Journal, n 106-M11.

5. Williamson. G. (2007). "Service Life Modeling of Virginia Bridge Decks". Tesis Doctoral. Virginia Polytechnic Institute. Blacksburg, Virginia.

6. Helland, S; Aarstein, R. and Maage, M. (2010). "In field performance of North Sea offshore platforms with regard to chloride resistance" Structural Concrete, 2010, 11 $N^{\circ} 1$, Thomas Telford and fib.

7. Shafiq, N (2004). "Effects of Fly Ash on Chloride Migration in Concrete and Calculation of Cover Depth required against the Corrosion of Embedded Steel Reinforcement" Structural Concrete, Vol 4, 2004. Thomas Telford.

8. Berke, N.S, Hicks, M.C. (1992). "Estimating the Life Cycle of Reinforced Concrete Decks and Marine Piles using Laboratory Diffusion and Corrosion Data" Corrosion 
Forms and Control for Infrastructure, ASTM STP 1137, Victor Chaker, ED. American Society for Testing and Materials, Philadelphia, 1992.

9. FIB (2006). "Model Code for Service Life Design". Bulletin 34. Lausanne, Switzerland.

10. Tanaka, Y; Kawano, H y otros (2001). "Study on required cover depth of concrete highways bridges in coastal environment" Tsukuba, Japan.

11. Ministerio de la Presidencia (2008). "Instrucción de Hormigón Estructural (EHE 08) Madrid.

12. CEDEX, Laboratorio Central de Estructuras (2015) "Puerto de Valencia. Estudio del hormigón del Muelle de la Aduana".

13. D’Andrea, R. (2010). "Predicción de la durabilidad del hormigón armado a partir de indicadores de corrosión: aplicación de la resistividad eléctrica". Tesis doctoral, ETSICCP, Universidad Politécnica de Madrid.

14. Ozaki, S. y Sugata, N. (1988) "Sixty-year-old concrete in a marine environment". SP 109-26. En American Concrete Institute. Concrete in Marine Environment. Second International Conference.ACI SP 109. Detroit: Ed. V.M.Malhotra.

15. Costa, A. y Appleton, J. (2002). "Case studies of concrete deterioration in a marine environment in Portugal”. Cement and Concrete Composites, Vol.24, 169-179.

16. Cramer, S. D., Covino, B. S. y otros (2002). "Corrosion prevention and remediation strategies for reinforced concrete coastal bridges". Cement and Concrete Composites 24.

17. Stewart, M.G, Rosowsky D.V (1998). "Structural Safety and Serviceability of Concrete Bridges subject to Corrosion" Journal of Infrastructure Systems, Vol.4 No 4 (ASCE).

18. Fukui J. Shirato M (2005). "Performanced-based specifications for Japanese highway bridges" Proceedings ICOSSAR 2005 "Safety and Reliability of Engineering Systems and Structures", Millpress, Rotterdam.

19. Costa, A. y Appleton, J. (1999). "Chloride penetration into contrete in marine environment. Part II: Prediction of long term chloride penetration". Materials and Structures, Vol.32, № 219, June, 354-359. 
20. Andrade. C, Castellote. M, D’Andréa. R, Picón. J.M, Sanjuán. M.A. (2009). "Difusión de Cloruros en Hormigones expuestos a Ambientes Marinos. Estudio de 15 años de exposición". Cemento Hormigón, No935, Diciembre 2009, 22-31.

21. ACI 365.1R-00. "Service-Life Prediction-State of the Art Report". (2000). 



\section{ANEJO 2: ESTUDIO DE LA CONCENTRACIÓN CRÍTICA DE CL $\left(\mathrm{C}_{\mathrm{TH}}\right)$.}

\section{INTRODUCCIÓN}

\section{1.-REVISIÓN BIBLIOGRÁFICA ESTUDIOS PREVIOS CEDEX EN AMB. Illa, Illb y III $\mathrm{C}^{1,2,3}$}

Para la realización de este apartado de revisión bibliográfica se ha consultado la tesis "Corrosión de las armaduras del hormigón armado en ambiente marino: zona de carrera de mareas y zona sumergida" realizada por D. Miguel Ángel Bermúdez Odriozola y se han resumido parte de los contenidos aportados por dicho documento sobre la concentración crítica de cloruros. Asimismo, se parte del trabajo previo de suficiencia investigadora "Corrosión de armaduras en el hormigón armado en ambiente marino aéreo" realizado por $D^{\mathrm{a}}$. Susana Fernández García y se han resumido parte de los contenidos aportados por dichos documentos sobre la concentración crítica de cloruros ${ }^{3}$.

La concentración crítica de cloruros $\left(\mathrm{C}_{\text {th }}\right)$, en ocasiones también denominada umbral de cloruros (del inglés chlorides threshold), es la concentración límite a partir de la cual comienza a desarrollarse la corrosión activa del acero.

Los cloruros pueden encontrarse en el hormigón combinados (fundamentalmente en forma de cloroaluminato o sal de Friedel) o bien libres en la solución de los poros del hormigón. Inicialmente los peligrosos frente al ataque por corrosión son los cloruros libres. Sin embargo, se ha demostrado que según avanza la corrosión, los cloruros combinados pueden liberarse, por ejemplo por una bajada de $\mathrm{pH}$, siendo susceptibles de iniciar o propagar la corrosión.

Por esta razón, la mayoría de las normativas limitan el contenido de cloruros totales (cloruros solubles en ácido) quedando, por tanto, más del lado de la seguridad. Es el caso de las recomendaciones $\mathrm{ACl} 365 \mathrm{R}$ "Service Life Prediction. State of the Art Report"30 que indican que puede establecerse una relación $c_{b}=R c_{f}$ entre cloruros combinados $\left(c_{b}\right)$ y libres $\left(c_{f}\right)$, aunque debido a la carbonatación y a que los iones sulfatos pueden liberar a los cloruros combinados, $\mathrm{R}$ se asume normalmente como 0.

Existe diversidad de valores en la proporción que se mantiene entre cloruros libres y combinados. Así, la elevada presencia de aluminato tricálcico $\left(C_{3} A\right)$ en el cemento contribuye a aumentar los iones cloruro fijados; los iones hidroxilo hacen disminuir la cantidad de cloruros en disolución y una mayor cantidad de sulfato cálcico favorece la 
corrosión, ya que afecta significativamente a la relación $\mathrm{Cl}^{-} / \mathrm{OH}^{-}$. Asimismo, la temperatura y duración del curado así como el pH del hormigón afectan a la capacidad de fijar cloruros.

En cuanto a la influencia de las adiciones sobre la capacidad de fijación de cloruros al hormigón, cabe decir que, en general la incorporación de humo de sílice, cenizas o escorias supone la reducción del contenido de cloruros fijados.

La concentración de cloruros libres se determina midiendo los cloruros solubles en agua (cloruros extraíbles del agua bajo condiciones definidas) y la de cloruros totales mediante la concentración de cloruros solubles atacando la muestra con ácido nítrico. La diferencia entre los dos valores es la concentración de cloruros combinados. Los resultados varían según el procedimiento de análisis, sobre todo respecto al tamaño de partícula, tiempo de extracción, temperatura, edad y ambiente de exposición. El resultado de la concentración crítica de cloruros se puede expresar tanto en peso de cemento como de hormigón.

La concentración crítica de cloruros no es un valor único, debido a que varía en función de las características del hormigón $(\mathrm{pH}$ de la solución de los poros, contenido de humedad, temperatura, tipo de catión que acompaña al cloruro, contenido de $\mathrm{C}_{3} \mathrm{~A}$ y finura del cemento, adiciones, etc) y del propio acero de las armaduras (composición, impurezas, desigualdades de la superficie, envejecimiento). Todos estos parámetros influyen en la naturaleza de la capa pasiva, lo que determina el potencial eléctrico que presenta la armadura. Además, la naturaleza de la capa pasiva evoluciona con el tiempo y por tanto, también lo hace el potencial. Pourbaix confirmó que el acero situado en soluciones alcalinas que contengan iones cloruros puede sufrir corrosión localizada, por lo que para un $\mathrm{pH}$ y una concentración de cloruros determinada, se puede detectar un potencial (llamado potencial de picadura), por encima del cual el acero se corroe.

Las concentraciones críticas de cloruros recogidas en la bibliografía presentan un gran rango, entre 0,17 y $2,2 \%$, expresado como $\% \mathrm{Cl}$ totales en peso de cemento. Esto se debe probablemente a que los materiales constituyentes del hormigón, especialmente el cemento, son diferentes en las distintas investigaciones, a la posible utilización de adiciones o al contenido inicial de cloruros en el hormigón.

Así, en la tabla 1, procedente de un estudio realizado sobre plataformas noruegas en el Mar del Norte ${ }^{4}$ con valores registrados entre los $0 \mathrm{~m}$ y los $28 \mathrm{~m}$ sobre el nivel del mar, se relaciona el contenido de cloruros con un determinado riesgo de corrosión, entendiendo los siguientes valores como una simplificación, ya que la concentración crítica de cloruros varía con la relación a/cementante (aumenta al reducirse la relación a/c) y con el tipo de exposición: 


\begin{tabular}{|c|c||}
\hline Contenido de Cloruros & Riesgo de Corrosión \\
\hline \hline $0,4 \%$ & Despreciable \\
\hline $0,4-1,0 \%$ & Posible \\
\hline $1,0-2,0 \%$ & Probable \\
\hline$>2,0 \%$ & Significativo \\
\hline
\end{tabular}

Tabla.1. Relación entre contenido de cloruros y riesgo de corrosión ${ }^{4,17}$.

Se han considerado los umbrales de cloruros para inicio de corrosión activa cuando los cloruros han alcanzado la concentración límite a $50 \mathrm{~mm}$ de profundidad. Puede observarse que el umbral de cloruros que indica como posible el desarrollo de corrosión se encuentra entre 0,4-1,0\% lo que corresponde con otros valores ya indicados.

Otras fuentes indican que se puede tomar como concentración crítica de cloruros que provoca el inicio de la corrosión, el 0,4\% en peso de cemento, y como concentración crítica de cloruros que hay en el momento en que la corrosión se ha propagado lo suficiente como para iniciar la fisuración y desprendimiento del recubrimiento del hormigón, el 1\% en peso de cemento ${ }^{1,21}$.

En la limitación de la concentración crítica de cloruros los modelos deterministas iniciales asignan un valor único pero en el momento actual se manejan modelos probabilistas que consideran la variabilidad de todos los parámetros de la Ley de Fick (incluyendo el umbral de cloruros). En el punto 4.4.3 "Modelos de difusión" desarrollado dentro del cuerpo principal de la tesis se detallan estos aspectos.

\subsubsection{Influencia de la relación a/c}

La tabla 2 muestra el estudio de la influencia de la relación a/c en la concentración crítica de cloruros en hormigón sin adiciones. Se observa que la reducción de la relación a/c ocasiona una disminución de la concentración crítica de cloruros.

\begin{tabular}{|c|c|c|}
\hline Exposición & Relación a/c & Media (\% cemento) \\
\hline \hline \multirow{3}{*}{ Saturado (sumergido) } & 0,5 & 1,5 \\
\cline { 2 - 3 } & 0,4 & 2,0 \\
\cline { 2 - 3 } & 0,3 & 2,2 \\
\hline \hline \multirow{3}{*}{ Otros } & 0,5 & 0,5 \\
\cline { 2 - 3 } & 0,4 & 0,6 \\
\cline { 2 - 3 } & 0,3 & 0,7 \\
\hline
\end{tabular}

Tabla.2. Influencia del ambiente de exposición y de la relación a/c sobre la concentración crítica de cloruros $^{1,16}$. 


\subsubsection{Influencia del Ambiente de exposición}

En la tabla 3 se establecen las concentraciones críticas de cloruros de acuerdo con algunos autores según la relación a/c, el ambiente de exposición y el contenido de adiciones (cenizas volantes y humo de sílice):

\begin{tabular}{|c||c||c||c||c||c|}
\hline \hline a/c & Tipo de ambiente & OPC & $\mathbf{2 0 \% C V}$ & $\mathbf{5 \%}$ HS & $\mathbf{1 0 \%}$ HS \\
\hline \hline \multirow{3}{*}{0,3} & Sumergido & 2,2 & 1,4 & 1,6 & 1,2 \\
\cline { 2 - 5 } & Carrera de Mareas & 1,0 & 0,5 & 0,6 & 0,4 \\
\cline { 2 - 6 } & Aéreo & 1,2 & 0,5 & 0,7 & 0,5 \\
\hline \hline \multirow{3}{*}{0,4} & Sumergido & 2,0 & 1,2 & 1,5 & 1,0 \\
\cline { 2 - 6 } & Carrera de Mareas & 0,8 & 0,4 & 0,5 & 0,3 \\
\cline { 2 - 6 } & Aéreo & 1,0 & 0,4 & 0,5 & 0,3 \\
\hline \multirow{3}{*}{0,5} & Sumergido & 1,5 & 0,7 & 1,0 & 0,6 \\
\cline { 2 - 6 } & Carrera de Mareas & 0,6 & 0,3 & 0,4 & 0,2 \\
\cline { 2 - 6 } & Aéreo & 0,6 & 0,3 & 0,4 & 0,2 \\
\hline
\end{tabular}

Tabla.3. Concentración crítica de cloruros según ambiente de exposición, a/c y empleo o no de adiciones $^{1,18}$.

Para analizar la influencia de cada una de estas variables (relación a/c, ambiente de exposición y contenido de adiciones) se plantean los siguientes diagramas de barras:

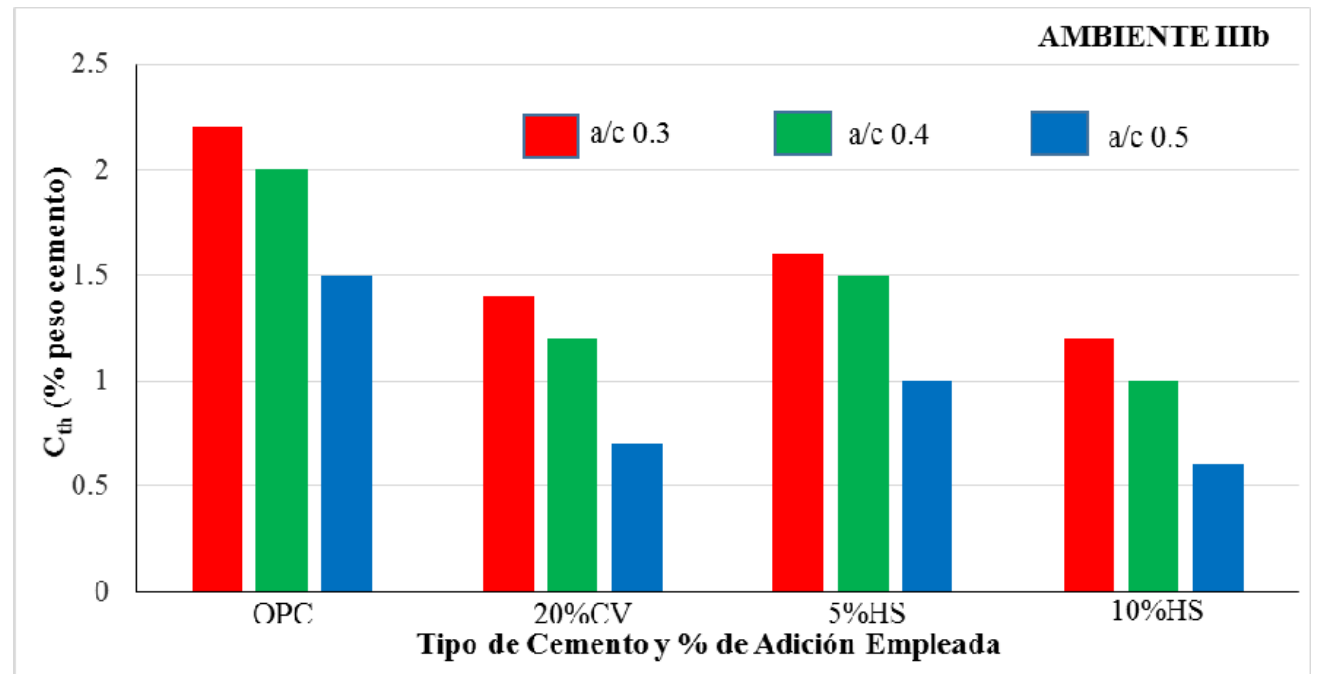

Fig.1. Cth según a/c y contenido de adiciones. Ambiente Sumergido. 


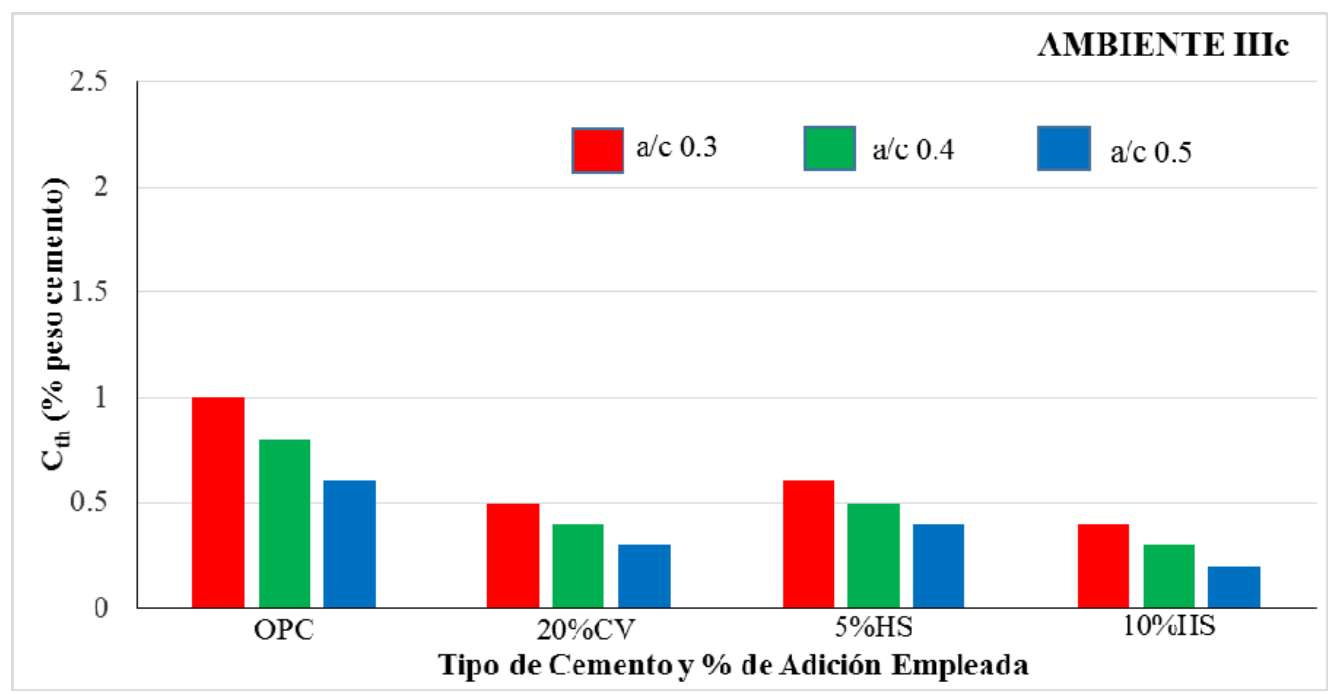

Fig.2. Cth según a/c y contenido de adiciones. Ambiente Carrera de Mareas.

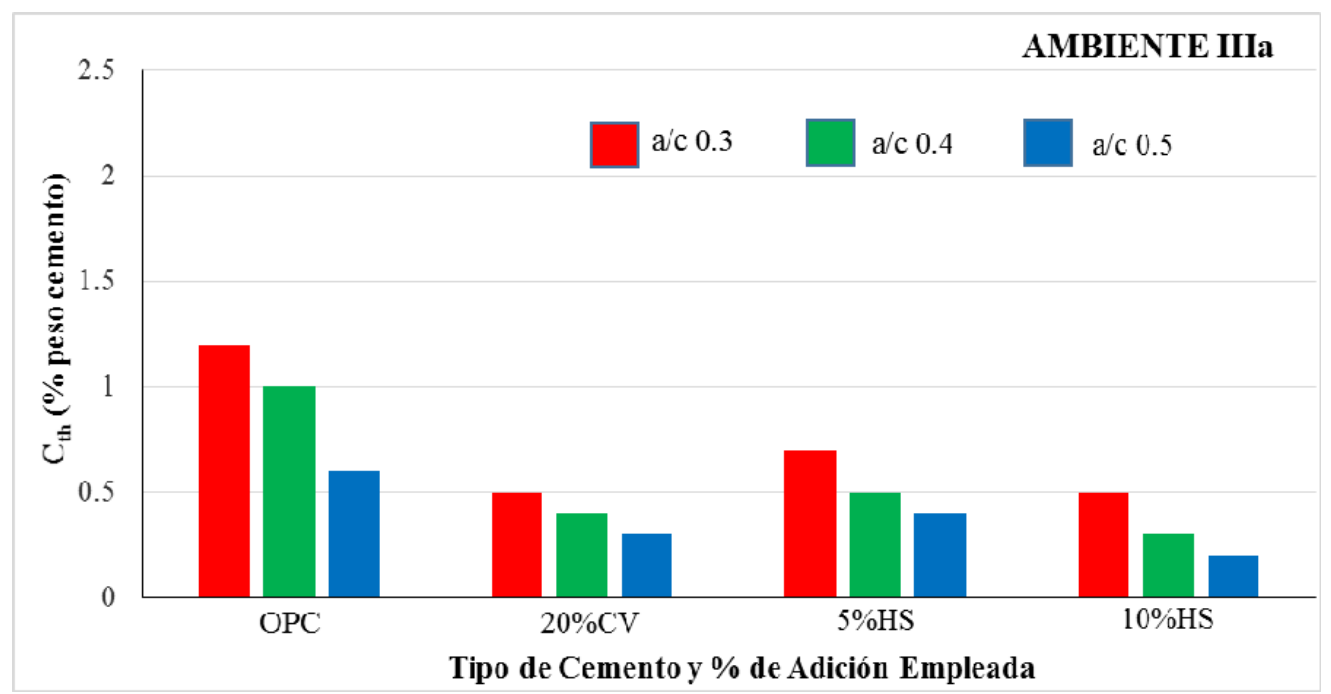

Fig.3. $C_{t h}$ según a/c y contenido de adiciones. Ambiente Aéreo.

Se observa en los gráficos que el factor más influyente en la concentración crítica de cloruros es el ambiente. Así, los valores de $\mathrm{C}_{\text {th }}$ mayores se dan en ambiente IIIb (sumergido), es decir se requiere un mayor contenido de cloruros para iniciar la corrosión. Esto resulta coherente puesto que en el ambiente sumergido los poros del hormigón se encuentran saturados de agua lo cual impide que entre el aire y se favorezca el inicio de la corrosión. Para el caso de los otros dos ambientes Illa y Illc (aéreo y carrera de mareas), los valores son muy similares.

Respecto a la relación a/c, puede observarse que a medida que aumenta su valor (por tanto, disminuye la calidad del hormigón) la concentración crítica de cloruros disminuye, es decir se requiere menor cantidad de $\mathrm{Cl}^{-}$para iniciar la corrosión en hormigones de relación a/c mayores. En general, el salto en el valor del umbral de cloruros es mayor al 
reducir la relación a/c de 0,5 a 0,4, reducir a 0,3 supone ya menores aumentos en el valor de $\mathrm{C}_{\text {th }}$.

En cuanto al empleo de las adiciones, su inclusión en el hormigón reduce el valor del umbral de cloruros respecto del hormigón fabricado con cemento portland. En los tres casos puede observarse que la barra correspondiente a OPC (hormigón sin adiciones) y de relación a/c 0,5 tiene valores similares a los obtenidos empleando $20 \%$ de cenizas volantes o 5\% de humo de sílice habiendo reducido también las relaciones a/c a 0,3-0,4. Esto se corresponde con lo expuesto por otros autores, que dicen que el contenido de cloruros tolerable para iniciar la corrosión disminuye al aumentar el contenido de cenizas volantes y esto podría eliminar en parte las ventajas de las cenizas de disminuir la difusión de cloruros en el hormigón.

\subsubsection{Influencia de las adiciones}

Ya se ha visto en el apartado anterior que la presencia de adiciones reduce el valor de la concentración crítica de cloruros. Otros resultados que también lo confirman se muestran en la tabla 4.

En dicha tabla puede observarse la reducción sustancial que experimenta el umbral de cloruros al incorporar en el hormigón cenizas volantes.

\begin{tabular}{|c||c||c||c|c|}
\hline Contenido de cenizas volantes (\%) & 0 & 15 & 30 & 50 \\
\hline \hline Concentración crítica de cloruros (\%) & 0,70 & 0,65 & 0,50 & 0,20 \\
\hline
\end{tabular}

Tabla.4. Concentración crítica de cloruros según contenido de cenizas volantes empleado ${ }^{1,19}$

Cabe señalar que el artículo 30 de la normativa EHE $08^{5}$ indica la limitación en el empleo de adiciones. Así en el caso de elementos no pretensados, la cantidad máxima de cenizas volantes adicionadas no podrá exceder del 35\% en peso de cemento y del $10 \%$ en peso de cemento en el caso del humo de sílice. En el caso de elementos pretensados, los límites no podrán superar el $20 \%$ y el $10 \%$ respectivamente. Y en el caso de hormigón de alta resistencia donde se requiera la adición simultánea de cenizas volantes y humo de sílice, el porcentaje total de adiciones empleadas no debe superar el $20 \%$ siendo el porcentaje de humo de sílice inferior al 10\%. En todos los casos, los porcentajes se expresan en peso de cemento.

\subsubsection{Influencia del tipo de acero}

El acero normal presenta un umbral de $0,74 \mathrm{~kg} \mathrm{Cl} / \mathrm{m}^{3}\left(0,25 \% \mathrm{Cl}^{-}\right.$en peso de cemento), mientras que para el acero inoxidable tipo 304 o el tipo 316, los umbrales de cloruros son de $11 \mathrm{~kg} \mathrm{Cl} / \mathrm{m}^{3}$ (3,67\% $\mathrm{Cl}$ en peso de cemento) y $18 \mathrm{~kg} \mathrm{Cl} / \mathrm{m}^{3}$ (6\% $\mathrm{Cl}^{-}$en peso de 
cemento), respectivamente. Una ventaja del acero inoxidable es que su umbral de cloruros supera los valores de las concentraciones de cloruros en superficie observados en puentes en Oregón ${ }^{3,8}$ por lo que en estos casos no debería existir corrosión por cloruros.

En el citado estudio realizado sobre puentes expuestos a ambiente marino en Oregón $\mathrm{n}^{3,8}$ se indica que numerosas fuentes consultadas han mostrado valores de umbral de cloruros comprendidos entre $0,6-1,2 \mathrm{~kg} \mathrm{Cl} / \mathrm{m}^{3}$ (0,2-0,4\% $\mathrm{Cl}^{-}$en peso de cemento). Una estimación frecuentemente empleada de umbral de cloruros es el $0,2 \% \mathrm{Cl}^{-}$del peso de cemento, que equivaldría a unos $0,74 \mathrm{~kg} \mathrm{Cl} / \mathrm{m}^{3}$. Esta estimación conservadora se empleó en este estudio para ilustrar el efecto de los cloruros en la corrosión de las armaduras.

Otro estudio ${ }^{3,9}$ concluye que los umbrales de cloruros para aceros de armar especiales se obtienen multiplicando a los de acero al carbono por los siguientes factores: 2,5 para acero galvanizado (Yeomans 2004), 10,4 para acero inoxidable (Clemena 2003) y 3,5 para acero tratado con cromo (Darwin et al. 2002). En la tabla 5 se muestran los valores mínimo, máximo y la moda de una distribución de datos recogidos para distintos aceros:

\begin{tabular}{|c|c|c|c|}
\hline Tipo de Acero & Mínimo $\left(\mathrm{kg} / \mathrm{m}^{3}\right)$ & Máximo $\left(\mathrm{kg} / \mathrm{m}^{3}\right)$ & Moda $\left(\mathrm{kg} / \mathrm{m}^{3}\right)$ \\
\hline Al carbono & 0,39 & 6,26 & 1,4 \\
\hline Galvanizado & 0,975 & 15,6 & 3,5 \\
\hline Inoxidable & 4,06 & 65,0 & 14,6 \\
\hline Tratado con Cromo & 1,36 & 21,9 & 4,9 \\
\hline
\end{tabular}

Tabla.5. Valores estadísticos de distribución de datos para distintos tipos de aceros ${ }^{3,9}$. 


\section{2.-CONCLUSIONES ALCANZADAS EN EST. CEDEX REALIZADO EN AMB. Illb y} IIIC $^{1,2}$

La concentración crítica de cloruros depende fundamentalmente del ambiente marino de exposición y en menor medida, del tipo de cemento. Los cementos con bajo contenido de $\mathrm{AC}_{3}$ (por lo tanto, con menor capacidad de fijación de cloruros) se asocian a concentraciones críticas inferiores. Por esta razón, los resultados más conservadores corresponderían a cementos SR, MR (siempre utilizados en estructuras en contacto con agua de mar) o bien a cementos con altos contenidos de adición.

En cuanto a la influencia del ambiente marino, éste es un factor determinante en el umbral de cloruros. Así, en estudios previos del CEDEX ${ }^{1,2}$ se observa que en los hormigones situados en zona sumergida las armaduras no presentan síntomas de corrosión, a pesar de que los contenidos de cloruros medidos a esa profundidad varían entre el 1,34 y el $1,81 \%$ en peso de cemento. Por lo tanto, en ambiente marino sumergido la concentración crítica de cloruros debe ser al menos superior al 1,8\% en peso de cemento, para aceros AEH-500S y cementos tipo SR. Este valor es semejante al apuntado por autores consultados en la bibliografía ${ }^{16}$, que lo sitúan entre el 1,5 y el $2 \%$ en función de la relación a/c, para hormigones sin adiciones.

En el hormigón analizado en zona de carrera de mareas, se han encontrado armaduras sin corrosión con contenidos de cloruros en el hormigón de hasta el 1,06\% en peso de cemento para cementos Portland y $0,96 \%$ para cemento con escorias (por lo que el valor de $0,6 \%$ indicado en la normativa podría considerarse conservador en este ambiente). En los artículos consultados $8,25,26$ sobre estructuras de hormigón armado situadas en zona de carrera de mareas y con síntomas de corrosión, los contenidos de cloruros al nivel de las armaduras eran de al menos el 1,07\% en peso de cemento. Por lo tanto, éste debe ser un valor muy aproximado de la concentración crítica de cloruros, que se podría situar en torno al 1,0\% en peso de cemento, para hormigones situados en zona de carrera de mareas.

En conclusión, los resultados indican umbrales de corrosión que pueden considerarse conservadores del 1,8\% y el $1 \%$ (expresados en peso de cemento) en ambiente sumergido y de carrera de mareas, respectivamente.

\section{3.-ASPECTOS NORMATIVOS}

En general, las normativas internacionales y en particular, la Instrucción EHE-08 española recogen una limitación al contenido inicial de cloruros que pueden presentar los componentes del hormigón, así como el valor de la concentración crítica de cloruros que provoca el inicio del mecanismo de la corrosión. 


\subsubsection{Concentración inicial de cloruros}

Así, según el artículo 31 de la Instrucción EHE 085 , los componentes del hormigón deben cumplir que el ión cloruro no exceda el 0,2\% en peso de cemento en el caso de las obras de hormigón pretensado y el $0,4 \%$ en peso de cemento en obras de hormigón armado u obras de hormigón en masa que contenga armaduras para reducir la fisuración, tal y como se indica en la tabla 6:

\begin{tabular}{|c|c|}
\hline Tipo de hormigón & Ion cloro total (\%) \\
\hline Armado & $\leq 0,4$ \\
\hline Pretensado & $\leq 0,2$ \\
\hline
\end{tabular}

Tabla.6.Contenido total ión cloro en el hormigón ${ }^{5}$.

En este sentido, la norma europea EN 206-1 ${ }^{15}$ establece unos límites de contenido inicial de cloruros divididos en clases, entre las cuales se encuentran los valores recogidos por la norma española, según indica la tabla 7:

\begin{tabular}{|c|c|c|}
\hline Uso del hormigón & Clase de contenido de $\mathrm{Cl}^{(1)}$ & $\begin{array}{l}\text { Contenido máximo de } \mathrm{Cl} \text { en } \\
\text { relación a la masa de cemento }\end{array}$ \\
\hline $\begin{array}{c}\text { Sin armaduras de acero ni } \\
\text { piezas metálicas embebidas con } \\
\text { la excepción de elementos de } \\
\text { elevación resistentes a la } \\
\text { corrosión }\end{array}$ & $\mathrm{Cl} 1,0$ & $1,0 \%$ \\
\hline \multirow{2}{*}{$\begin{array}{l}\text { Con armaduras de acero o } \\
\text { piezas metálicas embebidas }\end{array}$} & $\mathrm{Cl} \mathrm{0,2}$ & $0,2 \%$ \\
\hline & $\mathrm{Cl} \mathrm{0,4}$ & $0,4 \%$ \\
\hline \multirow{2}{*}{$\begin{array}{c}\text { Con armaduras de acero de } \\
\text { pretensado }\end{array}$} & Cl 0,1 & $0,1 \%$ \\
\hline & $\mathrm{Cl} \mathrm{0,2}$ & $0,2 \%$ \\
\hline
\end{tabular}

Tabla.7. .Limites contenido cloruros según EN 206-1 2000"15.

(1) Para un determinado uso del hormigón la clase a aplicar depende de las disposiciones válidas en el lugar de uso del hormigón.

(2) Cuando se hayan utilizado adiciones del tipo II y se hayan tenido en cuenta en el contenido de cemento, el contenido de cloruros se expresará como el porcentaje en masa de iones cloruros en relación a la masa de cemento más la masa total de adiciones que hayan sido tenidas en cuenta.

La separación en clases puede permitir escoger valores para condiciones de exposición del hormigón diferentes. Así, puede ser conveniente aplicar valores menores en ciertas condiciones, tales como humedades relativas permanentemente altas, regímenes higrométricos no estacionarios o con un hormigón carbonatado.

El Código de Requisitos para Hormigón Estructural, $\mathrm{ACl} 318-08^{23}$ define categorías y clases de exposición, entre ellas la clase C relacionada con el riesgo de corrosión por cloruros, como se indica en la tabla 8: 


\begin{tabular}{|c||c|c||c||}
\hline Categoría & Severidad & Clase & Condición \\
\hline \hline \multirow{2}{*}{ C } & No Aplicable & C0 & Hormigón seco o protegido de la humedad \\
\cline { 2 - 4 } & Moderada & C1 & $\begin{array}{r}\text { Hormigón expuesto a humedad pero no a } \\
\text { fuente externa de cloruros }\end{array}$ \\
\cline { 2 - 4 } & Severa & C2 & $\begin{array}{c}\text { Hormigón expuesto a humedad y a fuente } \\
\text { externa de cloruros ya sean productos químicos } \\
\text { descongelantes, sal, agua salobre, agua de mar } \\
\text { o salpicaduras de mismo origen }\end{array}$ \\
\hline \hline
\end{tabular}

Tabla.8.Categoría C extractada de la tabla de definición de categorías y clases del ACI 318-08 ${ }^{23}$.

Los límites de cloruros presentes en el hormigón para la clase C2 (ambiente marino) se recogen en la tabla 9:

\begin{tabular}{|c||c|c||}
\hline \multirow{2}{*}{ Clase de Exposición } & \multicolumn{2}{c|}{$\begin{array}{c}\text { Contenido máximo iones Cl'solubles en agua (\% peso } \\
\text { cemento) }\end{array}$} \\
\hline \hline \multirow{2}{*}{ C2 } & Hormigón Armado & Hormigón Pretensado \\
\cline { 2 - 3 } & 0,15 & 0,06 \\
\hline
\end{tabular}

Tabla.9.Contenido iones cloruro para clase C2 según ACI 318-08²3.

Asimismo, el ACl 201R31 (Guía sobre durabilidad del hormigón) y el ACl 222R30 (Factores que influyen en la corrosión) establecen los contenidos máximos de ión cloruro solubles en ácido y en agua (tabla 10), siendo coincidentes con lo recogido por el ACl 318 en la Tabla 9.

\begin{tabular}{|c|c|c|}
\hline Tipo de hormigón y condición & $\begin{array}{c}\text { Solubles en ácido } \\
\text { ASTM C 1152 }\end{array}$ & $\begin{array}{c}\text { Solubles en agua } \\
\text { ASTM C 1218 }\end{array}$ \\
\hline \hline Hormigón pretensado & 0,08 & 0,06 \\
\hline H. armado en ambiente húmedo & 0,10 & 0,08 \\
\hline H. armado en ambiente seco & 0,20 & 0,15 \\
\hline
\end{tabular}

Tabla.10. .Limites contenido cloruros según ACI $201 R^{31}$ y ACI222R ${ }^{30}$.

A modo de resumen, la tabla 11 recoge a continuación límites del contenido inicial de cloruros expresado en $\%$ en peso de cemento de acuerdo con varias fuentes internacionales consultadas $2,10,11,13,14$ : 


\begin{tabular}{|c||c||}
\hline Fuente & $\begin{array}{c}\text { Solubles en Acido (Cl totales en \% } \\
\text { peso cemento) }\end{array}$ \\
\hline EHE 08 (H.A./H.P.) & $\leq 0,4 / \leq 0,2$ \\
\hline EN 206-1 & $0,20-0,40 / 0,10-0,20$ \\
\hline ACI 222 R (H.A./H.P.) & $0,10-0,20^{(1)} / 0,08$ \\
\hline CP 110 British Code & $0,35^{(2)}$ \\
\hline NS 3420 L (H.A./H.P.) & $0,6 / 0,002$ \\
\hline ACI 357 R (H.A./H.P.) & $0,1 / 0,06$ \\
\hline Technical Standards for Port and Harbour & $<0,1^{(3)}$ \\
\hline Facilities in Japan & $<0,1 /<0,2^{(4)}$ \\
\hline Universidad de Kyoto & . \\
\hline Tabla.11. Umbraldectoros segun
\end{tabular}

Tabla.11. Umbral de cloruros según diversas fuentes internacionales.

(1) Diferencia entre hormigón armado en ambiente húmedo $(0,10)$ y en ambiente seco $(0,20)$.

(2) Con un $95 \%$ de los resultados de los ensayos no superior a $0,50 \%$.

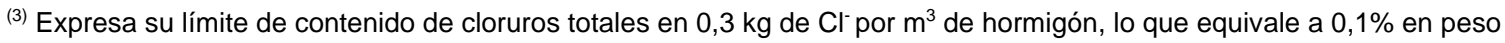
de cemento para hormigones con $300 \mathrm{~kg}$ de cemento por $\mathrm{m}^{3}$.

${ }^{(4)}$ Expresa su límite de contenido de cloruros totales en $0,3 \mathrm{~kg}$ de $\mathrm{Cl}^{-}$por $\mathrm{m}^{3}$ de hormigón para hormigones armados que precisen una durabilidad especialmente elevada, para hormigones pretensados con sistemas de postesado sometido a la acción de cloruros y para hormigones pretensado con sistemas de pretesado; 0,6 $\mathrm{kg} \mathrm{de} \mathrm{Cl}^{-}$por $\mathrm{m}^{3}$ para hormigón armado y para pretensado con sistemas de postesado. Si seguimos la equivalencia anterior de $300 \mathrm{~kg}$ de cemento por $\mathrm{m}^{3} \mathrm{de}$ hormigón serían $0,1 \%$ y $0,2 \%$ respectivamente.

\subsubsection{Concentración crítica de cloruros}

En el anejo $n^{\circ} 9$ relativo a durabilidad de la Instrucción EHE $08^{5}$, se indica que la concentración crítica de cloruros $\left(\mathrm{C}_{\mathrm{th}}\right)$ deberá ser establecida por el autor del proyecto de acuerdo con las consideraciones específicas de la estructura. En condiciones normales, puede adoptarse un valor de $0,6 \%$ en peso de cemento para el caso de corrosión de armaduras pasivas y en el caso de armaduras activas, puede adoptarse un valor límite de $0,3 \%$ en peso de cemento.

El estudio noruego de las plataformas del mar del Norte ${ }^{4}$ asigna el límite de $0,07 \% \mathrm{Cl}^{-}$en peso de hormigón siguiendo las recomendaciones del fib bulletin $34^{6}$ con una probabilidad asociada de presentar despasivación del 10\% y según Alonso ${ }^{22}$, como una probabilidad entre $10-15 \%$. La concentración crítica de cloruros para el inicio de la corrosión activa del acero se asume normalmente como una variable independiente de los parámetros que gobiernan la penetración de cloruros ( $C_{S}$, D y recubrimiento).

En este sentido, el fib bulletin ${ }^{6}$ en su apartado B.2.2.6 "Contenido Crítico de Cloruros" define el umbral de cloruros como el contenido de cloruros que produce la despasivación de la superficie de la armadura y el inicio de su disolución independientemente de si conlleva daños por corrosión visibles en la superficie del 
hormigón. El límite mínimo de la variable $\mathrm{C}_{\text {crit }}$ se especifica como $0,2 \%$ en peso de cemento y el valor medio de $\mathrm{C}_{\text {crit }}$ como $0,6 \%$ en peso de cemento. Dado que el límite inferior de la función es conocido y difiere de 0 , según el fib, resulta recomendable emplear una distribución restringida para la descripción del $\mathrm{C}_{\text {crit }}$ que produce la corrosión. Así pues, se establece una distribución beta con un límite inferior de 0,2\%, $m=0,6, s=0,15, a=0,2$ y $b=2,0$.

En la tabla 12 se presenta la concentración crítica expresado en \% en peso de cemento que provoca el inicio de la corrosión recogido en diferentes normativas ${ }^{2,20}$.

\begin{tabular}{||c||c||}
\hline Norma/Autor & Solubles en Ácido \\
\hline \hline BS 8110 & 0,40 \\
\hline Normas Australianas & 0,60 \\
\hline RILEM & 0,40 \\
\hline Normas Noruegas & 0,60 \\
\hline
\end{tabular}

Tabla.12. Concentraciones críticas de Cloruros expresados en $\mathrm{Cl}$ solubles en agua y ácido.

El $\mathrm{ACl}$ 318-08 sólo recoge valores límite del contenido inicial de cloruros, tal como se ha descrito en el apartado anterior, pero no sobre umbral de cloruros. De igual manera ocurre en las normativas americanas específicas sobre durabilidad $\mathrm{ACl} 201.2 \mathrm{R}-08^{31}$ y $\mathrm{ACl} 365.1 \mathrm{R}-00^{30}$.

Los estudios realizados en Japón ${ }^{7}$ han obtenido en las inmediaciones de las armaduras una concentración de cloruros que podría iniciar su corrosión en el entorno de 0,3-0,6 $\mathrm{kg} / \mathrm{m}^{3}$ en el caso de ensayos acelerados realizados con cloruros añadidos a la mezcla de hormigón fresco, mientras que para el caso de ensayos de exposición llevados a cabo en campo, los valores registrados son 1,2-2,4 kg/m ${ }^{3}$. Dado que la corrosión de la armadura también depende del aporte de oxígeno y del propio hormigón, este rango estará influenciado por el recubrimiento, la red de poros y la humedad. Estas diferencias entre los valores de la concentración crítica de cloruros pueden atribuirse a factores como las diferentes relaciones $\mathrm{a} / \mathrm{c}$ en los hormigones ensayados, el espesor de recubrimientos empleados, etc. Las altas temperaturas empleadas en los ensayos acelerados también pueden ser un factor a tener en cuenta.

Considerando todo lo expuesto anteriormente, las especificaciones japonesas establecen un límite de $1,2 \mathrm{~kg} / \mathrm{m}^{3}$ (cloruros por metro cúbico de hormigón) como la concentración crítica de cloruros que podría provocar corrosión en armaduras. Esto se correspondería con los límites ya expuestos, dado que si consideramos $2400 \mathrm{~kg} / \mathrm{m}^{3}$ como densidad del hormigón se obtendría un valor de $0,4 \% \mathrm{Cl}$ en peso de cemento si el contenido de cemento por $\mathrm{m}^{3}$ de hormigón fuera de $300 \mathrm{~kg}$. 


\section{OBJETIVOS}

Tras la revisión bibliográfica anterior, en el presente estudio se pretenden analizar los valores de concentración crítica de cloruros experimentales obtenidos en los distintos ambientes marinos que plantea la Instrucción EHE 08: Illa (Aéreo), Illb (Sumergido) y IIlc (Carrera de Mareas y Salpicaduras) y compararlos con los límites que propone dicha normativa con el fin de contrastar valores prácticos reales con los teóricos para establecer si tales límites resultan acordes.

\section{RESULTADOS}

Como punto de partida, la tabla 13 recoge los valores de $C_{s}, D_{1}$ y $C_{\text {th }}$ pertenecientes al estudio realizado en ambiente sumergido ${ }^{1,2}$; la tabla 14 aporta los datos de $C_{\mathrm{s}}, \mathrm{D}_{1}$ y $\mathrm{C}_{\text {th }}$ relativos al estudio llevado a cabo en ambiente de carrera de mareas ${ }^{1,2}$ y la tabla 15 , los correspondientes al ambiente de exposición aéreo ${ }^{3,24}$.

\begin{tabular}{|c|c|c|c|c|c|}
\hline $\begin{array}{c}\text { Muelles } \\
\text { MAB }\end{array}$ & Muestra & Designación & $\begin{array}{c}\mathrm{C}_{\mathrm{S}}\left({ }^{* *}\right) \\
\text { (\%p.hormigón) }\end{array}$ & $D_{1} 10^{-8}\left(\mathrm{~cm}^{2} / \mathrm{s}\right)$ & $\begin{array}{c}\mathrm{C}_{\text {th }}(\% \\
\text { p.cemento })\end{array}$ \\
\hline \multirow{3}{*}{ A (IIIb) } & A1-A2 & 67 & 0,2932 & 35,7 & $2,05^{(*)}$ \\
\hline & A3-A4 & 68 & 0,1802 & 48,1 & $1,81 \mathrm{no}^{(*)}$ \\
\hline & A5-A6 & 69 & 0,0881 & 34,4 & $1,49 \mathrm{no}^{(*)}$ \\
\hline \multirow{3}{*}{ B (IIIb) } & B1-B2 & 70 & 0,3257 & 30,5 & $1,34 \mathrm{no}^{(*)}$ \\
\hline & B3 & 71 & 0,6498 & 29,8 & -- \\
\hline & B4-B5 & 72 & 0,4566 & 41,2 & $1,24^{(*)}$ \\
\hline \multirow{3}{*}{ C (IIIb) } & C1-C2 & 73 & 0,2533 & 16,5 & 0,35 no \\
\hline & C3-C4 & 74 & 0,0893 & 28,2 & $1,50^{(*)}$ \\
\hline & C5-C6 & 75 & 0,5426 & 27,7 & $2,67^{(*)}$ \\
\hline
\end{tabular}

Tabla 13 Valores Cs, D y $C_{x}$ medidos en ambiente sumergido ${ }^{1,2}$.

$\left.{ }^{(}\right)$Concentración de cloruros estimada a partir de la extrapolación del perfil de cloruros y suponiendo un recubrimiento de $4 \mathrm{~cm}$.

$\left.{ }^{\star *}\right)$ En los muelles localizados en ambiente sumergido no se midió el contenido de cloruros en superficie por falta de accesibilidad; por esta razón se consideran los valores teóricos como calculados por extrapolación del perfil de cloruros. 


\begin{tabular}{|c|c|c|c|c|c|}
\hline $\begin{array}{c}\text { Muelles } \\
\text { MAB }\end{array}$ & Muestra & Designación & $\begin{array}{c}\mathrm{C}_{\mathrm{s}} \\
\text { (\%p.hormigón) }\end{array}$ & $\begin{array}{l}D_{1} 10^{-8} \\
\left(\mathrm{~cm}^{2} / \mathrm{s}\right)\end{array}$ & $\mathrm{C}_{\mathrm{th}}(\%$ p.cemento $)$ \\
\hline \multirow{3}{*}{ D (IIIc) } & D1 & 23 & 0,4842 & 26,7 & $1,79 \mathrm{si}$ \\
\hline & $\mathrm{D} 2$ & 24 & 0,4807 & 9,2 & 1,68 \\
\hline & D3 & 25 & 0,4944 & 29,3 & $1,43 \mathrm{si}$ \\
\hline \multirow{4}{*}{ E (IIIc) } & E1 & 26 & $0,3258^{(*)}$ & 55,4 & 1,59 \\
\hline & E2 & 27 & 0,2034 & 61,3 & 1,12 \\
\hline & E3 & 28 & 0,4343 & 58,2 & 1,06 no \\
\hline & E4 & 29 & 0,2471 & 44,7 & 1,36 \\
\hline \multirow{7}{*}{ F (IIIc) } & F1 & 30 & 0,6620 & 8,5 & $1,1,69$ \\
\hline & F2 & 31 & 0,5803 & 8,1 & 1,30 \\
\hline & F3 & 32 & 0,4514 & 12,2 & 1,26 \\
\hline & F4 & 33 & 0,4679 & 3,7 & 0,27 \\
\hline & F6 & 34 & 0,5948 & 5,1 & 1,95 \\
\hline & F7 & 35 & 0,6500 & 8,2 & $1,63 \mathrm{si}$ \\
\hline & F8 & 36 & 0,7340 & 11,5 & $1,21 \mathrm{si}$ \\
\hline \multirow{4}{*}{ G (IIIc) } & G1 & 37 & 0,3577 & 12,8 & 1,04 \\
\hline & G2 & 38 & 0,5945 & 2,9 & 0,07 \\
\hline & G3 & 39 & 0,5064 & 2,3 & 0,06 no \\
\hline & G4 & 40 & 0,4195 & 3,2 & 0,22 no \\
\hline \multirow{4}{*}{ H (IIIc) } & H1 & 41 & 0,6152 & 8,2 & 0,96 no \\
\hline & $\mathrm{H} 2$ & 42 & 0,3483 & 5,4 & 0,05 no \\
\hline & H3 & 43 & 0,5271 & 5,5 & 0,15 \\
\hline & $\mathrm{H} 4$ & 44 & 0,2910 & 5,6 & 0,09 no \\
\hline \multirow{5}{*}{ I (IIIC) } & I1 & 45 & $0,5010^{(*)}$ & 9,8 & $2,64 \mathrm{si}$ \\
\hline & I2 & -- & $0,6183^{(*)}$ & -- & $4,65 \mathrm{si}$ \\
\hline & I3 & 46 & $0,6244^{(*)}$ & 7,3 & $3,27 \mathrm{si}$ \\
\hline & I4 & 47 & 0,3604 & 8,6 & $2,49 \mathrm{si}$ \\
\hline & I5 & 48 & $0,4493^{(*)}$ & 8,7 & $1,31 \mathrm{si}$ \\
\hline
\end{tabular}

Tabla 14. Valores Cs, $D$ y $C_{t h}$ medidos en ambiente carrera de mareas ${ }^{1,2}$.

${ }^{(*)}$ Concentración de cloruros máxima, que no se alcanza en la rodaja superficial sino en el interior.

Los valores de $\mathrm{C}_{\mathrm{th}}$ recogen el contenido de cloruros a nivel de armadura expresado en $\%$ en peso de cemento y si la armadura encontrada presentaba o no síntomas de corrosión, para poder así analizar cuál es la concentración crítica de cloruros en los testigos estudiados. En los testigos donde no se ha encontrado armadura, simplemente se presenta el contenido de cloruros medido a la profundidad teórica (recubrimiento de proyecto) a la que se encontraría la armadura. 
La tabla 15 recoge los valores de contenido de cloruros en superficie, coeficiente de difusión y concentración crítica de cloruros obtenidos en el presente estudio:

\begin{tabular}{|c|c|c|c|c|c|}
\hline $\begin{array}{c}\text { Muelles } \\
\text { SFG }\end{array}$ & Muestra & Designación & $\begin{array}{c}\mathrm{C}_{\mathrm{S}} \\
\text { (\%p.hormigón) }\end{array}$ & $\begin{array}{l}D_{1} 10^{-8} \\
\left(\mathrm{~cm}^{2} / \mathrm{s}\right)\end{array}$ & $\mathrm{C}_{\text {th }}(\%$ p.cemento $)$ \\
\hline \multirow{4}{*}{ A } & TPS-H1 & 49 & 20,3481 & 1010,59 & $(* *)$ \\
\hline & TPS-H2 & 50 & 0,4617 & 12,24 & $(* *)$ \\
\hline & TPS-H3 & 51 & 0,2798 & 4,74 & 0,650 no \\
\hline & TPS-H4 & 52 & 0,1751 & 1,29 & $<0,140^{(*)}$ no \\
\hline \multirow{8}{*}{ B } & HU-H1 & 53 & 20,0330 & 4,26 & $<0,130^{(*)}$ no \\
\hline & HU-H2 & 54 & 0,0110 & 10,02 & $<0,060^{(*)}$ no \\
\hline & HU-H3 & 55 & 0,1530 & 49,02 & $(* *)$ \\
\hline & HU-H4 & 56 & 0,0050 & 3,73 & $(* *)$ \\
\hline & HU-H5 & 57 & 0,4790 & 9,50 & $(* *)$ \\
\hline & HU-H6 & 58 & 0,1670 & 7,61 & $0,310 \mathrm{si}$ \\
\hline & HU-H7 & 59 & 0,4410 & 11,27 & $1,150 \mathrm{si}$ \\
\hline & HU-H8 & 60 & 0,3280 & 7,02 & $(* *)$ \\
\hline \multirow{6}{*}{$\mathrm{C}$} & AV-T1 & 61 & 0,0639 & 2,14 & $<0,033^{(*)}$ no \\
\hline & AV-T2 & 62 & 0,0833 & 2,64 & $(* *)$ \\
\hline & $\mathrm{AV}-\mathrm{T} 3^{(1)}$ & 63 & 0,4185 & 2,79 & 0,840 no \\
\hline & AV-T4 & 64 & 0,3293 & 2,99 & $<0,027^{(*)}$ no \\
\hline & AV-T5 & 65 & 0,2478 & 2,41 & $1,575 \mathrm{si}$ \\
\hline & AV-T6 & 66 & 0,3583 & 3,97 & $<0,054^{(*)}$ no \\
\hline \multirow{5}{*}{$\mathrm{D}$} & MAV-T1 & 88 & "0,0920 & 5,75 & $<<0,146$ no \\
\hline & MAV-T2 & 89 & 0,0563 & 2,40 & $(* *)$ \\
\hline & MAV-T3 & 90 & 0,0706 & 4,31 & $<0,155$ no \\
\hline & MAV-T4 & 91 & 0,0493 & 4,18 & $(* *)$ \\
\hline & MAV-T5 & 92 & 0,0491 & 4,11 & $<0,075$ no \\
\hline
\end{tabular}

Tabla 15. Valores Cs, D y $C_{\text {th }}$ medidos en ambiente marino aéreo ${ }^{3,24}$.

${ }^{(*)}$ Cuando se indica que el valor de concentración de cloruros a la profundidad $x$ es menor que un valor se debe a que no hay corte del perfil de cloruros con la armadura a tal profundidad y se indica el valor más bajo del perfil.

${ }^{(* *}$ En los puntos en los que no se indica Cth es porque no se dispone de un valor.

${ }^{(1)}$ En el caso de AV-T3 no se dispone de armadura, sólo huella en hormigón sin manchas de corrosión.

\section{ANÁLISIS DE RESULTADOS}

A continuación se muestran las figuras 4,5 y 6, correspondientes a cada ambiente, en las que se representan los resultados de las tablas anteriores: en tonos rojos los datos de las barras con corrosión y en tonos verdes las barras sin síntomas de corrosión. 
Estos gráficos permiten visualizar el rango de valores entre los que se encuentra la concentración crítica de cloruros en cada uno de los ambientes de exposición. Se resaltan también los casos en los que se utilizó un cemento con y sin adiciones.

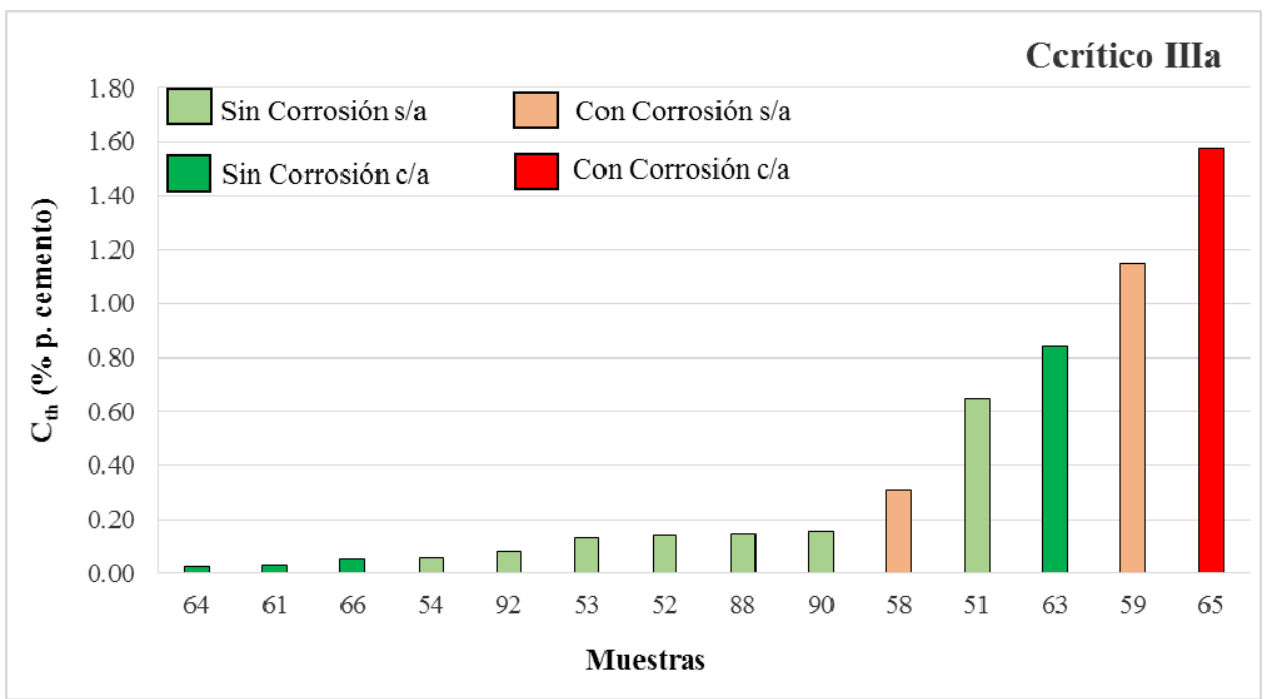

Fig 4. Valores $C_{\text {th }}$ en ambiente IIIa.,24

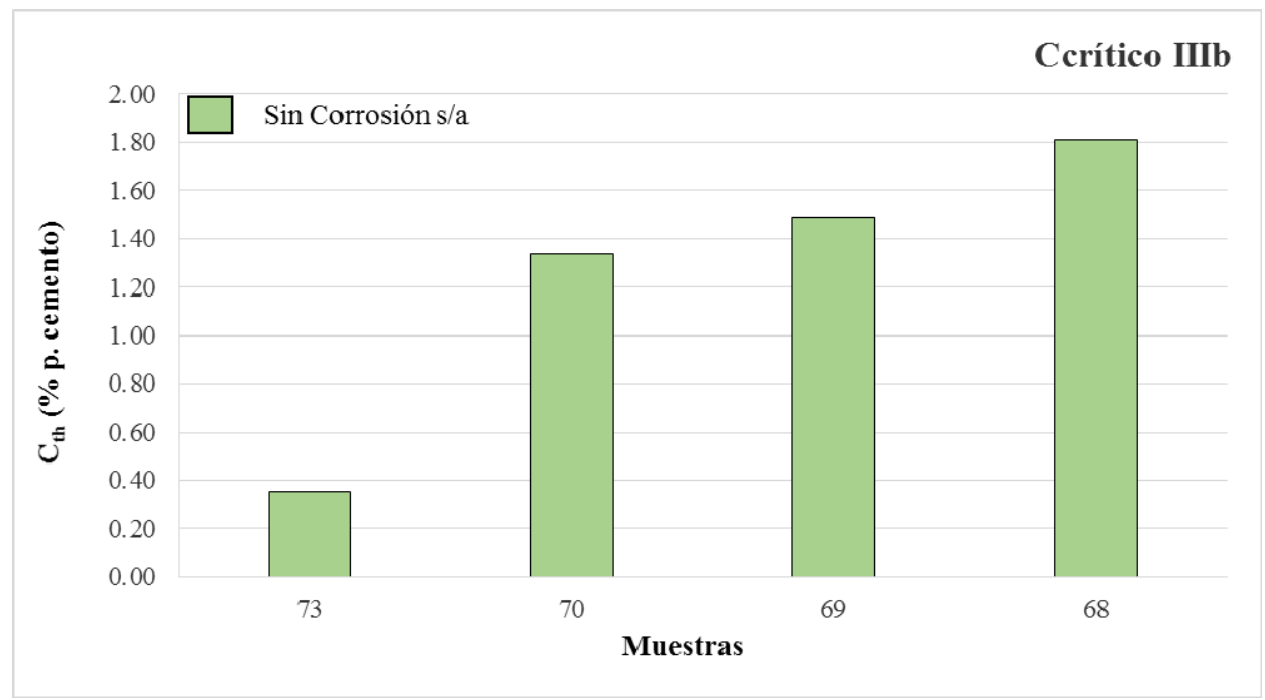

Fig 5. Valores $C_{t h}$ en ambiente $I_{I I b^{2}}$. 


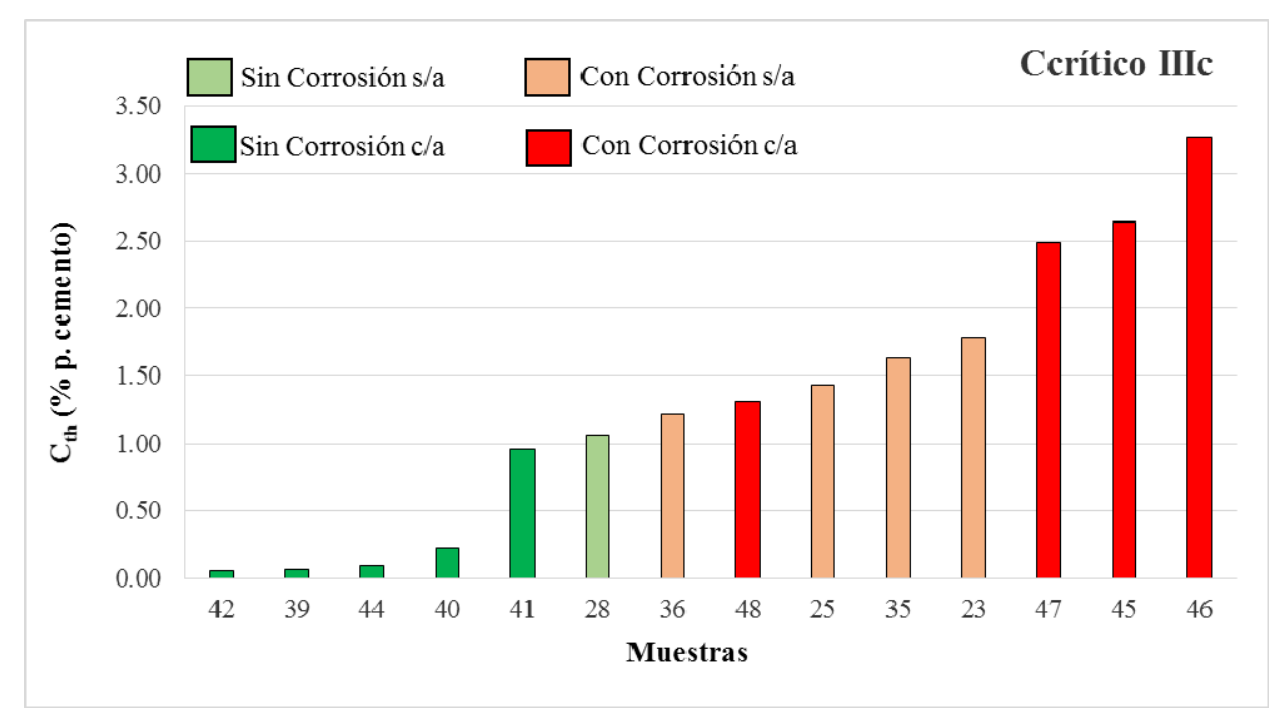

Fig 6. Valores $C_{t h}$ en ambiente III ${ }^{2}$.

Se observa una progresión coherente de valores de cloruros en el caso del ambiente de carrera de mareas (IIIc) (Fig.6), comenzando a aparecer armaduras con corrosión dentro del intervalo de $\mathrm{C}_{\text {th }}=1,06 \%$ y $\mathrm{C}_{\text {th }}=1,21 \%$. Por tanto la investigación realizada ${ }^{1,2}$ concluye que el valor de concentración crítica de cloruros en este ambiente es del $1 \%$ en peso de cemento.

En el caso del ambiente IIlb ninguna de las barras encontradas en los testigos presenta corrosión (Fig.5), por lo que en la investigación realizada ${ }^{1,2}$ se asigna un valor de $\mathrm{C}_{\text {th }}$ del $1,8 \%$ en peso de cemento.

En el presente estudio, los resultados recabados en cuatro muelles en el caso del ambiente IIla mostrados en la Fig.4 muestran una progresión coherente salvo el caso de la muestra 58, con un valor de concentración crítica de cloruros $\mathrm{C}_{\mathrm{th}}=0,31$ y signos de corrosión. Este valor se considera anómalo ya que se encuentra incluso por debajo del contenido inicial de cloruros admisible en el hormigón (0,4\% según EHE-08).

En ninguna de las figuras anteriores se observa un efecto de reducción del umbral de cloruros en hormigones con adiciones, si bien los resultados deben considerarse limitados.

Al objeto de ampliar el número de resultados a la serie obtenida experimentalmente en puertos españoles, se incorporan otros resultados tomados de la literatura mostrados en la tabla 16. 


\begin{tabular}{|c||c|c|}
\hline Ambiente Exposición & Lugar/Obra & $\begin{array}{c}\text { Contenido } \mathbf{C l}^{-} \\
\text {(\%p.cemento) }\end{array}$ \\
\hline \hline Ciclos, Carrera Mareas & Portugal & $1,07-3,06$ \\
\hline Ciclos, Carrera Mareas & Portugal & $1,15-1,45$ \\
\hline Marea Sumergido & Portugal & $1,38-0,99$ \\
\hline Salpicaduras-Marea & Portugal & $1,07-1,30$ \\
\hline Salpicaduras & Portugal & $0,54-0,38$ \\
\hline Atmosférico & Portugal & $0,15-0,65^{(1)}$ \\
\hline Atmosférico & Rocky Point & 1,33 \\
\hline Atmosférico & Rocky Point & 2,33 \\
\hline Atmosférico & Brush Creek & $1,17-2,00$ \\
\hline Marea Sumergido & Muroran & 0,75 \\
\hline Salpicaduras & Sydney & $0,10-0,50^{(2)}$ \\
\hline Salpicaduras & Tay Road & $0,15-0,89^{(3)}$ \\
\hline Ciclos, Carrera Mareas & Dique HA & $1,1-2,3$ \\
\hline
\end{tabular}

Tabla.16. Concentración crítica de cloruros correspondientes a distintas obras reales de la bibliografía $2,8,2526,27,28,29$.

\footnotetext{
(1) El valor siguiente sería $\mathbf{0 , 4 6}$ con dos por debajo

(2) el valor siguiente sería $\mathbf{0 , 5}$ con 2 por debajo.

(3) el valor siguiente sería $\mathbf{0 , 8 2}$ con dos por debajo.
}

En las siguientes figuras se incorporan estos resultados junto con los del estudio CEDEX, adoptando como criterio representar únicamente el valor inferior de cloruros en los que se ha observado corrosión. Las barras representadas en los casos de bibliografía internacional siempre son rojas puesto que en todos los casos se localiza corrosión.

En la figura 7 se muestran los umbrales de cloruros para el ambiente IIla, añadiendo tres datos adicionales extraídos de estructuras internacionales No se han representado los resultados en los que el umbral de cloruros se encontraba por debajo del $0,4 \%$ en peso de cemento propuesto por la normativa española como contenido límite de cloruros inicial en el hormigón armado, ya que no resulta coherente. En particular se han suprimido tres casos:

- Dato de estructura en Portugal $\mathrm{C}_{\mathrm{th}}=0,15 \%$ y $\mathrm{C}_{\mathrm{th}}=0,23 \%$ Se ha representado el primer valor inmediatamente por encima de 0,4\% (0,46\%).

- Muestra 58 estudio CEDEX. En este caso en el que $\mathrm{C}_{\mathrm{th}}=0,31 \%$, la inspección visual del testigo correspondiente ( $\mathrm{HU}-\mathrm{H} 6)$ muestra una corrosión muy leve y no hay mancha en la huella del hormigón, por lo que parece lógico pensar que se trata de una ligera corrosión de la propia armadura previa a la puesta en obra. 


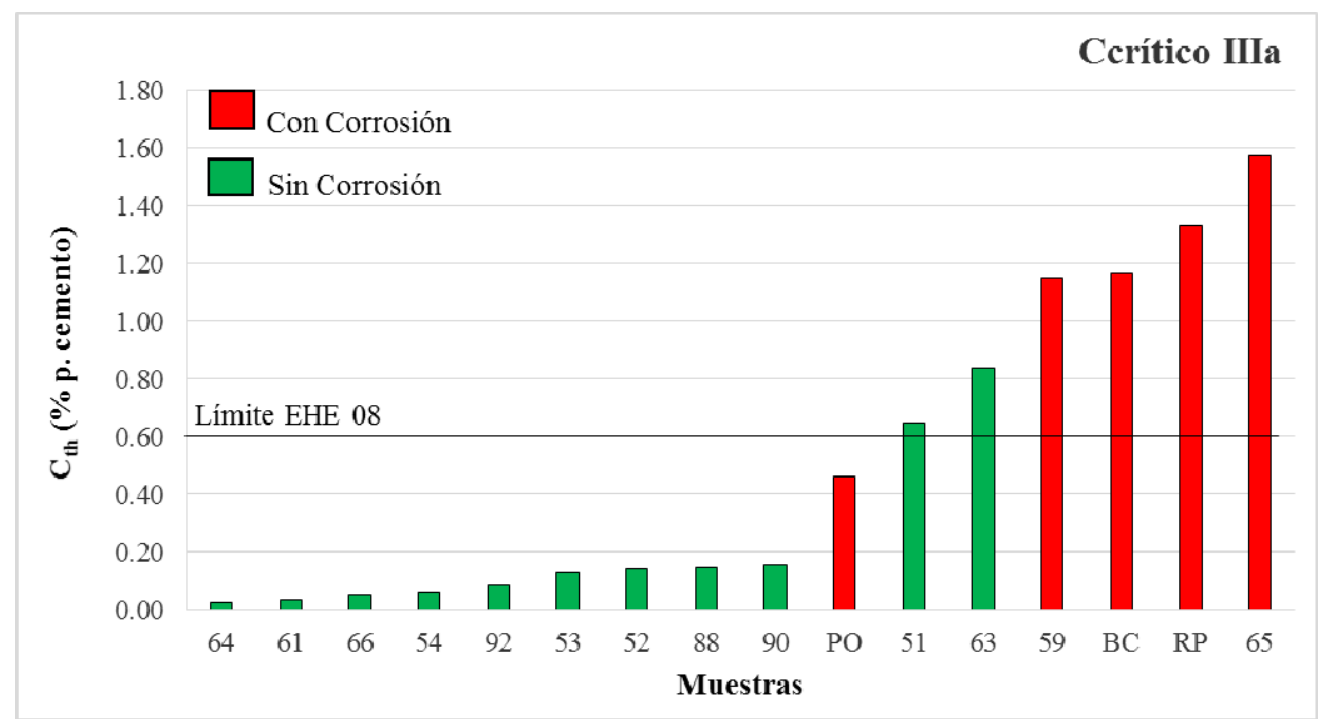

Fig 7. Valores $C_{\text {th }}$ experimentales y de bibliografía. Ambiente IIIa.

${ }^{(*)}$ Las siglas PO, BC y RP corresponden a Portugal, Brush Creek y Rocky Point, respectivamente.

Incluso descartando estos resultados muy bajos, se observa que en estructuras internacionales se ha presentado algún caso de corrosión con un umbral inferior al recogido en nuestra normativa.

La figura 8, correspondiente al ambiente $\mathrm{Illb}$, recoge dos resultados adicionales procedentes de obras reales en ambiente sumergido tomadas de la bibliografía, que sí presentan corrosión con valores inferiores a los obtenidos en los muelles españoles y superiores al umbral de la Instrucción EHE-08.

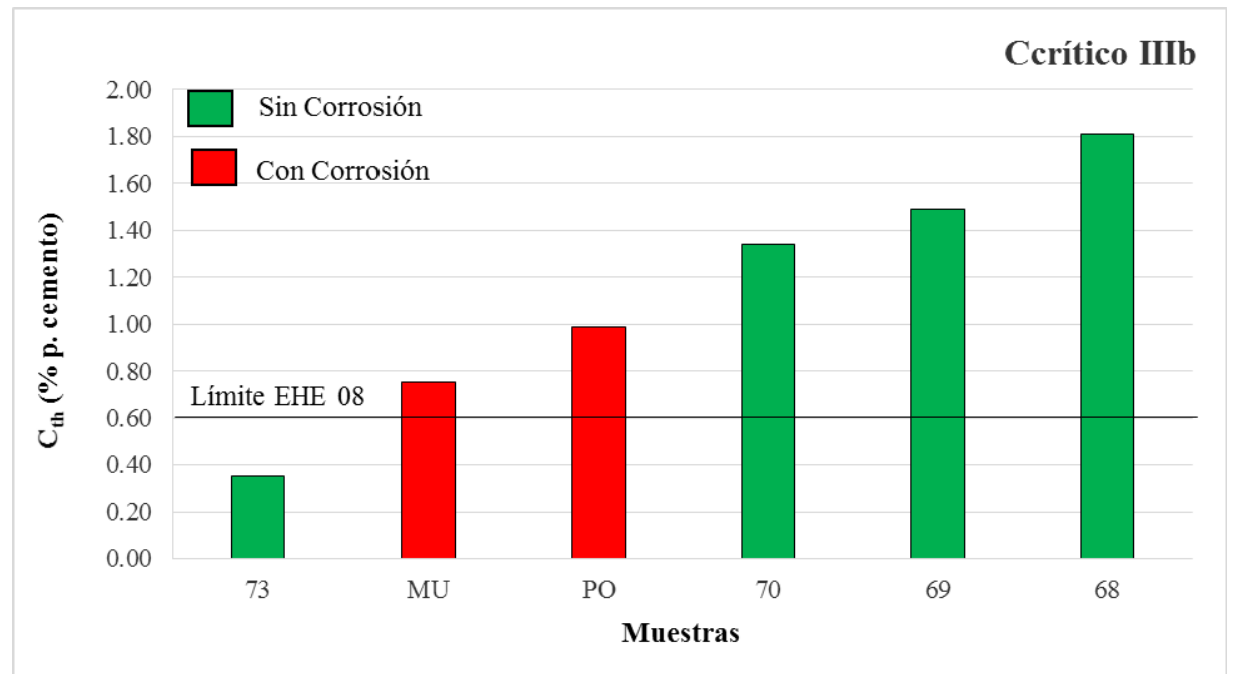

Fig 8. Valores $C_{\text {th }}$ experimentales y de bibliografía. Ambiente IIIb.

(*) Las siglas MU y PO corresponden a Muroran y Portugal, respectivamente. 
La figura 9 correspondiente al ambiente IIIc muestra la coherencia de los resultados CEDEX con seis datos adicionales extraídos de estructuras internacionales, ajustándose la mayoría de estos a la serie obtenida.

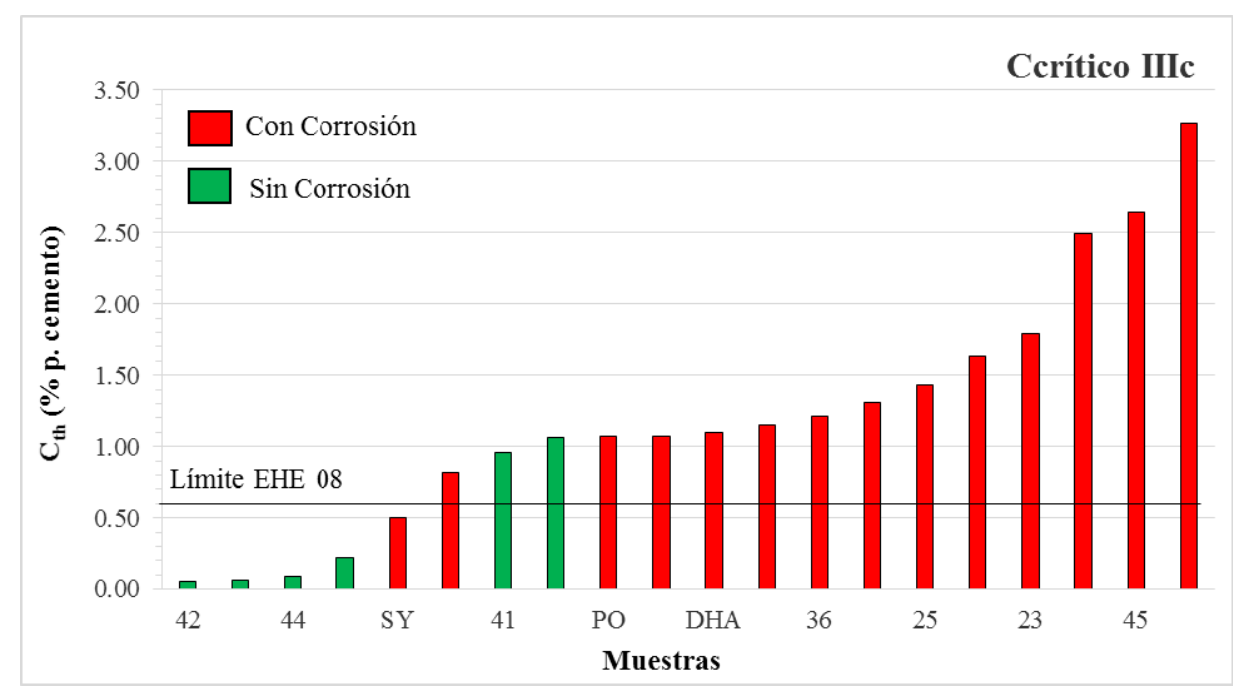

Fig 9. Valores $C_{\text {th }}$ experimentales y de bibliografía. Ambiente IIIc.

${ }^{(*)}$ Las siglas SY, TR, POD, HA corresponden a Sydney, Tay Road, Portugal y Dique de Hormigón Armado, respectivamente.

En la figura 9, de forma análoga al caso de la figura 7, no se han representado los resultados en los que el umbral de cloruros se encontraba por debajo del $0,4 \%$ en peso de cemento propuesto por la normativa española como contenido límite de cloruros inicial en el hormigón armado, ya que no resulta coherente. En particular se han suprimido cuatro casos:

- $\quad$ Datos de estructura en Sydney $\left(C_{t h}=0,10 \%\right.$ y $\left.C_{t h}=0,20\right)$.

- Datos de estructura en Tay Road $\left(C_{\text {th }}=0,15\right.$ y $\left.C_{\text {th }}=0,17\right)$

Se observa que los casos de corrosión se empiezan a presentar en contenidos de cloruros cercanos al límite de $0,6 \%$ de la Instrucción española, aunque ligeramente por debajo de este valor.

\section{CONCLUSIONES}

- En general, todas las normativas internacionales establecen límites al contenido inicial de cloruros presentes en el hormigón, aunque los valores difieren sustancialmente de unos países a otros, existiendo un número alto de normas que adoptan valores inferiores al recogido por la Instrucción EHE-08 (0,4\%). En particular, la normativa americana establece límites 0,06\% (hormigón pretensado) y 0,15\% (hormigón armado) para ambiente marino. 
- El umbral de cloruros que origina el comienzo de la corrosión de la armadura está muy influenciado por el ambiente marino al que está expuesto el hormigón, si bien la normativa internacional adopta un valor único que oscila del 0,4 al 0,6\% en función de las normas consultadas.

- El límite de la EHE-08 (0,6\%) ha resultado válido, incluso bastante conservador, para los resultados obtenidos en estructuras españolas en los tres ambientes. Así, los casos de corrosión se han presentado con contenidos de cloruros bastante muy por encima del límite actual normativo: 1\% para ambiente IIla y IIIc, 1,8\% para ambiente sumergido.

- Sin embargo, al considerar estudios realizados en estructuras internacionales se registran valores de cloruros que sí han ocasionado corrosión con concentraciones ligeramente superiores al $0,6 \%$ en ambiente IIIb e incluso con valores ligeramente superiores al $0,4 \%$ en los ambientes IIla y IIlc. Estos resultados se han obtenido descartando valores puntuales que resultaban anómalos por su bajo valor para llegar a ocasionar corrosión (entre 0,10 y 0,23\%).

- No se ha observado en los datos analizados una variación en la concentración crítica de cloruros por la utilización de cementos con adiciones o cementos portland.

\section{PROPUESTA DE VALORES DE $\mathrm{C}_{\mathrm{x}}$}

Los resultados obtenidos aconsejarían mantener el valor de concentración crítica de cloruros del $0,6 \%$ que ha resultado conservador y además también está recogido en otras normativas internacionales.

Sería necesario disponer de un mayor número de resultados experimentales para proponer un cambio de este límite.

\section{BIBLIOGRAFÍA CONSULTADA}

Para la elaboración del presente anejo se han consultado las siguientes fuentes bibliográficas a las que se hace referencia durante el documento:

1. Bermúdez, M.A; Alaejos, M.P. (2009). "Estudio experimental de la durabilidad del hormigón armado en ambiente marino. Zonas sumergida y de carrera de mareas" Monografía 103, CEDEX. Madrid.

2. Alaejos, M. P; Bermúdez, M.A. (2008). "Corrosión de las armaduras en el hormigón situado en ambiente marino". Monografía 96, CEDEX. Madrid. 
3. Fernández, S. (2011). "Corrosión de armaduras en el hormigón armado en ambiente marino aéreo". Suficiencia investigadora, ETSICCP, Universidad Politécnica de Madrid.

4. Helland, S; Aarstein, R. and Maage, M. (2010). "In field performance of North Sea offshore platforms with regard to chloride resistance" Structural Concrete, 2010, 11 No 1, Thomas Telford and fib.

5. Ministerio de la Presidencia (2008). “Instrucción de Hormigón Estructural (EHE 08) Madrid.

6. FIB (2006). "Model Code for Service Life Design". Bulletin 34. Lausanne, Switerland.

7. JSCE (2002) "Standard Specifications for Concrete Structures-2002. Materials and Construction" JSCE Guidelines for concrete $n^{\circ} 6$, Japan Society of Civil Engineers.

8. Cramer, S; Covino, B.S. y otros (2002) "Corrosion prevention and remediation strategies for reinforced concrete coastal bridges" Cement and Concrete Composites, 24, 101-117.

9. Williamson, G.S; Weyers, R.E. y otros (2009) "Concrete and Steel Type Influence on Probabilistic Corrosion Service Life" ACI Materials Journal n 106-M11.

10. $\mathrm{ACl}$ (2002) Protection of Metals in Concrete Against Corrosion. ACl 222R En "ACl Manual of Concrete Practice 2002 Part 1. Materials and General Properties of Concrete". Detroit: Ed. American Concrete Institute.

11. ACl (2002) Fixed Offshore Concrete Structures. ACl 357 R. En "ACl Manual of Concrete Practice 2002 Part 5. Design and Construction Practices". Detroit: Ed. American Concrete Institute.

12. Hwan $\mathrm{OH}$, B y Seok Jang, B. (2003) "Chloride diffusion analysis of concrete structures considering effects of reinforcements". ACI Materials Journal, Marzo-Abril, 143-149.

13. Bureau of Ports and Harbours (2002) "Technical Standards for Port and Harbour Facilities in Japan". Ministry of Transports. Tokio.

14. Miyagawa, T. (1991) "Durability Design and Repair of Concrete Structures: Chloride Corrosion of Reinforcing Steel and Alkali-Aggregate Reaction". Magazine of Concrete Research, Vol.43, № 156, 155-170.

15. UNE-EN 206-1 (2008) "Hormigón. Parte I: Especificaciones, prestaciones, producción y conformidad". 
16. Izquierdo, D. (2003) "Bases de diseño para un tratamiento probabilista de los procesos de corrosion de armaduras en el hormigón". Tesis Doctoral. E.T.S. Ingenieros de Caminos, Canales y Puertos, Madrid.

17. Browne, RD (1980) "Marine durability survey of the Tongue Sands Tower", In Concrete in the Oceans. Cement and Concrete Association, Wexham Springs, technical report 5.

18. Ferreira, RM (2004) "Probability-based durability analysis of concrete structures in marine environment". Tesis Doctoral. Universidade do Minho. Escola de Engenharia.

19. Thomas, M. (1996) "Chloride thresholds in marine concrete" Cement and Concrete Research, Vol.26, $n^{\circ} 4,513-519$.

20. Hwan Oh, B y Seok Jang, B (2003) "Chloride diffusion analysis of concrete structures considering effects of reinforcements". ACI Materials Journal, March-April, 143-149.

21. Shafiq, N (2004) "Effects of fly ash on chloride migration in concrete and calculation of cover depth required against the corrosion of embedded steel reinforcement". Structural Concrete, Vol.5, № 1, 6-7.

22. Alonso, MC (2008) "Chloride threshold values in literature" Proceedings of the COIN Workshop on Critical Chloride Contents in Concrete, Trondheim, Norway, 5-6 June 2008.

23. ACl 318S-08 (2008) "Building Code Requirements for Structural Concrete and Commentary".

24. CEDEX, Laboratorio Central de Estructuras (2015) "Puerto de Valencia. Estudio del hormigón del Muelle de la Aduana".

25. CEB (1998) "Strategies for testing and assesment of concrete structures". Guidance Report. Boletín CEB n² 243. Lausanne, Suiza.

26. Costa, A. Appleton, J. (2002) "Case studies of concrete deterioration in a marine environment in Portugal" Cement and Concrete Composites Vol 24,169-179.

27. Roper, $\mathrm{H}$ et al. (1988) "Site and laboratory evaluation of repairs to marine concrete structures and maintenance methodologies-two case studies. SP 109-25. En American Concrete Institute. Concrete in marine Environment. Second International Conference. ACI SP 109. Detroit. ED.V.M. Malhotra. 
28. Ozaki, S. y Sugata, N. (1988) "Sixty-year-old concrete in a marine environment". SP 109-26. En American Concrete Institute. Concrete in Marine Environment. Second International Conference.ACI SP 109. Detroit: Ed. V.M.Malhotra.

29. Wood, J.G.M. y CRERAR, J. (1997) "Tay Road Bridge: analysis of chloride ingress variability and prediction of long term deterioration". Construction and Building Materials, Vol.38, April, 313-320.

30. ACI 365.1R-00 (2000). "Service Life Prediction. State of The Art Report".

31. ACl 201.2R-08 (2008). "Guide to Durable Concrete". 



\section{ANEJO 3: MEDIDA DE LA RESISTIVIDAD ELÉCTRICA EN EL HORMIGÓN ARMADO.}

\section{1.-ANTECEDENTES.ESTADO DEL ARTE SOBRE RESISTIVIDAD}

\subsection{ASPECTOS GENERALES}

Las normas UNE 83988-13 y UNE 83988-24 definen la resistividad eléctrica del hormigón $\left(\rho_{\mathrm{e}}\right)$ como la resistencia eléctrica de la unidad de volumen del hormigón. La resistividad es la propiedad inversa de la conductividad y se obtiene de la relación entre la diferencia de potencial y la intensidad de corriente circulante referida a una geometría normalizada (cubo de $1 \mathrm{~m}$ de arista). Asimismo, ambas normas recogen la definición de resistencia eléctrica del hormigón $\left(\boldsymbol{R}_{\mathbf{e}}\right)$ como la relación entre la diferencia de potencial $(\mathrm{V})$ y la intensidad de corriente (I) que circula por el interior de la probeta o testigo.

En el hormigón, la resistividad proporciona una medida de su capacidad de actuar como electrolito y conducir las corrientes de la corrosión ${ }^{1,2}$. La resistividad eléctrica de un hormigón saturado ${ }^{3,4}$ es una medida indirecta de la conectividad y tamaño de sus poros. En un hormigón no saturado es una indicación del grado de saturación.

Durante el periodo de iniciación de la corrosión, la resistividad del hormigón se relaciona con la penetración de iones cloruro y del $\mathrm{CO}_{2}$ del ambiente; en el período de propagación, se correlaciona con la velocidad de corrosión ${ }^{1,5}$.

Dentro de una estructura, los puntos de baja resistividad indican dónde será más rápida la penetración de cloruros. Los mapas de resistividad no muestran si el acero del hormigón se está corroyendo; esta información se obtendrá con otros métodos: análisis de cloruros, profundidad de carbonatación, mapas de potencial, resistencia de polarización e inspección visual del acero' ${ }^{1,6}$. Si el acero se está corroyendo, los mapas de resistividad indicarán en qué zonas la corrosión será mayor ${ }^{1,6,7,8}$.

Por lo tanto, las medidas de la resistividad pueden ser útiles para los siguientes objetivos $^{1,8}$ :

- Evaluar el rango (o rango de valores) de la resistividad del hormigón de una estructura, para estimar el riesgo de corrosión en caso de que se despasive.

- Localizar las zonas más permeables de la estructura, para definir otras 
investigaciones o medidas de protección.

- Localizar puntos con mayor exposición al agua y a agentes agresivos disueltos.

- Ayudar a diseñar sistemas de protección catódica y otros tratamientos electroquímicos.

- Control de calidad del hormigón en la fase de producción.

\section{2.- REALIZACIÓN DE LA MEDIDA DE RESISTIVIDAD}

La resistividad de un material se define como la resistencia de un cubo de tamaño unitario, de longitud $L$ y sección $A^{1,7}$. El método más sencillo de medida supone la aplicación de una corriente alterna I a través de dos electrodos paralelos, separados una distancia $L$ y de sección $A$. Se mide el potencial resultante $V$ y la resistividad del material es:

$$
\rho=\left(V^{\star} A\right) /\left(I^{\star} L\right)
$$

Este método directo de medida de la resistividad precisa que los electrodos estén dentro del hormigón, por lo que sólo se puede aplicar a estructuras nuevas ${ }^{1,7}$.

Para medir la resistividad de estructuras existentes se emplea la sonda de cuatro puntas de Wenner ${ }^{1,7,8}$. Se colocan los electrodos en línea separados una distancia " $x$ " (inferior al espesor de recubrimiento) entre sí, se aplica una corriente alterna a través de los electrodos de los extremos (normalmente corriente alterna con una frecuencia entre 50 y $1000 \mathrm{~Hz}$, normalmente sinusoidal) y la caída de potencial resultante se mide con los electrodos intermedios. La resistividad es:

$$
\rho=2 \pi x V / I
$$

donde $\mathrm{x}$ es la distancia entre electrodos, $\mathrm{V}$ es el potencial aplicado entre ambos e I es la intensidad de corriente.

Al medir sobre barras que pueden estar situadas a $10-20 \mathrm{~mm}$ de profundidad, los errores cometidos pueden suponer un factor de 2 a 6 en la medida. Para minimizar este efecto, ninguno de los electrodos debe situarse encima o cerca de las armaduras; pero esto puede estar en contradicción con el objetivo de separar entre sí los electrodos para evitar el efecto de las partículas de árido (como la corriente la transportan los iones de la solución de los poros del hormigón, los áridos son cuerpos aislantes). Un compromiso práctico entre ambos efectos sitúa la separación mínima entre los electrodos en 30$50 \mathrm{~mm}^{1,8}$. 
Otra forma de medir la resistividad es la medida de la caída de "iR" cuando se aplica una corriente entre la armadura y un electrodo situado en la superficie del hormigón y de diámetro "D". La caída "iR" es igual al voltaje "V" necesario para que pase una corriente "i" a través de un hormigón de resistencia "R". La resistividad (cuando el tamaño de disco es menor que la distancia a la armadura) es s $^{1,7,8}$ :

$$
\rho=2 \mathrm{VD} / \mathrm{l}
$$

donde $\mathrm{D}$ es el diámetro del electrodo, $\mathrm{V}$ es el potencial aplicado entre electrodo y armadura e I es la intensidad de corriente.

Por último, la resistencia del hormigón se puede medir también empleando dos electrodos situados en la superficie del hormigón. En comparación con el método de un electrodo, supondría evitar la necesidad de establecer una conexión eléctrica con la armadura aunque la presencia de armaduras en el interior del hormigón podría distorsionar esta medida, como ya se ha indicado en el método de las 4 puntas ${ }^{1,8}$.

\section{3.- NORMAS DE ENSAYO DE RESISTIVIDAD}

En la normativa española y europea se localizan tres normas para la medida de la resistividad $3,4,11$ :

- UNE 83988-1(2008) "Método de ensayo para determinación de la resistividad eléctrica. Parte 1: método directo (método de referencia)".

- UNE 83988-2 (2014) "Método de ensayo para determinación de la resistividad eléctrica. Parte 2: método de las cuatro puntas o de Wenner".

- UNE EN 14617-13 (2013) "Piedra aglomerada. Métodos de ensayo. Parte 13: Determinación de la resistividad eléctrica".

Los fundamentos de los métodos utilizados en las tres normas se indican a continuación ${ }^{3,4,11}$ :

- $\quad$ Según la norma UNE 83988-1 consiste en la medida de la resistencia eléctrica del hormigón endurecido por método directo al aplicar un campo eléctrico uniforme mediante dos electrodos en contacto con las bases de la probeta. Será considerado como el método de referencia para la medida de la resistividad de probetas y testigos de hormigón.

- Según la norma UNE 83988-2 consiste en la determinación de la resistividad eléctrica del hormigón endurecido al aplicar una corriente entre dos electrodos 
situados en una generatriz de la probeta, y medir el voltaje entre otros dos electrodos interiores, alineados con los anteriores. El método proporciona la resistencia eléctrica del hormigón $R_{e}$. Conociendo el espaciado entre electrodos y las dimensiones de la muestra se calcula el factor geométrico $F_{g}$, el factor de forma $F_{t}$ y la resistividad eléctrica de la probeta $\rho_{\text {probeta. }}$

- La norma UNE 14617-13 especifica un método de ensayo para determinar la resistencia de aislamiento a la corriente continua, la resistencia y la resistividad superficiales, así como las correspondientes conductancia y conductividad eléctricas de las probetas de productos de piedra conglomerada conformes a la definición establecida en la norma europea EN 14618. Estos productos están compuestos normalmente de áridos de piedra aglomerados mediante resina y filler o cemento y agua (componentes de la pasta) o una mezcla de polímero/cemento y las adiciones correspondientes (tales como fibras de refuerzo, fillers eléctricamente aislantes/conductores, etc). La resistividad/conductividad también se puede utilizar como una medida indirecta de algunas propiedades de los productos de piedra aglomerada. Se utilizan para la medida electrodos con la configuración de tres terminales, con un electrodo de seguridad.

Seguidamente, se comparan los aspectos más relevantes del método de ensayo descrito por cada una de las normas:

\section{Dimensiones de las probetas ${ }^{3,4,11}$}

Según la norma UNE 83988-1: Serán de hormigón endurecido o probetas testigo de hormigón extraído. No podrán contener ninguna armadura en su interior y deben ser de geometría regular. Las bases deberán ser perfectamente planas y paralelas.

Según la norma UNE 83988-2: Serán de hormigón endurecido o probetas testigo de hormigón extraído. No podrán contener ninguna armadura en su interior y deben ser de geometría cilíndrica y altura mínima de $200 \mathrm{~mm}$.

Según la norma UNE-EN 14617-13: Debe utilizarse siempre que sea posible un método de muestreo aleatorio. Las probetas a ensayar serán representativas, pueden obtenerse en laboratorio y/o extraerse testigos in situ. Las superficies deben afinarse o pulirse. Pueden tener cualquier forma que permita la utilización de electrodos de tres bornes. Las probetas en forma de placa deberán presentar un espesor superior al $20 \%$ del tamaño máximo de árido y un diámetro comprendido entre $20 \mathrm{~mm}$ y $160 \mathrm{~mm}$. Al menos deben seleccionarse cinco probetas. 


\section{Resistivímetro}

Según la norma UNE 83988-1 será un aparato capaz de aplicar una tensión o intensidad de corriente estable sobre la probeta y a la vez medir respectivamente, intensidad y potencial. Se recomienda que se aplique una frecuencia inferior a los $500 \mathrm{~Hz}$ con una fuente de corriente alterna tal que haga que circulen entre $30 \mathrm{~mA}$ y $50 \mathrm{~mA}$ para el caso de la probeta cilíndrica. Se podrá usar menos corriente si el salto de potencial es el adecuado para la medida. También se podrá emplear una fuente de corriente alterna y dos multímetros externos para determinar intensidad I y tensión V. Se podrá utilizar un registrador para la realización de varias medidas al mismo tiempo. Los valores anteriores son sólo orientativos.

Según la norma UNE 83988-2 el resistivímetro de cuatro puntas tipo Wenner será un aparato capaz de aplicar una corriente estable. Se recomienda que ésta sea alterna de hasta $40 \mathrm{~mA}$ entre los electrodos externos, midiéndose el cambio de diferencia de potencial entre los electrodos internos. También se podrá emplear una fuente de corriente alterna o continua y dos multímetros para determinar intensidad I y tensión aplicada V. Se podrá utilizar un registrador para la realización de varias medidas al mismo tiempo. Los valores anteriores son sólo orientativos.

Según la norma UNE-EN 14617-13 siempre que sea posible debería usarse voltímetroamperímetro, suministrándose una tensión constante a través de un generador de tensión constante y estabilizado. El flujo de corriente a través de la probeta para una tensión fija y constante puede medirse con cualquier equipo que tenga la sensibilidad y precisión requeridas (normalmente $\pm 10 \%$ es adecuado) y la adquisición y tratamiento de datos puede realizarse mediante ordenador. También se pueden usar electrómetros o multímetros de lectura directa que posean una sensibilidad adecuada, dependiendo del rango de corriente exhibido por las probetas de piedra aglomerada sometidas al ensayo. A menos que se especifique lo contrario, debe aplicarse un tiempo de electrificación de 60 s y una tensión directa de $100 \mathrm{~V}$ (o valores más altos, dependiendo ambos del espesor de la probeta y de la resistividad de la muestra).

\section{Electrodos}

Según la norma UNE 83988-1 serán dos mallas de acero tupidas (abertura de malla $\leq$ $2 \mathrm{~mm}$ ) o chapas de acero, cobre o cualquier otro metal conductor libre de impurezas superficiales (depósitos, óxidos visibles, suciedad, etc) y de dimensiones iguales a las de la sección transversal de la probeta o testigo, con el fin de que ni sobresalgan ni sean más pequeñas que el tamaño de las caras de la muestra en las que se sitúen. 
Según la norma UNE 83988-2 serán cuatro puntas, fabricadas de cobre o de otro metal conductor libre de impurezas superficiales (depósitos, óxidos visibles, suciedad, etc) cuyo diámetro esté comprendido entre $4 \mathrm{~mm}$ y $6 \mathrm{~mm}$, que se acoplan en un soporte rígido de modo que su separación sea de $50 \mathrm{~mm}$.

Según la norma UNE 14617-13 deberán utilizarse electrodos planos circulares con la configuración de tres terminales. Existe un electrodo de seguridad que permite excluir cualquier contribución de conductividad superficial en las mediciones de conductividad transversal, que puede suprimirse solo para materiales en los que se haya verificado que existe un escape insignificante de carga superficial. Solamente debe utilizarse una configuración de dos terminales (es decir, sin el electrodo de seguridad) en la medición de la resistencia de aislamiento.

\section{Esponjas/material de contacto}

Según la norma UNE 83988-1 serán dos esponjas finas (espesor $\leq 5 \mathrm{~mm}$ ) de iguales dimensiones que los electrodos que deberán colocarse entre las chapas o mallas y las caras paralelas de la probeta o testigo.

Según la norma UNE 83988-2 serán cuatro esponjas individuales en la punta de los electrodos que se humedecerán para garantizar el contacto hormigón-electrodo.

En el caso de la norma UNE EN 14617-13 para un contacto efectivo entre electrodos y probeta, se debería emplear una capa conductora y lámina semiconductora del tamaño y la forma requerida en la superficie de las probetas y presionándola entre los sistemas de electrodos.

\section{Agua}

Tanto en el caso de la norma UNE 83988-1 como en la norma UNE 83988-2 el agua empleada para humectación de esponjas y saturación de probetas será potable.

En el caso de la norma UNE EN 14617-13 no ha lugar esta consideración puesto que el ensayo deberá realizarse sobre probetas secas, ya que se trata de comprobar su comportamiento como aislantes eléctricos.

\section{Acondicionamiento de las probetas}

En caso de las normas UNE 83988-1 y UNE 83988-2 el ensayo se debe realizar sobre probetas de hormigón endurecido completamente saturadas en agua. 
- Estas condiciones se alcanzan con probetas de ensayo recién fabricadas y sometidas a curado durante 28 días sumergidas en agua (temperatura $=20 \pm 2{ }^{\circ} \mathrm{C}$ ). Es importante tener especial cuidado en evitar la evaporación en la cara superior de la probeta durante las primeras 24 horas desde su fabricación, cuando permanece dentro del molde.

- Para el resto de los casos (probetas curadas en cámara húmeda o probetas testigo) se deberán introducir las probetas en un recipiente hermético para vacío (por ejemplo en un desecador). Tras su sellado, se hará el vacío hasta reducir la presión interna del recipiente a menos de $1 \mathrm{~mm}$ de $\mathrm{Hg}$. Se mantendrá en ese nivel de vacío durante 3h. Con la bomba de vacío funcionando se dejará entrar el agua en el desecador hasta cubrir las probetas y se dejará funcionando la bomba de vacío durante $1 \mathrm{~h}$ más. Después de desconectar el desecador, se permitirá la entrada de aire en él y las probetas quedarán sumergidas en agua mantenida a una temperatura de $20 \pm 2^{\circ} \mathrm{C}$ durante $(18 \pm 2) \mathrm{h}$. Después se mantendrán sumergidas hasta el ensayo.

Según la norma UNE-EN 14617-13 las mediciones se pueden realizar a temperatura ambiente o sobre probetas secas.

- En el primer caso, las probetas se deben medir después de su acondicionamiento adecuado (al menos $24 \mathrm{~h}$ ) en el ambiente en que se vaya a llevar a cabo la medición siguiendo otros procedimientos normalizados de acondicionamiento ya existentes.

- En el segundo caso, las probetas deberían secarse hasta obtener un peso constante dentro de un horno de circulación de aire $(50 \pm 2)^{\circ} \mathrm{C}$, es decir que la diferencia sea inferior al $0,1 \%$ de la masa en pesadas consecutivas efectuadas con un intervalo de $24 \mathrm{~h}$. Las probetas deben enfriarse a temperatura ambiente en un secador bajo atmósfera anhídrida o en un recinto al vacío hasta el ensayo.

\section{Método de ensayo}

Según la norma UNE 83988-1:

- Se conectan dos electrodos al resistivímetro. Las esponjas se humedecerán usando agua potable. Se introducirán entre los electrodos y se colocará una masa de $2 \mathrm{~kg}$ sobre ellos. Se aplicará la corriente con el resistivímetro y se medirá la diferencia de potencial una vez estabilizada la medida (normalmente al cabo de $5 \mathrm{~s}$ si se mide con corriente continua) obteniendo la resistencia de las esponjas solas. La resistencia eléctrica de las esponjas no deberá exceder los $100 \Omega$.

- Inmediatamente antes de someter la probeta al ensayo se secará cuidadosamente 
su superficie lateral con un paño ligeramente húmedo para retirar el agua sobrante. No se secarán las caras superior e inferior, donde se colocan las esponjas humedecidas y los electrodos, colocando sobre el superior la masa de unos $2 \mathrm{~kg}$.

- Se conectarán ambos electrodos al resistivímetro y se medirá la resistencia total del conjunto cuando se estabilice la corriente. El número de determinaciones de la resistividad será de dos en cada probeta de ensayo o probeta testigo.

Según la norma UNE 83988-2:

- Se conecta generador al amperímetro-voltímetro y a la sonda Wenner. Las esponjas se humectarán con agua potable.

- Inmediatamente antes de someter la probeta al ensayo, se secará cuidadosamente su superficie lateral con un paño ligeramente húmedo para retirar el agua sobrante.

- A continuación se apoyará una generatriz de la probeta sobre un soporte no conductor y se colocarán las 4 puntas centradas respecto de las caras laterales. Cuando se estabilice la corriente se realizarán seis medidas sobre seis generatrices separadas $60^{\circ}$ entre sí, alrededor de la muestra, para medir a lo largo de todo el perímetro de forma homogéneamente espaciada. El valor de la resistencia eléctrica de cada probeta será la media de estas seis medidas.

Según la norma UNE EN 14617-13:

- Deben medirse al menos 5 probetas. Se mide el diámetro de los electrodos, la anchura del espacio de seguridad y el espesor de la probeta con galgas adecuadas (se consideran aceptables aquellos calibres y micrómetros que tengan la sensibilidad y precisión apropiadas).

- Se realiza la medición eléctrica con dispositivos adecuados que tenga la sensibilidad y precisión requeridos dentro de una atmósfera controlada; se sugieren las siguientes condiciones normalizadas: para las probetas acondicionadas a temperatura ambiente, una temperatura de $23 \pm 2{ }^{\circ} \mathrm{C}$ y una humedad relativa de $50 \pm 10 \%$; para probetas secas, un ambiente al vacío o seco.

\section{4.- SELECCIÓN DEL ENSAYO DE MEDIDA DE LA RESISTIVIDAD}

Revisados los métodos de medida de resistividad normalizados se encuentran las siguientes limitaciones: 
- El método de cuatro puntas o Wenner es un ensayo enfocado para mediciones de campo y que presenta limitaciones debido al tamaño máximo de los áridos y a la posible longitud de las probetas si se utiliza en testigos de pequeño tamaño. En el cálculo del factor de forma, se especifica para tres casos de probeta cilíndrica $(30 \times 15 \mathrm{~cm} ; 20 \times 10 \mathrm{~cm}$ y $15 \times 7,5 \mathrm{~cm})$ y probeta prismática $(4 \times 4 \times 16 \mathrm{~cm})$; para otras configuraciones de tamaño de muestras o distancia de puntas, debe determinarse la constante de forma mediante su calibración con el método directo.

- El método de ensayo para piedra aglomerada no es específico para hormigón y está destinado a la medida de la capacidad de aislamiento eléctrico del material.

Se elige el método directo que no presenta las limitaciones anteriores y que es además el de referencia tal como indica la propia norma.

No obstante, a la hora de poner en práctica el ensayo de medida de resistividad por el método directo se han localizado una serie de aspectos que no aparecen suficientemente definidos en la norma y que se procede a evaluar para conocer su posible influencia y adoptar un criterio.

- $\quad$ Tipo de corriente empleada. Recomienda aplicar una fuente de corriente alterna para suministrar una corriente de intensidad comprendida entre 30-50mA.

- Electrodos elegidos. Pueden ser mallas de acero tupidas o chapas de acero, cobre o de cualquier otro metal conductor libre de impurezas.

- Diámetro y espesor de la probeta. No se especifican las dimensiones de la probeta a emplear en el ensayo.

- $\quad$ Humectación de las esponjas. Indica simplemente que se humedecen.

\section{2.-OBJETIVO}

Una vez revisada la normativa nacional relacionada con la medida de resistividad, se decide poner en marcha el ensayo siguiendo la norma 83988-1 de medida directa de la resistividad. Sin embargo, se considera necesario un ajuste previo del método con el fin de tratar de concretar, al no estar completamente definidos, algunos de los parámetros en la descripción del método de ensayo.

El objetivo del estudio es estudiar la influencia en el resultado del ensayo de algunos parámetros que no se concretan. 


\section{3.- METODOLOGÍA}

La metodología empleada para la elaboración de este anejo consta de dos partes. Una primera fase en la que se procede al ajuste del sistema de medida de la resistividad y una segunda en la que se procede a evaluar la influencia de la geometría de la probeta (diámetro y espesor) en la realización de la medida de la resistividad.

\subsection{AJUSTE DEL SISTEMA DE MEDIDA DE RESISTIVIDAD}

Se ha utilizado una probeta de hormigón H25 para comprobar la influencia de diferentes parámetros eléctricos en el resultado de medida de la resistividad:

- $\quad$ Tipo de corriente (continua-alterna).

- Electrodos.

- Procedimiento de contacto con esponjas

En esta fase se adoptan los criterios del procedimiento de ensayo.

\section{2.- INFLUENCIA DE LA GEOMETRÍA DE LA PROBETA}

Una vez fijado el procedimiento a seguir en el ensayo, se han utilizado probetas de $\mathrm{H} 25$ y de $\mathrm{H} 50$ con el fin de analizar dos calidades de hormigón estudiando la posible influencia en el resultado de la medida de la resistividad de la geometría de la probeta:

- Del espesor de la rodaja

- Del diámetro de la probeta

Se analizan los resultados obtenidos y se adoptan los valores finales de medida para su aplicación de forma sistemática a todas las probetas y testigos caracterizados en el desarrollo de la investigación (cuerpo de la tesis).

\section{4.- RESULTADOS}

\section{1.- AJUSTE DEL SISTEMA DE MEDIDA DE RESISTIVIDAD}

Una vez revisada la documentación referente a la normativa acerca de la resistividad eléctrica, se decide llevar a cabo un ensayo para la medida de esta propiedad siguiendo el método directo. 


\subsubsection{Utilización de corriente continua.}

Si bien la norma UNE 83988-1 recomienda de forma orientativa que se utilice corriente alterna en la realización del ensayo, se decide inicialmente utilizar un generador de $60 \mathrm{v}$ de corriente continua, del cual se dispone en el laboratorio.

De acuerdo con lo indicado por la norma UNE 83988-1, la intensidad registrada durante la medida de la resistividad eléctrica de una probeta cilíndrica de hormigón debe encontrarse dentro del intervalo (30mA-50mA).

Considerando como valores de resistividad del hormigón los que plantea la bibliografía ${ }^{1}$ para el caso de estructuras reales de hormigón de más de 10 años y localizadas en ambiente muy húmedo/sumergido:

- Para hormigón fabricado a partir de OPC (CEM I), se sugieren valores de la resistividad comprendidos entre 50-200 $\Omega \mathrm{m}$ (se toma $100 \Omega \mathrm{m}$ ).

- Para hormigón fabricado a partir de CEM III/B, se sugieren valores de la resistividad comprendidos entre 300-1000 $\Omega \mathrm{m}$ (se toma $400 \Omega \mathrm{m}$ ).

La tabla 1 indica los valores límite de voltaje (expresado en voltios) con los datos de resistencia anteriores:

\begin{tabular}{|c|c|c|}
\hline \multirow{2}{*}{ Intensidad (mA) } & \multicolumn{2}{|c|}{ Voltaje (v) } \\
\hline & OPC CEM I (100 $\Omega \mathrm{m})$ & CEM III cenizas (400 $\Omega \mathrm{m})$ \\
\hline 30 & 19,23 & 76,92 \\
\hline 50 & 32,05 & 128,21 \\
\hline
\end{tabular}

Tabla 1.Rangos de voltaje límite según intensidad de corriente y cemento empleado.

A la vista de los extremos del intervalo $(19,23$ y 128,21) se considera que el generador de corriente continua de $60 \mathrm{v}$ resulta apto para realizar el ensayo.

Para el ajuste de esta fase, se utiliza una probeta cilíndrica de $15 \mathrm{~cm}$ de diámetro y 30 cm de longitud de hormigón H25 denominada "H25 SD". Es una probeta localizada en laboratorio de la cual se conoce la resistencia pero se desconocen datos acerca de su dosificación, pero dado que se trata de realizar un ajuste del sistema eléctrico de medida, en esta fase no es necesario tener una caracterización del hormigón ensayado. Al ser los electrodos empleados unas chapas de $10 \mathrm{~cm}$ de diámetro embebidas en metacrilato y según la norma 83988-1, las dimensiones del electrodo deberán ser iguales que la sección transversal de la probeta, se decide extraer un testigo de este diámetro de la probeta. La figura 1 muestra fotografías de la probeta original así como 
del testigo extraído de ella posteriormente.
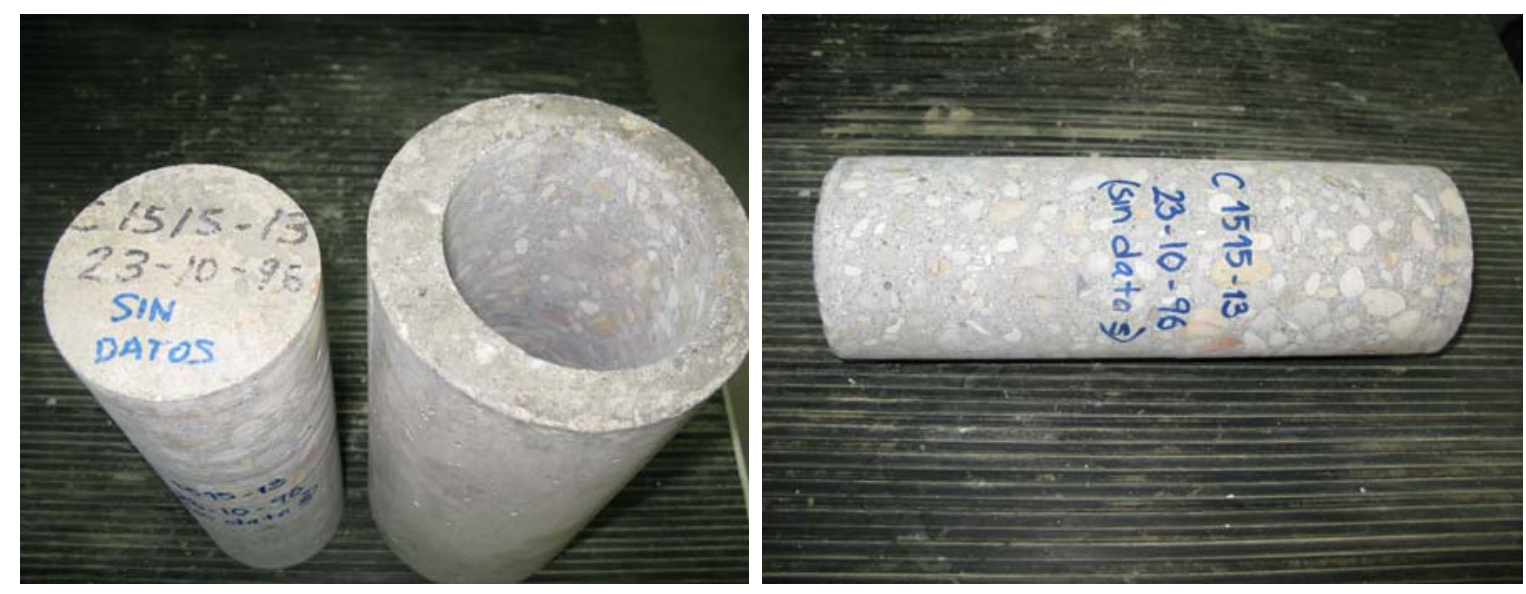

Fig.1. Probeta original H25 SD y testigo extraído.

Se decide dividir el testigo en rodajas ya que en posteriores pruebas se va a analizar la posible influencia del espesor en la medida de la resistividad eléctrica. Con este fin, se trocean las probetas en 6 rodajas comenzando por la cara de cierre e indicando mediante flechas el sentido de llenado de la probeta. Las rodajas 1 y 6 no se emplean para el ensayo por corresponder al saneo del testigo. Una vez cortadas, se procede a la medida de su espesor $\left(\mathrm{e}_{1} \mathrm{a} \mathrm{e}_{4}\right)$, diámetro y peso. Las tablas 2 y 3 recogen estos datos:

\begin{tabular}{|c||c||c|c|c|c|c||}
\hline Rodaja & $\mathrm{e}_{\mathbf{1}}(\mathbf{m m})$ & $\mathrm{e}_{\mathbf{2}}(\mathbf{m m})$ & $\mathrm{e}_{\mathbf{3}}(\mathbf{m m})$ & $\mathrm{e}_{\mathbf{4}}(\mathbf{m m})$ & $\mathrm{e}_{\mathbf{m}}(\mathbf{m m})$ & Peso $(\mathbf{g r})$ \\
\hline \hline $\mathbf{2}$ & 24,56 & 24,61 & 24,63 & 24,73 & $\mathbf{2 4 , 6 3}$ & $\mathbf{4 4 9 , 6 0}$ \\
\hline $\mathbf{3}$ & 48,30 & 48,35 & 48,32 & 48,44 & $\mathbf{4 8 , 3 5}$ & $\mathbf{8 8 2 , 6 0}$ \\
\hline $\mathbf{4}$ & 71,38 & 71,14 & 71,19 & 71,16 & $\mathbf{7 1 , 2 2}$ & $\mathbf{1 2 9 7 , 6 0}$ \\
\hline $\mathbf{5}$ & 97,33 & 97,57 & 98,16 & 97,74 & $\mathbf{9 7 , 7 0}$ & $\mathbf{1 7 8 6 , 1 0}$ \\
\hline
\end{tabular}

Tabla 2. Espesores y pesos de las rodajas de la probeta “H25-SD" (Ø $\left.\varnothing_{\text {medio }}=99,54 \mathrm{~mm}\right)$.

A continuación se procede al acondicionamiento de las rodajas para su ensayo, que como ya se ha indicado, consiste en saturarlas al vacío con el fin de extraer todo el aire de sus poros.

Una vez saturadas las rodajas, se retiran de la cámara y se mantienen sumergidas en una bandeja con agua durante 20 horas, tal y como se aprecia en la figura 2: 

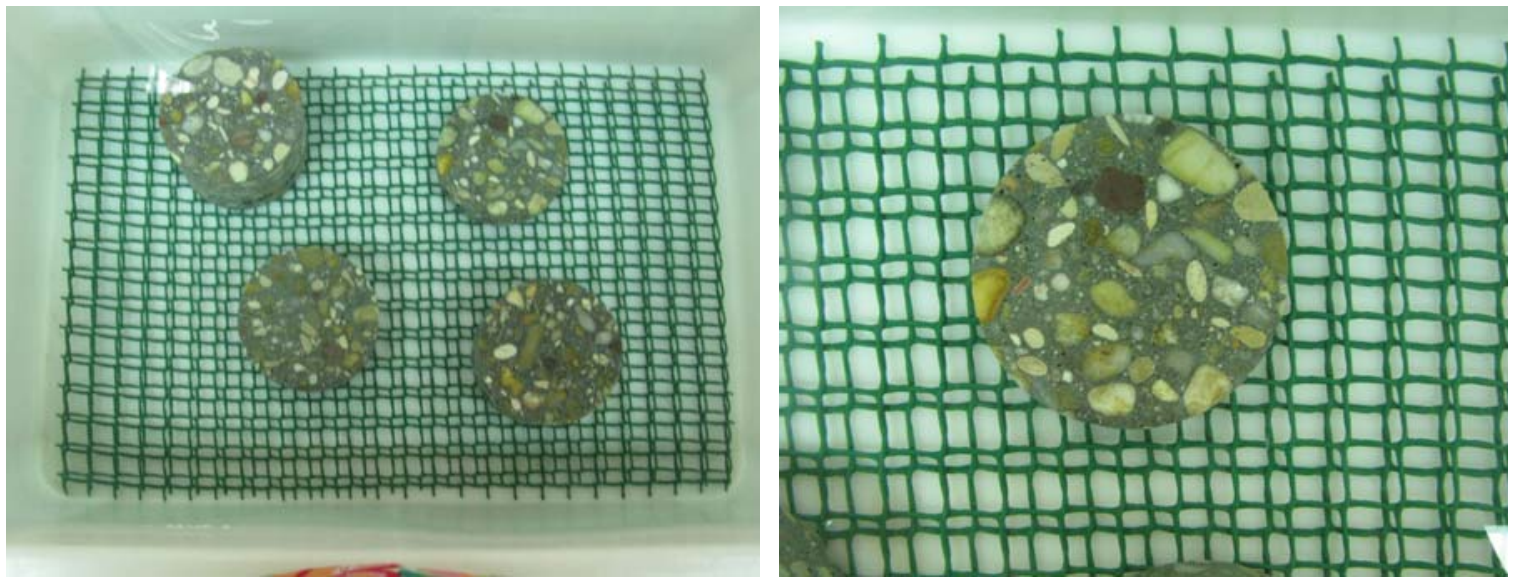

Fig.2. Vista general de las rodajas sumergidas para mantener su saturación. Detalle de una de ellas.

Seguidamente se procede al montaje eléctrico del ensayo, siguiendo el esquema de la figura 3:
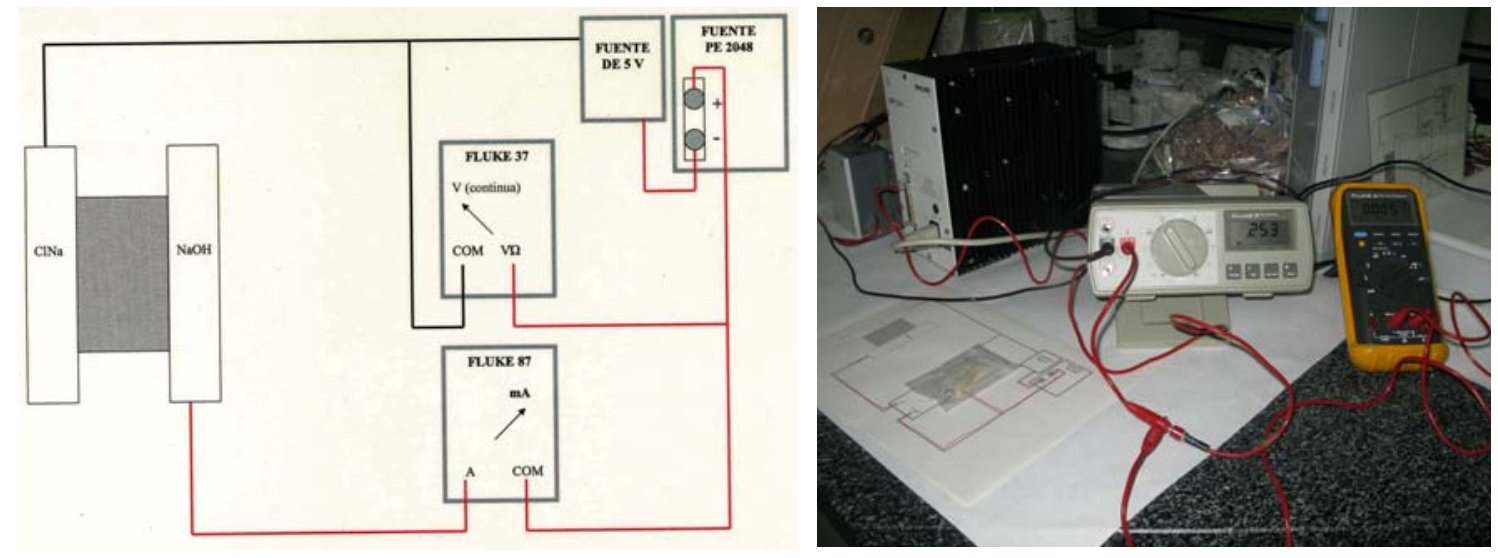

Fig.3. Esquema de montaje utilizado en el ensayo y vista general de una de las pruebas.

Una vez realizado el montaje eléctrico se humedecen las esponjas. Se coloca la esponja sobre uno de los electrodos, luego la probeta y sobre ella la otra, cerrándose el circuito con el electrodo de metacrilato. Sobre éste se coloca un peso aproximado de $2 \mathrm{~kg}$ para favorecer el contacto entre las distintas partes según indica la norma UNE 83988-1. A continuación, se hace circular la corriente manteniendo el voltaje fijo (60v) y se mide la intensidad.

La relación entre voltaje e intensidad, nos permite obtener la resistencia total del conjunto (hormigón más esponjas). Según la norma UNE 83988-1 a la resistencia total del conjunto se le debe restar la de las esponjas para conocer así la resistencia eléctrica del hormigón.

Las figuras 4, 5 y 6 muestran el montaje empleado para la realización del ensayo: 

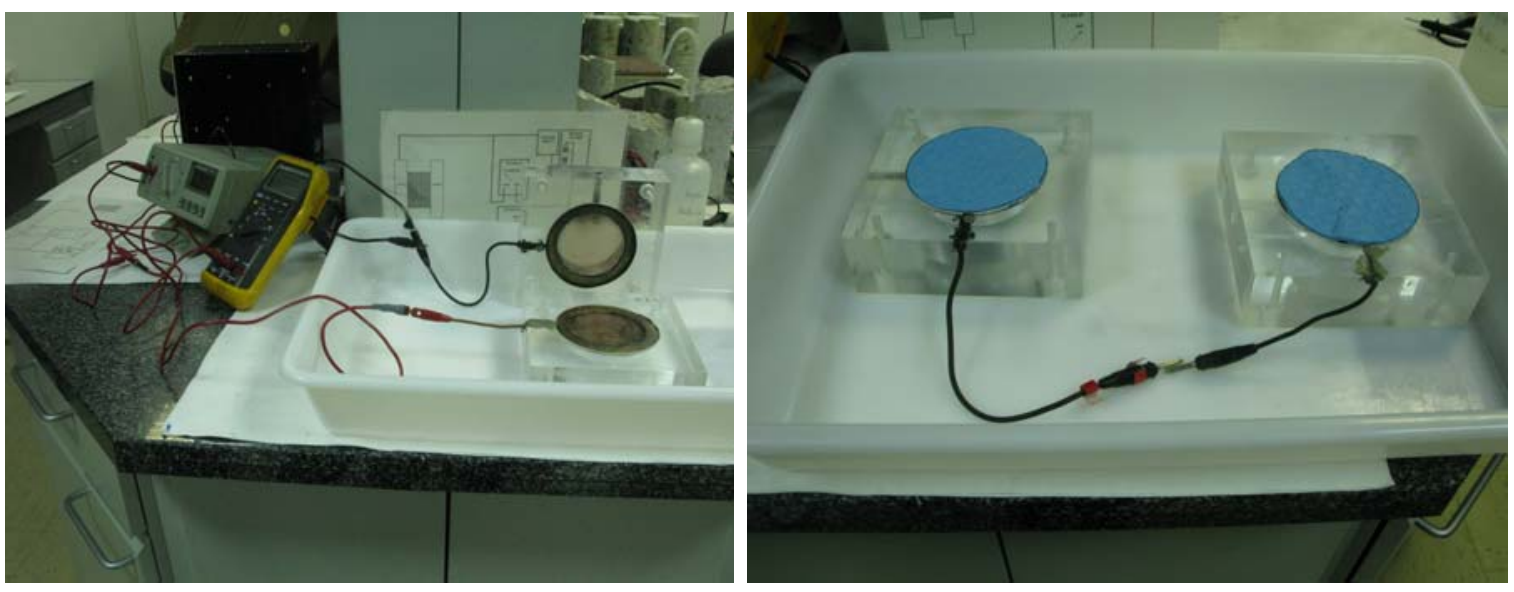

Fig.4. Vista general del montaje y detalle de los electrodos con las esponjas.
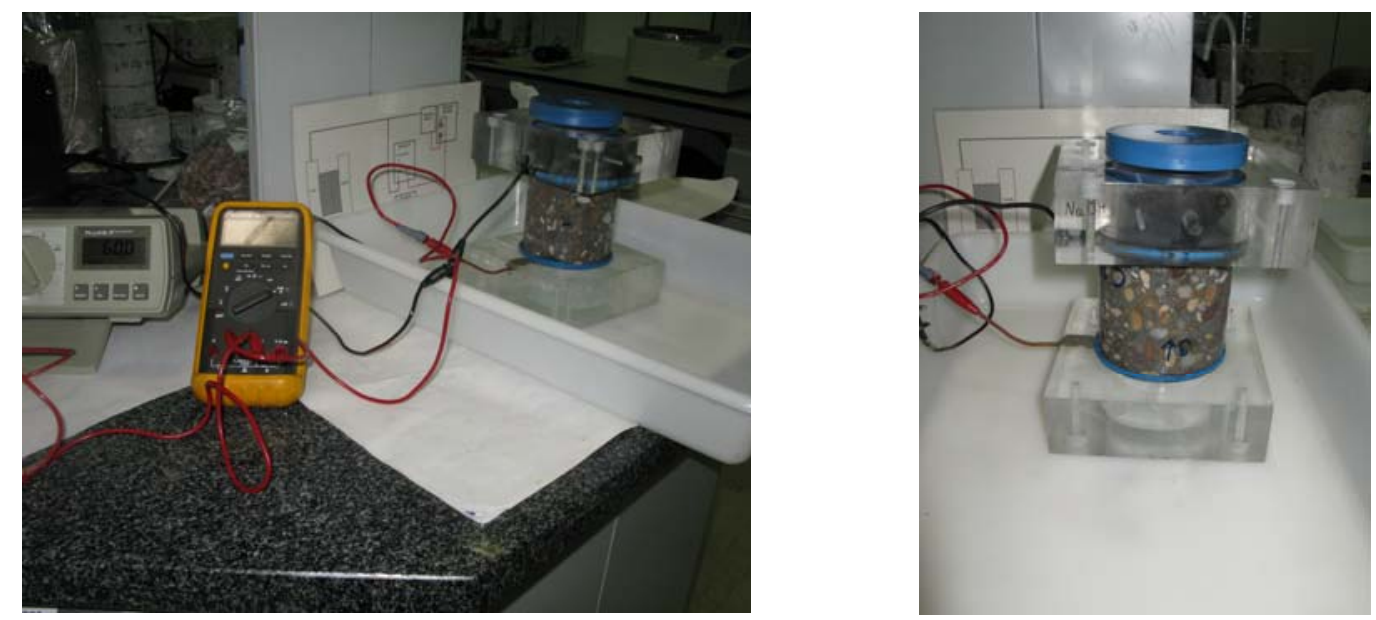

Fig.5. Medida de la resistividad de una de las rodajas (espesor $10 \mathrm{~cm}$ ) del testigo.

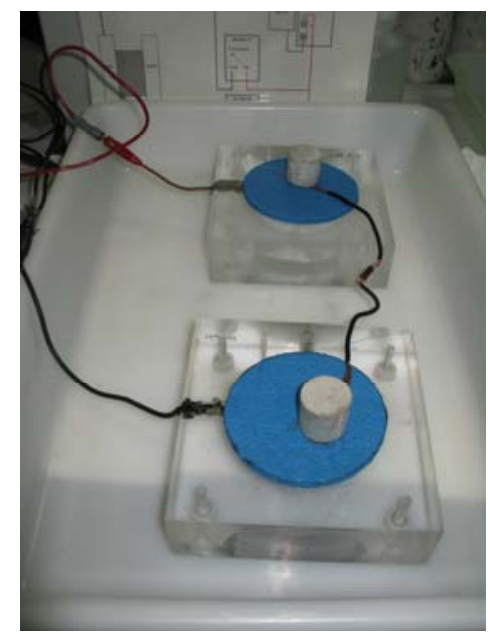

Fig.6. Operación auxiliar para determinar el valor de resistencia de las esponjas.

A continuación se detallan las distintas pruebas del ensayo realizadas en corriente continua: 


\section{Prueba con electrodos embebidos en metacrilato.}

Se utilizan electrodos embebidos en metacrilato tal como se muestra en la figura 4.

Para calcular la resistencia de las esponjas sin dañar los electrodos, se realiza una operación auxiliar a partir de una resistencia de valor conocido e igual a $6670 \Omega$. Conectamos dicha resistencia a las esponjas y medimos la del conjunto (electrodos, esponjas y resistencia conocida) para hallar la de las esponjas por diferencia. Dicha operación puede apreciarse en la figura 6.

El valor obtenido nos servirá para corregir $R_{T}$, obteniendo $R_{H}$.

$\mathrm{R}=60 /\left(8,49^{*} 10^{-3}\right)=7067,14 \Omega \quad$ con lo que $\mathrm{R}_{\text {esponjas }}=7067,14-6670=397,14 \Omega$.

En la tabla 3 se aportan los resultados de la primera prueba realizada con el generador de corriente continua de 60v. Tal y como indica la norma UNE 83988-1, se realiza la medida por duplicado sobre cada rodaja, después se calcula el valor medio de ambas medidas:

\begin{tabular}{|c|c|c|c|c|c|c|}
\hline Rodaja & I (mA) & $\mathrm{R}_{\mathrm{T}}(\mathbf{\Omega})$ & $\mathrm{R}_{\mathrm{H}}(\boldsymbol{\Omega})$ & $\rho н(\Omega \mathrm{m})$ & $\begin{array}{c}\rho \mathrm{H} \text { medio } \\
(\Omega \mathrm{m})\end{array}$ & $\rho\left(\mathrm{kg} / \mathrm{m}^{3}\right)$ \\
\hline \multirow{2}{*}{2} & 80,40 & 746,27 & 349,13 & 110,35 & \multirow{2}{*}{110,21} & \multirow{2}{*}{2347,34} \\
\hline & 80,20 & 745,34 & 348,20 & 110,06 & & \\
\hline \multirow{2}{*}{3} & 49,00 & 1224,49 & 827,35 & 133,19 & \multirow{2}{*}{133,19} & \multirow{2}{*}{2351,13} \\
\hline & 49,00 & 1224,49 & 827,35 & 133,19 & & \\
\hline \multirow{2}{*}{4} & 26,02 & 2305,92 & 1908,78 & 208,45 & \multirow{2}{*}{209,97} & \multirow{2}{*}{2342,74} \\
\hline & 25,17 & 2333,72 & 1936,58 & 211,49 & & \\
\hline \multirow{2}{*}{5} & 16,61 & 3612,28 & 3215,14 & 255,88 & \multirow{2}{*}{253,08} & \multirow{2}{*}{2350,99} \\
\hline & 16,94 & 3541,91 & 3144,77 & 250,28 & & \\
\hline
\end{tabular}

Tabla 3. Resultados obtenidos prueba del ensayo sobre probeta “H25 SD.

En la tabla anterior se recogen los valores de $R_{T}$ (resistencia total del conjunto) y $R_{H}$ (resistencia del hormigón).

A la vista del elevado resultado obtenido como resistencia de las esponjas (la norma

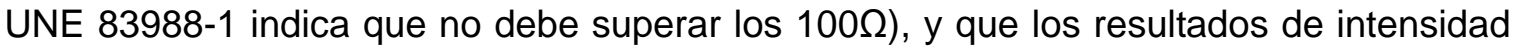
obtenidos quedan mayoritariamente fuera del intervalo fijado por la norma (30-50mA) se lleva a cabo una nueva prueba sustituyendo los electrodos embebidos en metacrilato por unos metálicos. 


\section{Prueba con electrodos metálicos.}

Se repite la prueba sustituyendo los electrodos embebidos en metacrilato por dos chapas tal y como muestra la figura 7 , donde se refleja una de las mediciones realizadas:
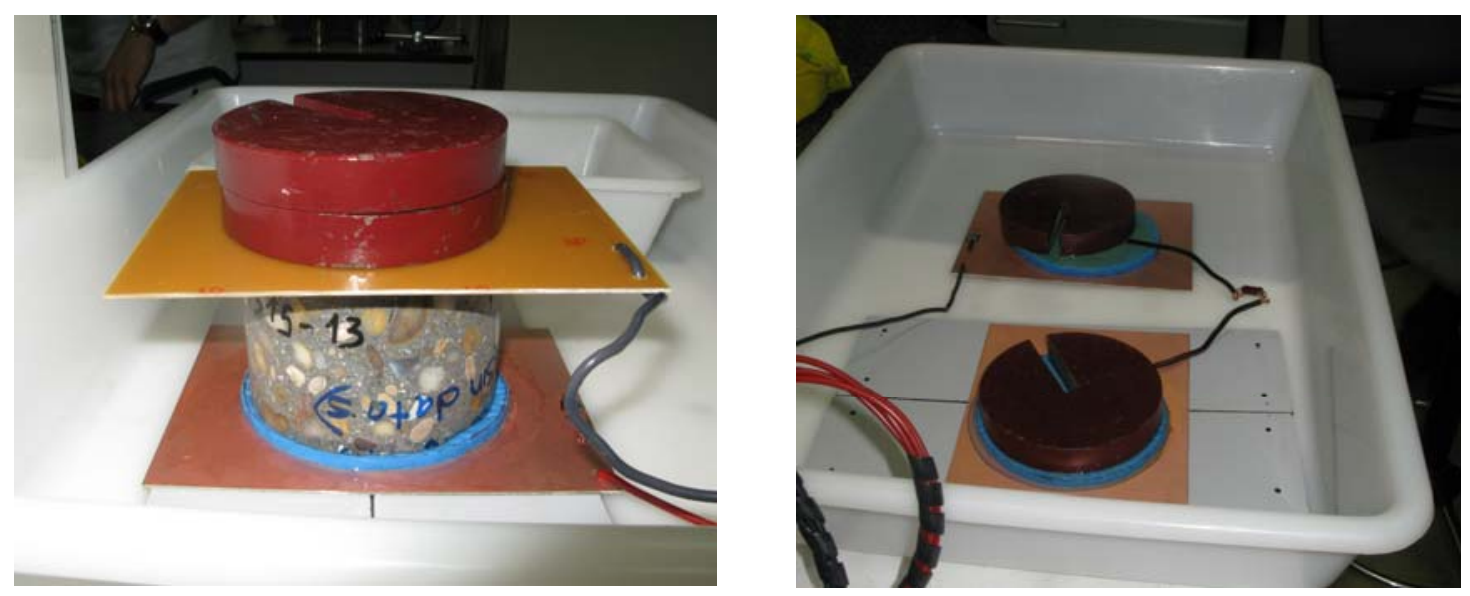

Fig.7. Vista de una de las rodajas durante el ensayo. Determinación del valor de la resistencia de las esponjas.

Para la medida de la resistencia inicial del conjunto se llevan a cabo diversas pruebas con una fuente de menor voltaje (unos $5 \mathrm{v}$ ) enfrentando las esponjas entre sí directamente, sin emplear resistencia auxiliar. La resistencia de las esponjas resulta:

$R_{\text {esponjas }}=5,16 \mathrm{v} /\left(345^{\star} 10^{-3}\right) A=14,95 \Omega$, valor a restar a $R_{\mathrm{T}}$ para obtener $R_{H}$.

El valor obtenido se ajusta a lo exigido por la norma, por lo que se realizan las medidas sobre las probetas de ensayo, obteniendo los resultados que se muestran en la tabla 4:

\begin{tabular}{|c|c|c|c|c|c|c|}
\hline Rodaja & I (mA) & $\mathbf{R}_{\mathrm{T}}(\boldsymbol{\Omega})$ & $\mathbf{R}_{\mathbf{H}}(\mathbf{\Omega})$ & рн $(\Omega \mathrm{m})$ & $\begin{array}{c}\rho \mathrm{H} \text { medio } \\
(\Omega \mathrm{m})\end{array}$ & $\rho\left(\mathrm{kg} / \mathrm{m}^{3}\right)$ \\
\hline \multirow{2}{*}{2} & 89,20 & 672,65 & 657,70 & 207,89 & \multirow{2}{*}{221,16} & \multirow{2}{*}{2347,34} \\
\hline & 79,30 & 756,62 & 741,67 & 234,43 & & \\
\hline \multirow{2}{*}{3} & 54,50 & 1100,92 & 1085,97, & 174,83 & \multirow{2}{*}{182,81} & \multirow{2}{*}{2351,13} \\
\hline & 50,00 & 1200,00 & 1185,05 & 190,78 & & \\
\hline \multirow{2}{*}{4} & 26,23 & 2287,46 & 2272,51 & 248,18 & \multirow{2}{*}{252,31} & \multirow{2}{*}{2342,74} \\
\hline & 25,39 & 2363,14 & 2348,19 & 256,44 & & \\
\hline \multirow{2}{*}{5} & 16,84 & 3562,95 & 3548,00 & 282,37 & \multirow{2}{*}{288,16} & \multirow{2}{*}{2350,99} \\
\hline & 16,18 & 3708,28 & 3693,33 & 293,94 & & \\
\hline
\end{tabular}

Tabla 4. Resultados obtenidos en prueba del ensayo sobre probeta “H25 SD”

Puede observarse que los valores de la resistividad aumentan respecto a la prueba 
anterior, aunque se registran intensidades similares, la mayoría de las cuales sigue quedando fuera del intervalo (30-50 mA). Dado que según la norma UNE 83988-1, la fuente de alimentación debe suministrar el voltaje suficiente para que la intensidad que circula por el hormigón esté comprendida dentro de tal intervalo, se plantea la necesidad de emplear un variador de tensión en corriente alterna que permita tal ajuste de la intensidad.

\subsubsection{Utilización de corriente alterna.}

Como se ha indicado al final del apartado anterior, el ensayo debe realizarse con un variador de tensión de corriente alterna que permita encajar la intensidad entre 30$50 \mathrm{~mA}$, controlando manualmente el voltaje. Las figuras 8 y 9 muestran el equipo empleado así como la realización de una de las medidas:

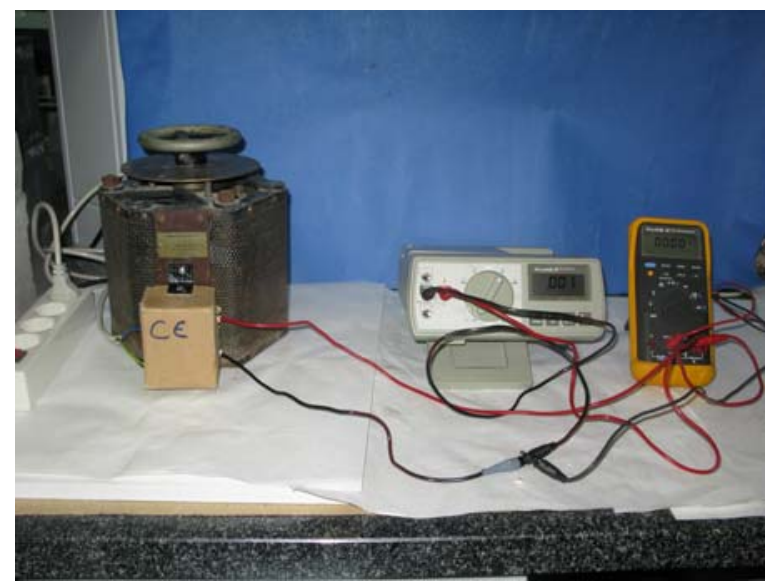

Fig.8. Montaje eléctrico para la realización del ensayo con variador de tensión c.alterna.
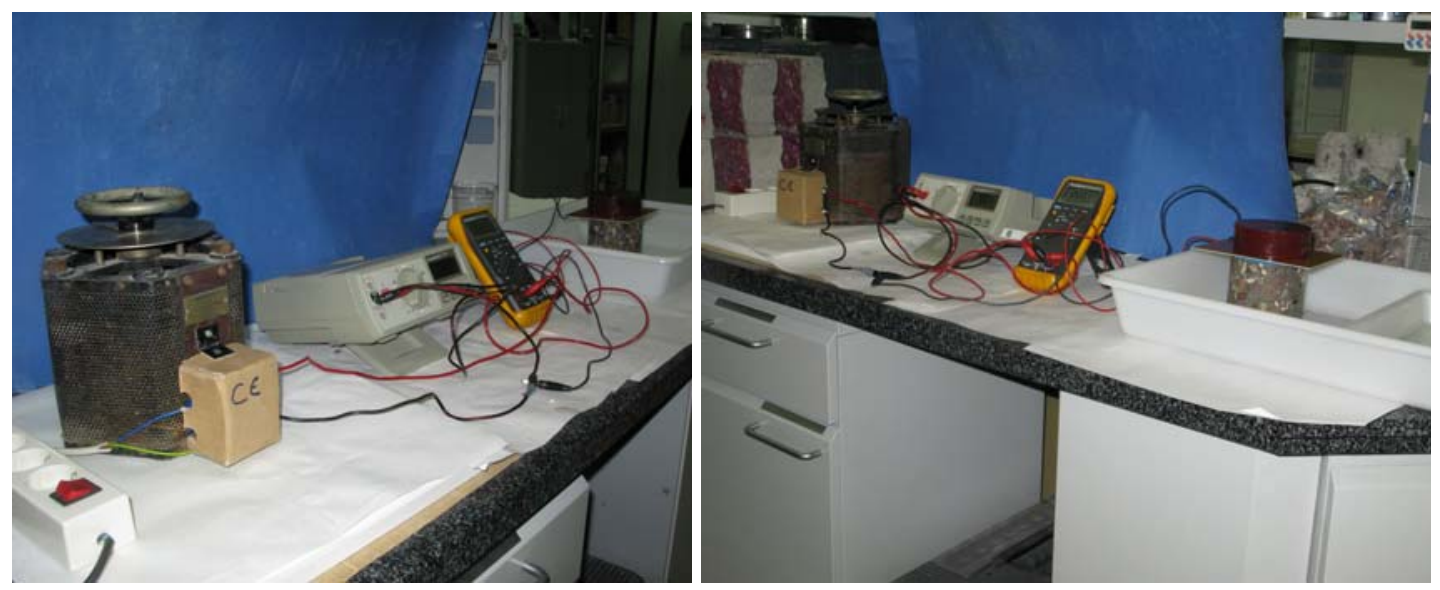

Fig.9. Vistas de la medida de la resistividad eléctrica de una de las rodajas. 
A continuación, la tabla 5 recoge los resultados obtenidos en el ensayo:

\begin{tabular}{|c|c|c|c|c|c|c|c|}
\hline Rodaja & V (v) & I (mA) & $\mathbf{R}_{\mathrm{T}}(\boldsymbol{\Omega})$ & $\mathbf{R}_{H}(\Omega)$ & $\rho_{\mathrm{H}}(\Omega \mathrm{m})$ & $\begin{array}{c}\rho_{\mathrm{H} \text { medio }} \\
(\Omega \mathrm{m})\end{array}$ & $\rho\left(\mathrm{kg} / \mathrm{m}^{3}\right)$ \\
\hline \multirow{2}{*}{2} & 32,28 & 40,80 & 791,18 & 776,18 & 245,34 & \multirow{2}{*}{248,26} & \multirow{2}{*}{2347,34} \\
\hline & 37,00 & 45,70 & 809,63 & 794,63 & 251,17 & & \\
\hline \multirow{2}{*}{3} & 47,40 & 40,55 & 1168,93 & 1153,93 & 185,77 & \multirow{2}{*}{189,55} & \multirow{2}{*}{2351,13} \\
\hline & 42,00 & 35,08 & 1197,26 & 1182,26 & 190,33 & & \\
\hline \multirow{2}{*}{4} & 88,70 & 40,10 & 2211,97 & 2196,97 & 239,93 & \multirow{2}{*}{242,72} & \multirow{2}{*}{2342,74} \\
\hline & 88,10 & 38,93 & 2363,04 & 2248,04 & 245,50 & & \\
\hline \multirow{2}{*}{5} & 110,10 & 31,10 & 3540,19 & 3525,19 & 280,56 & \multirow{2}{*}{281,20} & \multirow{2}{*}{2350,99} \\
\hline & 111,20 & 31,27 & 3556,12 & 3541,12 & 281,83 & & \\
\hline
\end{tabular}

Tabla 5. Resultados obtenidos en prueba del ensayo sobre probeta "H25 SD".

Se observa en la tabla que los valores de intensidad se ajustan al intervalo exigido por la norma 83988-1 en todos los casos.

\subsubsection{Utilización del nuevo variador de corriente.}

Se adquiere un nuevo variador de corriente, por lo cual se realiza un contraste de resultados con el nuevo equipo, obteniéndose los valores de medida recogidos en la tabla 6.

Anteriormente las esponjas se encontraban humedecidas sin escurrir, sin retirar el exceso de agua. Para ver si este detalle tiene influencia, con el nuevo variador de tensión adquirido se calcula el valor de resistencia de las esponjas humedecidas y escurridas, necesario para el cálculo de la resistencia del hormigón:

$R_{\text {esponjas }}=2,27 \mathrm{v} /\left(159^{\star} 10^{-3}\right) A=16,16 \Omega$, se toma $16 \Omega$ como valor a restar a $R_{T}$ para obtener $\mathrm{R}_{\mathrm{H}}$.

El valor es muy similar a los $15 \Omega$ obtenidos en la prueba anterior, por lo que no se considera un factor con influencia en la medida.

Se decide repetir el ensayo empleando el nuevo variador con las rodajas de la tabla 5 escurridas las esponjas después de humedecerse, obteniendo los resultados que se indican en la tabla 6. 


\begin{tabular}{|c|c|c|c|c|c|c|c|}
\hline Rodaja & $\mathrm{V}(\mathrm{v})$ & I (mA) & $\mathbf{R}_{\mathrm{T}}(\boldsymbol{\Omega})$ & $\mathbf{R}_{\mathbf{H}}(\boldsymbol{\Omega})$ & $\rho_{\mathrm{H}}(\Omega \mathrm{m})$ & $\begin{array}{c}\rho_{\mathrm{H}}^{\mathrm{m} m e d i o} \\
(\Omega \mathrm{m})\end{array}$ & $\rho\left(\mathrm{kg} / \mathrm{m}^{3}\right)$ \\
\hline \multirow{2}{*}{2} & 60,50 & 40,91 & 1478,86 & 1462,86 & 462,38 & \multirow{2}{*}{498,67} & \multirow{2}{*}{2347,34} \\
\hline & 70,90 & 41,50 & 1708,43 & 1692,43 & 534,95 & & \\
\hline \multirow{2}{*}{3} & 72,20 & 40,36 & 1788,90 & 1772,90 & 285,41 & \multirow{2}{*}{302,99} & \multirow{2}{*}{2351,13} \\
\hline & 83,30 & 41,50 & 2007,23 & 1991,23 & 320,56 & & \\
\hline \multirow{2}{*}{4} & 107,70 & 40,48 & 2660,57 & 2644,57 & 288,81 & \multirow{2}{*}{299,18} & \multirow{2}{*}{2342,74} \\
\hline & 115,10 & 40,38 & 2850,42 & 2834,42 & 309,54 & & \\
\hline & 165,30 & 40,46 & 4085,52 & 4069,52 & 323,88 & \multirow{2}{*}{315,32} & \multirow{2}{*}{2350,99} \\
\hline & 155,90 & 40,28 & 3870,41 & 3854,41 & 306,76 & & \\
\hline
\end{tabular}

Tabla.6. Resultados obtenidos en prueba del ensayo sobre probeta "H25 SD”.

La figura 10 muestra el gráfico donde se comparan los valores medios de los resultados de resistividad obtenidos en los ensayos realizados con las rodajas de hormigón H25 SD con ambos variadores. Los datos corresponden a las tablas 5 y 6 aportadas previamente.

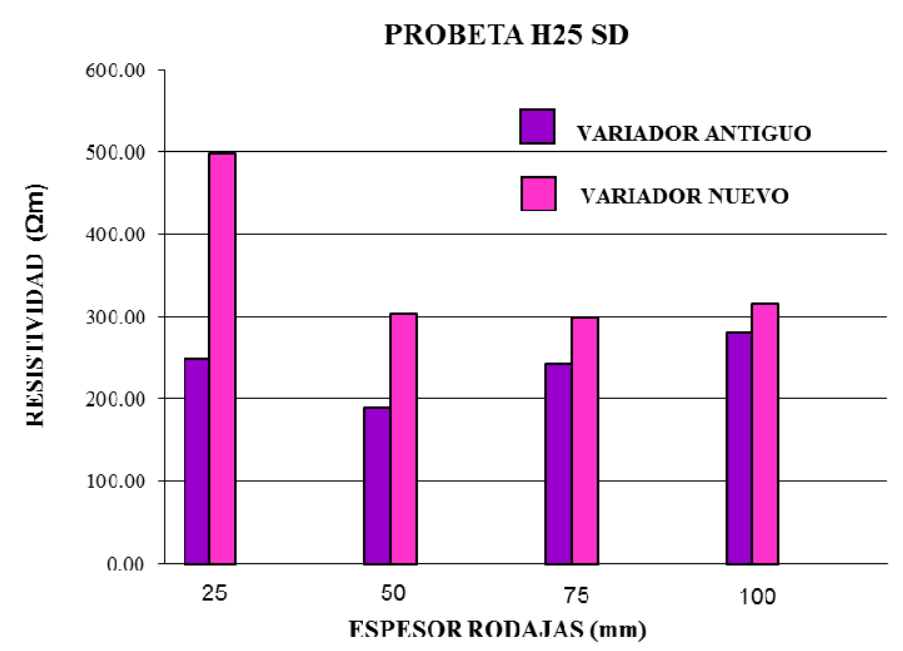

Fig.10. Valores medios de resistividad obtenidos a partir de ensayos en probeta H25-SD.

La comparación entre los valores de las tablas 5 y 6 muestra que el nuevo variador permite ajustar una intensidad de corriente mucho más estable para la realización de las medidas. Asimismo la figura 10 indica la gran sensibilidad de las rodajas de pequeño espesor a la medida realizada (nuevo y antiguo variador), que sin embargo es más uniforme en las rodajas de mayor espesor en las que ambos variadores proporcionan medidas similares.

Tras las pruebas realizadas con la probeta "H25-SD", se valida la utilización del nuevo 
variador de tensión.

\section{2.- INFLUENCIA DE LAS DIMENSIONES DE LA PROBETA}

\subsection{1.-Materiales Utilizados.}

Para valorar la influencia de las dimensiones de la probeta en el resultado de la medida de resistividad se utilizan dos calidades de hormigón, $\mathrm{H} 25$ y H50, con el fin de obtener así medidas en un rango amplio de resistencias del hormigón.

Se localiza una probeta conservada durante largo tiempo en el laboratorio, "H25-CD". De este hormigón se conoce su resistencia (H25), su dosificación (ver tabla 7) y su relación $a / c=0,65$. Dado que su diámetro $(15 \mathrm{~cm})$ era superior al tamaño de los electrodos empleados en el ensayo, se decide extraer un testigo de diámetro $10 \mathrm{~cm}$ para seguir lo dispuesto por la norma 83988-1. La figura 12 muestra la probeta inicial y el testigo extraído posteriormente de ella.
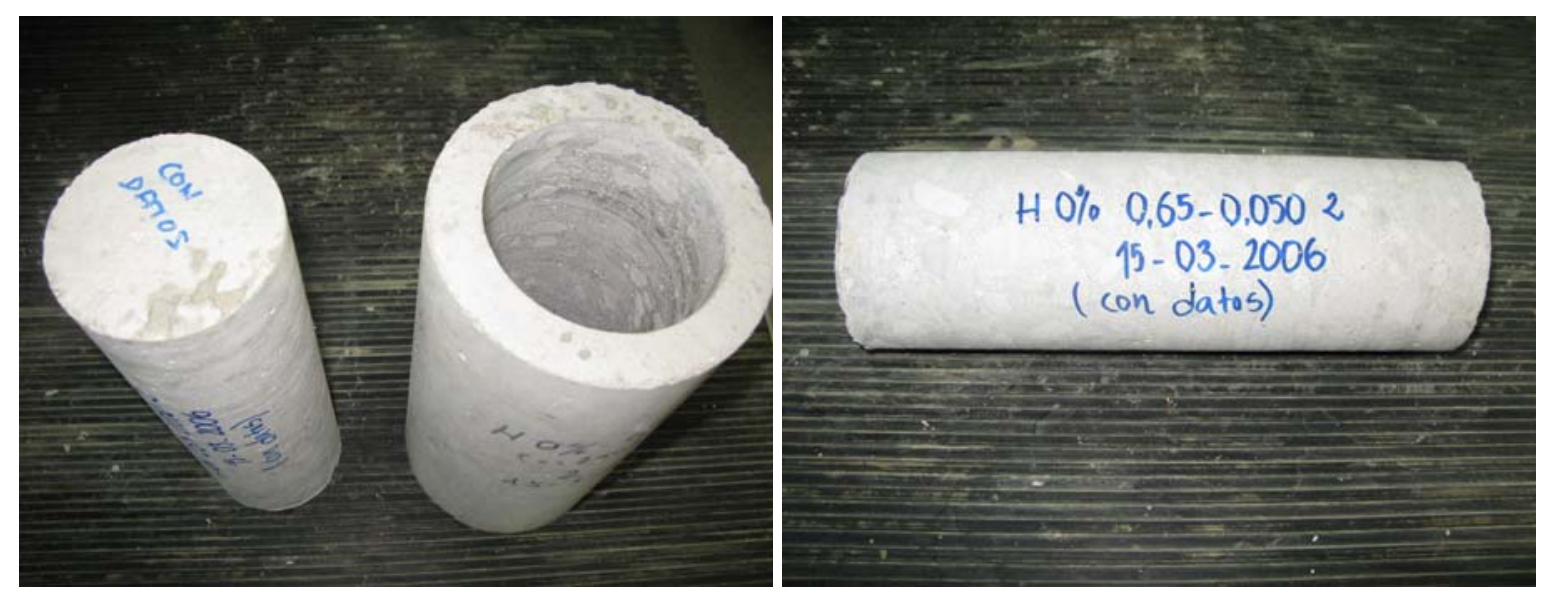

Fig.12. Probeta original H25 CD y testigo extraído.

\begin{tabular}{|c|c|}
\hline Material & Cantidad (kg)/ $\mathbf{m}^{\mathbf{3}}$ \\
\hline \hline Cemento & 275 \\
\hline Agua & 178,75 \\
\hline Arena (AN) & 843,01 \\
\hline Grava (GVN) & 751,96 \\
\hline Gravilla (GVLN) & 225,91 \\
\hline a/c & 0,65 \\
\hline
\end{tabular}

Tabla 7. Dosificación empleada para fabricación de hormigón H25.

De modo análogo a como se procedió con la probeta "H25-SD", se divide el testigo 
extraído en rodajas con el fin de analizar la posible influencia del espesor en la medida de la resistividad eléctrica. Con este fin, se trocea en 6 rodajas comenzando por la cara de cierre e indicando mediante flechas el sentido de llenado de la probeta. Las rodajas 1 y 6 no se emplean para el ensayo por corresponder al saneo del testigo. Una vez cortadas, se procede a la medida de su espesor ( $e_{1}$ a $\left.e_{4}\right)$, diámetro y peso. La tabla 8 recoge estos datos:

\begin{tabular}{|c|c|c|c|c|c|c|}
\hline \hline Rodaja & $\mathrm{e}_{1}(\mathbf{m m})$ & $\mathrm{e}_{\mathbf{2}}(\mathbf{m m})$ & $\mathrm{e}_{\mathbf{3}}(\mathbf{m m})$ & $\mathrm{e}_{\mathbf{4}}(\mathbf{m m})$ & $\mathrm{e}_{\mathbf{m}}(\mathbf{m m})$ & Peso (gr) \\
\hline \hline $\mathbf{2}$ & 25,54 & 25,54 & 25,59 & 25,63 & $\mathbf{2 5 , 5 8}$ & $\mathbf{4 6 1 , 3 0}$ \\
\hline $\mathbf{3}$ & 50,16 & 50,13 & 50,02 & 49,98 & $\mathbf{5 0 , 0 7}$ & $\mathbf{9 0 5 , 4 0}$ \\
\hline $\mathbf{4}$ & 75,25 & 75,30 & 75,50 & 75,30 & $\mathbf{7 5 , 3 4}$ & $\mathbf{1 3 5 7 , 9 0}$ \\
\hline $\mathbf{5}$ & 96,70 & 97,72 & 97,49 & 96,70 & $\mathbf{9 7 , 1 5}$ & $\mathbf{1 7 5 8 , 4 0}$ \\
\hline
\end{tabular}

Tabla 8. Espesores y pesos de las rodajas de la probeta “H25-CD” cuyo Ømedio $=99,64 m m$

Las probetas de hormigón $\mathrm{H} 50$ se fabrican en laboratorio incorporando humo de sílice (10\%). El árido es de machaqueo y su tamaño máximo es $20 \mathrm{~mm}$. La dosificación empleada para la amasada es la indicada en la tabla 9:

\begin{tabular}{|c|c|}
\hline Material & Cantidad (kg)/45 Litros \\
\hline \hline Cemento & 18,2 \\
\hline Humo de Sílice & 1,8 \\
\hline Arena (silícea) & 27,2 \\
\hline Gravilla (machaqueo) & 30,1 \\
\hline Grava (machaqueo) & 22,3 \\
\hline Aditivo (Sikament) & 0,4 \\
\hline Agua & 7,4 \\
\hline
\end{tabular}

Tabla 9. Dosificación empleada para fabricación de hormigón H50 con 10\% H.S.

Las figuras 13, 14 y 15 muestran el proceso de fabricación de las probetas de hormigón: 

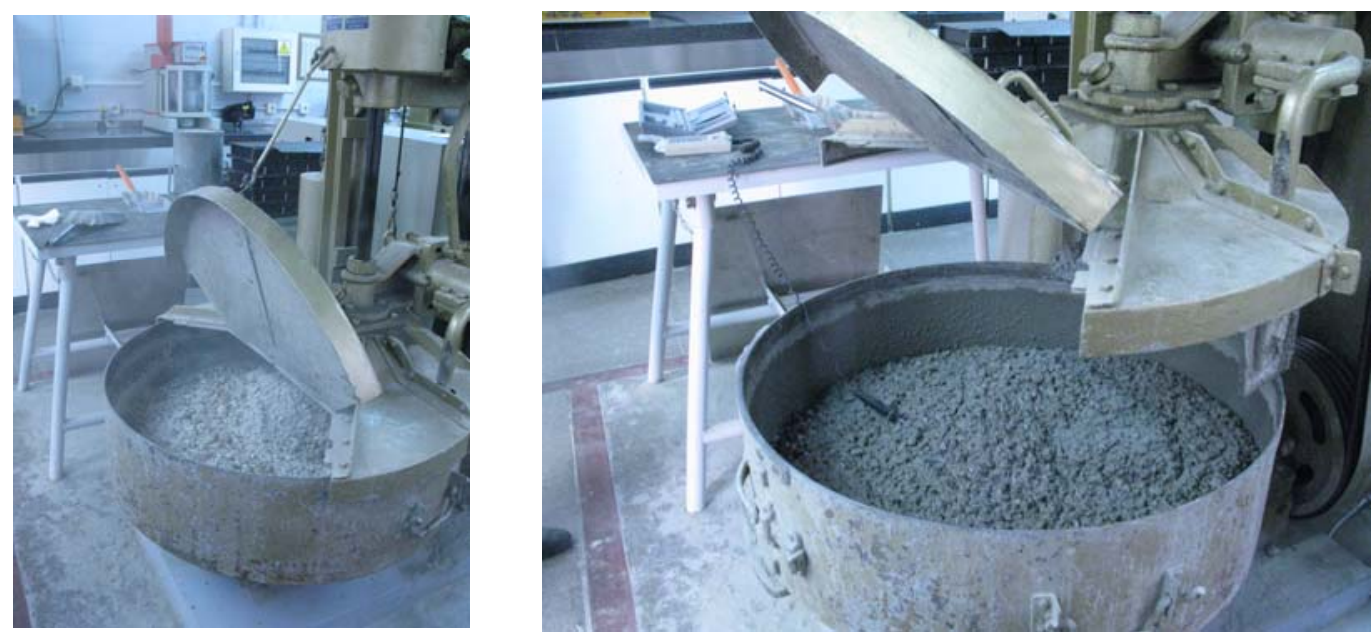

Fig.13. Proceso de hormigonado y medición de la temperatura.
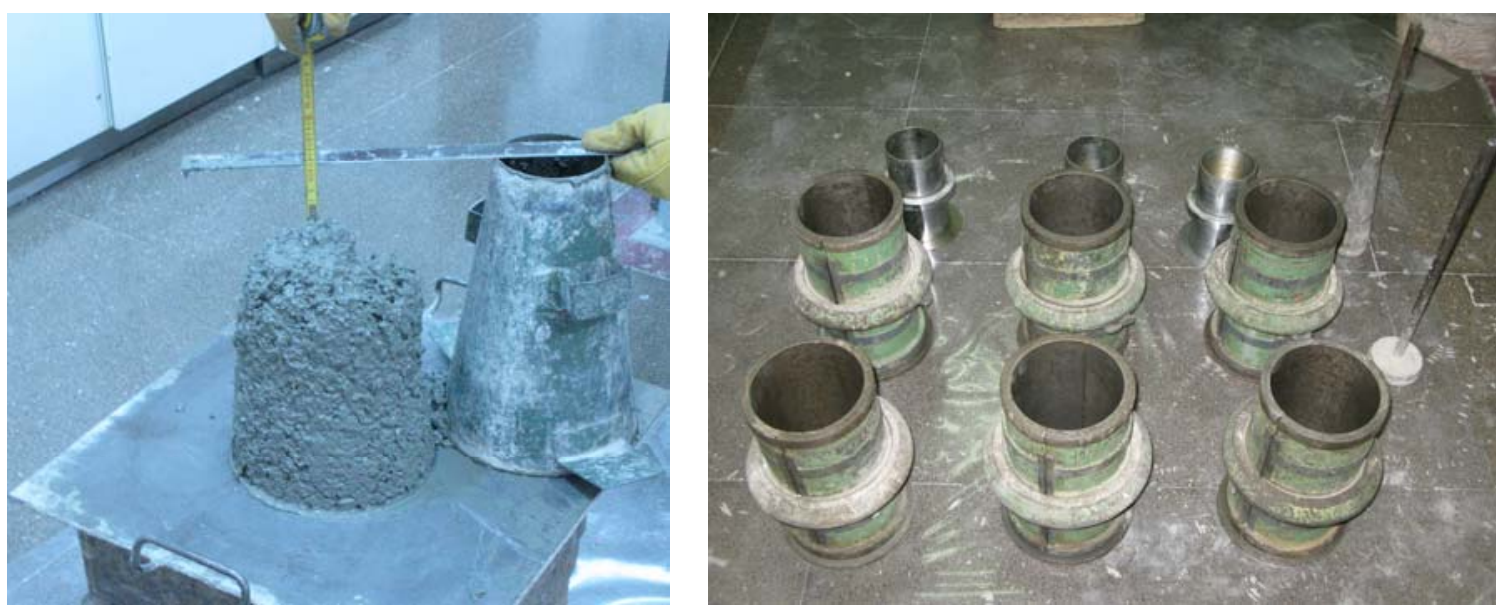

Fig.14 Cono de Abrams y moldes empleados para la fabricación de las probetas.
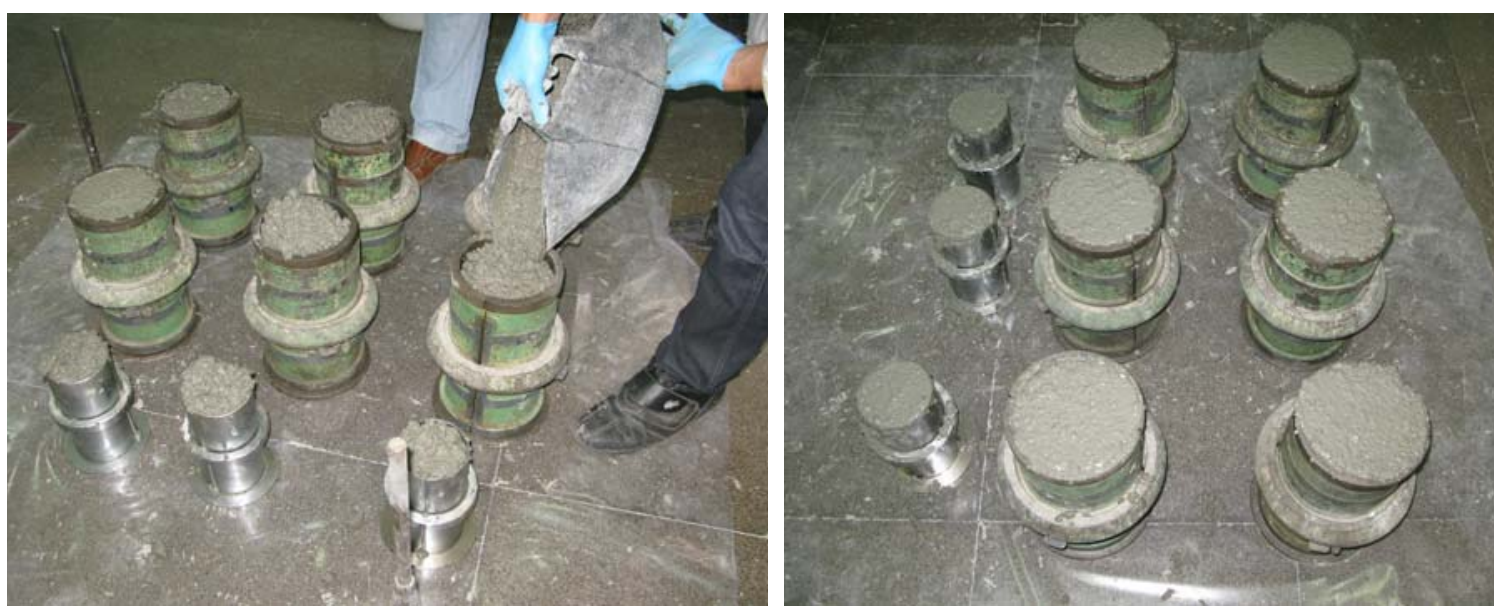

Fig.15. Fabricación de probetas y vista de los moldes una vez rellenados.

Se fabrican nueve probetas cilíndricas, tres de $10 \mathrm{~cm}$ (diámetro) $\times 20 \mathrm{~cm}$ (longitud) y seis de $15 \mathrm{~cm}$ (diámetro) $\times 30 \mathrm{~cm}$ (longitud) para evaluar también el posible efecto del diámetro de la probeta en la medida de la resistividad. 


\subsection{2.-Ensayos de Resistencia a Compresión.}

Una vez fabricadas, se dejan durante 28 días en la cámara de curado. Entonces se procede a la rotura a compresión de dos de ellas (15×30). La figura 16 muestra la prensa empleada durante el ensayo de rotura y las figuras 17 y 18 reflejan el aspecto de las probetas H50-1 y H50-2 antes y después del ensayo de rotura a compresión:

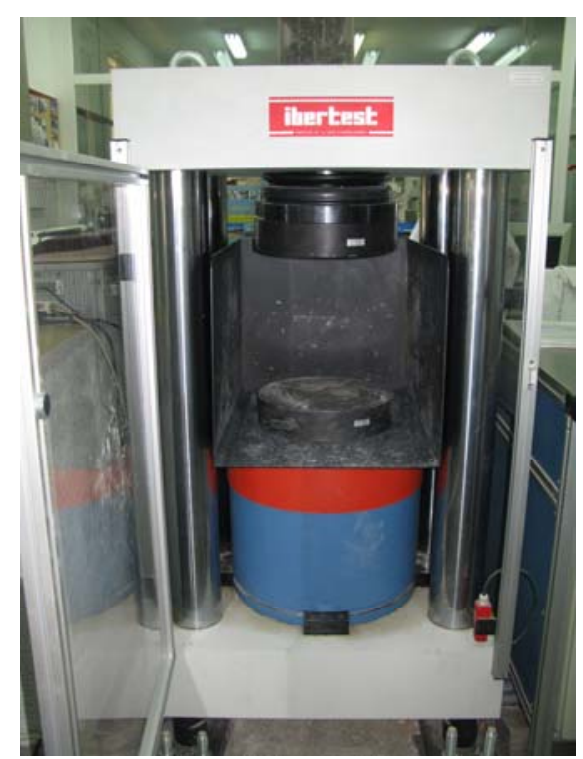

Fig.16. Vista de la prensa empleada para el ensayo de rotura a compresión

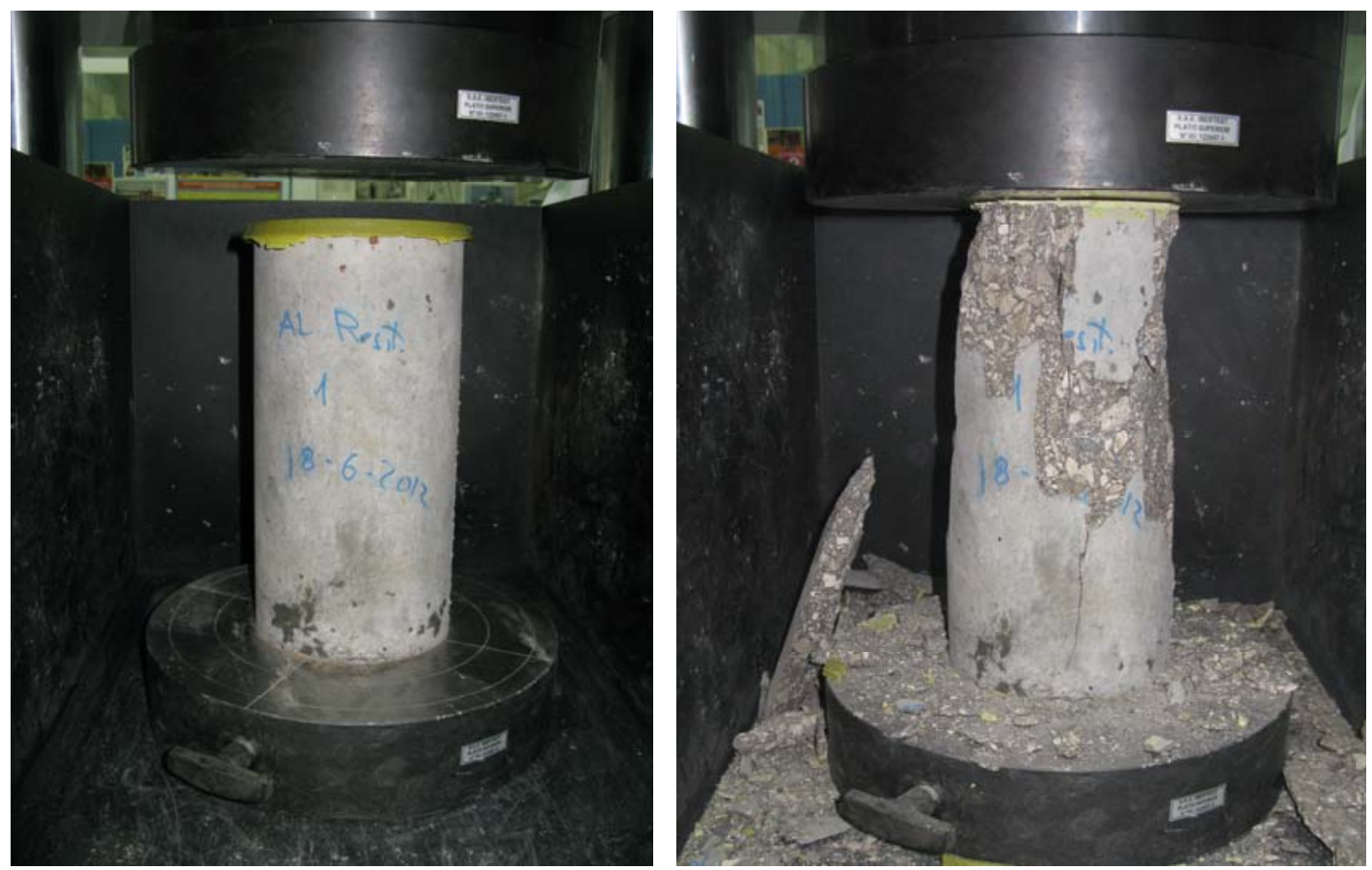

Fig.17. Aspecto de la probeta $n^{o} 1$ antes y después de la rotura. 

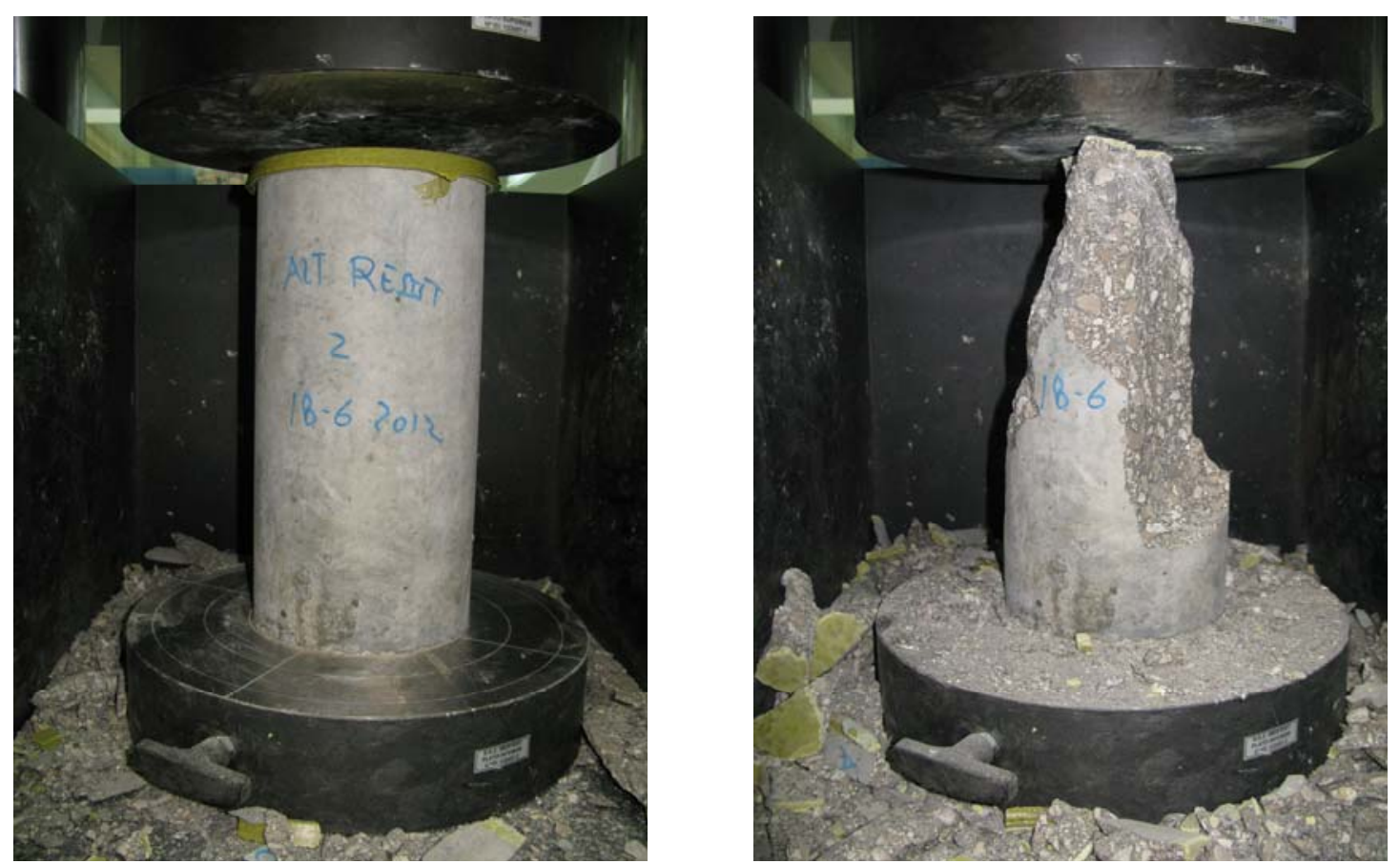

Fig.18.Aspecto de la probeta $n^{\circ} 2$ antes y después de la rotura.

Se obtienen cargas de rotura a compresión de 78,40MPa y $84,60 \mathrm{MPa}$, respectivamente.

\subsection{3.- Ensayos de Resistividad: Influencia del Espesor de Rodaja.}

\subsubsection{Resultados.}

A continuación, se procede a practicar cortes en las probetas para la obtención de rodajas. En el caso de las de $200 \mathrm{~mm}$ de longitud, se obtienen únicamente dos rodajas, de $75 \mathrm{~mm}$ y $100 \mathrm{~mm}$. De ese modo, se realiza el ensayo sobre rodajas de espesor igual a tres veces el tamaño máximo del árido $(20 \mathrm{~mm})$. En el caso de las de $300 \mathrm{~mm}$ de longitud se cortan las cuatro rodajas: 25; 50; 75 y 100mm. Por tanto los espesores de rodaja varían entre una y 10 veces el tamaño máximo del árido utilizado. Se ensayan dos probetas de cada diámetro, reservando el resto. La figura 19 muestra las probetas "H5010.1 " y "H50-10.2" ( $\varnothing=10 \mathrm{~cm})$ y la figura 20 las probetas "H50-15.1" y "H50-15.2" $(\varnothing=15 \mathrm{~cm})$ una vez cortadas las rodajas. En la nomenclatura utilizada se refleja el diámetro utilizado en cada caso (10 y $15 \mathrm{~cm})$. 


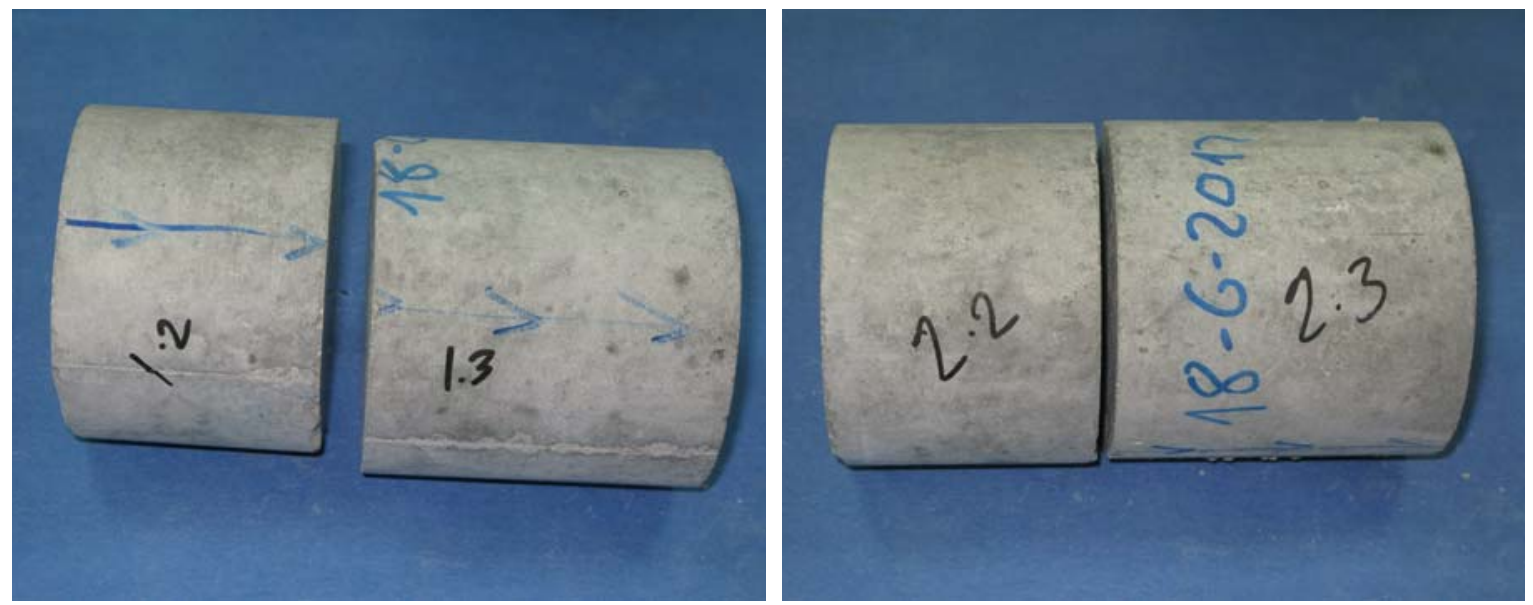

Fig.19. Vista frontal de las rodajas de las probetas “H50-10.1” y “H50-10.2” (10cm x 20cm).
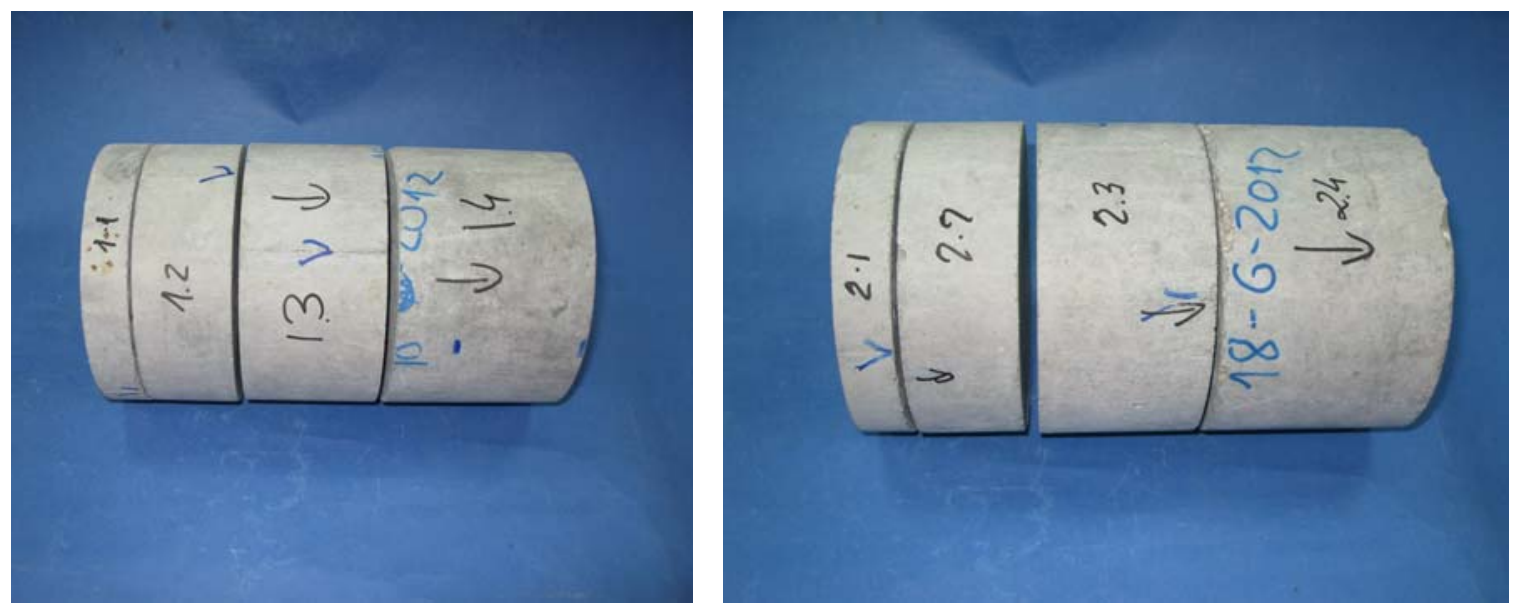

Fig.20. Vista frontal de las rodajas de las probetas “H50-15.1” $y$ “H50-15.2” (15cm x 30cm).

Antes de proceder a la saturación en vacío de las rodajas, se miden sus espesores, diámetros y pesos, tal y como se indica en las tablas 10, 11 y 12:

\begin{tabular}{|c|c|c|c|c|c|c|c|}
\hline Rodaja & $\varnothing_{\mathrm{m}}(\mathrm{mm})$ & $\mathbf{e}_{1}(\mathrm{~mm})$ & $\mathbf{e}_{2}(\mathrm{~mm})$ & $\mathbf{e}_{3}(\mathrm{~mm})$ & $\mathbf{e}_{4}(\mathrm{~mm})$ & $\mathbf{e}_{m}(\mathrm{~mm})$ & Peso (gr) \\
\hline 1.2 & 100,17 & 74,72 & 74,67 & 74,63 & 74,93 & 74,74 & 1421,80 \\
\hline 1.3 & 100,52 & 100,51 & 101,14 & 100,99 & 100,77 & 100,85 & 1939,60 \\
\hline 2.2 & 100,49 & 75,22 & 75,07 & 74,98 & 75,40 & 75,17 & 1439,10 \\
\hline 2.3 & 101,01 & 98,56 & 98,72 & 98,35 & 98,39 & 98,51 & 1926,20 \\
\hline
\end{tabular}

Tabla.10. Diámetros, espesores y pesos de las rodajas correspondientes a las probetas “H50-10.1” y

“H50-10.2”. 


\begin{tabular}{|c||c||c||c|c|c|c|c||}
\hline Rodaja & $\left.\boldsymbol{\emptyset}_{\mathbf{m}} \mathbf{( m m}\right)$ & $\left.\mathbf{e}_{\mathbf{1}} \mathbf{( m m}\right)$ & $\mathbf{e}_{\mathbf{2}}(\mathbf{m m})$ & $\left.\mathbf{e}_{\mathbf{3}} \mathbf{( m m}\right)$ & $\left.\mathbf{e}_{\mathbf{4}} \mathbf{( m m}\right)$ & $\left.\mathbf{e}_{\mathbf{m}} \mathbf{( m m}\right)$ & Peso (gr) \\
\hline \hline $\mathbf{1 . 1}$ & $\mathbf{1 5 0 , 2 1}$ & 24,50 & 24,70 & 25,15 & 26,40 & $\mathbf{2 5 , 1 9}$ & $\mathbf{1 0 6 4 , 0 0}$ \\
\hline $\mathbf{1 . 2}$ & $\mathbf{1 5 0 , 2 3}$ & 50,36 & 50,78 & 50,88 & 50,53 & $\mathbf{5 0 , 6 4}$ & $\mathbf{2 1 4 7 , 6 0}$ \\
\hline $\mathbf{1 . 3}$ & $\mathbf{1 5 0 , 4 5}$ & 75,20 & 75,35 & 75,06 & 74,77 & $\mathbf{7 5 , 1 0}$ & $\mathbf{3 2 1 2 , 1 0}$ \\
\hline $\mathbf{1 . 4}$ & $\mathbf{1 5 0 , 7 2}$ & 103,86 & 105,80 & 104,86 & 103,55 & $\mathbf{1 0 4 , 5 2}$ & $\mathbf{4 5 1 3 , 3 0}$ \\
\hline
\end{tabular}

Tabla.11. Diámetros, espesores y pesos de las rodajas correspondientes a la probeta "H50-15.1”.

\begin{tabular}{|c|c||c|c||c|c||c||c||}
\hline Rodaja & $\left.\boldsymbol{\emptyset}_{\mathbf{m}} \mathbf{( m m}\right)$ & $\mathbf{e}_{\mathbf{1}}(\mathbf{m m})$ & $\left.\mathbf{e}_{\mathbf{2}} \mathbf{( m m}\right)$ & $\left.\mathbf{e}_{\mathbf{3}} \mathbf{( m m}\right)$ & $\mathbf{e}_{\mathbf{4}}(\mathbf{m m})$ & $\left.\mathbf{e}_{\mathbf{m}} \mathbf{( m m}\right)$ & Peso (gr) \\
\hline \hline $\mathbf{2 . 1}$ & $\mathbf{1 4 9 , 6 2}$ & 26,52 & 26,50 & 25,95 & 24,67 & $\mathbf{2 5 , 9 1}$ & $\mathbf{1 0 7 9 , 6 0}$ \\
\hline $\mathbf{2 . 2}$ & $\mathbf{1 4 9 , . 8 6}$ & 50,12 & 50,13 & 50,51 & 50,17 & $\mathbf{5 0 , 2 3}$ & $\mathbf{2 1 4 0 , 5 0}$ \\
\hline $\mathbf{2 . 3}$ & $\mathbf{1 4 9 , 9 3}$ & 75,71 & 75,24 & 75,23 & 75,33 & $\mathbf{7 5 , 3 8}$ & $\mathbf{3 1 9 1 , 5 0}$ \\
\hline $\mathbf{2 . 4}$ & $\mathbf{1 5 0 , 0 2}$ & 101,40 & 100,35 & 100,96 & 102,06 & $\mathbf{1 0 1 , 1 9}$ & $\mathbf{4 3 1 3 , 3 0}$ \\
\hline
\end{tabular}

Tabla.12. Diámetros, espesores y pesos de las rodajas correspondientes a la probeta “H50-15.2”.

Se procede a su saturación en vacío preparándolas así para el ensayo de resistividad eléctrica, de acuerdo con la norma. La figura 21 muestra las rodajas en el momento de su transporte a la cámara de saturación y el detalle de los poros que presenta una de ellas.
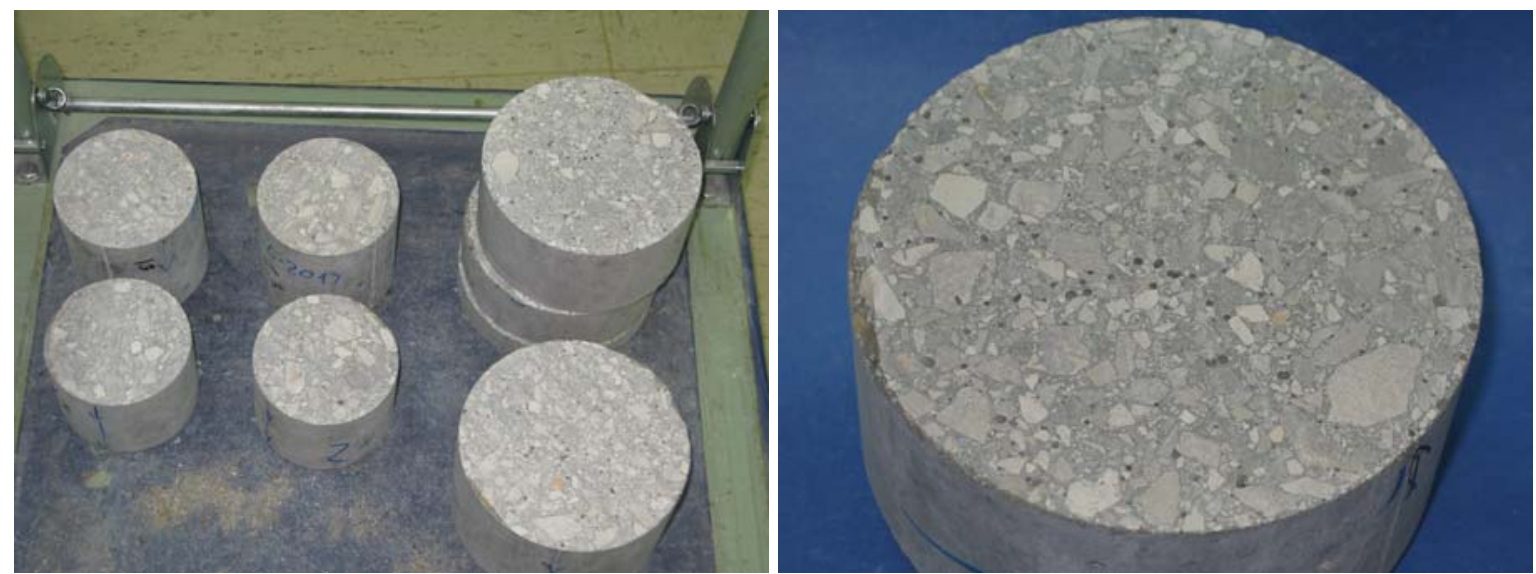

Fig.21. Vista general de las rodajas y detalle de una de ellas.

Después de llevar a cabo la saturación de las cuatro rodajas de hormigón H50 de $\varnothing 10 \mathrm{~cm}$ y de las pertenecientes a la probeta de "H25-CD", se realiza el ensayo de resistividad en estas rodajas.

La figura 22 muestra el montaje del ensayo así como la ejecución de una de las medidas: 

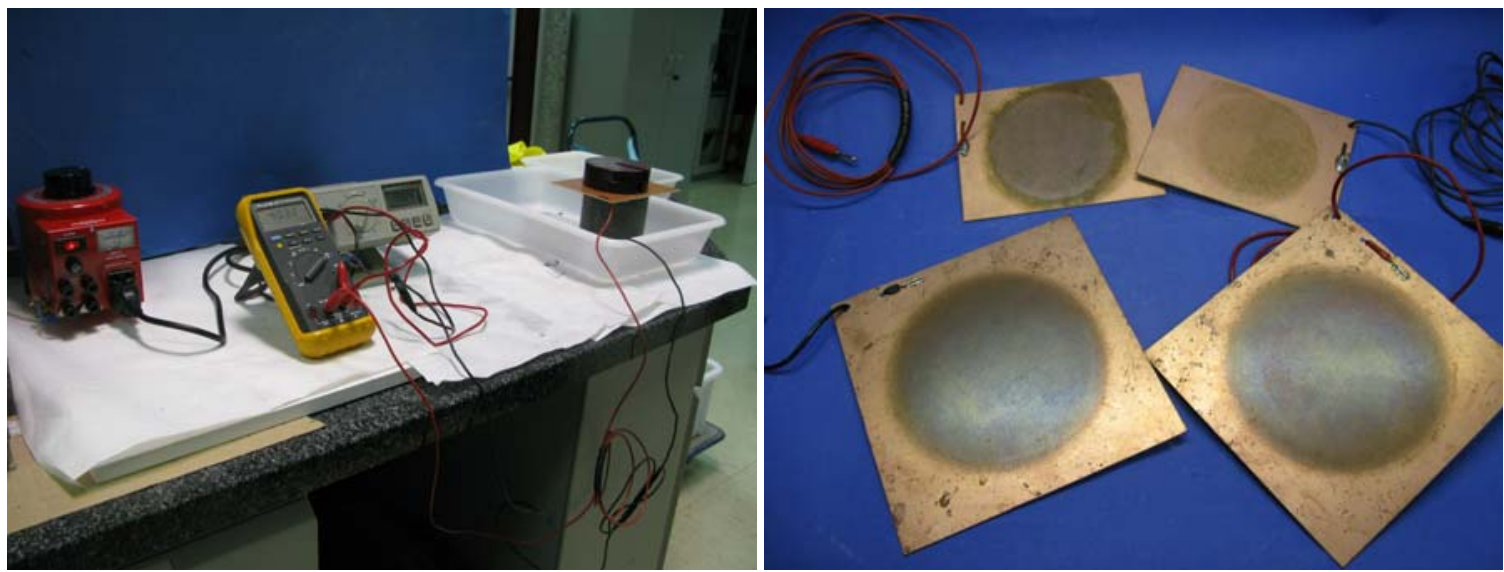

Fig.22. Vista gral del montaje en la realización de una de las medidas sobre testigo (electrodo de $10 \mathrm{~cm})$. A la derecha se observan los dos tipos de electrodos empleados en el ensayo (15cm y $10 \mathrm{~cm})$.

A continuación las tablas 13,14 , y 15 muestran los resultados obtenidos durante el ensayo:

\begin{tabular}{|c|c|c|c|c|c|c|c|}
\hline Rodaja & $V(v)$ & $I(m A)$ & $\mathbf{R}_{\mathrm{T}}(\mathbf{\Omega})$ & $\mathbf{R}_{\mathbf{H}}(\mathbf{\Omega})$ & $\rho н(\Omega m)$ & $\begin{array}{c}\rho \mathrm{H} \text { medio } \\
(\Omega \mathrm{m})\end{array}$ & $\rho\left(\mathrm{kg} / \mathrm{m}^{3}\right)$ \\
\hline \multirow{2}{*}{1.2} & 150,20 & 40,50 & 3708,64 & 3692,64 & 401,56 & \multirow{2}{*}{396,75} & \multirow{2}{*}{2343,40} \\
\hline & 146,00 & 40,33 & 3620,13 & 3604,13 & 391,93 & & \\
\hline \multirow{2}{*}{1.3} & 190,20 & 40,35 & 4713,75 & 4697,75 & 369,34 & \multirow{2}{*}{365,20} & \multirow{2}{*}{2423,75} \\
\hline & 186,00 & 40,36 & 4608,52 & 4592,52 & 361,06 & & \\
\hline
\end{tabular}

Tabla.13. Resultados obtenidos durante el ensayo probeta “H50-10.1” $\left(\emptyset_{m, 1.2}=101,70 \mathrm{~mm} ; \emptyset_{m, 1.3}=\right.$

$100,50 \mathrm{~mm})$.

\begin{tabular}{|c|c|c|c|c|c|c|c|}
\hline Rodaja & $V(v)$ & $I(m A)$ & $\mathbf{R}_{\mathrm{T}}(\boldsymbol{\Omega})$ & $\mathbf{R}_{\mathbf{H}}(\mathbf{\Omega})$ & $\rho_{H}(\Omega m)$ & $\begin{array}{c}\rho_{H} \text { medio } \\
(\Omega \mathrm{m})\end{array}$ & $\rho\left(\mathrm{kg} / \mathrm{m}^{3}\right)$ \\
\hline \multirow{2}{*}{2.2} & 147,40 & 40,34 & 3653,94 & 3637,94 & 383,76 & \multirow{2}{*}{380,07} & \multirow{2}{*}{2412,24} \\
\hline & 144,40 & 40,29 & 3584,02 & 3568,02 & 376,38 & & \\
\hline \multirow{2}{*}{2.3} & 184,50 & 40,30 & 4578,16 & 4562,16 & 371,08 & \multirow{2}{*}{368,44} & \multirow{2}{*}{2440,55} \\
\hline & 181,70 & 40,26 & 4513,16 & 4497,16 & 365,79 & & \\
\hline
\end{tabular}

Tabla.14. Resultados obtenidos durante el ensayo probeta H50-10.2 $\left(\varnothing_{m, 2.2}=100,50 \mathrm{~mm} ; \varnothing_{m, 2.3}=\right.$

$101,00 \mathrm{~mm})$. 


\begin{tabular}{|c|c|c|c|c|c|c|c|}
\hline Rodaja & $V(v)$ & I (mA) & $\mathbf{R}_{\mathrm{T}}(\boldsymbol{\Omega})$ & $R_{H}(\Omega)$ & $\rho_{\mathrm{H}}(\Omega \mathrm{m})$ & $\begin{array}{c}\rho_{\mathrm{H} \text { medio }} \\
(\Omega \mathrm{m})\end{array}$ & $\rho\left(\mathrm{kg} / \mathrm{m}^{3}\right)$ \\
\hline \multirow{2}{*}{2} & 26,56 & 40,30 & 659,06 & 643,06 & 195,71 & \multirow{2}{*}{ 199,11 } & \multirow{2}{*}{2311,28} \\
\hline & 28,21 & 41,40 & 681,40 & 665,40 & 202,51 & & \\
\hline \multirow{2}{*}{3} & 38,90 & 41,50 & 937,35 & 921,35 & 143,28 & \multirow{2}{*}{144,03} & \multirow{2}{*}{2318,47} \\
\hline & 39,30 & 41,50 & 946,99 & 930,99 & 144,78 & & \\
\hline \multirow{2}{*}{4} & 37,30 & 40,85 & 913,10 & 897,10 & 92,82 & \multirow{2}{*}{90,18} & \multirow{2}{*}{2314,71} \\
\hline & 35,60 & 41,30 & 861,99 & 845,99 & 87,53 & & \\
\hline & 47,40 & 40,65 & 1166,05 & 1150,05 & 92,18 & \multirow{2}{*}{90,40} & \multirow{2}{*}{2321,37} \\
\hline & 45,40 & 40,48 & 1121,54 & 1105,54 & 88,62 & & \\
\hline
\end{tabular}

Tabla.15. Resultados obtenidos durante el ensayo probeta “H25-CD” (Ø $\left.\varnothing_{m}=99,60 \mathrm{~mm}\right)$.

A continuación se aportan gráficos comparando los valores medios obtenidos a partir de las resistividades medidas en los ensayos realizados sobre las rodajas $75 \mathrm{~mm}$ y $100 \mathrm{~mm}$ de hormigón $\mathrm{H} 25$ y las de H50.

\subsubsection{Análisis de resultados.}

La figura 23 muestra el gráfico donde se comparan los valores medios de los resultados de resistividad obtenidos en los ensayos realizados con las rodajas de hormigón $\mathrm{H} 50$, de "H25 CD" y "H25 SD". Los datos representados corresponden a las tablas 6, 13, 14 y 15.

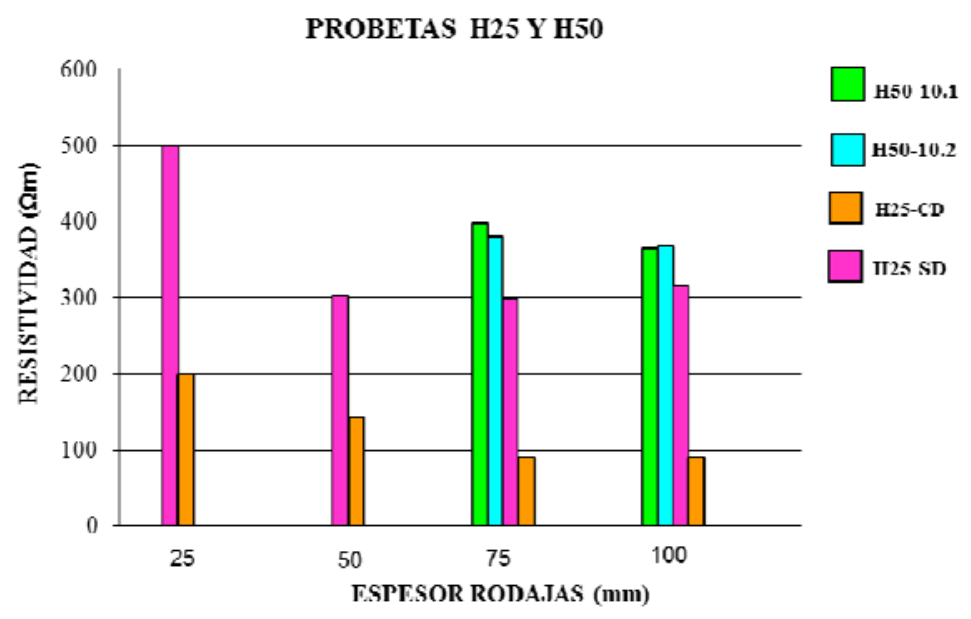

Fig.23. Valores de resistividad de probetas de hormigón H25 y H50.

Se observa que los valores de resistividad son mayores al utilizar rodajas de pequeño espesor ( 25 y 50mm, 1 ó 2 veces el Dmax del árido), ya que las medidas están muy influenciadas por la presencia del árido en el espesor de rodaja. Sin embargo, los 
valores se estabilizan en las probetas que cumplen al menos una proporción de 3 veces el Dmax (75-100 mm).

Se observa también en la figura la diferencia de valores de resistividad obtenidos entre hormigón H25-CD y H25-SD, mostrando que este último presenta una notable mejor calidad cercana a la que presenta el $\mathrm{H} 50$.

\subsection{4.- Medida de la Resistividad: Influencia del Diámetro de la Probeta.}

\subsubsection{Resultados}

La siguiente fase consiste en realizar el ensayo sobre las probetas "H50-15.1" y H5015.2" con el fin de analizar la posible influencia del diámetro de la muestra en la medida de la resistividad del hormigón. De acuerdo con lo indicado en la norma el tamaño del electrodo debe ajustarse al tamaño de la probeta por lo que se han empleado electrodos de lado $10 \mathrm{~cm}$ y lado $15 \mathrm{~cm}$ según el diámetro de la probeta ensayada.

La figura 24 muestra el montaje así como la realización de una de las medidas.
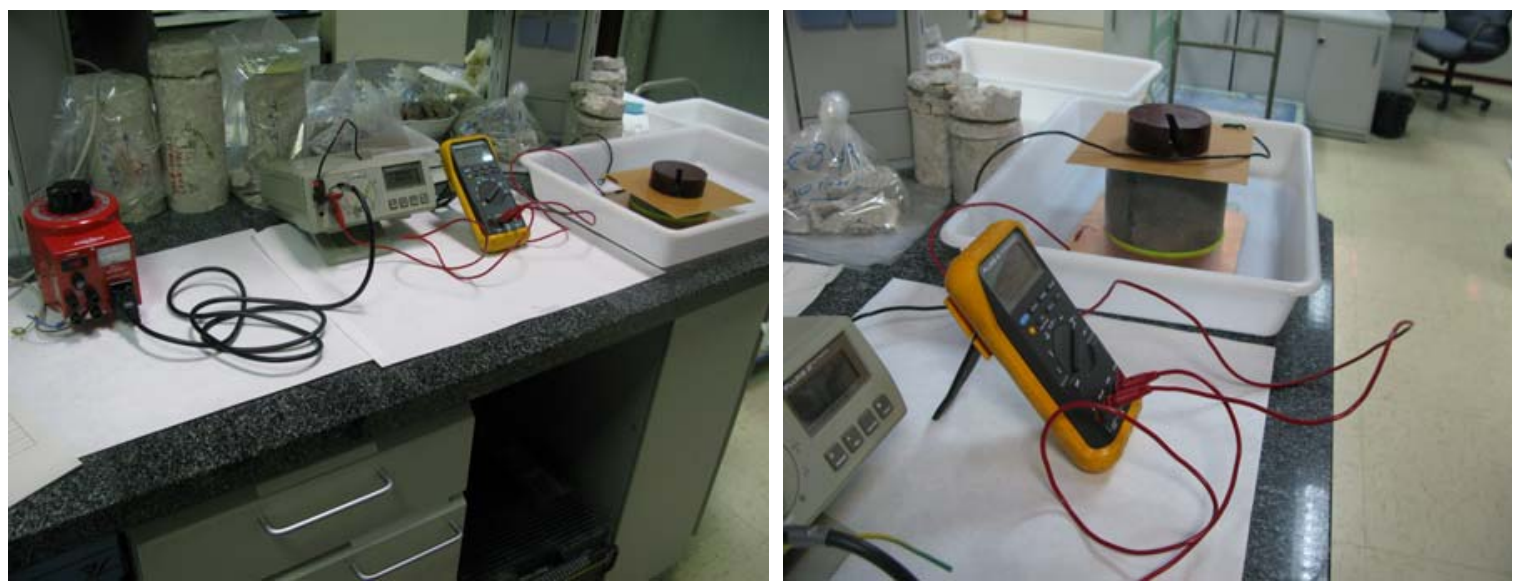

Fig.24. Vista del montaje del ensayo y de la realización de una de las medidas.

Las tablas 16 y 17 recogen los resultados de los ensayos que se realizaron con las rodajas de probetas $\mathrm{H} 50$ de diámetro $15 \mathrm{~cm}$. La geometría y peso se indica en las tablas 10 y 11. 


\begin{tabular}{|c|c|c|c|c|c|c|c|}
\hline Rodaja & V (v) & I (mA) & $\mathbf{R}_{\mathrm{T}}(\mathbf{\Omega})$ & $\mathbf{R}_{\mathbf{H}}(\boldsymbol{\Omega})$ & $\rho_{\mathrm{H}}(\Omega \mathrm{m})$ & $\begin{array}{c}\rho_{\mathrm{H} \text { medio }} \\
(\Omega \mathrm{m})\end{array}$ & $\rho\left(\mathrm{kg} / \mathrm{m}^{3}\right)$ \\
\hline \multirow{2}{*}{1.1} & 38,80 & 41,00 & 946,34 & 930,34 & 654,14 & \multirow{2}{*}{647,72} & \multirow{2}{*}{2382,93} \\
\hline & 38,70 & 41,70 & 928,06 & 912,06 & 641,29 & & \\
\hline \multirow{2}{*}{1.2} & 55,00 & 40,37 & 1362,40 & 1346,40 & 471,47 & \multirow{2}{*}{478,23} & \multirow{2}{*}{2394,70} \\
\hline & 56,60 & 40,40 & 1400,99 & 1384,99 & 484,98 & & \\
\hline \multirow{2}{*}{1.3} & 96,40 & 40,64 & 2372,05 & 2356,05 & 558,09 & \multirow{2}{*}{590,67} & \multirow{2}{*}{2404,21} \\
\hline & 108,00 & 40,80 & 2647,06 & 2631,06 & 623,24 & & \\
\hline \multirow{2}{*}{1.4} & 127,30 & 40,17 & 3169,03 & 3153,03 & 531,57 & \multirow{2}{*}{529,34} & \multirow{2}{*}{2391,46} \\
\hline & 126,30 & 40,19 & 3142,57 & 3126,57 & 527,11 & & \\
\hline
\end{tabular}

Tabla.16. Resultados obtenidos durante el ensayo de la probeta "H50-15.1".

\begin{tabular}{|c|c|c|c|c|c|c|c|}
\hline Rodaja & $\mathrm{V}(\mathrm{v})$ & I (mA) & $\mathbf{R}_{\mathrm{T}}(\mathbf{\Omega})$ & $\mathbf{R}_{\mathrm{H}}(\boldsymbol{\Omega})$ & $\rho_{\mathrm{H}}(\Omega \mathrm{m})$ & $\begin{array}{c}\rho \mathrm{H} \text { medio } \\
(\Omega \mathrm{m})\end{array}$ & $\rho\left(\mathrm{kg} / \mathrm{m}^{3}\right)$ \\
\hline \multirow{2}{*}{2.1} & 24,56 & 40,40 & 607,92 & 591,92 & 401,71 & \multirow{2}{*}{403,31} & \multirow{2}{*}{2372,31} \\
\hline & 24,86 & 40,58 & 612,62 & 596,62 & 404,90 & & \\
\hline \multirow{2}{*}{2.2} & 54,40 & 40,11 & 1356,27 & 1340,27 & 471,17 & \multirow{2}{*}{467,72} & \multirow{2}{*}{2416,68} \\
\hline & 54,40 & 40,70 & 1336,61 & 1320,61 & 464,26 & & \\
\hline \multirow{2}{*}{2.3} & 103,10 & 40,71 & 2532,55 & 2516,55 & 589,02 & \multirow{2}{*}{567,1} & \multirow{2}{*}{2398,07} \\
\hline & 95,10 & 40,55 & 2345,25 & 2329,25 & 545,18 & & \\
\hline \multirow{2}{*}{2.4} & 110,40 & 40,19 & 2746,95 & 2730,95 & 476,88 & \multirow{2}{*}{481,43} & \multirow{2}{*}{2411,72} \\
\hline & 112,30 & 40,12 & 2799,10 & 2783,10 & 485,98 & & \\
\hline
\end{tabular}

Tabla.17. Resultados obtenidos durante el ensayo de la probeta “H50-15.2”.

4.2.4.2. Análisis de resultados.

Con los valores medios de resistividad de las tablas 13, 14, 16 y 17 se obtiene la figura 25 que compara los valores de resistividad de las rodajas de las probetas de hormigón H50 de diámetro $10 \mathrm{~cm}$ y $15 \mathrm{~cm}$. 


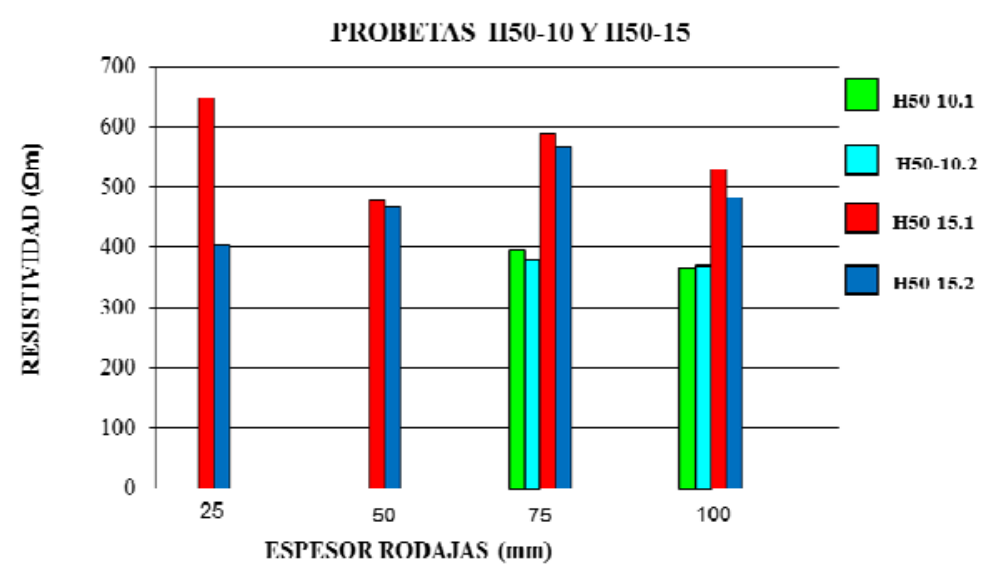

Fig. 25. Valores medios de resistividad de probetas de hormigón "H50-10" y “H50-15".

A partir de los valores representados en la figura 25, se observa la variabilidad de los resultados en el caso de las medidas registradas en las rodajas de bajo espesor (25-50 $\mathrm{mm}$ ) incluso en probetas del mismo hormigón, mientras que se obtienen resultados más uniformes en las probetas de mayor espesor. Esto ratifica la necesidad de utilizar probetas de espesor igual o superior a 3 veces el Dmax del árido, para evitar medidas poco fiables.

En cuanto al diámetro de la probeta, se aprecia una importante diferencia entre medidas de rodajas de distinto diámetro. Se observa que las probetas fabricadas de $15 \mathrm{~cm}$ de diámetro presentan mayor resistividad que las de $10 \mathrm{~cm}$. Se cuestiona si se trata de un efecto del proceso de fabricación de probetas grandes y pequeñas, tal como pasa en el caso de la resistencia a compresión, o bien de un efecto geométrico con influencia en la medida de la resistividad.

Para aislar el efecto geométrico y descartar el efecto de fabricación, se decide hacer una campaña de ensayos en la que las medidas se realizarán sobre rodajas de $15 \mathrm{~cm}$ de diámetro de las que, tras realizar la medida de resistividad, se extrae un testigo de 10 $\mathrm{cm}$ y se repite la medida.

Se ensayan de esta manera ocho rodajas de $15 \mathrm{~cm}$ de diámetro que se encontraban saturadas de agua, de hormigones de calidad buena, media y baja: cuatro de ellas pertenecientes a las probetas del hormigón H.50 cuyas dimensiones se encuentran en las tablas 11 y 12 (rodajas 1.3, 1.4, 2.3 y 2.4), una probeta perteneciente a un estudio realizado en laboratorio y tres testigos pertenecientes a un puerto analizado previamente en el laboratorio. Las dimensiones de estas cuatro se indican a continuación: 


\begin{tabular}{|c||c||c||}
\hline Rodaja & $\left.\boldsymbol{\emptyset}_{\mathbf{m}} \mathbf{( m m}\right)$ & $\left.\mathbf{e}_{\mathbf{m}} \mathbf{( m m}\right)$ \\
\hline C2-2001(b) & 150,13 & 151,39 \\
\hline CAJÓN 10 & 149,10 & 154,9 \\
\hline CAJÓN 11 & 149,93 & 145,8 \\
\hline CAJÓN 13 & 149,40 & 149,4 \\
\hline
\end{tabular}

Tabla.18. Diámetros y espesores de probetas procedentes de estudios realizados en laboratorio.

Dado que las probetas se encuentran saturadas, se procede a la medida de la resistividad del hormigón obteniendo los resultados que se indican en la tabla 19. De forma previa a realización del ensayo se mide la resistencia de las esponjas de $15 \mathrm{~cm}$ obteniendo un valor de $45 \Omega \mathrm{m}$ con el que se realizan los cálculos para obtener la resistividad:

\begin{tabular}{|c|c|c|c|c|c|c|}
\hline Rodaja & $V(v)$ & I (mA) & $\mathbf{R}_{\mathrm{T}}(\mathbf{\Omega})$ & $\mathbf{R}_{\mathbf{H}}(\mathbf{\Omega})$ & $\rho_{\mathrm{H}}(\Omega \mathrm{m})$ & $\begin{array}{c}\rho_{\mathrm{H}}^{\mathrm{m} m d i o} \\
(\Omega \mathrm{m})\end{array}$ \\
\hline \multirow{2}{*}{$1.3-15$} & 80,40 & 39,60 & 2030,30 & 1985,30 & 470,28 & \multirow{2}{*}{477,30} \\
\hline & 83,10 & 39,77 & 2089,52 & 2044,52 & 484,31 & \\
\hline \multirow{2}{*}{ 1.4-15 } & 111,70 & 40,29 & 2772,40 & 2727,40 & 459,81 & \multirow{2}{*}{466,57} \\
\hline & 114,30 & 40,07 & 2852,51 & 2807,51 & 473,32 & \\
\hline \multirow{2}{*}{ 2.3-15 } & 86,30 & 39,90 & 2162,91 & 2117,91 & 495,72 & \multirow{2}{*}{500,86} \\
\hline & 89,00 & 40,33 & 2206,79 & 2161,79 & 505,99 & \\
\hline \multirow{2}{*}{$2.4-15$} & 104,70 & 39,60 & 2643,94 & 2598,94 & 453,83 & \multirow{2}{*}{461,64} \\
\hline & 109,20 & 39,95 & 2733,42 & 2688,42 & 469,45 & \\
\hline \multirow{2}{*}{ C2-2001 (b) } & 125,10 & 40,60 & 3081,28 & 3036,28 & 355,03 & \multirow{2}{*}{351,59} \\
\hline & 120,20 & 39,77 & 3022,38 & 2977,38 & 348,15 & \\
\hline \multirow{2}{*}{ C10-15 } & 45,60 & 39,20 & 1163,27 & 1118,27 & 126,05 & \multirow{2}{*}{125,58} \\
\hline & 45,50 & 39,40 & 1154,82 & 1109,82 & 125,10 & \\
\hline \multirow{2}{*}{ C11-15 } & 51,50 & 39,09 & 1317,47 & 1272,47 & 152,80 & \multirow{2}{*}{150,03} \\
\hline & 49,20 & 38,70 & 1271,32 & 1226,32 & 147,26 & \\
\hline \multirow{2}{*}{ C13-15 } & 53,70 & 39,28 & 131367,11 & 1322,11 & 151,18 & \multirow{2}{*}{138,86} \\
\hline & 45,60 & 39,60 & 1151,52 & 1106,52 & 126,53 & \\
\hline
\end{tabular}

Tabla.19. Resultados obtenidos durante el ensayo de las muestras de diámetro $15 \mathrm{~cm}$.

Una vez realizada la medida de resistividad en las muestras de $15 \mathrm{~cm}$ de diámetro se procede a extraer testigos de diámetro $10 \mathrm{~cm}$ de tales muestras con el fin de realizar sobre ellos la medida de resistividad y observar su posible variación con el cambio de 
diámetro. La tabla 20 indica las dimensiones de los testigos extraídos:

\begin{tabular}{|c||c|c|}
\hline Rodaja & $\left.\boldsymbol{\emptyset}_{\mathbf{m}} \mathbf{( m m}\right)$ & $\left.\mathbf{e}_{\mathbf{m}} \mathbf{( m m}\right)$ \\
\hline $\mathbf{1 . 3 - 1 0}$ & 101,73 & 75,10 \\
\hline $\mathbf{1 . 4 . 1 0}$ & 101,72 & 105,80 \\
\hline $\mathbf{2 . 3 - 1 0}$ & 101,70 & 75,40 \\
\hline $\mathbf{2 . 4 - 1 0}$ & 101,75 & 101,20 \\
\hline $\mathbf{C 2 - 2 0 0 1 ( b )}$ & 101,28 & 151,39 \\
\hline $\mathbf{C 1 0 - 1 0}$ & 101,63 & 154,90 \\
\hline $\mathbf{C 1 1 - 1 0}$ & 101,62 & 145,80 \\
\hline $\mathbf{C 1 3 - 1 0}$ & 101,65 & 153,30 \\
\hline
\end{tabular}

Tabla.20. Diámetros y espesores de los testigos extraídos de diámetro $10 \mathrm{~cm}$.

Se mantiene la saturación de las muestras salvo durante el proceso de extracción. Tras la realización de la medida de la resistividad, estos son los resultados obtenidos. De forma análoga a cuando se realizaron las medidas sobre las rodajas de $15 \mathrm{~cm}$ de diámetro, se procede a medir la resistencia de las esponjas de $10 \mathrm{~cm}$ obteniendo un valor de $65 \Omega \mathrm{m}$ con el que se realizan los cálculos para obtener la resistividad:

\begin{tabular}{|c|c|c|c|c|c|c|}
\hline Rodaja & $V(v)$ & I (mA) & $\mathbf{R}_{\mathrm{T}}(\mathbf{\Omega})$ & $\mathbf{R}_{\mathbf{H}}(\mathbf{\Omega})$ & $\rho_{H}(\Omega m)$ & $\begin{array}{c}\rho_{\mathrm{H}} \text { medio } \\
(\Omega \mathrm{m})\end{array}$ \\
\hline \multirow{2}{*}{$1.3-10$} & 156,30 & 40,17 & 3890,96 & 3825,96 & 414,05 & \multirow{2}{*}{412,70} \\
\hline & 154,80 & 40,04 & 3866,13 & 3801,13 & 411,34 & \\
\hline \multirow{2}{*}{$1.4-10$} & 211,00 & 39,75 & 5308,18 & 5243,18 & 402,68 & \multirow{2}{*}{401,65} \\
\hline & 213,70 & 40,47 & 5281,44 & 5216,44 & 400,62 & \\
\hline \multirow{2}{*}{ 2.3-10 } & 154,20 & 40,45 & 3812,11 & 3747,11 & 403,71 & \multirow{2}{*}{408,37} \\
\hline & 157,50 & 40,40 & 3898,51 & 3833,51 & 413,02 & \\
\hline \multirow{2}{*}{ 2.4-10 } & 192,30 & 40,01 & 4806,30 & 4741,30 & 380,96 & \multirow{2}{*}{376,30} \\
\hline & 187,80 & 40,04 & 4690,31 & 4625,31 & 371,64 & \\
\hline \multirow{2}{*}{ C2-2001(b) } & 190,50 & 40,20 & 4738,81 & 4673,81 & 248,70 & \multirow{2}{*}{250,07} \\
\hline & 195,20 & 40,75 & 4790,18 & 4725,18 & 251,44 & \\
\hline \multirow{2}{*}{ C10-10 } & 66,70 & 40,23 & 1657,97 & 1592,97 & 83,42 & \multirow{2}{*}{83,94} \\
\hline & 66,10 & 39,40 & 1677,65 & 1612,65 & 84,45 & \\
\hline \multirow{2}{*}{ C11-10 } & 73,70 & 39,75 & 1854,09 & 1789,09 & 99,51 & \multirow{2}{*}{104,11} \\
\hline & 83,20 & 41,20 & 2019,42 & 1954,42 & 108,70 & \\
\hline \multirow{2}{*}{ C13-10 } & 76,40 & 40,58 & 1882,70 & 1817,70 & 96,23 & \multirow{2}{*}{93,57} \\
\hline & 74,50 & 41,80 & 1782,30 & 1717,30 & 90,91 & \\
\hline
\end{tabular}

Tabla.21. Resultados obtenidos durante el ensayo de las muestras de diámetro $10 \mathrm{~cm}$. 
En la siguiente tabla se aportan las medidas de la resistividad obtenidas para las rodajas de diámetro $15 \mathrm{~cm}$ (tabla 19) así como las de diámetro $10 \mathrm{~cm}$ (tabla 21) aportando la relación existente entre ellas a través del coeficiente de paso:

\begin{tabular}{|c|c|c|c|c|c|}
\hline Rodaja $^{1}$ & $\begin{array}{l}\text { emedio } \\
(\mathbf{m m})\end{array}$ & $\begin{array}{c}\rho_{\mathrm{H} \text { media }} \varnothing 15 \\
(\Omega \mathrm{m})^{2}\end{array}$ & $\begin{array}{c}\rho_{\mathrm{H} \text { media }} \varnothing 15 \\
(\Omega \mathrm{m})^{3}\end{array}$ & $\begin{array}{c}\rho_{\mathrm{H} \text { media }} \varnothing 10 \\
(\Omega \mathrm{m})^{3}\end{array}$ & Coef. Paso \\
\hline 1.3 (jun 2012) & 75,10 & 590,67 & 477,30 & 412,70 & 1,16 \\
\hline 1.4 (jun 2012) & 105,80 & 529,34 & 466,57 & 401,65 & 1,16 \\
\hline 2.3 (jun 2012) & 75,40 & 567,10 & 500,86 & 408,37 & 1,23 \\
\hline 2.4 (jun 2012) & 101,20 & 481,43 & 461,64 & 376,30 & 1,23 \\
\hline C2 2001 (b) & 151,39 & --- & 351,59 & 250,07 & 1,41 \\
\hline C10 (feb 2010) & 154,90 & 108,66 & 125,58 & 83,94 & 1,50 \\
\hline C11 (feb 2010) & 145,80 & 93,52 & 150,03 & 104,11 & 1,44 \\
\hline C13 (feb 2010) & 153,30 & 62,21 & 138,86 & 93,57 & 1,48 \\
\hline
\end{tabular}

Tabla.22. Coeficientes de paso obtenidos relacionando los valores medios de resistividad de ambos diámetro.

${ }^{1}$ El número que aparece junto al nombre corresponde a la fecha de fabricación. El hormigón del muelle no contiene adiciones, su cemento es CEM I 42,5 SR con relación a/c 0,5. Los testigos se extrajeron del muelle en mayo-junio de 2010 por lo que su exposición al agua fue mínima.

${ }^{2}$ Medidas realizadas en septiembre 2012.

${ }^{3}$ Medidas repetidas en octubre 2015, habiendo conservado las probetas en agua durante estos tres años.

La tabla anterior muestra la gran variación de la resistividad obtenida con un intervalo de tiempo de 3 años medida sobre las mismas probetas, consecuencia de la gran sensibilidad a la forma de conservación de las mismas:

- Las probetas fabricadas en laboratorio experimentan una reducción de la resistividad, que podría atribuirse a que hayan alcanzado un mayor grado de saturación durante el período de conservación (la medida inicial es sobre probetas con 28 días de conservación bajo agua sin saturación al vacío, la segunda medida tras tres años en agua). 
- Las probetas testigo de la estructura (medidas inicialmente tras saturación al vacío, y después conservadas en agua tres años) experimentan un incremento de resistividad, que podría atribuirse a una mejora de la calidad del hormigón por la continuada hidratación del cemento bajo el agua.

- En cualquier caso, el coeficiente de paso se obtiene con los resultados en probetas conservadas tres años en agua, extrayendo un testigo de $10 \mathrm{~cm}$ sobre la probeta inicial de $15 \mathrm{~cm}$, por lo que las condiciones de conservación de ambas medidas son idénticas.

Los resultados de resistividad obtenidos en las medidas actuales para diámetro $15 \mathrm{~cm}$ y $10 \mathrm{~cm}$ se representan en la figura 26 con el fin de observar la posible influencia del diámetro de la muestra.

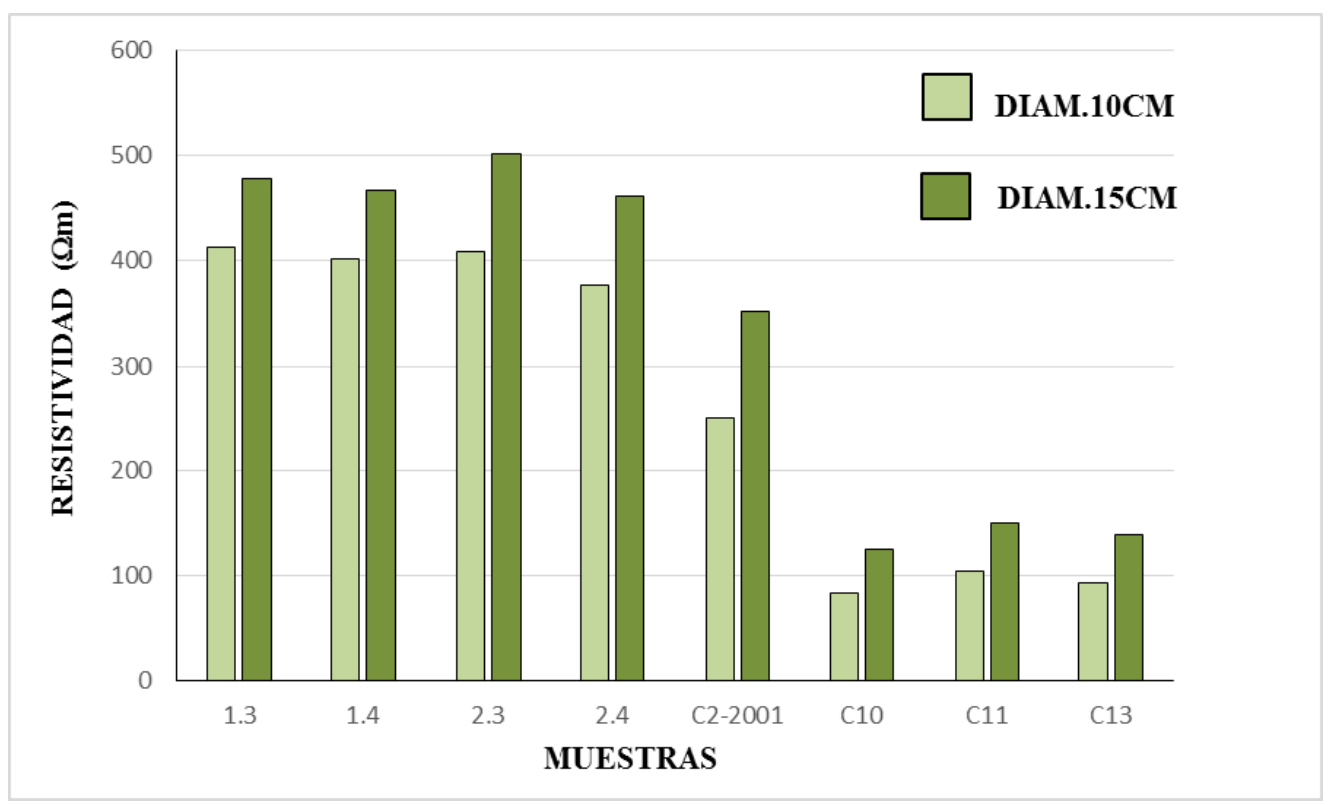

Fig.26. Resultados de resistividad de muestras de diámetro $15 \mathrm{~cm}$ y diámetro $10 \mathrm{~cm}$.

Se observa que, para un mismo espesor de rodaja, siempre es mayor el resultado de la resistividad en el diámetro más grande. Este resultado se aprecia en tres hormigones distintos, uno de buena calidad y ejecutado en laboratorio (con un efecto menos acusado), otro de calidad media también elaborado en laboratorio y el último, de peor calidad y procedente de una obra (con importantes diferencias en las medidas con ambos diámetros). En la figura 27 se representan todos los valores así como el ajuste entre ellos con el fin de establecer una relación de paso entre valores de resistividad de probetas de dos diámetros distintos: 


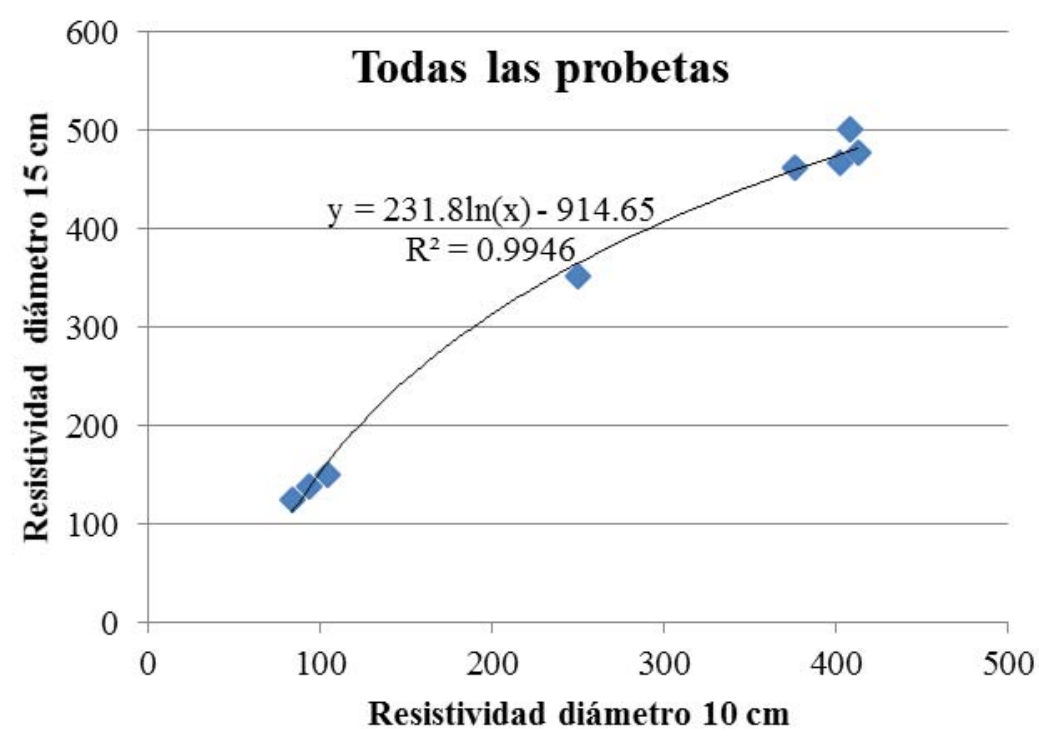

Fig.27. Relación entre resultados de resistividad de muestras de $\varnothing 10 \mathrm{~cm}$ y $\varnothing 15 \mathrm{~cm}$ de tres hormigones distintos.

Sin embargo, la Figura 17 muestra que los resultados son insuficientes para estimar con precisión el valor del coeficiente de paso, ya que se encuentran agrupados en tres valores de resistividad, y sería necesario obtener resultados barriendo un rango mayor de resultados.

\section{CONCLUSIONES}

Al término de la primera fase de pruebas de ensayo indicada en la metodología, se establecen los criterios de ajuste para la realización del ensayo de resistividad:

- Para conseguir el rango de intensidad (30-50mA) exigido por norma se debe utilizar corriente alterna.

Se comienza utilizando corriente continua ya que, por ejemplo, la norma europea UNE 14617-13 no especifica tipo de corriente y la norma UNE 83988-1 simplemente recomienda empleo de corriente alterna. Sin embargo, con corriente continua no se consigue ajustar la intensidad en el rango de valores establecido por la norma española UNE 83988-1, por lo que se precisa un variador de tensión en corriente alterna que permita fijar el voltaje para encajar la intensidad.

- Para conseguir que la resistencia propia del equipo se ajuste a lo exigido en norma (hasta $100 \Omega$ ) se deben emplear chapas metálicas como electrodos y las esponjas deben estar humedecidas y escurridas 
Los electrodos metálicos permiten reducir al mínimo la resistencia del equipo. Escurrir las esponjas evita que el agua discurra por la pared del testigo y que parte del flujo eléctrico pueda desviarse por el lateral.

- Se observa en las medidas realizadas que las rodajas de pequeño espesor (25-50 $\mathrm{mm}$ ) se ven influenciadas por la utilización de diferentes equipos de medida.

De forma análoga y al término de las operaciones que forman parte de la segunda fase indicada en la metodología (conocer la posible influencia de las dimensiones de la probeta: espesor y diámetro) se establecen los siguiente criterios para la realización del ensayo de resistividad:

- Emplear en la realización del ensayo probetas de espesor igual o superior a 3 veces el Dmax del árido

Tras analizar hormigones de distinta calidad ( $\mathrm{H} 25$ y H50), se observa que los valores de resistividad obtenidos en los casos de las rodajas de $25 \mathrm{~mm}$ presentan una gran variabilidad y resultan poco fiables, debido a la influencia del tamaño máximo de árido en la realización de la medida. Los resultados indican que deben utilizarse probetas de espesor igual o superior a 3 veces el Dmax del árido para realizar la medida de resistividad del hormigón.

- Los valores de la resistividad del hormigón son uniformes en rodajas de igual espesor

Si el espesor de probeta es el adecuado, se observa una buena repetitividad en medidas realizadas en distintas rodajas de un mismo hormigón. Esta conclusión se corrobora en hormigones de ambas calidades.

- A mayor resistencia a compresión, mayor resistividad del hormigón

Descartando los valores anómalos de las rodajas de pequeño espesor se observa gran diferencia entre la resistividad obtenida en el hormigón dependiendo de su calidad.

- La medida de resistividad es muy sensible a las condiciones de saturación

Las probetas fabricadas en laboratorio y ensayadas a los 28 días de edad tienen un grado de saturación inferior que si se saturan al vacío (por ejemplo testigos) lo cual aumenta el resultado de resistividad.

- El diámetro de la probeta ensayada tiene influencia en el resultado obtenido 
Las probetas de $15 \mathrm{~cm}$ dan un valor de resistividad superior a las de $10 \mathrm{~cm}$ de diámetro, en especial en hormigones de menor calidad. Este aspecto que no queda recogido en la norma y que obliga a ajustar coeficientes de paso si se utilizan ambos tipos de probetas o comparar siempre medidas de resistividad procedentes de muestras de mismo diámetro.

\section{BIBLIOGRAFÍA}

1. Alaejos, M. P; Bermúdez, M.A. (2008). "Corrosión de las armaduras en el hormigón situado en ambiente marino". Monografía 96, CEDEX. Madrid.

2. BRE CENTRE FOR CONCRETE CONSTRUCTION (2000) Corrosion of Steel in concrete. Digest 444 (parts 1 to 3). Londres: CRC.

3. UNE 83988-1 (2008) "Durabilidad del hormigón. Métodos de ensayo. Determinación de la resistividad eléctrica. Parte 1. Método directo (método de referencia)".

4. UNE 83988-2 (2008) "Durabilidad del hormigón. Métodos de ensayo. Determinación de la resistividad eléctrica. Parte 2: Método de las cuatro puntas o de Wenner".

5. Castellote, M; Andrade, C y Alonso, C. (2002) "Standardization, to a reference of $25^{\circ} \mathrm{C}$, of electrical resistivity for mortar and concretes in saturated or isolated conditions" ACI Materials Journal, Vol 99, No 2, March-April, 119-128.

6. Polder, R. B. (2001) "Test methods for on site measurement of resistivity of concrete"-A RILEM TC-154 Technical Recommendation" Construction and Building Materials, vol. 15, 125-131.

7. BRE CENTRE FOR CONCRETE CONSTRUCTION (1998) Corrosion of reinforcement in concrete: electrochemical monitoring. Digest 434 . Londres: CRC.

8. Polder, R. B. (2000) "Test methods for on site measurement of resistivity of concrete" Recommendation of RILEM TC-154 EMC:"Electrochemical techniques for measuring metallic corrosion" Materials and Structures, vol. 33, December, 603611.

9. RILEM. Corrosion of Steel in concrete. Report of the Technical Committee 60-CSC. P. Schiessl. 
10. Song, G. y Shayan, A. (1998). "Corrosion of Steel in concrete: causes, detection and prediction. State of the art review. ARRB Transport Research Ltd, Review Report 4.

11. UNE-EN 14617-13 (2006). "Piedra aglomerada. Métodos de ensayo. Parte 13: determinación de la resistividad eléctrica." 